\title{
WestVirginiaUniversity
}

THE RESEARCH REPOSITORY @ WVU

Graduate Theses, Dissertations, and Problem Reports

2009

\section{Weak floor stability in the Illinois Basin underground coal mines}

Murali M. Gadde

West Virginia University

Follow this and additional works at: https://researchrepository.wvu.edu/etd

\section{Recommended Citation}

Gadde, Murali M., "Weak floor stability in the Illinois Basin underground coal mines" (2009). Graduate Theses, Dissertations, and Problem Reports. 2923.

https://researchrepository.wvu.edu/etd/2923

This Dissertation is protected by copyright and/or related rights. It has been brought to you by the The Research Repository @ WVU with permission from the rights-holder(s). You are free to use this Dissertation in any way that is permitted by the copyright and related rights legislation that applies to your use. For other uses you must obtain permission from the rights-holder(s) directly, unless additional rights are indicated by a Creative Commons license in the record and/ or on the work itself. This Dissertation has been accepted for inclusion in WVU Graduate Theses, Dissertations, and Problem Reports collection by an authorized administrator of The Research Repository @ WVU.

For more information, please contact researchrepository@mail.wvu.edu. 


\title{
WEAK FLOOR STABILITY IN THE ILLINOIS BASIN UNDERGROUND COAL MINES
}

\author{
Murali M. Gadde \\ Dissertation submitted to the \\ College of Engineering and Mineral Resources \\ at West Virginia University \\ in partial fulfillment of the requirements \\ for the degree of \\ Doctor of Philosophy \\ In \\ Mining Engineering \\ Syd S. Peng, Ph.D. (Chairman) \\ Keith Heasley, Ph.D. \\ Felicia Peng, Ph.D. \\ Yi Luo, Ph.D. \\ Department of Mining Engineering, WVU \\ Christopher Mark, Ph.D. \\ The National Institute for Occupational Safety and Health, Pittsburgh, PA
}

\author{
Morgantown, West Virginia \\ 2009
}

Key Words: Illinois Basin, underclay, weak floor stability, numerical modeling

Copyright 2009 Murali M. Gadde 


\author{
ABSTRACT \\ Weak Floor Stability in the Illinois Basin Underground Coal Mines \\ BY \\ Murali M. Gadde,
}

The research described in this dissertation is a direct consequence of the author's quest to find solutions to several problems he faced while designing optimum pillar layouts for some Illinois Basin coal mines over weak immediate floor strata. When using the existing methods of floor stability analysis, conclusions were sometimes drawn that were either not supported by real-world mining experience or in some cases even physically impossible results were obtained. Therefore, it was necessary to delve deeper into the existing methods and understand their limitations to arrive at alternatives that were consistent with practical observations. In improving upon the existing methods, however, it was not necessary to radically alter the way floor stability was being currently investigated in the Illinois Basin. Rather, it was necessary to gather a large amount of additional laboratory and in-situ data to develop improved design equations. It was also necessary to adopt advanced numerical modeling tools to investigate the accuracy of bearing capacity equations used currently.

For this research, the largest database of laboratory and in-situ properties was put together from all three states of the Illinois Basin. Analysis of the laboratory data showed that the engineering characteristics of the weak floor in the Basin differed between the Eastern and Western shelves. Therefore, the past practice of using single design approach for the entire Basin must be replaced by the two-shelf methodology for a satisfactory floor stability analysis. Guidelines and the necessary design equations for this purpose were developed in this dissertation. The in-situ plate test data revealed the conservative nature of the Speck and SIUC floor strength equations used currently. It was also shown that for some moisture content values, such as those determined at a few Western shelf mines, both the Speck and SIUC equations predicted physically meaningless floor strength.

The laboratory and in-situ data showed that the simple and reliable moisture content test could be used to estimate all the necessary design parameters for a preliminary floor stability analysis. Empirical correlations between the moisture content and several engineering properties of the floor were developed in this research. It was shown that critical properties of the floor like cohesion, peak and residual angle of internal friction, modulus of deformation and permeability could be approximately estimated as a function of its natural moisture content.

Back analysis of several stable and unstable floor case histories showed that while the current practice of using the Vesic's non-homogeneous soil bearing capacity solution for routine stability analysis could be continued, the Speck's equation to estimate floor strength need to be replaced by the author's relations. Finally, it has been shown that several important aspects of the coal mine bearing capacity problem that have significant impact on the floor strength could be considered in the design using the numerical modeling methodology. With the modeling technique, it was also possible to investigate floor stability under very complex pillars such as those created during 'perimeter mining' as practiced at some Illinois Basin mines. 
To

My beloved brother

Late Dr. Srinivas Chowdhary 


\section{Disclaimer}

The opinions, conclusions and recommendations given in this research belong solely to the author and do not reflect those of Peabody Energy or its affiliates. The author and Peabody Energy disclaim any responsibility for the applicability or correctness of the information, recommendations and guidelines presented in this research, or the consequences resulting from the use thereof. Any use or misuse of the information contained in this document is the sole responsibility of the user. 


\section{ACKNOWLEDGEMENTS}

At the outset, I would like to thank my AEC members for sparing some time amidst their busy schedules. I want to acknowledge the insights and valuable advice I received from Dr. Christopher Mark, Dr. Keith Heasley, Dr. Felicia Peng and Dr. Yi Luo on different aspects of the research described in this dissertation. Their constructive criticism helped me refine the work and produce a better product as you see it here.

I would like to express my sincere and heart-felt sense of gratitude to Dr. Syd S. Peng, my research advisor and the AEC chairman. I enjoyed the opportunity to work with him and appreciate the support I received over the past few years. He is truly an inspiration to many up-and-coming researchers like me and I want to thank him for everything he did in these years of association.

Grateful acknowledgement is also made of Dr. Yoginder P. Chugh of Southern Illinois University, Carbondale, for the several candid discussions on the state-of-the-art of floor design and for sharing some of his weak floor data. Scott Elrick and John Nelson of the Illinois State Geological Survey (ISGS) along with Phil Ames of Peabody Energy helped me understand the geology of the IL Basin in general, and the underclays, in particular. Their support is greatly appreciated. Similarly, Bob Gibson of the Illinois Abandoned Mined Land Reclamation Council and Robert Bauer of the ISGS provided some of the basic information related to a few case histories discussed in Chapter 4. I thank them for this help.

This research would not have been possible without the support and encouragement of several of my colleagues at Peabody Energy. In particular, I want to thank John Rusnak, Vice President, Geology, for the freedom he gave me to pursue any research of interest to Peabody and myself. John has been largely responsible for much of the research I did at Peabody which received recognition at the national level over the past four years.

The support I received from Casey Huber of Peabody Energy is immeasurable in conducting the plate tests that formed the backbone to the development of Gadde's equations for the two shelves of the IL Basin. Thank you, Casey! Much of the laboratory data used in this research was available because of the visionary thinking of Marc Silverman some two decades ago and I thank him for this initiative. The initial plate test set-up was put together for my research by Guy Hunt (Now with MaRyan Mining) and later modified by Bob Jerrels of Peabody. Their help is explicitly acknowledged.

I also want to express my gratefulness to the engineers and managers at all Peabody Midwest underground operations for their support. The research in this dissertation was taken up to address some of the issues that I faced while answering their questions related to floor stability. Engineers and geologists with Peabody corporate engineering group also helped me at several stages of this research. Thank you all for that! In particular, I want to thank Jay Honse, David Beerbower, George Schuller, Charles Meintjes, Jeane Hull, Chuck Burgraff, Mike Anderson, Mike Shetley, Tom Benner, Cliff Walker, Grady White, Jon Dever, Dick Reisinger, Bertis Hall, Steve Mescher, Jamie Haantz, James Miller, Mark Cavinder, Todd Grounds, Bob Gerth, Brain Butts, Charlie Lilly, Rick Wells and John Constantine for their encouragement and support. Similarly, Patrice Zagar and Cheryl Anderson helped with several administrative matters at Peabody and their help is greatly appreciated. Finally, I want to formally recognize the constant help I received from my long-time friend and colleague, Dr. Anil Ray. I and Anil have been known to each other for over thirteen years now and during this entire period I can not recall an incident where he did not support me when I needed help. Thank you, Anil for being a true friend!

I also appreciate the help I received from Dr. Brijes Mishra (West Virginia University) and Dr. Rajagopala Reddy Kallu (Montana Tech) over the past few years in relation to the work described in this dissertation. They helped me get most of the technical articles I needed for this research. Aid of Ms. Karen Centofanti and Ms. Karla Vaughan of the mining engineering department, West Virginia University, in administrative matters is expressly acknowledged.

Finally, I come to my beloved ones. I guess this is where words fail miserably. The journey from a modest background in India to this stage would not have been possible without the love, support, 
encouragement and sacrifices of my parents. In fact, I credit all the achievements in my life to my mother's confidence in my abilities more than my own. The patience that I still try to learn from my dad has been invaluable in my life. I feel blessed to have such parents. While working full-time on a very demanding job, completing a research of this magnitude would simply have not been possible without the understanding and cooperation of my wife, Shirisha. She always made sure I had the environment at home to work on this research after office hours. I can not thank her enough for the sacrifices she made over the past two years. If I completed my dissertation, it was mainly because of her help. I also want to apologize to my three-year's old son, Rishil, for not spending enough time with him due to the work I put for this dissertation. I want to formally recognize the unconditional love and support of my brother, Hari Gadde, who has always been my best buddy since childhood. Grateful acknowledgement is also due to Rani attayya, Laxmi attayya; Apparao mamayya, Krishnaiah mamayya; Karuna vadina, Manju and Abhi for their support and encouragement. 


\section{TABLE OF CONTENTS}

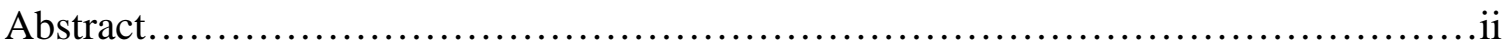

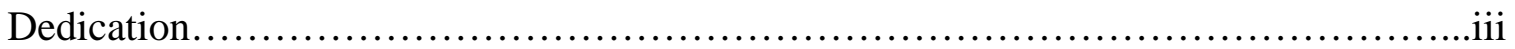

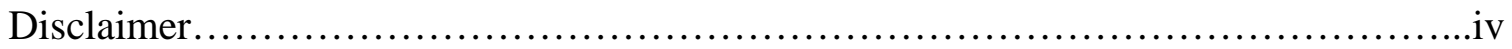

Acknowledgements...........................................................

Table of Contents..........................................................vii

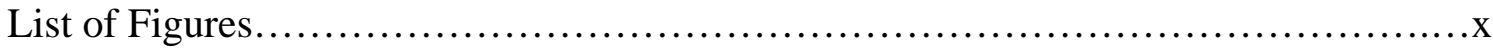

List of Tables....................................................................

CHAPTER 1: INTRODUCTION...................................................................... 1

1.1 SNAPSHOT OF GLOBAL EXPERIENCE WITH WEAK FLOOR STABILITY ........................................... 4

1.2 BRIEF OVERVIEW OF THE U.S. AND THE ILLINOIS BASIN WEAK FLOOR RESEARCH..................... 9

1.2.1 Illinois Basin Weak Floor Research ……….................................................................... 12

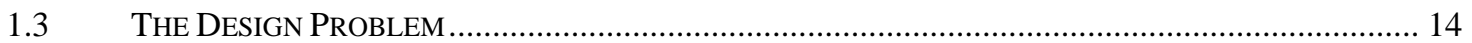

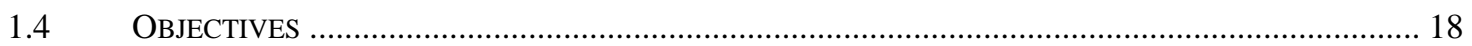

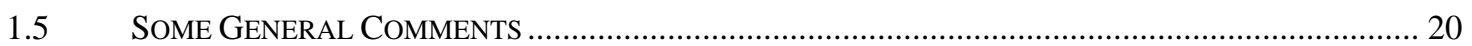

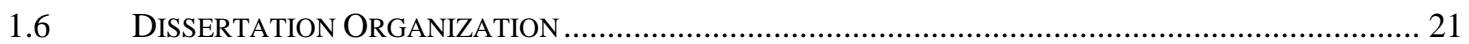

\section{CHAPTER 2: NATURE OF THE IMMEDIATE FLOOR IN THE ILLINOIS}

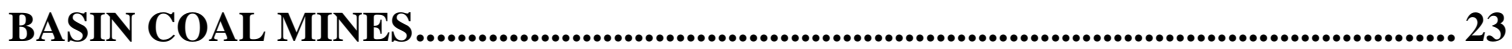

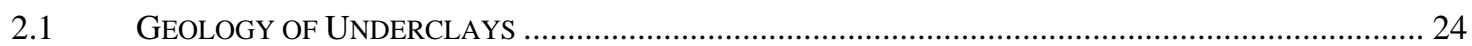

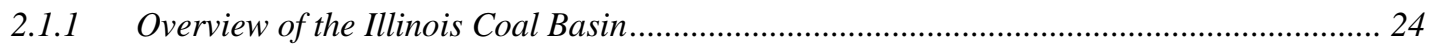

2.1.2 Depositional History of the Pennsylvanian Rocks.................................................................. 28

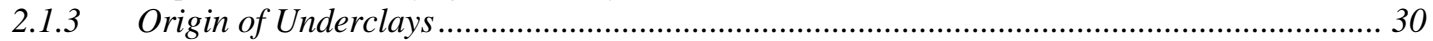

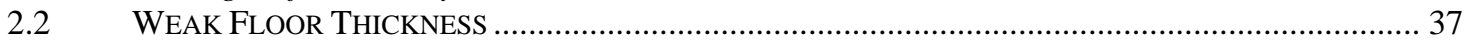

2.3 LABORATORY BEHAVIOR OF THE WEAK FLOOR MATERIALS.................................................... 48

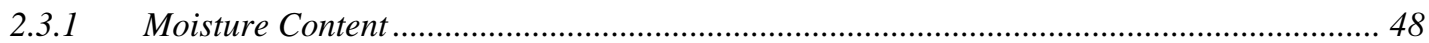

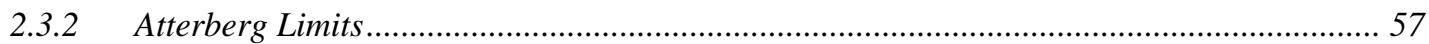

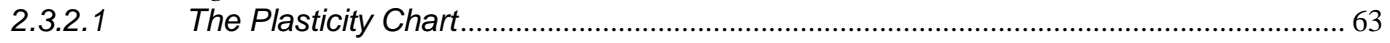

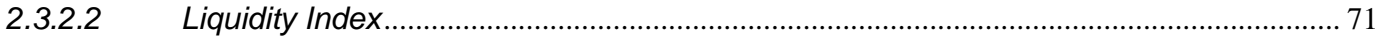

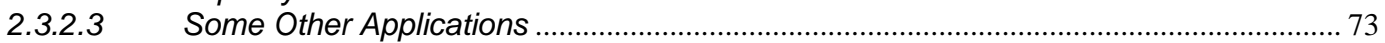

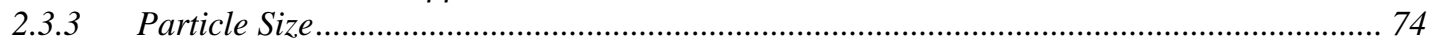

2.3.3.1 Potential Expansiveness ........................................................................................ 77

2.3.3.2 Angle of Internal Friction ............................................................................................. 79

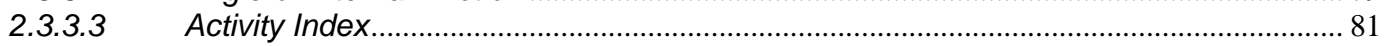

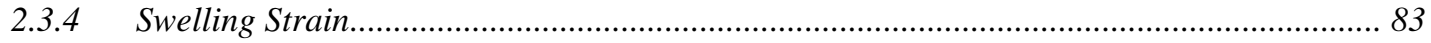

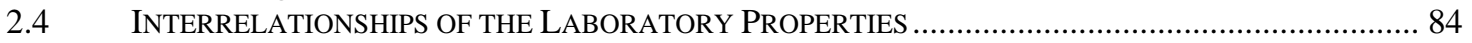

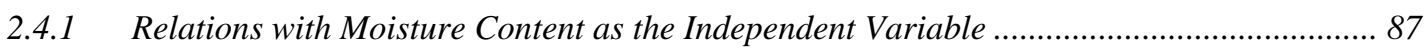

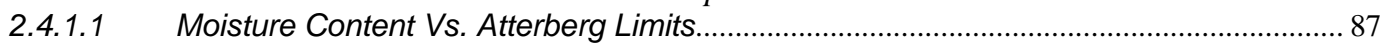

2.4.1.2 Moisture Content Vs. Particle-size ....................................................................................... 90

2.4.1.3 Moisture Content Vs. Uniaxial Compressive Strength ...................................................... 92

2.4.1.4 Moisture Content Vs. Tensile Strength......................................................................... 92

2.4.1.5 Moisture Content Vs. Sonic Properties ............................................................................... 94

2.4.1.6 Moisture Content Vs. Slake Durability …………………………………………………... 96

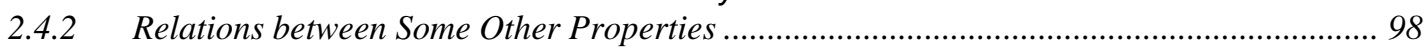

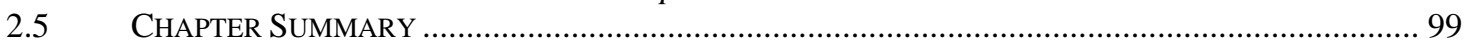

\section{CHAPTER 3: IN-SITU BEHAVIOR OF WEAK FLOOR IN THE ILLINOIS}

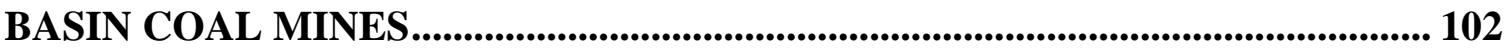

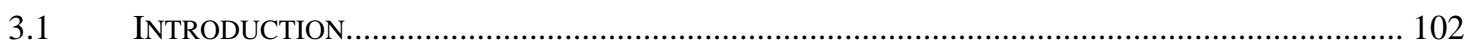

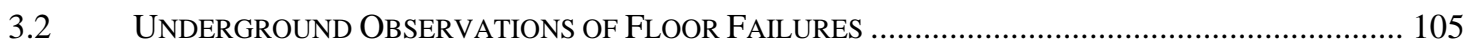




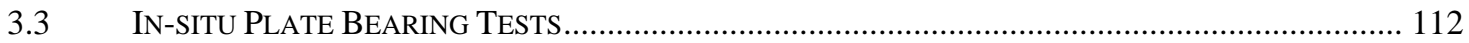

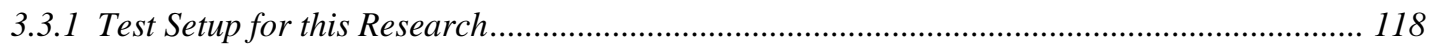

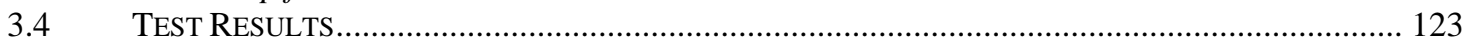

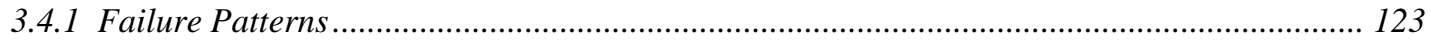

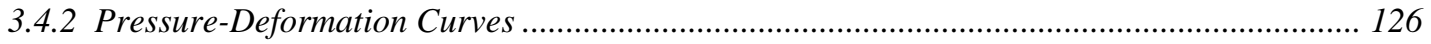

3.4.3 Plate Bearing Strength................................................................................................... 131

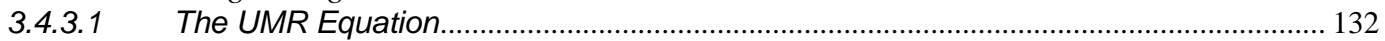

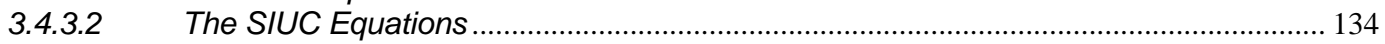

3.4.3.3 The Plate Bearing Test Database ................................................................................... 135

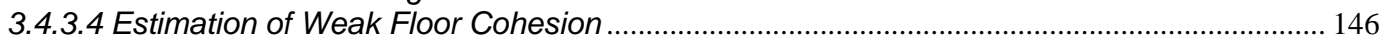

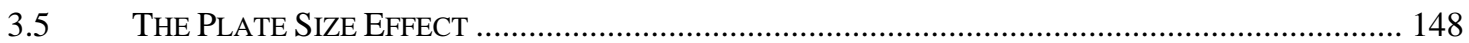

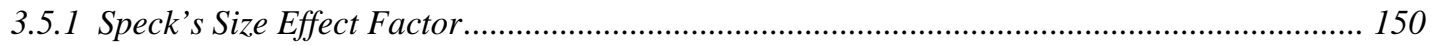

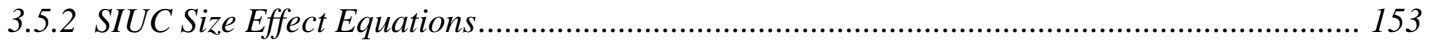

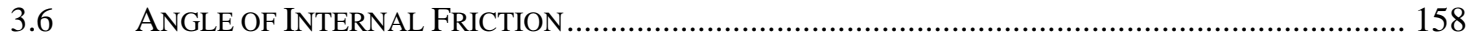

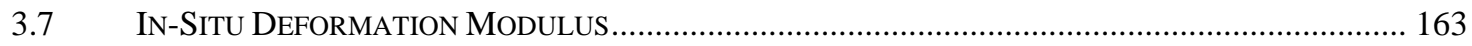

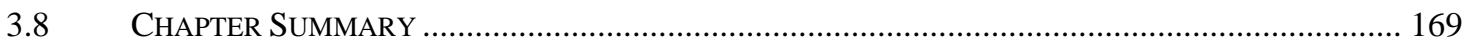

\section{CHAPTER 4: DETERMINATION OF FLOOR BEARING CAPACITY - SOIL}

MECHANICS APPROACH.................................................................... 171

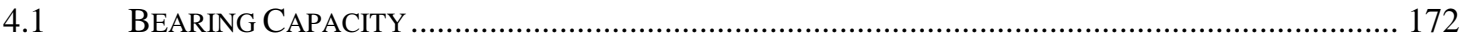

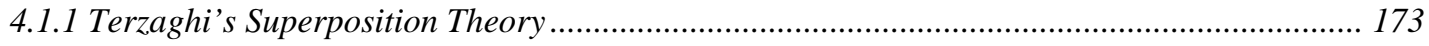

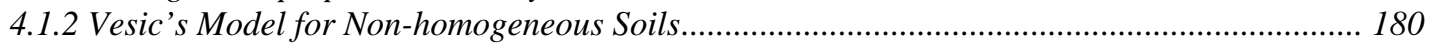

4.1.3 Pytel and Chugh's Adaptation of the Mandel and Salencon's model ..................................... 189

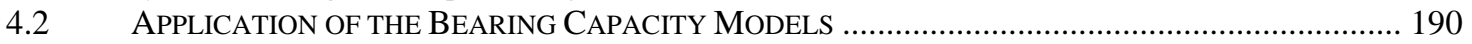

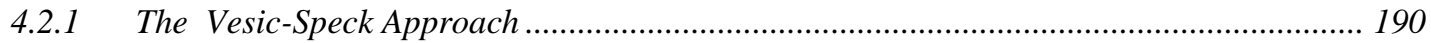

4.2.2 The Vesic-Chugh-Haq-Chandrashekhar (Vesic-CHC) Approach ....................................... 191

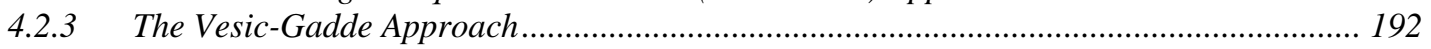

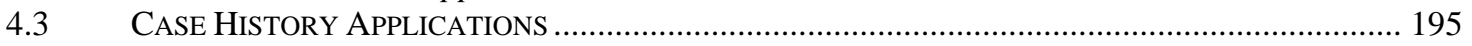

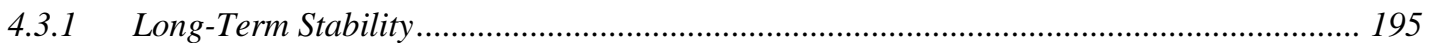

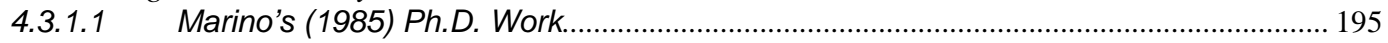

4.3.1.2 Illinois Abandoned Mined Lands Reclamation Council Database .................................... 207

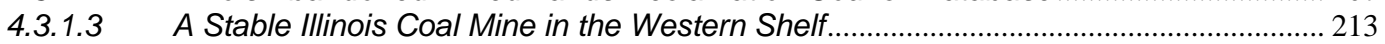

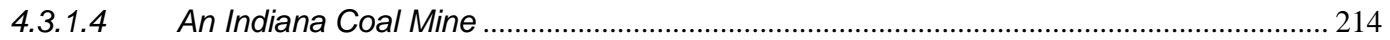

4.3.1.5 Some Other Stable Case Histories .............................................................................. 218

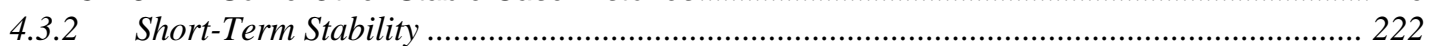

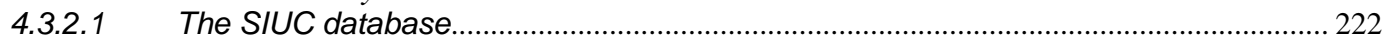

4.3.2.2 Two Illinois Coal Mines in the Eastern Shelf ................................................................... 227

4.3.2.3 A Western Kentucky Coal Mine....................................................................................... 229

4.3.2.4 An Indiana Coal Mine .......................................................................................... 232

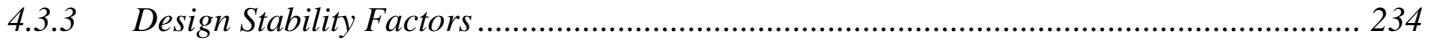

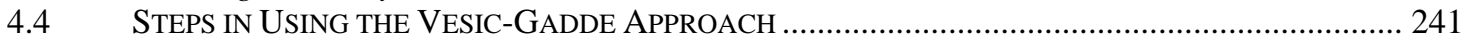

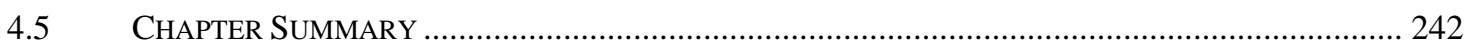

\section{CHAPTER 5: DETERMINATION OF FLOOR BEARING CAPACITY -}

NUMERICAL MODELING .......................................................................................... 244

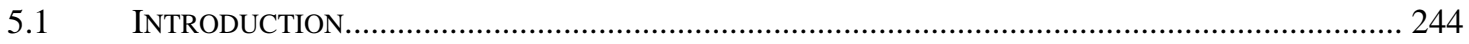

5.2 APPLICATION OF NUMERICAL MODELING IN THE FOUNDATION ENGINEERING LiTERATURE ... 256

5.3 DEVELOPMENT OF A NUMERICAL ModELING METHODOLOGY ……...................................... 265

5.4 EFFECT OF DiFFERENT VARIABLES ON THE ClasSicAl BEARING CAPACITY SOLUTION........... 274

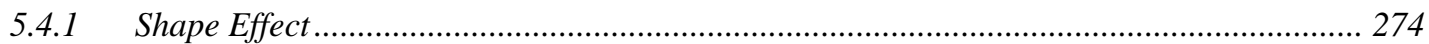

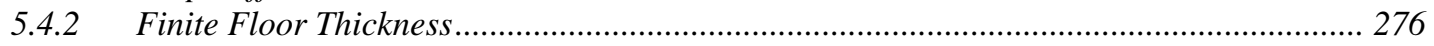

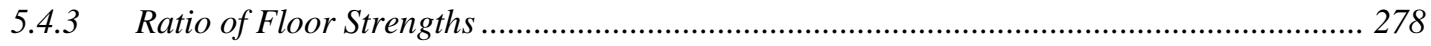

5.4.4 Strength Variation with Depth ............................................................................................ 279

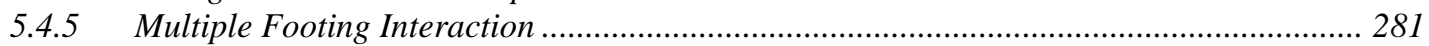

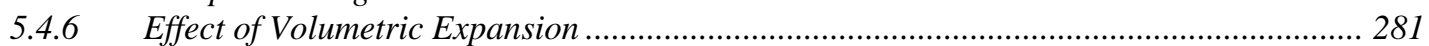

5.5 VERIFICATION OF VESIC's NON-HOMOGENEOUS BEARING CAPACITY EQUATION ................... 284 


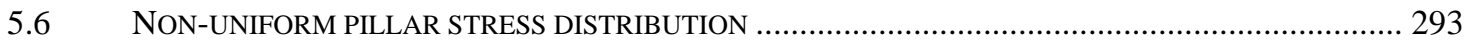

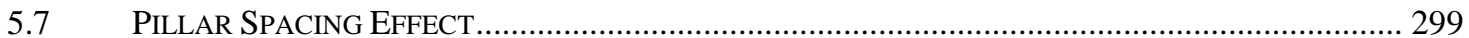

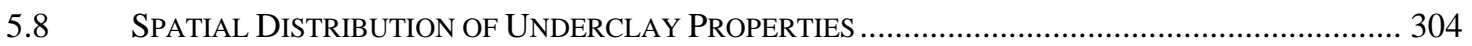

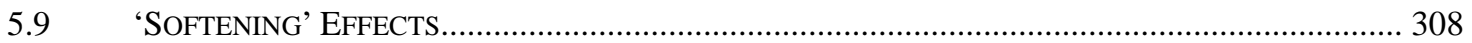

5.10 STEPS IN USING THE AUTHOR’s NUMERICAL MODELING APPROACH .......................................... 314

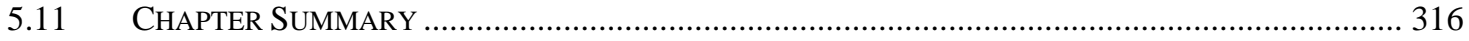

CHAPTER 6: FLOOR STABILITY DURING PERIMETER MINING ................ 320

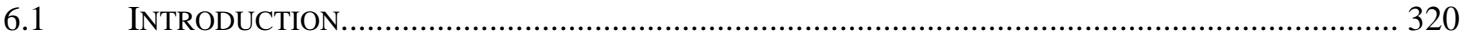

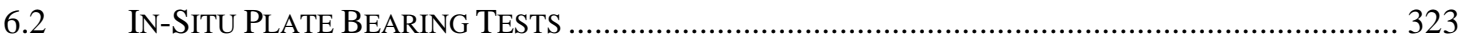

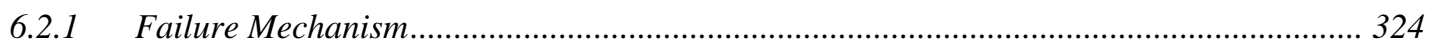

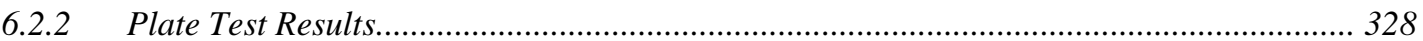

6.3 NUMERICAL BEARING CAPACITY ANALYSIS OF THE PERIMETER CUTS .................................... 332

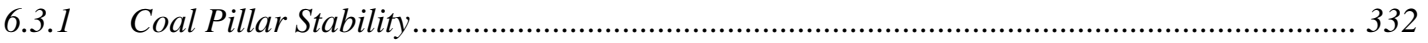

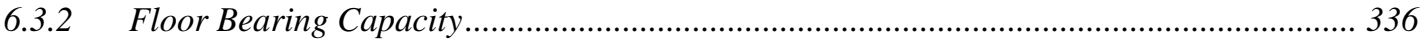

6.4 STEPS IN ASSESSING THE PERIMETER PILlar FloOR STABILITY ............................................ 345

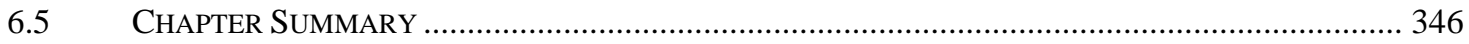

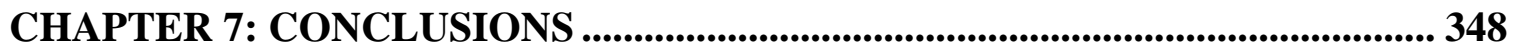

REFERENCES........................................................................................................ 356

APPENDIX - I .................................................................372

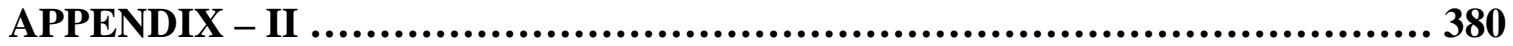

VITA...................................................................................393 


\section{LIST OF FIGURES}

Figure 1.1. Muddy conditions created by wet underclay floor.

Figure 1.2. Excessive closure of a mine entry due to unstable floor (the floor is almost touching the bottom idlers of the belt).

Figure 1.3. Gradual entry closure over a few years due to swelling floor under excess moisture (the closure at a few points in the entry exceeded $2 \mathrm{ft}$ ).

Figure 1.4. Water accumulation in a farm field due to changed drainage pattern after unplanned surface subsidence over a partial extraction room-and-pillar panel (a tensile subsidence crack found in the field is shown in the inset).

Figure 1.5. Two different types of floor heave at an Australian coal mine (Vasundhara, 2001)............ 6

Figure 1.6. Rib instability due to floor heave at an Australian mine (Vasundhara, 2001) ....................... 7

Figure 1.7. Abrupt floor failure in a longwall tailgate at a Colorado mine (after Haramy and McDonnell, 1986).

Figure 1.8. The two most common situations for floor stability analysis in

U.S. underground coal mines.

Figure 1.9. The first three runs of the immediate floor taken from a coal mine in the Western shelf of the Basin. 16

Figure 2.1. The outline of the Illinois Basin (Hatch and Affolter, 2002) ................................................ 25

Figure 2.2. General stratigraphic column of the Desmoinesian series. 26

Figure 2.3. Stratigraphic correlations of the Pennsylvanian rocks

in the three states of the IL Basin (the two major seams are marked). 27

Figure 2.4. North-South cross-section of the Pennsylvania rocks in the IL Basin (Hatch and Affolter, 2002). 27

Figure 2.5. Major geological structures in the IL Basin (Hatch and Affolter, 2002)................................ 28

Figure 2.6. An ideal cyclothem of Illinois (left) and its variability (right) .............................................. 29

Figure 2.7. Development stages of a Pennsylvanian swamp (O’Brien, 1964). ..................................... 34

Figure 2.8. Clay mineral facies variation in the underclay associated with the Herrin seam (Parham, 1964).

Figure 2.9. The two shelves of the Illinois Basin for floor stability analysis (the solid blue line forms the hypothetical divider). 37

Figure 2.10. Moisture change with depth below coal seam for three different mines. 40

Figure 2.11. Moisture change with depth below coal seam for a number of boreholes from two different mines 40

Figure 2.12. Driller's log, core pictures, gamma and density logs for example 1 44

Figure 2.13. Driller's log, core pictures, gamma and density logs for example 2.................................. 45

Figure 2.14. Driller's log, core pictures, gamma and density logs for example 3. 46 
Figure 2.15. Driller's log, core pictures, gamma and density logs for example 4

Figure 2.16. Key statistics and histograms of moisture content from three coal seam floors

(the moisture content statistics in the tables are in \%).

Figure 2.17. Key statistics and histograms of moisture content

for the Eastern and Western shelf of the No.6 seam floor

(the moisture content statistics in the tables are in \%).

Figure 2.18. Key statistics and histograms of moisture content for the Eastern and Western shelf of the No.5 seam floor (the moisture content statistics in the tables are in \%).

Figure 2.19. Porosity of the claystone floor for three different seam floors (the porosity statistics in the tables are in \%). 55

Figure 2.20. Degree of saturation of the claystone floor for three different seam floors (the degree of saturation statistics in the tables are in \%) . ............................................... 56

Figure 2.21. Percussion cup test set up for the liquid limit determination............................................ 58

Figure 2.22. Test set up for the plastic limit determination. 58

Figure 2.23. Liquid limit data for a) No.6 seam, b) No. 5 seam and c) No. 7 seam and their equivalent floors (the statistics in the tables are in \%). 60

Figure 2.24. Plastic limit data for a) No.6 seam, b) No. 5 seam and c) No. 7 seam and their equivalent floors (the statistics in the tables are in \%).

Figure 2.25. Plasticity index data for a) No.6 seam, b) No. 5 seam and c) No. 7 seam and their equivalent floors (the statistics in the tables are in \%).

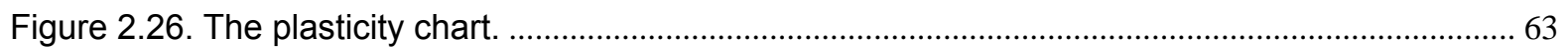

Figure 2.27. The plasticity chart for the No.6 seam floor data. ............................................................64

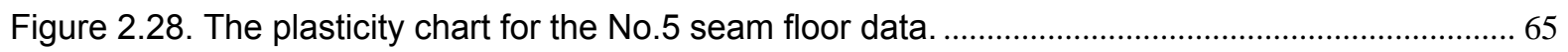

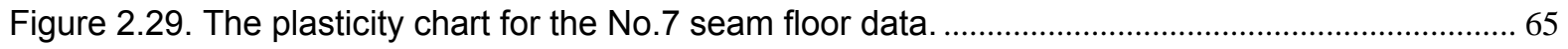

Figure 2.30. Comparison of the liquid limit data from the (a) Western and (b) Eastern shelf mines for the No.6 seam floor (the statistics in the tables are in \%).

Figure 2.31. Comparison of the plastic limit data from the mines in the (a) Western and (b) Eastern shelf for the No.6 seam floor (the statistics in the tables are in \%). 68

Figure 2.32. Comparison of the liquid limit data from the mines in the (a) Western and (b) Eastern shelf for the No.5 seam floor (the statistics in the tables are in \%)......

Figure 2.33. Comparison of the plastic limit data from the mines in the (a) Western and (b) Eastern shelf for the No.5 seam floor (the statistics in the tables are in \%). 70

Figure 2.34. Liquidity index data for the a) No.6, b) No.5 and c) No.7 seam floors. 72

Figure 2.35. Relation between the liquidity index and the degree of consolidation.

Figure 2.36. Distribution of a) sand-size, b) silt-size, and c) clay-size fractions for the Herrin No. 6 and its equivalent seam floors (the statistics in the table are in \%). 75 
Figure 2.37. Distribution of a) sand-size, b) silt-size, and c) clay-size fractions for the Springfield No. 5 and its equivalent seam floors (the statistics in the tables are in \%) ................................. 76

Figure 2.38. Potential expansiveness chart given in the Army manual................................................. 77

Figure 2.39. Potential expansiveness of the No.6 seam floor.............................................................. 78

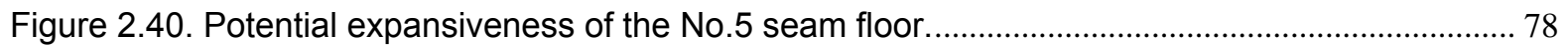

Figure 2.41. Peak friction angle as a function of plasticity index (Mesri and Abdel-Ghaffar, 1993)...... 80

Figure 2.42. Residual friction angle as a function of the liquid limit and clay-size fraction

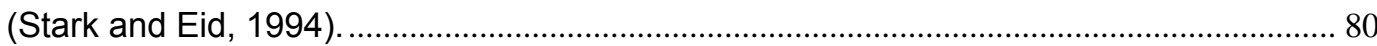

Figure 2.43. Activity index data for a) No. 6 and b) No.5 seam floors. ................................................... 82

Figure 2.44. Peak swelling strain for a) No. 6 and b) No.5 seam floors

(the statistics in the tables are in \%).

Figure 2.45. Relation between a) uniaxial compressive strength, b) elastic modulus and moisture of weak floor samples from NSW, Australia (Seedsman and Gordan, 1991)............................................ 86

Figure 2.46. Relation between uniaxial compressive strength and moisture of weak floor samples ( $\mathrm{Li}$ and Smith, 1998).

Figure 2.47. Relation between the moisture content and the Atterberg limits88 for the No.6 seam floor.

Figure 2.48. Relation between the moisture content and the Atterberg limits for the No.5 seam floor.89 Figure 2.49. Relation between the moisture content and the Particle-size for the No.6 seam floor.... 90 Figure 2.50. Relation between the moisture content and the Particle-size for the No.5 seam floor. ... 91 Figure 2.51. Relation between the moisture content and the UCS for_a) No.6 and b) No.5 seam floors.

Figure 2.52. Relation between the moisture content and tensile strength for_a) No.6 and b) No.5 seam floors 94

Figure 2.53. Relation between the moisture content and sonic properties_for the a) No.6, and b) No. 5 seam floors. 96

Figure 2.54. Relation between P-wave velocity and the uniaxial compressive strength_for the a) No.6, and b) No. 5 seam floors. 97

Figure 2.55. Relation between the moisture content and slake durability indices for the a) No.6, and b)

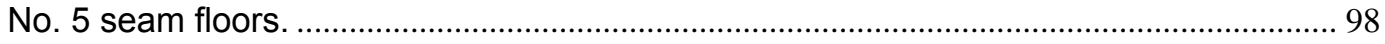

Figure 3.1. Different modes of shear failure below a foundation (Vesic, 1963).................................... 104

Figure 3.2. Different modes of floor failure in underground coal mines (Rockaway and Stephenson, 1979). 106

Figure 3.3.'Softening' mode of floor failure (Marino and Choi, 1999). 107

Figure 3.4. Failure mechanism suggested by the Australian Coal Industry Research Laboratories Ltd. (ACIRL, 1987) 109

Figure 3.5. Condition of the floor in the test pit dug in the split pillar (Vasundhara et al., 2001). 111 
Figure 3.6. Test setup for the deformation modulus determination using the ISRM suggested procedure.

Figure 3.7. Plate test setup used by Chlumecky (1968). 114

Figure 3.8. Test setup used for the Barry and Nair (1970) work. ....................................................... 115

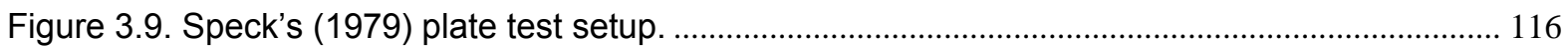

Figure 3.10. Plate test setup used by the SIUC (Chugh, 1986b)................................................... 117

Figure 3.11. Plate test setup used in the Su et al., (1993) tests....................................................... 118

Figure 3.12. Field view of the plate test set up used in the present research. ..................................... 120

Figure 3.13. Schematic of the plate test set up used in the current research. ...................................... 121

Figure 3.14. Contact stress distribution for (a) flexible and (b) rigid footing (Das, 1999).................... 121

Figure 3.15. Failure patterns noticed during a test that exhibited general shear failure....................... 124

Figure 3.16. Punching floor failure under very wet floor conditions. ...................................................... 125

Figure 3.17. Wedge of floor stuck to the plate at the end of an in-situ test.......................................... 126

Figure 3.18. Stress-deformation curves obtained at an Illinois coal mine (Chugh, 1986b)................ 127

Figure 3.19. Example pressure-settlement curves obtained at different mines in this research with no

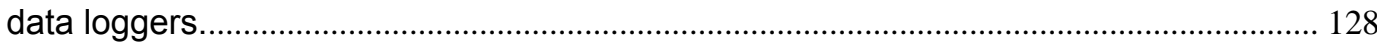

Figure 3.20. Example pressure-settlement curve obtained via a data logger. ..................................... 128

Figure 3.21. Pressure-settlement curves obtained by the "let-the-floor-decide-the-loading-rate"

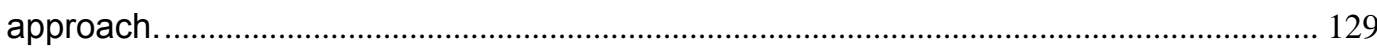

Figure 3.22. Plate pressure-settlement curve obtained with uniform rate of loading. ........................ 130

Figure 3.23. Laboratory triaxial strength data obtained by Speck (1979)........................................... 133

Figure 3.24. Moisture content versus ultimate plate bearing capacity for all the test data................. 139

Figure 3.25. Performance of the Speck and SIUC floor strength equations against plate test data from (a) the Western and (b) Eastern shelf mines. 141

Figure 3.26. The best fit equation if individual site liquid limit data are included in the regression. ... 142 Figure 3.27. Plot of individual Gadde's equations against a) Eastern shelf,_b) Western shelf and c) all

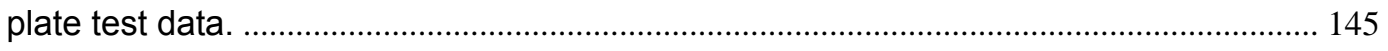

Figure 3.28. Size effect for different floor types tested by Jenkins (1960)......................................... 149

Figure 3.29. Size effect displayed by Chlumecky data (1968)................................................................ 150

Figure 3.30. Size effect displayed by Barry and Nair data (1970)......................................................... 151

Figure 3.31. SIUC size effect factors against the moisture content. ...................................................... 155

Figure 3.32. Plate bearing strength predicted by different SIUC equations.......................................... 156

Figure 3.33. UBC vs plate size for the SIUC tests (Yu et al., 1993).................................................. 156

Figure 3.34. UBC vs plate size for the plate test database in this research. ........................................ 157

Figure 3.35. Bore hole shear tester developed by Haramy (1981)...................................................... 159

Figure 3.36. Relation between Atterberg Limits and moisture content for the data in Tables 3.2 and 3.3. 
Figure 3.37. Relation between Atterberg Limits and peak friction angle (Mesri and AbdelGhaffar, 1993).

Figure 3.38.Deformation modulus versus moisture content 167

Figure 4.1. Load-vertical displacement relationship for a shallow foundation (after Vesic, 1975)...... 173

Figure 4.2. Outlines of the plastic zones when the soil reached limit state for a strip footing (Terzaghi et al., 1996). 175

Figure 4.3. Typical underground coal mine geometry in the IL Basin coal mines. 179

Figure 4.4. Two common situations of soil nonhomogeneity (after Vesic, 1975)................................. 182

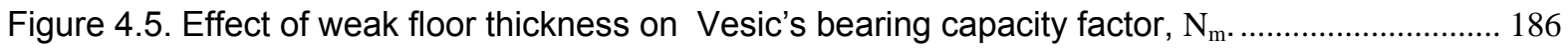

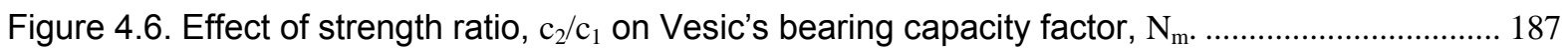

Figure 4.7. Effect of the pillar aspect ratio, L/B on Vesic's bearing capacity factor, $\mathrm{N}_{\mathrm{m}}$ 187

Figure 4.8. The unstable area, the representative geological column and the pillars selected for floor stability factor estimation for Case 1, Case 2 and Case 3. 197

Figure 4.9. The geologic column and the moisture content data from Hole 1 in Figure 4.8............... 198 Figure 4.10. The geologic column and moisture content data form Hole 2 in Figure 4.8. 199

Figure 4.11. Subsidence measurements along the monument lines shown in Figure 4.8 for a) case 1, b) case 2 and c) case 3 (Marino, 1985). 200

Figure 4.12. The subsided area and representative geological column for Case 4 (Marino, 1985)... 205 Figure 4.13. The subsided area, sag profile and representative geological column for Case 4 (Marino, 1985). 206

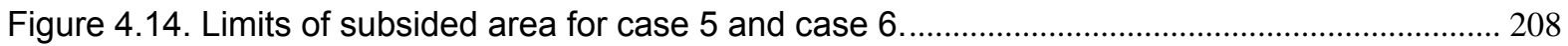

Figure 4.15. Portion of the mine involved in the subsidence for case history 7................................... 209

Figure 4.16. Portion of the mine involved in the subsidence for case history 8. ................................... 209

Figure 4.17. Pillar geometry near a rock mechanics borehole for the case history 9......................... 213

Figure 4.18. Stable and unstable areas for the case history 10 .......................................................... 216

Figure 4.19. Change in the moisture content with depth below the coal seam for two boreholes near the unstable area for case history 10 ................................................................................... 217

Figure 4.20. Stable and unstable areas for the case history 11 ...................................................... 217

Figure 4.21. Stable and unstable areas for the case history 12......................................................... 218

Figure 4.22. Cumulative frequency plot of floor stability factors for failed pillars (Pytel and Chugh, 1992).

Figure 4.23. Cumulative frequency plot of floor stability factors for stable pillars (Pytel and Chugh, 1992). 223

Figure 4.24. Comparison of floor stability factors for the SIUC No.6 seam data.................................. 226

Figure 4.25. Comparison of floor stability factors for the SIUC No.5 seam data.................................. 227

Figure 4.26. Initial stage of localized floor heave in a Zeigler coal mine (Speck, 1979).................... 228

Figure 4.27. Area affected by floor instability at a Western Kentucky mine.......................................... 231 
Figure 4.28. Pictures showing (a) rib rash and (b) floor heave adjacent to the rib line at a Western Kentucky coal mine

Figure 4.29. Short-term floor instability at an Indiana coal mine. 233

Figure 4.30. The long-term case history FSF distribution for the Vesic-Speck approach.................... 234

Figure 4.31. The long-term case history FSF distribution for the Vesic-CHC approach..................... 235

Figure 4.32. The long-term case history FSF distribution for the Vesic-Gadde approach................... 237

Figure 5.1. Features of a typical coal mine bearing capacity problem.

Figure 5.2. The finite element mesh and the results for a two-layered floor system obtained by Rockaway and Stephenson (1979). 250

Figure 5.3. The finite element mesh and the results for a three-layered floor system obtained by Rockaway and Stephenson (1979). 250

Figure 5.4. Change in maximum shear stress as a function of underclay thickness (Bandopadhay, 1982).

Figure 5.5. Concept of floor softening developed by Marino and Choi (1999). 253

Figure 5.6. Distribution of yield zones around longwall face area under weak floor conditions simulated by Deb et al., (2000).

Figure 5.7. Floor heave in a longwall gallery simulated by Yavuz et al., (2003). 255

Figure 5.8. the finite element mesh used in the Griffiths' (1982)study. 257

Figure 5.9. Comparison of theoretical and modeling computed $N_{c}$ values (after Griffiths, 1982)...... 257

Figure 5.10. Diagonal symmetry of surface displacements for a smooth square footing (Michalowski and Dawson, 2002). 259

Figure 5.11. Displacements and deformed geometry of two interfering footing over stochastic clay (Griffiths et al., 2006). 261

Figure 5.12. Bearing capacity under vertical loading $\left(\mathrm{V}_{\mathrm{ult}}\right)$ normalized by limit strength of an isolated footing $\left(\mathrm{V}_{\text {ult(single) }}\right)$ as a function of spacing (s) over footing width (B)_(Gourvenec and Steinepreis, 2007). 262

Figure 5.13. Variation of efficiency factor with spacing for different friction angles(after Kumar and Kouzer, 2007). 263

Figure 5.14. FLAC ${ }^{3 \mathrm{D}}$ mesh used in the verification models. 267

Figure 5.15. Pressure-deformation curve obtained from $\mathrm{FLAC}^{3 \mathrm{D}}$ modeling for $\mathrm{c}=150 \mathrm{psi}$ and $\phi=5^{\circ}$ for a strip footing on semi-infinite homogeneous soil. 271

Figure 5.16. Extent of yielding for different loading points identified in Figure 5.15 (Blue elements are elastic and the other colors indicate yield zones at different stages of solution). 272

Figure 5.16 (Continued). Extent of yielded elements for different loading points identified in Figure 5.15. 273

Figure 5.17. Contours of a) shear strain rate and b) velocity for the loading state corresponding to point $\mathrm{H}$ in Figure 5.15. 
Figure 5.18. Contours of a) displacement and b) shear strain rate for a square footing on semi-infinite homogeneous floor for $\phi=5^{\circ}$ (parameter values highest for red, lowest for blue with

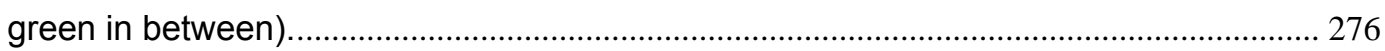

Figure 5.19. Change in bearing capacity as a function of floor thickness. ........................................... 277

Figure 5.20. Shear strain rate contours along with displacement vectors for $a) B / H=2 b$ ) $B / H=13.3$.

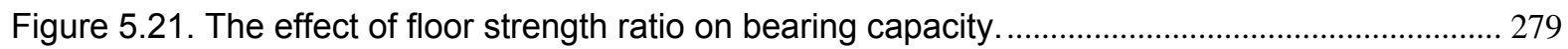

Figure 5.22. Change in Bearing Capacity for a linear variation of floor cohesion................................. 280

Figure 5.23. The effect of footing spacing on bearing capacity............................................................ 281

Figure 5.24. Ratio of model ultimate bearing capacity with and without including dilation angle for different model conditions.

Figure 5.25. Contours of shear strain rate along with displacement vectors for the case of semi-infinite strip footing with a) $\psi=5^{\circ}$ and b) $\psi=20^{\circ}$.

Figure 5.26. FLAC ${ }^{3 \mathrm{D}}$ mesh used for Vesic equation verification for a square footing with $\mathrm{B} / \mathrm{H}=10$ and $\mathrm{C}_{2} / \mathrm{C}_{1}=3$ (also shown is the footing) ............................................................................... 286

Figure 5.27. Change in model bearing capacity factor with $\mathrm{B} / \mathrm{H}$ for a square footing. ......................... 288

Figure 5.28. Change in model bearing capacity factor with $\mathrm{C}_{2} / \mathrm{C}_{1}$ for a square footing....................... 289

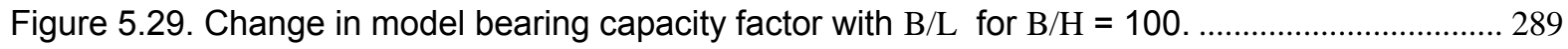

Figure 5.30. Change in the ratio of model- to Vesic bearing capacity factors as a function of $\mathrm{B} / \mathrm{H}$ for a

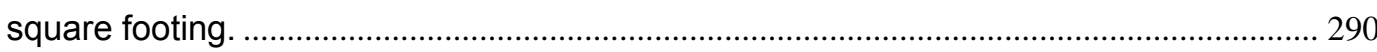

Figure 5.31. Increasing in bearing capacity factor, $N_{m}$ with $B / H$ for a square footing when a) $c_{2} / c_{1}=2$, b) $\mathrm{c}_{2} / \mathrm{c}_{1}=5$. 292

Figure 5.32. Part of the modeled geometry to study the non-uniform vertical stress distribution effect on bearing capacity 294

Figure 5.33. The variation of resultant vertical stress on floor for a non-uniform pillar stress distribution.

Figure 5.34. Part of the modeled geometry to study the uniform loading effect on bearing capacity. 296

Figure 5.35. The variation of resultant vertical stress on floor for the uniform vertical displacement induced loading ..................................................................................................................... 296

Figure 5.36. Localized floor instability noticed in an Illinois Basin coal mine. 298

Figure 5.37. Typical meshes used for the simulation of adjacent pillar effect for a) strip and b) square pillars. 300

Figure 5.38. Model results for multiple strip pillars, a) contours of minimum principal stress, (negative numbers indicate compression) and b) displacement vectors at the limit state. 303

Figure 5.39. Model results for multiple square pillars, a) contours of minimum principal stress, (negative numbers indicate compression) and b) displacement vectors at the limit state. 
Figure 5.40. Random values of cohesion assigned to different points in the floor. 306

Figure 5.41. Uniform cohesion value (596 psi) assigned to different points in the floor for the same conditions as in Figure 5.40 . 307

Figure 5.42. Average pressure-vertical deformation curves for a) uniform, and b) randomly distributed floor properties. 307

Figure 5.43. Schematic of progressive deterioration of clay shales (Botts, 1986). 310

Figure 5.44. Schematic of the possible change in the constitutive behavior as a function of softening illustrated in Figure 5.43 (Botts, 1986).

Figure 5.45. Different depths of softening considered for the analysis................................................ 313

Figure 6.1. Perimeter cut sequence for four pillars wide rooming....................................................... 321

Figure 6.2. Perimeter cut sequence for two pillars wide rooming.......................................................... 321

Figure 6.3. Geometry of the perimeter plate used in the field tests. .................................................... 324

Figure 6.4. Perimeter plate loaded by a solid rectangular plate. ............................................................. 325

Figure 6.5. Two views of the initial stage of failure development in the perimeter cuts. ...................... 326

Figure 6.6. Two views of the final stage of failure in the perimeter cuts............................................... 326

Figure 6.7. Pressure-deformation curve obtained from No.6 seam floor. ............................................. 327

Figure 6.8. Pressure-deformation curve obtained from No.9 seam floor in KY..................................... 327

Figure 6.9. Pressure-deformation curve obtained from No.7 seam floor in IN. .................................... 328

Figure 6.10. Natural moisture content vs bearing capacity plot for all the square and perimeter plate tests conducted at the five mines in Table 6.1 ..................................................................... 331

Figure 6.11. Vertical stress distribution on different pillars in a panel using perimeter mining. .......... 335

Figure 6.12. Partitioning of perimeter pillar into individual components. ............................................... 336

Figure 6.13. Part of the model used for the perimeter pillar floor bearing capacity analysis............... 338

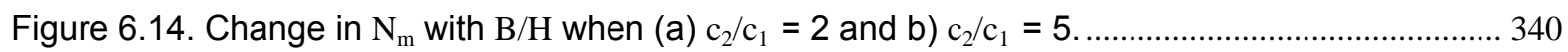

Figure 6.15. Change in the ratio of the model computed perimeter and square pillar bearing capacity for different $\mathrm{c}_{2} / \mathrm{c}_{1}$ values. 340

Figure 6.16. Vertical displacement contours at the limit state for $\mathrm{B} / \mathrm{H}=20$ and $\mathrm{c}_{2} / \mathrm{c}_{1}=3$ (negative sign shows downward movement). 341

Figure 6.17. Vertical stress contours at the limit state for $\mathrm{B} / \mathrm{H}=20$ and $\mathrm{c}_{2} / \mathrm{c}_{1}=3$ (negative sign shows compression). 341

Figure 6.18. Deformed floor and displacement vectors for perimeter pillar when $\mathrm{B} / \mathrm{H}=20$ and $\mathrm{c}_{2} / \mathrm{c}_{1}=3$ (only half width is shown).

Figure 6.19. Deformed floor and displacement vectors for square pillar when $B / H=20$ and $c_{2} / c_{1}=3$ (only a quarter pillar area shown). 343

Figure 6.20. Deformed floor and displacement vectors for a strip pillar when $B / H=20$ and $\mathrm{c}_{2} / \mathrm{c}_{1}=3$ (only half pillar area shown) 344

Figure 7.1. Peak friction angle as a function of plasticity index (Mesri and Abdel-Ghaffar,1993)...... 351 
xviii

Figure 7.2. Residual friction angle as a function of the liquid limit and clay-size fraction (Stark and Eid, 1994). . 


\section{LIST OF TABLES}

Table 2.1. Engineering behavior of a soil in relation to the plasticity chart (Casagrande, 1948)... 64

Table 2.2. Activity Index values for some common clay minerals (Mitchell and Soga, 2005)........ 82

Table 2.3. Equations to estimate floor triaxial strength as a function of several index tests

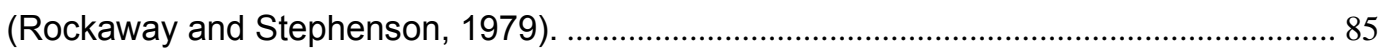

Table 2.4. Equations to estimate different weak floor properties (Pula et al., 1990)........................ 85

Table 2.5. Interrelations between different properties for two seam floors. ...................................... 99

Table 3.1. Laboratory triaxial strength data of underclay used in deriving Speck's equation...... 133

Table 3.2. Plate test data from the Eastern Shelf coal mines.......................................................... 136

Table 3.3. Plate test data from the Western Shelf coal mines........................................................ 137

Table 3.4. In-situ borehole shear tests on underclay material at two Illinois coal mines (Chugh, 1986b). 160

Table 3.5. Comparison of friction angles from Chugh (1986b) tests and those computed using equations (3.22) and (3.25) in conjunction with Figure 3.37 ............................................. 163

Table 3.6. Match between the numerical model results and field data............................................ 166

Table 3.7. Deformation modulus and other details from the plate test sites................................... 168

Table 4.1. Floor stability factors for Marino's case 1 . ......................................................................... 202

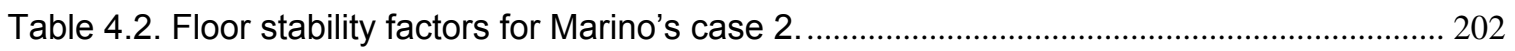

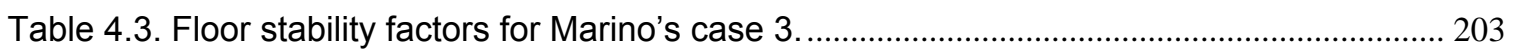

Table 4.4. Floor stability factors for stable pillars adjacent to unstable Case 1 through Case 3. 204

Table 4.5. Floor stability factors for unstable pillars in Marino's case 4 .......................................... 206

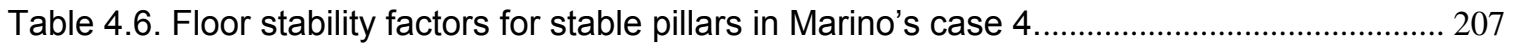

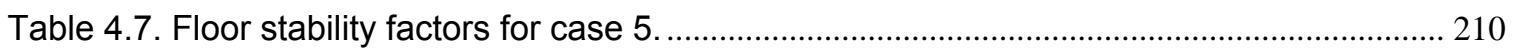

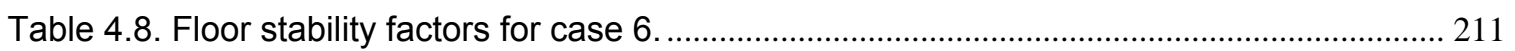

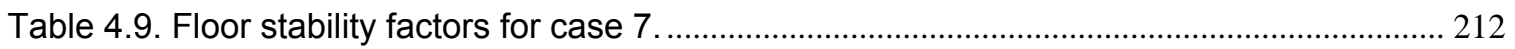

Table 4.10. Floor stability factors for case 8. ................................................................................ 212

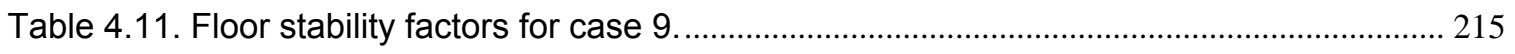

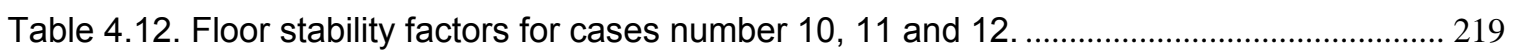

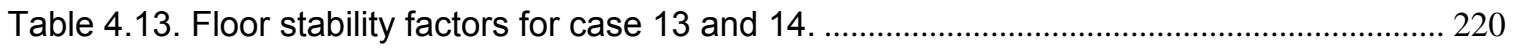

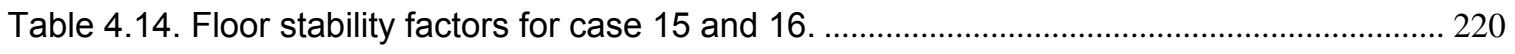

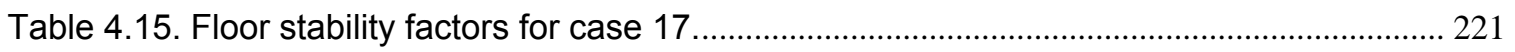

Table 4.16. Floor stability factors for Speck's case histories. ........................................................ 230

Table 4.17. Floor stability factors for the Western Kentucky mine................................................... 231

Table 4.18. Floor stability factors in the mains at an Indiana coal mine........................................... 233

Table 5.1. Numerical convergence studies for the mesh size effect. ............................................. 269

Table 5.2. Comparison of theoretical and modeling based bearing capacity factor, $\mathrm{N}_{\mathrm{c}}$ for $\mathrm{a}$ constant cohesion equals to $150 \mathrm{psi}$. 
Table 5.3. Comparison of Model and traditional bearing capacity estimates for an isolated square footing resting on a semi-infinite homogeneous floor. ........................................................... 276

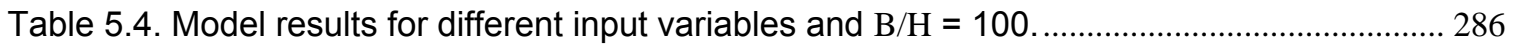

Table 5.5. Model results for different input variables and $\mathrm{B} / \mathrm{H}=40,20$ and 10.......................... 287

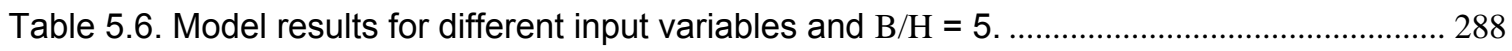

Table 5.7. Effect of interference of multiple square footings in close proximity. ............................ 301

Table 5.8. Effect of interference of multiple strip footings in close proximity................................... 302

Table 5.9. Change in the bearing capacity factor, $\mathrm{N}_{\mathrm{c}}$ with depth of softening. ................................ 313

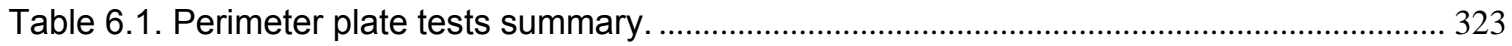

Table 6.2. Individual perimeter and square plate test results from each site at the five mines. .. 330

Table 6.3. Average values of the bearing capacity and moisture content from the plate tests.... 330

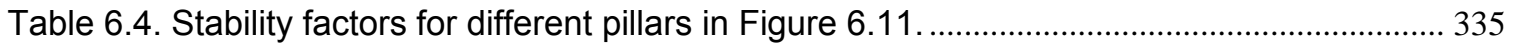

Table 6.5. Summary of the numerical modeling results for the perimeter pillar models............... 339 


\section{CHAPTER}

\section{1 introouction}

In the Illinois Basin, all major mineable coal seams are associated with weak immediate floor materials. Geologically, the weak bed right below the coal seam is termed underclay. Miners refer to the same material as fireclay while a majority of drillers log it as claystone. Some other terms like seat earth, seat rock, Wurzelböden, clunch, girt and ganister were also used in different parts of the world to describe such weak foundation materials (Speck, 1979). When extracting coal over the underclay floors, it is possible to encounter several operational and stability issues. Operationally, in wet areas of a mine, the easily degradable underclay creates muddy conditions that hamper equipment movement and produce uncomfortable working conditions for the miners such as those shown in Figure 1.1.

From the ground control point of view, underclay can create both shortand long-term stability problems. In this context, the category short-term refers to the useful life span of an opening for any mining related activity. Any issue that arises after the opening is abandoned will fall under the long-term category. By this definition, the short-term stability issues could arise in a matter of days to a few years. Since it is hard to differentiate the short- and long-term stability by an absolute number, the above definition has been used for its practical convenience. Besides, when past experience with surface subsidence due to weak floor instability is considered, the working definition adopted in this work for the short and long-term stability will serve the purpose.

In the short-term, the weak floor when acted upon by excess stresses can fail and the resulting deformations can lead to partial or complete closure of a mine opening as seen in Figure 1.2. Past experience shows that the short-term floor instability may occur over a limited length of a single opening or may necessitate abandonment of a whole panel or a section of a mine. Further, if the 


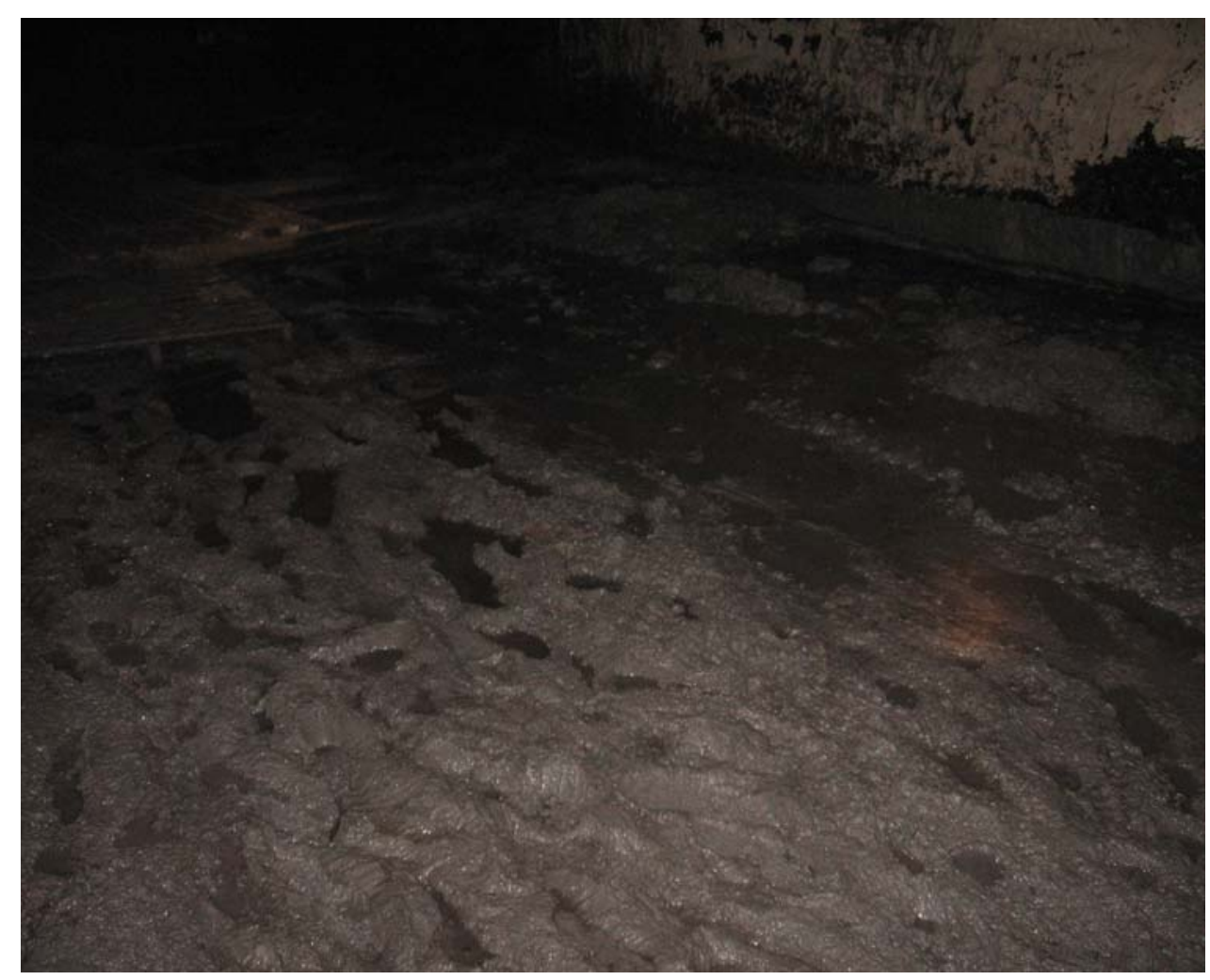

Figure 1.1. Muddy conditions created by wet underclay floor.

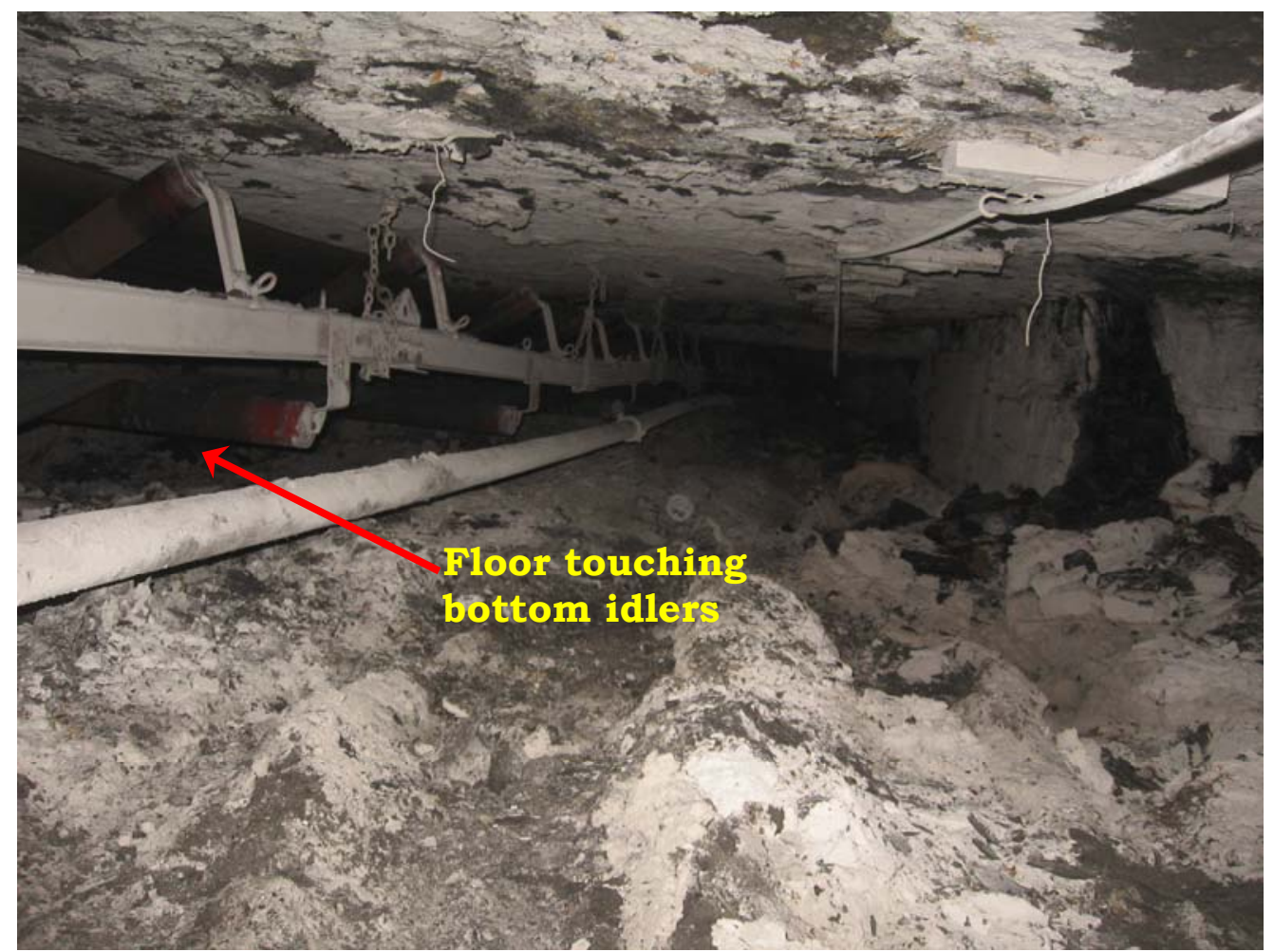

Figure 1.2. Excessive closure of a mine entry due to unstable floor (the floor is almost touching the bottom idlers of the belt). 


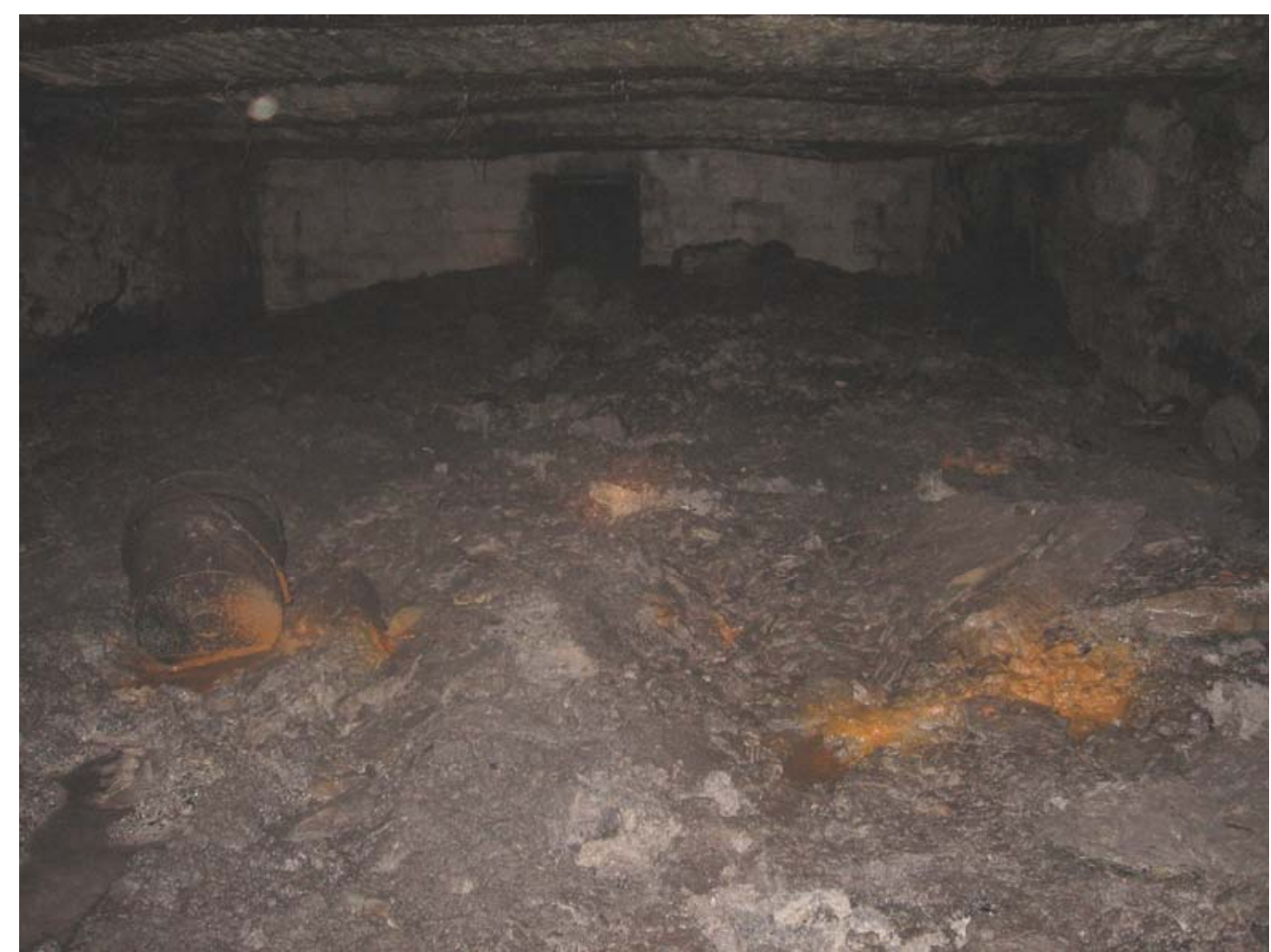

Figure 1.3. Gradual entry closure over a few years due to swelling floor under excess moisture (the closure at a few points in the entry exceeded $2 \mathrm{ft}$ ).

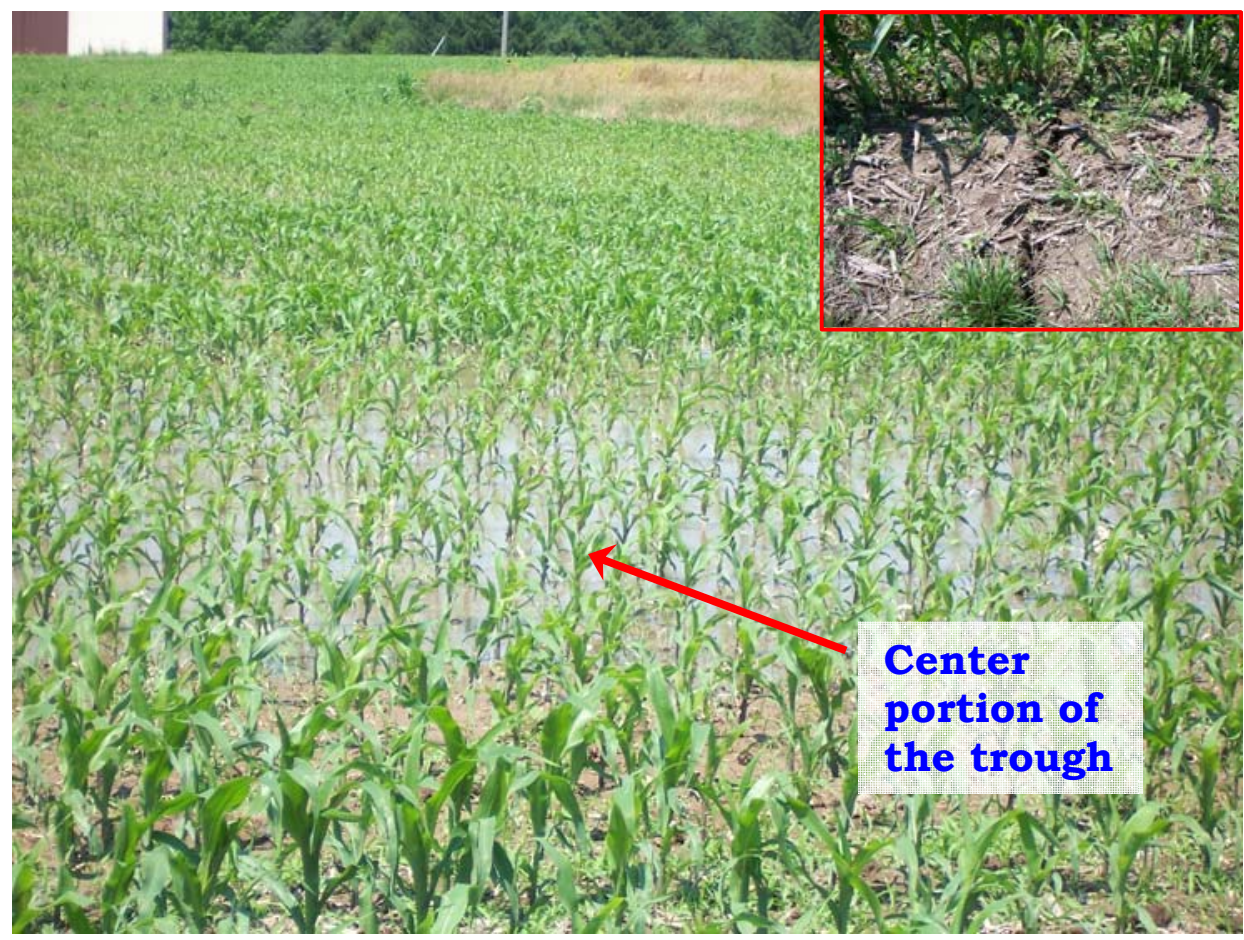

Figure 1.4. Water accumulation in a farm field due to changed drainage pattern after unplanned surface subsidence over a partial extraction room-and-pillar panel (a tensile subsidence crack found in the field is shown in the inset). 
nature of the floor beneath adjacent pillars varies, then the resulting differential settlement of the pillars could cause roof failures. Experience shows that some localized floor "swelling" may also occur over a period of time when excess moisture is available for the floor to absorb and expand such as that shown in Figure 1.3.

In the long-term, an unstable underclay floor can lead to unplanned surface subsidence and cause damage to surface features similar to that happened to the farm land in Figure 1.4. A major portion of the mineable area in the Illinois Basin is covered by prime farm lands or some other surface structures, which do not tolerate surface subsidence. In fact, excluding a few longwalls, almost all the current Illinois Basin underground mines conduct partial extraction such that no planned surface subsidence occurs. Despite such preventive measures, instances of structural and farm land damage claims are frequently filed in the Basin. However, unlike roof failures, an unstable weak floor rarely poses an immediate danger to the safety of the miners working underground.

\subsection{Snapshot of Global Experience with Weak Floor Stability}

Some experience with mining over weak immediate floor exists in all major coal producing countries around the world. Based on the primary focus of the work, the available research on weak immediate floor stability could be identified with one of the two applications: standing support or coal pillar and entry stability. In fact, the bulk of the fundamental work done prior to 1975 was mainly to determine if the floor beneath a standing support would provide an adequate foundation or not. However, starting with the late 1970s, the weak floor research emphasis has shifted to pillar and entry stability. A few publications could still be found on floor stability from the standing supports point of view, which are mainly focused on longwall mining applications.

Some of the classic earlier studies on floor were conducted by Jenkins (1955, 1957, 1958, 1960) in Great Britain in connection with standing support designs. His research on support bearing capacity led to the conclusion that the 
floor strength depended on the shape and perimeter of the support base more than on the support's area. Jenkins showed that the bearing capacity of floor would decrease with an increase in the support base size and also that the floor strength was dependent on the rate of loading and could vary from place to place significantly. In a research on weak floor issues in the South Wales coalfields, Wilson (1965) found that the plastic behavior of the underclay was due to the material's texture, particle-size distribution of non-clay minerals and the extent of ionic substitution in the clays. Some physical model studies on floor stability were conducted by Hobbs (1969a, 1969b), Shepherd (1970) and Whittaker and Batchelor (1972) to explain different issues related to the problem.

Krishna and Whittaker (1973) were among the first researchers to categorize floor heave into several types. Their observations led to the following three categories of floor heave: 1) extrusion of underclay from under a solid coal pillar, 2) buckling of floor strata, and 3) penetration of the floor by steel arch legs when steel sets were used for support. They recommended floor bolting to handle the problem. Afrouz (1975a, 1975b) reported that floor behavior could be significantly impacted by increased water content. His studies showed that for every $1 \%$ increase in water content, the underclay heave increased by $0.7 \%$.

In Australia, weak floor stability issues were reported in three areas: Newcastle, Bowen Basin and Southern coalfields (Vasundhara, 2001). It appears that floor heave in galleries was the main problem faced by collieries with weak floor in the Newcastle coalfield as shown in Figure 1.5 and Figure 1.6. Vasundhara (2001) provided an extensive literature review and a summary of several case histories from Australia where floor squeeze, pillar rash, roof falls and surface subsidence were noticed due to weak floor failure. Her review of Australian case histories showed that multiple factors played a role in the observed instability and no single technique would have solved all the problems. Recently, Nemcik et al., (2000) from Australia developed a simple analytical model using multiple sliding blocks to explain floor failure ahead of a longwall face. 
Latilla and Oldroyd (1996) reported a few case histories from South Africa where pillar instability was triggered by weak floor conditions. They reported pillar instability issues from three coal seams underlain by $1.5 \mathrm{ft}$ thick soft strata at depths between $100 \mathrm{ft}$ and $560 \mathrm{ft}$. These South African researchers concluded that excess pillar stresses and smaller pillar width to floor thickness ratio were the responsible factors for the noticed instability. Pillar failures under the influence of thick weak floor at Emaswati Colliery in South Africa occurred even though the traditional safety factors of those pillars were very high (Latilla, 2004). Extensive literature review by Latilla (2004) showed that some coal seams in

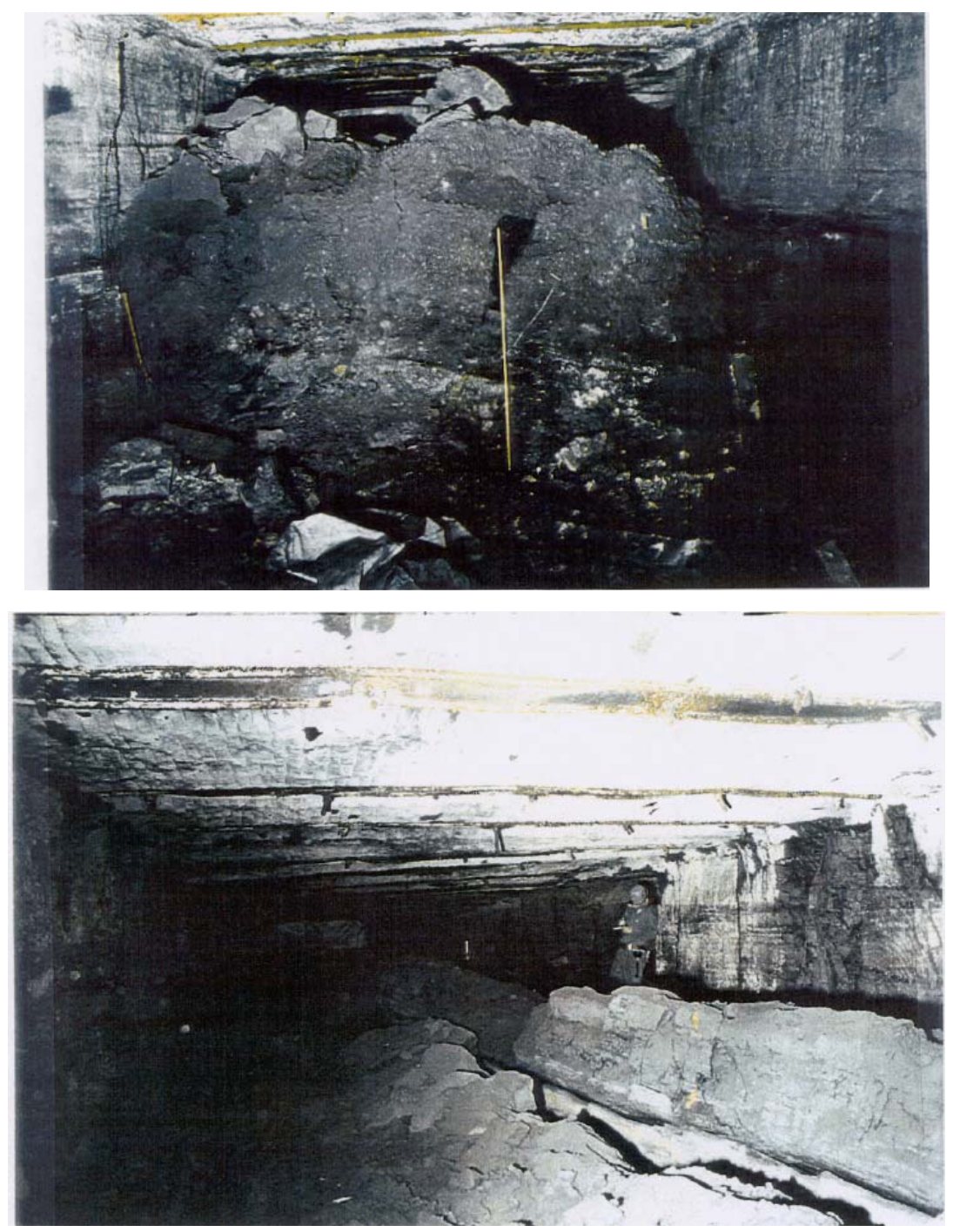

Figure 1.5. Two different types of floor heave at an Australian coal mine (Vasundhara, 2001). 

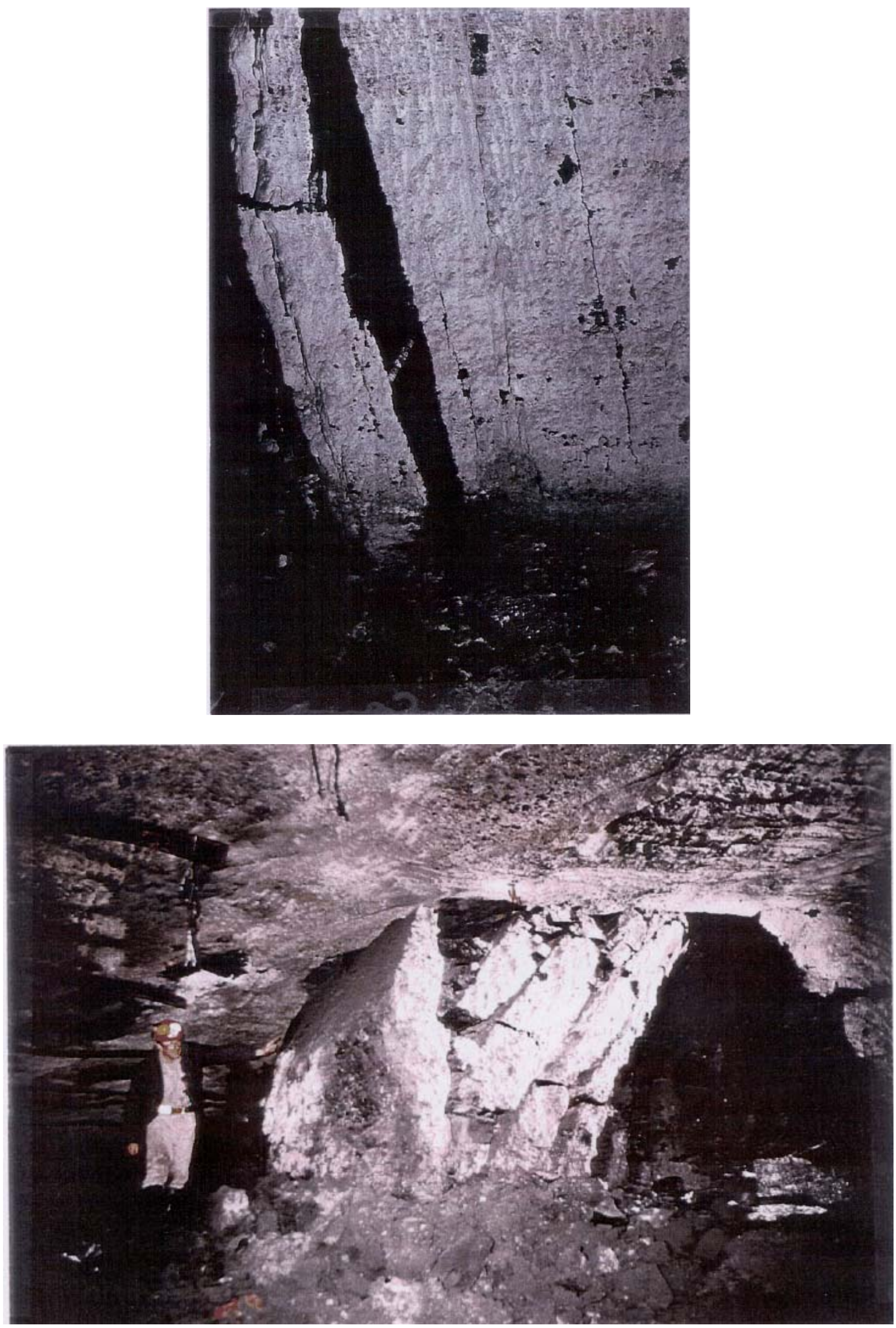

Figure 1.6. Rib instability due to floor heave at an Australian mine (Vasundhara, 2001). 
South Africa were more prone to floor stability problems than others. His studies revealed that the 5 seam of the Witbank and Highveld coalfields, the 3 seam of the Free State coalfield as well as the Alfred and Main seams in KwaZulu-Natal were susceptible to floor issues. Analysis of four unstable and four stable pillar case histories from different coal seams helped Latilla (2004) devise a Floor Stability Rating [FSR] system to identify problematic weak floors. The different factors and their corresponding ratings for the Latilla's FSR system are shown in Table 1.1. In this table, "SD" represents the slake durability of the first $0.5 \mathrm{~m}$ of the floor and "IS" is the impact splitting rating system used in South Africa.

Table 1.1. Parameters and the ratings used in the FSR system (Latilla, 2004).

\begin{tabular}{|c|c|c|c|c|c|}
\hline \multirow[b]{2}{*}{ Mining height } & \multicolumn{5}{|l|}{ Range of values } \\
\hline & Thickness (m) & $<2.3$ & $2.3-2.8$ & $2.8-3.2$ & $>3.2$ \\
\hline & Description & Low seam & & Medium seam & High seam \\
\hline & Rating value & 2 & 4 & 6 & 8 \\
\hline \multirow[t]{3}{*}{ Dip } & Dip ( $\left(^{\circ}\right)$ & $<1$ & $1-3$ & $3.1-5$ & $>5$ \\
\hline & Description & Flat & Slight dip & Moderate dip & $\begin{array}{l}\text { Steeply } \\
\text { dipping }\end{array}$ \\
\hline & Rating value & 1 & 2 & 3 & 4 \\
\hline \multirow{3}{*}{$\begin{array}{l}\text { Weighted averag } \\
\text { SD rating for } \\
0.5 \mathrm{~m}\end{array}$} & $\begin{array}{l}\text { e0.5m floor SD } \\
\text { rating }\end{array}$ & $<10$ & $10-30$ & $31-50$ & $>50$ \\
\hline & Description & $\begin{array}{l}\text { Low slaking } \\
\text { potential. } \\
\text { Good floor }\end{array}$ & $\begin{array}{l}\text { Moderate } \\
\text { slaking } \\
\text { potential. } \\
\text { Moderate to } \\
\text { poor floor }\end{array}$ & $\begin{array}{l}\text { Moderate } \\
\text { slaking } \\
\text { potential. Very } \\
\text { poor floor }\end{array}$ & $\begin{array}{l}\text { High slaking } \\
\text { potential. } \\
\text { Extremely } \\
\text { poor floor }\end{array}$ \\
\hline & Rating value & 1 & 2 & 3 & 4 \\
\hline \multirow[t]{3}{*}{ Roof IS rating } & $\begin{array}{l}\text { IS rating for } 2 \mathrm{~m} \\
\text { of immediate } \\
\text { roof }\end{array}$ & $<<88$ & $89-113$ & $114-130$ & $>130$ \\
\hline & Description & $\begin{array}{l}\text { Moderate to } \\
\text { good roof }\end{array}$ & Good roof & Very good roof & $\begin{array}{l}\text { Very good to } \\
\text { excellent } \\
\text { roof }\end{array}$ \\
\hline & Rating value & 1 & 2 & 3 & 4 \\
\hline
\end{tabular}

Kwasniewski (1990) investigated some weak, moisture sensitive floor stability issues in the Lublin coal basin in Poland. Although continuous dinting of floor was practiced in unstable entries to prevent floor heave, such material removal resulted in higher horizontal floor movements which affected arch support stability.

In India a few soft floor related problems were noticed at GDK-5A incline mine of the Singareni Collieries Company Limited (CMRI report, 2000). The soft 
claystone floor under the No. 2 seam at the mine was heaving in entries that were near perpendicular to the maximum horizontal stress direction while openings in-line with the regional stress did not have much problem. Panel reorientation was suggested as the solution to combat the problem. Physical modeling studies to investigate the effect of different variables on floor strength were reported by Kumar and Das (2005). This study provided additional confirmation of the known facts about the influence of variables like the footing size, weakness planes, moisture etc., on the bearing capacity.

Using 3D numerical modeling Yavuz et al., (2003) investigated the mechanism of floor heave in the transport road of a longwall mine in Turkey. At this mine, due to the presence of a weak floor bed, up to $70 \mathrm{~cm}$ of heave was recorded, which created some issues with the longwall move.

A Russian case history was reported by Thakur (1972) where de-stress blasting of the floor under pillar edges was successful in preventing floor instability. Surkov et al., (1997) found that some kind of floor heaving occured in the development workings of $58 \%$ of the coal mines in the Kuzbass basin of Russia. They noted that bulk of the floor problems occured at depths in excess of $300 \mathrm{~m}$ and a large number of them were in longwall drifts. In a few Kuzbass coal mines where floor movement was monitored, it was noticed that argillaceous floor deformed plastically under excess moisture influence at rates up to 15-20 $\mathrm{mm} /$ day during the first 4-5 months after development. Surkov et al., (1997) also noticed that the floor heave progressively decreased with time to stabilize at some final value after about $12-13$ months. With the longwall face nearing the instrumentation station, the floor heave continued again (Surkov et al., 1997). Using extensive measured data from different Kuzbass coal mines, the Russians developed empirical relationships to estimate floor heave at different times after an opening was developed.

\subsection{Brief Overview of the U.S. and the Illinois Basin Weak Floor Research}

The earliest U.S. reference that could be found was that of Freer (1892) who observed that smaller pillars, thicker floor and variable strength properties 
led to floor failures. Later, Hall (1909) noticed the time-dependent nature of the floor instability and attributed such deformations to the action of water and air, which he inferred would have a negative impact on floor strength. Hall (1909) also made some qualitative observations on the effect of seam dip on asymmetric floor failure in entries. It appears that Young and Stock (1916) were the first to report shear strength values for underclay. Their testing showed that the shear strength of underclay varied between 55 and 110 psi.

An explanation of floor instability from a clay mineralogy point of view was first provided by White $(1954,1956)$ based on his studies on the Illinois Basin underclay. He concluded that when the clay-size fraction was higher or when the clay fraction had abundant montmorillonite, the chances of floor failure were higher. Dulaney (1960) conducted in-situ floor testing at six coal mines and found that moisture could have a deleterious effect on the floor, especially when the floor had more than 5-10 percent montmorillonite or over $40 \%$ clay-size fraction. Holland (1962a, 1962b), based on Dulaney's studies, concluded that the average stress on an underclay floor should not exceed $1 / 2$ to $2 / 3$ of its unconfined compressive strength determined at its natural moisture content.

When the immediate floor below the coal was somewhat stiff and stronger, Ganow (1975) proposed that buckling type floor failures were possible with the necessary driving forces provided by the plastic clay member below. Although buckling type floor failures are rare in the IL Basin, several cases of that nature were reported from other coal fields in the U.S. Aggson (1978), Aggson and Curran (1978) reported buckling floor failures from a West Virginia mine where excess horizontal stress and stiff immediate floor caused such behavior. Their research showed that re-orienting development workings would reduce the problem and some stress relief techniques were suggested to further mitigate excess stress concentrations in the floor. Haramy and McDonnell (1982) reported a case history from a Colorado mine, where abrupt failure of floor was occurring in the tailgate of longwall panels as shown in Figure 1.7. Based on their research, they suggested stress release in the immediate stiff floor members as the way to control the dynamic floor failures. 


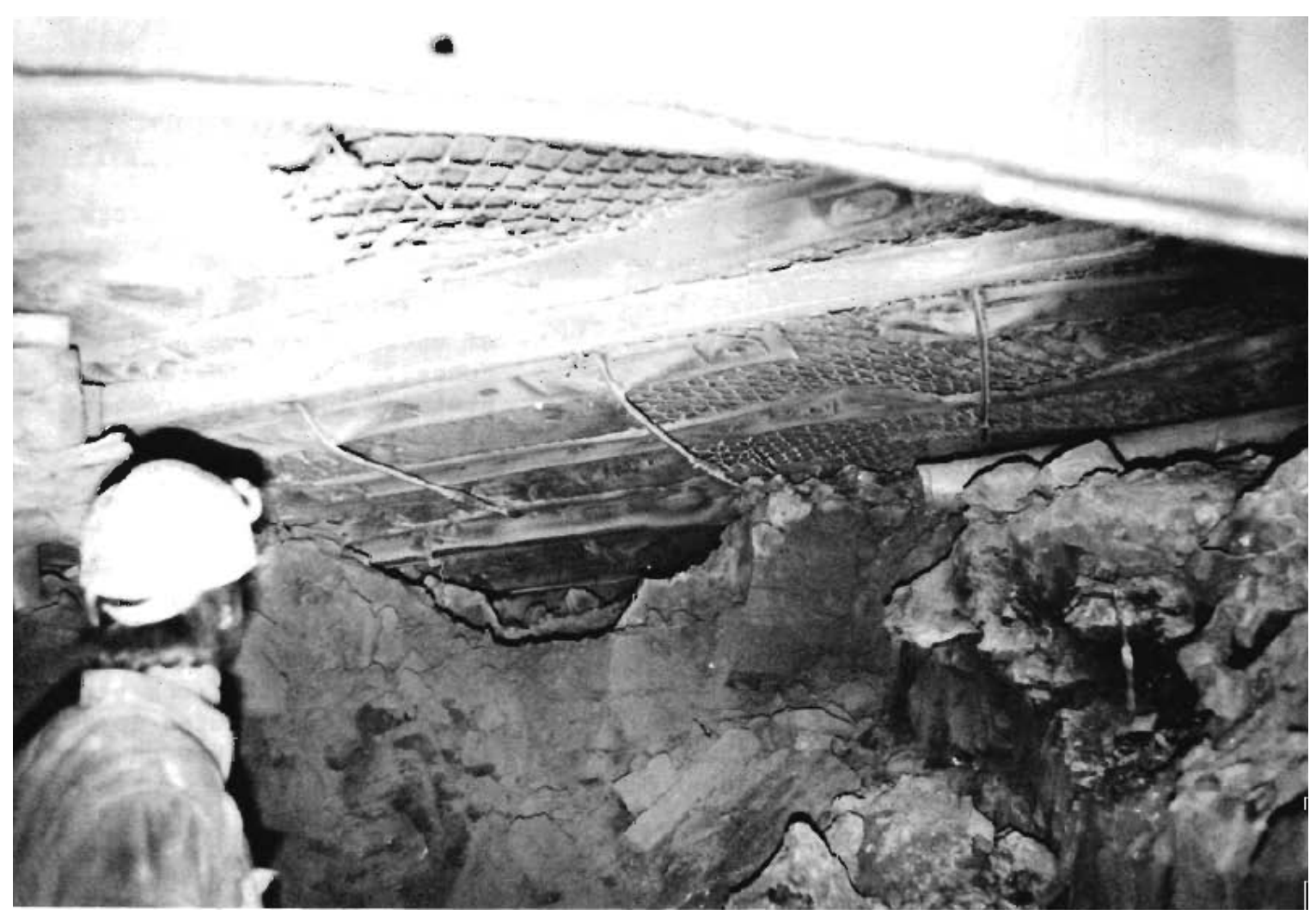

Figure 1.7. Abrupt floor failure in a longwall tailgate at a Colorado mine (after Haramy and McDonnell, 1986).

In addition to those listed above, a few more U.S. publications on floor stability are also available in the literature. Tsang and Peng (1992) developed a model to estimate stress and deformation of weak floor using Winkler's elastic foundation assumption. Heasley and Salamon (1994) studied the effect of weak immediate floor on coal pillar strength and found that the strength estimated by conventional pillar design equations may have to be reduced by as much as $20 \%$ to account for the negative impact of lower confinement available at the coalweak floor contact. Field measurements from a mine where floor bolting was adopted to control heave were reported by Stankus and Peng (1994). Their study showed that floor instability could be successfully controlled by floor bolting for the conditions encountered at that mine.

In order to quantify the engineering nature of floor materials, Riefenberg (1995) proposed a rating system similar to the Coal Mine Roof Rating (CMRR) 
called the Floor Rating (FR) and studied interrelations between FR and some geotechnical parameters like uniaxial compressive strength, CMRR, etc. Faria Santos and Bieniawski (1989) took a different approach to floor stability analysis using the Rock Mass Rating (RMR) system and the Hoek-Brown rock mass strength model. They did not modify the RMR system in anyway to account for the idiosyncrasies of coal mines. The rockmass version of the Hoek-Brown failure criterion available at the time was directly adopted for estimating the shear strength of the floor. The ultimate stress that a floor could sustain was expressed as (Faria Santos and Bieniawski, 1989)

$$
\sigma_{u l t}=m T_{o}\left[\left(\frac{1}{2} \sin ^{2} \phi_{E Q}\right)+\sin \phi_{E Q}\right]+K
$$

where $\phi_{E Q}$ is the equivalent friction angle; $m$, Hoek-Brown constant; $T_{o}$, tensile strength and $K$, an empirical constant. Faria Santos and Bieniawski (1989) provided some case history analyses to explain their rock mass strength based approach.

An overview of the ground control considerations associated with floor heave was provided by Wuest (1993) in a special U.S. Bureau of Mines publication. While no analytical details were provided, the state-of-the-art available on the subject at that time was nicely summarized in this Bureau's publication for both stiff and soft immediate floor situations.

\subsubsection{Illinois Basin Weak Floor Research}

As described before, although some qualitative research on the Illinois Basin weak floors was being done at least since 1892, major quantitative work was done almost exclusively by two research groups starting in the late 1970s. The first group was from the University of Missouri-Rolla (UMR, now known as the Missouri University of Science and Technology) led by Drs. Rockaway and Stephenson and the other was from the Southern Illinois University, Carbondale (SIUC) under the leadership of Dr. Yoginder P. Chugh. Additionally, some useful research was also done by the University of Illinois, Urbana-Champaign, mainly as a part of the Ph.D. work by Marino (1985) where the emphasis was on 
predicting surface subsidence due to abandoned underground partial extraction mines. For mine design purposes, however, all the work that has found wider practical application was done either by UMR or SIUC. It is interesting that almost all the published work from both these research groups was based on their work in coal mines in the state of Illinois although weak floor issues existed in Indiana and Western Kentucky as well. While it is known that UMR and SIUC did some work in Indiana and Western Kentucky, such studies were of a proprietary nature and are not available for a general review.

When it comes to understanding the geology of underclays, the Illinois State Geological Survey has made tremendous contributions over the past century. Several extremely knowledgeable geologists played pivotal role in deciphering the depositional history of the Pennsylvanian strata in the Basin. A list of publications on the Illinois Basin geology can be found on the geologic survey's website, http://www.isgs.illinois.edu. Similarly, useful information is also collected by the Abandoned Mine Land Reclamation Division of the Illinois Office of Mines and Minerals on unplanned surface subsidence in the state of Illinois.

Although there is more than one publication, all the major UMR research on floor stability can be found in two documents. One is the Ph.D. dissertation of Robert Speck (1979) and the other is the UMR report submitted to the Bureau of Mines (Rockaway and Stephenson, 1979). In contrast, the SIUC research was published in a large number of papers presented at different conferences or printed in scientific journals. A handful of Ph.Ds (e.g., Shankar, 1987; Tandon, 1987; Chandrashekhar, 1990; Jayanti, 1991) was also completed at SIUC on floor stability. However, the bulk of the SIUC research can be found in three documents. Earlier laboratory and in-situ floor characterization studies done at a few mines in Illinois were summarized in two reports submitted to the Illinois Mine Subsidence Research Program (Chugh, 1986a, 1986b). A summary of subsequent laboratory, field investigations and all the analytical work done by SIUC were provided in a book written by Pytel (1998). Both the UMR and SIUC research will be discussed at length at several places throughout this dissertation when relevant topics are addressed. 
Even though the SIUC work is more comprehensive and included several more case histories than the UMR's, the most popular design approach used in the Basin's mines was developed by the UMR. The so called Vesic-Speck approach developed as a part of the USBM contract in 1976 is still the de facto method for pillar design in the Basin. Credit must, however, be given to SIUC for developing several concepts on weak floor stability and for attempting to develop more realistic analytical models.

In terms of the timing, it is interesting that there was almost no overlap between the UMR and SIUC research. After they submitted the final report to USBM in 1979, no further significant work was done by the UMR on floor stability. SIUC started conducting major research on weak floors from the early 1980s and continued their progressively intensifying work until about 1992. Subsequently, probably due to funding shortage and production cutbacks in the Illinois Basin, basic research on floor at SIUC or elsewhere almost stopped other than for a few consulting type assignments. In the ensuing 16 years or so, there was no significant research publication on the Illinois Basin floor stability. Ironically, tremendous advancements in numerical modeling - which did not have the same limitations of the closed-from models that were used before - have occurred in this very same period of inactivity. Further, more practical experience with the application of empirical floor design models has been gained in this interim period.

\subsection{The Design Problem}

In a typical coal mine setting in the U.S., when floor stability is a major concern, the design problem falls under one of the two categories illustrated in Figure 1.8. In one case, the coal pillar sits over a weaker bed, which in turn is supported by a stronger layer of rock - Figure 1.8 (a). The second case is just the reverse, where a stronger immediate bed with an underlying weaker stratum supports the coal pillar - Figure 1.8 (b). The response of a mining system in the two cases described could differ substantially depending on several site specific conditions. Since the focus of this dissertation is on floor stability issues in the 
Illinois Basin mines and considering that almost all underground coal mines in the Basin have weak underclay in their immediate floor, only the situation illustrated in Figure 1.8 (a) will be discussed in the rest of this research.

The underclay material typically encountered in the Illinois Basin mines is partially indurated as shown in Figure 1.9 where three runs of the immediate floor taken from a mine in the Western shelf of the Basin are shown. As a result, the weak floor's engineering behavior can not be adequately described within the framework of classical rock mechanics principles. The friable nature of underclay, however, brings it closer to a soil and thus could be studied using soil mechanics concepts. As a matter of fact, historically, in the Illinois Basin mines the weak floor stability has almost always been investigated within the realm of soil mechanics.

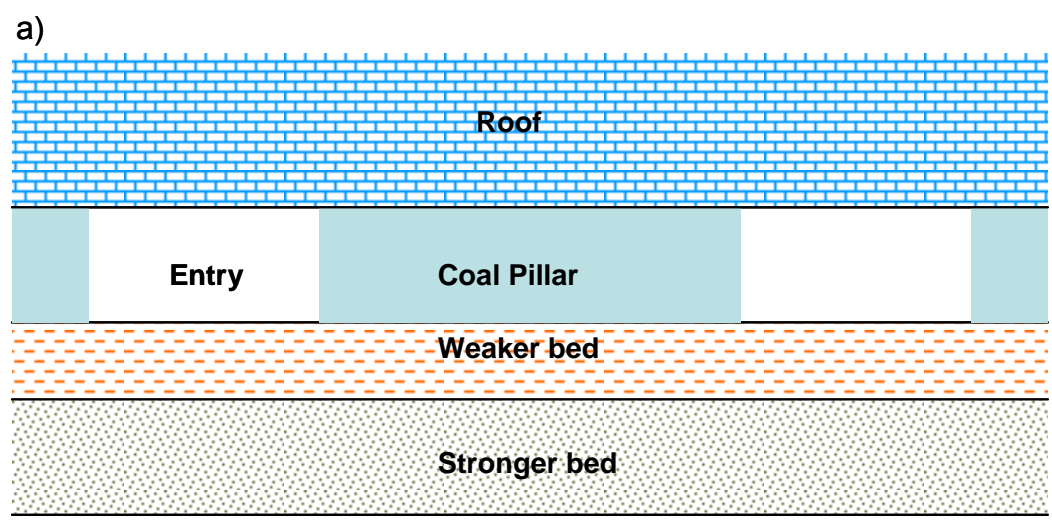

b)

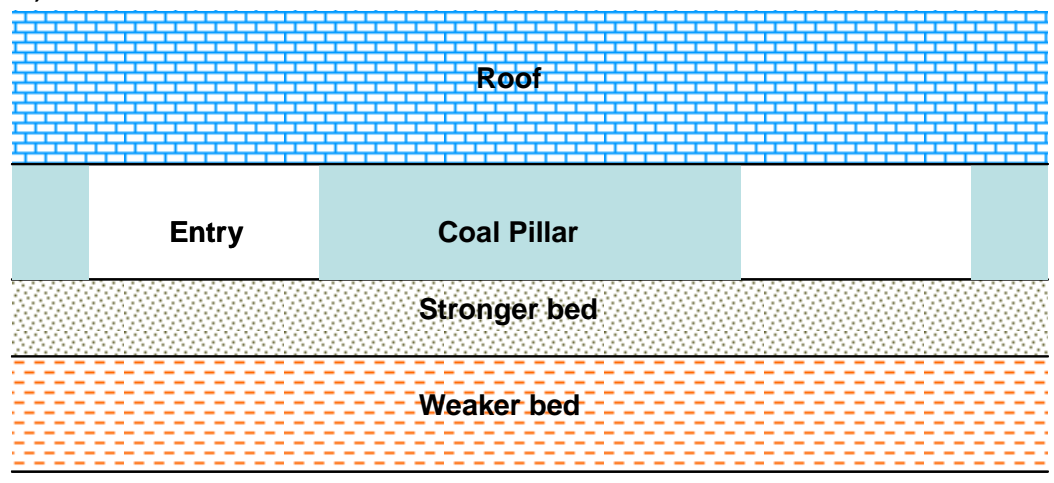

Figure 1.8. The two most common situations for floor stability analysis in U.S. underground coal mines. 
When studying floor stability in the situation illustrated in Figure $1.8(a)$, the first major challenge is estimating the different engineering properties of the underclay needed for the analysis. Because the underclay is extremely friable, adequate size samples are rarely available to conduct meaningful laboratory strength tests. Thus, some indirect approaches must be adopted to estimate the necessary engineering properties of the floor. The next complication is defining the thickness of the weak floor itself. Examination of a large number of cores from several Illinois Basin coal mines revealed that in a majority of cases the

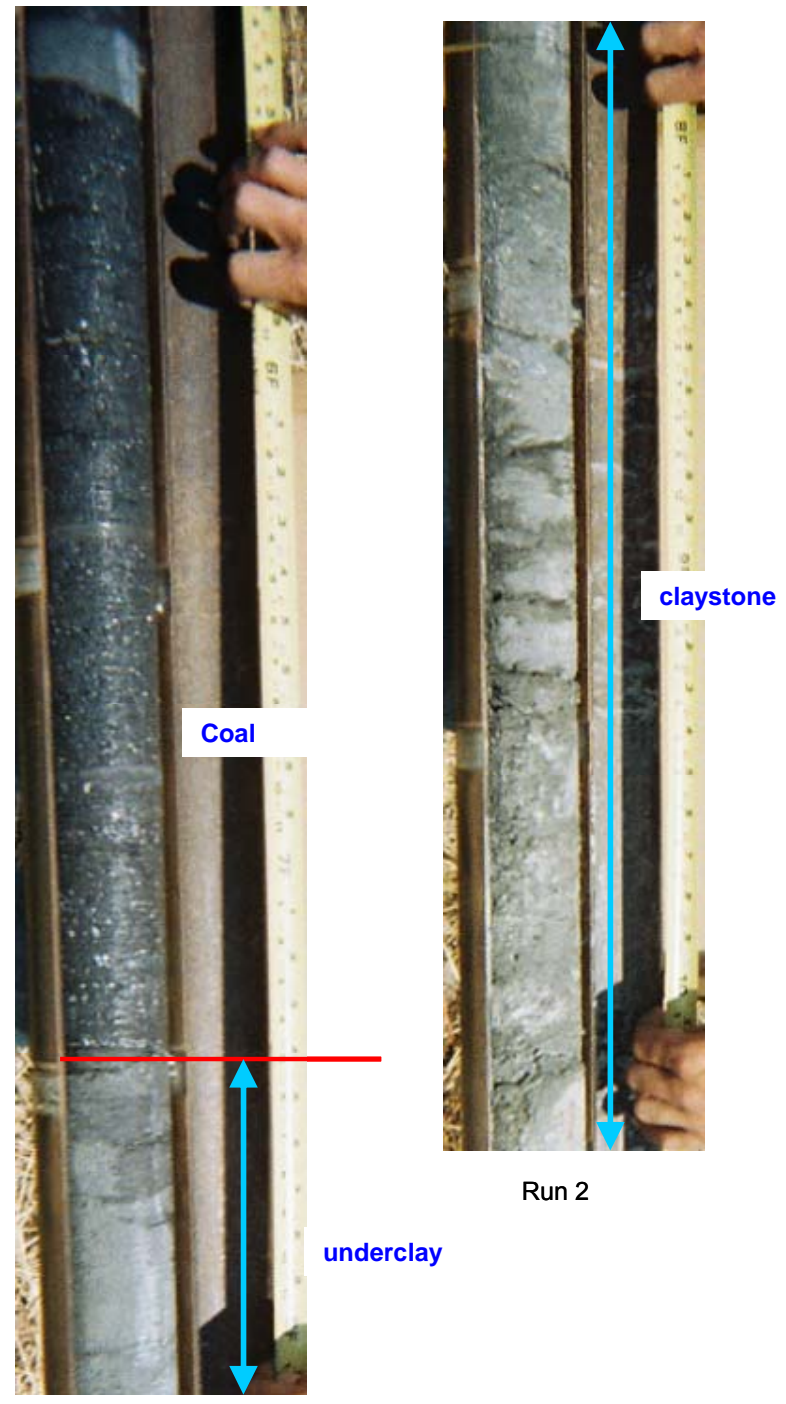

Run 1

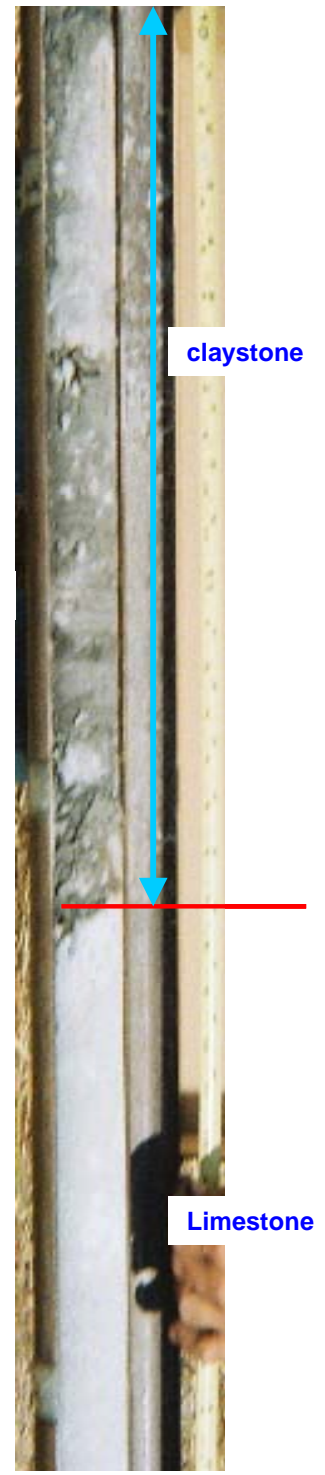

Run 3

Figure 1.9. The first three runs of the immediate floor taken from a coal mine in the Western shelf of the Basin. 
contact between the underclay and the stronger claystone bed below is highly gradational. Occasionally, however, when shale, limestone or sandstone is in the main floor, a sharp contact exists between the weaker and stronger sections. Even though the issue of identifying what constitutes the weaker section of the immediate floor has not received as much attention as it deserved, it seems that sometimes the distinction between a successful and a failed design - both from stability and economics point of view - could very well be due to improper identification of the weak floor thickness.

By whatever approach, once the thickness of the underclay is estimated and its engineering properties are determined, the next issue is that of computing the bearing capacity of the floor for the situation in Figure 1.8 (a). Since the geometrical and material complexities of the problem defy any closed-form solution, several assumptions are necessary to obtain an approximate, yet acceptable solution.

Therefore, in summary, the following major issues need to be resolved when addressing floor stability problems in the Illinois Basin:

- what physico-mechanical properties of the floor, both in the laboratory and field setting, are useful for design? What procedures will provide acceptable values of such properties?

- how to identify the thickness of weak floor when the contact with the bed below is not sharp?

- what analytical models will provide an acceptable estimate of the floor bearing capacity considering the idiosyncrasies of a typical coal mine geomining setting?

- finally, what values of floor stability factors will provide desired mining system performance while camouflaging the limitations imposed by our inability to estimate realistic inputs and by using approximate analysis methods?

Several of the above identified issues do not have any simple or conclusive answers and require extensive further research. For instance, when it comes to the thickness of the weak bed, the normal practice is to treat the 
entire claystone as a weak layer if detailed geophysical logs and moisture content variations with depth are not known. For non-cored boreholes where the identification of lithology is based on drill cuttings, without geophysical logs it is almost impossible to identify what constitutes the weaker section of the immediate floor when the contact with the bed below is gradational. The research described in this dissertation will attempt to address some of the above questions on floor stability.

\section{$1.4 \quad$ Objectives}

In order to prevent or minimize floor instability related problems, a proper understanding of the nature of underclay and its response to mining induced stress fields is absolutely necessary. As discussed in sections 1.1 and 1.2, several useful studies focusing on these matters were conducted in the past (Rockaway and Stephenson, 1979; Speck, 1979; Chugh 1986a, 1986b). These previous studies, however, have the following limitations:

a) enough laboratory data has not been collected to represent different regions of the Basin,

b) the laboratory data has not been analyzed in sufficient detail to see if any differences in the nature of the floor exists across the Basin,

c) existing equations to predict the in-situ floor bearing capacity are developed from limited data and some of the equations predict physically meaningless floor strength at certain moisture content values,

d) validity of the different floor bearing capacity equations has not been verified through case history analysis,

e) accuracy of the most popular Vesic's floor bearing capacity theory used in the Basin has not been examined,

f) finally, some aspects of the floor stability were never investigated. For instance, there is no work available on the stability of floor below special shaped pillars created during perimeter mining.

Keeping the above limitations in mind, in this work an effort is made to address them using extensive laboratory and in-situ floor strength data, case 
histories of failed and stable floors, and numerical modeling. Specifically, the following objectives will be accomplished:

1. collect a large amount of laboratory data on several physico-mechanical properties of the underclays which includes,

- natural moisture content,

- Atterberg Limits,

- particle size analysis,

- slake durability,

- swelling strains,

- sonic properties (P- and S-wave and sonic modulus),

- void ratio and degree of saturation,

- compressive and tensile strengths.

2. put together a laboratory database for the weak floor associated with three major coal seams (Herrin No.6, Springfield No.5 and Danville No.7 and their equivalents) from all three states of the Basin.

3. analyze the laboratory data for broad variability across the Basin. The laboratory data will also be used to examine if any geographic differences in the nature of the immediate floor exists in the Basin.

4. develop interrelationships between different laboratory properties. The idea is to come up with simple relations that can provide a reasonable first estimate of different properties as a function of the most easily obtainable moisture content.

5. conduct plate tests on floor at five coal mines representing the three states and different coal seams of the Basin. Additional data will be gathered from published literature and through personal communications. It will be attempted to create the largest plate test database for the Illinois Basin mines.

6. examine the validity of the available strength equations against the collected plate strength data. If the analysis shows any inadequacy of the current equations, then new plate strength relationships will be developed. 
Again, the idea is to compute the plate strength as a function of the most easily obtainable moisture content.

7. scrutinize different floor bearing capacity theories borrowed from the soil mechanics discipline for their strengths and weaknesses. Some failed and stable floor case histories will be collected to examine the validity of the existing methods. Again, if the current methods are not satisfactory, then a new floor bearing strength method will be developed. Also, the case history information will be used to suggest the design floor stability factors.

8. owing to the limitations of the traditional soil mechanics theories, several aspects of the coal mine floor bearing capacity problem can not be realistically analyzed. As an alternative to the traditional approaches, threedimensional nonlinear numerical modeling will be used in this research to study the effect of different mining variables on floor bearing capacity. In addition to the parametric studies, an attempt will be made to examine the accuracy of the popular Vesic's two-layer floor bearing capacity model. Even though Vesic's model is the de facto method of floor design in the Basin, never in the past has an attempt been made to examine its accuracy. Modeling will also be used to study the effect of the presence of multiple coal pillars in close proximity, pillar shape, floor "softening", finite thickness of the floor, non-associated flow rule, non-uniform vertical stress on the pillar and random variability of floor properties on the bearing strength.

9. finally, the stability of weak floor below the special shape pillars created during perimeter mining will be studied. For this purpose, some plate tests will be conducted using a specially designed plate template at five Illinois Basin coal mines. Additionally, some numerical modeling parametric studies will be conducted to develop a simple approach to study the floor stability under such complex pillars.

\subsection{Some General Comments}

In the rest of this study when the weak immediate floor is referred to in the discussions, the terms underclay and claystone are used interchangeably. 
Geologically, there exist some differences between the underclay and claystone mainly in terms of the presence of small slickensided surfaces in the former, the slight difference in the color and clay mineralogy. Unfortunately, however, in practice very few core loggers pick those small differences and log the strata accurately. Consequently, when the lithology from the available boreholes is examined, the distinction between underclay and claystone is not always found. In fact, the common practice of the loggers is to call all the immediate floor beds as claystone when there is no well developed fissility to identify them as shale. In view of this historical routine logging practice, in this dissertation the terms underclay and claystone are interchangeably used. However, when the immediate floor bed is referred to as "claystone", the reference is basically made to either underclay or "weak claystone". In the later discussions, when the claystone bed in the "main floor" is referenced, it will be labeled as "strong claystone".

\subsection{Dissertation Organization}

This dissertation is organized into seven chapters. Considering the broad scope of the dissertation, the conventional "Literature Review" chapter has not been included. Instead, in a "text book like fashion", the relevant work is discussed in applicable chapters to provide smooth reading of the material and to avoid the disconnect that might be felt if all the past work is lumped in a single chapter.

In Chapter 2, a large amount of data on laboratory properties of underclay floor has been gathered and analyzed. The database created for this research is the largest such data ever analyzed from all three states of the Illinois Basin. Practical implications of the trends shown by the laboratory data have also been presented in the chapter. In-situ strength and deformation characteristics of the floor materials are the main topics of Chapter 3. Based on several plate tests conducted as a part of this research and some published and unpublished data, correlations have been developed to estimate plate bearing capacity from simple 
laboratory index tests. The plate test data has also been used to examine the validity of some other strength prediction equations developed in the past.

Chapter 4 examines different approaches borrowed from soil mechanics discipline to predict floor bearing capacity beneath full-size coal pillars in underground mines. Some bearing capacity models used in the past are critically examined for their strengths and limitations. Case histories of stable and unstable floors are analyzed in this chapter with the intent to identify the most reliable design method and to arrive at the design floor stability factors. A more general purpose approach for floor bearing capacity estimation has been developed in Chapter 5 using numerical modeling. Two- and three-dimensional modeling studies were done to examine the effect of different variables that might influence the floor strength. The modeling methodology was used to shed some light on several outstanding issues related to the bearing capacity problem.

In Chapter 6, a special form of partial extraction technique known as "perimeter mining" has been examined for any potential floor stability issues. Field tests conducted with a uniquely designed plate template and threedimensional numerical modeling were used as the primary tools in conducting the stability studies. Finally, conclusions and summary of the dissertation are provided in Chapter 7. 


\section{CHAPTER}

\section{NATURE OF THE IMMEDIATE FLOOR IN THE ILLINOIS BASIN COAL MINES}

Designing a mining system to ensure stable floor conditions demands a clear understanding of the physico-mechanical characteristics of the constituent materials. When attempts are made to formulate meaningful design guidelines for an area as vast as the Illinois Basin, any data collected must come from a reasonable number of mines that represent the entire basin. Several attempts were made in the past to understand the nature of the floor materials using laboratory and field characterization studies. Such past studies, however, were limited by the number of mines, their locations or the amount of data collected. In fact, within the knowledge of the author, no published work is available that dwelled into the characteristics of the weak floor materials covering all three states of the Illinois Basin.

In understanding the nature of the floor materials, two different approaches make practical sense: laboratory and in-situ investigations. Equally important, however, is the depositional history of the coal bearing strata in general, and underclays, in particular. With these considerations in mind, this chapter begins with a brief narrative on the depositional history of the Basin and underclays. Physico-mechanical properties that could be obtained in the laboratory are discussed next and a large amount of data on individual parameters has been collected from several mines from all three states of the Basin. Practical implications of the trends shown by the laboratory data are provided. In-situ characterization of the floor is discussed separately in Chapter 3.

The laboratory data discussed in this chapter has been collected from several mines that belong to a major U.S. coal company which has been systematically accumulating such data for over two decades. It must be mentioned that the coal company's data came from a large number of inactive 
mines and a few active operations which together well represent all mineable portion of the Basin in three states. Also, much of the data available in the published literature has been gathered and included in this study. Individual publications will be identified at the appropriate locations in this chapter.

\subsection{Geology of Underclays}

\subsubsection{Overview of the Illinois Coal Basin}

The Illinois Basin is a vast area of rich coal deposits covering a big portion of the state of Illinois, parts of Western Indiana and Western Kentucky as shown in Figure 2.1. In the Illinois Basin, coal-bearing rocks are of the Pennsylvanian age and were formed between 325 and 290 million years ago (Hatch and Affolter, 2002). A general Pennsylvanian stratigraphic column involving the Desmoinesian strata is shown in Figure 2.2 and the stratigraphic correlations of the rocks in the three states are given in Figure 2.3. In the Illinois Basin, the Pennsylvanian rocks have their maximum thickness in southeastern Illinois and generally thin towards north, northeast and northwest as shown in Figure 2.4. As an example, the interburden between the Herrin No.6 and Springfield No.5 seams varies from 10 to $40 \mathrm{ft}$ in the eastern and western Illinois to from 40 to $120 \mathrm{ft}$ in the southern Illinois (Speck, 1979). Consequently, for its shallow depth all the coal mining conducted so far is concentrated around the rim of the Basin.

Almost all the mineable coal in the Basin is present in the Desmoinesian strata and the bulk of it is contained in the Carbondale formation. Among the coal beds in the Illinois Basin, the majority of mining is conducted in the Herrin No.6, Springfield No.5 and Danville No.7 or their equivalent coal seams in the three states given in Figure 2.3.

The major structural features in the Illinois Basin are the La Salle anticlinal belt, the DuQuoin monocline, and the Cottage Grove-Rough Creek fault systems (Hatch and Affolter, 2002). In the state of Illinois, these structures bound the Fairfield Basin as shown in Figure 2.5. The western flank of the DuQuoin monocline forms the relatively shallow Sparta shelf, which is the southern edge 


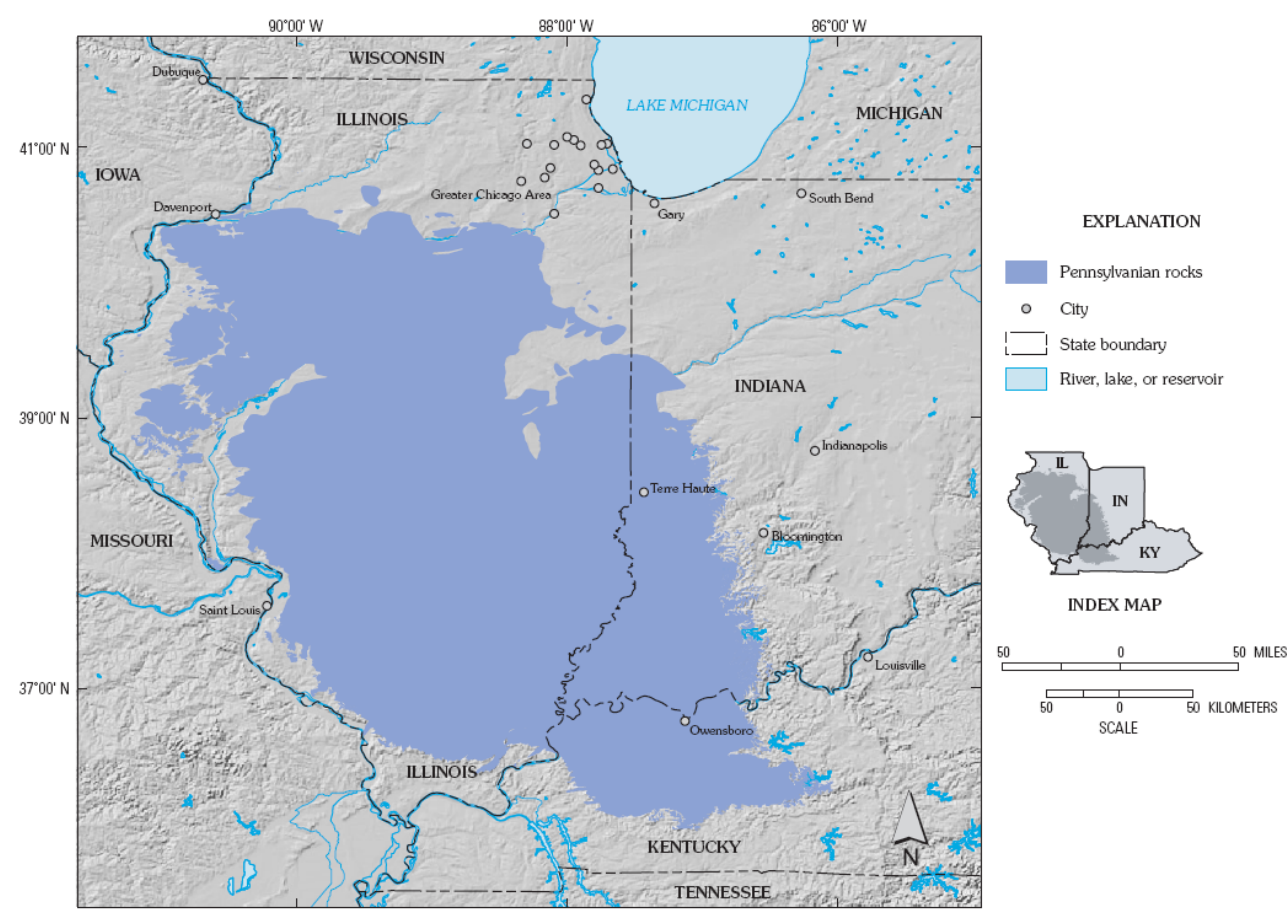

Figure 2.1. The outline of the Illinois Basin (Hatch and Affolter, 2002).

of the larger Western shelf. Based on the geographic positions of these major geologic structures, the Illinois Basin could be broadly divided into the Western and Eastern Shelves with a broad transition zone in between. There is no sharp line that separates these two shelves throughout the Basin. For practical purposes, the DuQuoin monocline may be assumed to be that separating line. Even though the DuQuoin monocline may be treated as the eastern boundary of the western shelf, it is not the unambiguous western edge of the eastern shelf. This is because the eastern shelf lacks a clear starting point east of the DuQuoin monocline and Its margin lies to the east of the axis of the Marshall-Sidell Syncline, a north-trending trough that flanks the east side of the La Salle Anticlinorium (Nelson, 2008; Elrick, 2008). Despite the existence of a transition zone, for practical ground control design purposes, the whole Basin may be assumed to consist of just two shelves. Further, when it is considered that very few coal mines exist in the Fairfield Basin area, treating the transition zone as a part of the eastern shelf will not be a major issue. In order to define the boundary between the two shelves over the entire Basin, Nelson (2008) suggests extending the DuQuoin monocline hypothetically in the northern direction. 


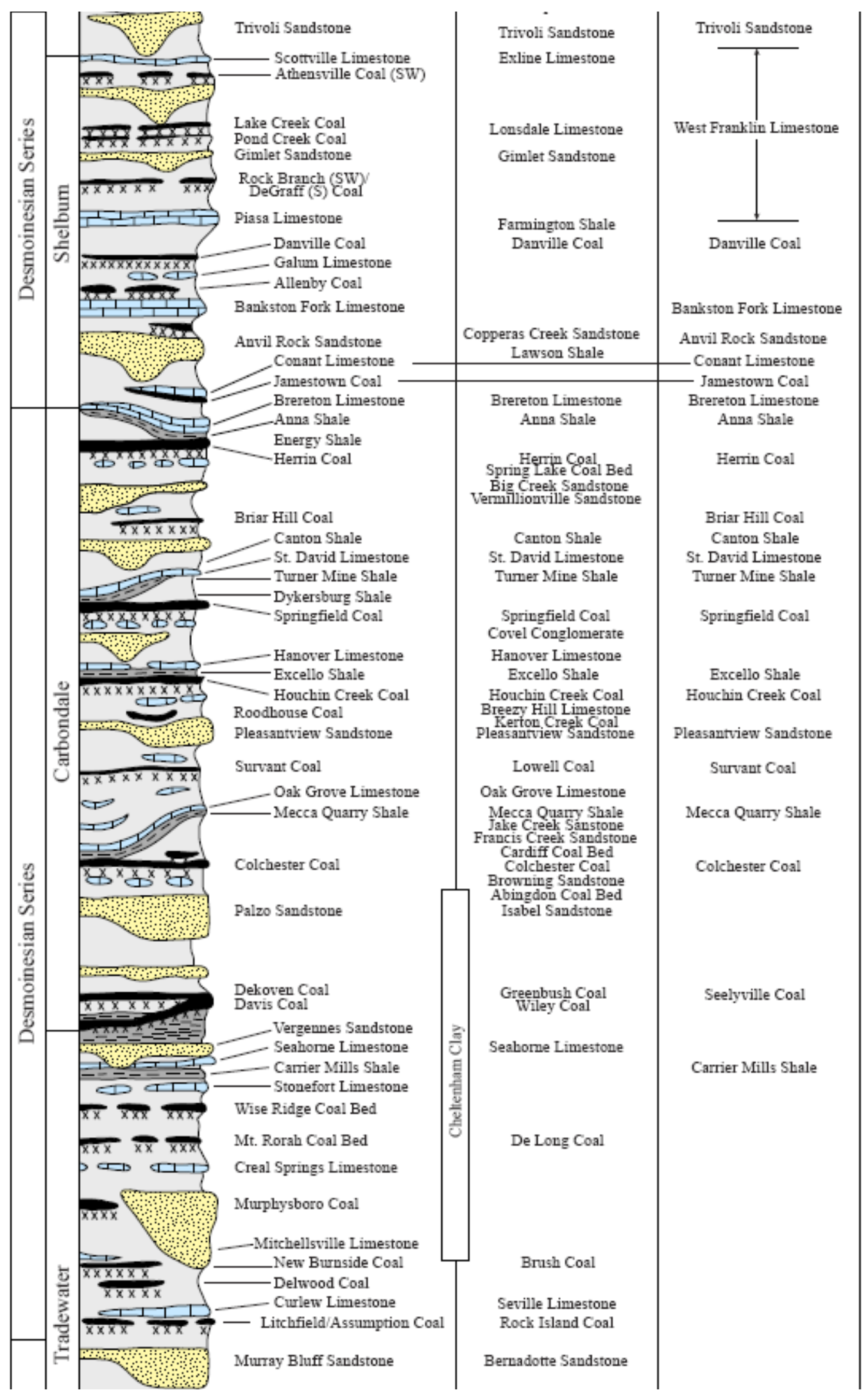

Figure 2.2. General stratigraphic column of the Desmoinesian series. 


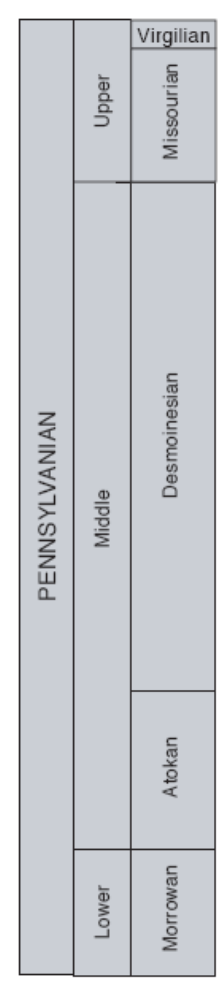

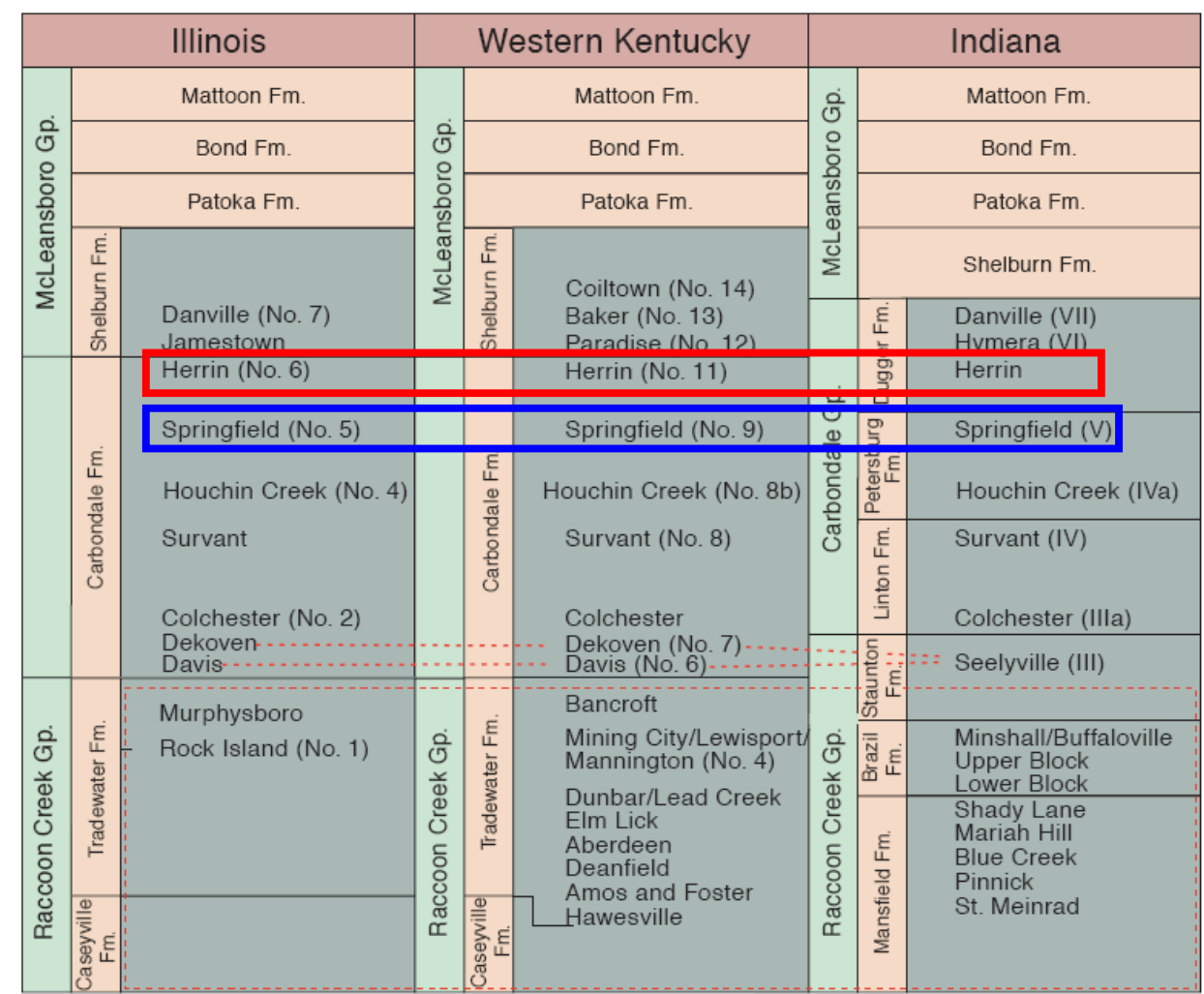

Figure 2.3. Stratigraphic correlations of the Pennsylvanian rocks in the three states of the IL Basin (the two major seams are marked).

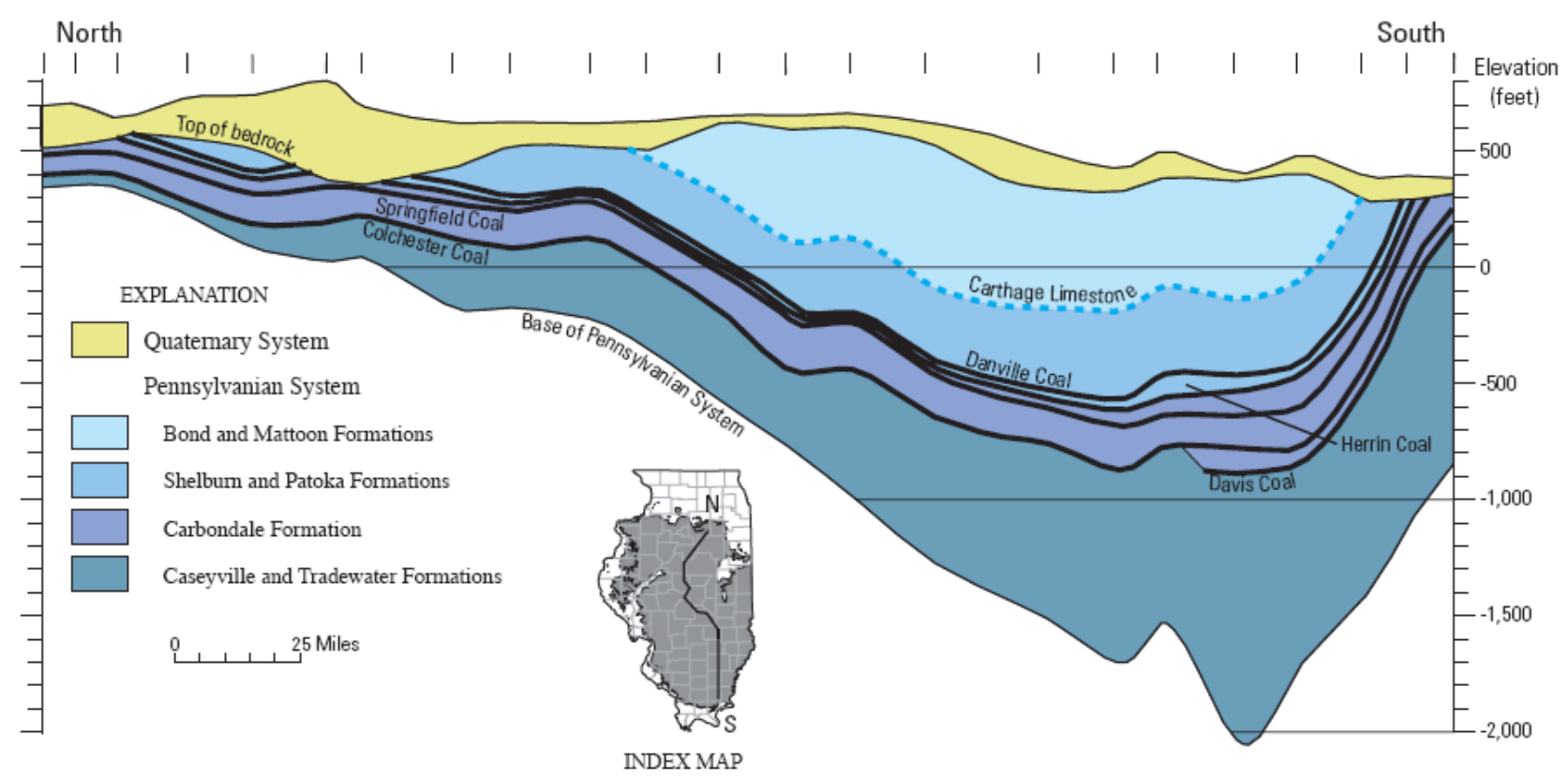

Figure 2.4. North-South cross-section of the Pennsylvania rocks in the IL Basin (Hatch and Affolter, 2002). 


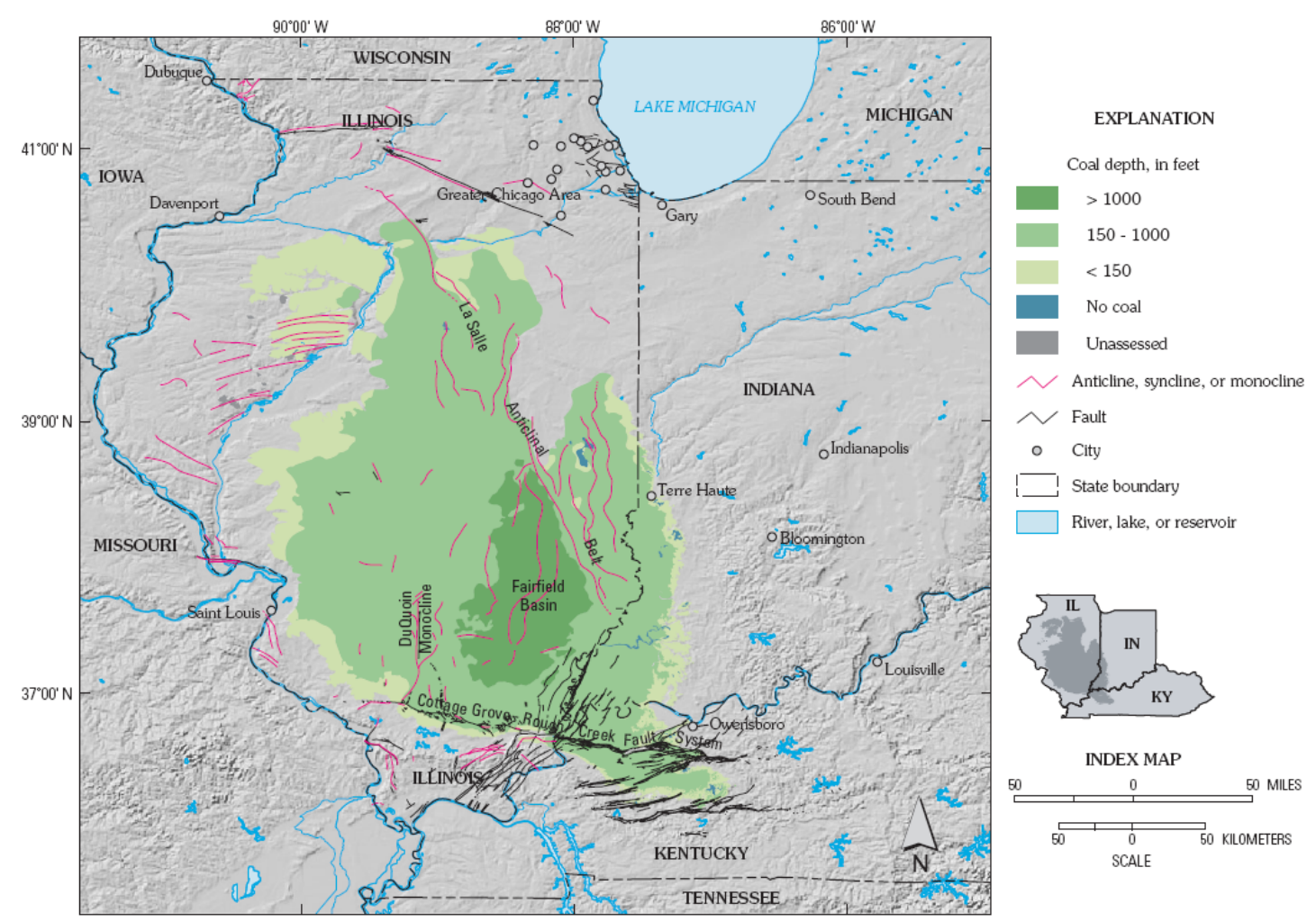

Figure 2.5. Major geological structures in the IL Basin (Hatch and Affolter, 2002).

\subsubsection{Depositional History of the Pennsylvanian Rocks}

During the Pennsylvanian age, the Illinois Basin was near the paleoequator (Hatch and Affolter, 2002). The warm and wet climatic conditions of the equatorial regions were favorable for coal deposition. Several southwestward flowing river systems existed at the time which brought clastic sediments from north depositing them in vast delta plains which prograded into the shallow sea that covered much of the present day Illinois Basin. It appears that shallow, fresh or brackish-water existed over larger areas of the deltas and a combination of dense swamp and forest vegetation grew on the water logged soil. Peat formation occurred when the vegetation decayed. Owing to the change in sediment supply, basin subsidence rates and general sea-level change, the location of the delta systems and the shorelines of the resulting coastal plains shifted throughout the Pennsylvania period. Such frequent shifts in the coastline position caused the depositional conditions at any locality in the Basin to 
alternate between marine and nonmarine to produce the so called cyclothems (Udden, 1912).

Although the Pennsylvanian strata in the IL Basin exhibit extreme variations in their thickness and composition both laterally and vertically, owing to the depositional environment described in the above paragraph, consistent regular successions of sandstone, shale, limestone, coal and other strata could be seen on a broader scale. Each succession of these lithologies, called the cyclothem, consists of a series of marine and nonmarine rock units and preserves a total cycle of sea transgression and regression. Cyclothem lithologies upward from sandstone to and including coal are nonmarine and those strata above coal up to the next sandstone are marine (Parham, 1964). Based on the research in the Midwest (Moore, 1936; Kosanke et al., 1960), it was found that an ideal cyclothem must contain ten different rock units shown in Figure 2.6. However over large distances such ideal cyclothems rarely exist. About 50 cyclothems were recorded in the IL Basin and only a few of them contain all ten units.
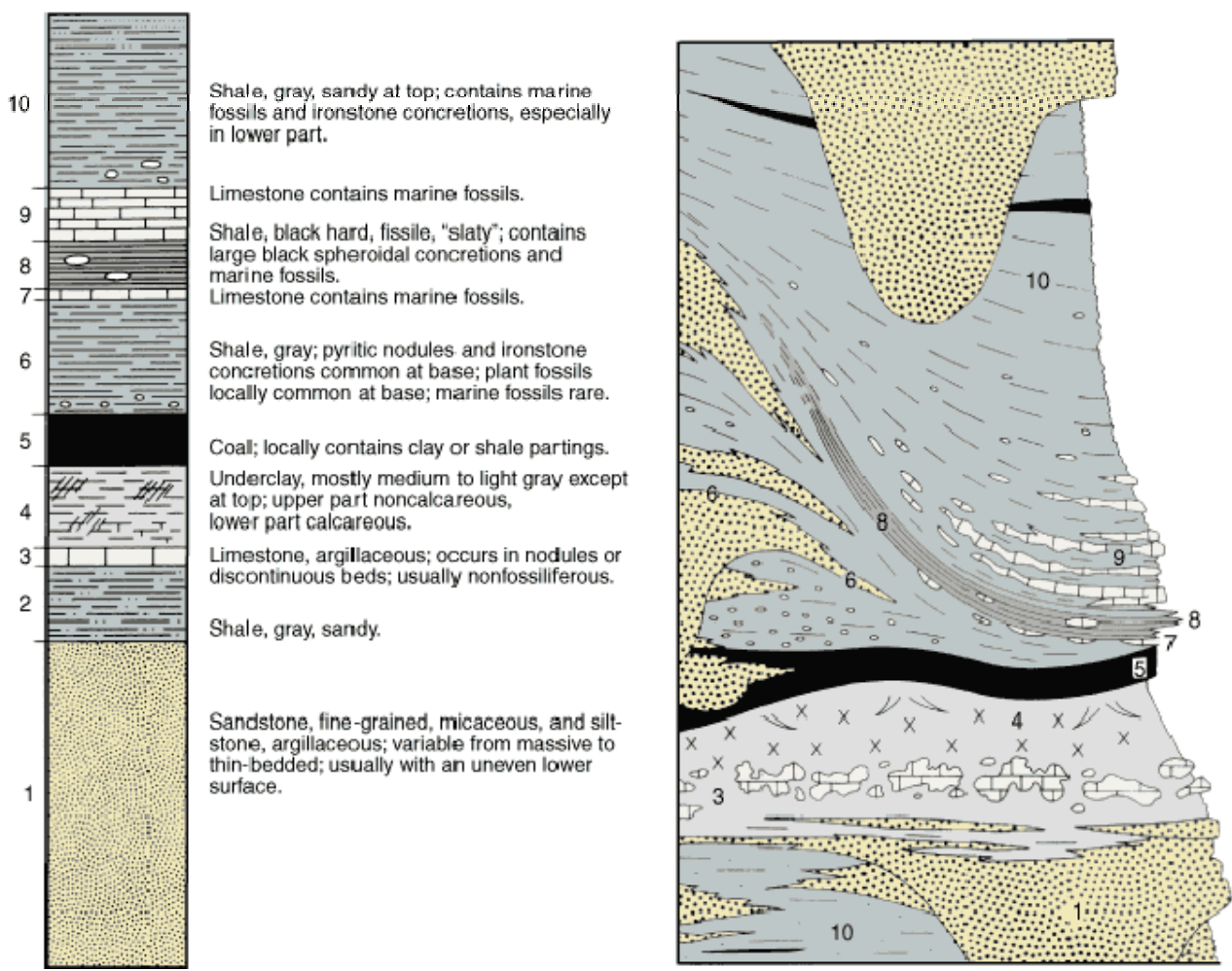

Figure 2.6. An ideal cyclothem of Illinois (left) and its variability (right). 
While all of the ten components of the ideal cyclothem do not exist consistently, it appears that the following five units are almost always found in the Basin (Speck, 1979):

10. Upper shale,

9. Upper limestone,

5. Coal,

4. Underclay,

1. Sandstone.

It is this consistent existence of the underclay member throughout the Basin that makes it a critical component in the mine system design.

\subsubsection{Origin of Underclays}

Underclays are fine grained, argillaceous, nonfissile, sedimentary rocks that exist below the coal seams in the Illinois Basin. These clayey rocks are normally gray in color but due to the presence of abundant organic material, the upper few inches are darker in appearance. Randomly oriented slickensided surfaces are also a common feature of the Pennsylvanian underclays (Speck, 1979). At a few mines, traces of plant roots, called stigmaria, are found in these materials. Huddle and Patterson (1961) defined underclay as "a seat rock composed mainly of clay minerals that is generally nonbedded, slickensided, associated with a coal bed, fractured irregularly, and contains traces of plant roots and concentrations of iron or calcium compounds in the lower part." The underclays of the Illinois Basin could be calcareous, noncalcareous or mixed. When it is mixed, a bed of underclay normally grades upward from calcareous to noncalcareous. In Western Illinois, calcareous underclays and limestone nodules in the underclay are common, but the upper part is normally noncalcareous (Huddle and Patterson, 1961). In general, the contact between a coal seam and the underclay is sharp, whereas it is gradational with the strata below. Below the underclay, variable lithologies including claystone, shale, limestone and sandstone are found at different mines in the Basin. 
Based on extensive literature review, Speck (1979) found that there were three basic types of underclays in the Pennsylvanian strata: flint, semiflint, and plastic. According to him, "flint underclay is composed of more than 95 percent kaolinite, is hard and nonplastic, and rarely contains fissures. Semiflint underclay contains from 60 to 80 percent kaolinite, up to 40 percent quartz, and lesser amounts of illite and mixed-layer clay minerals. Fissures are common and, when moist, the clay behaves in a plastic manner. Plastic underclay is the most common type, is highly fissured, and is very plastic when wet. Illite or mixed-layer illite-smectite, and vermiculite are also present. Feldspar is also found locally in plastic clays, but only rarely in flint or semiflint clays. The kaolinite in plastic clays is poorly crystallized while that in flint clays is well crystallized."

Many factors played a role in developing the slickensided features noticed in the underclays. These discontinuities are randomly oriented and are of very limited length not exceeding a few inches. According to Huddle and Patterson (1961) the slippage along the stigmarian rootlets when the underclay consolidated was the primary mechanism that produced these slip planes. When limestone nodules existed in the underclays, the differential compaction that occurred due to the differing stiffness of the materials could also have produced some slickensided features.

An outstanding account of the fundamental issues related to the origin of underclays is provided in Huddle and Patterson (1961). It appears that geologists differed on such fundamental questions as whether the clay was formed within or outside the Basin. Some clay mineralogy studies showed that the source material for the underclays formed outside the Basin and that certain characteristics of clays were acquired as a result of the sedimentary winnowing process. Some others believed that the clays underwent different amounts of alteration in peat swamps and the nature of the source material at the time of introduction to the swamp had nothing to do with the final characteristics of underclays (Huddle and Patterson, 1961).

Several theories exist on the origin of the underclays associated with coal seams in the Pennsylvanian strata. The difference of opinion among geologists is 
mainly about whether the underclays were formed during, immediately preceding or long before coal formation (Huddle and Patterson, 1961). It appears that Logan (1842) was the first one to propose that a connection between coal and the underclay below existed based on the stigmarian rootlets seen in underclays. He concluded that these seat rocks must have been forming at the same time the peat swamp was developing. It was also observed, however, that underclay or coal could locally exist without the other, but if the unit was laterally traced over enough distance then the chances of finding the missing member were very high. Stout (1923) suggested that the peat must have accumulated immediately after underclay deposition by saying "clays appear to have formed in swamps during period of decay of plant life, and to be made up primarily of terrigenous sediments modified by plant action and other plant ash. There was no break in the plant life during the formation of clay and coal but a change in the degree of decomposition or decay."

Researchers who disagree on the genetic relationship of coal and underclay point out the lack of a consistent correlation between their thicknesses and the quality of underclay (Weller, 1931). They argue that If the coal and underclay are contemporaneously formed, then thicker coals should correspond to thicker underclays. In such a situation, the purest clay must occur beneath the coal with underclay gradually grading down to shales. But, such is not always the case. However, most coals, especially the thicker ones, are associated with plastic underclays containing a large proportion of clay minerals other than kaolinite. Based on the lack of connection between the coal and underclay characteristics, some concluded that the clay materials were formed before coal deposition. Further, researchers who favor this fossil soil theory (Logan, 1842; Worthen, 1866; Hopkins, 1901; Weller, 1931; Moore, 1940; Huddle and Patterson, 1961) suggested that the Pennsylvanian underclays were a product of weathering and acquired their non-fissile characteristic as they were reworked by plant roots or biological agents. These investigators point out how the underclays grade from calcareous to noncalcareous from bottom to top. The noncalcareous zone was believed to be due to the leaching of the fossil soil and 
thus supports the argument that the underclays must have formed long before the coal.

Some workers, however, found evidence that did not support sub-aerial weathering of underclays (Grim and Allen, 1938; Keller, 1946; Spencer, 1955; Schultz, 1958; Parham, 1964; O'Brien, 1964). This latter group argued that the massive character of underclays was mainly due to the random orientation of clay particles as they were transported and deposited under a deltaic environment. Based on field observations and laboratory experimental studies, O'Brien (1964) concluded that the Illinois Basin underclays must have been formed during a period of very slow sedimentation of flocculated clay particles. He further stated that the existence of shallow plant rootlets in underclays supported the postulate that the underclays were ancient transported soils rather than residuals. This was because if the rootlets disturbed the fissility of underclays as quoted by residual soil theorists, then there were no nutritional or other reasons why Pennsylvanian flora would penetrate deeper than a foot or so while the underclays as thicker as $4 \mathrm{ft}$ were found in the Basin. O'Brien also suggested that the change in calcareous content in underclays was due to the change in the chemical environment in which the flocculated clay was deposited.

Based on his research, O'Brien (1964) proposed the sequence of events shown in Figure 2.7 to explain the development of a Pennsylvanian swamp. In reference to Figure 2.7, the following details are reproduced from O'Brien's 1964 paper:

"Preceding stage 1, clay deposited in a marine basin formed marine shale. As the sea regressed, the salinity of the basin water was lowered by the diluting action of rivers. The rivers carried very fine clay material, and flocculated clay was deposited in the slightly saline water...

During stage 1, the water near shore had a low electrolyte concentration and was quite shallow. A pioneer colony of vegetation was established in the tidal-flat marsh region. As the sea regressed, lowering the water level, the water farther from the shore also became shallower and fresher. Vegetation began to migrate basinward as the environment became more tolerable (stage 2). The first plants in the swamp anchored their rootlets in the upper part of the underlying mud. As the plants died, their remains began to accumulate under water as a mat of peat on the top of the mud. During the time of peat 
accumulation, the flocculated clay compacted further under its own weight, expelling additional liquid water. Sufficient overburden had not accumulated to collapse the clay floccules completely. During this stage there was continual increase of adsorbed water in proportion to liquid water in the clay.

At the end of stage 3 the water in the swamp was fresher and shallower. Various species of plants grew out into the basin to point $X$, where the salinity and depth prohibited further growth; no peat accumulated basinward from this point. The clay had consolidated considerably by the end of stage 3 . The plastic clay, because of the adsorbed water in the system, possessed sufficient strength to resist reorientation of the clay flakes as overburden accumulated. Although orientation of individual flakes would be difficult at this stage, slight deformation along shear planes could result. Slickensides would then be produced.

A transgressing sea initiated stage 4 . With incursion of saline water, plant growth was abruptly halted."

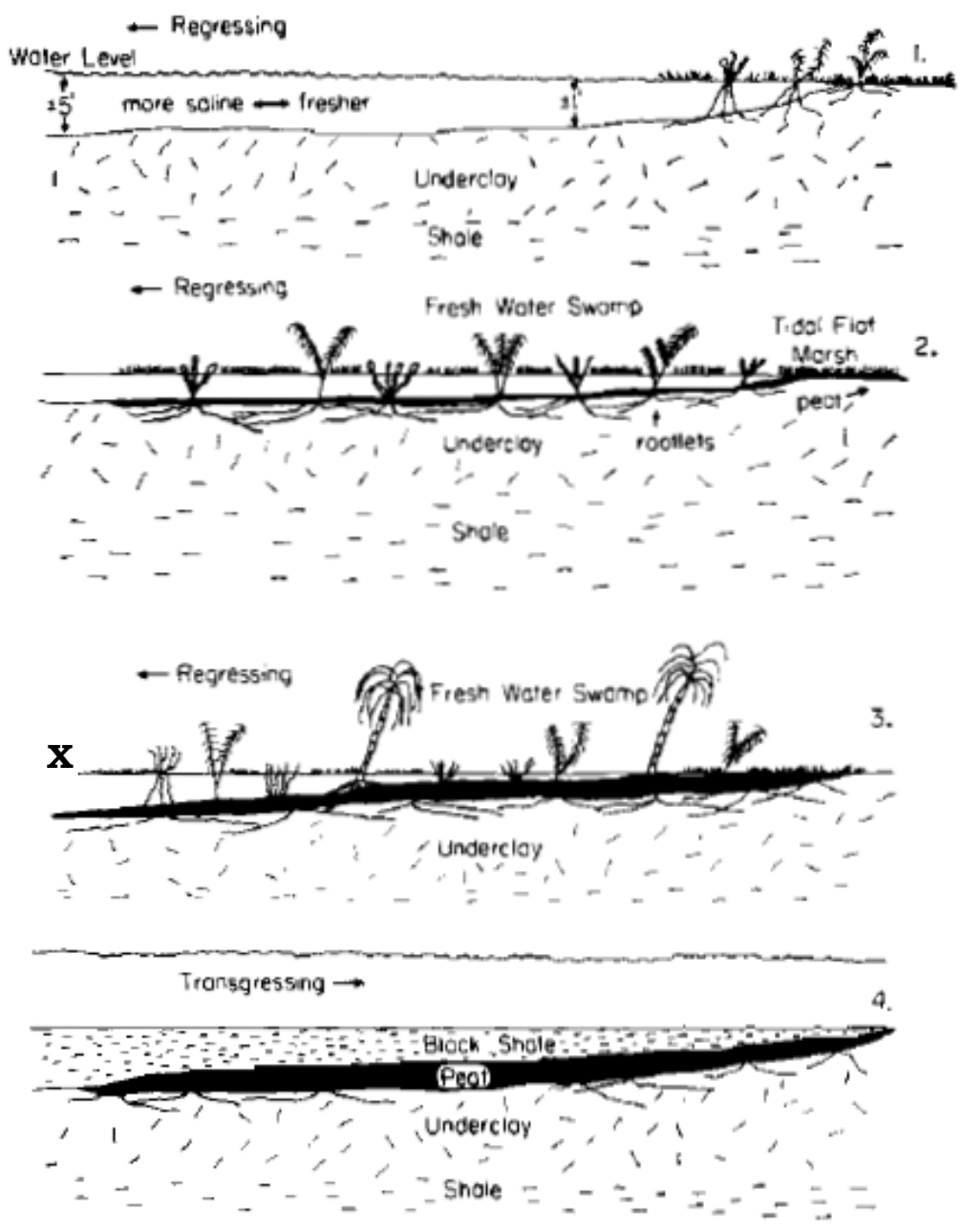

Figure 2.7. Development stages of a Pennsylvanian swamp (O’Brien, 1964). 
Despite the existence of different theories, it appears that majority of geologists believe that the underclays were formed before the coal was deposited. There is no consensus on the cause of the non-bedded nature of the underclay, however. Field observations over vast areas do not support any one theory of underclay origin. Sometimes, the characteristics of coal seam and underclay show that they were formed contemporaneously at a certain part of a swamp, while a different area of the same swamp may suggest a time gap in the formation (Huddle and Patterson, 1961). For underground mining application, however, it is not as important to know how the underclay was formed as it is to know how its engineering properties are affected. For floor stability analysis it is helpful to know what engineering properties of underclay are impacted by the depositional environment and the manner in which such properties exhibit spatial variability in the Basin. One of the earliest studies that focused on the spatial

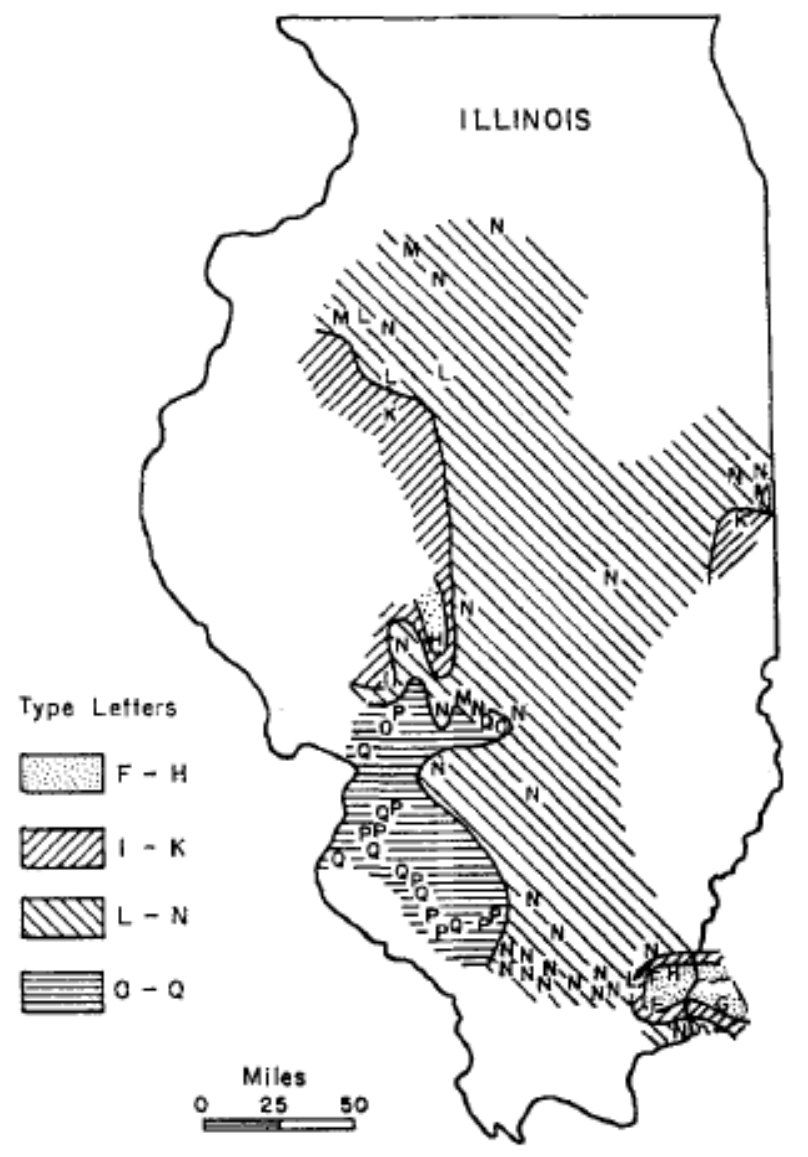

Figure 2.8. Clay mineral facies variation in the underclay associated with the Herrin seam (Parham, 1964). 
variability of underclay below the Herrin No.6 seam was conducted by Parham (1964). In this very resourceful study, Parham found that the mineral composition of underclays varies below the No. 6 seam across the IL Basin as shown in Figure 2.8. Different letter symbols in this figure indicate different clay minerals. The way Parham (1964) used the letters was that the underclay that had the highest amount of kaolinite was shown by "A" and the one with the least Kaolinite by " $Q$ " with the others in between. Also, in Parham's classification, the underclays that had less Kaolinite also had more mixed-layer clay minerals. Therefore, in essence Parham's plot in Figure 2.8 shows that the underclay below the No. 6 seam in the western shelf is more plastic than that in the eastern shelf. Further, the zone that marks the transition between the different clay minerals in Figure 2.8 approximately coincides with the position of the DuQuoin monocline and its hypothetical northward extension shown in Figure 2.9.

Parham's (1964) clay mineralogy study provides a very strong support to the conclusion later in this chapter that the nature of the weak floor below the Herrin No. 6 seam differs significantly between the western and eastern shelf coal mines. For depositional reasons, it is possible that the underclay floors associated with other mineable coal seams in the Basin may also exhibit similar differences in the engineering nature between the two shelves. In fact, Elrick (2008) believes that "the western shelf of the Illinois basin during the time of deposition of the Herrin and Springfield coals ( 300 MYA) was slightly higher topographically, therefore leading to enhanced weathering and the resulting higher clay fraction in the developed soils. The higher clay fraction presumably results in greater plasticity and moisture content in the underclay floors (i.e. the ancient paleosols) of the Herrin and Springfield coals in the western shelf mines."

Therefore, based on the above geological reasons and some of the data discussed later in this chapter, the Illinois Basin may be divided into two broad geographical regions for floor stability analysis. The two regions are the Western and Eastern shelves with the DuQuoin monocline and its hypothetical northward extension forming the demarcation line as shown in Figure 2.9. For an easy identification of the dividing line between the two shelves, US route 51 may be 
used as a reference line. Mines that are east of US route 51 in Illinois could be treated as in the Eastern shelf while those west of the highway would fall in the Western shelf. It will be shown in the next chapter that different equations will be necessary to estimate some of the key engineering properties of the weak floors for the two shelves of the Basin.

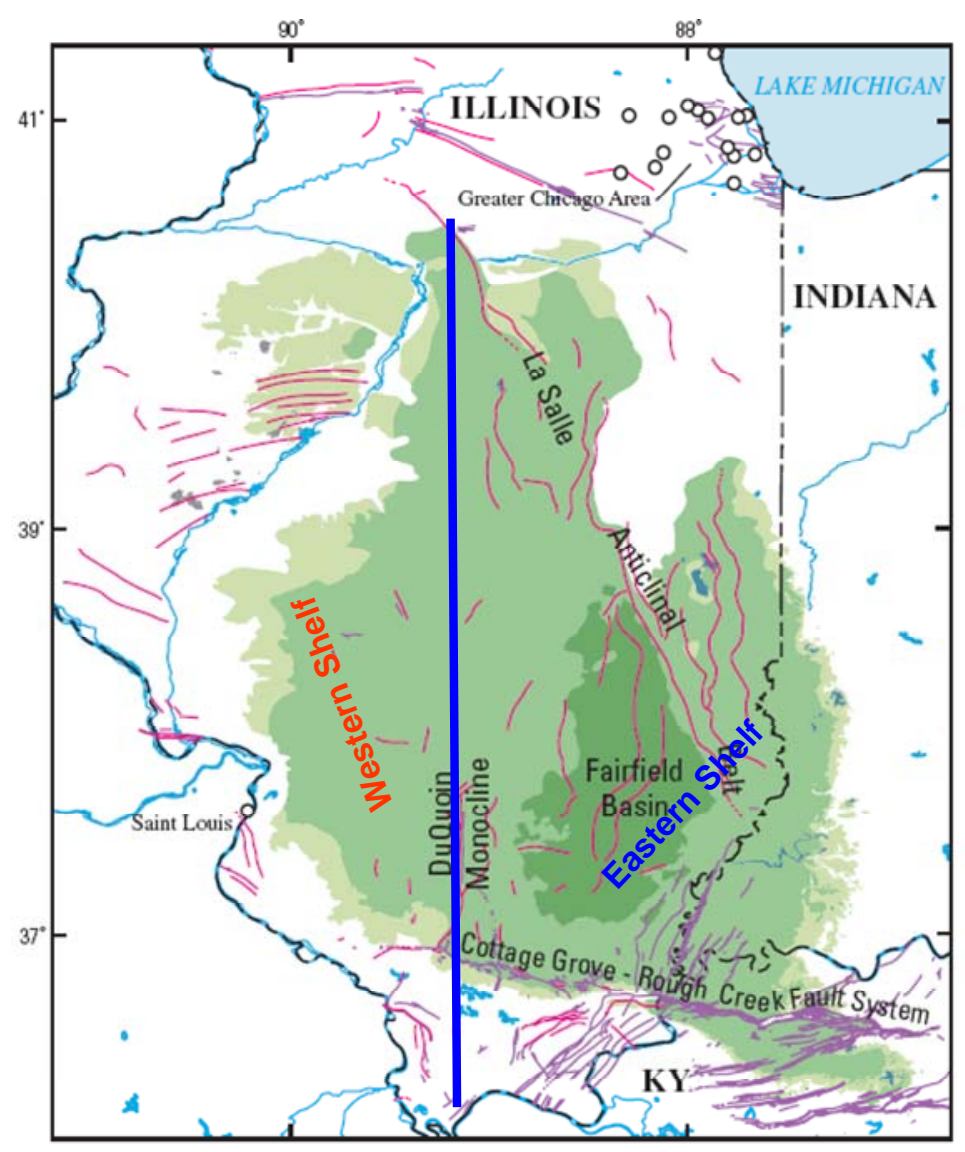

Figure 2.9. The two shelves of the Illinois Basin for floor stability analysis (the solid blue line forms the hypothetical divider).

\section{$2.2 \quad$ Weak Floor Thickness}

One of the fundamental problems that a designer faces when conducting floor stability analysis is identifying what constitutes the weaker section of the immediate floor. This is not an issue if the underclay is thin and when the stronger floor below is markedly different in lithology. Interpretation problems normally occur when the following two conditions exist: 
- when the floor lithology is vaguely defined as claystone, and

- when the claystone is more than 3.5 to $4 \mathrm{ft}$ thick.

Unless a very experienced geologist is associated with the exploratory drilling and logging program, it is common for the drillers to log the floor material as claystone even if the immediate bed is underclay. This is especially true for noncored holes. When the lithology is identified by observing the color and character of drill cuttings, even well experienced geologists may not differentiate between underclay and claystone since the contact between the two is highly gradational. Project economics do not always allow coring more than $50 \%$ of the total exploration holes. Some of the smaller coal companies may not even core that many. In such circumstances, the designer is normally forced to conservatively assume the entire "claystone" to be weak thus leading to unnecessarily large coal pillars and sterilization of valuable resource.

Experience shows that when the so called "claystone" exceeds 3.5 to $4 \mathrm{ft}$ in thickness, efforts must be made to examine if only the upper part of the bed is in reality underclay or weak claystone. This is important because the strength of the weak floor is normally estimated based on the lab tests conducted within the first $2 \mathrm{ft}$ of the strata. For thicker immediate floor, it is normally observed that the strength improves with depth below the coal seam. If the entire "claystone" bed is assigned the conservative strength computed from the lab properties obtained within the top $2 \mathrm{ft}$, excessive pillar sizing will be necessary to ensure long-term stability of the workings. If the "claystone" bed is 4 to $8 \mathrm{ft}$ thick and the upper part is underclay, then ideally the floor bearing capacity should be computed by treating the floor as a three-layered structure rather than the popular two-layer model discussed in Chapter 4. However, treating the three-layer floor as twolayered will only lead to conservative floor strength estimation and thus will err on the safer side.

Another common problem in determining the weak floor thickness occurs with older exploration holes drilled prior to 1990's. In those days, very few coal companies required drilling well into the floor. Normally drilling was terminated as soon as the thickness of the coal was determined. In such cases, the depth to 
which drilling continued in the floor was determined by the length available from the last run of the drill steel used. When analyzing surface subsidence events over old workings, it is very common to deal with such incomplete floor thickness information. If the drilling is terminated before a distinct change in lithology occurred in the floor, it is not possible to estimate the thickness of the weak floor. Information from such incomplete holes must be discarded for any type of floor stability analysis. Considering past experience in the Illinois Basin coal mines, drilling must be continued to a distance of at least 10 to $20 \mathrm{ft}$ below the coal seam to estimate the weak bed thickness with confidence.

Some suggestions were made in the past to identify the thickness of the weaker section in a thick "claystone" floor. Chugh (1986b) recommended that a plot of change in moisture content with depth below the coal seam could be used for this purpose. He wrote, "The depth below the coal seam where the natural moisture content markedly decreases defines the thickness of the weak floor..." When the moisture content of the immediate floor is determined at a minimum of 6 inch intervals, experience shows that Chugh's recommendation works well to identify the weak floor thickness. As an example of the usefulness of this recommendation, the moisture content is plotted against depth below the coal seam for three coal mines in the No.6 seam in Figure 2.10. Similar plots for several holes from two different coal mines are shown in Figure 2.11. The data in Figure 2.11(a) came from a mine in the Herrin seam and the other from the Danville No.7 seam.

The plots in figures 2.10 and 2.11 show that the moisture content variation with depth serves as a useful indicator to identify the weak floor thickness. There are situations, however, where no trends are visible. Similarly, in some cases, the moisture increased with depth. Such moisture plots show the real world variability in the nature of the immediate floor and prove the rule rather than the exceptions in our research. In fact, the moisture plots in Figure 2.10 and Figure 2.11 show that there may be several thin layers of strata of variable strength in the immediate floor area which are normally ignored in the floor stability analysis. 
Despite this variability, the visual observation of the "marked" change in the moisture will help identify the weaker section of the bed. It must be apparent that

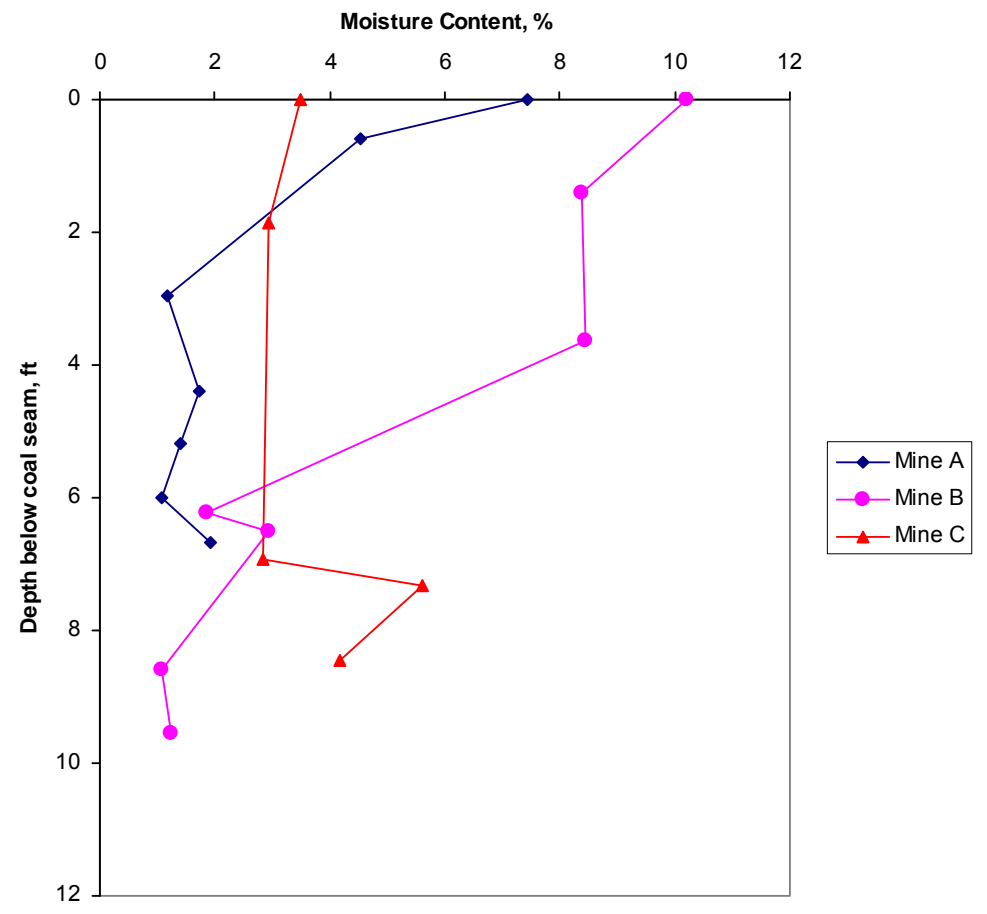

Figure 2.10. Moisture change with depth below coal seam for three different mines.

a)

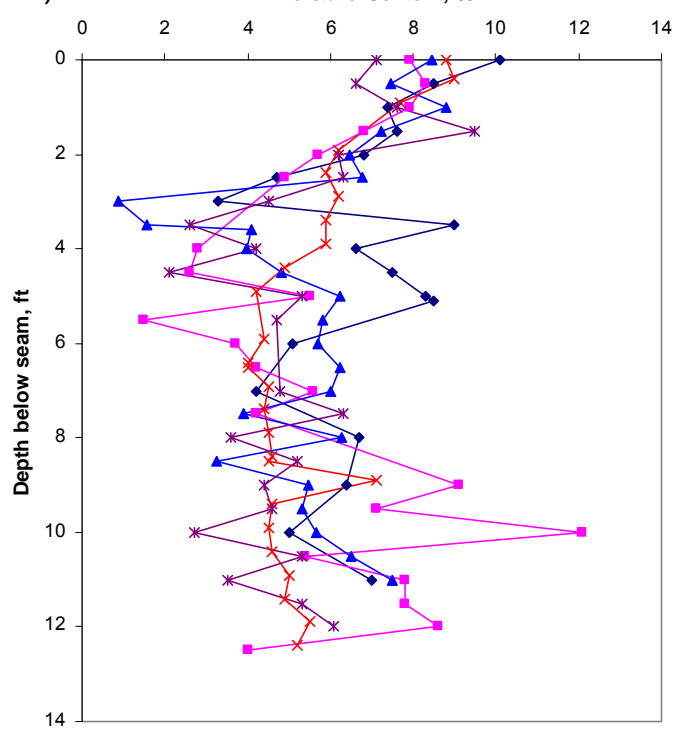

b)

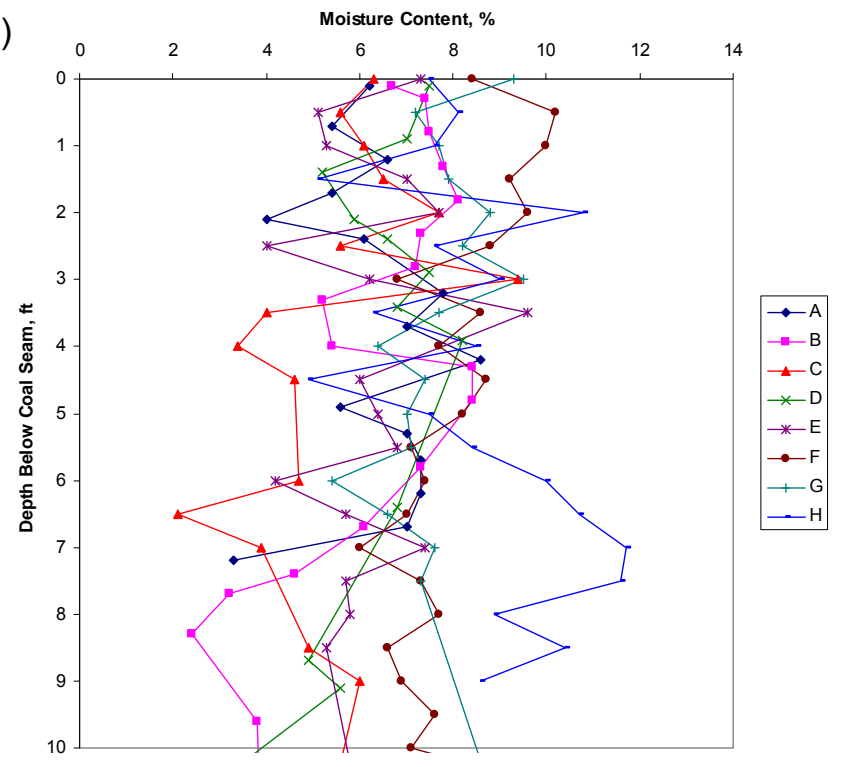

Figure 2.11. Moisture change with depth below coal seam for a number of boreholes from two different mines. 
what constitutes the "marked" change is an arbitrary decision that the designer has to make based on the overall moisture trends. In some cases, a $0.5 \%$ change may be "marked" while in others perhaps as high as $1.5 \%$ or more may be necessary. The most realistic way to account for the kind of variability displayed by the moisture content in figures 2.10 and 2.11 is to estimate the bearing capacity of the floor using the numerical modeling approach discussed in Chapter 5. The traditional soil mechanics models like those described in Chapter 4 can not include such variability.

The moisture content change with depth can only be used when rock cores are available for laboratory testing. As mentioned before, not all the exploration boreholes are cored. Further, the moisture content may not always be determined on close enough spacing to be a helpful indicator of the change in the floor nature. However, a majority of coal companies these days run at least a few types of geophysical logs in their exploration boreholes. Information from such logs could be extremely helpful in identifying the variability in the floor lithology. The most popular geophysical logs used in the Basin are the density, gamma and caliper. Recently, some larger coal companies started running sonic logs in addition to the three basic logs.

The caliper logs measure the borehole diameter. Quantitative interpretation of the caliper logs for ground control purposes is normally not done in the Basin. They, however, qualitatively indicate the relative strength of the beds as a function of the measured diameter. If the diameter of the borehole becomes larger in a certain portion of the immediate floor, then that zone may be assumed to represent the weaker section of the floor. From the past experience, significant variation of the borehole diameter is rarely seen from the caliper logs and thus their use for weak floor identification is limited.

Tremendous potential, however, exists with density and gamma logs for weak floor identification. Even though systematic research on this subject is yet to be done in the Basin, some preliminary thoughts are proposed here. A density $\log$ is a porosity log that basically measures the electron density of a formation (Asquith and Gibson, 1982). The device used for density logging is a contact tool 
that contains a medium-energy gamma ray source, which is either Cobalt-60 or Cesium-137. When the gamma rays emitted by the device collide with the electrons in the formation, the gamma particle loses some of its energy resulting in what is called Compton Scattering (Asquith and Gibson, 1982). The scattered gamma rays counted by a detector located at a certain fixed distance from the source will provide an estimate of the density of the formation.

The gamma ray logs measure the natural radioactivity of the strata (Asquith and Gibson, 1982). They record the amount of natural gamma radiation emitted by the strata. It appears that the most significant natural gamma radiation sources are potassium- 40 and daughter products of the uranium- and thoriumdecay series. Owing to the presence of potassium feldspar and mica, and also due to the existence of some uranium and thorium by ion absorption and exchange, clay- and shale-bearing rocks emit relatively high gamma radiation. Therefore, a significant "gamma kick" in a gamma log basically indicates the presence of some clay or shale at that horizon. Shale-free sandstones and carbonates have low concentrations of radioactive material and thus have low gamma ray counts.

In standard textbooks and other research materials dealing with geophysical logs, suggested density and gamma count values for common sedimentary rocks are available. Considering the natural variability of rocks, however, it is prudent to compare the signature of some geophysical logs with rock cores so that site- or region-specific baseline values corresponding to different lithologies could be established (Ames, 2008). Once a reasonable correlation has been established between a site-specific geophysical log parameter value and rock lithology, routine use of logging for site characterization becomes a trustworthy exercise. Within the knowledge of this author, such validation studies to identify the weak floor thickness have never been published in the Illinois Basin. Geologists with a major coal company in the Midwest have been attempting to establish baseline gamma and density values for weak floor identification at a few of their coal mines. Some information available from this exercise is presented next to show the usefulness of 
geophysical logging in identifying the weak floor thickness. In Figure 2.12 through Figure 2.15 some examples are shown where better characterization of the immediate floor was accomplished by analyzing the geophysical logs and rock cores. In these examples, if the driller's logs alone were taken as the basis, then the thickness of the weak floor for stability analysis would have been significantly greater thus requiring unnecessarily large coal pillars for the long-term floor stability.

In interpreting the geophysical logs in figures 2.12 through 2.15 , it may be noted that the gamma ray count in the coal seam is exceptionally low and the contact between the coal and the immediate weak floor bed is always easily distinguishable. The "gamma kick" for the underclay or claystone did not have a fixed value in the four example cases. Similarly, no consistent values were noted for density either. However, in addition to the "gamma kick" below the coal seam, the density of the rock must be somewhat lower for the underclays. If the density is greater than $2.5 \mathrm{gm} / \mathrm{cc}$, then the claystone or underclay might have limestone nodules in it.

From these example plots and discussions with a very well experienced geologist who has used geophysical logs for weak floor identification for years (Ames, 2008), it appears that successful identification of weaker section of the floor is possible by comparing the relative variation of the gamma count and density values rather than by any fixed absolute numbers. Indeed comparison of several cores and geophysical logs for each mine is necessary in order to develop a "feel" for the signature of different rock types in a log. Extensive further research is required to develop quantitative methods of interpreting the geophysical logs and to remove the subjectivity in drawing conclusions.

The information available from the gamma and density logs appears to provide an accurate means of identifying the weak floor. However, their use is limited if rock physico-mechanical properties are to be predicted. Recent research shows that the sonic logging will provide a convenient mean to estimate rock engineering properties (Hatherly et al., 2003). Some of the laboratory data discussed later in this chapter will show the strong relationship that exists 
between the P-wave velocity and the natural moisture content of the weak floor materials from the Illinois Basin. Therefore, it appears that tremendous potential exists for sonic logging as a substitute to expensive rock coring and testing. More research is required to develop relationships and procedures to interpret the sonic logs for estimating weak floor properties.
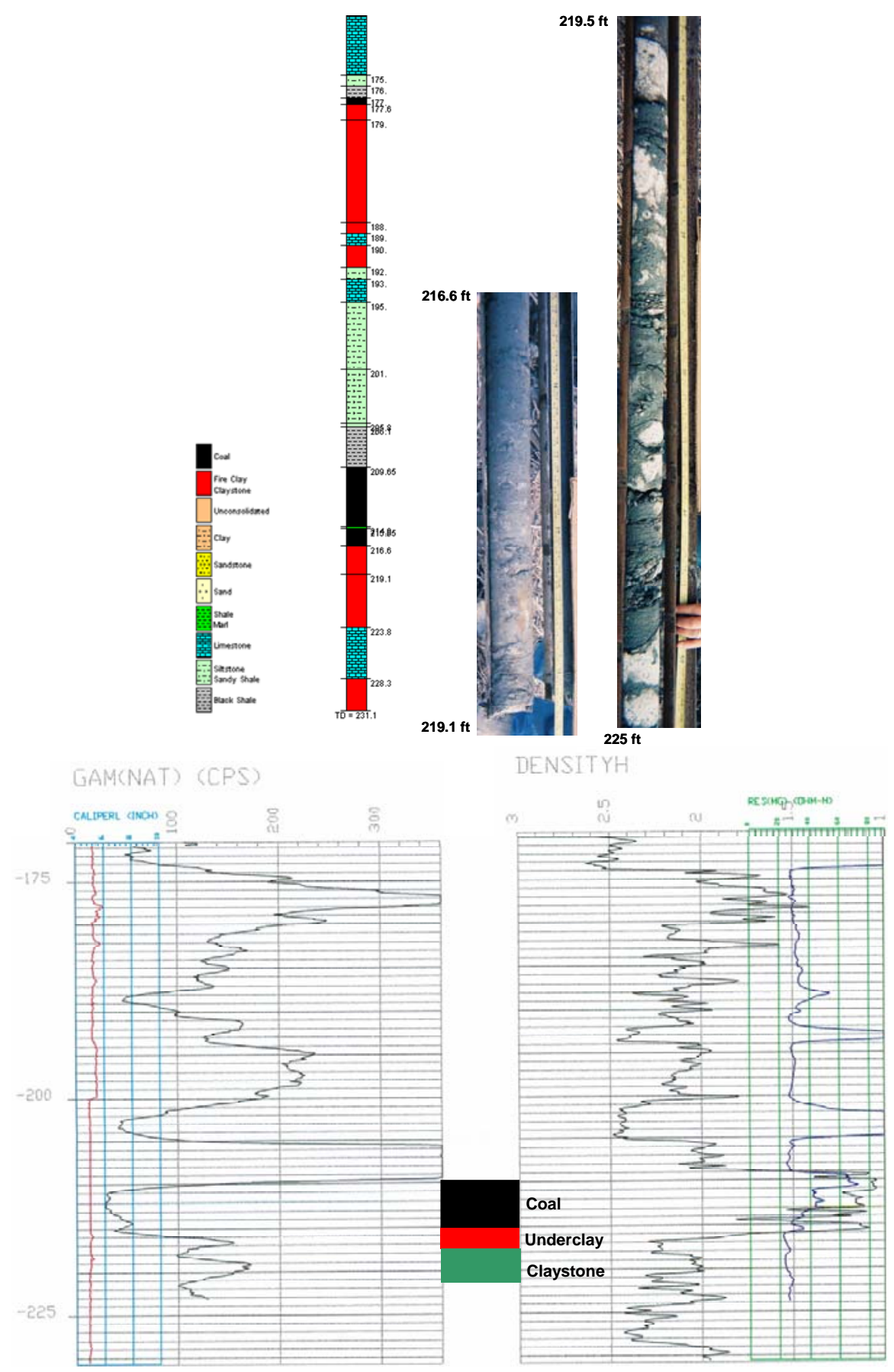

Figure 2.12. Driller's log, core pictures, gamma and density logs for example 1. 


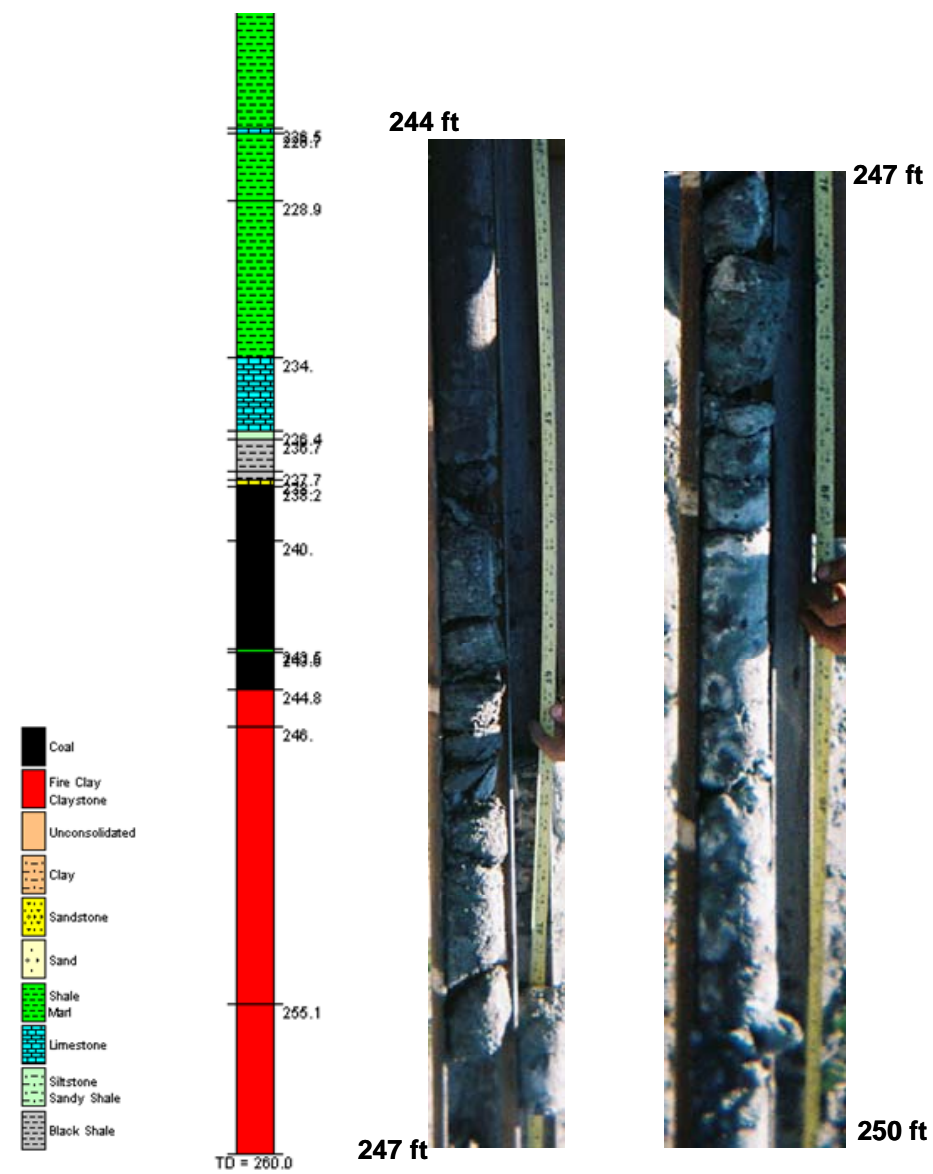

\section{GAM(NAT) (CPS) DENSITYH}

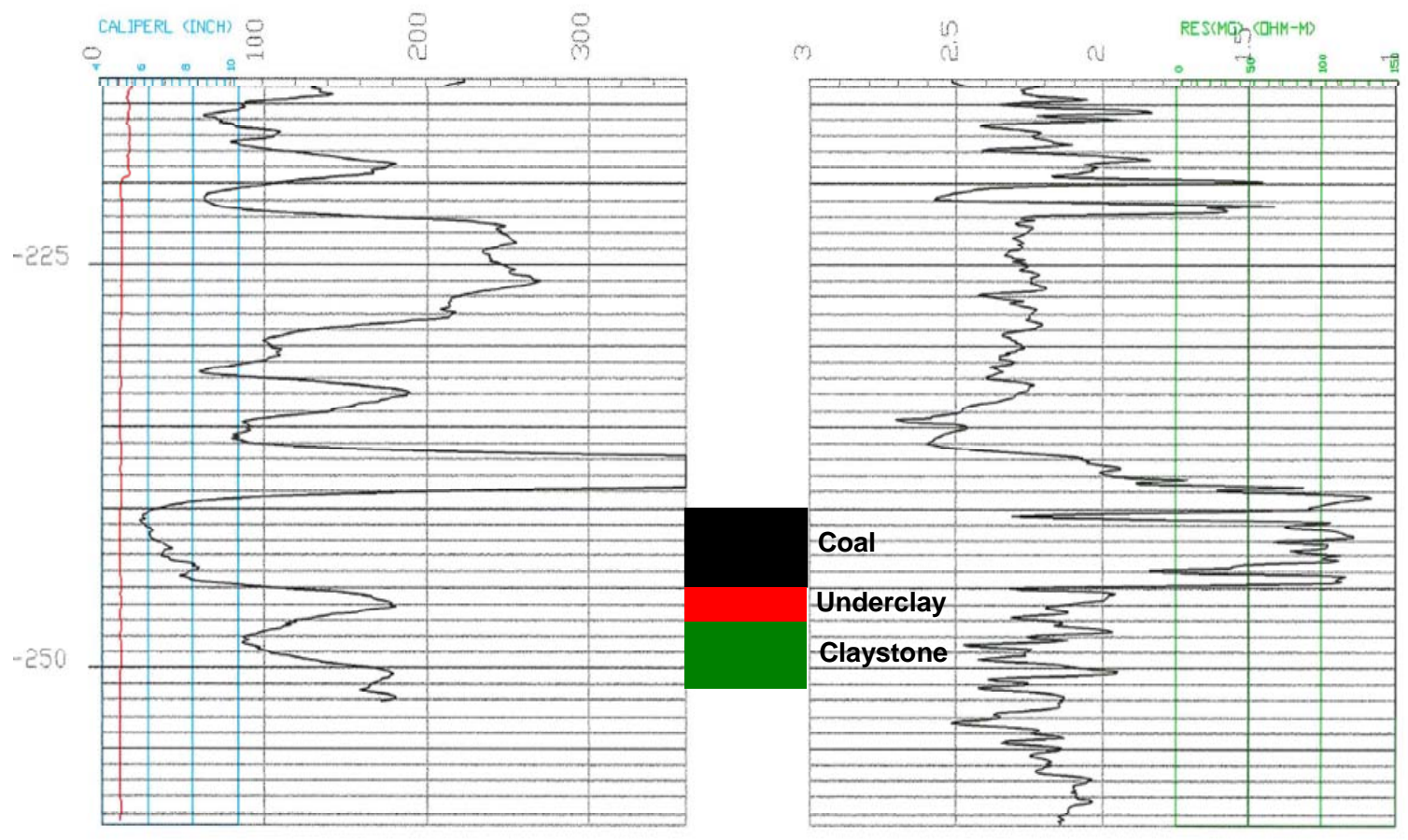

Figure 2.13. Driller's log, core pictures, gamma and density logs for example 2. 


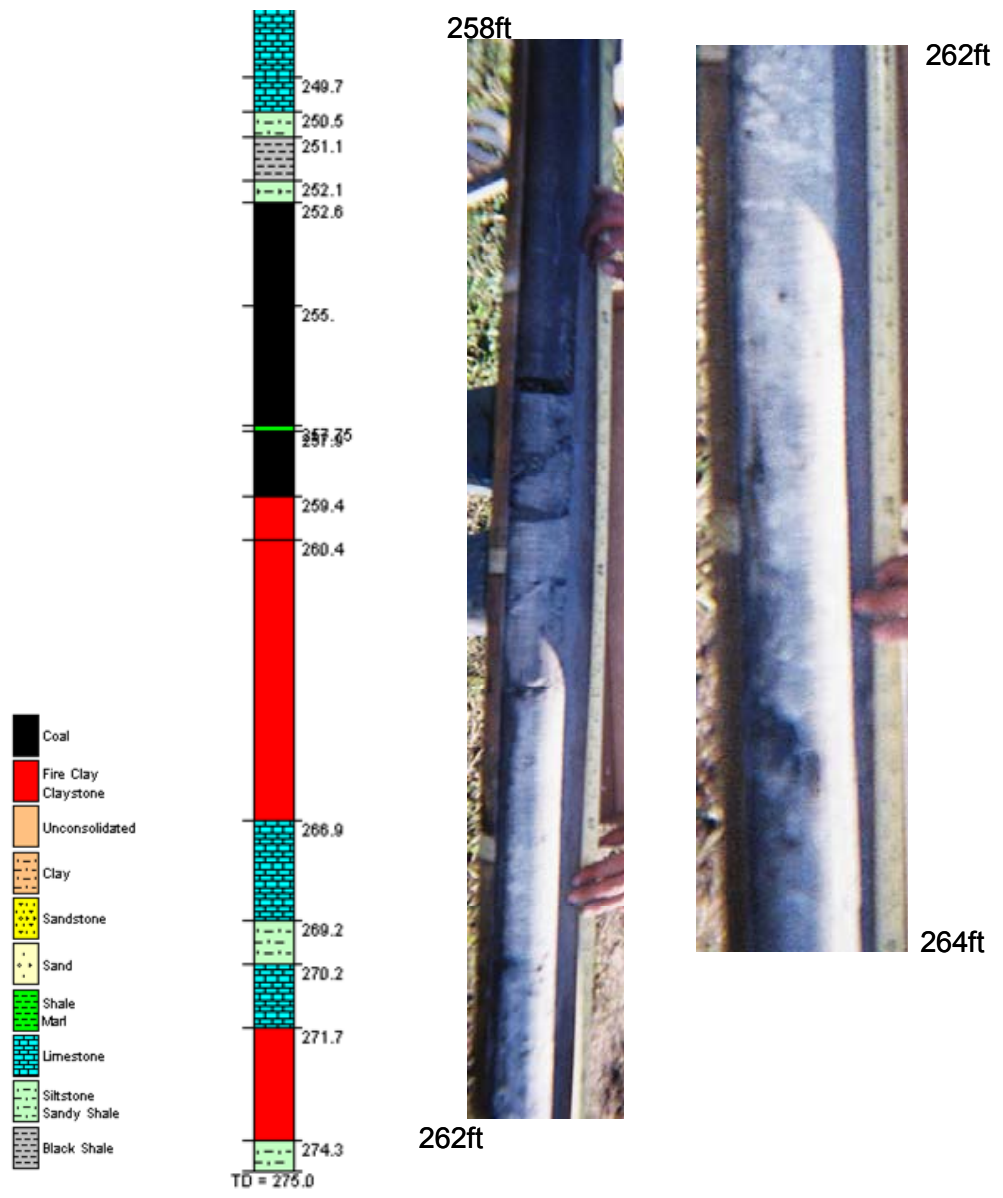

GAM(NAT) (CPS)

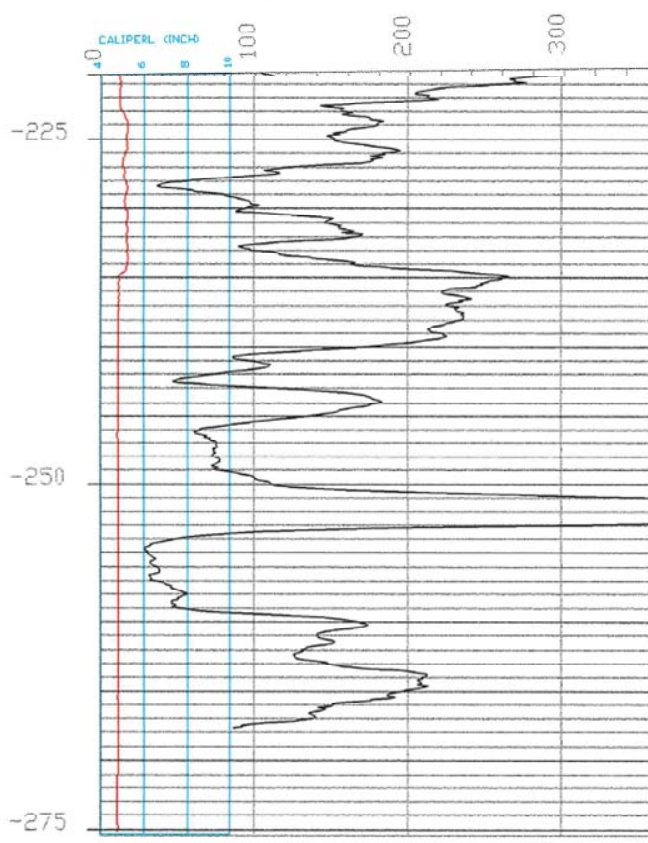

\section{DENSITYH}

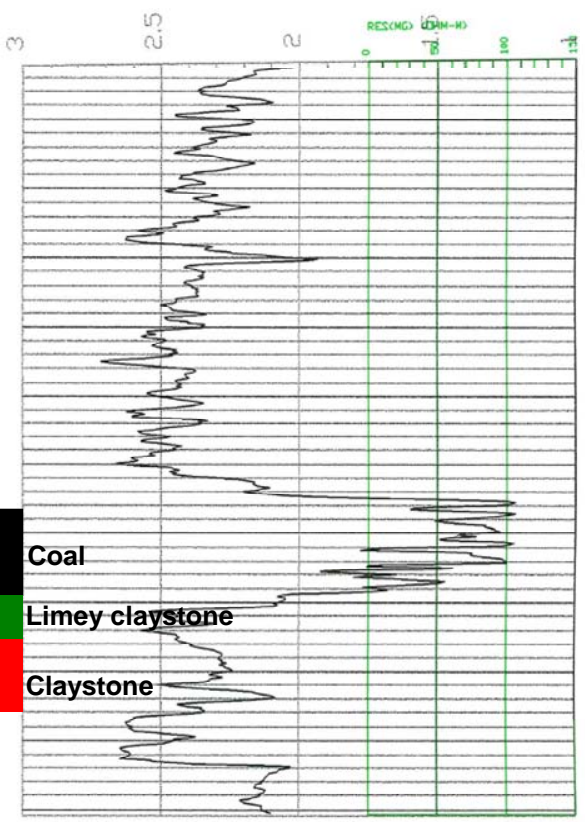

Figure 2.14. Driller's log, core pictures, gamma and density logs for example 3. 

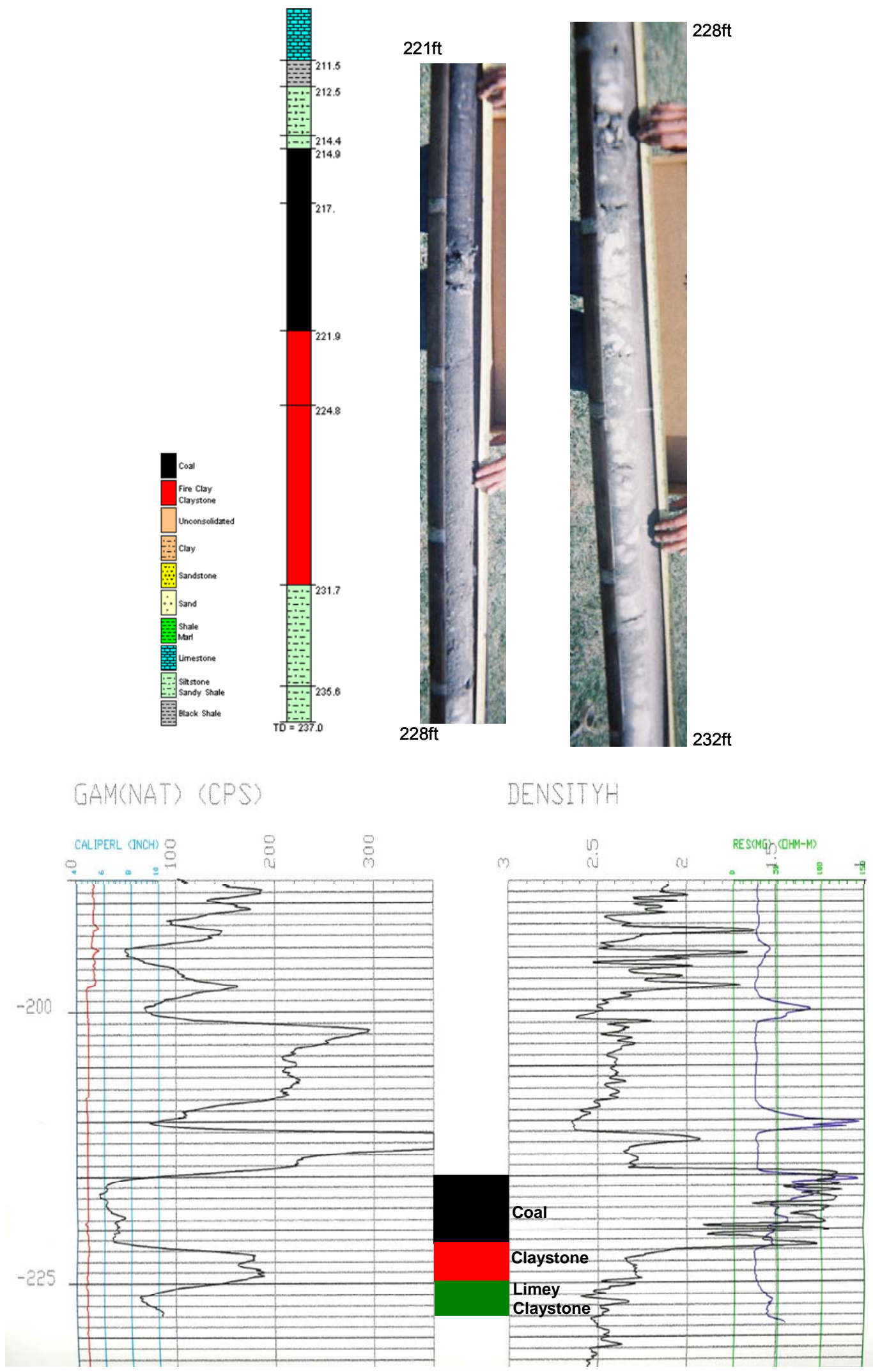

Figure 2.15. Driller's log, core pictures, gamma and density logs for example 4. 


\subsection{Laboratory Behavior of the Weak Floor Materials}

Laboratory properties provide the simplest and a convenient means to understand the engineering nature of rocks. Owing to the poor induration of the underclay and weak claystone in the Illinois Basin coal mines, rarely cores of sufficient length are available for conducting a standard suite of rock tests. Consequently, several index tests borrowed from soil mechanics are routinely used for floor characterization as well as for assessing its engineering behavior. The principal types of tests used in the past are:

- moisture content,

- Atterberg Limits,

- particle size analysis,

- swelling strain,

- slake durability,

- sonic properties,

- uniaxial compressive strength,

- indirect tensile strength.

Even though rare, a few researchers in the past have conducted some limited triaxial strength tests on the claystone floor (Speck, 1979; Chugh, 1986a). In the following sections, each of the above identified tests will be briefly discussed along with a large amount of data collected from several active and inactive mines from all three states of the Basin. Effort was made to collect the data from immediate floors related to all major coal seams in the Basin. It must be mentioned that due to the lack of complete information, the data corresponding to underclay and claystone materials in the floor are combined together in this analysis. The data put together in this chapter on the laboratory properties is easily the most comprehensive set of data ever analyzed for the Illinois Basin immediate floor.

\subsubsection{Moisture Content}

Among all the laboratory tests, the moisture or water content of the underclay is the simplest, cheapest and the most powerful index value for 
predicting its engineering behavior. The moisture content $(M C)$ in percentage is defined as (Terzaghi et al., 1996),

$$
M C=\frac{\text { weight of the water }}{\text { dry weight of the soil }} \times 100
$$

Because of the way it is defined, it is possible that the $M C$ value could exceed $100 \%$. The tests to determine the moisture content of the floor materials are run in accordance with the American Society for Testing Materials (ASTM) standard. The ASTM standard D2216 (ASTM, 2009) deals with this particular test. Depending on the particle size of the floor material, different minimum sample sizes are suggested in this standard. For instance, if $100 \%$ of the particles pass through a no.10 sieve, then at least 20 grams of the floor material is needed for the test. The test specimen is dried in an oven at a temperature of $110 \pm 5^{\circ} \mathrm{C}$ and the loss of the mass due to drying indicates the amount of water in the sample. Using the different weights measured before and after drying the sample and Equation (2.1), the moisture content of the sample is computed. The key aspect of the moisture content determination is proper protection of the floor samples to preserve the in-situ conditions. In addition to proper protection of the sample, it is extremely important to test the samples as soon as possible after they reach the laboratory.

Even though some published literature (Rockaway and Stephenson, 1979; Chugh, 1986a) provides moisture content values for the immediate floor materials in the Illinois Basin mines, detailed accounts on the trends of the moisture were never provided. In addition to being very limited, the past research mainly focused on developing interrelationships between several underclay engineering properties and the moisture content. No attempts were made to analyze the moisture content itself to see if any broad trends exist which could define the nature of the floor in different parts of the Basin. In fact, within the knowledge of this author no publication exists that talk about the moisture content trends from all three states of the Basin and from a decent number of mines. 
A huge database of moisture content of the immediate floor material was put together from published and unpublished sources. As mentioned before, the lion's share of the data came from different mines that belonged to a major U.S. coal company, which collected the data over a span of about two decades. For this database, the floor material below three major coal seams was considered. The seams included were the Herrin No. 6, the Springfield No. 5 and their equivalents in the three states and the Danville No. 7 in Indiana. Among the three states of the Basin and the coal seams considered, the moisture content data was available for 44 coal mines for a total of 7819 individual tests. Obviously, not all the mines contributed equally to the database. Some mines provided only a few hundred data points while others have exceeded a thousand tests. It appeared that the amount of data generated for different mines depended on the extent of floor instability experienced. Mines with relatively unstable floors did more tests than their stable counterparts.

Some key statistics related to the moisture content tests for different coal seam floors are provided in Figure 2.16 along with a few histograms. The values on the abscissa of these histograms represent the higher bound for each bin with the lower bound given by the preceding number. For instance, in Figure 2.16, for the No.6 seam there are 15 tests that had moisture value less than 1\%, 436 tests between 5 and $6 \%$ inclusive, and so on. Finally, "More" in the histograms represents the number of data points that have a variable value greater than the preceding bin value.

For the moisture content data, the immediate floor "claystone" bed (which includes underclay, weak and strong claystones) varied in thickness from about 0.5 to $18 \mathrm{ft}$ for the 6 seam, from about 0.2 to $14 \mathrm{ft}$ for the 5 seam, and from about 0.8 to $7 \mathrm{ft}$ for the 7 seam. However, for about $90 \%$ of the data, the "claystone" thickness did not exceed $6 \mathrm{ft}$ for the No. 5 and No. 6 seams. Purely by the average moisture values alone, it appears that the deeper the coal seam, the lower the floor moisture. This can be seen by the fact that the average moisture content of the deepest No. 5 seam is $5.81 \%$ and that of the shallowest No. 7 seam is $6.88 \%$ with the moisture content of No. 6 seam in between. However, 
the distribution of the moisture must also be considered when comparing the average values. From Figure 2.16, it is apparent that the floor moisture for the Springfield and Danville seams exhibits near normal distribution while that of the Herrin seam is bi-modal, left-skewed with a good number of points exceeding $12 \%$ moisture. Additionally, there is also a difference in the total number of tests available for each seam.

\begin{tabular}{|l|r|}
\hline \multicolumn{2}{|c|}{ No.6 Seam and its equivalents } \\
\hline Mean & 6.74 \\
\hline Median & 6.10 \\
\hline Mode & 5.70 \\
\hline Standard Deviation & 3.24 \\
\hline Minimum & 0.54 \\
\hline Maximum & 24.89 \\
\hline Count & 2742 \\
\hline Confidence Level(95.0\%) & 0.12 \\
\hline
\end{tabular}
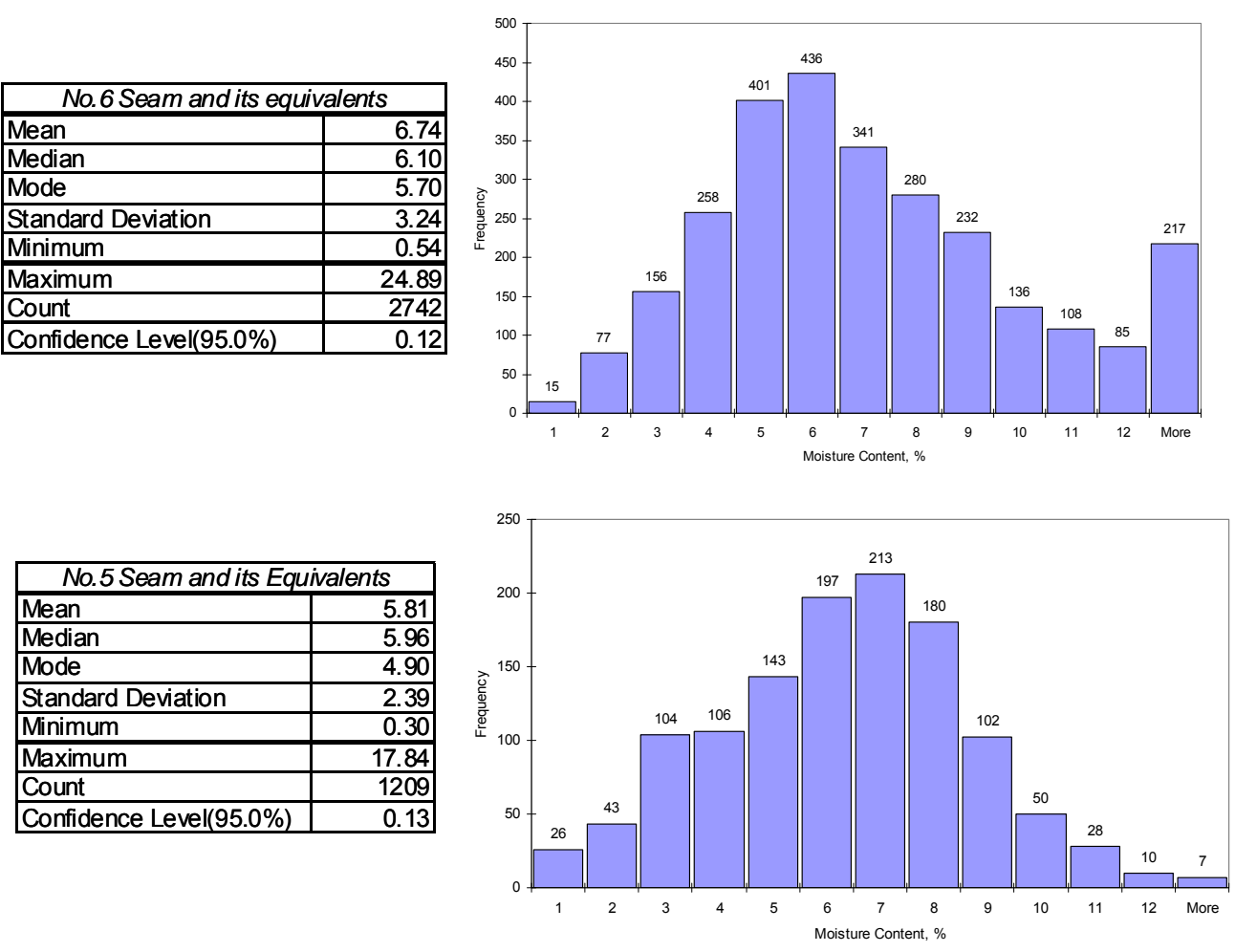

\begin{tabular}{|l|r|}
\hline \multicolumn{2}{|c|}{ Danville No.7 Seam } \\
\hline Mean & 6.88 \\
\hline Median & 6.85 \\
\hline Mode & 7.30 \\
\hline Standard Deviation & 1.83 \\
\hline Minimum & 1.00 \\
\hline Maximum & 18.50 \\
\hline Count & 4059 \\
\hline Confidence Level(95.0\%) & 0.06 \\
\hline
\end{tabular}

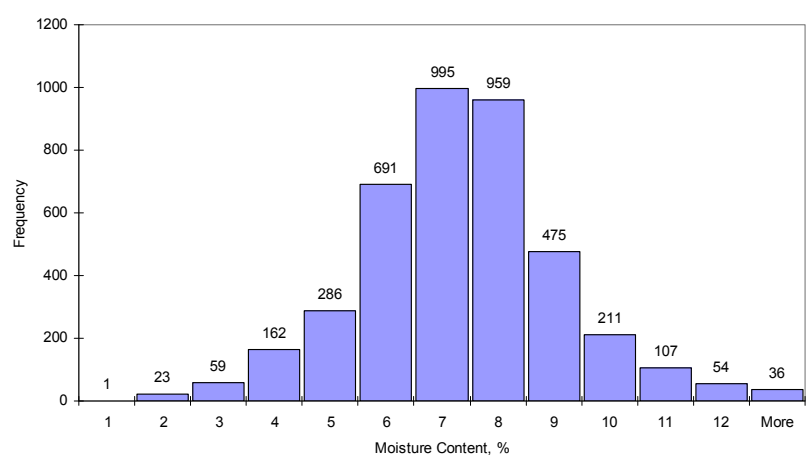

Figure 2.16. Key statistics and histograms of moisture content from three coal seam floors (the moisture content statistics in the tables are in \%).

The most significant finding of the moisture data analysis is that the floor in the Herrin No.6 seam exhibits somewhat different nature as compared to the 
remaining two seams. As seen from the moisture content histograms in Figure 2.16, the No.6 seam floor has a sizeable chunk of data with values in excess of $10 \%$ (about $15 \%$ of all the data). Among the several variables investigated, only the geographical location of the mines could explain the higher moisture values noted for the No.6 seam. In fact, when the No.6 seam data was split into the Eastern and Western shelves, the moisture distributions were obtained as shown in Figure 2.17. It can be seen from this figure that the average moisture content of the immediate floor in the Western shelf mines is higher than the Eastern shelf by about $1.7 \%$. Similarly, the number of points that had moisture values in excess of $10 \%$ were only about $4 \%$ for the Eastern shelf whereas it was a whopping $33 \%$ for the mines in the Western shelf. From these trends and for the depositional reasons discussed in section 2.2, it can be concluded that the nature of the floor associated with the Herrin No.6 and its equivalent seams differs significantly between the two shelves of the Basin.

\begin{tabular}{|l|r|}
\hline \multicolumn{2}{|c|}{ 6 seam Westem Shelf data } \\
\hline Mean & 7.77 \\
\hline Median & 7.32 \\
\hline Mode & 3.79 \\
\hline Standard Deviation & 4.34 \\
\hline Minimum & 0.56 \\
\hline Maximum & 24.89 \\
\hline Count & 1027 \\
\hline Confidence Level(95.0\%) & 0.27 \\
\hline
\end{tabular}

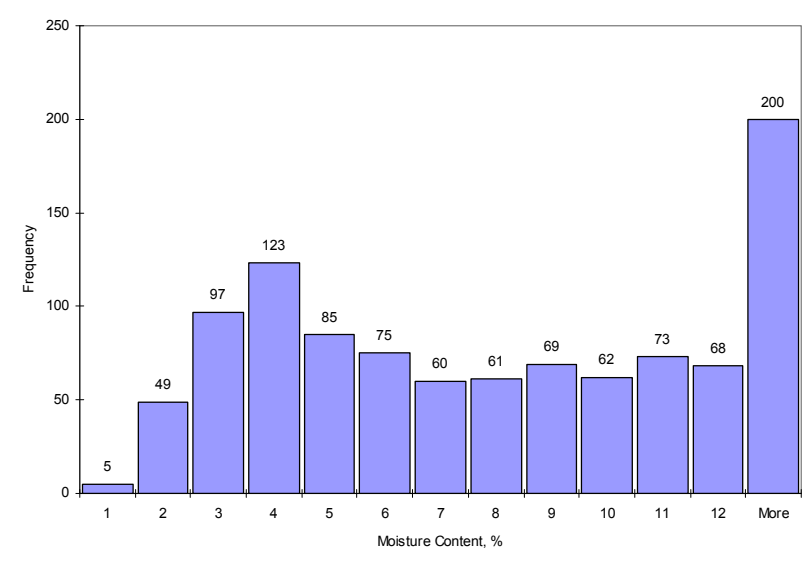

\begin{tabular}{|l|r|}
\hline \multicolumn{2}{|c|}{ 6 seam Eastern Shelf data } \\
\hline Mean & 6.12 \\
\hline Median & 5.90 \\
\hline Mode & 5.70 \\
\hline Standard Deviation & 2.12 \\
\hline Minimum & 0.54 \\
\hline Maximum & 15.32 \\
\hline Count & 1715 \\
\hline Confidence Level(95.0\%) & 0.10 \\
\hline
\end{tabular}

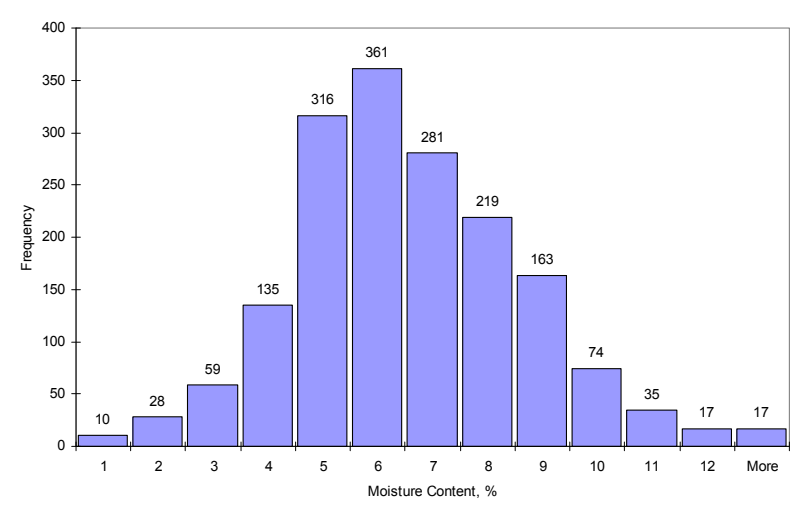

Figure 2.17. Key statistics and histograms of moisture content for the Eastern and Western shelf of the No.6 seam floor (the moisture content statistics in the tables are in \%). 
When the No.5 seam floor data was split into two shelves to see if similar differences like the 6 seam would be seen, the trends were inconclusive as illustrated in Figure 2.18. This is because of the very limited data that was available from the 5 seam floor in the Western shelf. Very few mines extract the Springfield seam in the Western shelf as compared to the extensively mined No. 6 seam. Despite the lack of enough supporting data, considering the depositional environment described in section 2.2, it is recommended that the Springfield seam floor may also be treated differently in the two shelves of the Basin.

\begin{tabular}{|l|r|}
\hline \multicolumn{2}{|c|}{ 5 seam Eastern Shelf data } \\
\hline Mean & 5.88 \\
\hline Median & 6.02 \\
\hline Mode & 4.90 \\
\hline Standard Deviation & 2.33 \\
\hline Minimum & 0.30 \\
\hline Maximum & 15.00 \\
\hline Count & 1137 \\
\hline Confidence Level(95.0\%) & 0.14 \\
\hline
\end{tabular}

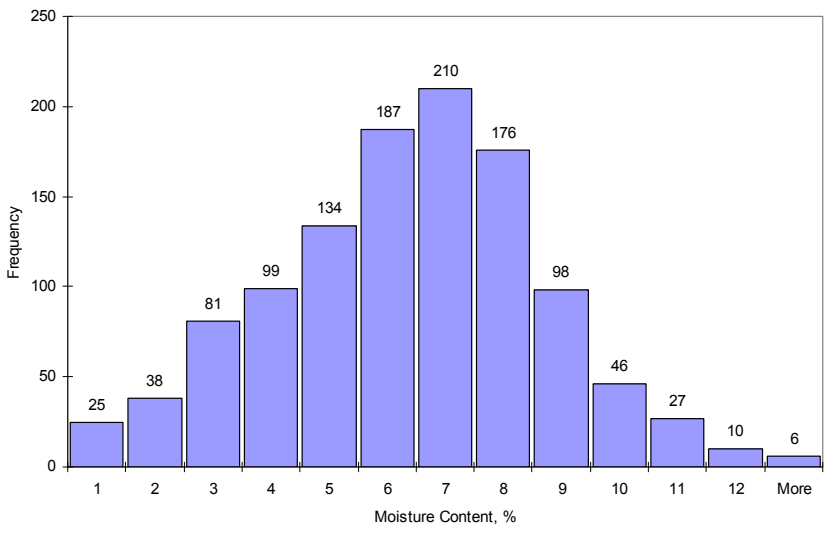

\begin{tabular}{|l|r|}
\hline \multicolumn{2}{|c|}{ 5 seam Western Shelf } \\
\hline Mean & 5.48 \\
\hline Median & 4.77 \\
\hline Mode & 2.41 \\
\hline Standard Deviation & 3.34 \\
\hline Minimum & 0.97 \\
\hline Maximum & 17.84 \\
\hline Count & 89 \\
\hline Confidence Level(95.0\%) & 0.70 \\
\hline
\end{tabular}

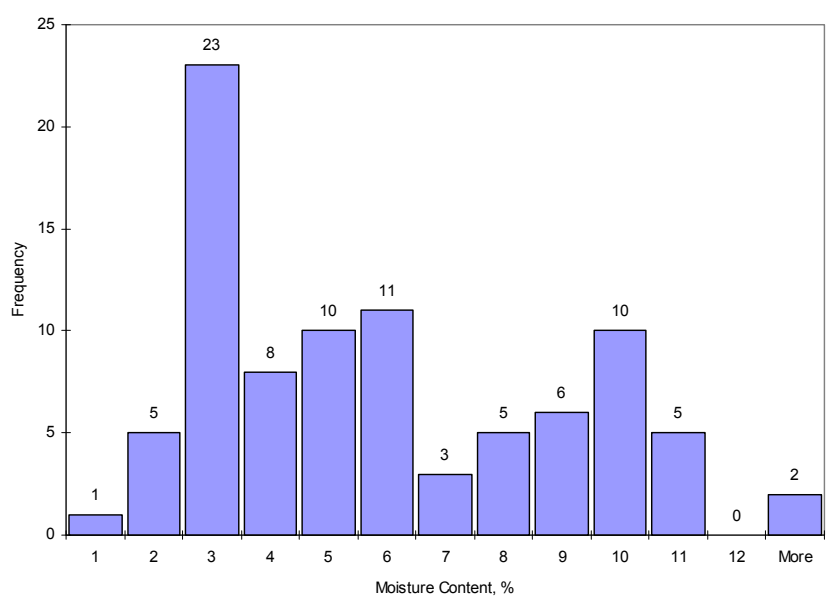

Figure 2.18. Key statistics and histograms of moisture content for the Eastern and Western shelf of the No.5 seam floor (the moisture content statistics in the tables are in \%).

If the apparent specific gravity of the soil particles and bulk density values are known along with the moisture content, then the void ratio of the soil can be computed using the following equation (Terzaghi et al., 1996): 


$$
e=\frac{G \gamma_{\text {water }}\left[\frac{M C}{100}+1\right]-\gamma_{\text {wet }}}{\gamma_{\text {wet }}}
$$

where, $e \quad$ is the void ratio,

$G \quad$ the specific gravity,

$\gamma_{\text {water }}$ unit weight of water,

MC moisture content in \%,

$\gamma_{\text {wet }}$ bulk density of the sample.

Similarly, from the void ratio, the porosity $(n)$ can be computed by

$$
n=\frac{e}{1+e}
$$

and, the degree of saturation $(S)$ by using the following equation

$$
S=\left[\frac{M C}{100} \times \frac{\gamma_{d}}{\gamma_{\text {water }}} \times \frac{1+e}{e}\right] \times 100
$$

where $\gamma_{d}$ is the unit weight of the solid particles which could be computed from the specific gravity, $G$.

For every test in Figure 2.16, the bulk density and specific gravity values were not available. In fact, for none of the data in Figure 2.16, the individual specific gravity of the soil particles was available. For a few tests, however, the bulk density was known. Using the published data (Chugh, 1986a), the specific gravity of the clay particles for the Herrin and Springfield seam floors were computed to be 2.62 and 2.68, respectively. No information on the specific gravity for the Danville seam was available and thus the Springfield seam value was used for the void ratio computations. This was done owing to the similarities between the two seam floors revealed by the Atterberg limit values discussed in the next section. For those cases where the moisture content and bulk density values were known, equations (2.2) to (2.4) were used to compute the porosity and the degree of saturation as given in Figures 2.19 and 2.20. Enough data was not available for any of the seams to split the information into the two shelves. The data in figures 2.19 and 2.20 show that even though the claystone floor is 


\begin{tabular}{|l|r|}
\hline \multicolumn{2}{|c|}{ 6 Seam } \\
\hline Mean & 17.36 \\
\hline Median & 17.05 \\
\hline Standard Deviation & 8.11 \\
\hline Minimum & 1.85 \\
\hline Maximum & 47.91 \\
\hline Count & 467 \\
\hline Confidence Level(95.0\%) & 0.74 \\
\hline
\end{tabular}

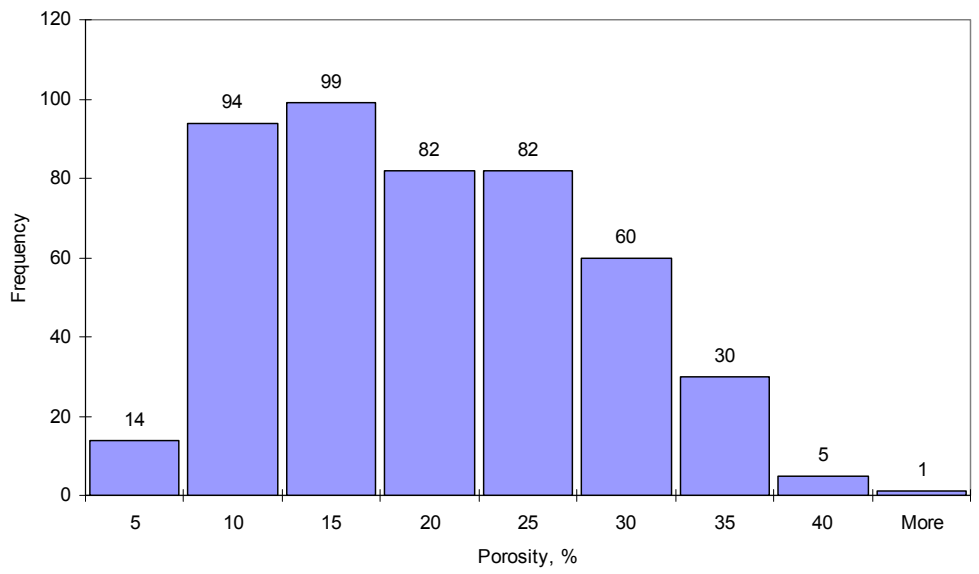

\begin{tabular}{|l|r|}
\hline \multicolumn{2}{|c|}{ 5 Seam } \\
\hline Mean & 14.55 \\
\hline Median & 14.73 \\
\hline Mode & 20.24 \\
\hline Standard Deviation & 7.02 \\
\hline Minimum & 0.71 \\
\hline Maximum & 40.52 \\
\hline Count & 445 \\
\hline Confidence Level(95.0\%) & 0.65 \\
\hline
\end{tabular}

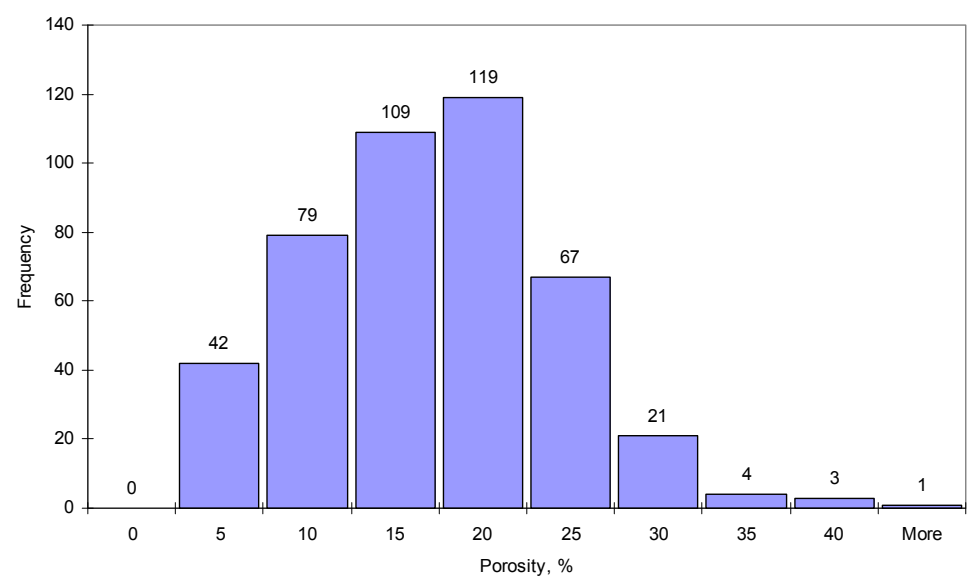

\begin{tabular}{|l|r|}
\hline \multicolumn{2}{|c|}{ 7 Seam } \\
\hline Mean & 13.33 \\
\hline Median & 13.16 \\
\hline Standard Deviation & 6.06 \\
\hline Minimum & 2.53 \\
\hline Maximum & 36.88 \\
\hline Count & 60 \\
\hline Confidence Level(95.0\%) & 1.57 \\
\hline
\end{tabular}

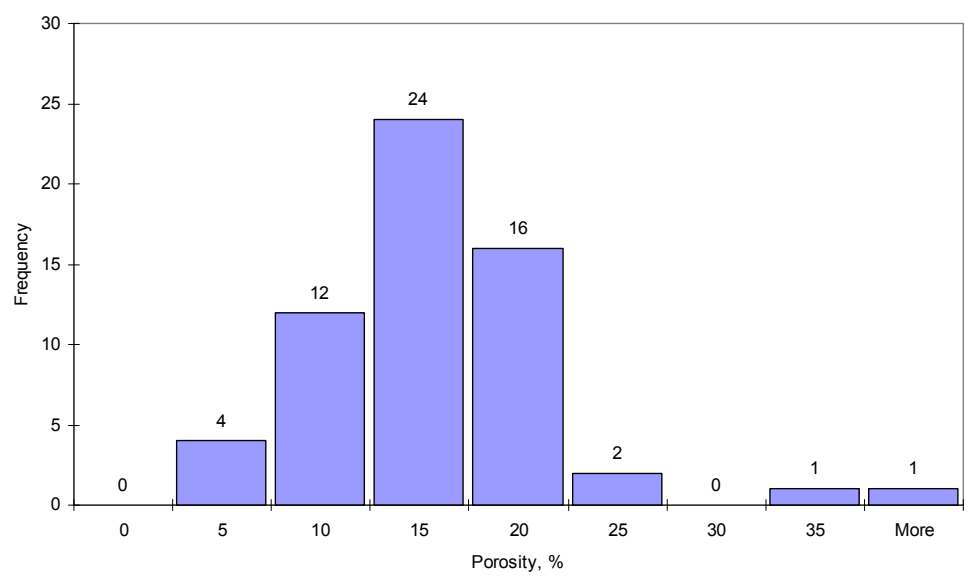

Figure 2.19. Porosity of the claystone floor for three different seam floors. (the porosity statistics in the tables are in \%).

not very porous, it is very close to being fully saturated. In soil mechanics, it is commonly assumed that if the clay is fully saturated, then its angle of internal friction is zero. Looking at the data in Figure 2.20, it appears that the zero friction 
angle assumption made by the most popular floor bearing capacity model developed by Vesic (1975) is perhaps not very unrealistic. Further, considering that a vast majority of the floor samples have $70 \%$, or higher pores saturated, it may be expected that the angle of internal friction for these weak materials will not be very high.

\begin{tabular}{|l|r|}
\hline \multicolumn{2}{|c|}{ 6 seam } \\
\hline Mean & 83.95 \\
\hline Median & 83.46 \\
\hline Standard Deviation & 30.42 \\
\hline Minimum & 20.27 \\
\hline Maximum & 342.61 \\
\hline Count & 467 \\
\hline Confidence Level(95.0\%) & 2.77 \\
\hline
\end{tabular}

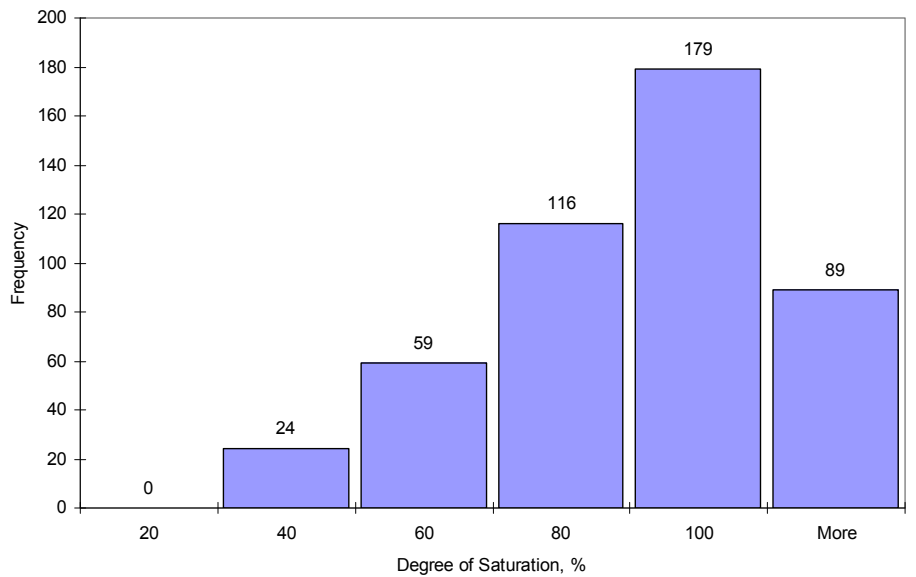

\begin{tabular}{|l|r|}
\hline \multicolumn{2}{|c|}{ 5 Seam } \\
\hline Mean & 98.49 \\
\hline Median & 89.95 \\
\hline Mode & 88.08 \\
\hline Standard Deviation & 46.68 \\
\hline Minimum & 23.66 \\
\hline Maximum & 375.32 \\
\hline Count & 445 \\
\hline Confidence Level(95.0\%) & 4.35 \\
\hline
\end{tabular}

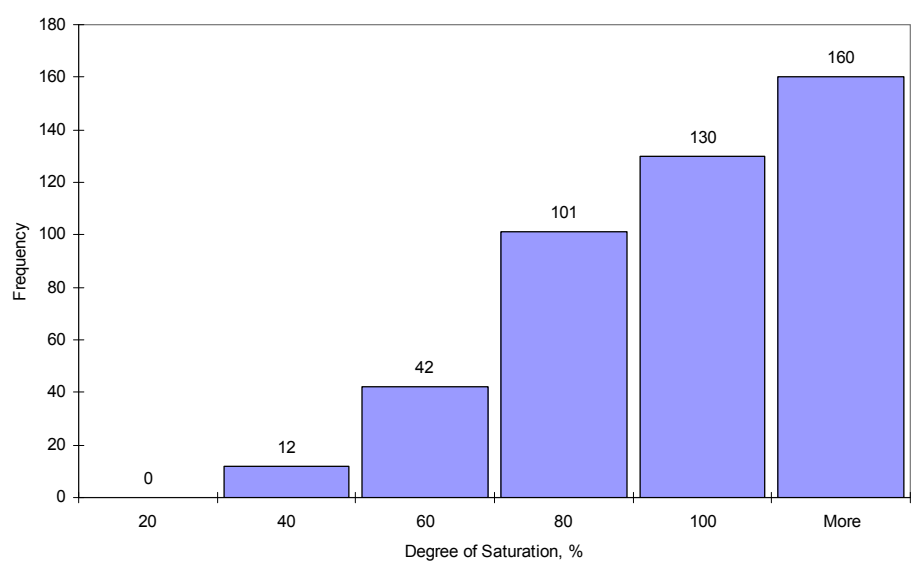

\begin{tabular}{|l|r|}
\hline \multicolumn{2}{|c|}{ 7 Seam } \\
\hline Mean & 109.62 \\
\hline Median & 101.11 \\
\hline Standard Deviation & 49.22 \\
\hline Minimum & 29.76 \\
\hline Maximum & 353.60 \\
\hline Count & 60 \\
\hline Confidence Level(95.0\%) & 12.72 \\
\hline
\end{tabular}

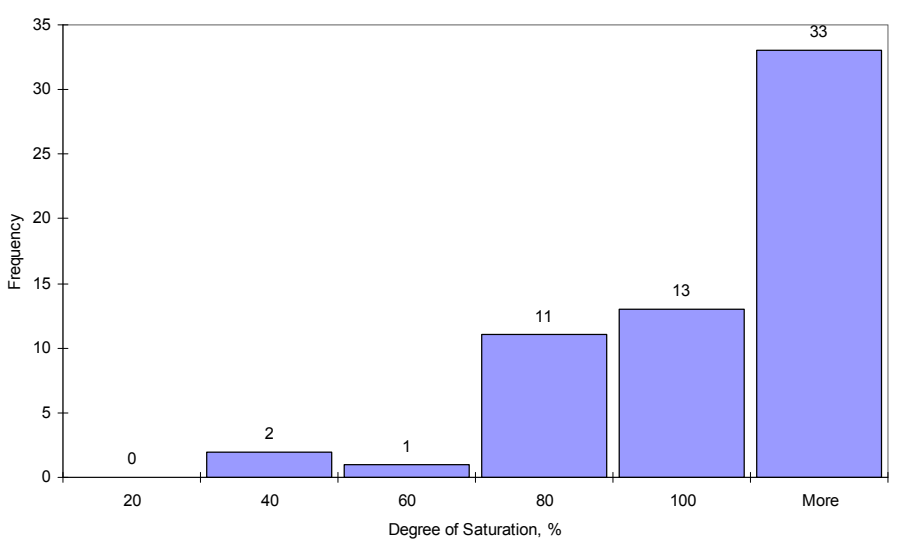

Figure 2.20. Degree of saturation of the claystone floor for three different seam floors (the degree of saturation statistics in the tables are in \%). 


\subsubsection{Atterberg Limits}

It has been long recognized that a hard, and sometimes brittle, clayey soil could be converted to a soft, pliable plastic material with the addition of a proper amount of water. Such water induced "softening" of a cohesive soil material is formally described using the so called Atterberg limits (Terzaghi et al., 1996). Among different Atterberg limits (liquid limit, sticky limit, cohesion limit, plastic limit and shrinkage limit), only two are important in describing the plasticity of a clay material called the 'liquid limit' and the 'plastic limit' (Casagrande, 1932). In the context of this research, the term "plasticity" refers to the ease with which irreversible deformations could be induced in a soil material as a function of its moisture content. Atterberg limits are extensively used for identification, description and classification of cohesive soils and also for a preliminary assessment of their mechanical properties (Mitchell and Soga, 2005).

The liquid limit $(L L)$ of a cohesive soil is the water content (in percent of the dry weight) at which two sections of a pat of soil of certain dimensions barely touch each other but do not flow together when subjected in a cup to the impact of sharp blows from below (Terzaghi et al., 1996). Casagrande (1932) defines the liquid limit as the water content at which the soil has a shear strength of about $2.5 \mathrm{kPa}(0.36 \mathrm{psi})$. To put it in practical terms, the liquid limit of a soil represents the highest water content up to which a soil behaves plastically. At water contents greater than the liquid limit, the soil flows just like water. The liquid limit of a soil is determined as per the ASTM standard D4318 (ASTM, 2009) using the test set up shown in Figure 2.21.

Experimentally, the plastic limit $(P L)$ of a soil is the water content at which the soil begins to crumble when rolled into thin threads (Terzaghi et al., 1996). Therefore, the plastic limit represents the minimum water content below which the soil loses its plasticity. From a strength point of view, at the plastic limit, the shear strength of the soil is approximately 100 times that at the liquid limit (Sharma and Bora, 2003). Using the Casagrande's $2.5 \mathrm{kPa}$ shear strength at the liquid limit, the soil will likely have a shear strength of about $250 \mathrm{kPa}$ (36 psi) when its moisture content is equal to the plastic limit. Similar to the liquid limit, 
the plastic limit of a soil is also determined as per the ASTM standard D4318 (ASTM, 2009) using the set up shown in Figure 2.22.
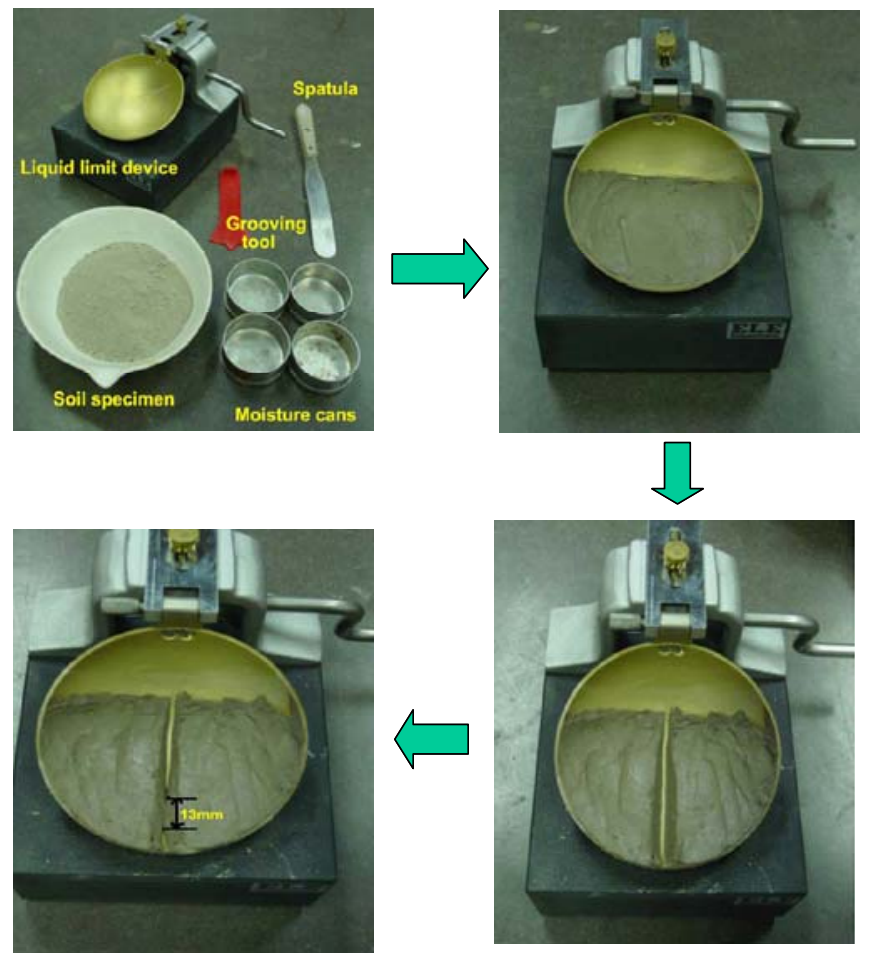

Figure 2.21. Percussion cup test set up for the liquid limit determination.
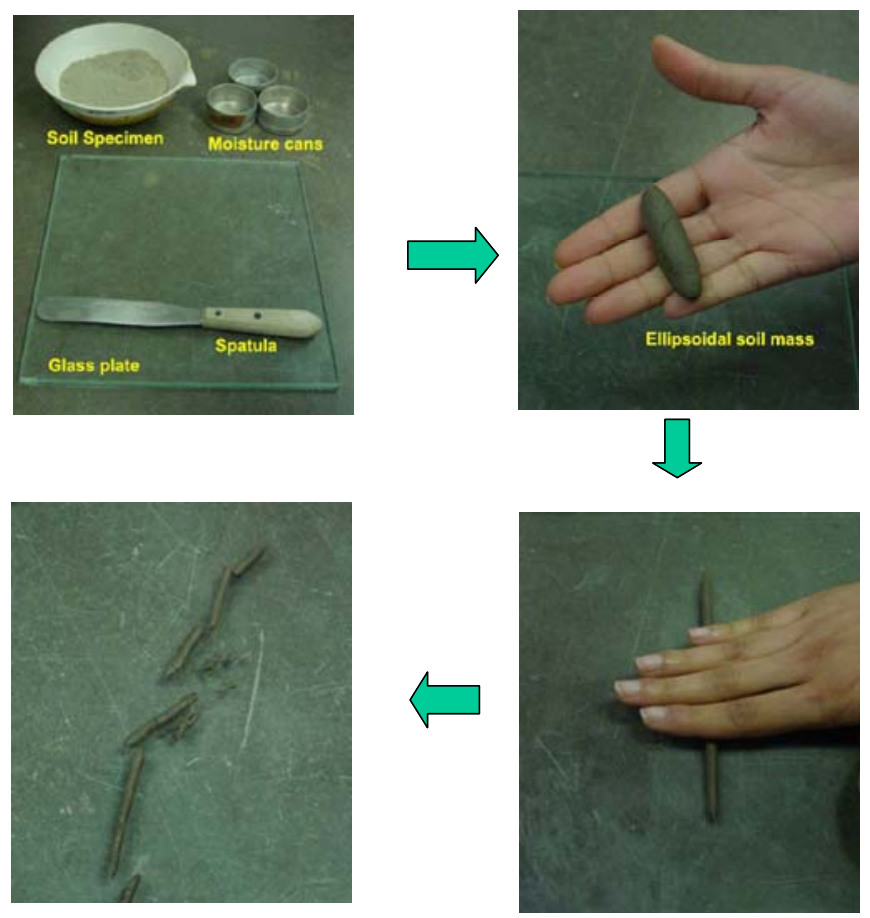

Figure 2.22. Test set up for the plastic limit determination. 
The algebraic difference between the liquid limit and the plastic limit is termed as the 'plasticity index' $(P I)$ of the soil. Thus,

$$
P I=L L-P L
$$

From the above definitions of the liquid and plastic limits, it is clear that when the water content of a soil lies in between the two limits, the soil exhibits plasticity characteristics. Because of the similarity in the physical mechanisms that determine the strength and permeability of soils in the field and those acting in the simplified tests used to determine the Atterberg limits, extensive use of the limits is made in soil mechanics for several design purposes (Casagrande, 1932). In addition to those available in the published literature (Chugh 1986a), the Atterberg limits data collected from a number of mines in the Illinois Basin for three major coal seam floors are described below. Similar to the moisture content, the floors studied include the Herrin No. 6, Springfield No. 5 and Danville No. 7 and their equivalents in the three states of the Basin. Key statistics on the liquid limit, plastic limit and the plasticity index for the three seam floors are shown in Figure 2.23 through Figure 2.25 along with some histograms.

For the No.6 seam floor, the liquid limit, plastic limit and the plasticity index values were available from 16 coal mines in Illinois and 2 mines in Western Kentucky (locally called the No.11 seam). A total of 241 tests were available for these 18 coal mines. Similarly, the Atterberg limits data was available from a total of 21 mines for the No. 5 seam floor and its equivalents. The data was available from 12 mines in Western Kentucky (locally called No.9 seam), 5 from Illinois and 4 from Indiana. The database comprised of 321 individual sets. Finally, all the No. 7 seam data came from two mines in Indiana. In fact, except for one set, the rest of the data came from a single mine. There were a total of 147 sets of Atterberg limits data available for the floor of this seam. Together the entire database comprises 709 Atterberg limit tests for the weak floor from 41 coal mines in the three states.

The trends shown by the Atterberg limits in Figure 2.23 through Figure 2.25 suggest the following: 
- the liquid limit, plastic limit and plasticity index values show a broader range for the No. 6 seam floor than the remaining two,

- the average values of the liquid limit, plastic limit and plasticity index are the highest for the No.6 seam floor and comparable for the No. 5 and No. 7 seams,

- in the presence of temporary standing water, it takes longer for the Herrin seam floor to become liquefied when compared to the No.5 or No.7 seam as indicated by their respective average liquid limit values,

a)

\begin{tabular}{|l|r|}
\hline \multicolumn{2}{|c|}{ 6 Seam } \\
\hline Mean & 56 \\
\hline Median & 52 \\
\hline Mode & 34 \\
\hline Standard Deviation & 22.26 \\
\hline Minimum & 20.7 \\
\hline Maximum & 107 \\
\hline Count & 241 \\
\hline Confidence Level(95.0\%) & 2.82 \\
\hline
\end{tabular}

b)

\begin{tabular}{|l|r|}
\hline \multicolumn{2}{|c|}{ 5 Seam } \\
\hline Mean & 31 \\
\hline Median & 30 \\
\hline Mode & 31 \\
\hline Standard Deviation & 6.83 \\
\hline Minimum & 14.58 \\
\hline Maximum & 70 \\
\hline Count & 321 \\
\hline Confidence Level(95.0\%) & 0.75 \\
\hline
\end{tabular}

c)

\begin{tabular}{|l|r|}
\hline \multicolumn{2}{|c|}{ 7Seam } \\
\hline Mean & 32 \\
\hline Median & 31 \\
\hline Mode & 33 \\
\hline Standard Deviation & 6.93 \\
\hline Minimum & 17.2 \\
\hline Maximum & 55 \\
\hline Count & 147 \\
\hline Confidence Level(95.0\%) & 1.13 \\
\hline
\end{tabular}
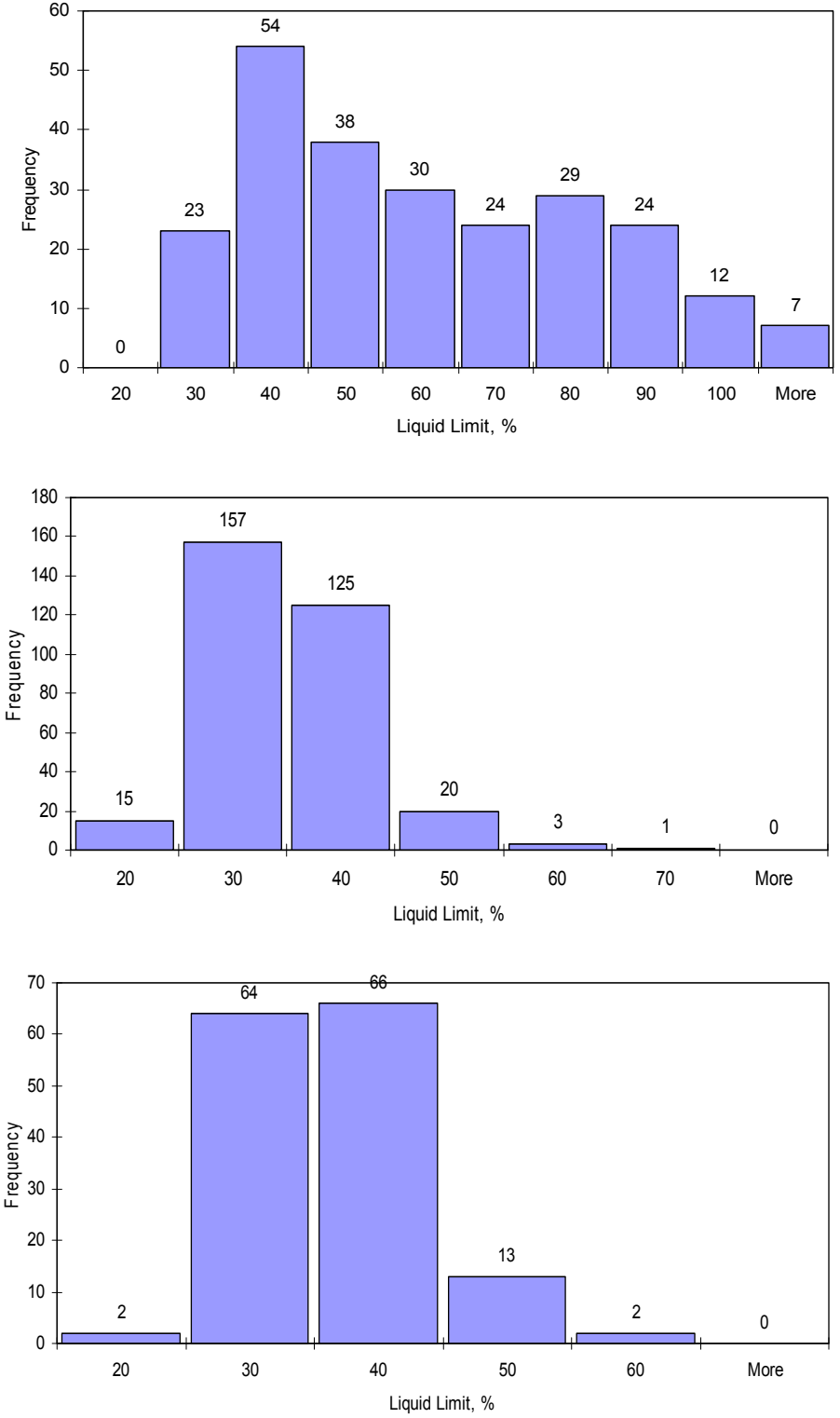

Figure 2.23. Liquid limit data for a) No.6 seam, b) No. 5 seam and c) No. 7 seam and their equivalent floors (the statistics in the tables are in \%). 
- under the influence of excess water below the liquid limit, on average the Herrin seam workings will experience more sticky floor conditions than either No. 5 or No. 7 seams,

- in general, it takes more moisture to soften the No. 6 seam floor than either No.5 or No.7 seam as indicated by the respective average plastic limit values.

a)

\begin{tabular}{|l|r|}
\hline \multicolumn{2}{|c|}{ 6 Seam } \\
\hline Mean & 35 \\
\hline Median & 26 \\
\hline Mode & 18 \\
\hline Standard Deviation & 19.43 \\
\hline Minimum & 11 \\
\hline Maximum & 85 \\
\hline Count & 241 \\
\hline Confidence Level(95.0\%) & 2.47 \\
\hline
\end{tabular}

b)

\begin{tabular}{|l|r|}
\hline \multicolumn{2}{|c}{ 5 Seam } \\
\hline Mean & 17 \\
\hline Median & 17 \\
\hline Mode & 18 \\
\hline Standard Deviation & 4.32 \\
\hline Minimum & 6 \\
\hline Maximum & 52 \\
\hline Count & 321 \\
\hline Confidence Level(95.0\%) & 0.47 \\
\hline
\end{tabular}

c)

\begin{tabular}{|l|r|}
\hline \multicolumn{2}{|c|}{ 7 Seam } \\
\hline Mean & 19 \\
\hline Median & 19 \\
\hline Mode & 22 \\
\hline Standard Deviation & 2.83 \\
\hline Minimum & 13 \\
\hline Maximum & 28.1 \\
\hline Count & 147 \\
\hline Confidence Level(95.0\%) & 0.46 \\
\hline
\end{tabular}
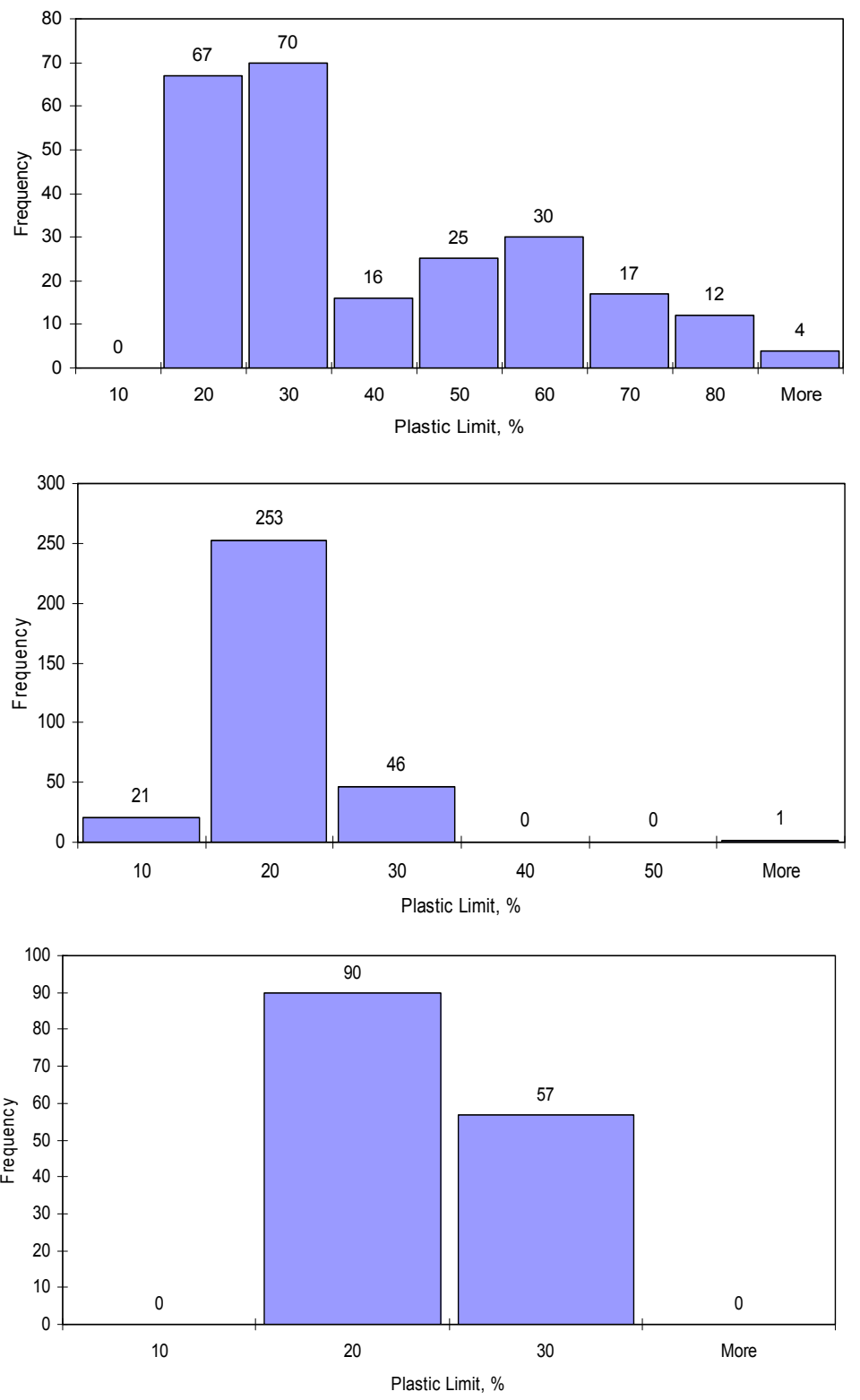

Figure 2.24. Plastic limit data for a) No.6 seam, b) No. 5 seam and c) No. 7 seam and their equivalent floors (the statistics in the tables are in \%). 
a)

\begin{tabular}{|l|r|}
\hline \multicolumn{2}{|c|}{ 6 Seam } \\
\hline Mean & 21 \\
\hline Median & 19 \\
\hline Mode & 18 \\
\hline Standard Deviation & 9.58 \\
\hline Minimum & 4.7 \\
\hline Maximum & 67 \\
\hline Count & 241 \\
\hline Confidence Level(95.0\%) & 1.22 \\
\hline
\end{tabular}

b)

\begin{tabular}{|l|r}
\hline \multicolumn{2}{|c|}{ 5 Seam } \\
\hline Mean & 14 \\
\hline Median & 14 \\
\hline Mode & 14 \\
\hline Standard Deviation & 5.37 \\
\hline Minimum & 1.14 \\
\hline Maximum & 37 \\
\hline Count & 321 \\
\hline Confidence Level(95.0\%) & 0.59 \\
\hline
\end{tabular}

c)

\begin{tabular}{|l|r|}
\hline \multicolumn{2}{|c|}{ 7 Seam } \\
\hline Mean & 12 \\
\hline Median & 11 \\
\hline Mode & 11 \\
\hline Standard Deviation & 5.20 \\
\hline Minimum & 3.6 \\
\hline Maximum & 33 \\
\hline Count & 147 \\
\hline Confidence Level(95.0\%) & 0.85 \\
\hline
\end{tabular}
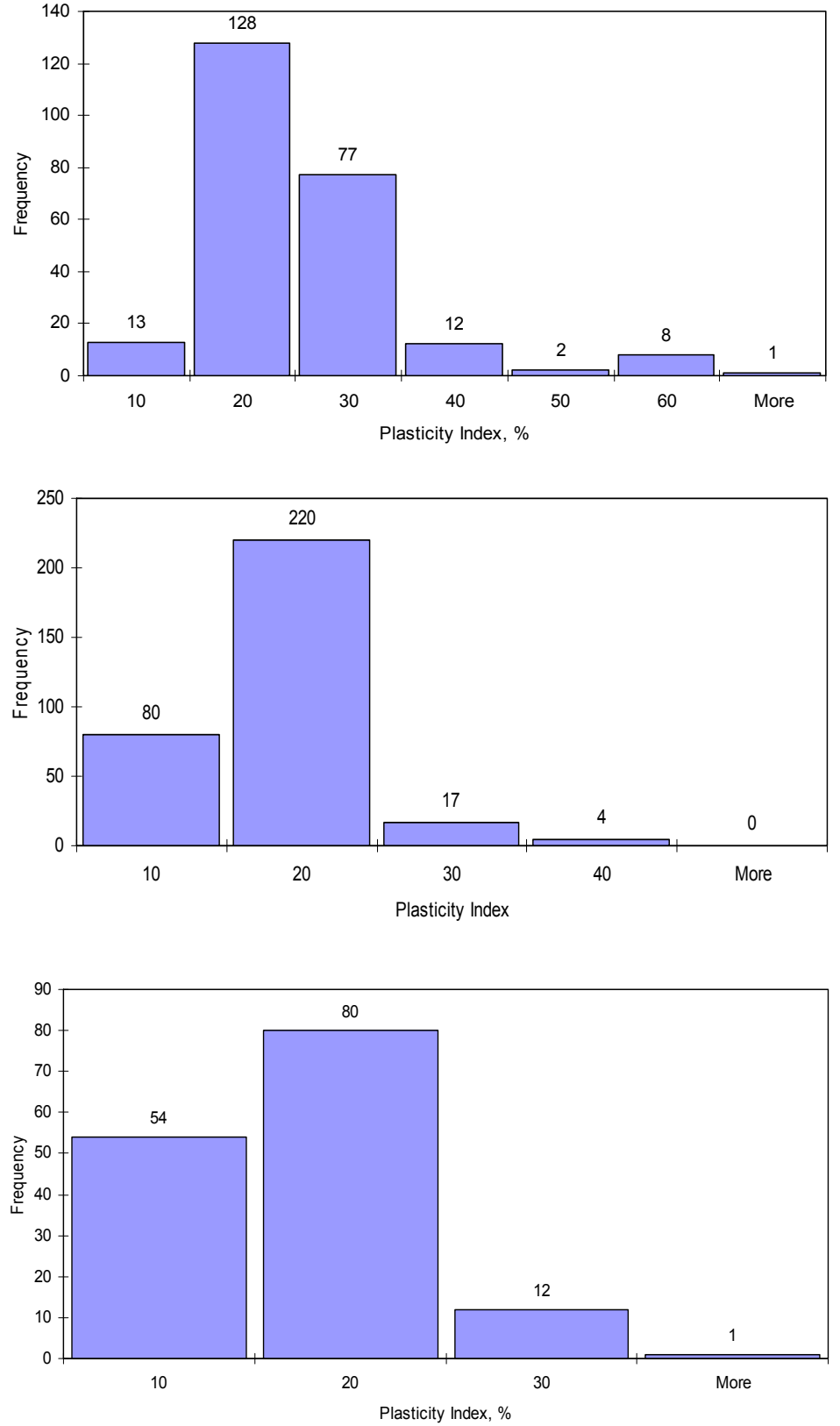

Figure 2.25. Plasticity index data for a) No.6 seam, b) No. 5 seam and c) No. 7 seam and their equivalent floors (the statistics in the tables are in \%).

There are several ways in which the above Atterberg limits data could be interpreted for practical use. For instance, in general the data show that the No. 6 seam floor is more plastic than the No.5 or No. 7 seams as evidenced by the higher average liquid limit, plastic limit and the plasticity index values. However, one of the most concise ways to make sense of the data is by using the 'plasticity 
chart' developed by Arthur Casagrande (1932). Rockaway and Stephenson (1979) and Chugh (1986b) were some of the first to use the plasticity chart for interpreting the nature of coal mine floors. In addition to the plasticity chart, in what follows, some other approaches available to interpret and use the Atterberg limits are discussed.

\subsubsection{The Plasticity Chart}

The plasticity chart is a plot made between the liquid limit and the plasticity index of a soil. The location of a point on the chart indicates the class to which a soil belongs and also provides qualitative information on the engineering properties of the soil. The standard plasticity chart used in the Unified Soil Classification System or USCS (ASTM, 2009) is shown in Figure 2.26.

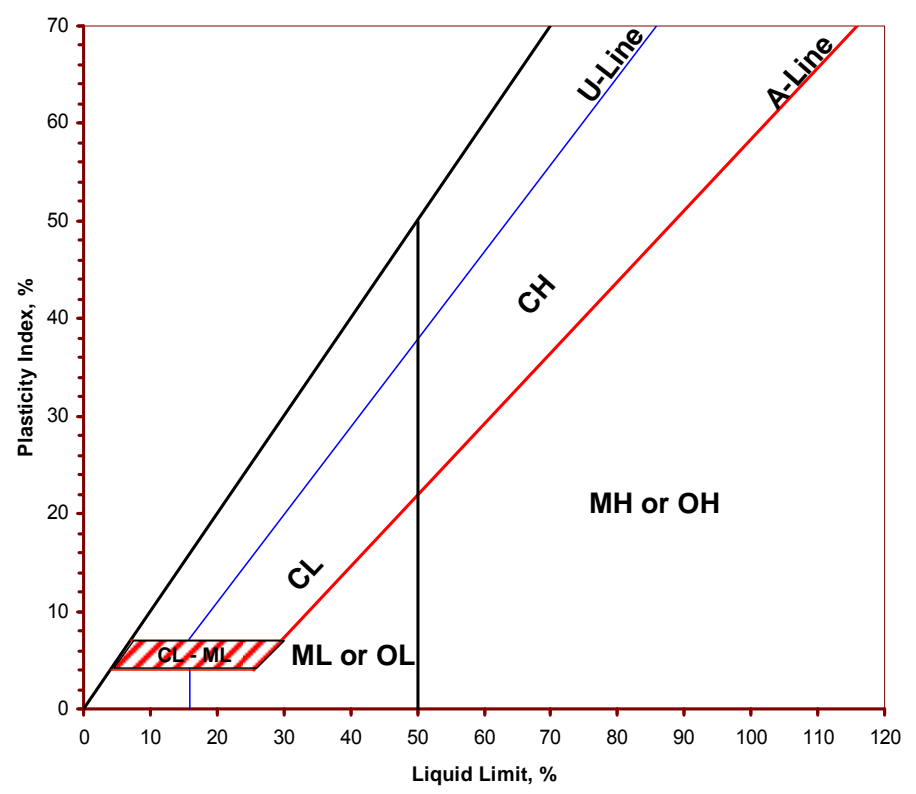

Figure 2.26. The plasticity chart.

There are two important empirical inclined lines that are shown in the plasticity chart in Figure 2.26. The A-line separates inorganic and organic clays with inorganic lying above the line. Also, typical inorganic silts and silty clays fall below the A-line (Casagrande, 1948). Similarly, the U-line represents the upper limit for the Atterberg limits for any soil type encountered in nature. As shown in Figure 2.26, a full two-lettered cohesive soil classification scheme is available 
that is based completely on the plasticity chart (ASTM, 2009). In the USCS scheme, letters $C, M$ and $O$ stand for clay, silt and organic, respectively, whereas the letters $L$ and $H$ represent "low" and "high" plasticity, respectively. Therefore, a soil classified as $\mathrm{CH}$, for instance, indicates a high plastic clay in the USCS scheme.

The position of a soil on the plasticity chart not only identifies the class of the soil, but also gives a qualitative indication of the soil's engineering properties. Table 2.1 reproduced from the landmark paper by Casagrande (1948) explains the expected engineering behavior of a soil in relation to the plasticity chart.

Table 2.1. Engineering behavior of a soil in relation to the plasticity chart (Casagrande, 1948).

\begin{tabular}{|l|l|l|}
\hline \multicolumn{1}{|c|}{ Characteristic } & $\begin{array}{l}\text { Comparing soils at } \\
\text { equal liquid limit with } \\
\text { plasticity index increasing }\end{array}$ & $\begin{array}{l}\text { Comparing soils at } \\
\text { equal plasticity index with } \\
\text { liquid limit increasing }\end{array}$ \\
\hline Compressibility & About the same & Increases \\
\hline Permeability & Decreases & Increases \\
\hline Rate of volume change & Decreases & --- \\
\hline Toughness near plastic limit & Increases & Decreases \\
\hline Dry strength & Increases & Decreases \\
\hline
\end{tabular}

The Atterberg limits data described in Section 2.3.2 for the three coal seams considered in this study are plotted on the plasticity charts in Figure 2.27 through Figure 2.29 below.

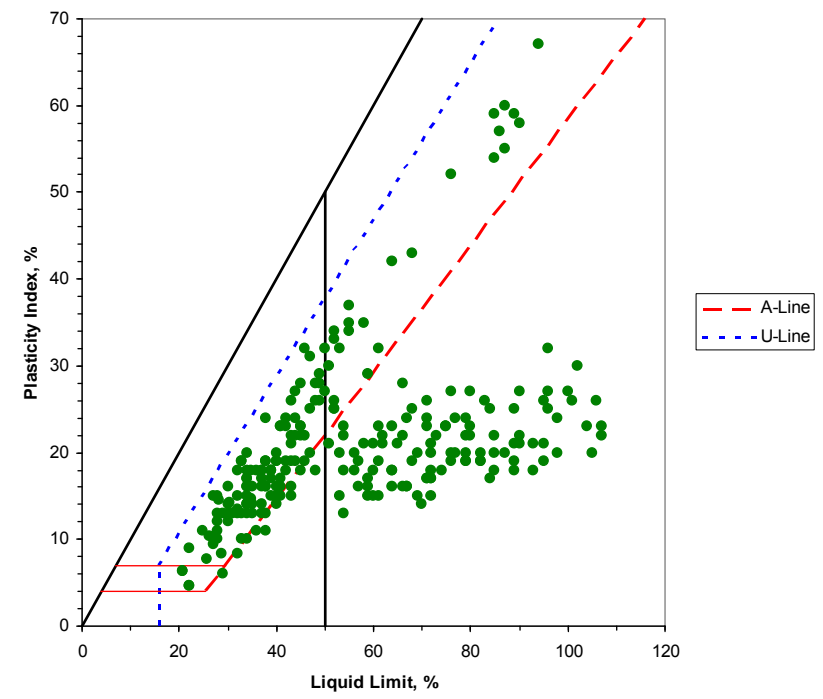

Figure 2.27. The plasticity chart for the No.6 seam floor data. 


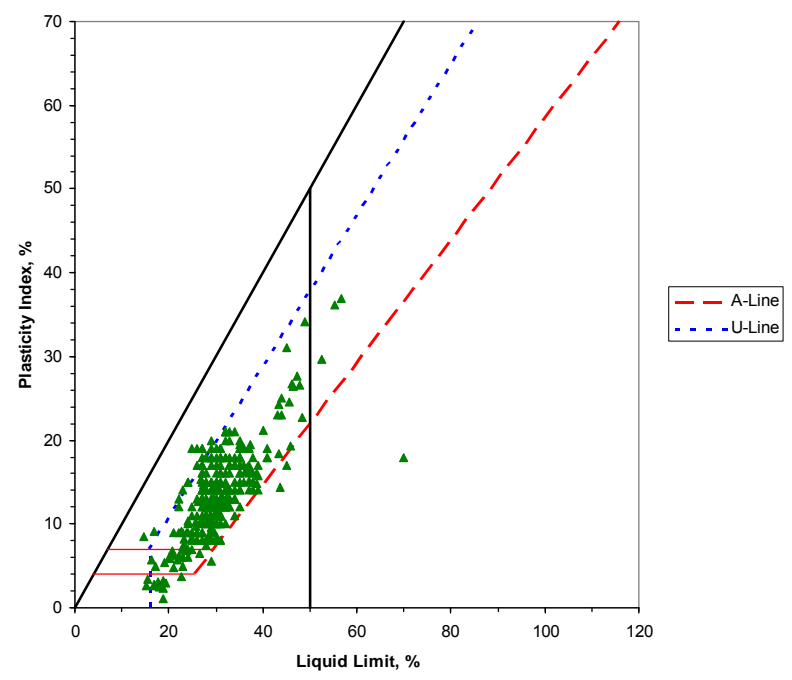

Figure 2.28. The plasticity chart for the No.5 seam floor data.

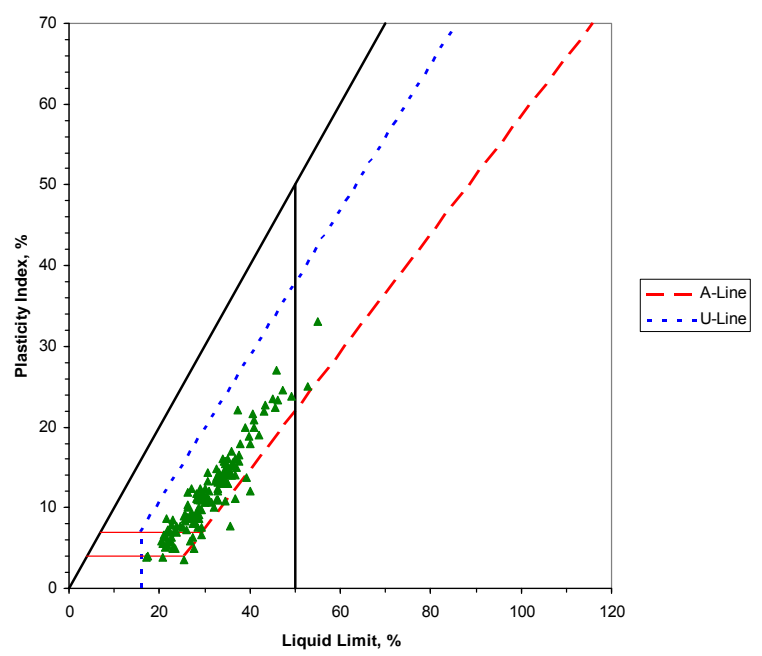

Figure 2.29. The plasticity chart for the No.7 seam floor data.

Based on the plasticity charts for the three seams and using Table 2.1, the following conclusions could be drawn about the general nature of the weak immediate floor:

- Almost all the data from the Springfield and Danville seams show that the floor associated with these two seams could be classified as low plastic clay $(C L)$.

- The Herrin seam data show a different trend. The immediate floor for this seam fall under three classes: low plastic clay $(C L)$, high plastic clay $(C H)$ and high plastic silty clay or high plastic organic soil ( $\mathrm{MH}$ or $\mathrm{OH})$. 
- If all the soil samples come from the same deposit, then the Atterberg limits data when plotted on a plasticity chart should lie parallel to the A-line (Casagrande, 1948). The limits data from the No.5 and No.7 seam floors show such a parallelism. A big portion of the data from the No.6 seam, however, is not parallel to the A-line. Such a trend by the Herrin seam floor indicates two possibilities: one, the source material for the floor may not be the same throughout the Basin and second, in some parts of the Basin, the floor contains a totally different clay mineral like allophane (Terzaghi et al., 1996). No evidence is available so far to show that allophane was ever found in the 6 seam floor though.

- Almost all the data from the No. 5 and No.7 seam floors and some portion of the 6 seam indicate low to medium dry strength, compressibility and permeability for the underclay. A portion of the 6 seam data suggest medium to very high dry strength, compressibility and permeability.

Further analysis of the No. 6 seam floor data showed that almost all the data that had liquid limit values greater than $50 \%$ came from mines that are on the Western shelf of the basin. When the geographic location of the mines and their individual Atterberg limits were considered, mines in the Western shelf of the Illinois Basin exhibited higher average liquid limit, plastic limit and plasticity index values than those in the Eastern Shelf for the Herrin seam floor. A summary of the Atterberg limits data for the two shelves is provided in Figure 2.30 through Figure 2.33. It may also be mentioned that all the Atterberg limits data for the No.7 seam floor came from mines located on the Eastern shelf of the Basin. Considering that the No.6, No.5 and No.7 seam floors in the database have lower Atterberg limit values, it appears that the underclay floor in the Eastern shelf of the Basin exhibit lower plasticity compared to those in the Western shelf. For the Springfield seam, however, the Atterberg limits data did not indicate any statistically significant difference in the floor nature between the two shelves. Again, considering the limited amount of data from the Western shelf and the depositional environment given in section 2.2, it is suggested to treat the 5 seam floor as different in the two shelves. These conclusions are 
consistent with the ones reached from the moisture content data analysis described in section 2.3.1.

a)

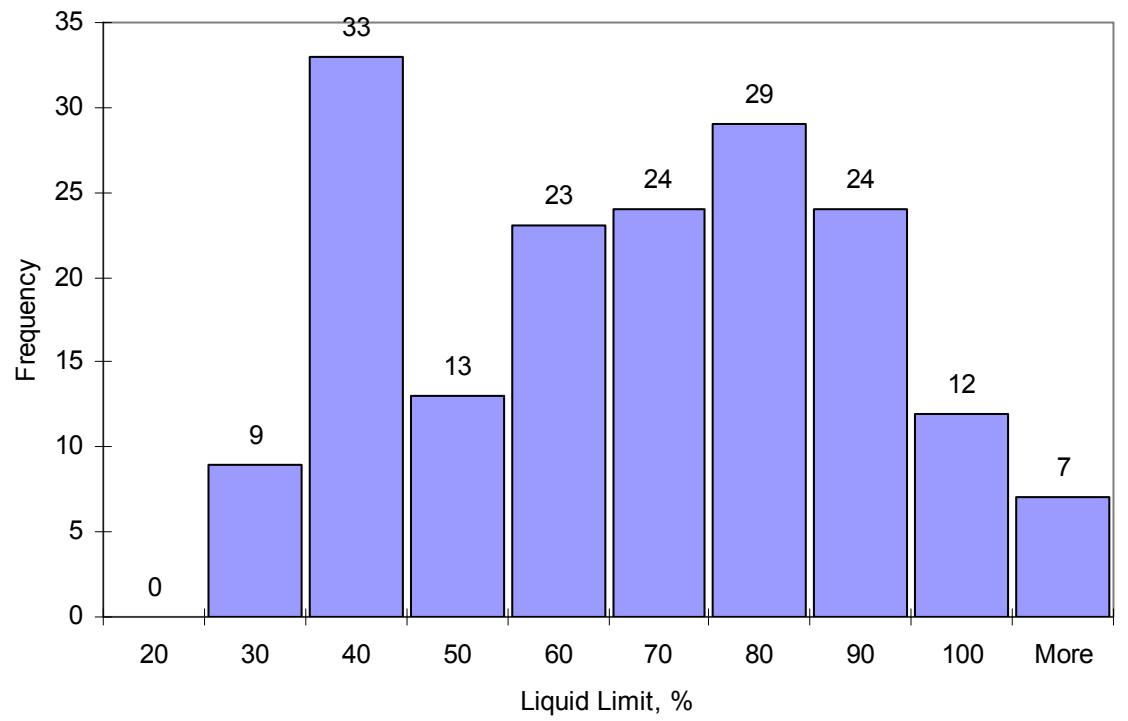

b)

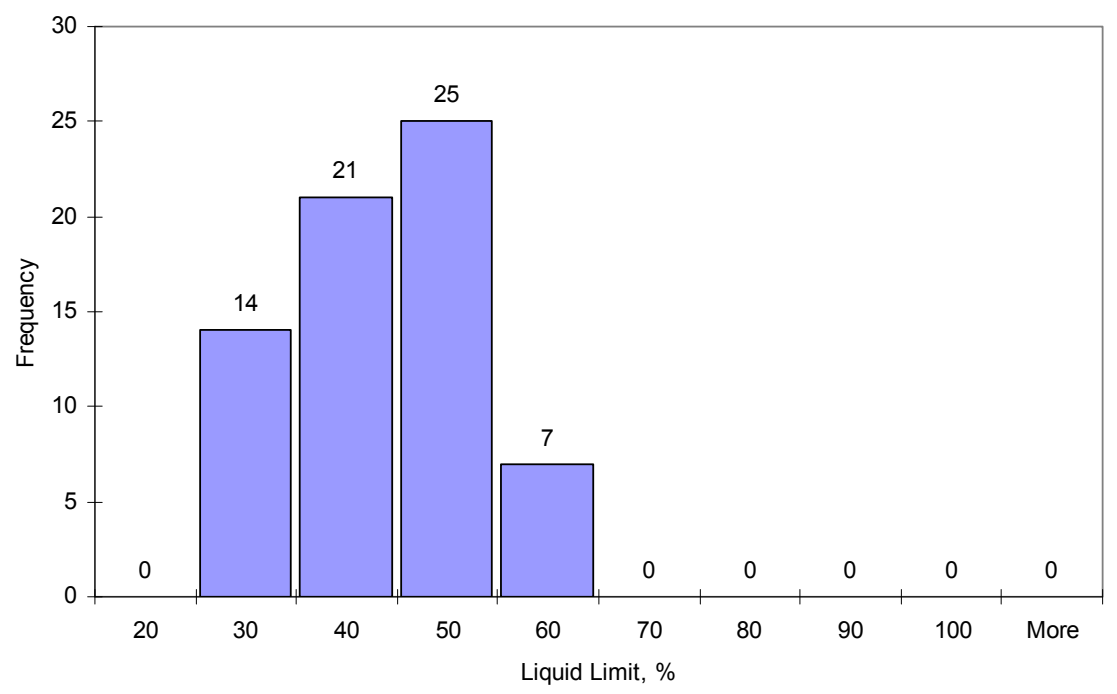

\begin{tabular}{|l|r|r|}
\hline & $\begin{array}{l}\text { lestern } \\
\text { Shelf }\end{array}$ & $\begin{array}{l}\text { Eastern } \\
\text { Shelf }\end{array}$ \\
\hline Mean & 63 & 39 \\
\hline Median & 64 & 40 \\
\hline Mode & 34 & 34 \\
\hline Standard Deviation & 22.01 & 9.22 \\
\hline Minimum & 25 & 20.7 \\
\hline Maximum & 107 & 55 \\
\hline Count & 174 & 67 \\
\hline Confidence Level(95.0\%) & 3.29 & 2.25 \\
\hline
\end{tabular}

Figure 2.30. Comparison of the liquid limit data from the (a) Western and (b) Eastern shelf mines for the No.6 seam floor (the statistics in the tables are in \%). 
a)

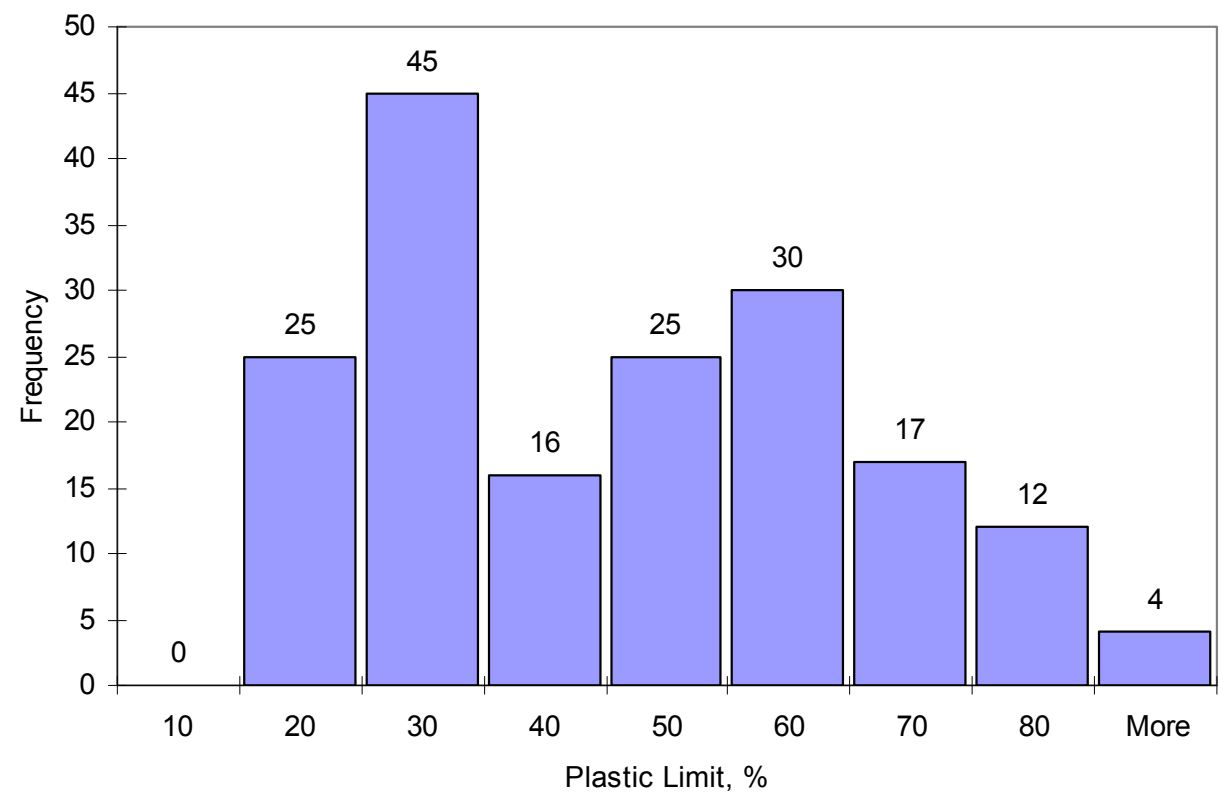

b)

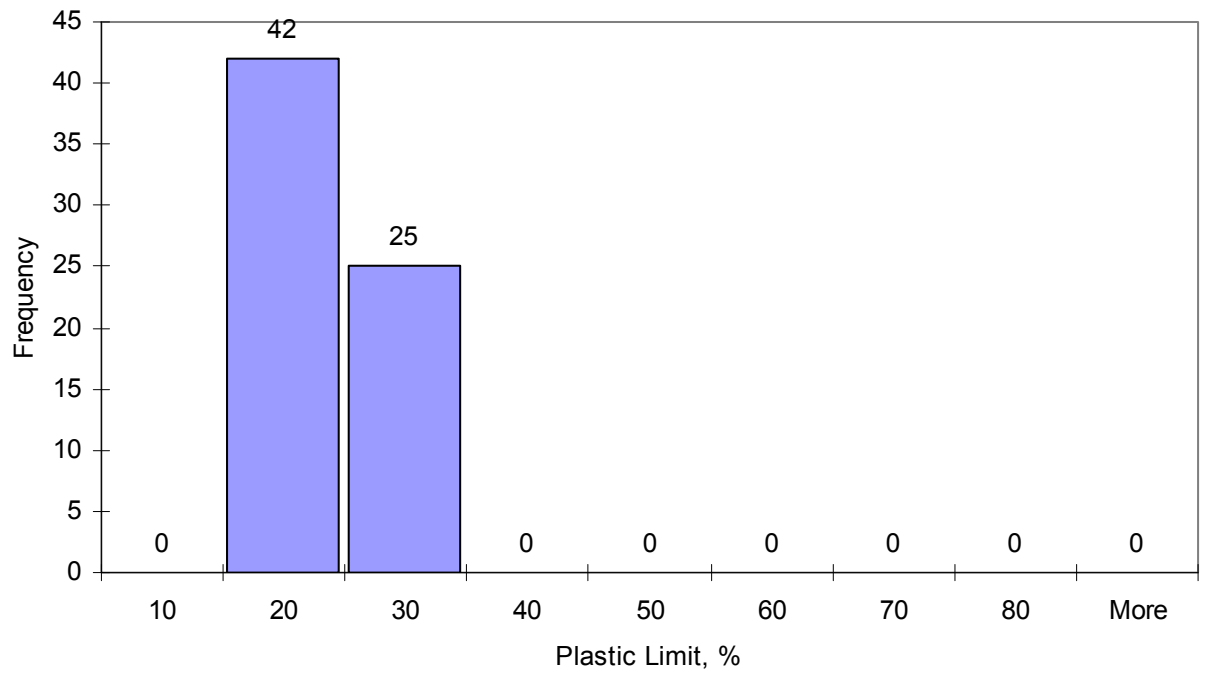

\begin{tabular}{|l|r|r|}
\hline & $\begin{array}{l}\text { Western } \\
\text { Shelf }\end{array}$ & $\begin{array}{l}\text { Eastern } \\
\text { Shelf }\end{array}$ \\
\hline Mean & 42 & 19 \\
\hline Median & 41 & 19 \\
\hline Mode & 21 & 18 \\
\hline Standard Deviation & 19.48 & 3.48 \\
\hline Minimum & 12 & 11 \\
\hline Maximum & 85 & 27 \\
\hline Count & 174 & 67 \\
\hline Confidence Level(95.0\%) & 2.92 & 0.85 \\
\hline
\end{tabular}

Figure 2.31. Comparison of the plastic limit data from the mines in the (a) Western and (b) Eastern shelf for the No.6 seam floor (the statistics in the tables are in \%). 
a)

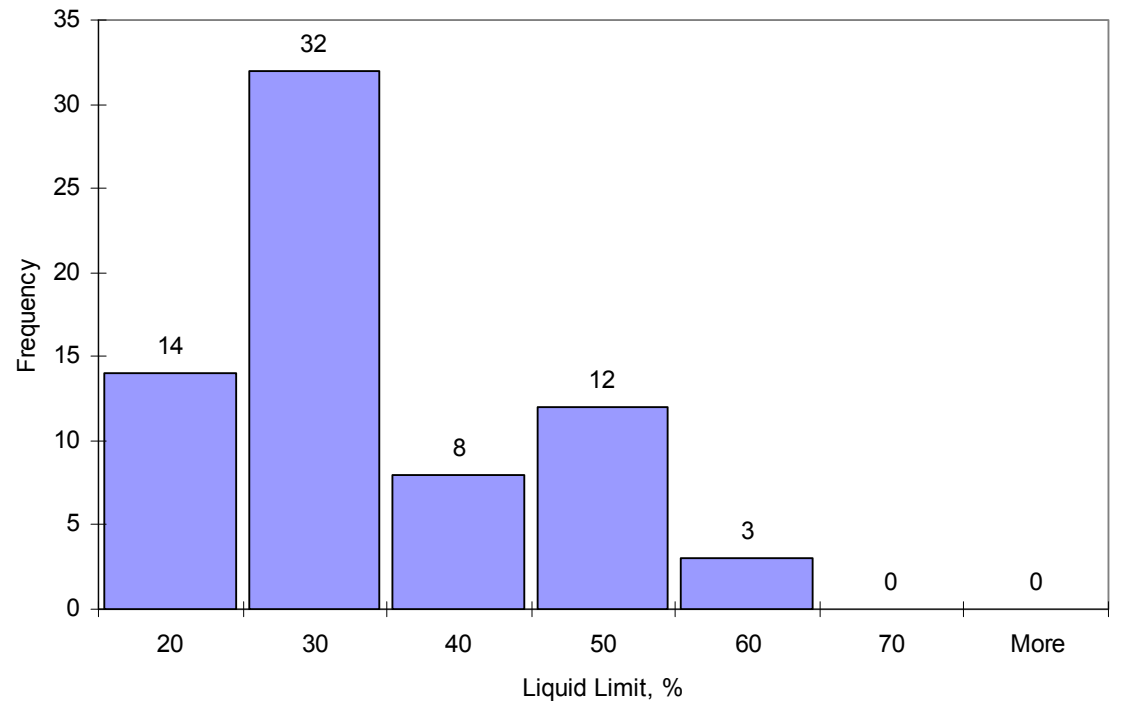

b)

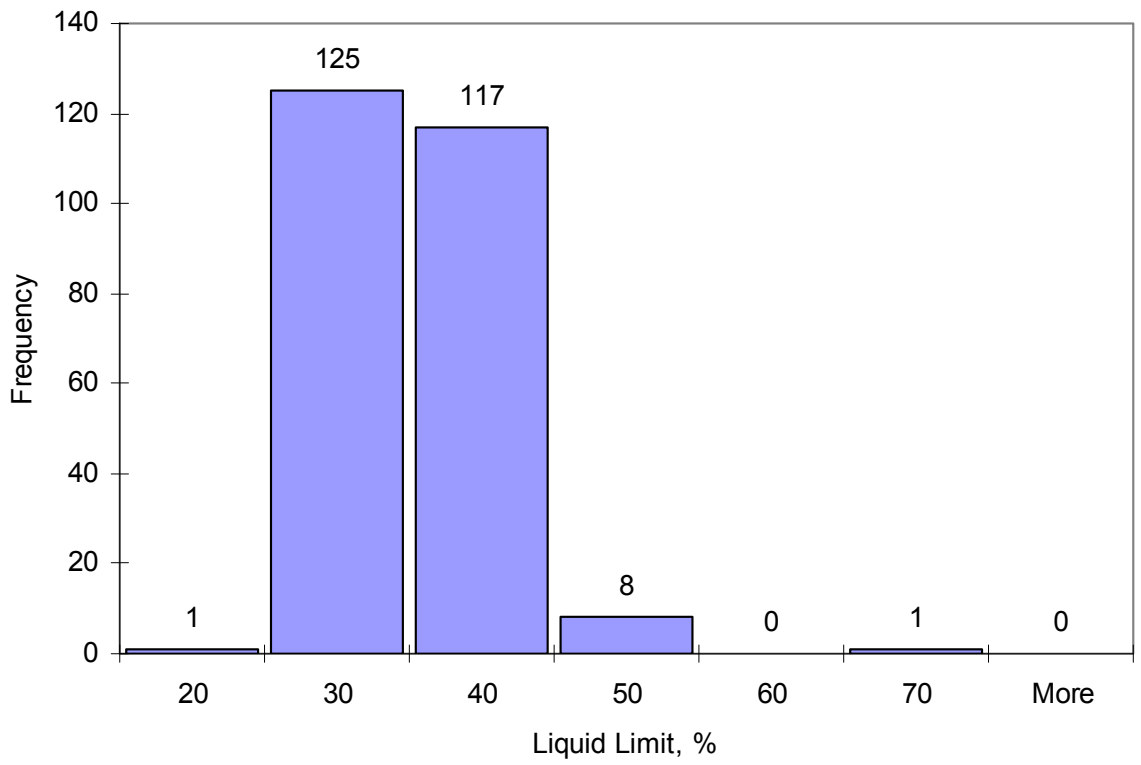

\begin{tabular}{|l|r|r|}
\hline & $\begin{array}{l}\text { Western } \\
\text { Shelf }\end{array}$ & $\begin{array}{l}\text { Eastern } \\
\text { Shelf }\end{array}$ \\
\hline Mean & 30 & 31 \\
\hline Median & 28 & 30 \\
\hline Mode & 29 & 31 \\
\hline Standard Deviation & 11.07 & 5.09 \\
\hline Minimum & 14.58 & 18.9 \\
\hline Maximum & 56.6 & 70 \\
\hline Count & 69 & 252 \\
\hline Confidence Level(95.0\%) & 2.66 & 0.63 \\
\hline
\end{tabular}

Figure 2.32. Comparison of the liquid limit data from the mines in the (a) Western and (b) Eastern shelf for the No.5 seam floor (the statistics in the tables are in \%). 
a)

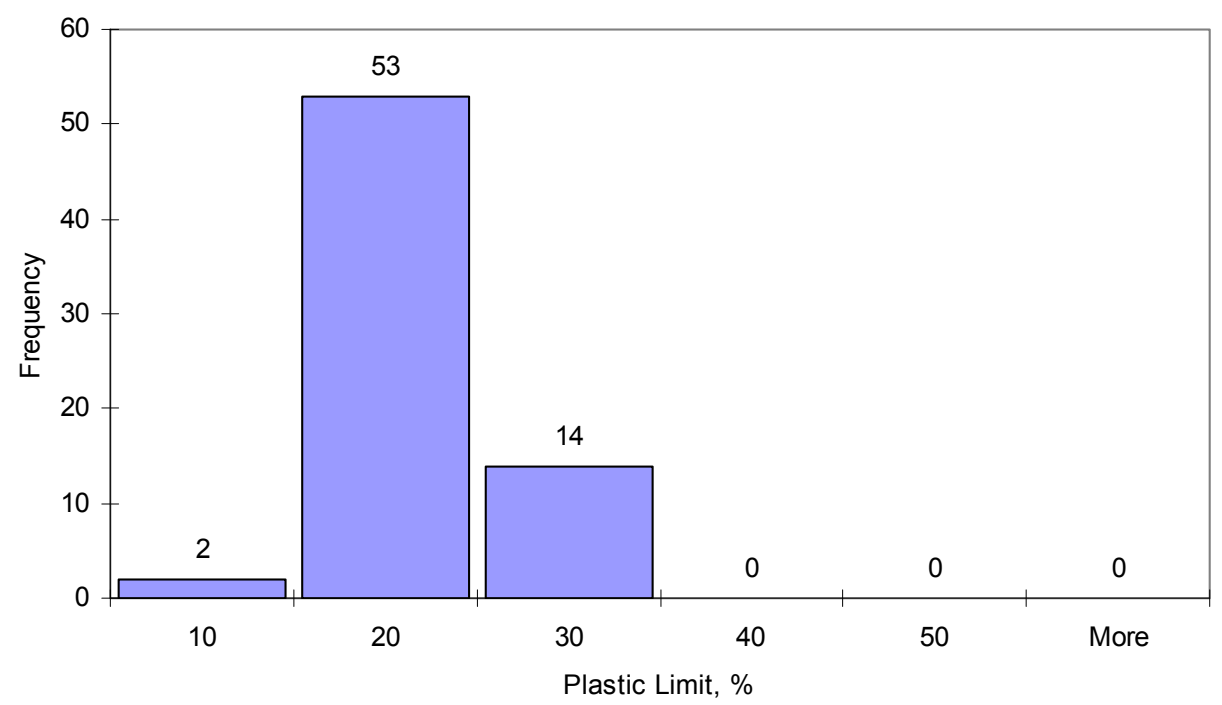

b)

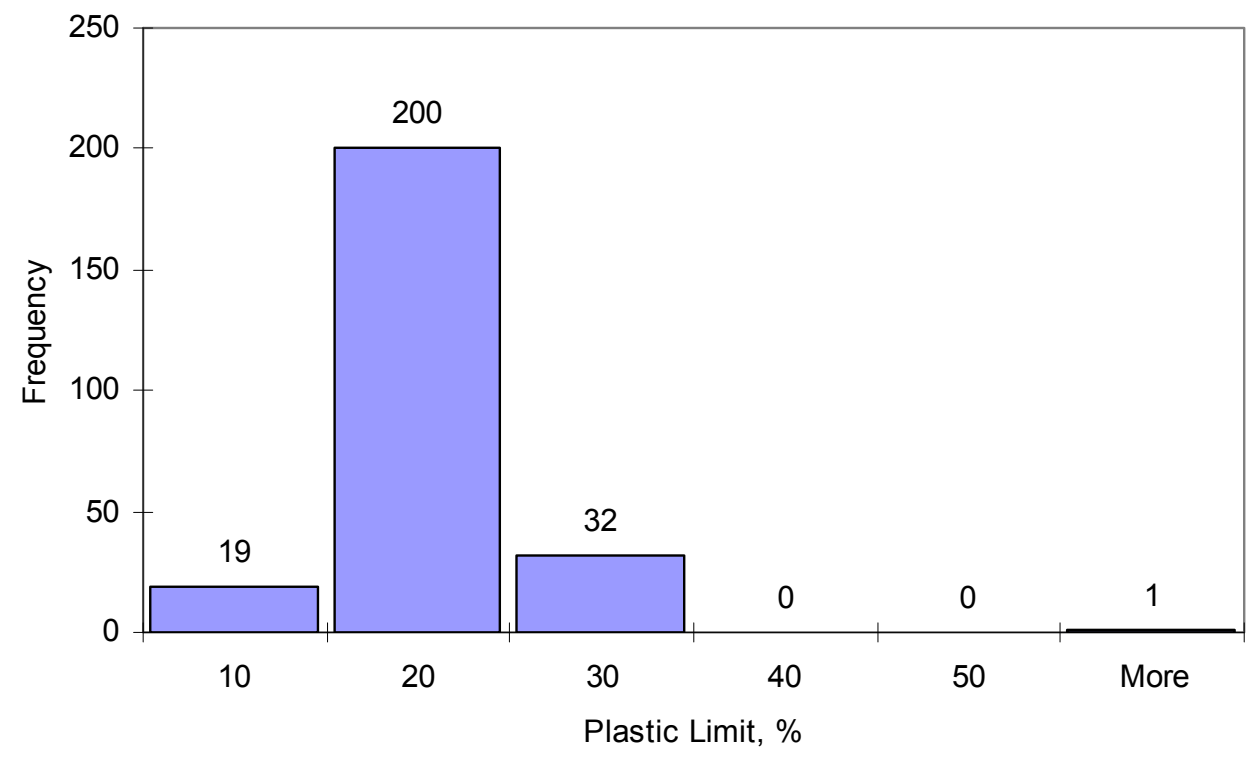

\begin{tabular}{|l|l|l|}
\hline & Western & Eastern \\
& Shelf & Shelf \\
\hline Mean & 17 & 17 \\
\hline Median & 16 & 17 \\
\hline Mode & 21 & 18 \\
\hline Standard Deviation & 4.19 & 4.36 \\
\hline Minimum & 6.02 & 6 \\
\hline Maximum & 29.4 & 52 \\
\hline Count & 69 & 252 \\
\hline Confidence Level(95.0\%) & 1.01 & 0.54 \\
\hline
\end{tabular}

Figure 2.33. Comparison of the plastic limit data from the mines in the (a) Western and (b) Eastern shelf for the No.5 seam floor (the statistics in the tables are in \%). 
Based on the general guidelines in Table 2.1, it is evident that the higher average plastic and liquid limits for the 6 seam floor in the Western shelf mean it will have appreciable strength even at higher natural moisture content. This finding is extremely significant and provides an engineering explanation for the noticed inapplicability of Speck's (1979) equation for floor strength estimation in the mines on the Western shelf of the Basin as discussed in Chapter 3. The Atterberg limits data once again shows that the floor materials for the Herrin seam must be treated differently for the mines in the Eastern and Western shelves of the Basin. Using a single approach for floor stability analysis throughout the Basin may lead to unnecessarily larger pillar sizes which add little to the long-term stability.

\subsubsection{Liquidity Index}

The liquidity index indicates the relative softness of the floor material and provides an idea on how far or close the natural moisture content is to the plastic limit or liquid limit of the floor (Spangler and Handy, 1982). The liquidity index is computed by

$$
L_{i}=\frac{M C-P L}{L L-P L}
$$

where $M C$ is the natural moisture content; $P L$ is the plastic limit; and $L L$ is the liquid limit of the weak floor. If the liquidity index value is equal to 1.0 , then the floor is at the liquid limit and a zero value indicates the moisture in the floor is equal to the plasticity index. If the $L_{i}$ value is less than 1.0, then the floor is not plastic and has significant material strength to resist any mining induced loads.

The natural moisture content and the Atterberg limit values determined for the same floor bed are necessary to compute the liquidity index using equation (2.6). Such information was available from 18 coal mines in the No.6 seam to give a total of 232 tests; from 19 mines in the No.5 seam for a total of 289 tests; and from 2 mines in the No. 7 seam to give 97 tests. The information available from this database is shown in Figure 2.34. The liquidity index data clearly show that none of the tested floors for any of the seams had natural moisture content 
anywhere close to make it a soft, pliable material to create floor problems during mining.

a)

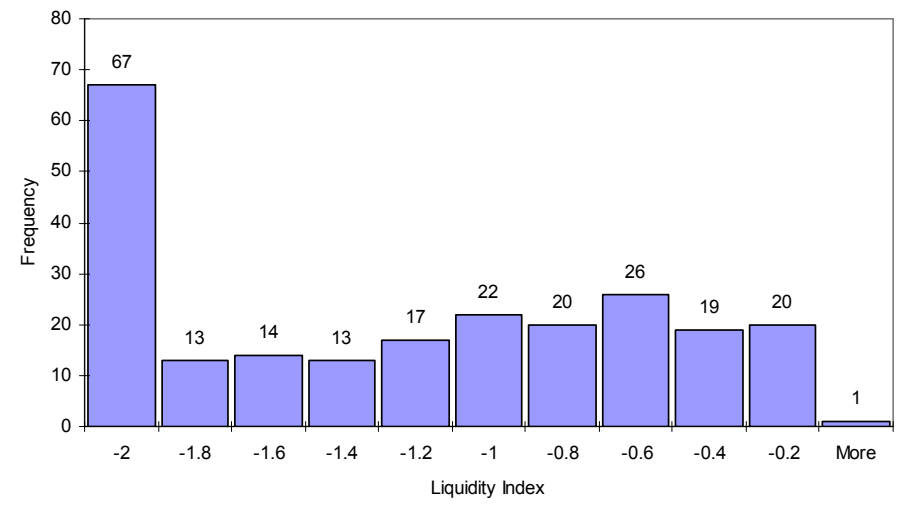

b)

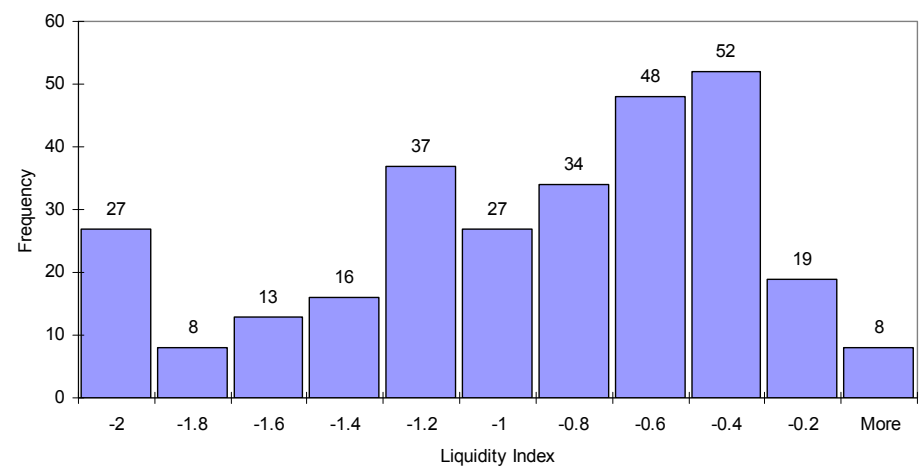

c)

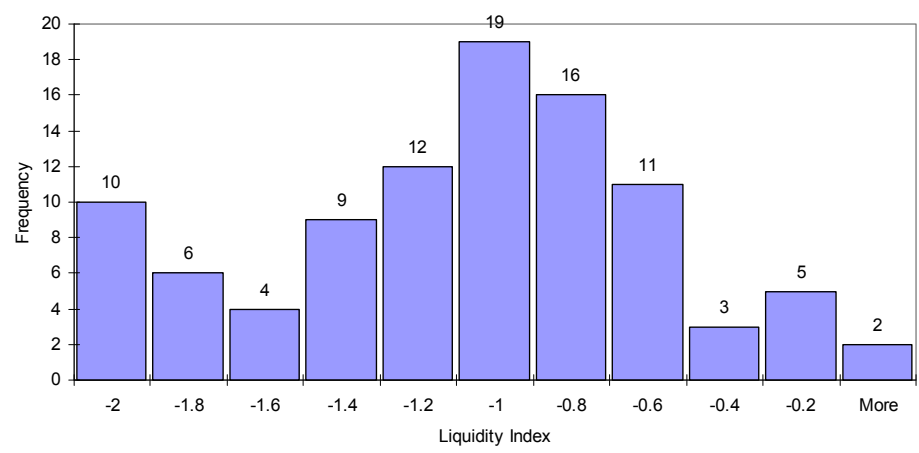

Figure 2.34. Liquidity index data for the a) No.6, b) No.5 and c) No.7 seam floors.

Some studies are also available (Yilmaz, 2000) that link the liquidity index with the shear strength of the clay material. For not heavily overconsolidated clays, Yilmaz (2000) derived the following relation between the liquidity index $\left(L_{i}\right)$ and the undrained shear strength $\left(c_{u}\right)$,

$$
C_{u}=e^{\left(0.026-1.21 L_{i}\right)}
$$


In the above equation $c_{u}$ is computed in $\mathrm{kg} / \mathrm{cm}^{2}$. Since the liquidity index of the clays used to derive equation (2.7) lied between -0.3 and 1.7, the equation could not directly be used for the Illinois Basin mines. The relationship, however, qualitatively indicate that the lower the liquidity index, the stronger the floor. Additionally, the liquidity index also qualitatively indicates the degree of consolidation of clays as shown in Figure 2.35 (Yilmaz, 2000). Given the data in Figure 2.34 and the information in Figure 2.35, it can be concluded that the underclay in the Illinois Basin mines is very heavily overconsolidated and thus has significantly greater dry strength than a typical near surface clay.

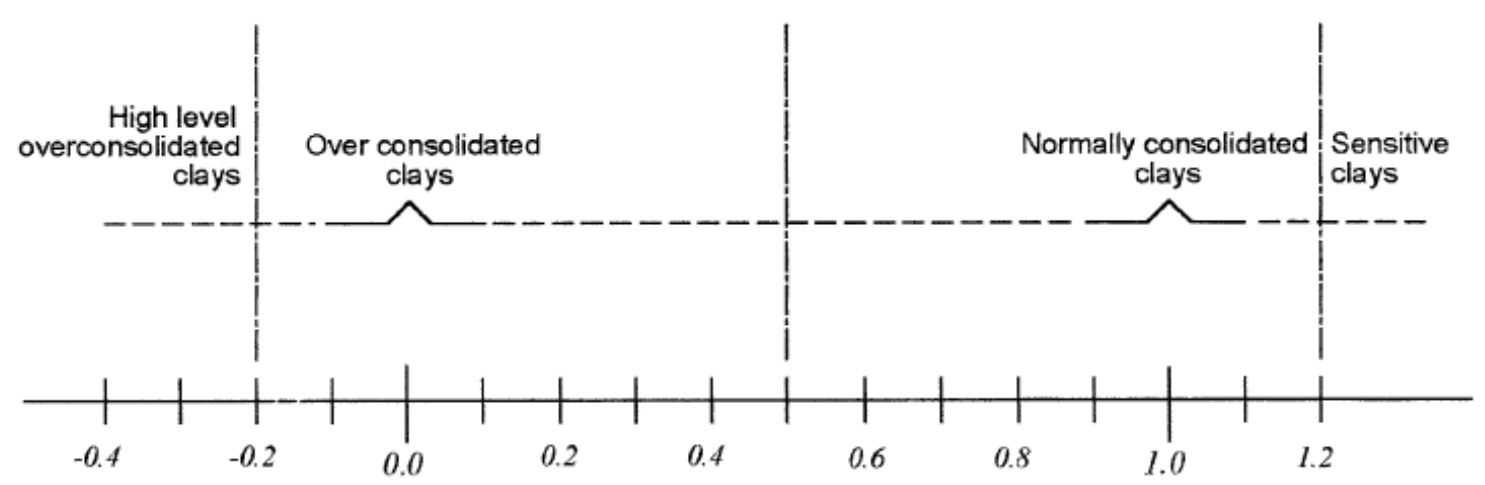

Liquidity Index,

Figure 2.35. Relation between the liquidity index and the degree of consolidation.

\subsubsection{Some Other Applications}

In addition to the plasticity chart described in section 2.3.2.1, the Atterberg limits can also be used to make some first approximations of several other parameters useful for engineering design purposes. For instance, correlations have been developed between the Atterberg limits and particle surface area (Dolinar et al., 2007), P-wave velocities (Fener et al., 2005), compression index (Giasi et al., 2003), cation exchange capacity (Yukselen and Kaya, 2006), undrained shear strength (Sharma and Bora, 2003), residual shear strength (Wesley, 2003) and preconsolidation stress (Department of the Army, 1983). However, one other important engineering property that may be of importance for underground floor design is the permeability of the floor. Sridharan and Nagaraj 
(2005) developed the following relation between the hydraulic conductivity, $k$ and the plasticity index,

$$
k=0.0104 P I^{-5.2}\left[\frac{e^{4}}{1+e}\right]
$$

where, $P I$ is the plasticity index and $e$ is the void ratio. Equation (2.8) provides the hydraulic conductivity value in meters/sec. The permeability estimated by Equation (2.8) corresponds to the soil matrix and thus may form the lower bound for a coal mine floor considering that several discontinuities which increase the permeability may be encountered underground.

\subsubsection{Particle Size}

The particle-size analysis of the floor materials provides an idea of the distribution of different size grains comprising the material. Such information is typically used in a few soil classification systems and for estimating some engineering properties of the soil (Terzaghi et al., 1996). The ASTM standard D422 (ASTM, 2009) describes the test procedure for particle-size analysis. The sample needed for the test is prepared in accordance with the ASTM standard D 421 (ASTM, 2009). However, for all the data discussed later in this section, the particle-size was determined using the procedures described in The Environmental Protection Agency's (1978) guide, "Field and Laboratory Methods Applicable to Overburdens and Minesoils." Since no disbanded particles exist for cohesive materials, the soil is normally disintegrated mechanically to conduct the size analysis. The most common method to disaggregate the underclay or claystone floor is by pulverizing it in a ball mill until the material passes through the U.S. standard sieve no.10 $(2.0 \mathrm{~mm})$. The floor sample is normally air dried before grinding. If the crushed material looks sandy, then about 100 grams of the sample is used for the particle-size analysis. Within the test sample, particles that have a size below $2 \mu \mathrm{m}$ are labeled as "clay-size", those between $2 \mu \mathrm{m}$ and the U.S. standard sieve no. 270 are labeled as "silt-size" and those above the 270 mesh size are considered as "sand-size." It may be mentioned that some authors (Chugh, 1986a) treated $5 \mu \mathrm{m}$ as the size that separated silt- and clay-size 
fractions for the Illinois Basin floor materials. For all the data discussed in this section, sizes below $2 \mu \mathrm{m}$ are considered as clay-size.

The particle-size information was available for the immediate weak floors from 11 mines in the No. 6 seam for a total of 138 data sets and from 7 mines in the No. 5 seam for 118 individual tests. No data were available for the No. 7 seam. Some key statistics and histograms for the Herrin and the Springfield seam floors are shown in Figure 2.36 and Figure 2.37, respectively.

a)
\begin{tabular}{|l|r|}
\hline Mean & 21 \\
\hline Median & 10 \\
\hline Mode & 6 \\
\hline Standard Deviation & 22.96 \\
\hline Minimum & 0 \\
\hline Maximum & 91 \\
\hline Count & 138 \\
\hline Confidence Level(95.0\%) & 3.86 \\
\hline
\end{tabular}
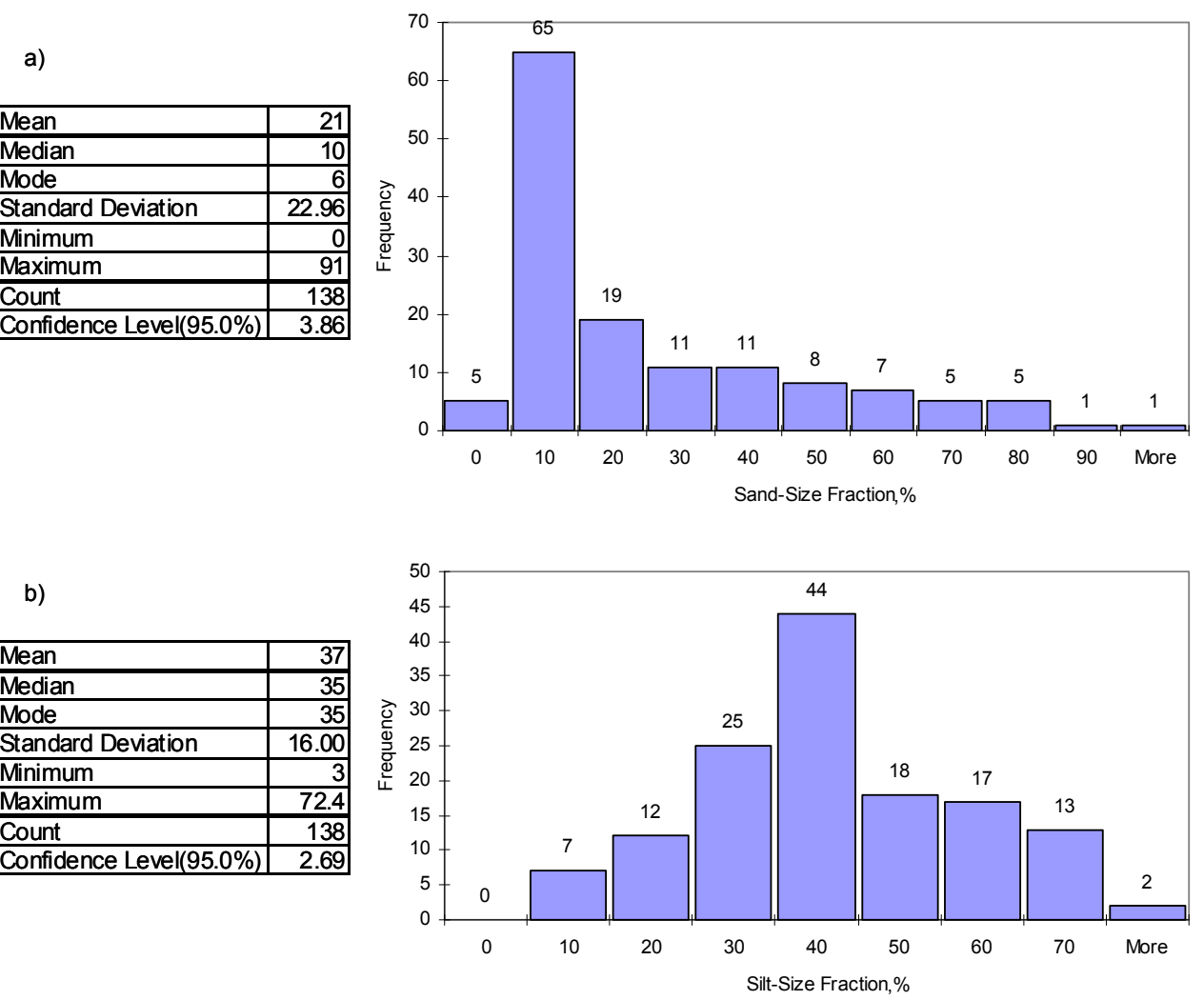

c)
\begin{tabular}{|l|r|}
\hline Mean & 42 \\
\hline Median & 45 \\
\hline Mode & 23 \\
\hline Standard Deviation & 18.38 \\
\hline Minimum & 3.2 \\
\hline Maximum & 71.8 \\
\hline Count & 138 \\
\hline Confidence Level(95.0\%) & 3.09 \\
\hline
\end{tabular}

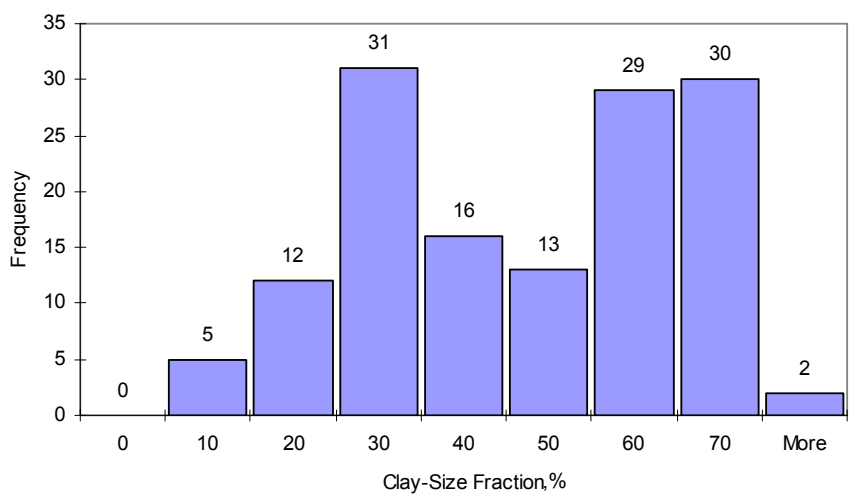

Figure 2.36. Distribution of a) sand-size, b) silt-size, and c) clay-size fractions for the Herrin No. 6 and its equivalent seam floors (the statistics in the table are in \%). 
a)

\begin{tabular}{|l|r|}
\hline Mean & 25 \\
\hline Median & 13 \\
\hline Mode & 5 \\
\hline Standard Deviation & 25.45 \\
\hline Minimum & 0 \\
\hline Maximum & 92.2 \\
\hline Count & 118 \\
\hline Confidence Level(95.0\%) & 4.64 \\
\hline
\end{tabular}

b)

\begin{tabular}{|l|r|}
\hline Mean & 30 \\
\hline Median & 30 \\
\hline Mode & 33 \\
\hline Standard Deviation & 12.87 \\
\hline Minimum & 2.4 \\
\hline Maximum & 67.4 \\
\hline Count & 118 \\
\hline Confidence Level(95.0\%) & 2.35 \\
\hline
\end{tabular}

c)

\begin{tabular}{|l|r|}
\hline Mean & 43 \\
\hline Median & 47 \\
\hline Mode & 50 \\
\hline Standard Deviation & 17.72 \\
\hline Minimum & 1 \\
\hline Maximum & 69 \\
\hline Count & 155 \\
\hline Confidence Level(95.0\%) & 2.81 \\
\hline
\end{tabular}

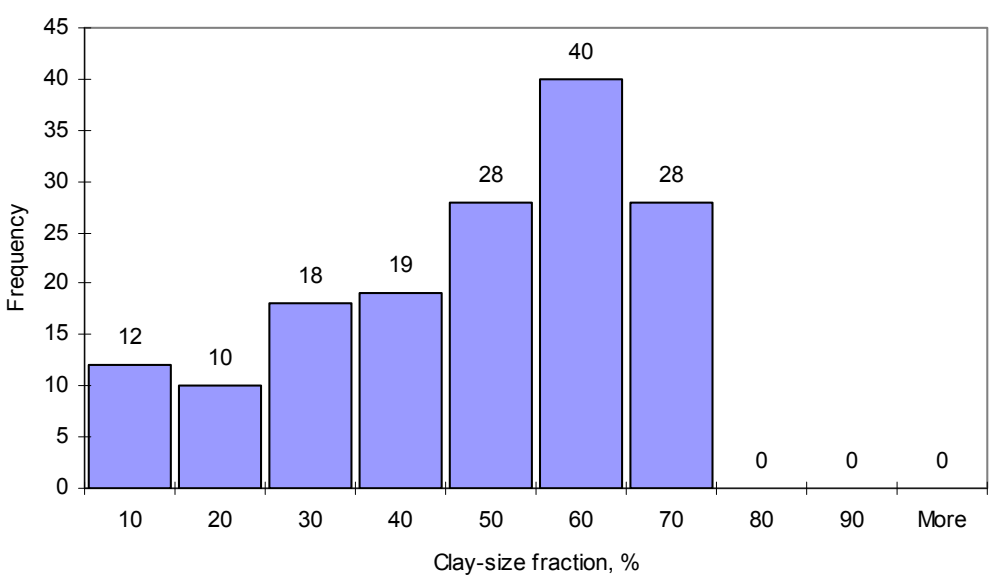

Figure 2.37. Distribution of a) sand-size, b) silt-size, and c) clay-size fractions for the Springfield No. 5 and its equivalent seam floors (the statistics in the tables are in \%).

It may be noted in Figure 2.37 that there were more number of tests available for the clay-size fraction for the No.5 seam than the silt- and sand- 
sizes. This happened because in one of the data sources (Chugh, 1986a), only clay-size fraction was reported. The data in figures 2.36 and 2.37 indicate that very little difference in the nature of the floor exists between the No.6 seam and No.5 in terms of particle size. It is not known, however, to what extent the mechanical grinding of the floor samples in the ball-mill affected the particle-size distributions for both seams. Since all the samples in figures 2.36 and 2.37 were subjected to similar preparation process, it is felt that any effects of the mechanical grinding would be similar for all of them. In the following sections, some practical applications of the particle-size data are discussed.

\subsubsection{Potential Expansiveness}

One major issue with the weak floor material is related to the closure of mine entry due to floor heave. While several mechanisms could be responsible for the floor heave, one important factor is the inherent nature of clay material to swell and shrink with a change in its moisture. The Atterberg limits data in conjunction with the amount of clay size fraction (less than 2-micron size particles) could provide some useful indication of the clay material's potential expansiveness (The Department of Army, 1983). The Army's technical manual on "Foundations in Expansive Soils" (1983) provides one empirical approach to estimate the potential expansiveness as given in Figure 2.38. The term "PE" in this figure indicate the potential expansiveness in inches per foot of underclay thickness.

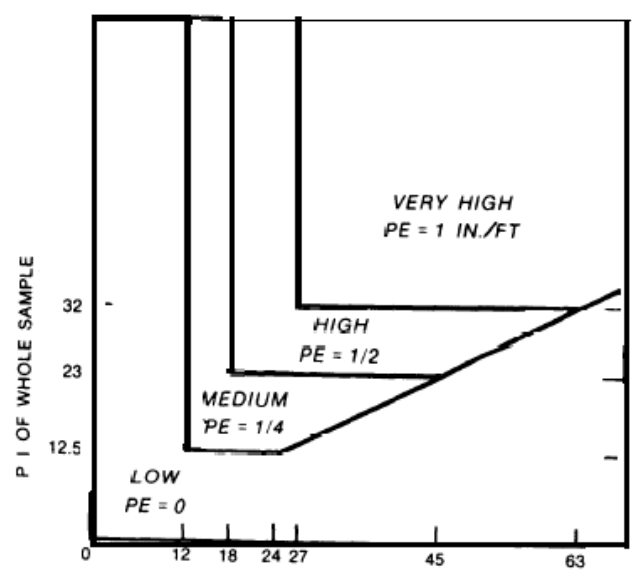

Clay TRACTION OF WHOLE SAMPLE $(\%<2 \mu)$

Figure 2.38. Potential expansiveness chart given in the Army manual. 
It must be recognized that the amount of floor heave estimated from Figure 2.38 is solely because of the swelling characteristics of the soil and does not include any dilation due to stresses. The clay-size and the plasticity index determined for the same floor bed are required to use Figure 2.38. Such data available for the No.6 and No.5 seam floors are plotted in Figures 2.39 and 2.40.

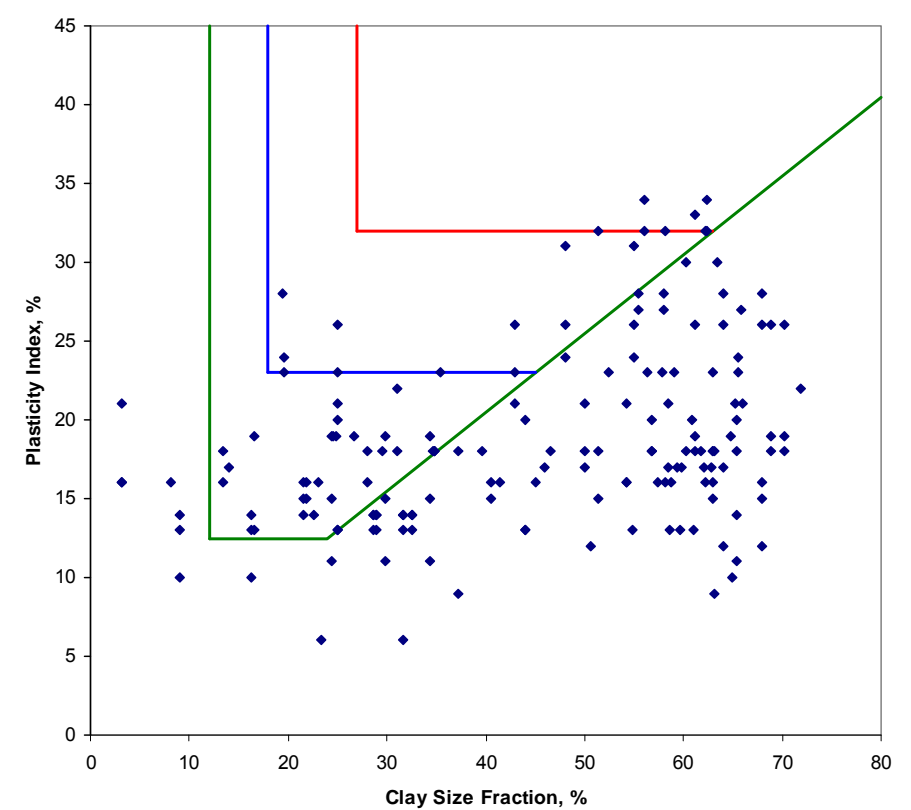

Figure 2.39. Potential expansiveness of the No.6 seam floor.

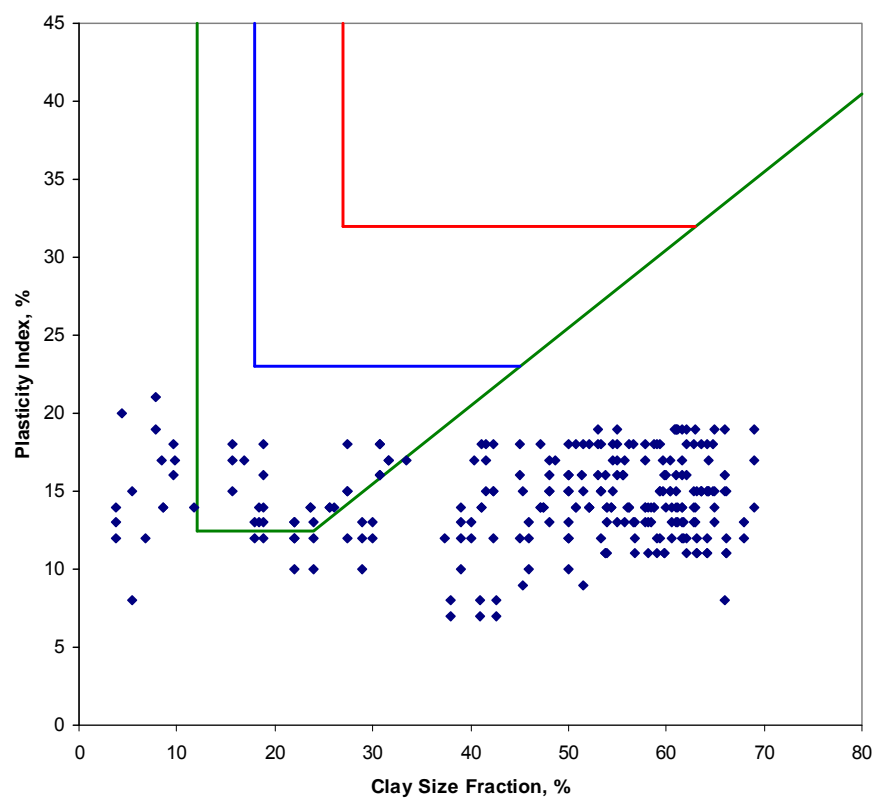

Figure 2.40. Potential expansiveness of the No.5 seam floor. 
The information in Figures 2.39 and 2.40 suggest the following:

- all the data from the Springfield seam and its equivalents show low to medium potential expansiveness of the floor,

- The bulk of the 6 seam underclay also exhibits low to medium swell potential,

- a few data points from the Herrin seam floor exhibit high to very high expansiveness,

- overall, the underclay floor associated with the principal coal seams in the Basin exhibit low to medium inherent swelling potential and in general, the 6 seam floor is slightly more prone to swelling than the 5 seam underclay, which seems to be borne out by the practical observations in the mines.

\subsubsection{Angle of Internal Friction}

In computing the bearing capacity of the floor material below coal pillars, information on the angle of internal friction of underclay is required. Laboratory determination of the friction angle is fraught with difficulties due to the friable nature of the floor material. In fact, very few attempts have ever been made to conduct triaxial or direct shear tests on underclay even for research purposes. Obviously, such tests are not even considered during a routine floor design exercise. Therefore, it is highly desirable to have an indirect approach to estimate the angle of internal friction of the floor material. Even if such an approach is approximate in nature, it is still better than not having any information or guessing the value.

During the search for an indirect method to estimate the friction angle, the author came across the research done by Mesri and Abdel-Ghaffar (1993) which is reproduced in Figure 2.41. From this figure it is possible to make the first approximation on the peak angle of internal friction given the underclay's plasticity index. It must be mentioned that Figure 2.41 was developed for normally consolidated cohesive soils and thus will provide slightly underestimated friction angles considering that the underclays in coal mines are very heavily overconsolidated. 
In-situ plate load tests discussed in Chapter 3 revealed that the underclay floor could exhibit brittle behavior with associated post-failure strain-softening. In order to simulate such brittle behavior, it is desirable to have an estimate of the residual friction angle of the floor. An indirect approach to estimate the residual friction angle as a function of the liquid limit and clay-size fraction $(C F)$ is provided by Stark and Eid (1994) and is reproduced in Figure 2.42.

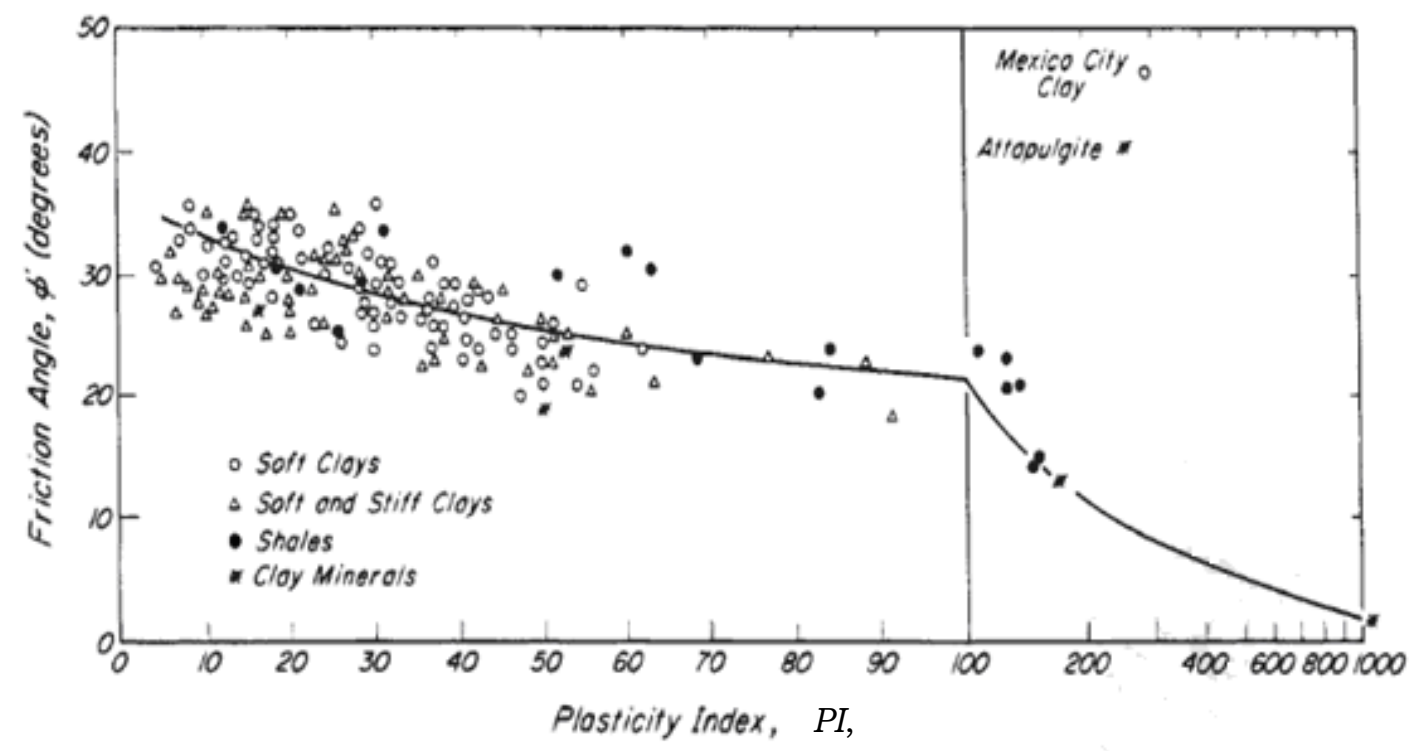

Figure 2.41. Peak friction angle as a function of plasticity index (Mesri and Abdel-Ghaffar,1993).

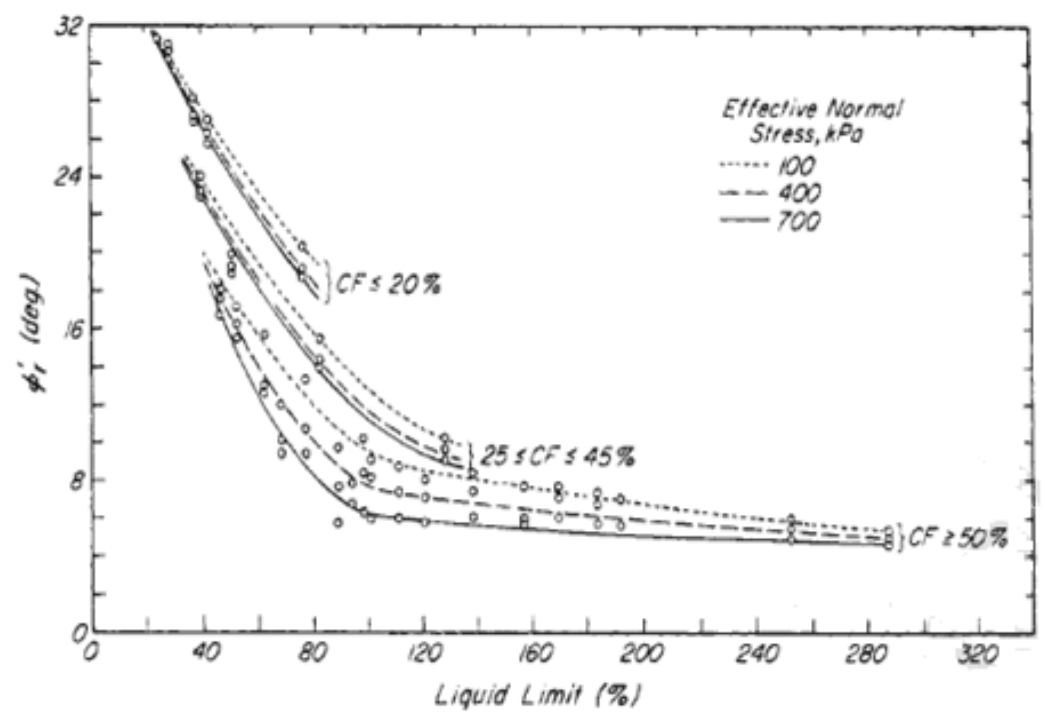

Figure 2.42. Residual friction angle as a function of the liquid limit and clay-size fraction (Stark and Eid, 1994). 
Once the Atterberg limits are determined and the clay fraction in the underclay material is estimated, Figure 2.41 and Figure 2.42 could be used for a rough estimation of the peak and residual friction angles. Using these values, it is possible to estimate the floor bearing strength by using foundation bearing capacity theories available in soil mechanics literature or by numerical modeling as discussed in Chapters 4 and 5 .

\subsubsection{3 $\quad$ Activity Index}

The values of the Atterberg limits are normally influenced by both the type of clay mineral and the amount of clay-size particles in the soil (Spangler and Handy, 1982; Mitchell and Soga, 2005). Skempton (1953) found that by determining the so called activity or activity index (Al), it is possible to determine the type of clay mineral present in the soil. For this purpose, the activity index is defined as

$$
\text { Activity }=\frac{\text { Plasticity Index }}{\%<2 \mu m \text { clay }}
$$

It appears that for soils with greater activity, the amount of clay-size fraction will greatly influence the engineering properties. Further, higher activity also indicates greater susceptibility of the soil's engineering behavior to such factors as the type of exchangeable cations and pore fluid properties (Mitchell and Soga, 2005). The range of activity index values for some common clay minerals is given in Table 2.2. From the laboratory database put together for this research, all the immediate floor beds for which the necessary information to determine the activity index was available were analyzed and plotted in Figure 2.43. Activity was computed for 174 tests from 11 coal mines in the No.6 seam floor and for 258 tests from 5 mines for the Springfield seam floors. The results in these figures show that the floors in both the Herrin and Springfield seams could be classified as low to medium plasticity materials, similar to the conclusion drawn from the plasticity charts in section 2.3.2.1. The predominant clay mineral in the floor material at the mines where the data came from appears to be kaolinite, which does not swell like smectites. The practical experience at these 
mines is in-line with this conclusion as they did not report any major swelling type floor problems.

Table 2.2. Activity Index values for some common clay minerals (Mitchell and Soga, 2005).

\begin{tabular}{|l|l|}
\hline Mineral & Activity \\
\hline Smectites & $1-7$ \\
\hline Illite & $0.5-1$ \\
\hline Kaolinite & $<0.5$ \\
\hline
\end{tabular}

a)

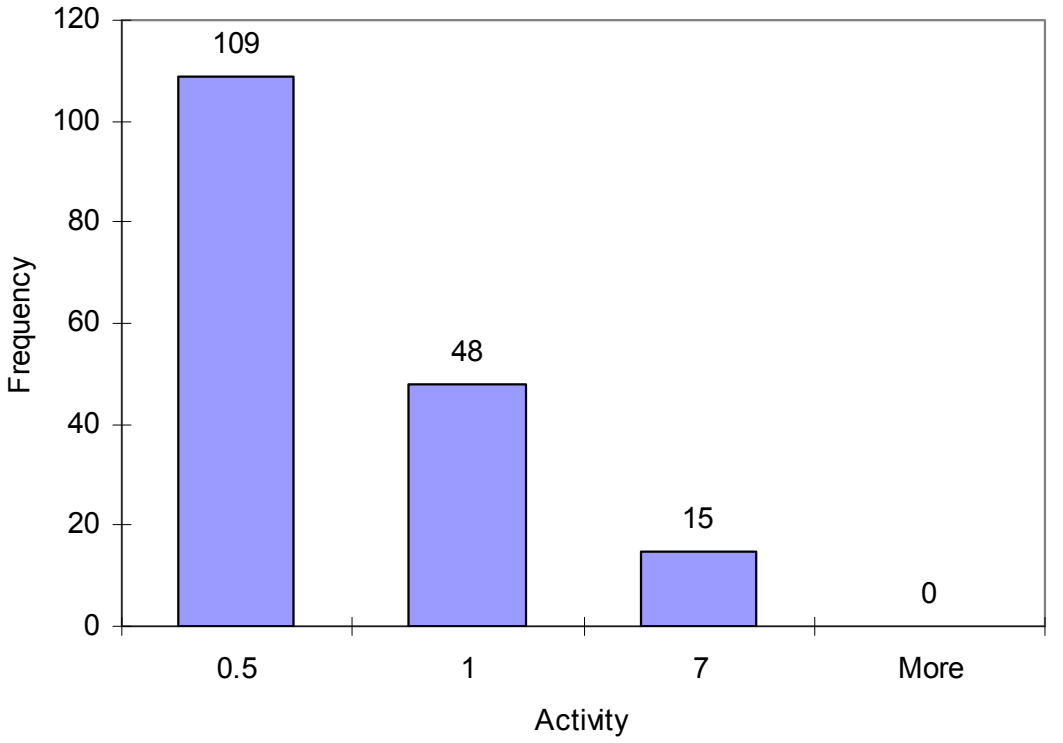

b)

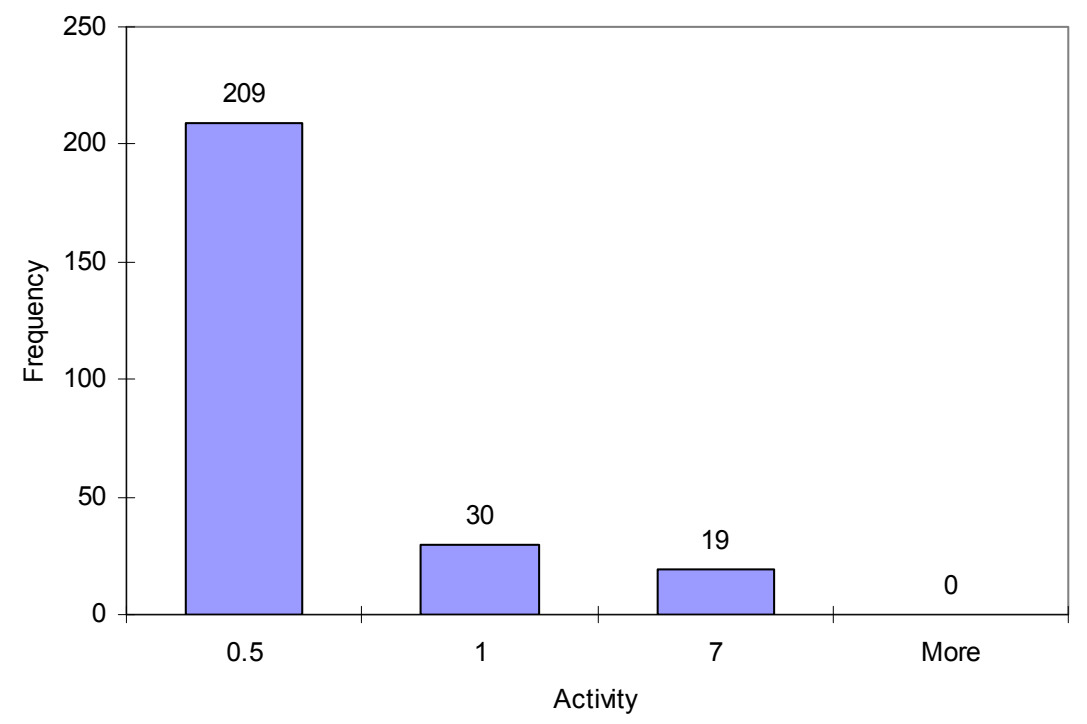

Figure 2.43. Activity index data for a) No. 6 and b) No.5 seam floors. 


\subsubsection{Swelling Strain}

The unconfined axial swelling strain is measured to test the floor material's inherent expandability when put in contact with water. Although of limited practical use by itself, the swelling strain could qualitatively indicate the plasticity characteristics of the floor. Regular shaped cylindrical specimens of different length-to-diameter ratios were used in the past for this test (Chugh, 1986a). The only standard available for the swelling strain test seems to be that developed by the International Society for Rock Mechanics (Madsen, 1999). All the test data in this section was obtained by following the general guidelines in the ISRM standard. Information on the peak swelling strain recorded in a period of 24 hours when immersed in water was available from 13 coal mines for a total of 196 individual tests on the No.6 seam floor, and from 10 mines for a total of 136 tests on the No.5 floor. The data is plotted in Figure 2.44.

a)

\begin{tabular}{|l|r|}
\hline Mean & 5.99 \\
\hline Median & 5.43 \\
\hline Mode & 6.00 \\
\hline Standard Deviation & 3.98 \\
\hline Minimum & 0.03 \\
\hline Maximum & 19.33 \\
\hline Count & 196 \\
\hline Confidence Level(95.0\%) & 0.56 \\
\hline
\end{tabular}

b)

\begin{tabular}{|l|r|}
\hline Mean & 3.64 \\
\hline Median & 2.64 \\
\hline Mode & 2.05 \\
\hline Standard Deviation & 3.32 \\
\hline Minimum & 0.04 \\
\hline Maximum & 17.30 \\
\hline Count & 136 \\
\hline Confidence Level(95.0\%) & 0.56 \\
\hline
\end{tabular}
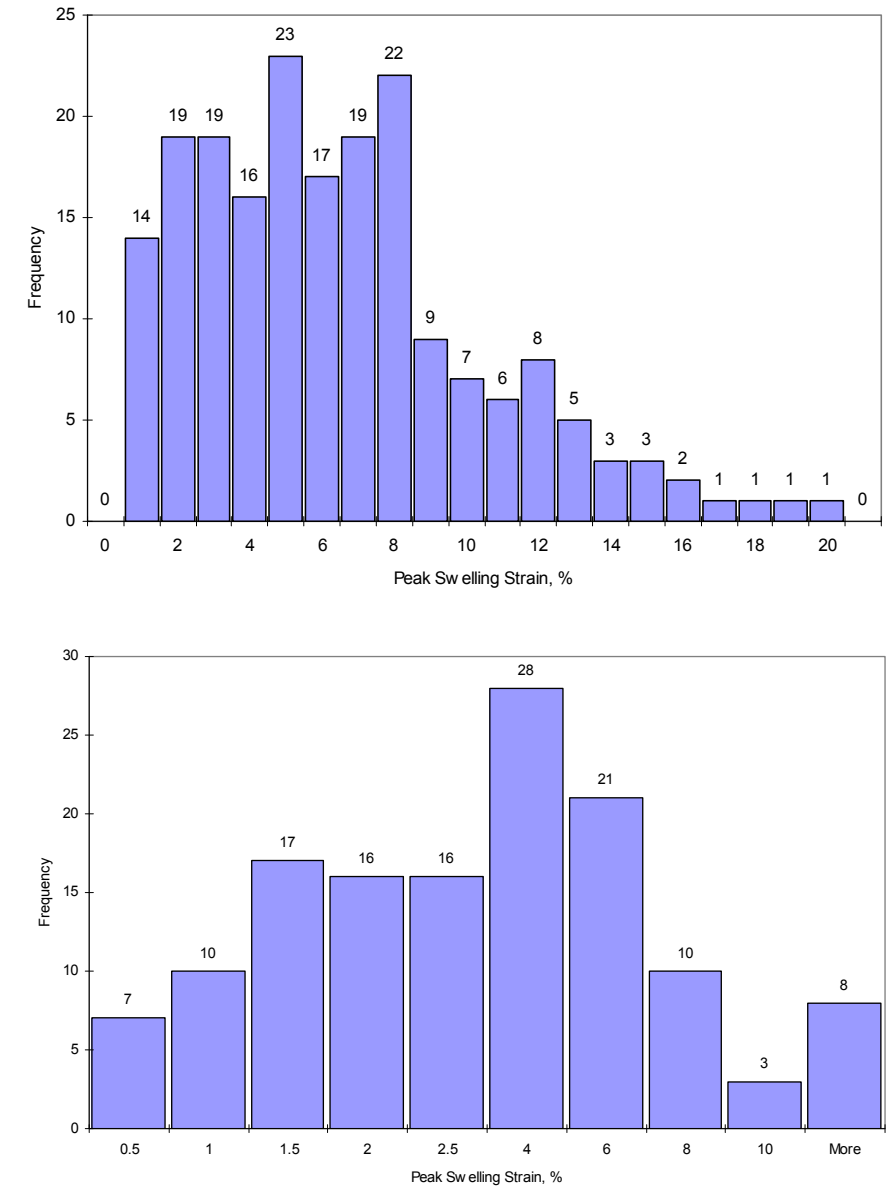

Figure 2.44. Peak swelling strain for a) No. 6 and b) No.5 seam floors (the statistics in the tables are in \%). 
The data in Figure 2.44 clearly shows that on average, the Herrin seam floor material is more plastic than the No. 5 seam floor. When the data was further analyzed, it was found that out of the 196 tests on the No. 6 seam floor, 166 came from mines in the Western shelf of the Basin. Similarly, of the 136 data points for the 5 seam floor, 132 came from Western Kentucky, which is the Eastern shelf of the Basin. In essence, the differences displayed by the peak swelling strain in Figure 2.44 were probably due to the difference in the floor nature between the two shelves of the Basin. This lends additional support to the conclusion that the floor in the Basin must be treated differently depending on the geographic location of the mine.

\subsection{Interrelationships of the Laboratory Properties}

Attempts to develop simple empirical relationships to estimate weak floor engineering properties in the Illinois Basin were made by several researchers in the past. Rockaway and Stephenson (1979) developed the suite of relationships given in Table 2.3 between the triaxial strength of the floor at 300 psi confining pressure and several simple indices. It seems that the improvement in the $R^{2}$ value with the addition of increasing number of variables in the equations in Table 2.3 is perhaps fictitious. It is known in linear regression that for the same amount of data $(N)$, with the addition of new variables, the $R^{2}$ keeps on increasing until it attains the value of 1.0 when the number of independent variables becomes equal to $N-1$. Therefore, without knowing the statistical significance of each independent variable in the regression, it is hard to conclude if the improvement in the $R^{2}$ is significant or not.

Pula et al., (1990) have developed the most recent set of equations to estimate weak floor properties based on regression analysis of data from seven Illinois coal mines. Some key relationships from Pula's work are reproduced in Table 2.4 below. It is interesting to note that the equations for compressive strength as a function of liquid limit and tensile strength as a function of moisture content are exactly the same in Table 2.4. While the $R^{2}$ values are reasonable, Pula's study was strictly limited to mines from the state of Illinois. Further, in 
Pula's paper it was not described where the mines were located or how many of the tests were from different coal seams.

Table 2.3. Equations to estimate floor triaxial strength as a function of several index tests (Rockaway and Stephenson, 1979).

\begin{tabular}{|l|c|c|}
\hline \multicolumn{1}{|c|}{ Equation } & $\begin{array}{c}\text { Number of } \\
\text { data points }\end{array}$ & $R^{2}$ \\
\hline $\log ($ TR300 $)=3.54-0.0951 W C$ & 64 & 0.49 \\
\hline $\log (T R 300)=1.44+0.392(P L / W C)$ & 43 & 0.62 \\
\hline $\log (T R 300)=1.01+0.441(P L / W C)+0.0116(P I)$ & 32 & 0.68 \\
\hline $\log (T R 300)=1.04+0.303(P L / W C)+5.84 \times 10^{-5}(P P A R A)$ & 32 & 0.69 \\
\hline $\log (T R 300)=0.282+0.386(P L / W C)+0.0171(P I)+6.96 \times 10^{-5}(P P A R A)$ & 32 & 0.81 \\
\hline $\log ($ TR300 $)=1.27+0.26(P L / W C)+0.0181(P I)+5.75 \times 10^{-5}(P P A R A)$ & 32 & 0.83 \\
$-0.0578 W C$ & & \\
\hline
\end{tabular}

WC : moisture content; $P L$ : plastic limit; PI : plasticity index; PPARA : P-wave velocity parallel to the bedding planes; TR300 : triaxial compressive strength at 300 psi confining pressure.

Table 2.4. Equations to estimate different weak floor properties

(Pula et al., 1990).

\begin{tabular}{|l|c|c|}
\hline \multicolumn{1}{|c|}{ Equation } & Number of data points & $R^{2}$ \\
\hline $\operatorname{Ln}\left(C_{o}\right)=4.092-0.775 \operatorname{Ln}(M C)$ & 110 & 0.53 \\
\hline $\operatorname{Ln}\left(C_{o}\right)=1.733-0.881 \operatorname{Ln}(L L)$ & 66 & 0.53 \\
\hline $\operatorname{Ln}\left(T_{o}\right)=1.773-0.881 \operatorname{Ln}(M C)$ & 197 & 0.63 \\
\hline $\operatorname{Ln}\left(T_{o}\right)=2.167-0.511 \operatorname{Ln}(C L A Y)$ & 87 & 0.51 \\
\hline $\operatorname{Ln}\left(T_{o}\right)=4.017-1.020 \operatorname{Ln}(L L)$ & 113 & 0.44 \\
\hline
\end{tabular}

$M C$ : moisture content, \%; $L L$ : liquid limit, \%; CLAY : clay-size fraction, \%; $C_{0}$ : unconfined compressive strength, $\mathrm{MPa} ; T_{o}$ : tensile strength, $\mathrm{MPa}$

In Australia, based on extensive studies at some New South Wales coal mines, Seedsman and Gordan (1991) found a strong relation between the uniaxial compressive strength, modulus of deformation and the floor's moisture content as shown in Figure 2.45. Similarly, Li and Smith (1998) found that a strong correlation existed between the uniaxial compressive strength of weak floor strata in coal mines and the moisture content as shown in Figure 2.46. 
a) In Chain Valley Q Cooranbong + Wyee - Regression

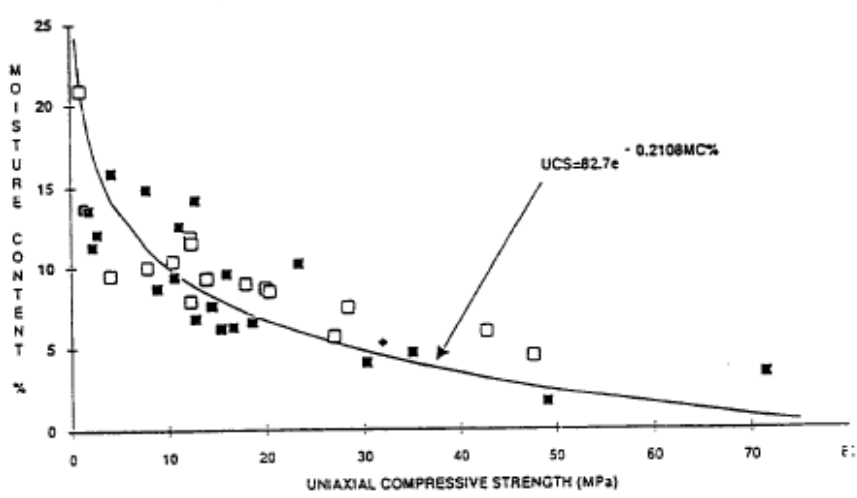

b)

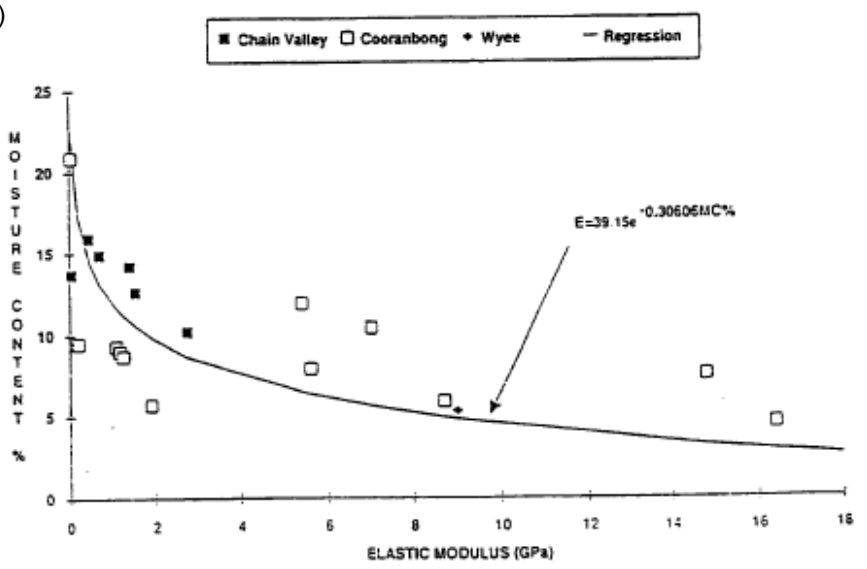

Figure 2.45. Relation between a) uniaxial compressive strength, b) elastic modulus and moisture of weak floor samples from NSW, Australia (Seedsman and Gordan, 1991).

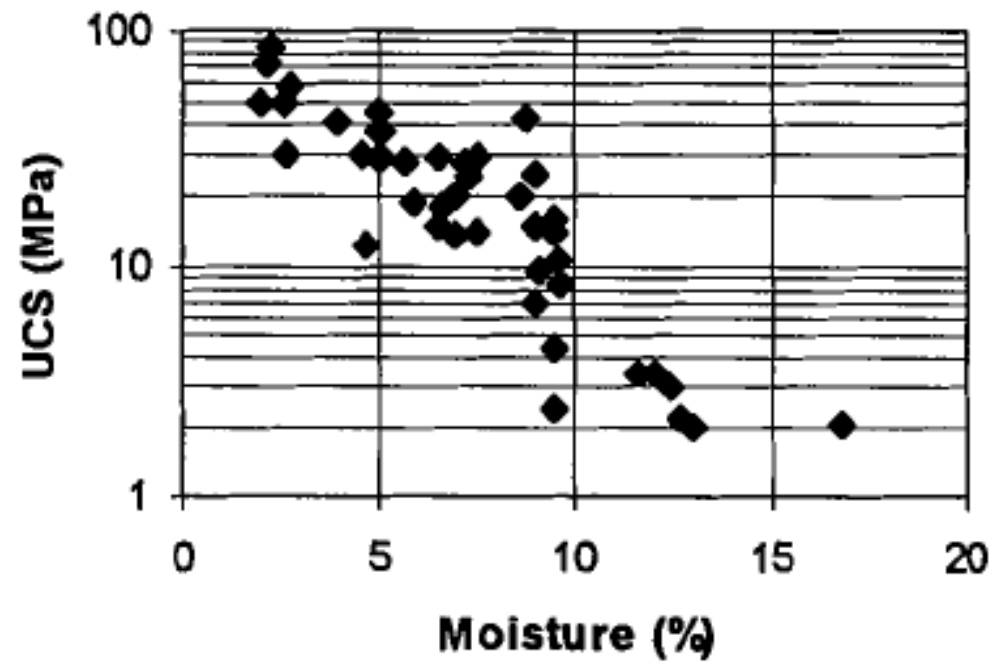

Figure 2.46. Relation between uniaxial compressive strength and moisture of weak floor samples (Li and Smith, 1998). 
Discussions in Section 2.3 showed that the laboratory index properties borrowed from soil mechanics helped in understanding qualitatively the engineering nature of the weak floor materials. Those discussions also showed that some of the index tests could be used to estimate a few engineering properties like the angle of internal friction, needed for stability analysis. When it comes to practical application, it will be useful if some of the index properties that require elaborate tests could be estimated using indices that are relatively easy to determine in the laboratory. Further, it would be extremely useful if an acceptable first approximation could be made of some key engineering properties using simple, inexpensive index tests. The huge database put together for this research will be used to develop some relations between key engineering properties of the floor and simple index tests discussed in section 2.3. It must be mentioned that in developing the regression equations discussed below, no attempt has been made to screen or edit any data points that might improve the performance of the derived relationship. All the data had been used in the analysis since the bulk of the information was historical and no laboratory notes were available to provide support to edit any seemingly anomalous data.

\subsubsection{Relations with Moisture Content as the Independent Variable}

The moisture content of floor is the simplest and the least expensive index test among all the laboratory tests. Past research (Rockaway and Stephenson, 1979; Chugh, 1986a; Pula et al., 1990) showed that in the Illinois Basin some of the key engineering properties of weak floors could be estimated as a function of the moisture content with an acceptable accuracy. The large database of laboratory properties put together here will be used to develop empirical relations between the moisture content and some key engineering properties.

\subsubsection{Moisture Content Vs. Atterberg Limits}

The two Atterberg limits, the liquid and plastic limit, could be estimated if the moisture content of the floor is known using the following relationships. 
The Herrin seam and its equivalents:

$$
\begin{aligned}
& L L=39+3.0 M C \\
& \left(R^{2}=0.23 ; \text { Number of data points }=191 ; \text { Number of mines }=18\right) \\
& P L=22+2.2 M C \\
& \left(R^{2}=0.18 ; \text { Number of data points }=191 ; \text { Number of mines }=18\right)
\end{aligned}
$$

The relationships in equations (2.10) and (2.11) are plotted in Figure 2.47.

a)

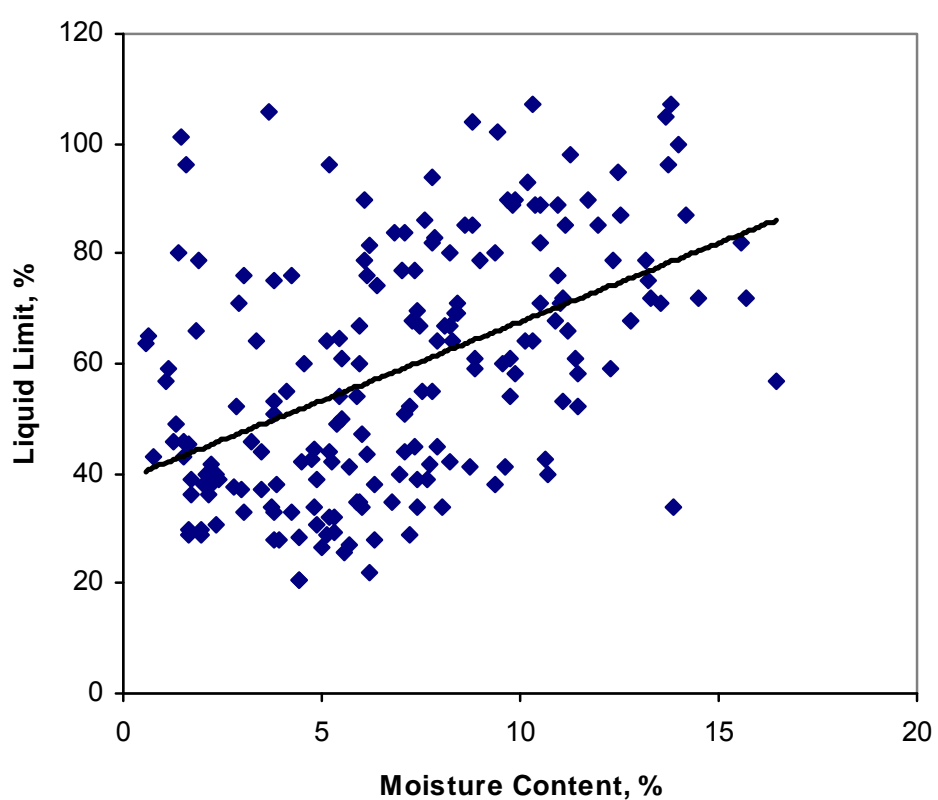

b)

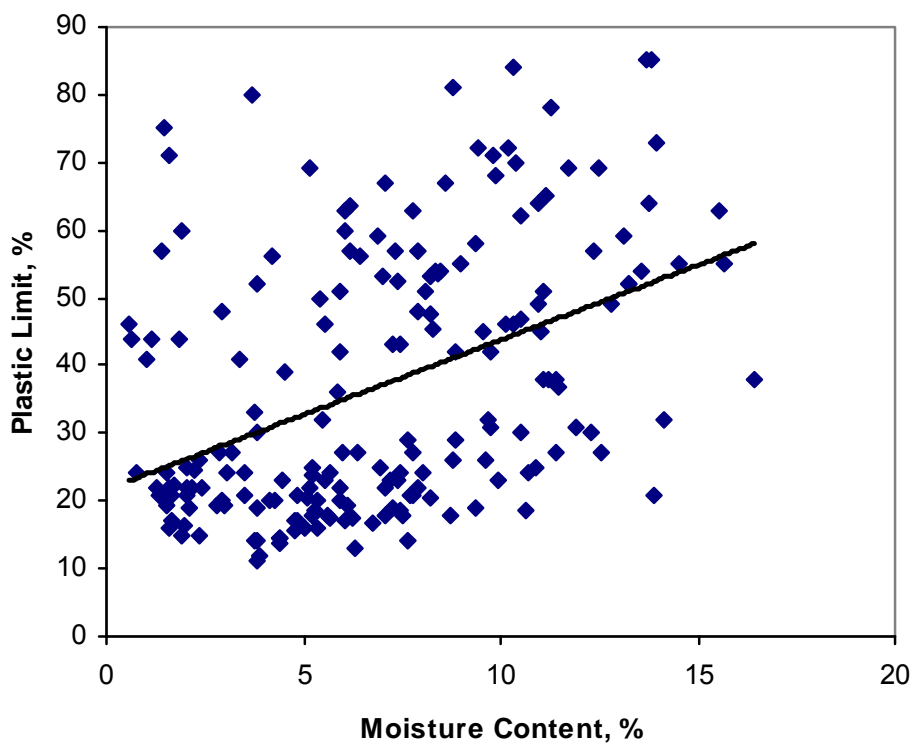

Figure 2.47. Relation between the moisture content and the Atterberg limits for the No.6 seam floor. 
The Springfield seam and its equivalents:

$$
\begin{aligned}
& L L=23+1.46 M C \\
& \left(R^{2}=0.23 ; \text { Number of data points }=220 ; \text { Number of mines }=20\right) \\
& P L=13.5+0.7 M C \\
& \left(R^{2}=0.15 ; \text { Number of data points }=220 ; \text { Number of mines }=20\right)
\end{aligned}
$$

The relationships in equations (2.12) and (2.13) are plotted in Figure 2.48.

a)

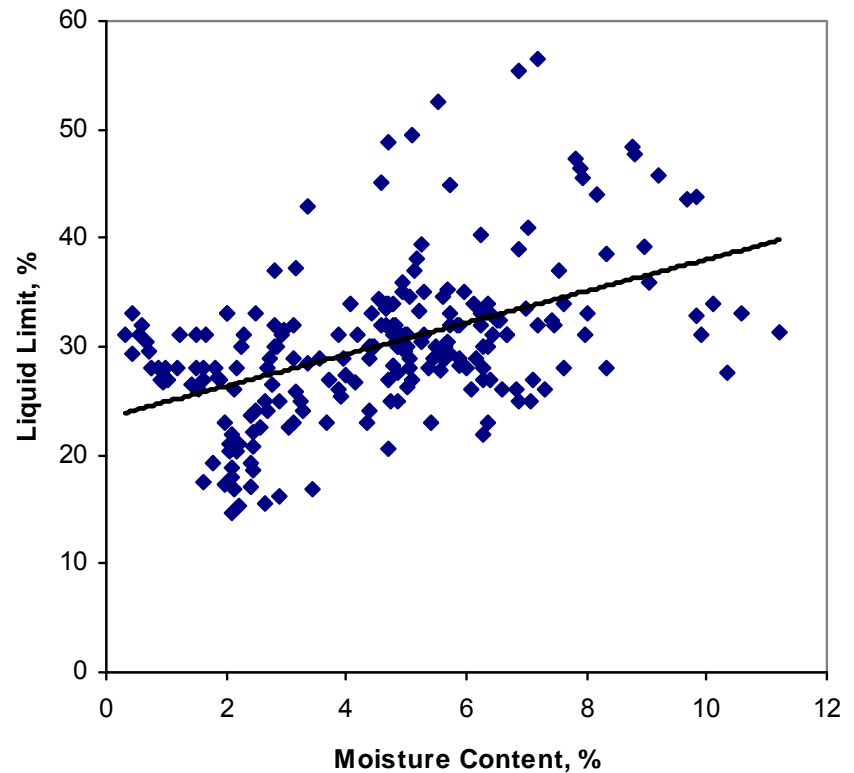

b)

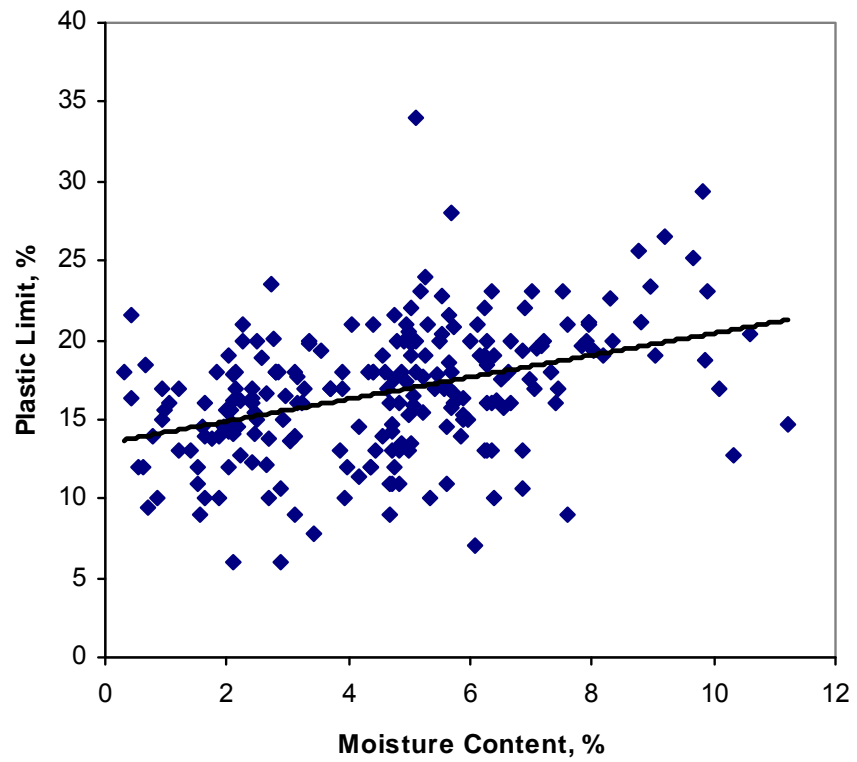

Figure 2.48. Relation between the moisture content and the Atterberg limits for the No.5 seam floor. 


\subsubsection{Moisture Content Vs. Particle-size}

The sand-size and clay-size fractions of the weak floor could be estimated as a function of its natural moisture content. The specific relationships derived for this purpose are given below.

The Herrin seam and its equivalents:

$$
\begin{aligned}
& S A N D_{F R A C}=43-17 \operatorname{Ln}(M C) \\
& \left(R^{2}=0.34 ; \text { Number of data points }=87 ; \text { Number of mines }=10\right) \\
& C L A Y_{F R A C}=21 M C^{0.48} \\
& \left(R^{2}=0.50 ; \text { Number of data points }=87 ; \text { Number of mines }=10\right)
\end{aligned}
$$

The relationships in equations (2.14) and (2.15) are plotted in Figure 2.49.

a)

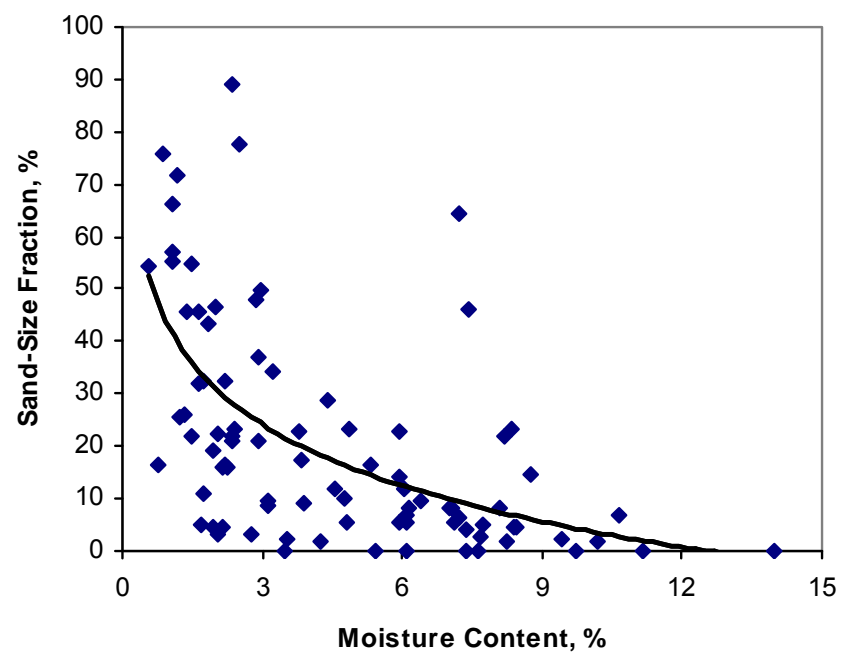

b)

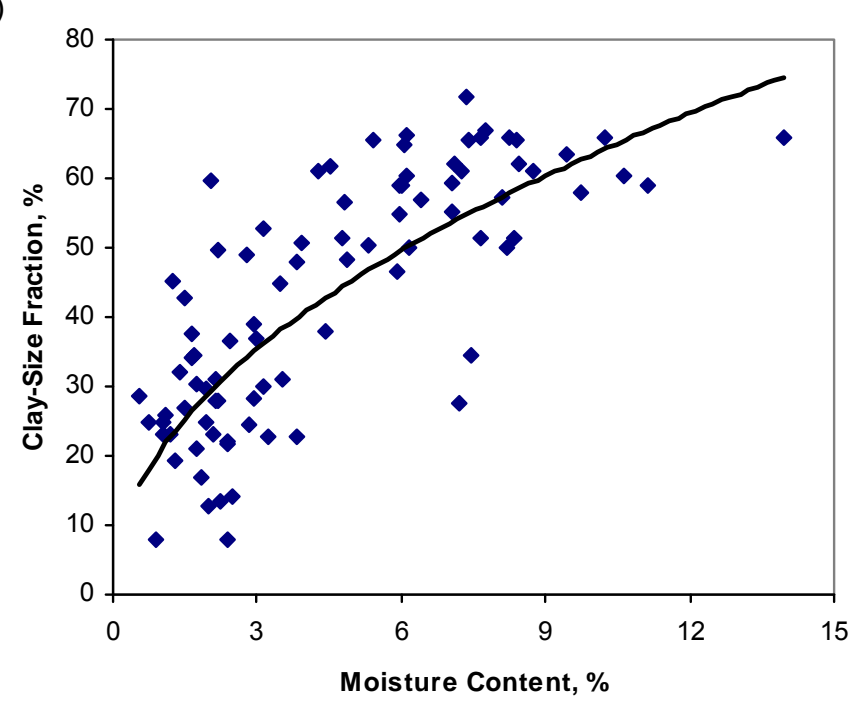

Figure 2.49. Relation between the moisture content and the Particle-size for the No.6 seam floor. 
The Springfield seam and its equivalents:

$$
\begin{aligned}
& S A N D_{F R A C}=45-16 \operatorname{Ln}(M C) \\
& \left(R^{2}=0.34 ; \text { Number of data points }=61 ; \text { Number of mines }=5\right) \\
& C L A Y_{F R A C}=20 M C^{0.46} \\
& \left(R^{2}=0.36 ; \text { Number of data points }=97 ; \text { Number of mines }=7\right)
\end{aligned}
$$

The relationships in equations (2.16) and (2.17) are plotted in Figure 2.50.

a)

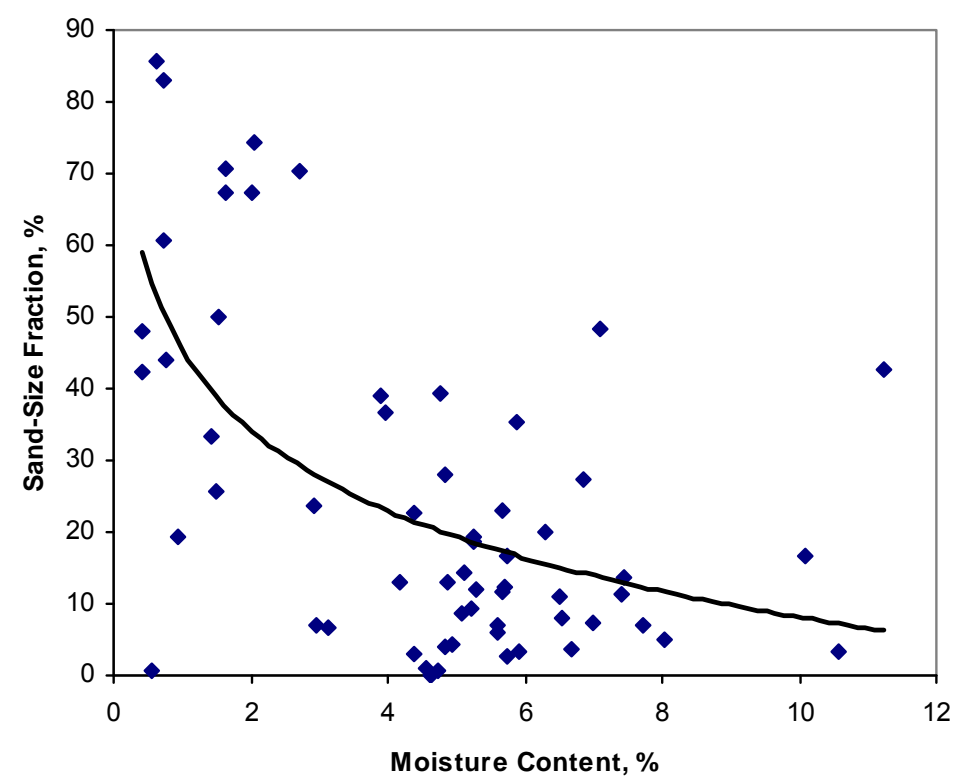

b)

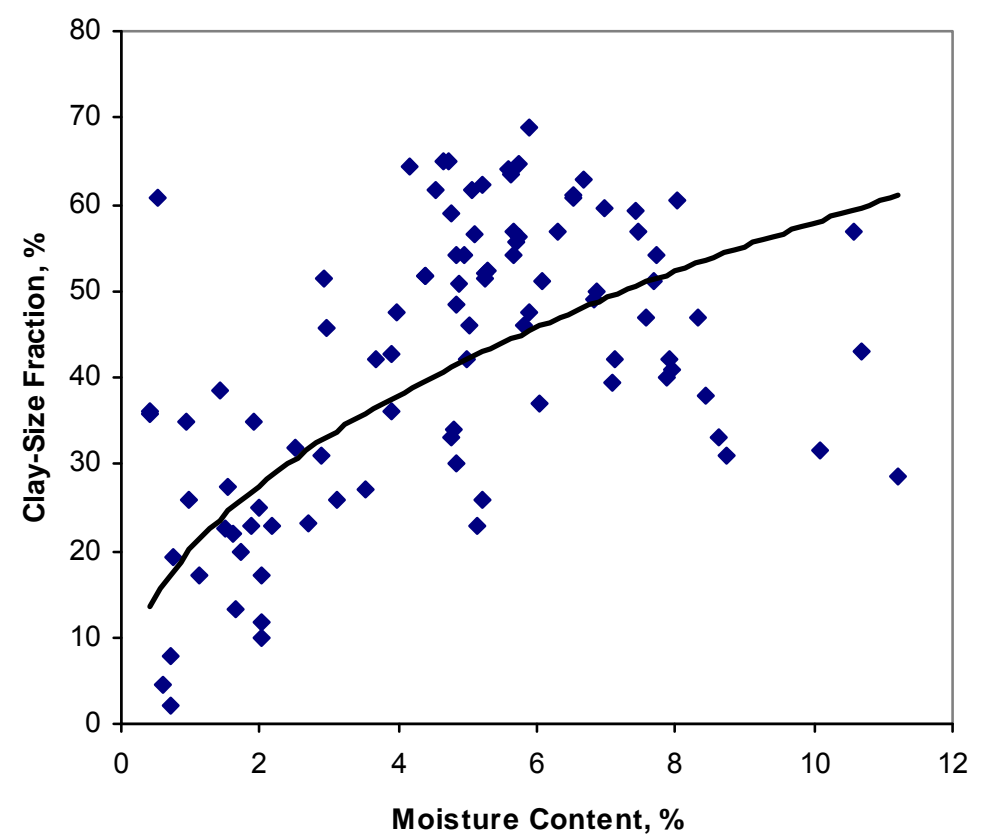

Figure 2.50. Relation between the moisture content and the Particle-size for the No.5 seam floor. 


\subsubsection{Moisture Content Vs. Uniaxial Compressive Strength}

Some information was available on the unconfined compressive strength (UCS) of the immediate floor from several mines in the database. Since it was possible to get enough core recovery to be able to test in the laboratory as per the ASTM standards, the "claystone" material tested must not be the underclay or the weak claystone typically seen within the first one to two feet below the coal seam. Additionally, when the depth of the UCS test was noted where available, it was clear that most of the samples came from a few feet below the coal seam. Therefore, the UCS data collected is representative of the strong claystone that exists below the underclay or the weak immediate claystone floor. Consequently, the relationships developed between the UCS and the moisture content below represent the strength of the "main floor" when the immediate underclay or weak claystone floor grades into strong claystone. In the absence of site-specific laboratory tests, the relationships in equation (2.18) and (2.19) could be used to estimate the necessary properties needed for the "strong" bed in Vesic's (1975) bearing capacity formula discussed in Chapter 4 .

The specific relations for the UCS in psi derived for the floors associated with the No.6 and No.5 seams and their equivalents are given below.

The Herrin seam and its equivalents:

$$
\begin{gathered}
U C S=6443 e^{-0.34 M C} \\
\left(R^{2}=0.64 ; \text { Number of data points }=210 ; \text { Number of mines }=14\right)
\end{gathered}
$$

The Springfield seam and its equivalents:

$$
\begin{gathered}
U C S=10041 e^{-0.4 M C} \\
\left(R^{2}=0.54 ; \text { Number of data points }=157 ; \text { Number of mines }=15\right)
\end{gathered}
$$

The relationships in equations (2.18) and (2.19) are plotted in Figure 2.51.

\subsubsection{Moisture Content Vs. Tensile Strength}

Similar to compressive strength, some data on indirect tensile strength for the strong claystone material was also available. Even though the tensile strength is not needed for the traditional soil mechanics bearing capacity analysis, the information will be useful for numerical estimation of floor strength 
discussed in Chapter 5. The specific relations for the tensile strength derived for the two shelves are given below.

The Herrin seam and its equivalents:

$$
\begin{aligned}
& \text { Tensile }_{\text {strength }}=505 e^{-0.26 M C} \\
& \left(R^{2}=0.64 ; \text { Number of data points }=253 ; \text { Number of mines }=12\right)
\end{aligned}
$$

The Springfield seam and its equivalents:

$$
\begin{aligned}
& \text { Tensile }_{\text {strength }}=1045 e^{-0.35 \mathrm{MC}} \\
& \left(R^{2}=0.5 ; \text { Number of data points }=266 ; \text { Number of mines }=14\right)
\end{aligned}
$$

The relationships in equations (2.20) and (2.21) are plotted in Figure 2.52.

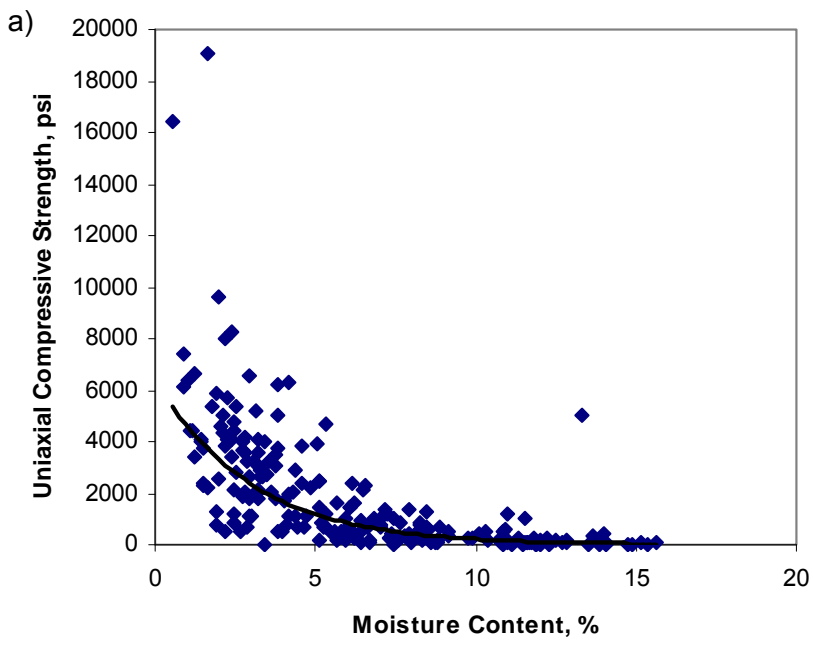

b)

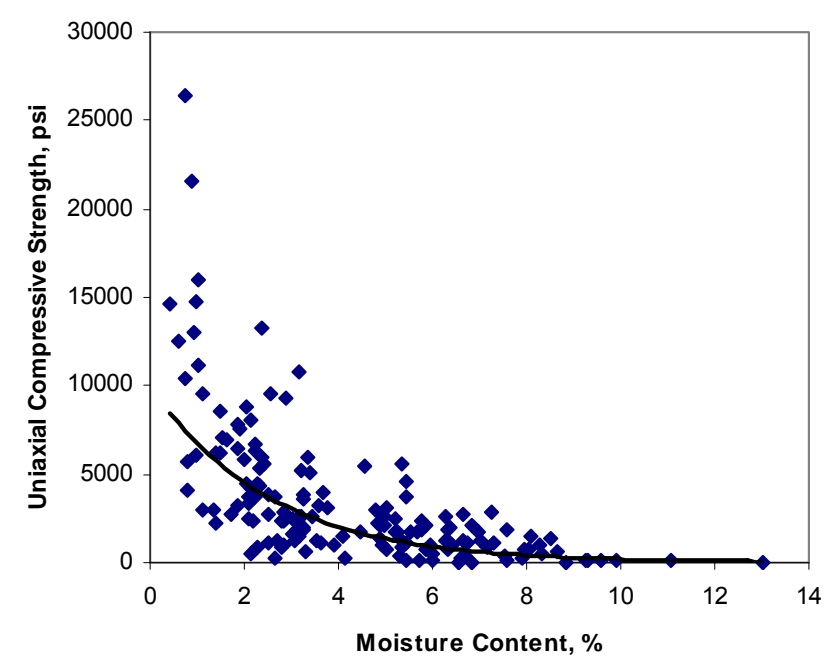

Figure 2.51. Relation between the moisture content and the UCS for a) No.6 and b) No.5 seam floors. 
a)

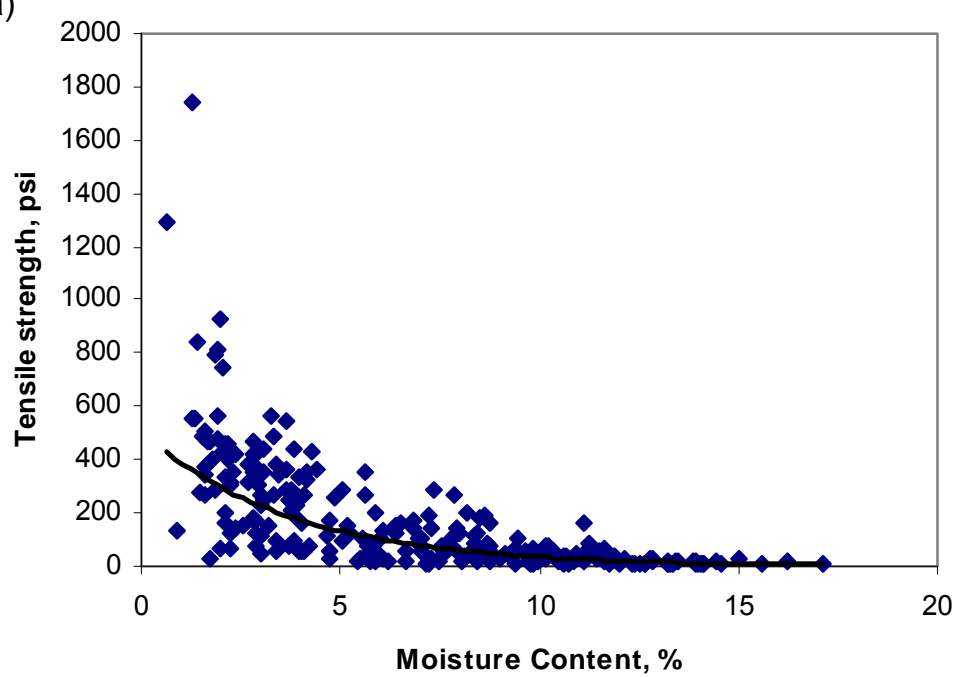

b)

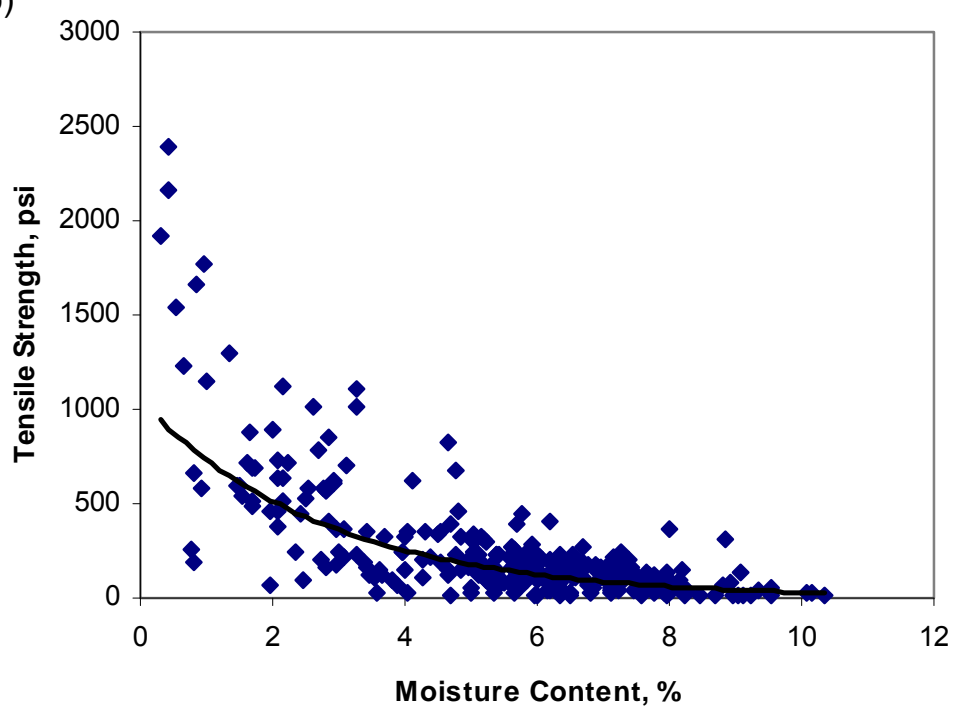

Figure 2.52. Relation between the moisture content and tensile strength for a) No.6 and b) No.5 seam floors.

\subsubsection{Moisture Content Vs. Sonic Properties}

With the increased use of sonic logging as a basic exploration tool in recent years, it would be useful if relationships are developed between the moisture content and the weak floor's sonic properties. The first step in this direction is to examine if such a relationship exists at the laboratory scale. In the database, a reasonable amount of data on laboratory P- and S-wave velocities was available along with the moisture content of the corresponding floor bed. Information was also available on the sonic modulus of the floor. The ASTM 
standard D 2845 (ASTM, 2009) describes the test procedure to determine the pulse velocities in compression and shear as well as the ultrasonic elastic constants. All the sonic data in this section was determined as per that ASTM standard. The relationship between the moisture content and the P-wave, and Swave velocities and the sonic modulus are given below for the two major seam floors.

The Herrin seam and its equivalents:

$$
\begin{aligned}
& P_{\text {Wave }}=12174-2773 \operatorname{Ln}(M C) \\
& \left(R^{2}=0.44 ; \text { Number of data points }=103 ; \text { Number of mines }=12\right) \\
& S_{\text {Wave }}=6549 M C^{-0.49} \\
& \left(R^{2}=0.44 ; \text { Number of data points }=103 ; \text { Number of mines }=12\right) \\
& E_{\text {Sonic }}=4.0 M C^{-1.0} \\
& \left(R^{2}=0.46 ; \text { Number of data points }=103 ; \text { Number of mines }=12\right)
\end{aligned}
$$

The Springfield seam and its equivalents:

$$
\begin{aligned}
& P_{\text {Wave }}=13212-2827 \operatorname{Ln}(M C) \\
& \left(R^{2}=0.35 ; \text { Number of data points }=59 ; \text { Number of mines }=10\right) \\
& S_{\text {Wave }}=5616 M C^{-0.27} \\
& \left(R^{2}=0.23 ; \text { Number of data points }=59 ; \text { Number of mines }=10\right) \\
& E_{\text {Sonic }}=3.16 M C^{-0.59} \\
& \left(R^{2}=0.26 ; \text { Number of data points }=59 ; \text { Number of mines }=10\right)
\end{aligned}
$$

In the above equations, the wave velocities are in $\mathrm{ft} / \mathrm{sec}$ and the sonic modulus is in $10^{6}$ psi. The relationships in equations (2.22) to (2.24) are plotted in Figure 2.53 (a) and those in equations (2.25) to (2.27) are shown in Figure 2.53 (b).

Even though weak, the above correlation between the sonic properties and moisture content indicates that with additional extensive testing it may be possible to establish the potential that exists for sonic logging as a substitute for expensive coring and laboratory testing. In addition to moisture content, the claystone lab data also shows some correlation between the sonic parameters and the uniaxial compressive strength. These latter relationships are depicted in Figure 2.54 . 
a)
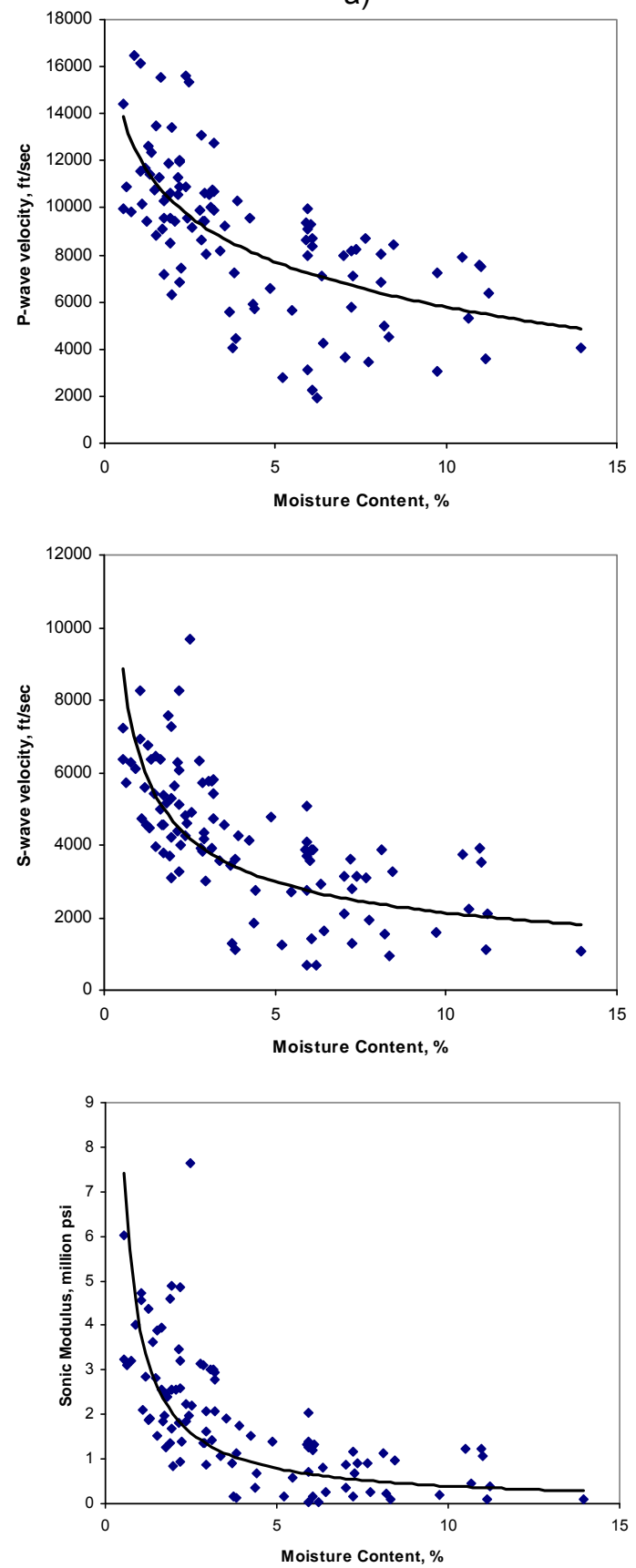

b)
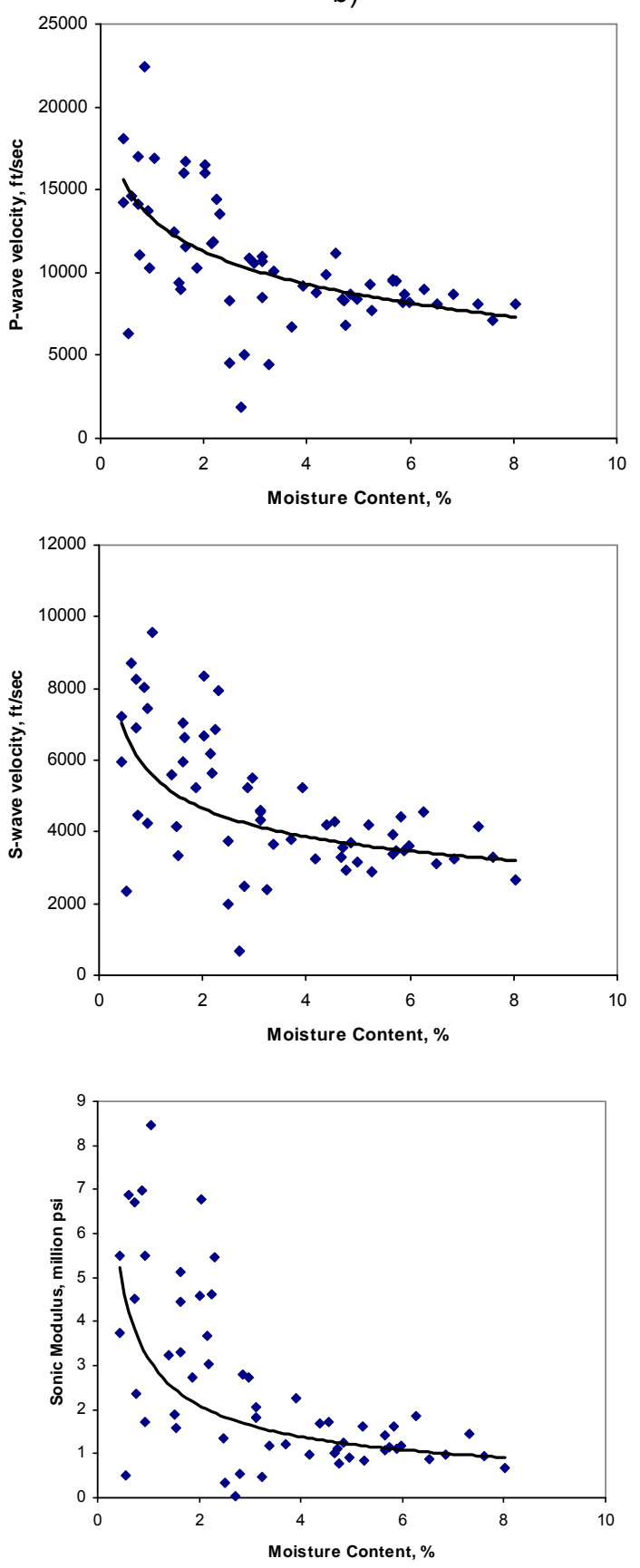

Figure 2.53. Relation between the moisture content and sonic properties for the a) No.6, and b) No. 5 seam floors.

\subsubsection{Moisture Content Vs. Slake Durability}

The simple moisture content also exhibits a decent correlation with the slake durability index value of the floor. Even though of limited direct practical use, the slake durability indicates the floor material's resistance to weathering. 
Qualitatively, the floors with higher slake durability index value will weather the effect of excess moisture better than those with a lower index value. The relations shown in Figure 2.55 provide an approximate value of the floor's $1^{\text {st }}$ and $2^{\text {nd }}$ cycle slake durability as a function of its natural moisture content.

a)

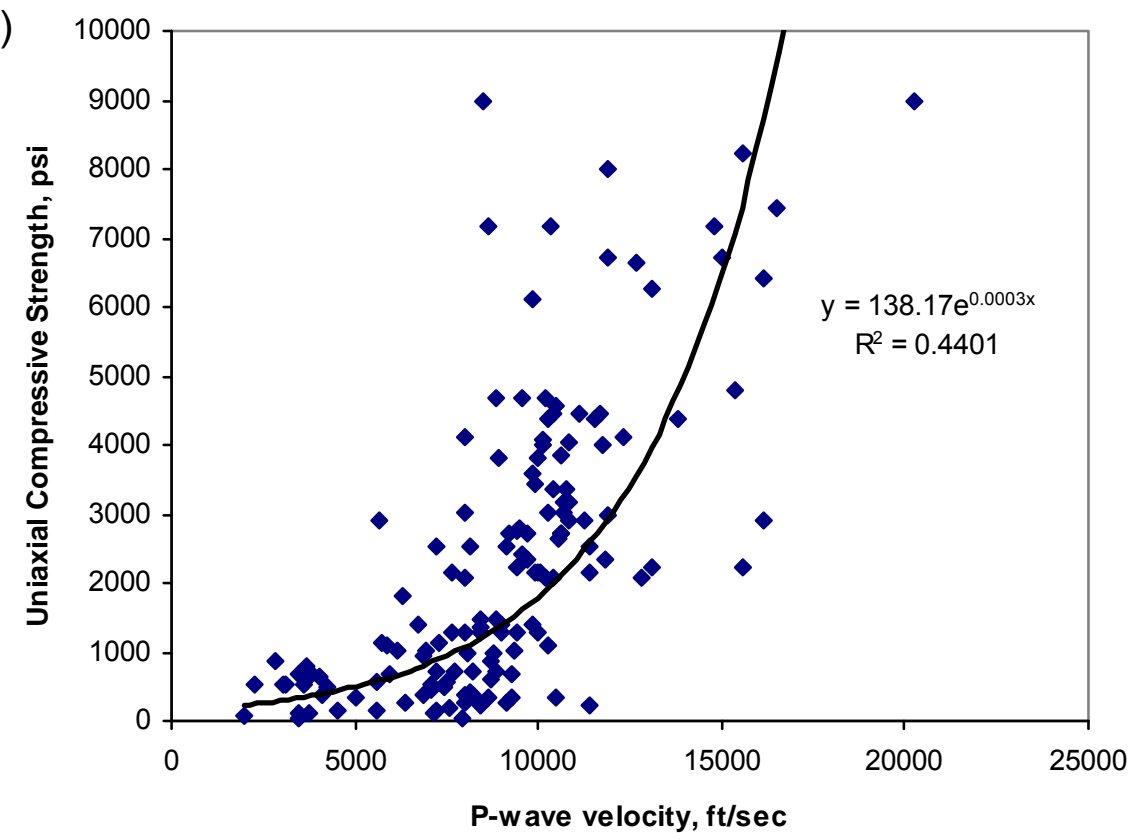

b)

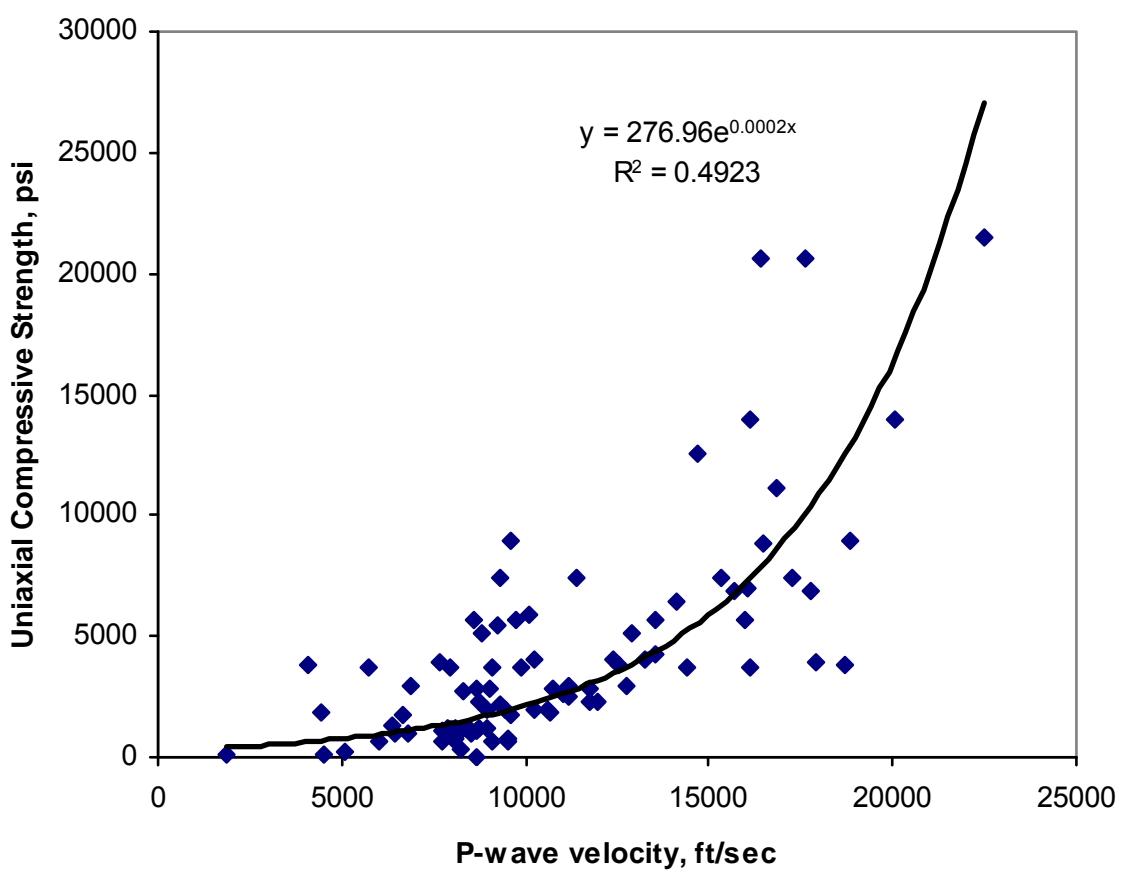

Figure 2.54. Relation between P-wave velocity and the uniaxial compressive strength for the a) No.6, and b) No. 5 seam floors. 
a)
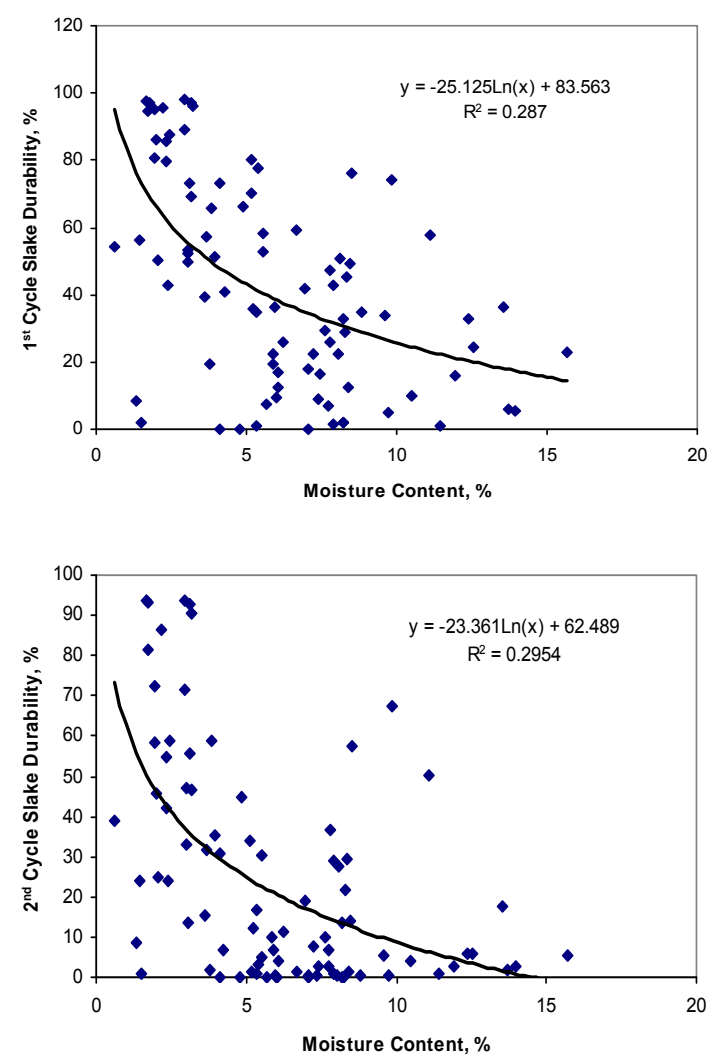

b)
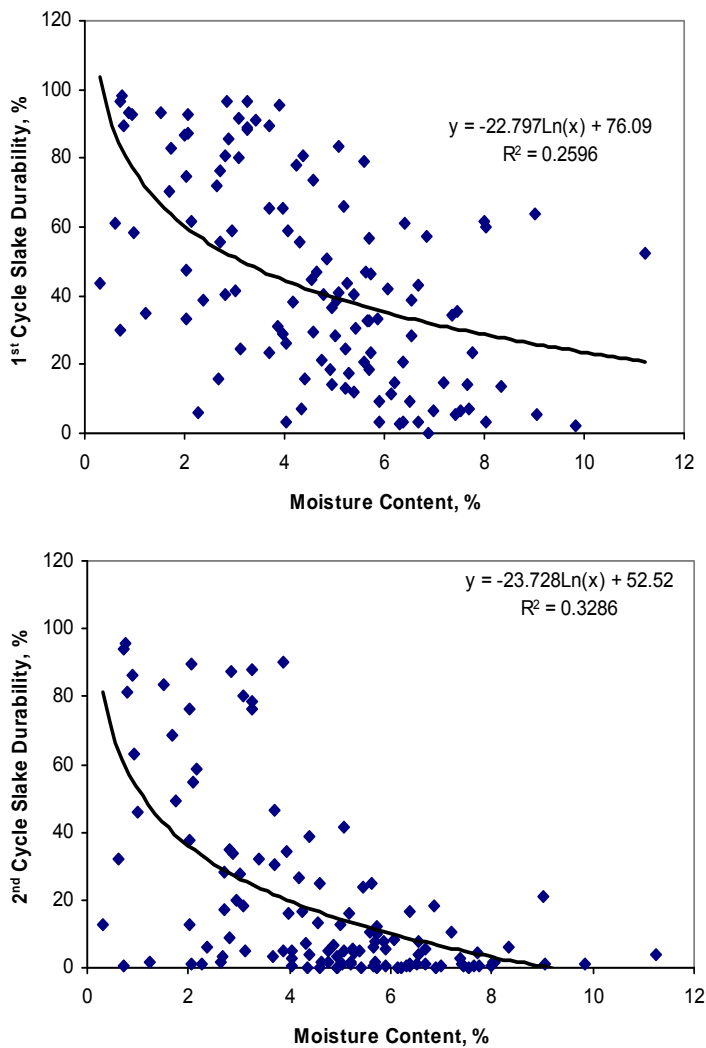

Figure 2.55. Relation between the moisture content and slake durability indices for the a) No.6, and b) No. 5 seam floors.

\subsubsection{Relations between Some Other Properties}

In section 2.4.1 relationships between moisture content and several floor properties that have some practical significance have been examined in detail. This was done because of the ease with which the moisture content for the floor could be determined. The analysis in the preceding section showed the potential usefulness of the simple moisture content in providing the first approximation of some engineering properties of the Illinois Basin weak floor materials. From a practical point of view, the relationships given in Section 2.4.1 are all that are necessary for floor stability analysis. However, the huge database put together for this research provided a unique opportunity to examine the correlations that might exist between other variables as well. Without going into much detail, some of the statistically significant relationships determined between different properties are provided in Table 2.5. As long as the limited accuracy of the 
equations is borne in mind and concessions are made accordingly, for preliminary studies or when the project economics do not permit laboratory testing, the relationships given in Table 2.5 could be used for rough design purposes.

Table 2.5. Interrelations between different properties for two seam floors.

\begin{tabular}{|c|c|c|c|}
\hline Equation & $R^{2}$ & No. of data points & No. of mines \\
\hline \multicolumn{4}{|c|}{ No. 6 seam and its equivalents } \\
\hline$U C S=1503+45 S A N D_{F R A C}$ & 0.29 & 92 & 10 \\
\hline$U C S=5385-73 C L A Y_{F R A C}$ & 0.39 & 92 & 10 \\
\hline$U C S=223 e^{0.0004 S_{\text {Wave }}}$ & 0.45 & 145 & 12 \\
\hline$U C S=574+960 E_{\text {Sonic }}$ & 0.50 & 145 & 12 \\
\hline$P_{\text {Wave }}=7568+66 S A N D_{F R A C}$ & 0.25 & 92 & 10 \\
\hline$S_{\text {Wave }}=3420+32 S A N D_{F R A C}$ & 0.19 & 92 & 10 \\
\hline$E_{\text {Sonic }}=1.21+0.028 S A N D_{F R A C}$ & 0.24 & 92 & 10 \\
\hline$P_{\text {Wave }}=14392 e^{-0.013 C L A Y_{F R A C}}$ & 0.32 & 92 & 10 \\
\hline$S_{\text {Wave }}=7273 e^{-0.017 C L A Y_{F R A C}}$ & 0.30 & 92 & 10 \\
\hline$E_{\text {Sonic }}=5.1 e^{-0.036 C L A Y_{\text {FRAC }}}$ & 0.32 & 92 & 10 \\
\hline \multicolumn{4}{|c|}{ No. 5 seam and its equivalents } \\
\hline$U C S=282 e^{0.0004 S_{\text {Wave }}}$ & 0.55 & 90 & 10 \\
\hline$U C S=27.6+1577 E_{\text {Sonic }}$ & 0.57 & 90 & 10 \\
\hline$U C S=1819+73 S A N D_{F R A C}$ & 0.25 & 63 & 4 \\
\hline$U C S=7470-89 C L A Y_{F R A C}$ & 0.20 & 63 & 4 \\
\hline$P_{\text {Wave }}=9246+50 S A N D_{F R A C}$ & 0.17 & 65 & 4 \\
\hline$S_{\text {Wave }}=3763+26 S A N D_{\text {FRAC }}$ & 0.19 & 65 & 4 \\
\hline$E_{\text {Sonic }}=1.37+0.03 S A N D_{F R A C}$ & 0.28 & 65 & 4 \\
\hline$E_{\text {Sonic }}=3.2 e^{-0.015 C L A Y_{F R A C}}$ & 0.14 & 65 & 4 \\
\hline
\end{tabular}

$U C S=$ uniaxial compressive strength in psi; $S A N D_{F R A C}=$ sand-size fraction, \%; CLAY $F R A C=$ claysize fraction, \%; $P_{\text {Wave }}=$ P-wave velocity, $\mathrm{ft} / \mathrm{sec} ; S_{\text {Wave }}=\mathrm{S}$-wave velocity, $\mathrm{ft} / \mathrm{sec} ; E_{\text {Sonic }}=$ Sonic modulus, million psi.

\subsection{Chapter Summary}

Based on the research presented in this chapter, the following broad conclusions are drawn:

- owing to the sea transgression and regression on a geological time scale and the resulting cyclothems, in the Illinois Basin coal mines, every major 
coal seam is consistently underlain by underclay or weak claystone material;

- the depositional environment and the laboratory data presented in this chapter show that the nature of the immediate floor material differs appreciably between the Eastern and Western shelf of the Basin for the Herrin No. 6 seam and its equivalents. Consequently, a single design equation to predict the floor's engineering properties for the entire basin may not produce satisfactory results. Even though conclusive data for the No.5 seam floor does not exist at this time, until contrary evidence is found, it is suggested that the two-shelf approach may be used for all coal seam floors in the Basin;

- the DuQuoin monocline and its northward projection into the state of Illinois could be used as the demarcation line between the two shelves of the Basin. For practical application purposes, U.S. route 51 in Illinois could be used to separate the Eastern and Western shelves;

- the issue of identifying what depth constitutes the weaker section of the floor has not received as much attention as it deserves. When the immediate floor is thicker than 3.5 to $4 \mathrm{ft}$ and the underclay grades into claystone, efforts must be made to delineate the weaker and stronger sections of the floor. Otherwise, unnecessarily larger pillars will be designed for the long-term stability. In addition to the physical inspection of cores, the change in moisture content with depth below the seam can provide some indication of the different layers of floor materials of varying strengths. Initial research presented in this chapter reveals that the standard geophysical logs used in routine exploration work might provide powerful information on the nature of floor materials. Additional detailed research on this subject is necessary to develop systemic guidelines to interpret the floor lithology. Similarly, more work is needed to develop relations that help estimate the weak floor's engineering properties using sonic logging;

- a huge database of many laboratory properties has been assembled for this research to understand the nature of the floor materials in the Basin. For the 
first time, a comprehensive analysis of different engineering properties collected from mines in all three states of the Basin has been made. Also, the practical meaning of some of the simple index tests borrowed from soil mechanics has been explored. Interpretation of the index tests using the soil mechanics guidelines may seem inadequate given the lack of direct validation studies for mining application. Nonetheless, the general qualitative interpretation of the index tests in understanding the nature of the floor is perhaps still valid as the fundamental mechanisms remain the same;

- finally, it has been shown that some of the engineering properties of the floor needed for stability analysis could be approximately estimated by just knowing its moisture content. Although this finding is not new, the volume of data and the number of different relations developed were unique for the research discussed in this chapter. Given the low to moderate $R^{2}$ values, it may be tempting to dismiss the value of the developed empirical correlations. It must be remembered, however, that the equations were developed by lumping together data collected from different coal mines that are scattered in three states of the Basin. When some variability in rock properties exist even on such small scales as a few feet, it is not surprising to see significant scatter when data from an area as vast as the Illinois Basin is analyzed with a single equation and as a function of a single independent variable. When the multitude of variables that could impact the floor properties are kept in mind, the correlations developed in this chapter are significant for the trends they display. It is not recommended, however, to use the empirical relationships as a substitute for site-specific laboratory testing when such an opportunity exists. It is anticipated that the relationships will mainly be used to analyze abandoned mine cases where information other than moisture content is normally not available. 


\section{CHAPTER}

\section{IN-SITU BEHAVIOR OF WEAK FLOOR IN THE ILLINOIS BASIN COAL MINES}

\subsection{Introduction}

In Chapter 2, a large amount of data from laboratory testing was examined to understand the nature of the weak immediate floor materials in the Illinois Basin coal mines. In this chapter, information available from in-situ testing and inmine observations will be analyzed to decipher the floor behavior in its natural environment. When the floor material in an underground coal mine reaches the limit state, its response is normally manifested by the large plastic movements that appear in the mine opening called 'floor heave'. The limit state could be reached due to excess mining induced stresses or due to a significant increase in the moisture content above the natural levels or both. Rockaway and Stephenson (1979) define floor heave as "the process which occurs when the stress applied to the floor material (lithologically termed underclay) by a coal pillar exceeds the bearing capacity of the floor strata." Peng (2008) notes that "floor heave refers to either breaking or lifting up of immediate floor strata, or extrusion of floor strata into the entry/crosscut. Floor heave may range from barely visible to fully filling the entry/crosscut."

Floor heave can cause both short- and long-term stability problems. Depending on the location, in the short-term, the unstable floor movements may result in inaccessible work areas, unavailability of escapeways, reduced ventilation, roof falls and increased operational cost. In the long-term, floor failure is the main reason for the unplanned surface subsidence in a majority of cases in the Illinois Basin. The excess deformation of the floor in the long-term can also affect the integrity of the mine seals used to isolate working sections from the abandoned areas. For both the short- and long-term cases, normally the surface will not be affected unless the underground instability occurs over a reasonably 
large area. If floor heave occurs in a single entry or in a few isolated spots in a panel, such instability may not cause any damage to the surface. The size of the unstable area needed to induce surface damage depends on the depth of the mine, nature of the materials in the overburden, the amount by which coal pillars move vertically downwards, etc.

For the geo-mining setting of the Illinois Basin coal mines, three different types of floor instability could be identified. These three classes correspond to the modes of failures identified by Vesic (1963) for surface foundations. Based on the observations of foundation failures, it is normally accepted that the soil failure occurs when the shear stresses exceed the shear strength of the soil. The three principal modes of shear failure noticed by soil mechanics researchers were summarized by Vesic (1963) as shown in Figure 3.1. In the general shear failure shown in Figure 3.1(a), the instability is characterized by a well defined continuous slip surface from one edge of the footing to the surface accompanied by significant floor heave. The load-deformation behavior for the general shear failure shows a well defined peak followed by a drop in the post-peak area. The failure mode shown in Figure 3.1(b) is called local shear as the failure pattern is clearly defined only below the foundation. A marginal amount of bulging is noticed at the edges of the foundation in local shear failure and in order to have noticeable failure at the surface, a significant amount of vertical movement of the foundation is necessary. The load-deformation curve shown in Figure 3.1(b) does not indicate a well defined peak value. In contrast with the above two failure modes, in the case of punching shear, it is extremely difficult to notice any failure patterns. With increasing load, the soil right below the foundation experiences compression with no noticeable effects through vertical shear around the foundation perimeter (Vesic, 1975). As the load-deformation curve in Figure 3.1(c) shows, for continued foundation movement, additional vertical stress is necessary in the punching mode of failure.

It appears that the mode of shear failure in field conditions is determined principally by the soil's compressibility (Vesic, 1975). For stiff clays and very well compacted granular soils, general shear failure is the predominant mode. If the 
soil is highly compressible and loosely packed, then punching failure is most likely. For the intermediate soil compressibility, the soil might fail in local shear. In addition to the soil's compressibility, the depositional character of the soil and depth of embedment also plays some role in determining the mode of failure (Vesic, 1975).
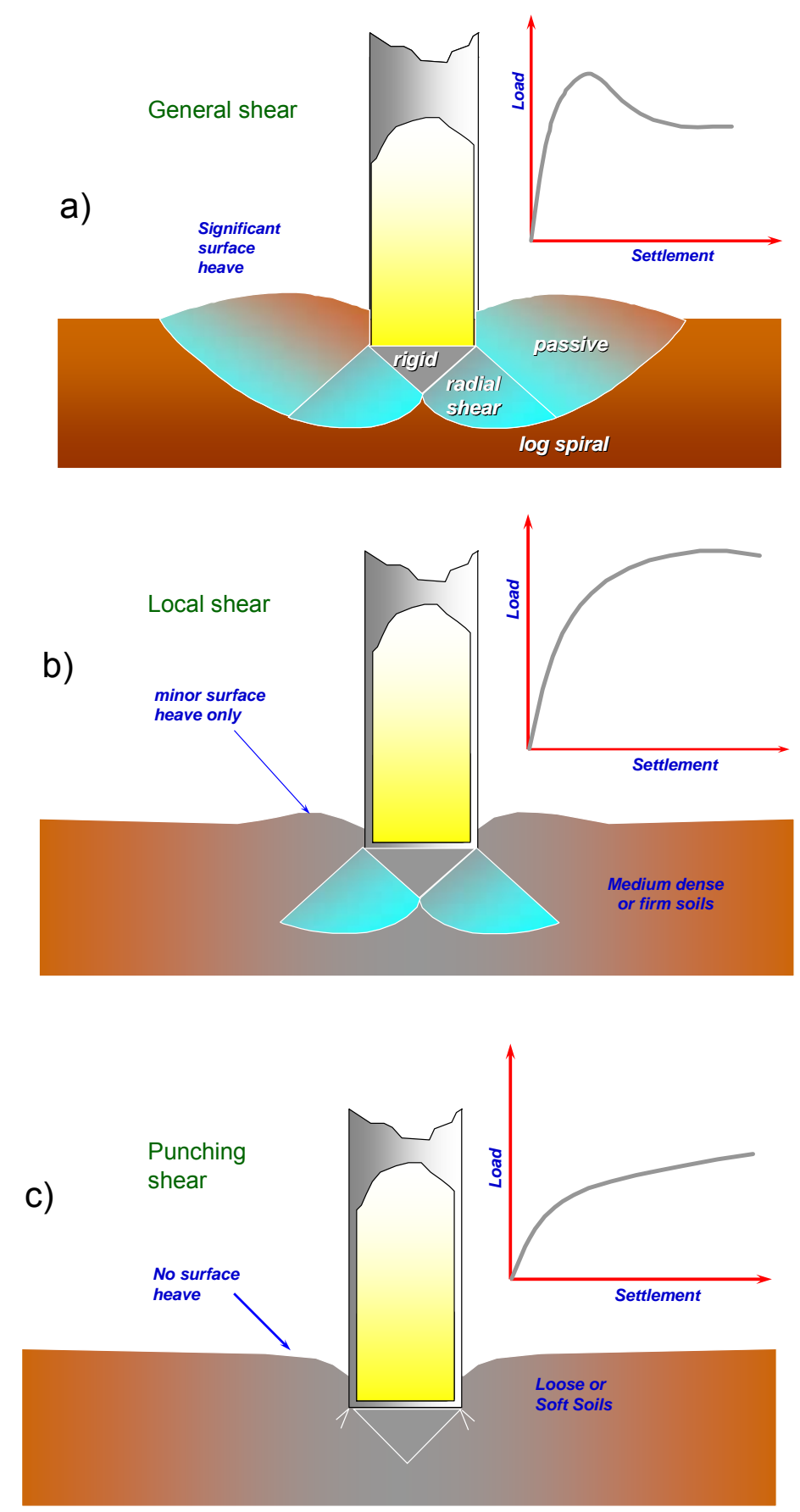

Figure 3.1. Different modes of shear failure below a foundation (Vesic, 1963). 
From the load-deformation curves shown in Figure 3.1, it may be seen that from a short-term stability view point, it is the general shear failure of the floor that poses the greatest difficulty in a coal mine. This is because of the relatively abrupt nature of the failure and the manifestation of the shear failure in the adjacent opening in the form of floor heave. The punching failure mode, where no significant movement in the floor adjacent to a coal pillar occurs, is perhaps the least detrimental for short-term stability. From a surface subsidence view point, any of the failure modes can have significant impact if the area of instability is sufficiently large.

\subsection{Underground Observations of Floor Failures}

Coal mine floor heave has been physically observed in the Illinois Basin mines at least since 1892 (Freer, 1892). From the early times, researchers have been attempting to at least qualitatively describe the failure processes. In the knowledge of the author, it was only after about 1979 (Rockaway and Stephenson, 1979) that some quantitative approaches were developed to analyze the floor stability problem. In one of the earliest studies, Hall (1909) noted that the underclay material "spreads rather than compresses, bursts outward, oozes outward under load, and the coal, weakest in opposing force operating at right angles to its face and butt cleavage planes, is disrupted along its edges." Underground observations by Nelson (1947) showed that when excess stresses act, the underclay breaks readily along slickensided planes or carbonaceous material layers. He proposed that the weak floor fails in two fundamental modes: disintegration and buckling. In-situ monitoring through convergence measurement by Ganow (1975) showed that the form of the convergence plot suggested a buckling type floor failure.

Field investigations at two coal mines in Illinois, visual observations at twenty coal mines and available literature at the time led Rockaway and Stephenson (1979) to suggest three different modes of floor failure as shown in Figure 3.2. In the general shear failure mode in Figure 3.2 (a), the strong and stiff underclay fails under excess stresses and moves from under the coal pillar 


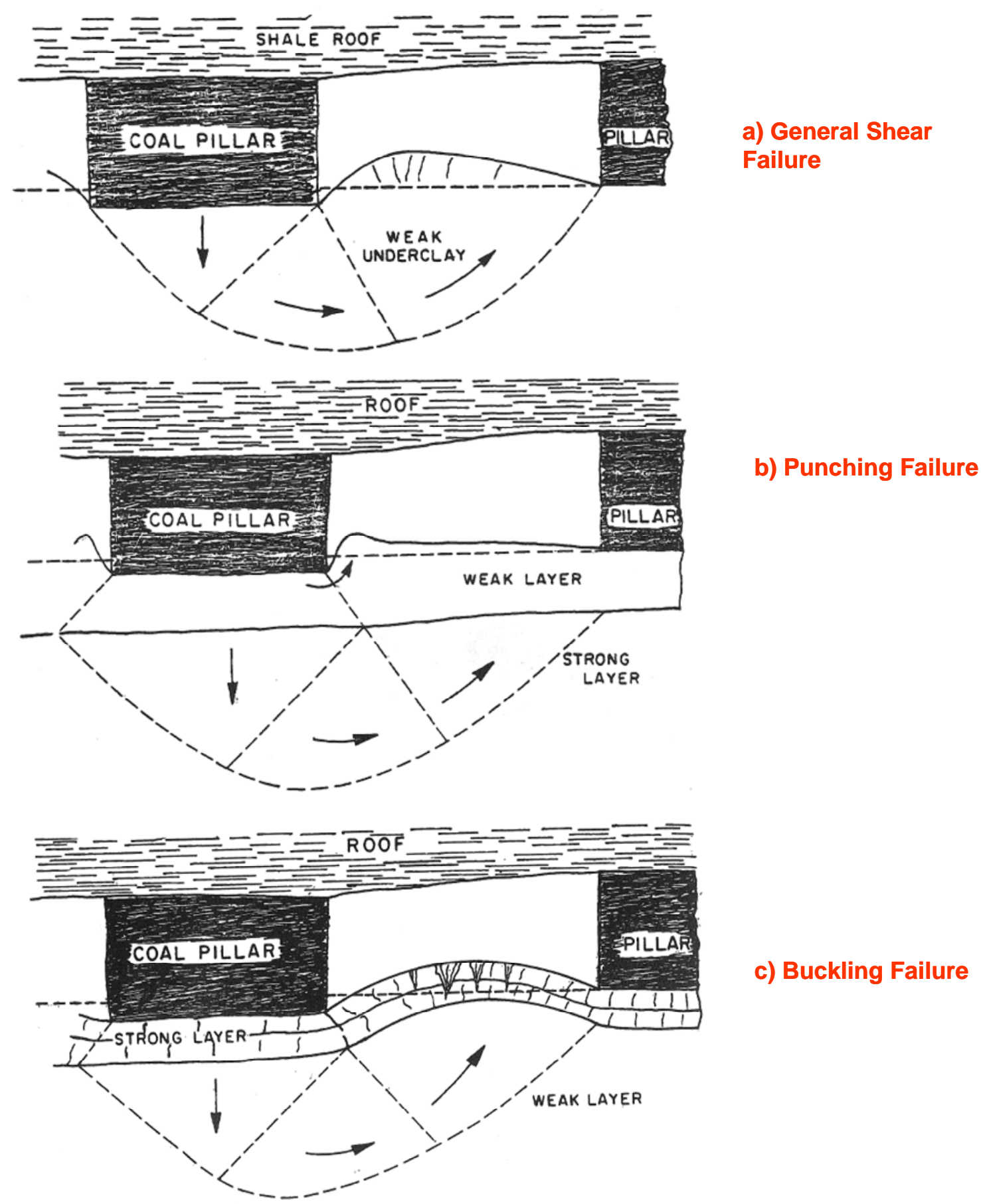

Figure 3.2. Different modes of floor failure in underground coal mines (Rockaway and Stephenson, 1979).

to heave in the adjacent entry. If the floor is soft or becomes soft under the action of excess moisture, the pillar can punch into the floor as shown in Figure 3.2(b). The buckling type failure occurs when the immediate floor is stronger than the 
bed below as illustrated in Figure 3.2 (c). Although the failure mode in Figure 3.2(b) was labeled by Rockaway and Stephenson as punching failure, by comparing the floor deformation with that in Figure 3.1(b), it is perhaps more appropriate to call the failure as local shear. This is because in the punching mode there is no bulging of the floor adjacent to the pillar and the floor movements are imperceptible until a large amount of pillar vertical settlement occurs.

The failure modes illustrated in Figure 3.2 cover most of the short-term and a few long-term floor problems noticed in the Illinois Basin coal mines. However, there appears to be at least one more mode of floor failure when the long-term stability is considered. Examination of the case histories described in Chapter 4 and the author's personal experience in investigating some subsidence events in the Basin indicates that 'softening' of the weak floor as defined by Marino and Choi (1999) is a dominant mechanism leading to floor failures in the long-term. When the abandoned mine working accumulate some water, the resulting physical degradation of the underclay floor below the mine openings and the increase in the moisture content of the floor below the coal pillar as a consequence of water seepage, will form a zone of softened floor as illustrated in Figure 3.3. Once the floor properties are modified due to the 'softening', it is most likely that true punching shear failure as shown in Figure 3.1(c) or a combination of punching and local shear failure might lead to floor instability.

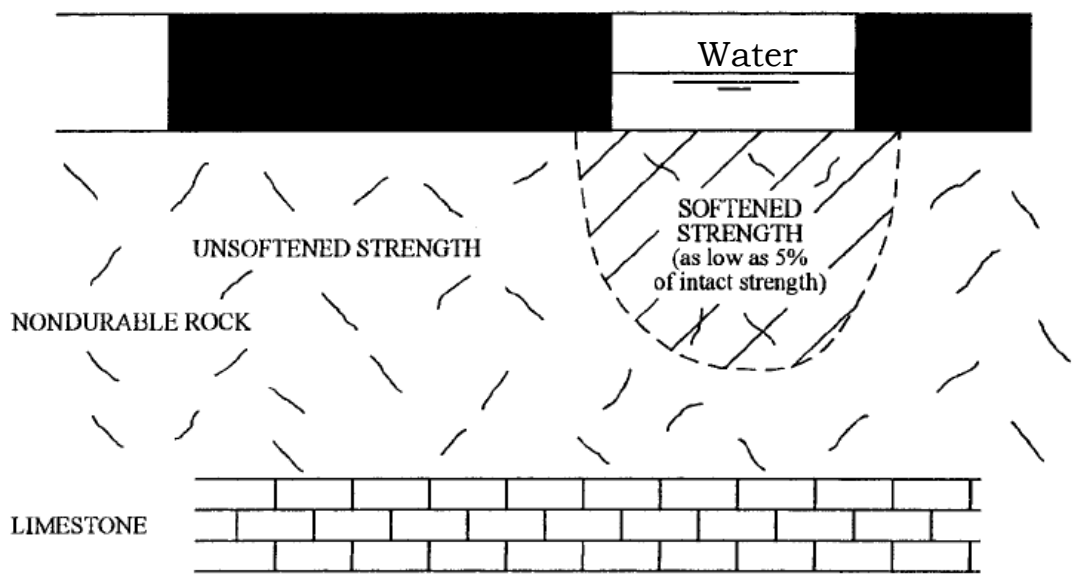

Figure 3.3.'Softening' mode of floor failure (Marino and Choi, 1999). 
Physical observations of the floor failure and underground instrumentation in two Illinois coal mines by Rockaway and Stephenson (1979) showed that the floor instability at the subject mines occurred progressively. Initially, underclay was squeezed from under the coal pillar and a bulge of displaced material formed along the leading edge of the pillar. Owing to the resistance of the floor material to horizontal movement and to the contact friction between the coal and floor, the pillar became convex in shape downward into the underclay. Further, the resulting drag force applied on the coal pillar by the outward moving underclay caused the pillar ribs to "rash" or break in tension. The area of the base of the coal pillar was reduced by this "pillar rashing." With further movement of the floor, deeper and deeper strata became involved. Although none of the four sites that had extensometers and inclinometers installed in the floor experienced floor heave, the data showed that both the underclay and the claystone bed below were involved in the large deformations measured (Rockaway and Stephenson, 1979). It was also observed at these two Illinois mines that the floor movement increased very rapidly after initial mining and the rate reduced slowly with time. Rockaway and Stephenson (1979) inferred the initial rapid floor movements were due to the elastic rebound of underclay after the coal was removed.

Chugh et al., (1984) reported a case history where 4-6 inches of pillar punching into the soft underclay was noticed in a partial extraction room-andpillar mine in the Illinois Basin. In this case, some pillar sloughing was also noticed. Based on field observations at a West Virginia coal mine and numerical modeling, Peng et al., (1992) postulated that there were three different stages in floor failures: elastic deformation, failure initiation and propagation. For the relatively strong fireclay at this mine $(5,720$ psi unconfined compressive strength), bedding plane separation and horizontal movement along the weakness planes preceded the floor heave. From the description in the paper, the proposed mechanism by Peng et al., (1992) applies to the buckling type floor failures. Underground observations at a few mines led Wang (1996) to classify floor failures into two classes: type I and II. When the immediate floor member is 
relatively strong and excess stresses act on it, the floor fails in buckling mode, which is labeled as type I floor heave by Wang (1996). Similarly, the traditional shear driven plastic flow noticed in foundation engineering is labeled as type II in this classification.

In Australia, Seedsman (1987) studied weak floor stability at a Newcastle coalfield mine and suggested three possible sources of floor heave: elastic rebound, swelling of claystone, and bearing capacity failure of pillars. Since the field measurements and analytical studies did not provide a good match for the first two mechanisms, Seedsman (1987) concluded that it was perhaps the bearing capacity failure that played the dominant role in the floor heave at the mine.

Extensive research conducted at the Cooranbong Colliery in Newcastle coalfield, New South Wales, shows the sequence of events in Figure 3.4 leading to surface subsidence (ACIRL, 1987). Numerical finite element and displacement discontinuity analysis revealed that the large amount of surface subsidence at the mine was due to pillar failures triggered by foundation instability.

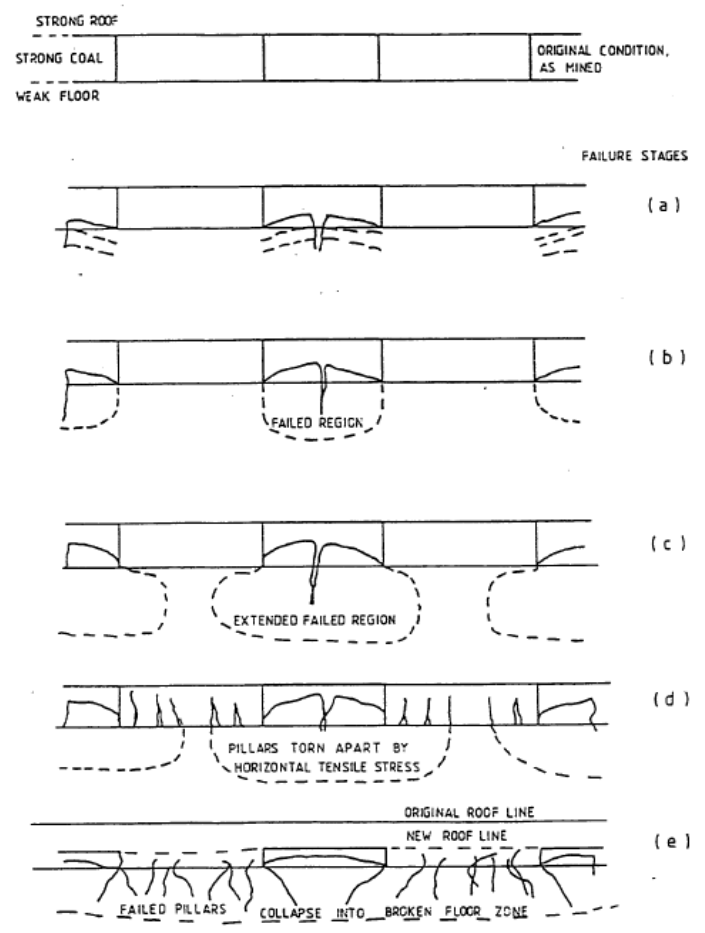

Figure 3.4. Failure mechanism suggested by the Australian Coal Industry Research Laboratories Ltd. (ACIRL, 1987) 
An extensive review of the studies conducted at several Australian mines with weak floor problems broadly shows the same failure mechanisms as in Figure 3.2 (Vasundhara, 2001). Australian experience, however, points to the consolidation settlement of coal pillars as the primary cause of long-term surface subsidence over partial extraction bord-and-pillar mines. Based on the past Australian investigations, Vasundhara et al., (2001) concluded that the claystone unit below coal pillars might exhibit consolidation by drainage of natural moisture under increased mining stresses and the weak bed in the roadway might deteriorate and exhibit floor heave. They also hypothesized that if the surface movements did not level out with time, then it was not consolidation but the progressive failure of claystone below coal pillar that would cause continued subsidence.

A very interesting case study was reported by Vasundhara et al., (2001) where a 15 year old coal pillar was split in the middle to study the condition of claystone right next to a heaved mine entry. Laboratory studies along with physical observations in a test pit dug deep into the floor as shown in Figure 3.5 indicated that the claystone disintegration was restricted only to the roadway and the floor below the coal pillar was very stable with no apparent swelling or fracturing. Further, it was found that there was a significant difference in the natural moisture content of the claystone in the roadway and below the coal pillar. The moisture in the roadway was as high as $30 \%$ while that below the coal pillar was only about $12 \%$. It appears that the edge of the pillar marked a sharp boundary between the deteriorated and stable claystone floor with no apparent transition zone (Vasundhara et al., 2001).

The Australian field study reported by Vasundhara et al., (2001) provides strong support to the conclusion in Chapter 5 where it is mentioned that the instability noticed in roadways should not always be considered in developing guidelines for surface subsidence prevention. The modeling studies described later will show that due to the non-uniform vertical stress distribution on coal pillars, localized floor instability in the mine openings could be noticed without 
significantly affecting the stability of the floor below the coal pillar, the same conclusion reached by Vasundhara et al., (2001) from the field investigations.
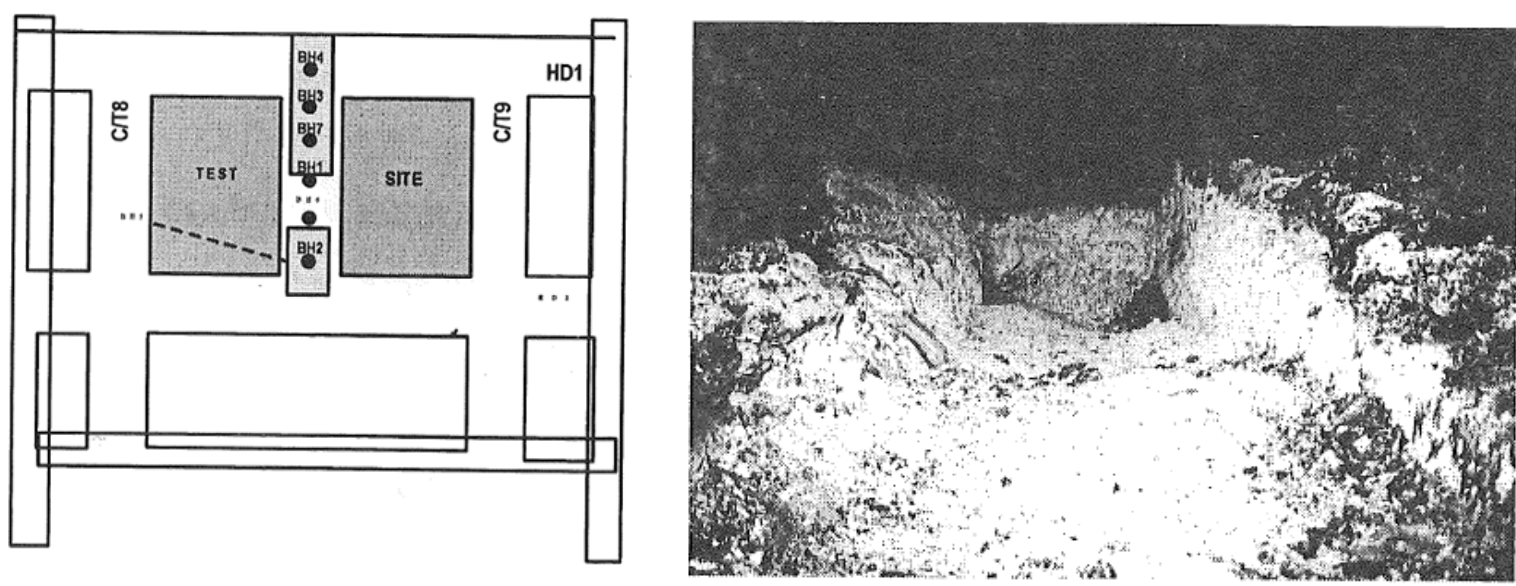

Figure 3.5. Condition of the floor in the test pit dug in the split pillar (Vasundhara et al., 2001).

As mentioned before, it appears that in addition to the mechanisms in Figure 3.2, the Australian experience suggests consolidation of claystone as another process which could lead to long-term surface subsidence. Considering that the consolidation settlement is a time-dependent process primarily driven by the pore water migration from saturated soils (Terzaghi et al., 1996), it is doubtful if such mechanism could play a dominant role in underground coal mines. This is particularly so because of the very low amount of water present in typical weak floors in their natural state (less than $15 \%$ or so). Further, Vasundhara (2001) points out that in an research study where consolidation was concluded as the primary mode of floor settlement, the use of FLAC modeling to reach that conclusion was flawed. This is because of the use of Mohr-Coulomb plasticity model in that analysis, which cannot simulate the consolidation settlement of the floor. Vasundhara (2001) opined that the researchers in the case mentioned, misinterpreted the deformation of the numerical analysis as consolidation settlement when in reality it was a combination of elastic and plastic movements in the floor. None of the U.S. research showed consolidation of the floor material as the primary mechanism behind long-term surface subsidence. 


\subsection{In-situ Plate Bearing Tests}

The general understanding from underground observations is that floor failures occur when the mining induced stresses exceed its strength. Whatever mechanism is responsible for such failures and in order to prevent them, knowledge of the engineering properties of the floor materials is required. It is preferable to obtain such information from in-situ studies as several factors could alter the condition of laboratory samples from their natural states. For an engineering stability analysis of weak floors, basically three major material inputs are necessary: the cohesion, the angle of internal friction, and the modulus of deformation. In singling out these three properties it has been assumed that the strength of the weak floor could be described by the Mohr-Coulomb failure criterion and the floor material could be assumed to be homogeneous and isotropic. Past research shows that such assumptions are not unrealistic (Rockaway and Stephenson, 1979; Chugh, 1986a).

The most preferred technique to obtain the in-situ strength and deformation properties is by conducting bearing tests underground using a reasonable size plate. Several researchers have done plate testing in the Illinois Basin coal mines in the past (Barry and Nair, 1970; Rockaway and Stephenson, 1979; Chugh, 1986b; Su et al., 1993). Excluding some minor details, all these researchers used a very similar test setup for these tests. An excellent review of the existing test setups before 1970's was provided by Barry and Nair (1970). Similar reviews were also provided by Speck (1979) and Chugh (1986b).

While there are no formal standard procedures available for coal mine floor bearing capacity tests, the American Society for Testing Materials (ASTM, 2002) has developed some standards for use in soil testing. The ASTM procedure D1194-94 (which was withdrawn in 2003) covers estimation of the bearing capacity of the soil in-place by means of field testing. The standard requires use of at least a 50 ton hydraulic jack and circular steel plates thicker than 1 inch with diameters between 12 and 30 inches. For any two adjacent tests, a minimum spacing of five times the plate diameter was recommended. 
The ASTM standard does not recommend using any loading pad and allows placing the test plate directly over the soil. It was suggested that the load to the plates be applied at increments not exceeding 1.0 ton $/ \mathrm{ft}^{2}$ or no more than $1 / 10^{\text {th }}$ of the estimated bearing capacity. After each load increment, it was recommended by the ASTM standard to hold the load steady for at least 15 minutes before applying the next increment. Alternatively, it was suggested that the time duration over which the loads need to be kept constant might be determined by how fast the plate settlement became steady (ASTM, 2002).

Even though not for the plate bearing capacity tests, the International Society for Rock Mechanics (ISRM, 1981) has developed some standards for determining the in-situ deformation modulus by conducting field tests in rock tunnels. The elaborate test setup required by the ISRM standard is shown in Figure 3.6. In terms of the test procedure, the ISRM standard also recommends a number of load increments before reaching the predetermined maximum pressure and allowing sufficient time gaps between successive increments (ISRM, 1981). In order to induce uniform displacements in the plate, a concrete pad is recommended between the test plate and the rock as shown in Figure 3.6. Without the pad, owing to the surface irregularities, the plate may experience non-uniform movements as the high spots get crushed under increased loads.

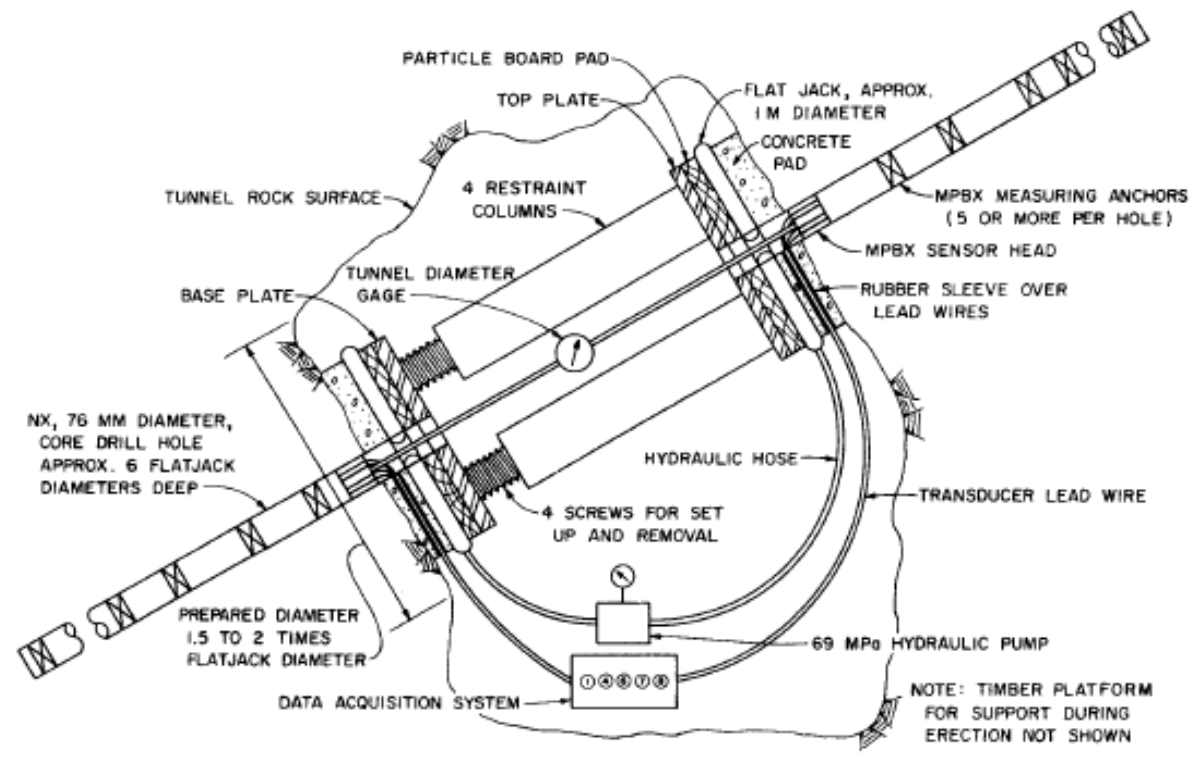

Figure 3.6. Test setup for the deformation modulus determination using the ISRM suggested procedure. 
When it comes to in-situ plate testing in the U.S. coal mines, perhaps the first reported tests were conducted by Dulaney (1960) using rigid square plates ranging in size from 1.5 to 12 inches in six coal seams. To ensure uniform loading, Dulaney used a layer of plaster of paris between the plate and the floor. The next set of U.S. tests was reported by Chlumecky (1968) using the test setup shown in Figure 3.7. These tests were done to determine the floor bearing strength for standing support design. Different size plates were used by Chlumecky to study the size effect on the measured bearing capacity.

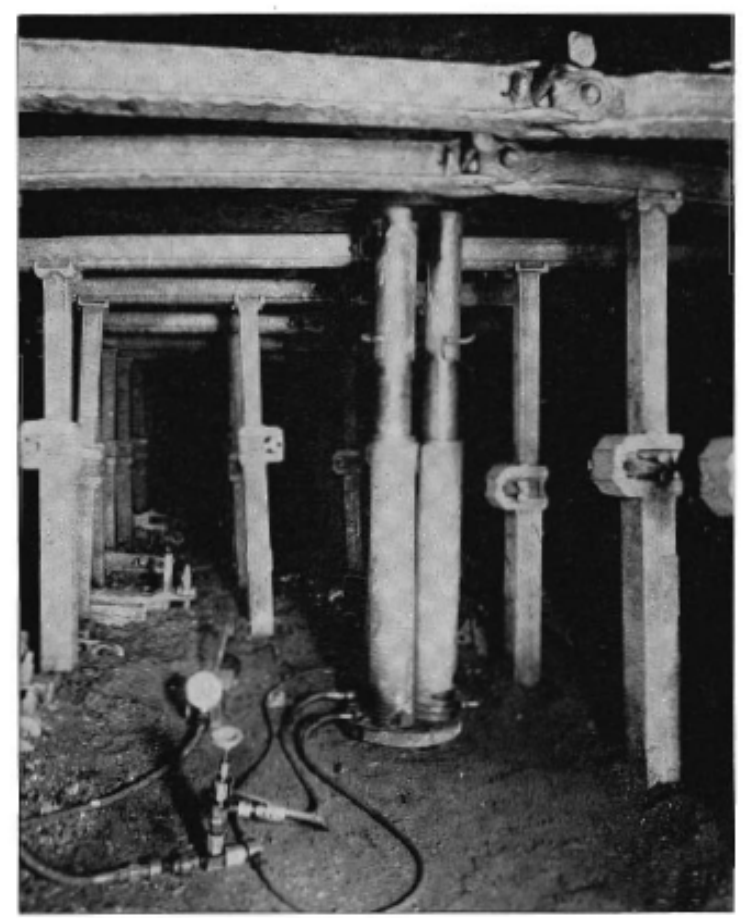

Figure 3.7. Plate test setup used by Chlumecky (1968).

Barry and Nair (1970) conducted plate tests at nine U.S. coal mines including one in the state of Illinois to determine the floor strength for longwall support design. The test setup used by Barry and Nair (1970) is shown in Figure 3.8, which includes a 100 ton hydraulic ram, an air-hydraulic pump, a 0 - to 10,000 psi continuous pressure recorder and a level telescope to monitor the deformations remotely. Test sites with an abnormal amount of water, fractures in the roof or floor and with any geological anomalies were avoided. The roof and floor at the test site were cleaned of any loose material and the test surface was 
made flat to achieve uniform loading. No layer of plaster of paris was applied below the plates. During the test, the load on the plates was controlled via an airline regulator to the air-hydraulic pump such that the penetration rate was maintained at 0.2 inch per 5-minute interval. The tests were terminated when the total penetration of the plate reached 4 inches or the floor failed or the hydraulic ram capacity was reached (Barry and Nair, 1970). When multiple plates were tested at a location, the distance between any two tests was always more than 5ft. Unfortunately, the tests conducted by Barry and Nair (1970) in one Illinois mine had 14 to 20 inches coal in the floor and thus the data can not be used in the present research.

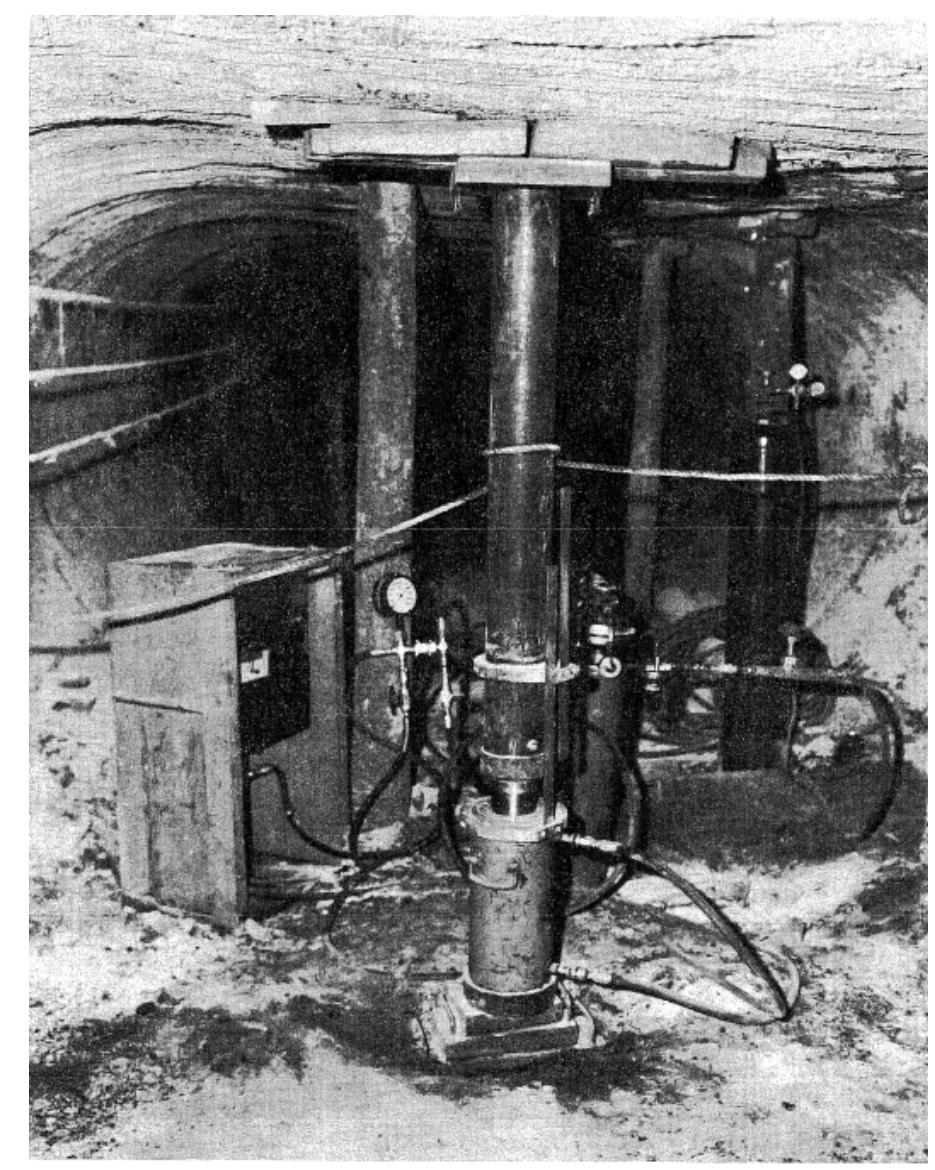

Figure 3.8. Test setup used for the Barry and Nair (1970) work.

Speck (1979) conducted in-situ plate bearing tests at three separate sites in two Illinois coal mines using the setup in Figure 3.9. The different components 
numbered 1 through 13 in Figure 3.9 are: 1) hardwood blocking, 2) top plate, 3) compression flat load cell, 4) swivel head, 5) reaction beam, 6) hydraulic jack, 7) extension plate, 8) penetration plates, 9) plaster of paris, 10) LVDT's, 11) dial gauges, 12) bridge support and 13) portable strain indicator. After the roof and floor at each test site was cleaned of any loose material, a thin layer of plaster of paris was applied to ensure uniform loading. The plaster of paris layer was allowed to set for 15 to 20 minutes before the tests began. It appears that Speck (1979) conducted some plate tests right at the surface of the floor and a few at a certain depth in a test pit dug in the floor. Some loading and unloading cycles were performed to close any fissures in the floor and to seat the plaster of paris layer in the mine floor. Failure in the tests was reached when the plate began to penetrate rapidly into the floor.
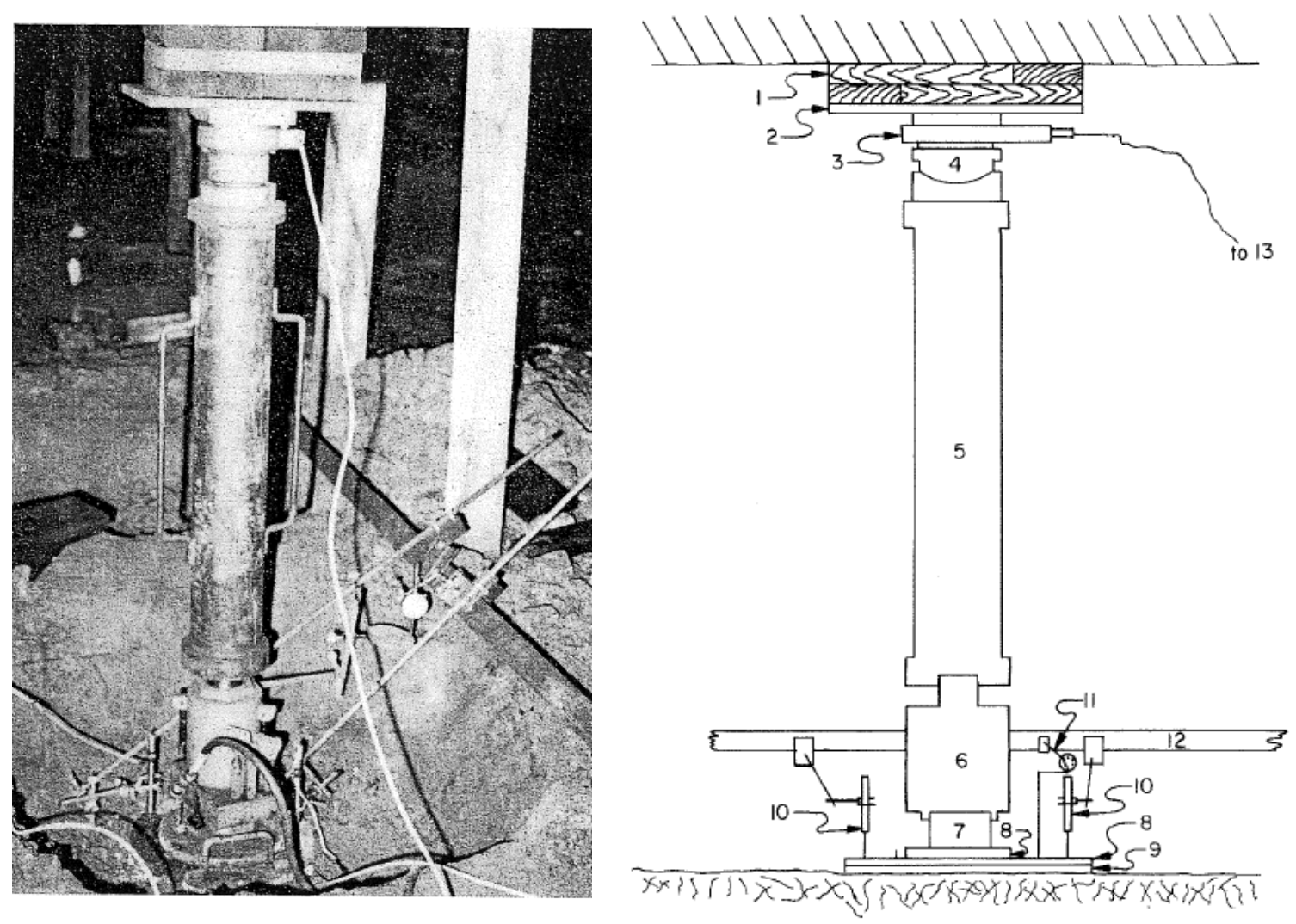

Figure 3.9. Speck's (1979) plate test setup.

Chugh (1986b) used the test setup in Figure 3.10 to conduct several plate tests at two Illinois coal mines. The same setup was later used by the Southern 
Illinois University, Carbondale (SIUC) to conduct plate tests at seven coal mines in the state of Illinois (Pula et al., 1990). The SIUC setup employed a 100 ton hydraulic jack which allowed a maximum plate deformation of 2 inches. The data during a test was automatically collected using the LVDTs and pressure transducers. An electric motor-driven hydraulic pump automated the load application to the plate. Rigid square plates of different sizes were used for the tests. Tubular steel props, 6-8 inches diameter and of various heights were used to apply loads to the plates. Three LVDT's at three corners of the plate measured the plate settlement. Data loggers were used to collect all the information from each test (Chugh, 1986b).

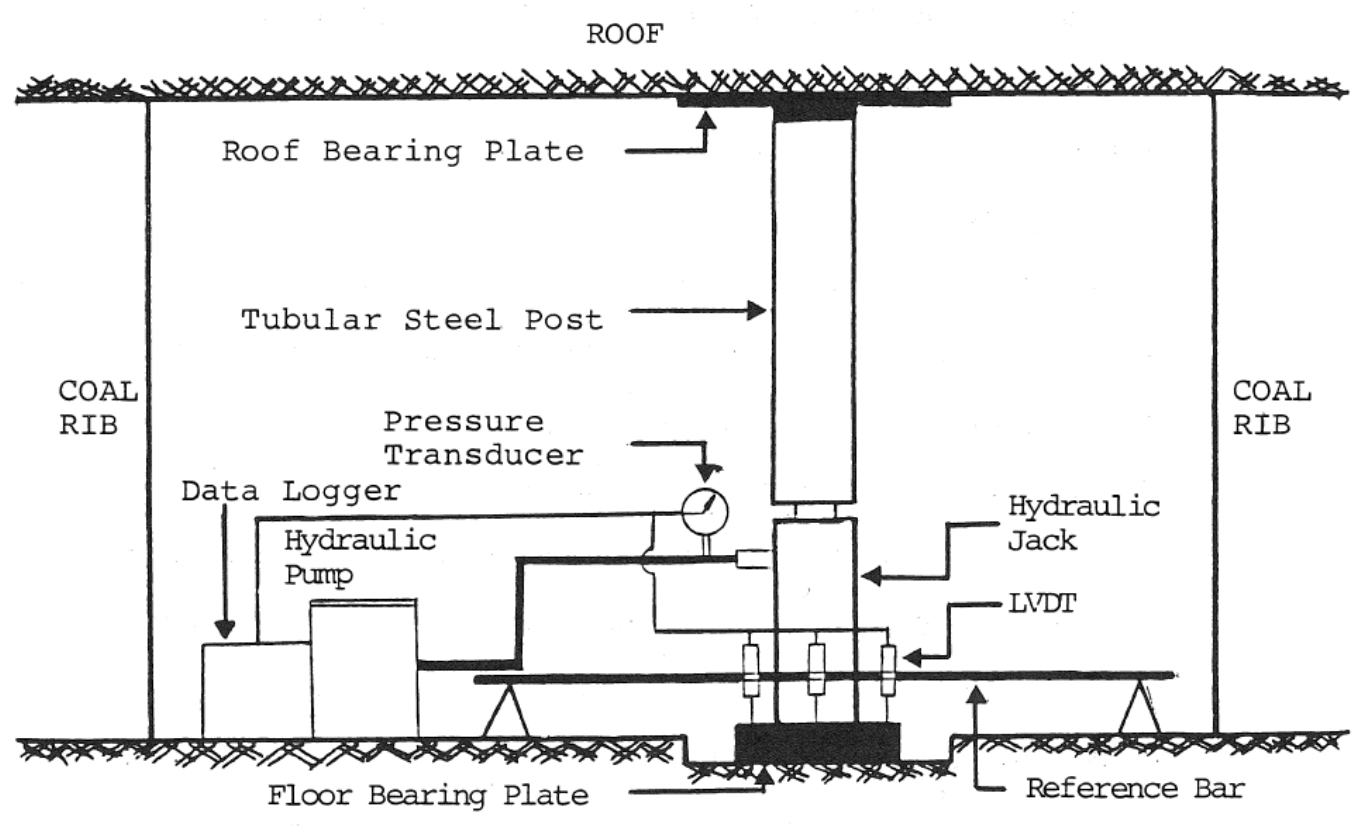

FLOOR

Figure 3.10. Plate test setup used by the SIUC (Chugh, 1986b).

Five plate tests at each of the two mines were conducted by Chugh (1986b) in entries that were mined less than 30 days. At each site, tests were conducted under as-mined and soaked-wet conditions. To wet the floor, the test sites were allowed to soak in water for 24 hours. It was ensured that the test sites had strong roof and without any significant geologic anomalies. In addition to cleaning any loose material, the floor was normally chipped to sufficient depth to expose the actual floor. Normally, about 3-5 inches of chipping opened up the 
true floor (Chugh, 1986b). A thin layer of quick setting plaster was used in all the tests. A uniform loading rate varying from $200-500$ psi/min was applied to the plate until the floor failed. The floor was assumed to have failed when the plate could not sustain any further load or the rate of deformation increased significantly with a sustained load.

The most recent published plate tests from the Illinois Basin were conducted by Su et al., (1993) using the setup shown in Figure 3.11. In this setup, three 50-ton hydraulic rams were used for the load application. A 10,000 psi electrohydraulic or manual hydraulic pump was used along with a 10,000 psi rated pressure transducer for the data collection. Square plates of 2-16 inch edge lengths were used in different tests. The tests were terminated when the peak load was reached, or a 2 inches total penetration of the plate occurred or when the peak capacity of the hydraulic rams was reached.
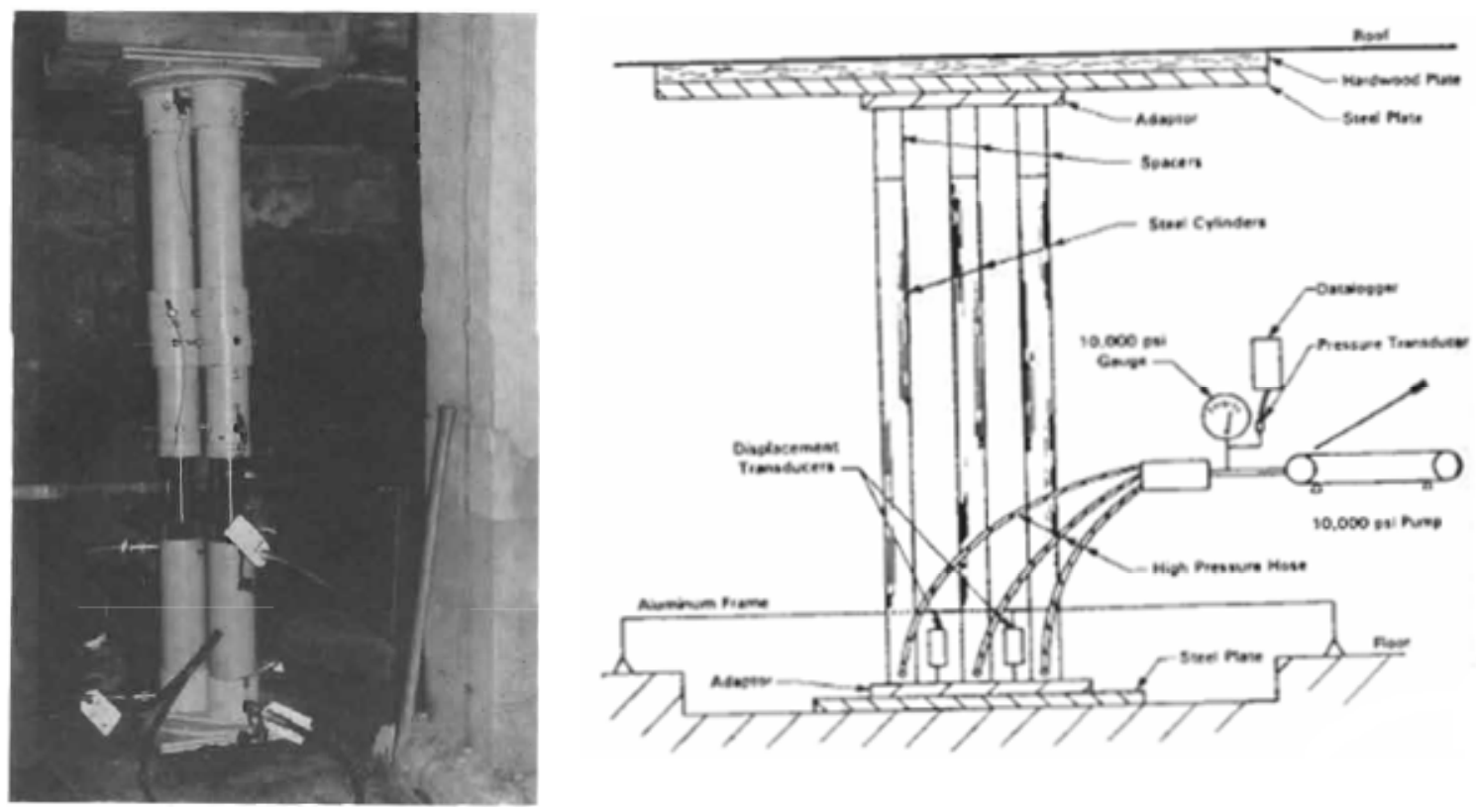

Figure 3.11. Plate test setup used in the Su et al., (1993) tests.

\subsubsection{Test Setup for this Research}

From the above summary of different plate test setups used by different researchers, it is clear that except for some minor details, all of them were very 
similar. One major difference between the different approaches is that some used a layer of plaster or concrete between the plate and the floor and some did not. There was also some differences in the rate of loading applied in the tests. A few used fresh water to soak the test site for 24 hours to simulate the effect of water pooling, while others conducted all their tests under as-mined conditions. In identifying the floor failure, all the researchers used similar criteria except when the tests were terminated for a predefined total plate settlement.

In order to generate additional plate test data from different mines in the three states of the Basin, the plate test setup shown in Figure 3.12 and Figure 3.13 was put together for the current research. The setup is very similar to the ones used by the previous researchers discussed above. A 100 ton hydraulic jack and a 10,000 psi pressure transducer with a manual hydraulic pump constitute the components needed for load application and monitoring. Similarly, three potentiometer displacement gauges were used for plate settlement monitoring. The displacement gauges were mounted on a specially fabricated reference stand whose legs were placed outside the zone of influence of the test. A 9-inch square plate was used in all the tests along with a specially designed "perimeter plate" described in Chapter 6. In order to make the plates rigid, the plates were cut from a 2 inch thick steel sheet. Data loggers were used for continuous data recording during a test. In some of the initial tests before automating the data collection, dial gauges were used for the displacement and pressure monitoring. When the tests were conducted in return ventilation air, the electronic data logging could not be used.

Similar to the previous researchers, each test site was cleaned off of any loose material and no site was chosen with any abnormal geo-mining conditions. At each site, the floor material was chipped off to a depth of about 4-6 inches to expose the true floor material. This was necessary as some of the gob material became compacted by the equipment movement to give the impression of regular floor. No layer of plaster of paris or concrete was used in any of the tests conducted for this research except for the first three. The use of plaster layer was discontinued as the author believed that its existence could have some unknown 
effect on the test results. This is because of the flexible nature of the plaster as opposed to the desired rigid behavior. Depending on the stiffness of the loading surface, the stress distribution on the floor changes as illustrated in Figure 3.14. For a rigid plate, the vertical stress on the floor will be non-uniform similar to a real coal pillar. With increasing flexibility of the loading surface, the stresses tend to attain near uniform distribution (Das, 1999). Additionally, as the plaster conforms to the undulations in the floor, the overall roughness of the contact between the plaster and floor increases which will most likely have a positive effect on the floor strength due to the improved confinement. It is also not known if the 20-30 minutes cure time recommended for the plaster will provide enough strength to the material.
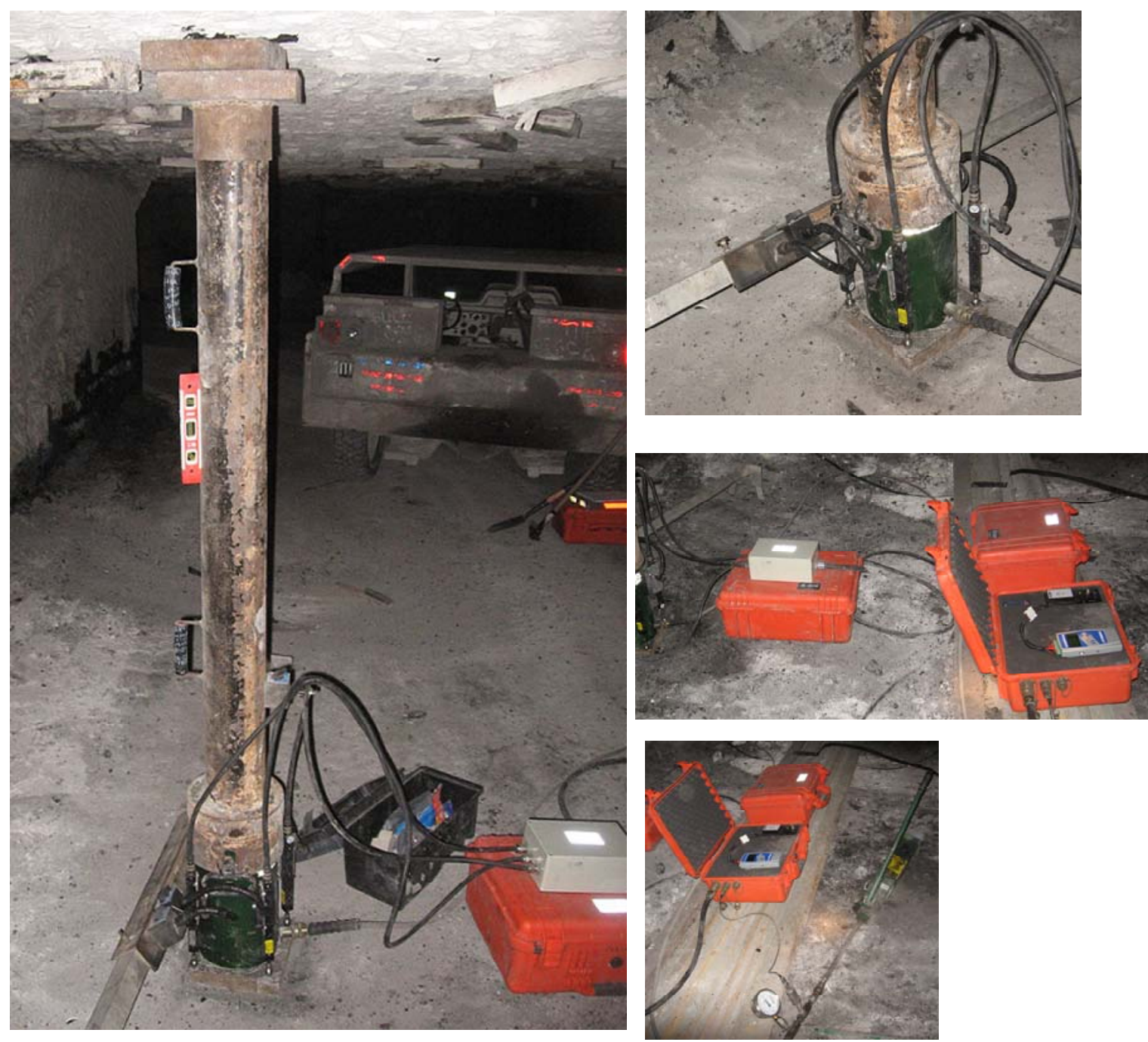

Figure 3.12. Field view of the plate test set up used in the present research. 


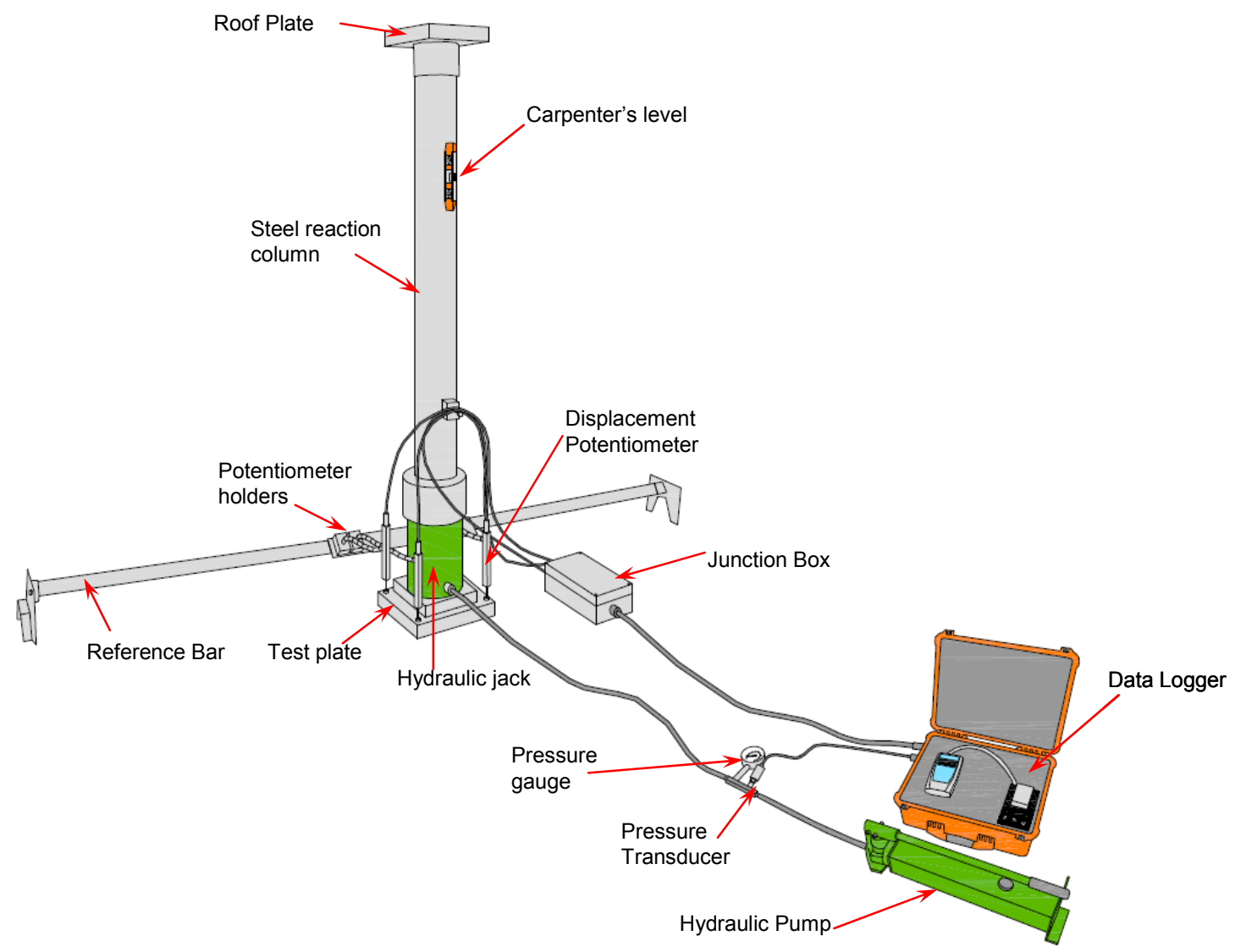

Figure 3.13. Schematic of the plate test set up used in the current research.

a)

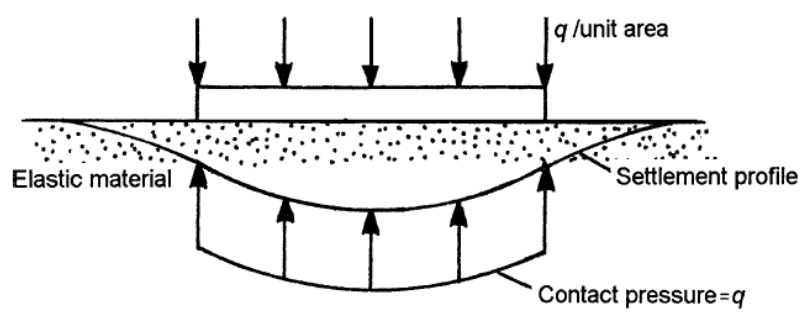

b)

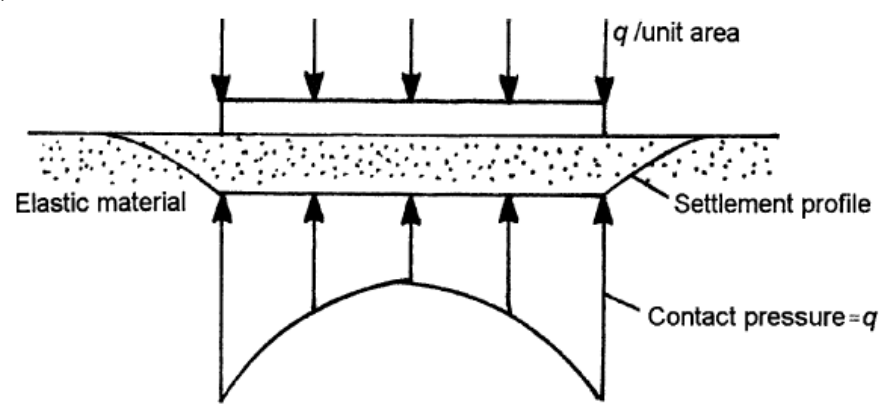

Figure 3.14. Contact stress distribution for (a) flexible and (b) rigid footing (Das, 1999). 
Not using the plaster layer, on the other hand, could have some negative impact on the accuracy with which plate settlements could be measured. When the plate is directly placed over the floor, in the initial phase of a test, higher plate settlement could occur as small ridges in the floor get crushed under increasing loads. Further, the small layer of crushed floor material may make the contact between the plate and the floor smoother thus reducing the confinement in the floor. However, since such reduction in confinement will only lead to a conservative estimate of the floor strength, it is better than positively affecting the strength with the use of the plaster. To not obtain ultra conservative floor strength values without the plaster layer, however, it is extremely important to keep the plate level in the test. Therefore, proper test surface preparation is crucial in this case.

In contrast to some of the previous plate tests described above, in this research a uniform rate of loading was not applied. Up to about $80 \%$ of the anticipated peak load, the loads were applied in 250 psi gauge pressure increments. For each increment, an arbitrary time gap was given before further load application to watch if any plate deformation occurred under the constant load. When the plate settlement became steady, the next increment of load was applied. If the load on the plate had shown any drop, even due to some localized failure, no further load was applied until the plate deformation settled down as suggested by the ASTM standard discussed above. In each event when the plate pressure had dropped, the maximum pressure before the drop was recorded for the tests where data was collected manually. As a result of this "let-the-floordecide-the-loading-rate" approach, some interesting observations were made as described in the following section. Where possible, the tests were conducted well into the post-failure state to obtain the complete load-settlement curves. The tests were terminated when the floor could not sustain any further increase in the load, or the peak capacity of the hydraulic ram was reached. If the floor exhibited perfectly-plastic or strain hardening behavior, the test was stopped after a significant amount of plate settlement had occurred in the post-failure state. None of the tests were terminated at a certain predefined plate settlement. 
All of the tests for this research were conducted under as-mined floor condition. In a one test, however, the floor was much wetter than was normal at the mine. It was deliberately decided to conduct this particular test in an area where some water was seeping out of the roof near a sandstone channel. It was felt that such "naturally soaked" floor condition created over a long period of time was more representative of the negative effect of excess water than the $24 \mathrm{hr}$ soaking used in the previous studies described above. When only a small amount of water is poured in the depression created for the test, owing to the very low permeability of the underclay material, softening of the floor may not occur beyond a limited depth. In contrast, if the floor becomes wet by naturally flowing water over a reasonably long period of time (a few days to weeks), then the depth to which the softening effects may reach will be sufficient to study the negative influence of soaking.

\subsection{Test Results}

The results obtained from plate tests conducted in this research, data available in the published literature and information obtained through personal communications are analyzed in this section. For this analysis, only plate tests conducted in the Illinois Basin coal mines were considered.

\subsubsection{Failure Patterns}

Detailed description of the failure patterns noticed during plate tests were not provided by any of the previous investigators who conducted tests in the Illinois Basin mines. Depending on the natural moisture content of the floor, the in-situ tests conducted in this research showed that the floor materials can fail in all three modes illustrated in Figure 3.1. For the case of general shear failure, the sequence in which the floor failed during the plate tests is depicted in Figure 3.15. Until the load on the plate reached its peak, no visually observable floor movements occurred around the periphery of the plate. Right around the time when the peak capacity was reached or in some cases at about $80 \%$ of the peak 
capacity, cracks started appearing around the edges of the plate with some noticeable floor heave as shown in Figure 3.15 (a). With further deformation of the plate, the cracks extended outwards in all directions as seen from Figure 3.15 (b) and (c). Since it takes less energy to propagate a crack than to initiate it, the load-deformation curves showed a sharp drop in the post-peak stage as expected for general shear failure.

a)

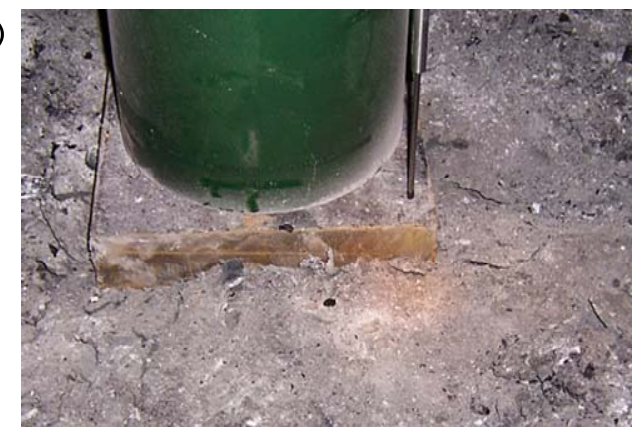

b)

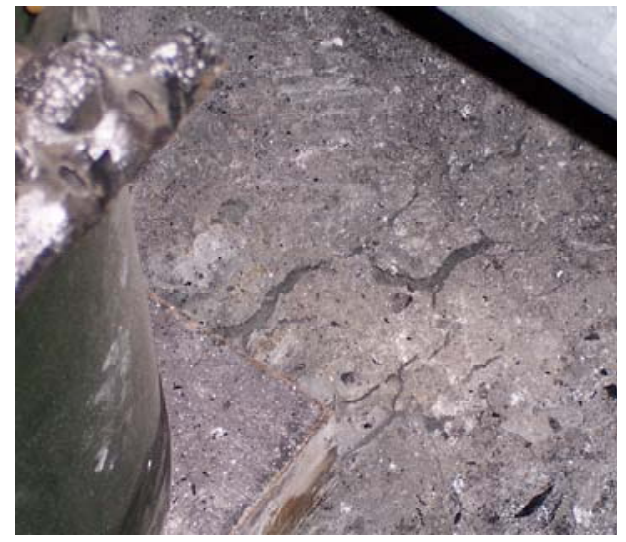

c)

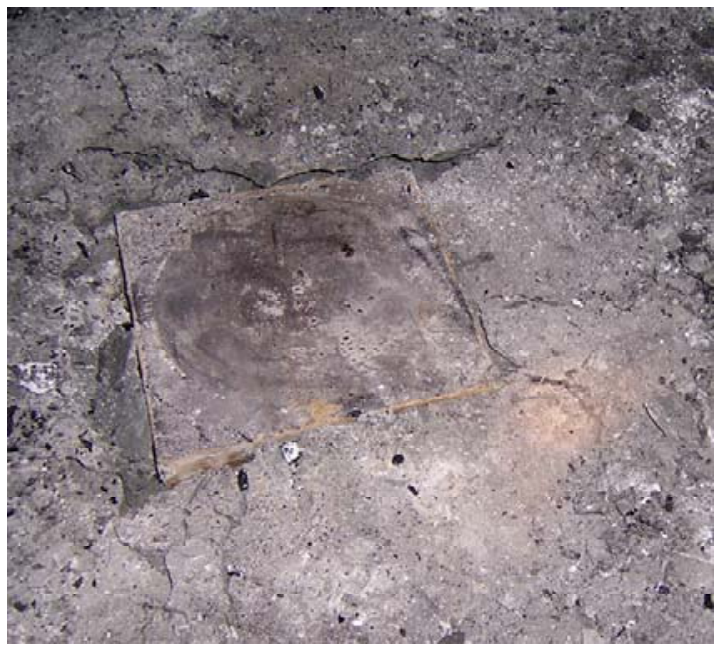

Figure 3.15. Failure patterns noticed during a test that exhibited general shear failure.

From the field tests it appears that for the punching failure to occur, a significant increase in the floor moisture is necessary. At one mine, a site was selected to test the floor where the moisture content was well in excess of its natural levels. From the feel of the floor material, it appeared that the moisture was above its plastic limit. This site was adjacent to an area where water had accumulated due to excess seepage from a nearby sandstone channel. The floor in this case failed in punching shear mode as shown in Figure 3.1(c). Even though the plate was well leveled at the start of the test, due to the very soft nature of the floor and perhaps due to the existence of some relatively hard 
spots, the plate tilted to one side when the test was continued well into the postfailure zone. The condition of the floor and the plate at the end of the test is shown in Figure 3.16. Except for some very small upward movement at the plate edges, the adjacent floor in this case did not show any visually noticeable deformation at any stage of the test.

a)

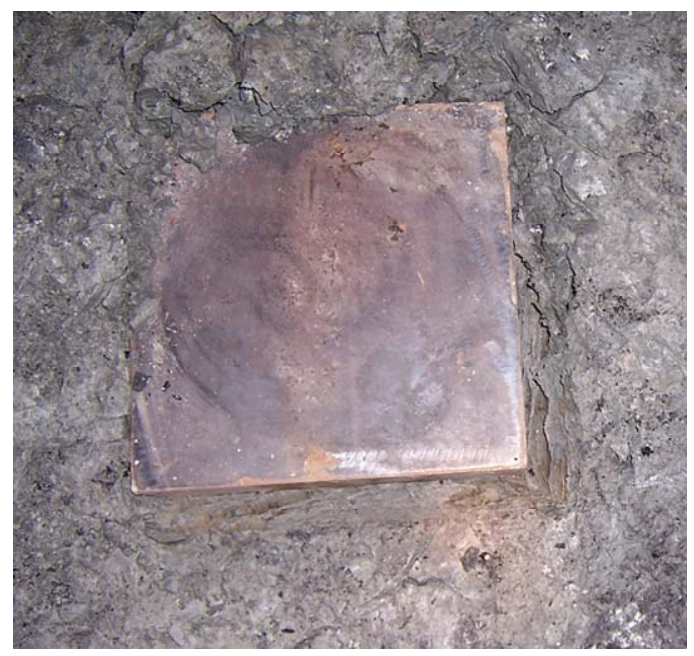

b)

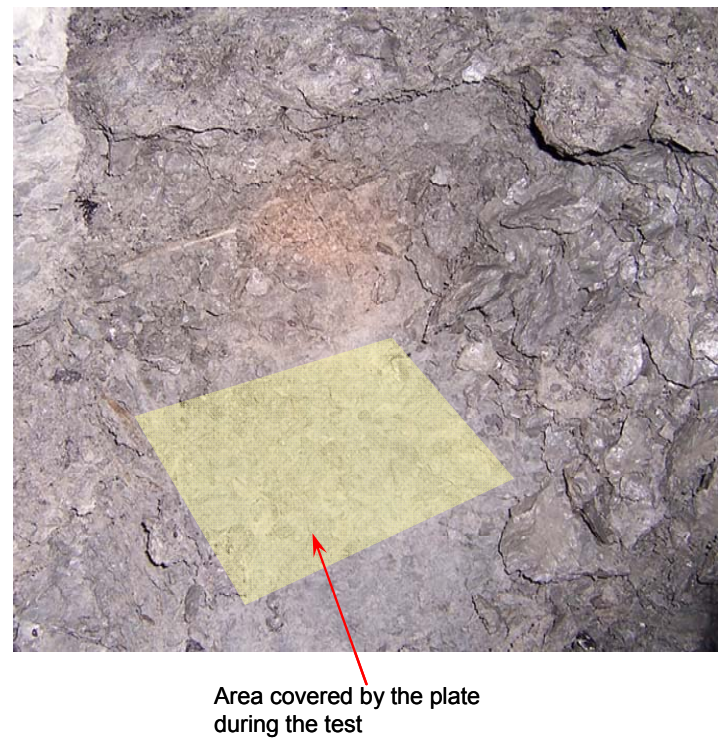

Figure 3.16. Punching floor failure under very wet floor conditions.

During the tests conducted at a Western shelf coal mine for this research, at the end of the test when the plate was retracted from the test site, it was noticed that a wedge of floor material was strongly adhered to the bottom of the plate as shown in Figure 3.17 (a). The shape of the adhered material looked similar to the Prandtl elastic wedge below a footing shown in Figure 4.2. When the floor wedge along with the plate was removed, the test site appeared like that shown in Figure 3.17 (b). In none of the plate tests conducted at the four Eastern shelf mines such behavior was noticed. This contrasting display of the floor behavior might be explained by the differences in the nature of the floor revealed by the laboratory properties discussed in Chapter 2 . Since there appears to be some differences in the plasticity of the floor in the Basin, there are higher chances of finding such strong adherence shown in Figure 3.17 in the Western shelf mines than in the Eastern shelf ones. 
a)

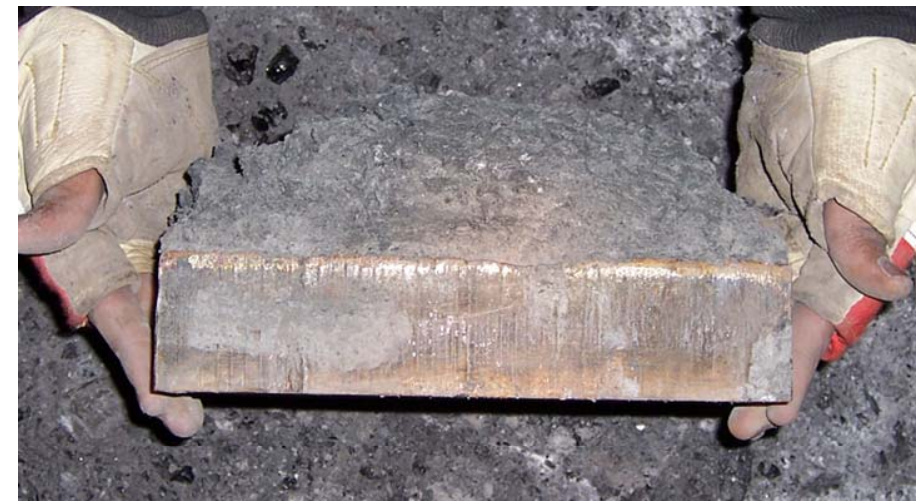

b)

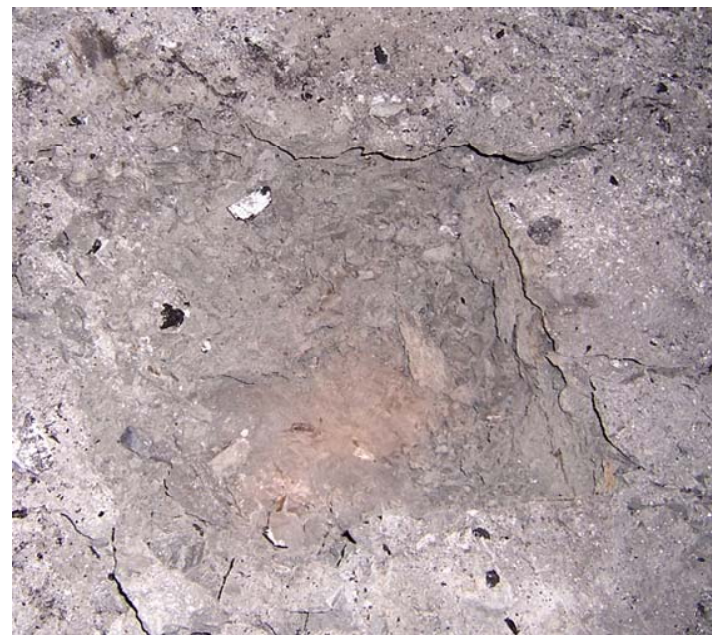

Figure 3.17. Wedge of floor stuck to the plate at the end of an in-situ test.

\subsubsection{Pressure-Deformation Curves}

The only published in-situ load-deformation curves from the Illinois Basin that the author could find were those obtained by Chugh (1986b) from his plate tests conducted at two mines. An example of the curves obtained by Chugh (1986b) with an 8 inche square plate is shown in Figure 3.18. These curves clearly show that the floor behavior could be described as perfectly-plastic, strain-softening or strain-hardening and corresponds to all three modes of failures and load-settlement curves in Figure 3.1. The pressure-deformation curves obtained in the current research looked similar to those in Figure 3.18. However, the similarity was noticed only for the tests where continuous data recording via a data logger was not done. As mentioned before, for some of the 


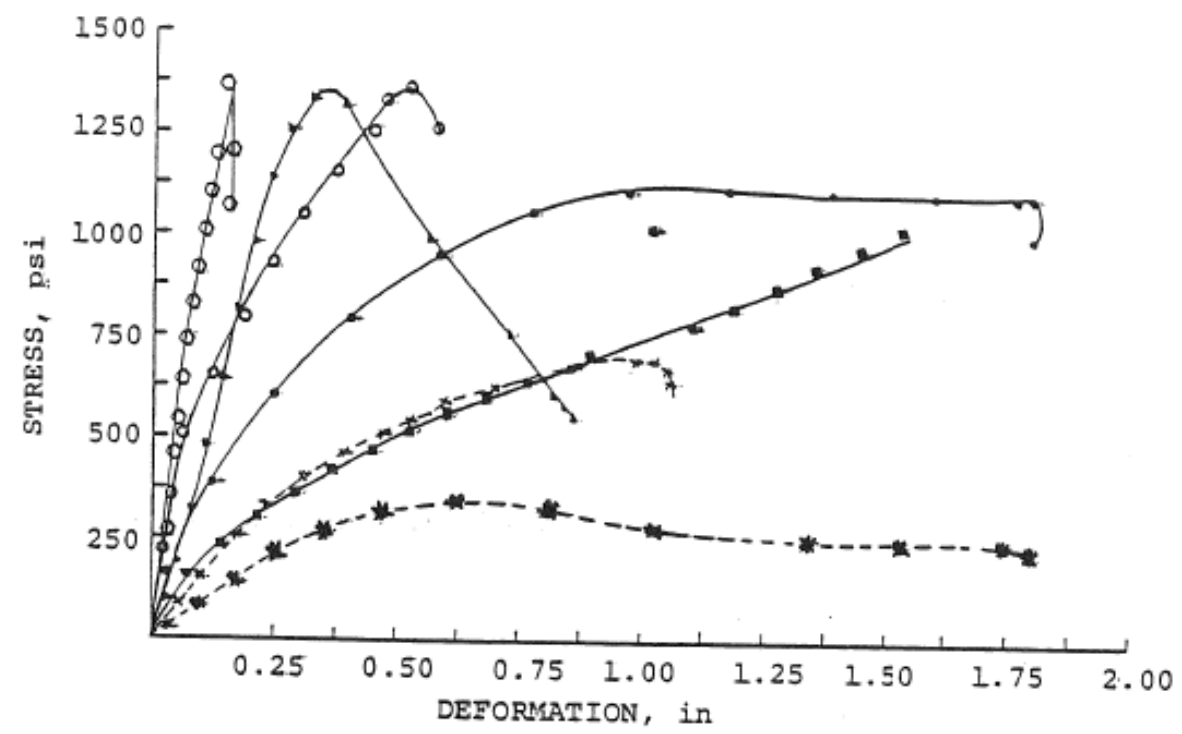

Figure 3.18. Stress-deformation curves obtained at an Illinois coal mine (Chugh, 1986b).

initial tests, complete automation of the data recording was not accomplished and the plate settlement and the pressure applied to the hydraulic jack were manually read off of dial gauges. While waiting for the plate settlements to become steady before the dial gauges were read during each load increment, the transient change in the plate load and deformation could not be obtained. When the data obtained at these discrete time intervals was plotted, the load-settlement curves looked similar to those in Figure 3.18. Some example plots obtained in this research at different test sites are shown in Figure 3.19.

Once the data collection was automated, it was possible to monitor the plate settlement and load continuously between any two successive pressure increments. While no change in the behavior was noticed in the elastic portion of the pressure-settlement curves, some significant differences were obtained in the post-failure state as illustrated in Figure 3.20. Also shown in this figure is the plot which would have been obtained if the data were collected manually in the same test. The saw-tooth behavior seen in the pressure-settlement curves clearly shows that several small-scale failures occur in the floor before the final extensive cracking and failure are visually noticed. Each time there was a drop in the pressure, it appeared that some new cracks were either initiated or the existing ones were extended. Further, if no additional load was supplied to the 


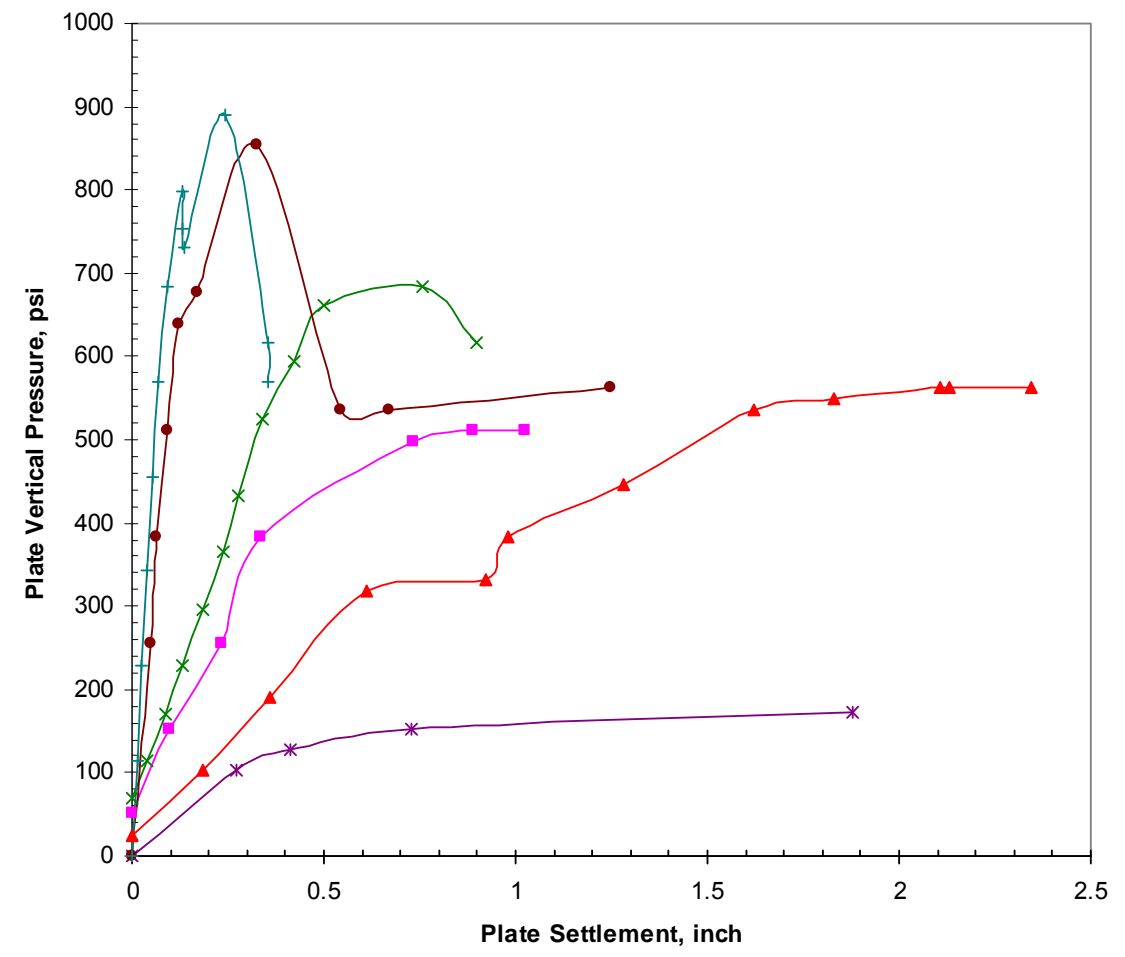

Figure 3.19. Example pressure-settlement curves obtained at different mines in this research with no data loggers.

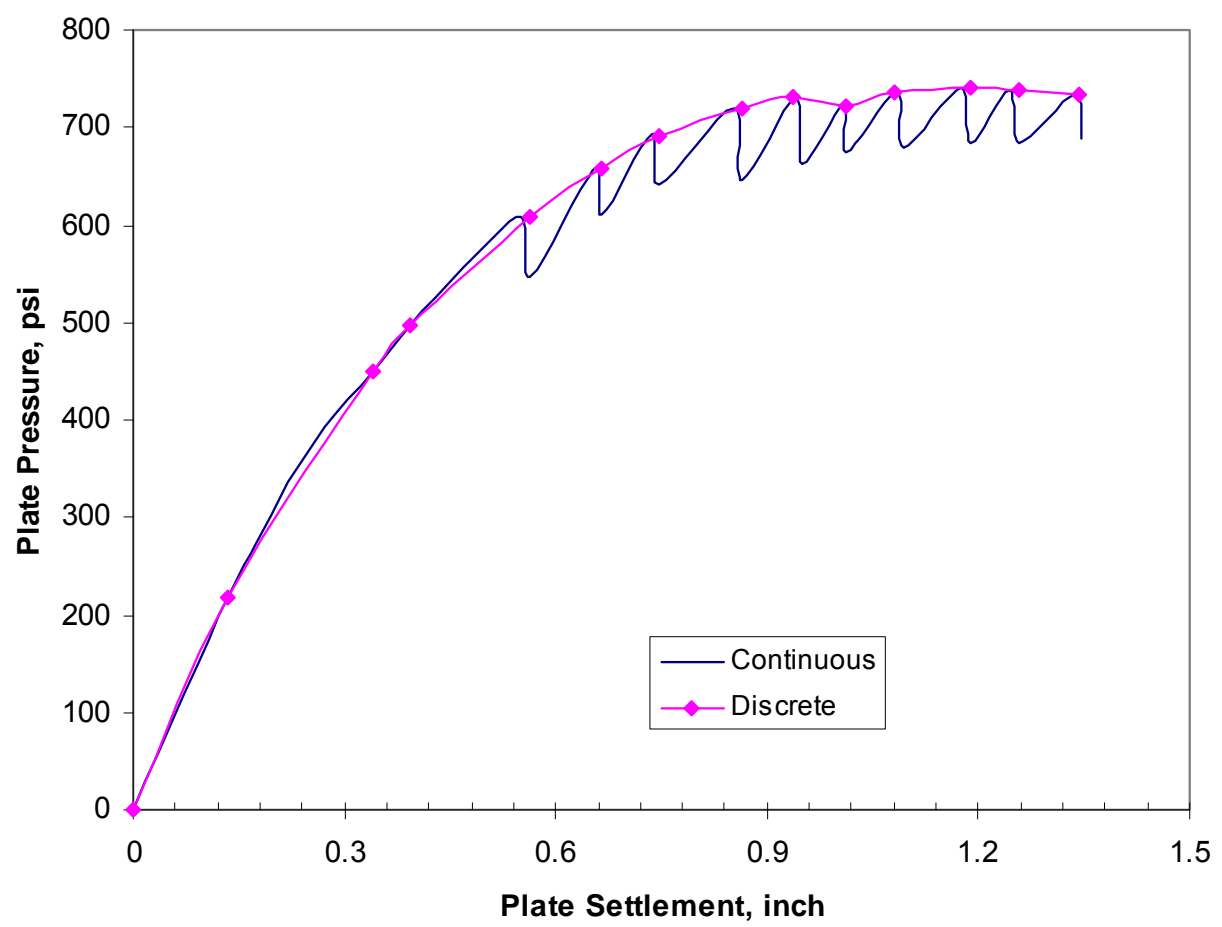

Figure 3.20. Example pressure-settlement curve obtained via a data logger. 
plate then the crack propagated in a stable manner until the strain energy stored was insufficient to sustain the propagation. This can be inferred by the fact that the pressure drop continued only for a certain time after which both the plate settlement and the pressure stabilized with negligible further change. If the crack propagation was unstable, then the pressure drop should have indefinitely continued after initiation of the failure. The practical implication of the pressuresettlement behavior in Figure 3.20 is that owing to the quasi-brittle to perfectlyplastic nature of the immediate floor in the Illinois Basin coal mines, unstable crack propagation may not normally occur and thus the resulting floor heave will most likely not occur very rapidly as is possible for a purely brittle floor. Practical experience in the Basin supports this conclusion. Within the knowledge of the author no dynamic or extremely rapid floor heaves were ever reported from the Illinois Basin coal mines. Some other examples of the saw-tooth type curves obtained in this work are shown in Figure 3.21.

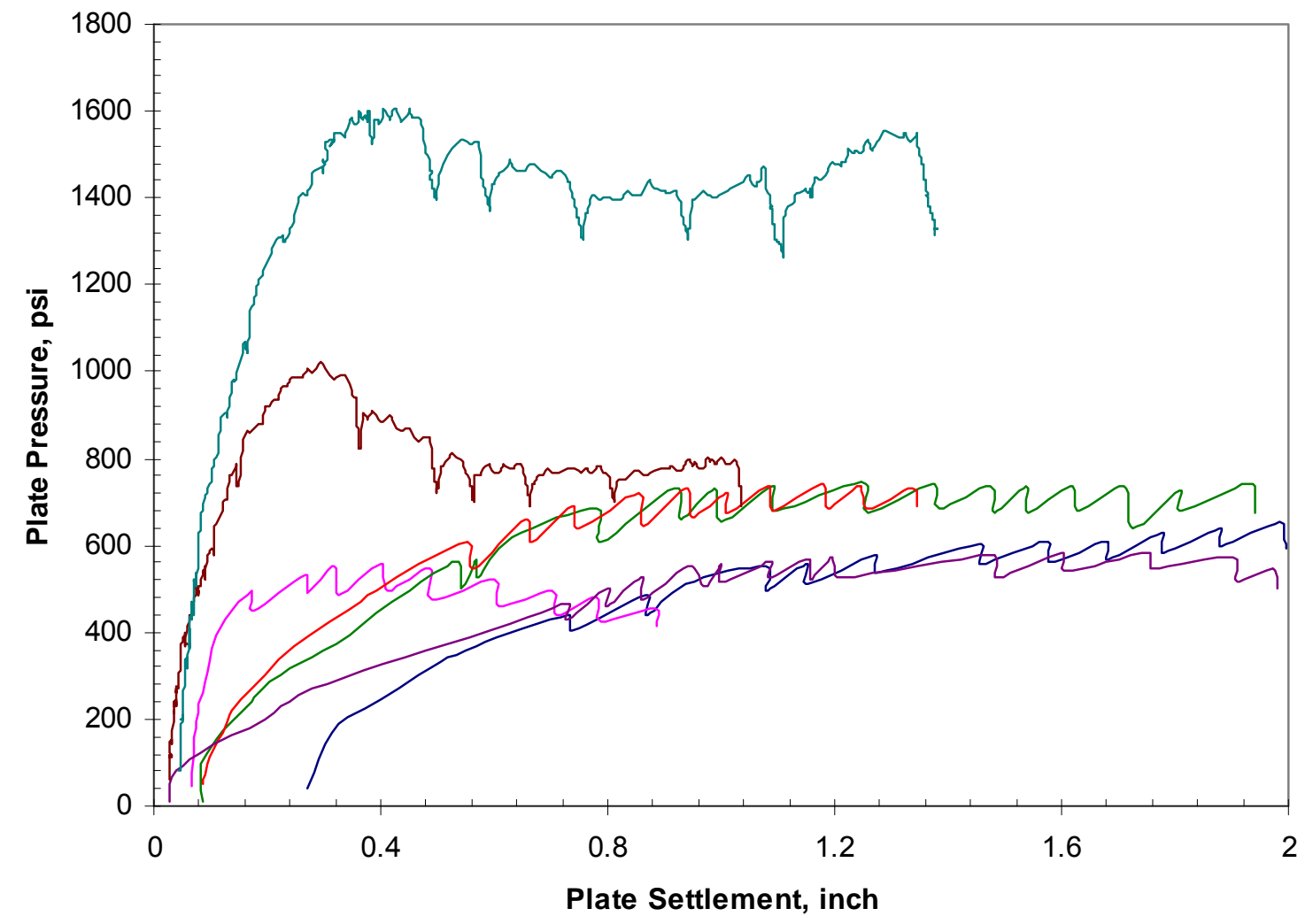

Figure 3.21. Pressure-settlement curves obtained by the "let-the-floor-decide-the-loading-rate" approach. 
If the plate tests were conducted with a uniform rate of loading or rate of penetration like some previous investigators attempted, then the pressuresettlement curves obtained were similar to the ones shown in Figure 3.18. The pressure-settlement curve obtained from one plate test with a uniform rate of loading and continuous data recording is shown in Figure 3.22. As expected, this curve did not display the saw-tooth behavior noticed with the "let-the-floordecide-the-loading-rate" approach.

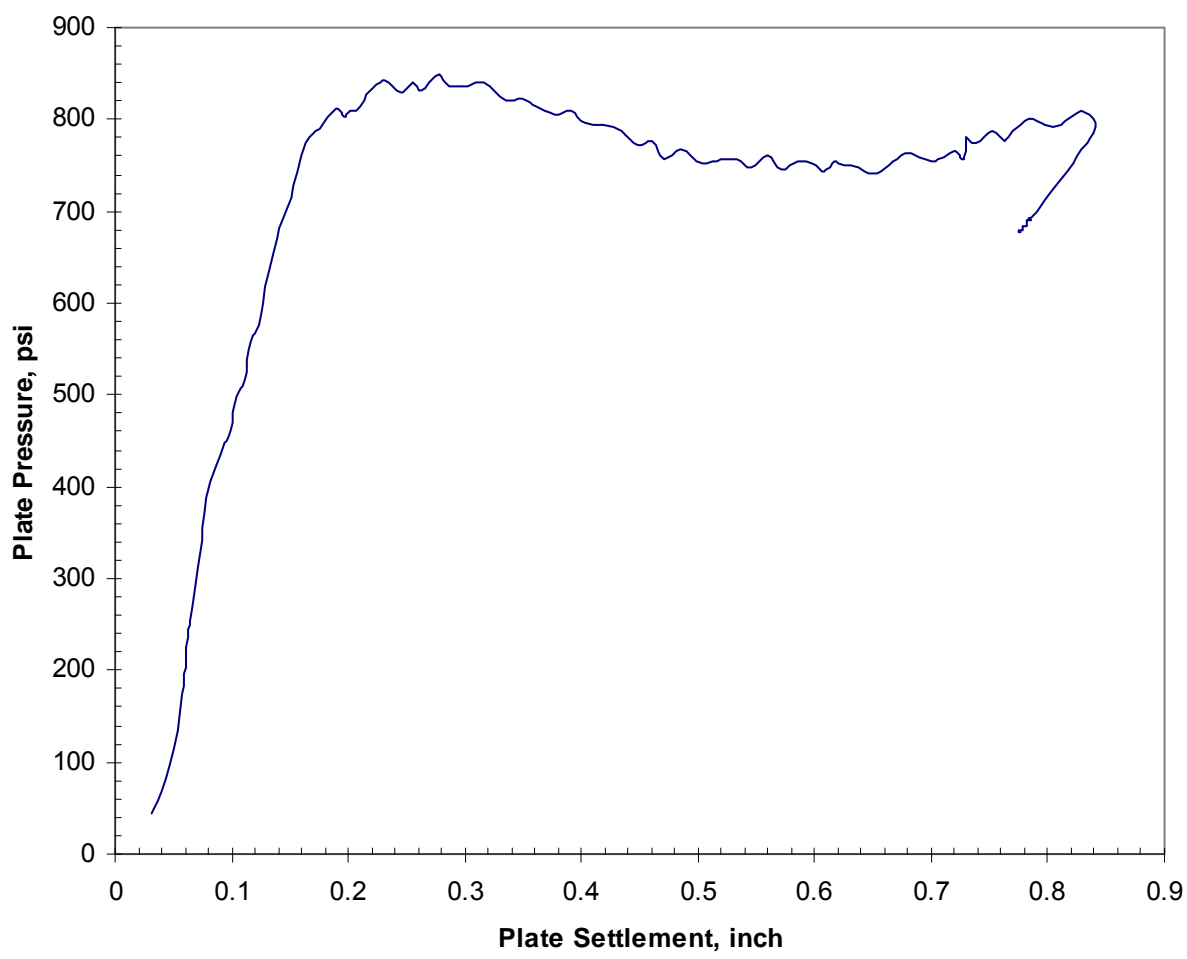

Figure 3.22. Plate pressure-settlement curve obtained with uniform rate of loading.

In an underground coal mine that employs partial extraction methods, the loading on a coal pillar occurs discontinuously. As the pillar is being developed, additional loads are applied in several increments depending on the length and number of cuts taken around the pillar. If the pillar size is sufficient, then the floor may only experience elastic displacement and the pillar settlement will stabilize within a short time after development. On the other hand, if the pillar is inadequately sized such that excess stresses are transferred to the floor with time, then the floor can fail. In such instances, however, experience from the 
Basin shows that the manifestation of surface subsidence or underground floor heave occur over a period of time rather than instantly. Such delayed pillar settlement can occur due to two different reasons: progressive failure and creep. Owing to the non-uniform strength properties and other geo-mining factors, the floor below the pillar with the lowest floor stability factor fails first in a panel. As a consequence of the reduced floor bearing capacity of the failed pillar, some of its load is shed to the adjacent pillar thus initiating a domino effect. Even in this case of progressive failure of floor in a panel, the additional vertical stresses on the pillars are imposed in steps rather than continuously as done in some of the previous plate tests.

From the experience gained by the plate tests in this research, past experience with floor failures in the Basin and the way vertical stress increases over a pillar, it is believed that the "let-the-floor-decide-the-loading-rate" approach is preferable than the uniform rate of loading used by the previous researchers. Moreover, the relatively slower loading rate suggested here will yield a conservative plate bearing capacity than will the faster loading rate used by the others. Where possible, it is suggested that the plate tests be continued well into the post-failure state so that the appropriate constitutive model for the floor can be chosen with confidence. It is only by getting the curve well into the post-peak range that one can decide whether the floor exhibits strain-softening, perfectlyplastic or strain-hardening behavior.

\subsubsection{Plate Bearing Strength}

The friable nature of the underclay and weak claystone makes it difficult to test them in the laboratory for their strength properties. As a result, the practice so far in the Basin has been to use the information gathered from the in-situ plate tests to estimate the floor strength values. Currently, equations developed by the University of Missouri, Rolla (UMR) and the Southern Illinois University, Carbondale (SIUC) are used by designers for calculating the plate bearing strength. Before proceeding to the plate test database assembled for this research, a brief discussion on the UMR and SIUC equations is in order. 


\subsubsection{The UMR Equation}

From laboratory triaxial strength tests on reasonably competent underclay samples, Speck (1979) developed the following equation to estimate the floor strength:

$$
q_{\text {triax }}=2070-167 M C
$$

where $q_{\text {triax }}$ is the triaxial strength in psi, $M C$ is the natural moisture content of the samples. The original data used to derive equation (3.1) is provided in Table 3.1. For these triaxial tests, Speck (1979) used a constant confining pressure equal to 300 psi. It is interesting to note that when the data in Table 3.1 has been linearly regressed, the best fit curve obtained by this author was

$$
q_{\text {triax }}=2184-177 M C
$$

which is different from Speck's version in Equation (3.1). From Speck's dissertation, however, it was not found if any data in Table 3.1 was not considered for his regression analysis to obtain Equation (3.1).

Even though Equation (3.1) is basically the best fit curve for laboratory triaxial strength estimated at a constant confining pressure, in practice it has been used to calculate the in-situ plate bearing strength. While the floor unit has been termed underclay, the strata tested by Speck are somewhat stronger than the underclay typically encountered in the Basin. This can be seen by the core recovery obtained, which was good enough to test the material in the laboratory. Further, when the triaxial strength data obtained by Speck (1979) for the "claystone" samples together with the "underclay" data were analyzed, there was no noticeable difference in the strength between the two different lithologies as shown in Figure 3.23. In fact, when the claystone and underclay data were individually regressed against the moisture content, the best-fit equations differed only by less than $10 \%$ as given below:

$$
\begin{aligned}
& q_{\text {triax-underclay }}=10014 e^{-0.38 \mathrm{MC}} \\
& q_{\text {triax-claystone }}=9209 e^{-0.38 \mathrm{MC}}
\end{aligned}
$$


Table 3.1. Laboratory triaxial strength data of underclay used in deriving Speck's equation.

\begin{tabular}{|c|c|}
\hline Triaxial Strength, psi & Moisture Content, \% \\
\hline 219 & 9.03 \\
\hline 82 & 12.31 \\
\hline 81 & 12.1 \\
\hline 70 & 11.2 \\
\hline 81 & 10.4 \\
\hline 54 & 14.5 \\
\hline 31 & 11.3 \\
\hline 205 & 9.7 \\
\hline 634 & 8.8 \\
\hline 454 & 9.1 \\
\hline 64 & 12.5 \\
\hline 1594 & 3.44 \\
\hline 473 & 10.6 \\
\hline 1204 & 6.6 \\
\hline 642 & 9.9 \\
\hline 485 & 10.2 \\
\hline 1834 & 6.2 \\
\hline 574 & 7.3 \\
\hline 656 & 8.5 \\
\hline 1457 & 4.3 \\
\hline 1435 & 4.1 \\
\hline 1217 & 5.73 \\
\hline 149 & 9.2 \\
\hline
\end{tabular}

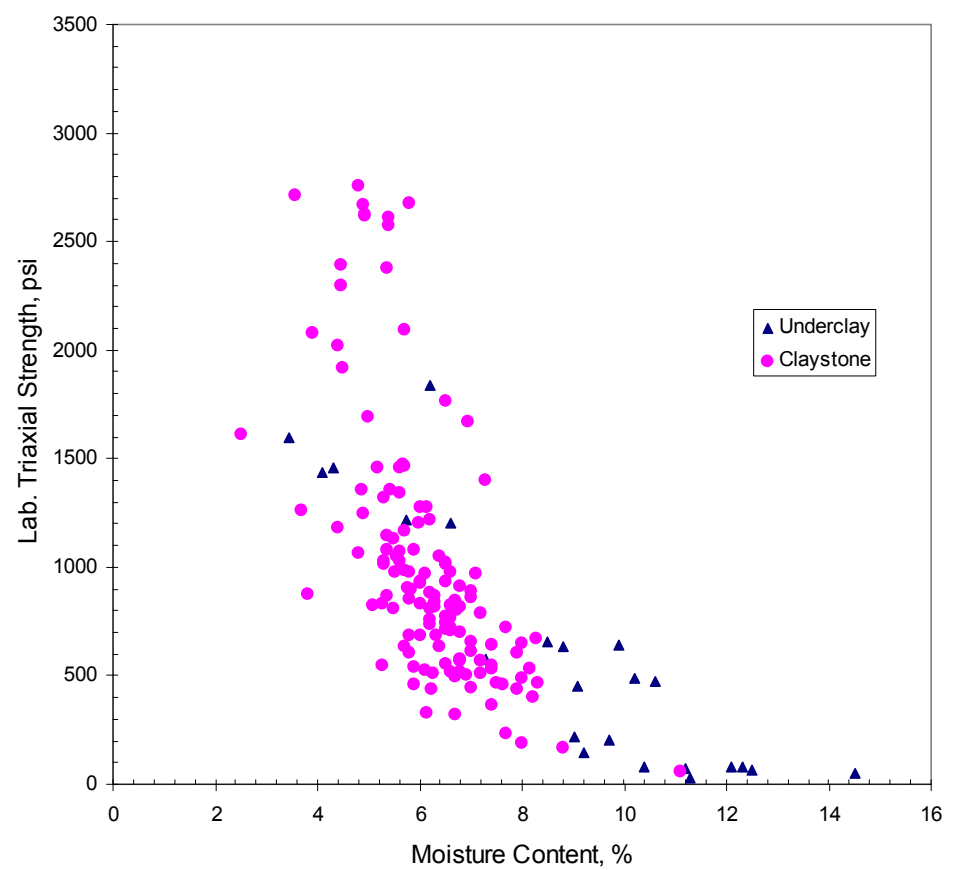

Figure 3.23. Laboratory triaxial strength data obtained by Speck (1979). 
In summary, it appears that the floor tested by Speck (1979) in the laboratory did not appear to be significantly different from the stronger claystone typically found in other Illinois Basin mines. It further seems that there is negligible strength difference between the underclay and the claystone strata encountered at the Zeigler mines studied by Speck. Therefore, other than for geological description purposes, the two floor units should have been treated as the same for pillar design purposes.

\subsubsection{The SIUC Equations}

In-situ plate bearing tests were conducted in seven Illinois coal mines by Pula et al. (1990) to derive the following relations between the ultimate bearing capacity $(U B C)$ and the natural moisture content of the floor:

$$
\begin{array}{ll}
U B C=1274.1 e^{(-0.112 M C)} & \text { for claystone floor, } \\
U B C=2416.3 e^{(-0.209 M C)} & \text { for siltstone floor, and } \\
U B C=1603.5 e^{(-0.145 M C)} & \text { for all weak floor strata }
\end{array}
$$

In the above equations $M C$ is the moisture content of the floor and the $U B C$ is obtained in psi. It appears that equations (3.5) to (3.7) were obtained from a total of 96 field tests of which 68 were conducted on claystone floors and 29 were on siltstone (Pula et al., 1990). The SIUC database has not been published in its totality and details on only a few tests were given in Chugh (1986b). What is interesting is that in any of the published papers or reports, the SIUC plate test data was not even plotted graphically. As a result, this valuable database is not available in detail for further analysis here.

Another lesser known version of the plate bearing strength equation developed by SIUC is occasionally used in the Basin. This equation links the plate strength with moisture content and liquid limit of the floor as given below (Chugh et al., 1990):

$$
U B C=1406.5-86 M C-1.92 L L
$$

where $M C$ is the natural moisture content and $L L$ is the liquid limit. Very little details on the derivation of Equation (3.8) were ever published by SIUC. 
However, as the results in Chapter 2 showed, there is a reasonable direct linear relation between the moisture content and liquid limit value. Thus higher moisture content in the floor also means higher liquid limit value. This is the reason for the negative sign for both the $M C$ and $L L$ terms in Equation (3.8). As a consequence of this collinearity between $M C$ and $L L$, the regression in Equation (3.8) is perhaps statistically not meaningful.

\subsubsection{The Plate Bearing Test Database}

A comprehensive database of ultimate bearing capacity of the immediate floor determined from the in-situ plate tests is assembled for this research. In addition to the tests conducted as a part of this research, all the information available in published literature and data gathered through personal communications were used to develop the database. Tests conducted in the Illinois Basin coal mines were only considered for this purpose. It had been shown in Chapter 2 that there were some differences in the nature of the weak floor materials between the Eastern and Western shelf mines. Consequently, the plate test database has been split into two groups corresponding to these two geographical areas. All the information available for the plate tests is provided in Table 3.2 and Table 3.3 for the Eastern and the Western shelf mines, respectively.

The final database consists of tests from 9 mines in the Eastern shelf and from 8 mines in the Western shelf for a total of 17 coal mines. Similarly, there were 74 and 58 individual plate tests from the Eastern and the Western shelf mines, respectively, to give a total of 132 plate tests from all three states of the Basin. The underclay and weak claystone floors associated with the three major coal seams of the Basin were included in the database. Plates of different shapes and sizes were used in the tests conducted by different researchers over a span of three decades. All the plate test data are plotted against the natural moisture content of the floor in Figure 3.24. The ultimate plate bearing capacity in this figure shows a remarkably strong correlation with moisture content and the 
Table 3.2. Plate test data from the Eastern Shelf coal mines.

\begin{tabular}{|c|c|c|c|c|c|c|c|c|c|}
\hline Mine & Coal Seam & State & $\begin{array}{l}\text { Plate } \\
\text { type }\end{array}$ & $\begin{array}{l}\text { Plate size, } \\
\text { inch }\end{array}$ & $\begin{array}{c}\text { Moisture } \\
\text { content, } \\
\% \\
\end{array}$ & $\begin{array}{c}\text { Bearing } \\
\text { Capacity, } \\
\text { psi }\end{array}$ & $\begin{array}{c}\text { Liquid } \\
\text { Limit, } \\
\%\end{array}$ & $\begin{array}{c}\text { Plastic } \\
\text { Limit, } \\
\% \\
\end{array}$ & Source \\
\hline A & Herrin No.6 & $\mathrm{IL}$ & Circular & 12 & 11.5 & 127 & & & Speck (1979) \\
\hline B & Herrin No.6 & IL & $\begin{array}{l}\text { Circular } \\
\text { Circular }\end{array}$ & $\begin{array}{r}12 \\
18 \& 24\end{array}$ & $\begin{array}{l}9.2 \\
9.1\end{array}$ & $\begin{array}{l}265 \\
210\end{array}$ & & & Speck (1979) \\
\hline C & Danville No. 7 & IN & $\begin{array}{l}\text { Square } \\
\text { Perimeter } \\
\text { Square } \\
\text { Square } \\
\text { Square } \\
\text { Perimeter } \\
\text { Square } \\
\text { Square } \\
\text { Square } \\
\text { Square } \\
\text { Square } \\
\text { Square }\end{array}$ & $\begin{array}{r}9 \times 9 \\
12 \times 13 \\
9 \times 9 \\
9 \times 9 \\
9 \times 9 \\
12 \times 13 \\
9 \times 9 \\
9 \times 9 \\
9 \times 9 \\
9 \times 9 \\
9 \times 9 \\
9 \times 9 \\
\end{array}$ & $\begin{array}{l}8.19 \\
8.26 \\
6.94 \\
8.07 \\
5.79 \\
8.82 \\
4.92 \\
6.96 \\
7.31 \\
6.89 \\
8.46 \\
8.64 \\
\end{array}$ & $\begin{array}{r}562 \\
798 \\
511 \\
1085 \\
894 \\
684 \\
740 \\
511 \\
638 \\
766 \\
1034 \\
421 \\
\end{array}$ & $\begin{array}{l}37 \\
37 \\
36 \\
34 \\
35 \\
38 \\
35 \\
42 \\
37 \\
35 \\
36 \\
32 \\
\end{array}$ & $\begin{array}{l}20 \\
19 \\
19 \\
19 \\
19 \\
23 \\
21 \\
20 \\
20 \\
21 \\
18 \\
18 \\
\end{array}$ & This research \\
\hline $\mathrm{D}$ & No. 9 & $\mathrm{KY}$ & $\begin{array}{l}\text { Square } \\
\text { Perimeter } \\
\text { Square } \\
\text { Perimeter } \\
\text { Square } \\
\text { Perimeter }\end{array}$ & $\begin{array}{r}9 \times 9 \\
12 \times 13 \\
9 \times 9 \\
12 \times 13 \\
9 \times 9 \\
12 \times 13 \\
\end{array}$ & $\begin{array}{r}9.31 \\
10.42 \\
9.44 \\
10.72 \\
6.1 \\
7.84 \\
\end{array}$ & $\begin{array}{r}421 \\
935 \\
753 \\
958 \\
1481 \\
1186 \\
\end{array}$ & $\begin{array}{l}41 \\
43 \\
38 \\
40 \\
31 \\
28\end{array}$ & $\begin{array}{l}21 \\
22 \\
22 \\
23 \\
18 \\
17\end{array}$ & This research \\
\hline$E$ & $\begin{array}{l}\text { Herrin No.6 } \\
\text { Herrin No.6 }\end{array}$ & IL & $\begin{array}{l}\text { Square } \\
\text { Square } \\
\text { Square } \\
\text { Square } \\
\text { Perimeter } \\
\text { Square } \\
\text { Perimeter } \\
\text { Square } \\
\text { Perimeter }\end{array}$ & $\begin{array}{r}8 \times 8 \\
8 \times 8 \\
8 \times 8 \\
9 \times 9 \\
12 \times 13 \\
9 \times 9 \\
12 \times 13 \\
9 \times 9 \\
12 \times 13 \\
\end{array}$ & $\begin{array}{r}7.66 \\
9.5 \\
8.12 \\
11.82 \\
11.79 \\
7.75 \\
7.41 \\
9.46 \\
8.55 \\
\end{array}$ & $\begin{array}{r}781 \\
1031 \\
406 \\
445 \\
656 \\
556 \\
749 \\
580 \\
740 \\
\end{array}$ & & & $\begin{array}{l}\text { Old mine reports } \\
\text { This research }\end{array}$ \\
\hline $\mathrm{F}$ & 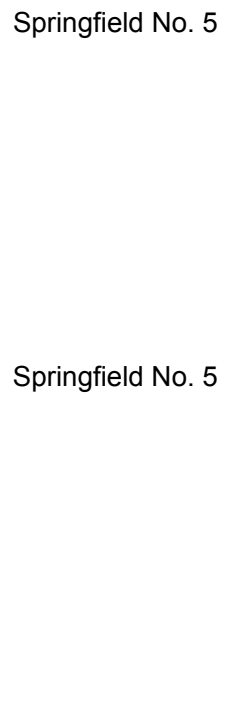 & 更 & $\begin{array}{l}\text { Square } \\
\text { Perimeter } \\
\text { Square } \\
\text { Perimeter } \\
\text { Square } \\
\text { Perimeter } \\
\text { Square } \\
\text { Perimeter } \\
\text { Square } \\
\text { Square } \\
\text { Square } \\
\text { Square } \\
\text { Square } \\
\text { Square } \\
\text { Square } \\
\text { Square }\end{array}$ & $\begin{array}{r}9 \times 9 \\
12 \times 13 \\
9 \times 9 \\
12 \times 13 \\
9 \times 9 \\
12 \times 13 \\
9 \times 9 \\
12 \times 13 \\
6 \times 6 \\
6 \times 6 \\
6 \times 6 \\
6 \times 6 \\
6 \times 6 \\
6 \times 6 \\
6 \times 6 \\
6 \times 6\end{array}$ & $\begin{array}{l}8.49 \\
8.71 \\
7.82 \\
7.65 \\
6.15 \\
5.19 \\
4.25 \\
2.09 \\
5.83 \\
7.45 \\
8.12 \\
8.38 \\
9.15 \\
7.98 \\
9.43 \\
8.05\end{array}$ & $\begin{array}{r}912 \\
1230 \\
886 \\
921 \\
1479 \\
1700 \\
1765 \\
2074 \\
2222 \\
694 \\
1806 \\
556 \\
1250 \\
556 \\
667 \\
806\end{array}$ & $\begin{array}{l}32 \\
34 \\
38 \\
36 \\
27 \\
26 \\
22\end{array}$ & $\begin{array}{l}20 \\
20 \\
22 \\
21 \\
18 \\
16 \\
17\end{array}$ & Old mine reports \\
\hline
\end{tabular}


Table 3.2 (continued). Plate test data from the Eastern Shelf coal mines.

\begin{tabular}{|c|c|c|c|c|c|c|c|c|c|}
\hline Mine & Coal Seam & State & $\begin{array}{l}\text { Plate } \\
\text { type }\end{array}$ & $\begin{array}{c}\text { Plate size, } \\
\text { inch }\end{array}$ & $\begin{array}{c}\text { Moisture } \\
\text { content, } \\
\%\end{array}$ & $\begin{array}{c}\text { Bearing } \\
\text { Capacity, } \\
\text { psi }\end{array}$ & $\begin{array}{l}\text { Liquid } \\
\text { Limit, } \\
\%\end{array}$ & $\begin{array}{c}\text { Plastic } \\
\text { Limit, } \\
\%\end{array}$ & Source \\
\hline \multirow[t]{3}{*}{ G } & \multirow[t]{3}{*}{ No. 5} & \multirow[t]{3}{*}{ IN } & Square & $6 \times 6$ & 5 & 730 & & & \multirow[t]{3}{*}{ Chugh (2008) } \\
\hline & & & Square & $6 \times 6$ & 5 & 710 & & & \\
\hline & & & Square & $6 \times 6$ & 5 & 1075 & & & \\
\hline \multirow[t]{21}{*}{$\mathrm{H}$} & \multirow[t]{21}{*}{ No. 9} & \multirow[t]{21}{*}{$\mathrm{KY}$} & Square & $12 \times 12$ & 9.12 & 783 & 32 & 20 & \multirow[t]{21}{*}{ Chugh (2008) } \\
\hline & & & Square & $8 \times 8$ & 9.51 & 915 & 32 & 21 & \\
\hline & & & Square & $8 \times 8$ & 10.97 & 1084 & 32 & 22 & \\
\hline & & & Square & $12 \times 12$ & 8.14 & 1157 & 29 & 20 & \\
\hline & & & Square & $8 \times 8$ & 9.06 & 869 & 30 & 22 & \\
\hline & & & Square & $8 \times 8$ & 9.1 & 1413 & 29 & 21 & \\
\hline & & & Square & $8 \times 8$ & 8.57 & 1058 & 30 & 20 & \\
\hline & & & Square & $8 \times 8$ & 7.95 & 935 & 29 & 20 & \\
\hline & & & Square & $8 \times 8$ & 7.77 & 1038 & 29 & 21 & \\
\hline & & & Square & $8 \times 8$ & 5.74 & 1128 & 28 & 18 & \\
\hline & & & Square & $8 \times 8$ & 5.82 & 907 & 27 & 17 & \\
\hline & & & Circular & 6 & 8.56 & 1768 & & & \\
\hline & & & Circular & 6 & 9.06 & 637 & & & \\
\hline & & & Circular & 6 & 8.67 & 920 & & & \\
\hline & & & Circular & 6 & 9.67 & 637 & & & \\
\hline & & & Circular & 6 & 9.7 & 1450 & & & \\
\hline & & & Circular & 6 & 7.99 & 1273 & & & \\
\hline & & & Circular & 6 & 7.77 & 1167 & & & \\
\hline & & & Circular & 6 & 9.77 & 1025 & & & \\
\hline & & & Circular & 6 & 7.47 & 1131 & & & \\
\hline & & & Circular & 6 & 7.26 & 1238 & & & \\
\hline \multirow[t]{4}{*}{ I } & \multirow[t]{4}{*}{ No. 5} & \multirow[t]{4}{*}{ IN } & Square & $8 \times 8$ & 8.9 & 600 & \multirow[t]{4}{*}{24.2} & \multirow[t]{4}{*}{17.6} & \multirow[t]{4}{*}{ Chugh (2008) } \\
\hline & & & Square & $8 \times 8$ & 9.3 & 600 & & & \\
\hline & & & Square & $8 \times 8$ & 6.4 & 1200 & & & \\
\hline & & & Square & $8 \times 8$ & 7.4 & 680 & & & \\
\hline
\end{tabular}

Table 3.3. Plate test data from the Western Shelf coal mines.

\begin{tabular}{|c|c|c|c|c|c|c|c|c|c|}
\hline Mine & Coal Seam & State & $\begin{array}{l}\text { Plate } \\
\text { type }\end{array}$ & $\begin{array}{c}\text { Plate size, } \\
\text { inch }\end{array}$ & $\begin{array}{c}\text { Moisture } \\
\text { content, } \\
\%\end{array}$ & $\begin{array}{c}\text { Bearing } \\
\text { Capacity, } \\
\text { psi }\end{array}$ & $\begin{array}{l}\text { Liquid } \\
\text { Limit, } \\
\%\end{array}$ & $\begin{array}{c}\text { Plastic } \\
\text { Limit, } \\
\%\end{array}$ & Source \\
\hline \multirow[t]{5}{*}{1} & \multirow[t]{5}{*}{ Herrin No.6 } & \multirow[t]{5}{*}{ IL } & Square & $8 \times 8$ & 9.85 & 938 & & & $\begin{array}{l}\text { Old mine } \\
\text { report }\end{array}$ \\
\hline & & & Square & $8 \times 8$ & 8.98 & 719 & & & \\
\hline & & & Square & $8 \times 8$ & 7.14 & 563 & & & \\
\hline & & & Square & $8 \times 8$ & 9.78 & 719 & & & \\
\hline & & & Square & $8 \times 8$ & 7.81 & 1031 & & & \\
\hline \multirow[t]{7}{*}{2} & \multirow[t]{7}{*}{ Herrin No.6 } & \multirow[t]{7}{*}{ IL } & Square & $8 \times 8$ & 12.2 & 290 & 36 & 23 & $\begin{array}{l}\text { Old mine } \\
\text { report }\end{array}$ \\
\hline & & & Square & $8 \times 8$ & 9.8 & 1075 & 37 & 21 & \\
\hline & & & Square & $8 \times 8$ & 11.3 & 750 & 48 & 25 & \\
\hline & & & Square & $8 \times 8$ & 11.6 & 775 & 51 & 24 & \\
\hline & & & Square & $8 \times 8$ & 11 & 625 & 44 & 22 & \\
\hline & & & Square & $8 \times 8$ & 10.6 & 750 & 54 & 24 & \\
\hline & & & Square & $8 \times 8$ & 10.4 & 650 & 41 & 25 & \\
\hline
\end{tabular}


Table 3.3 (continued). Plate test data from the Western Shelf coal mines.

\begin{tabular}{|c|c|c|c|c|c|c|c|c|c|}
\hline Mine & Coal Seam & State & $\begin{array}{l}\text { Plate } \\
\text { type }\end{array}$ & $\begin{array}{r}\text { Plate } \\
\text { size, inch }\end{array}$ & $\begin{array}{l}\text { Moisture } \\
\text { content, } \\
\% \\
\end{array}$ & $\begin{array}{l}\text { Bearing } \\
\text { Capacity, } \\
\text { psi }\end{array}$ & $\begin{array}{l}\text { Liquid } \\
\text { Limit, } \\
\% \\
\end{array}$ & $\begin{array}{l}\text { Plastic } \\
\text { Limit, } \\
\% \\
\end{array}$ & Source \\
\hline \multirow[t]{14}{*}{3} & \multirow[t]{14}{*}{ Springfield No.5 } & \multirow[t]{14}{*}{ IL } & unknown & & 8.1 & 469 & 55 & 26 & \multirow[t]{14}{*}{ Hunt (2006) } \\
\hline & & & unknown & & 9.8 & 664 & 59 & 25 & \\
\hline & & & unknown & & 9.5 & 584 & 41 & 22 & \\
\hline & & & unknown & & 8.5 & 885 & 38 & 22 & \\
\hline & & & unknown & & 10.2 & 527 & & & \\
\hline & & & unknown & & 11 & 792 & 45 & 25 & \\
\hline & & & Circular & 6 & 10.6 & 829 & 49 & 24 & \\
\hline & & & Circular & 10 & 9.7 & 839 & 59 & 25 & \\
\hline & & & Circular & & 9.3 & 393 & 57 & 20 & \\
\hline & & & Circular & 12 & 9.6 & 587 & 56 & 22 & \\
\hline & & & Circular & 6 & 7.4 & 554 & 43 & 22 & \\
\hline & & & Circular & 12 & 14.5 & 391 & 53 & 25 & \\
\hline & & & Circular & 12 & 10.96 & 762 & & & \\
\hline & & & Circular & 6 & 9.32 & 469 & & & \\
\hline \multirow[t]{3}{*}{4} & \multirow[t]{3}{*}{ Springfield No.5 } & \multirow[t]{3}{*}{ IL } & Square & $8 \times 8$ & 4.48 & 1110 & & & \multirow[t]{3}{*}{ Chugh (1986b) } \\
\hline & & & Square & $8 \times 8$ & 3.02 & 1100 & & & \\
\hline & & & Square & $8 \times 8$ & 5.83 & 1138 & & & \\
\hline \multirow[t]{4}{*}{5} & \multirow[t]{4}{*}{ Herrin No. 6} & \multirow[t]{4}{*}{ IL } & Square & $8 \times 8$ & 4.19 & 1247 & & & \multirow[t]{4}{*}{ Chugh (1986b) } \\
\hline & & & Square & $8 \times 8$ & 3.14 & 1147 & & & \\
\hline & & & Square & $8 \times 8$ & 5.78 & 1340 & & & \\
\hline & & & Square & $8 \times 8$ & 5.34 & 1147 & & & \\
\hline \multirow[t]{12}{*}{6} & \multirow[t]{12}{*}{ Herrin No. 6} & \multirow[t]{12}{*}{ IL } & Square & $9 \times 9$ & 10.43 & 855 & 104 & 26 & \multirow[t]{12}{*}{ This research } \\
\hline & & & Square & $9 \times 9$ & 11.37 & 689 & 62 & 24 & \\
\hline & & & Square & $9 \times 9$ & 11.71 & 172 & 55 & 29 & \\
\hline & & & Square & $9 \times 9$ & 9.78 & 638 & 53 & 29 & \\
\hline & & & Perimeter & $12 \times 13$ & 10.75 & 890 & 53 & 23 & \\
\hline & & & Perimeter & $12 \times 13$ & 9 & 875 & & & \\
\hline & & & Perimeter & $12 \times 13$ & 11 & 535 & & & \\
\hline & & & Square & $9 \times 9$ & 10.88 & 854 & 125 & 34 & \\
\hline & & & Square & $9 \times 9$ & 7.87 & 1606 & 56 & 24 & \\
\hline & & & Square & $9 \times 9$ & 13.38 & 1024 & 67 & 27 & \\
\hline & & & Square & $9 \times 9$ & 11.66 & 714 & 91 & 30 & \\
\hline & & & Perimeter & $12 \times 13$ & 13.17 & 998 & 50 & 26 & \\
\hline \multirow[t]{10}{*}{7} & \multirow[t]{10}{*}{ Herrin No. 6} & \multirow[t]{10}{*}{ IL } & Square & $12 \times 12$ & 8.32 & 947 & & & \multirow[t]{10}{*}{$\begin{array}{l}\text { Su et al., } \\
\text { (1993) }\end{array}$} \\
\hline & & & Square & $12 \times 12$ & 7.63 & 751 & & & \\
\hline & & & Square & $12 \times 12$ & 7.73 & 628 & & & \\
\hline & & & Square & $12 \times 12$ & 10.69 & 550 & & & \\
\hline & & & Square & $12 \times 12$ & 4.94 & 1465 & & & \\
\hline & & & Square & $12 \times 12$ & 6.38 & 837 & & & \\
\hline & & & Square & $12 \times 12$ & 5.64 & 1065 & & & \\
\hline & & & Square & $12 \times 12$ & 19 & 322 & & & \\
\hline & & & Square & $12 \times 12$ & 5.57 & 631 & & & \\
\hline & & & Square & $12 \times 12$ & 3.85 & 1024 & & & \\
\hline \multirow[t]{3}{*}{8} & Herrin No. 6 & IL & Square & $8 \times 8$ & 5.47 & 710 & 21 & 14 & Chugh (2008) \\
\hline & & & Square & $12 \times 12$ & 5.47 & 750 & 28 & 15 & \\
\hline & & & Square & $8 \times 8$ & 4.41 & 1880 & 39 & 20 & \\
\hline
\end{tabular}




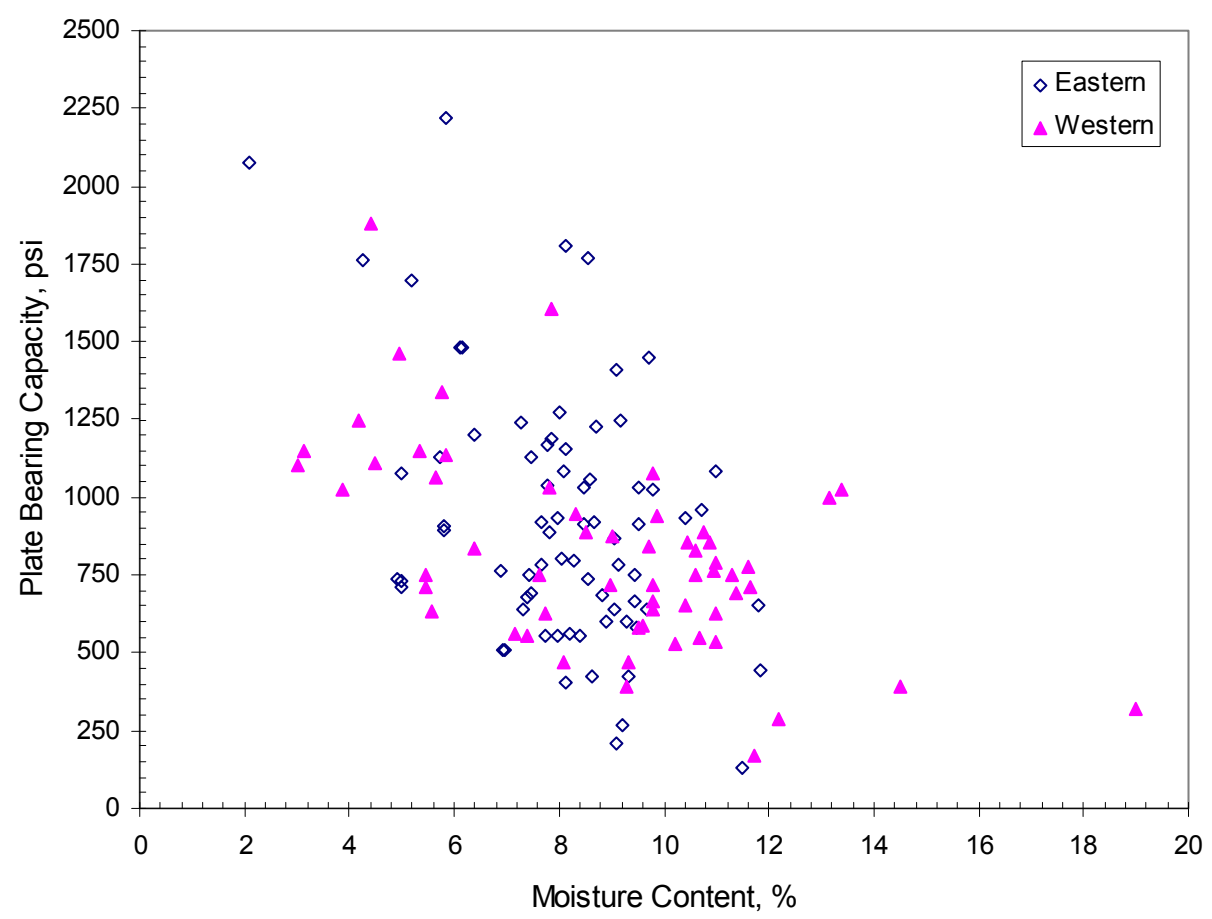

Figure 3.24. Moisture content versus ultimate plate bearing capacity for all the test data.

trend is extremely significant considering the following:

1. the data was obtained from different coal mines that are spread over all three states of the Basin;

2. the tests were conducted by different researchers over a span of three decades using different floor preparation methods, rates of loading, etc;

3. although all the tests were conducted on underclay or weak claystone floors, the thickness of these beds could have been different at the test sites;

4. it is very likely that the main floor below the weak bed could be different in different tests;

5. different shape plates and varying sizes were used in these tests.

Despite these significant variables, it is remarkable that the data show such a broad consistency as in Figure 3.24. Further, the plot of the test data shows that up to about $12 \%$ moisture, the ultimate plate bearing capacity of the floor is somewhat higher in the Eastern shelf mines than their Westen shelf counterparts. However, when the expected floor strength values corresponding 
to the liquid and plastic limit values are added to the plot, differences between the two shelves become even more significant. Before discussing this matter further, it is interesting to see how the existing plate bearing capacity equations fare against the large database in Figure 3.24. When the Eastern and Western shelf test data are plotted along with the Speck and SIUC equations in Figure 3.25 , the following observations could be made:

- Speck's equation, which was developed from laboratory triaxial testing on competent floor samples obtained from two Illinois coal mines, predicts the plate bearing strength reasonably well when the moisture content is less than about $8 \%$ for the Western shelf mines. It consistently underestimates the strength for the Eastern shelf;

- when the floor moisture exceeds $8 \%$, Speck's equation drastically underestimates the floor strength. Despite the fact that the maximum moisture content of the underclay used in developing Speck's equation was $14.5 \%$, because of the linear form of the equation, it predicts physically unrealistic negative compressive strength when the floor moisture exceeds $12.4 \%$;

- both the original and liquid limit versions of the SIUC plate strength equations provide the lower bound to the floor strength. The liquid limit version in Equation (3.8) estimates a slightly higher strength than the original version for all floor types given in Equations (3.2) - (3.7). For plotting Equation (3.8) in Figure 3.25, the average liquid limit values obtained for the Eastern $(L L=32)$ and the Western shelf $(L L=54)$ for all the data in Chapter 2 were used.

- In essence, none of the current equations available in the Basin predict the ultimate plate bearing capacity well. In fact, all the existing equations significantly underestimate the floor strength.

It is understandable that since the Speck's equation was derived from the laboratory triaxial strength data, it may not fit very well with the larger in-situ plate test data. However, it is not immediately clear why the SIUC equation, which was 
supposedly derived from 96 plate tests, would fare as bad as in Figure 3.25. This is even after some of the data that were used in developing the SIUC equations
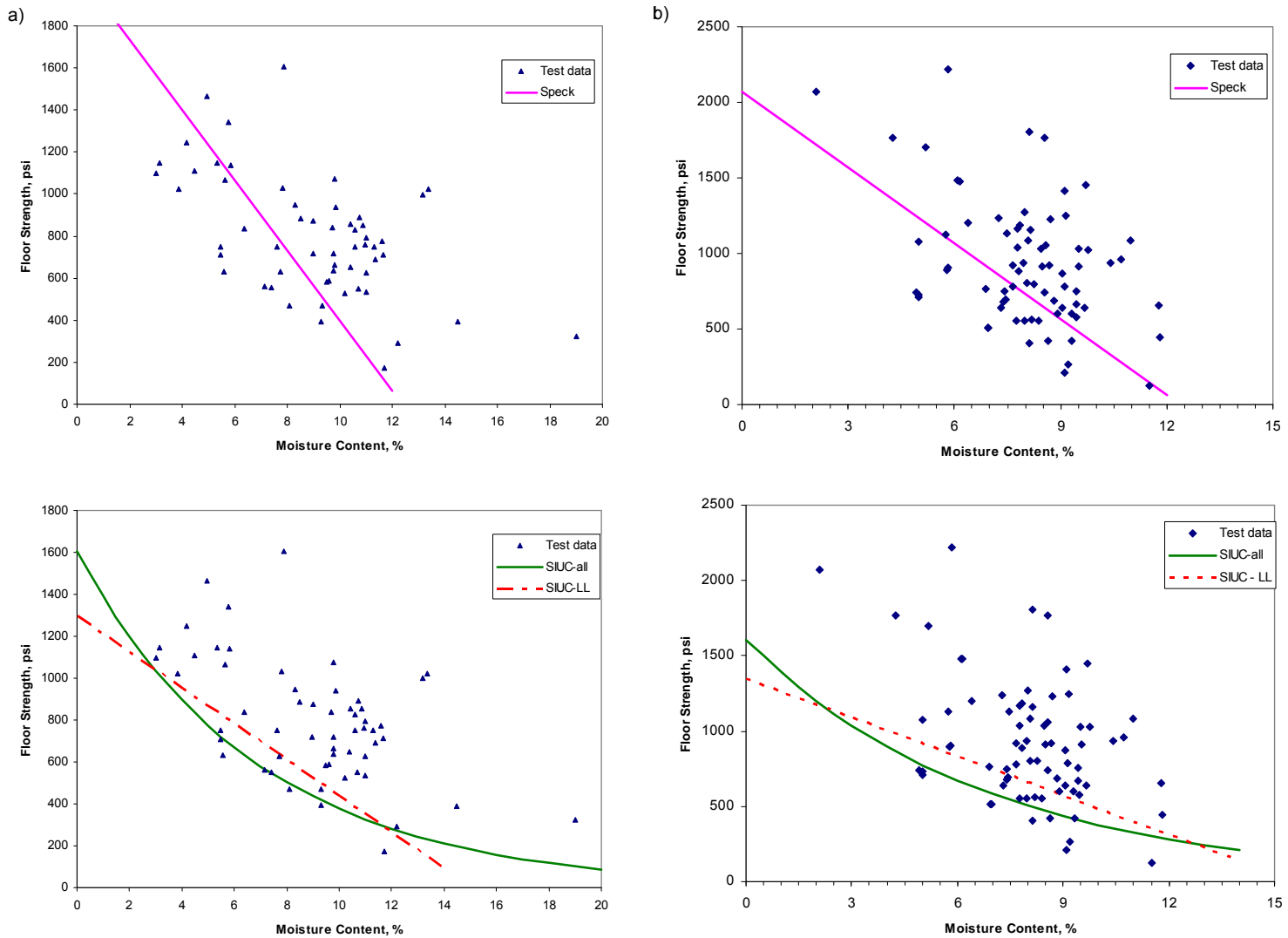

Figure 3.25. Performance of the Speck and SIUC floor strength equations against plate test data from (a) the Western and (b) Eastern shelf mines.

is included in Figure 3.25. Even though none of the SIUC publications mention how the regression was carried out to derive equations (3.5) - (3.7), it was found that if the individual site liquid limit data and the expected floor strength at that moisture content were included along with the plate test data in the regression, then similar conservative equation like the SIUC's would be obtained. As mentioned in Chapter 2, when the moisture content in the floor is equal to its liquid limit, the cohesion of the material can be taken as $2.5 \mathrm{kPa}(0.36 \mathrm{psi})$. By including this limiting data point in the regression for all the sites for which the liquid limit is known, the regression curve will be forced to attain the form similar to the SIUC's as illustrated in Figure 3.26. For this plot, the liquid limit data from 68 test sites in Table 3.2 and Table 3.3 were included in the regression. In other 
words, the individual site liquid limit data points exerted significantly overriding influence over the outcome of the regression, which is not realistic. However, in order for any plate bearing equation to be valid over a broad range of moisture contents, it must yield zero strength only at moisture contents close to the liquid limit value. For physical reasons, the floor strength can not become zero unless the moisture content value exceeds its liquid limit. Therefore, to develop any meaningful strength predictive equation, it is necessary that this limiting condition be included in the regression someway.

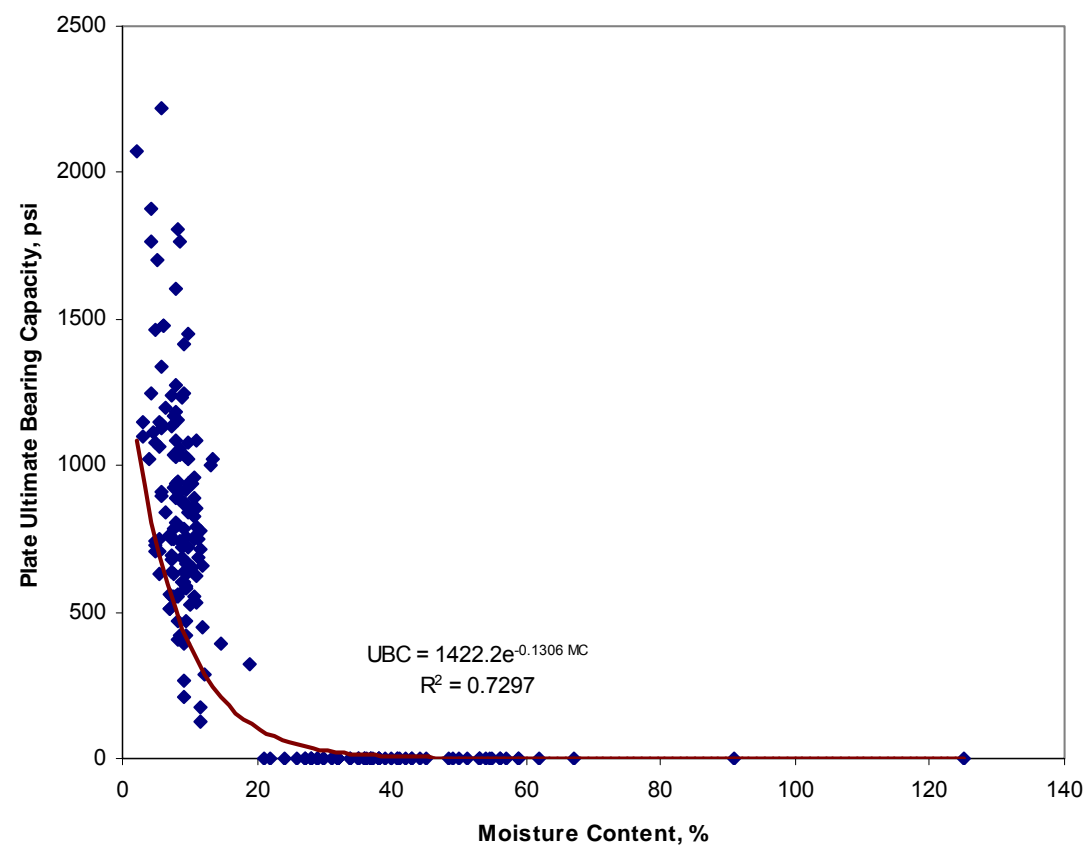

Figure 3.26. The best fit equation if individual site liquid limit data are included in the regression.

Since none of the existing plate bearing capacity equations provided a good match with the larger database, it is necessary to derive new equations that provide a better fit to the field data. As mentioned before, the derived plate strength equation must work over a broad range of moisture content values and should produce near zero cohesion only above the liquid limit. It was also mentioned in Section 2.3.2 that when the moisture content in the floor was equal to its plastic limit, the cohesion of the floor could be taken as 36.25 psi. Therefore, the ideal plate bearing capacity should not only provide a good fit to the plate test data in Table 3.2 and Table 3.3, but must also pass through the two 
limiting points corresponding to the plastic and liquid limits. In Figure 3.26 it was shown that if the individual site liquid limit values were considered in the regression, then the best fit curve would be forced to become the lower bound to the plate test data. By trial and error it was found that the overriding influence on the regressed equation could be avoided by using the average liquid and plastic limit values in the analysis instead of the individual limit values. This is a reasonable simplification given that the individual site floor cohesion values will most likely be different from 0.36 psi and 36.25 psi fixed values assumed here when the moisture content is equal to the liquid and plastic limits.

The combined data plot in Figure 3.24 shows that there is a slight difference in the floor strength between the Eastern and Western shelf mines up to a moisture content of about $12 \%$. At higher moistures, no data are available from the Eastern shelf. For the Western shelf, however, the four test sites with moistures above $12 \%$ show higher strength than the overall trend would suggest. Further, it has been shown in Chapter 2 that for the No.6 seam floor, there is a significant difference in its engineering nature between the two shelves of the Basin. Even though enough data are not available for the other seam floors to find similar differences in the nature between the two shelves, owing to the slight differences in the depositional environments, it is likely that some differences might exist. For these reasons, it has been decided to treat the two parts of the Basin as different entities and the best fit regression equations were developed separately. In addition to the data in tables 3.2 and 3.3, the following limiting points were included in the regression:

for the Western shelf:

average liquid limit $=54$, plate $U B C=6.17 \times 0.36 \mathrm{psi}$, average plastic limit $=35$, plate $U B C=6.17 \times 36.5 \mathrm{psi}$, for the Eastern shelf:

average liquid limit $=32$, plate $U B C=6.17 \times 0.36 \mathrm{psi}$, average plastic limit $=18$, plate $U B C=6.17 \times 36.5$ psi.

The 6.17 multiplier above was necessary to convert the expected floor cohesion into equivalent plate strength following the logic given in the next section. If for 
any reasons it is decided to treat the floor in the entire Basin to be of similar geologic origin, or if the geographical location of the mine is not known to use the appropriate shelf equation, then the best fit equation derived from the entire plate test data given below could be used. The author's individual best fit equations to estimate the plate bearing capacity are given below:

for the Western shelf mines:

$$
q_{\text {plate-Gadde-West }}=1905 e^{(-0.1 M C)} \quad\left(R^{2}=0.76\right)
$$

for the Eastern shelf mines:

$$
q_{\text {plate-Gadde-East }}=4164 e^{(-0.2 M C)} \quad\left(R^{2}=0.66\right)
$$

for the entire Illinois Basin:

$$
q_{\text {plate-Gadde-all }}=2240 e^{(-0.12 M C)} \quad\left(R^{2}=0.64\right)
$$

where $M C$ is the moisture content of the immediate floor. The above equations will provide the ultimate floor strength in psi as determined by the plate tests. Performance of equations (3.9) to (3.11) against the field data is shown in Figure 3.27. For better readability, the $\mathrm{X}$-axis in these figures is truncated.

Discussions in Chapter 2 showed that in some cases the moisture content of the floor changes with depth. However, if the traditional soil mechanics bearing capacity theories discussed in Chapter 4 are used for pillar design, then it is normally assumed that the entire weak floor bed has the same strength properties. Therefore, for these conventional theories, an average estimate of the floor strength is needed. Since equations (3.9) to (3.11) were derived without explicitly considering the moisture variability with depth at the test sites, they provide such a mean value of the strength. It is very likely, however, that a few of the test sites in tables 3.2 and 3.3 have had variable floor moisture, and hence the equations 3.9 to 3.11 indirectly reflect such variability despite the use of a single moisture value in the equations.

Since the moisture might change with depth in the weak floor, the obvious question that needs to be answered is at what depth below the coal seam the 
a)

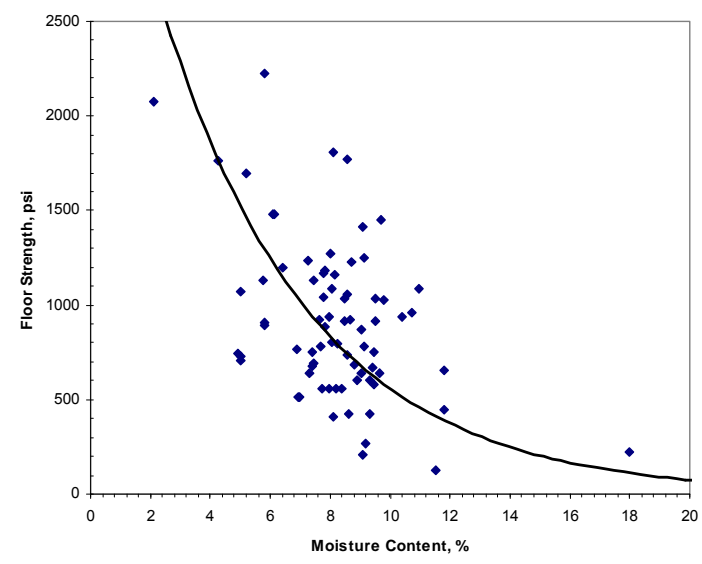

b)

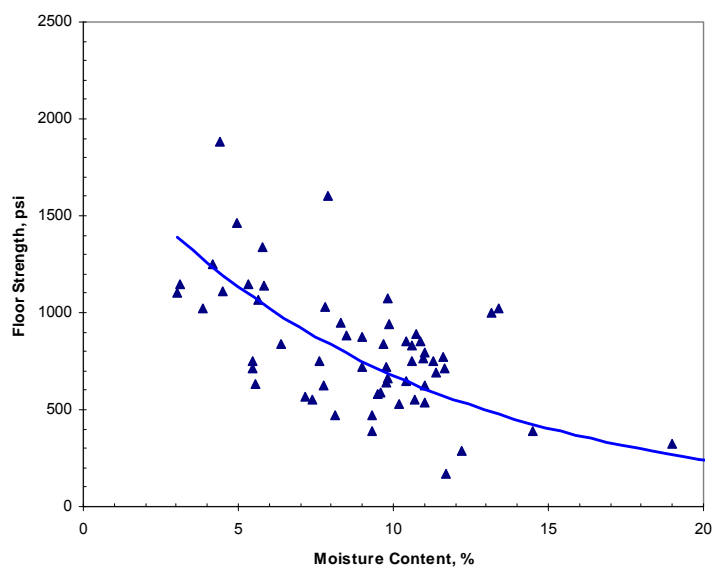

c)

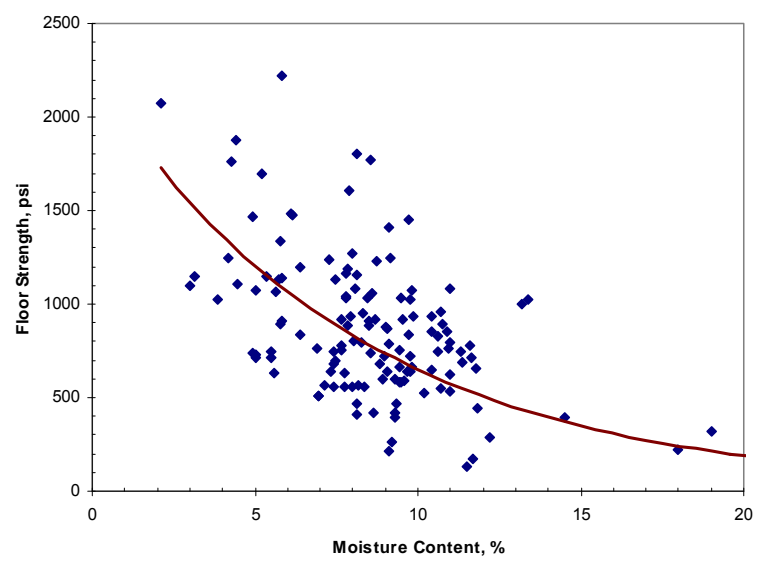

Figure 3.27. Plot of individual Gadde's equations against a) Eastern shelf, b) Western shelf and c) all plate test data.

moisture should be determined for use with the Gadde's equations. Because of the two conditions that existed at some of the plate test sites in Table 3.2 and Table 3.3, it is recommended that the moisture content measured between 8 and 12 inches below the coal seam be used for this purpose. First, in a majority of the Illinois Basin mines, the coal seam is rarely thick enough that no floor material is cut by the continuous miner. Even by very experienced continuous miner operators, up to 4-6 inches of floor material is normally cut during mining. Sometimes, more floor material is taken deliberately to provide room for equipment movement. Second, an additional 4-6 inches of floor material was removed during the in-situ plate tests and the moisture determined at this depth was used for the analysis. For these two reasons, it is recommended to use the 
moisture values from 8-12 inches deep in the floor for equations (3.9) to (3.11). Alternatively, the average moisture of the entire weak floor could also be used. Unless no other data exists, it is recommended to not use the moisture content of the first six inches of the floor material obtained from exploratory cores.

When it is considered that the underclay material typically exists right below the coal seam and 8-12 inches of that material is not involved in some of the plate tests in Tables 3.2 and 3.3, it may be argued that such plate tests basically reflect the in-situ strength of the weak claystone material instead of the underclay's. This possibility will not invalidate the application of Gadde's equations, however. While some of the plate tests may not have any underclay involved, some were conducted over it. When all the tests were grouped together for the analysis, it is conceivable that no significant bias in the regression occurred. Irrespective of whether full underclay, a part or none is involved in the tests, it is conclusive from the plate tests that the immediate floor materials show a very strong correlation between the strength and the moisture content. It is anticipated that the relationships given in equations (3.9) through (3.11) will remain valid over the entire range of moisture contents encountered in the Illinois Basin mines and thus could be used with confidence to estimate the strength of underclay as well. Since it is known that the underclay typically has higher moisture than the strong claystone below, if the floor is properly subdivided into different lithological units, the use of equations (3.9) through (3.11) will provide lower strength estimate for the underclay as expected.

\subsubsection{Estimation of Weak Floor Cohesion}

The Gadde's equations given above only provide an estimate of the weak immediate floor's strength when it is subjected to a plate bearing test. For the bearing capacity computation below a coal pillar, however, an estimate of the floor's cohesion is needed. This material property of the floor could be estimated by two different methods from the plate bearing capacity tests. First, the plate could be treated as a surface foundation resting on a semi-infinite floor and the foundation bearing capacity theories available in soil mechanics could be used to 
compute the cohesion. Second, if a very high accuracy in the cohesion estimate is needed, then a detailed numerical model may be constructed of the test site and iteratively provide different cohesion inputs to the model until the field computed plate bearing capacity is reproduced in the models using the procedure described in Chapter 5.

For a majority of the routines uses, the soil mechanics approach is sufficient. For the commonly encountered weak immediate layer thickness and for the common plate sizes (less than 12 inches) used in the in-situ tests, it is correct to assume that the test is conducted on a semi-infinite floor (Pytel, 1998). It will be shown in Chapters 4 and 5 that if the thickness of the weak floor is greater than the width of a square plate, then the effect of any stronger layer below will not materially influence the bearing capacity. Since the plate size used in routine floor tests rarely exceeds 12 inches, the semi-infinite assumption for interpreting the plate test results is reasonable. As discussed in Chapter 4, when a foundation sits at the surface of the floor and the weight of the soil is ignored, its bearing capacity can be estimated by,

$$
q_{\text {plate }}=c N_{c} s_{c}
$$

where $c$ is the soil cohesion and $N_{c}$ is called the bearing capacity factor for cohesion and is given by

$$
N_{c}=\cot \phi^{\prime}\left[e^{\pi \tan \phi^{\prime}} \tan ^{2}\left(45^{\circ}+\frac{\phi^{\prime}}{2}\right)-1\right]
$$

where $\phi^{\prime}$ is the effective soil friction angle. When $\phi^{\prime}=0^{\circ}, N_{c}=5.14 . s_{c}$ in equation (3.12) is called the shape factor and is given by

$$
s_{c}=1+\left[\frac{B}{L}\left(\frac{N_{q}}{N_{c}}\right)\right]
$$

where $B$, is the footing width; $L$, the footing length; $N_{c}, N_{q}$ are the bearing capacity factors, with

$$
N_{q}=\left[e^{\pi \tan \phi^{\prime}} \tan ^{2}\left(45^{\circ}+\frac{\phi^{\prime}}{2}\right)\right]
$$

For a square plate and when $\phi^{\prime}=0^{\circ}$, the shape factor $s_{c}$ becomes 1.2. 
It will be discussed in Chapter 4 that currently in the Illinois Basin coal mines the bearing capacity of weak floor beneath a coal pillar is computed using Vesic's (1975) two-layer soil model. For the Vesic's model, it is assumed that the angle of internal friction for both the weak and strong layers is equal to zero. For this frictionless material, the cohesion of the floor could be estimated by rearranging equation (3.12) as

$$
c=\frac{q_{\text {plate }}}{N_{c} s_{c}}
$$

In equation (3.16), $q_{\text {plate }}$ is computed using the appropriate Gadde's equation given above and for the Vesic's assumptions, the denominator becomes equal to $6.17\left(=5.14 \times 1.2\right.$ for $\left.\phi^{\prime}=0^{\circ}\right)$ or

$$
c=\frac{q_{\text {plate-Gadde }}}{6.17}
$$

It is not necessary to assume zero friction angle to compute the floor cohesion, however. As equations (3.13) to (3.15) show, the denominator in (3.16) could be computed for any value of $\phi$.

\subsection{The Plate Size Effect}

For geological materials, the strength of a field scale structure is normally less than that determined from a laboratory sample. Several nice accounts of this "size effect" are available in rock mechanics literature. Perhaps the most studied geological material for its size effect is coal (Hustrulid, 1976). Based on extensive laboratory and field tests conducted on coal specimens of different sizes, it has been found that coal strength decreases with increasing size up to a certain "critical size" after which the rate of fall is negligible. For coal, it has been found that a 36-inch cube represents the critical size and thus strength tests conducted on such cubes could be used directly for design. If the laboratory tests are conducted on samples less than the critical size, then some form of size correction is necessary to compute the in-situ strength.

Using the data obtained from plate tests underground, Jenkins (1960) concluded that the size effect could be adequately described by an equation of 
the form, $q=k d^{m}$, where the exponent $m$ is less than zero for geologic materials. From the tests performed by Jenkins (1960) it was found that the size effect was negligible for soft floor materials and significant size effect was exhibited only by strong floors as illustrated in Figure 3.28. Among the different curves drawn in this figure, the one labeled (c) corresponds to a soft wet clay floor. Similar tests conducted by Afrouz (1975a, 1975b) showed measurable size effect for underclay floor exhibiting as much as $20-35$ percent reduction in strength with increasing size of circular and square plates.

In the U.S., the first in-situ floor tests to study the size effect were conducted by Dulaney (1960) using square plates of 1.5 to 12 inches in size. His tests did not show any clear trends and thus he concluded that there might not be appreciable size effect in the soft floor materials. Later field tests conducted

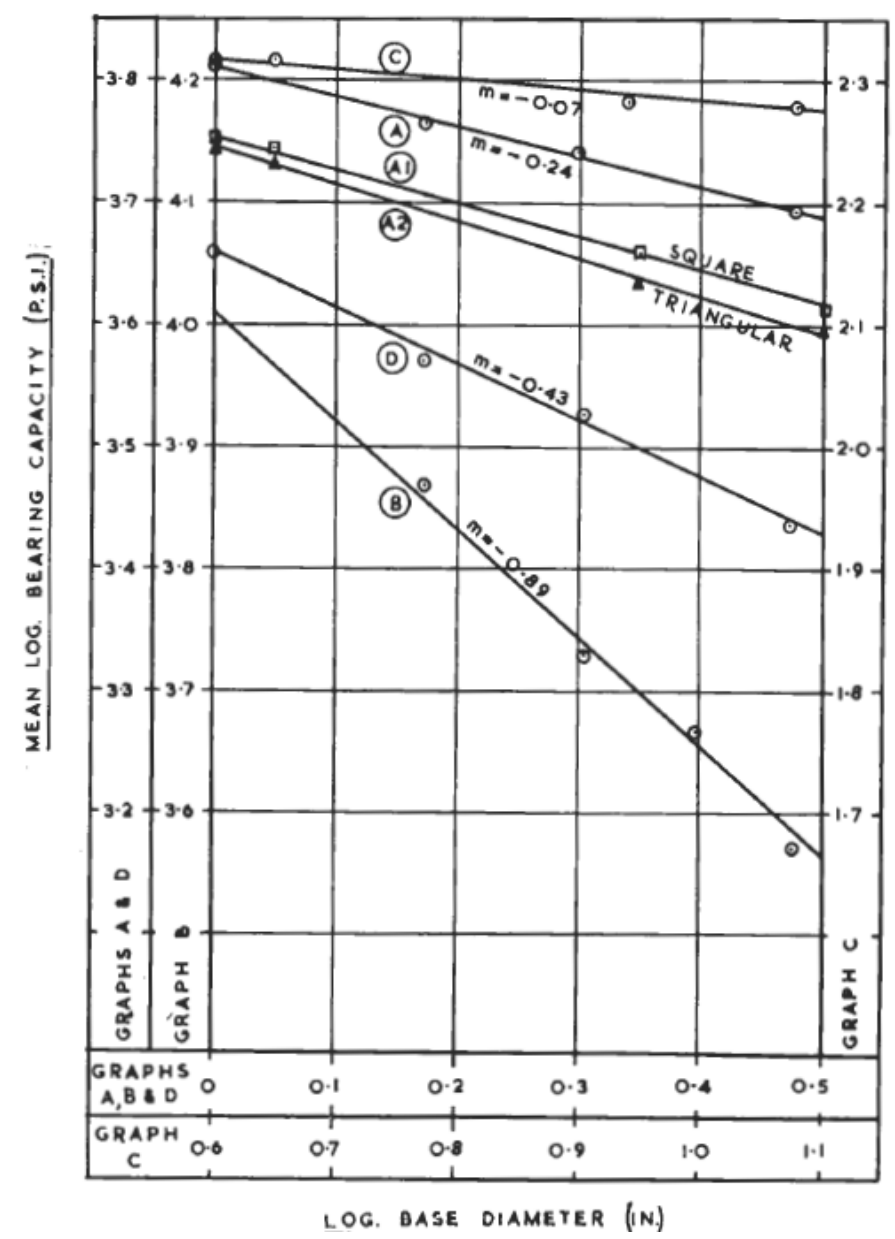

Figure 3.28. Size effect for different floor types tested by Jenkins (1960). 


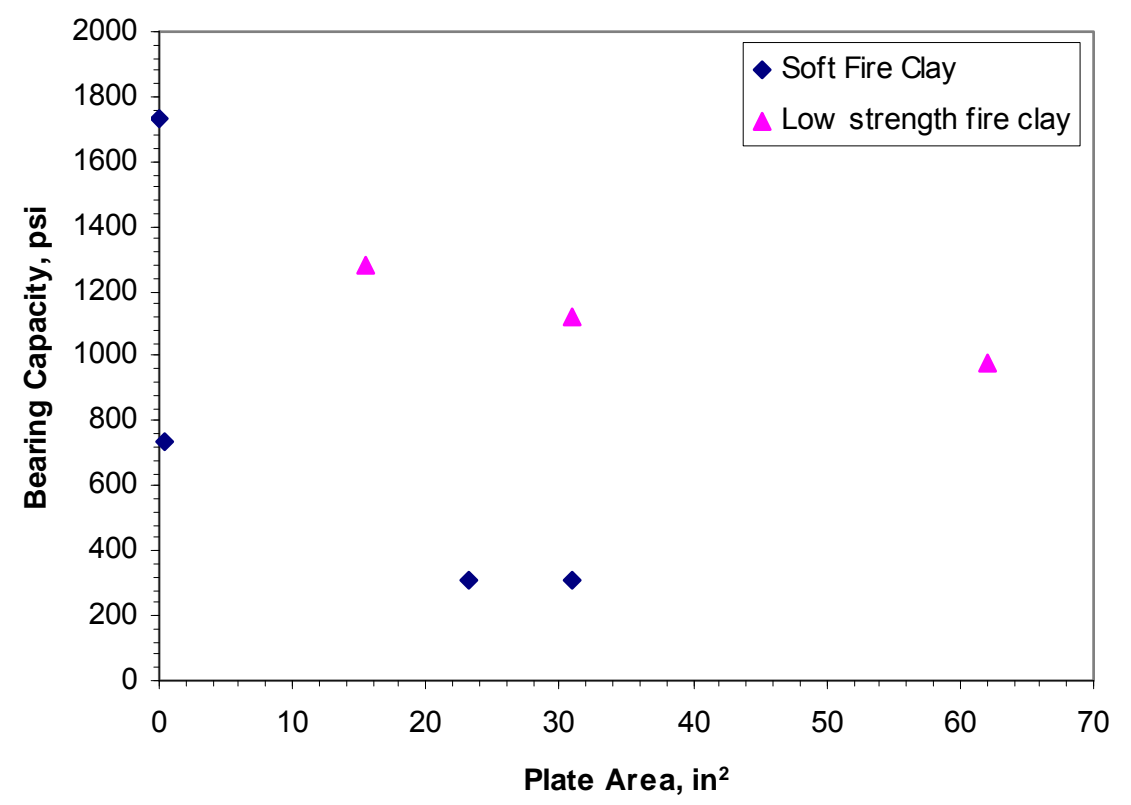

Figure 3.29. Size effect displayed by Chlumecky data (1968).

by Chlumecky (1968) with different size plates showed some reduction in the bearing capacity for soft fireclay floors up to a plate size of $25 \mathrm{in}^{2}$, after which the effect was negligible as shown in Figure 3.29. Similarly, extensive in-situ plate bearing tests were conducted by Barry and Nair (1970) on different type floors using 1-12 inches circular plates and rectangular plates varying in size between 6 $x 12$ inches to $8 \times 16$ inches. The results from these tests basically show the same general trends as Chlumecky's data. The Barry and Nair (1970) data plotted in Figure 3.30 clearly show that when the plate area exceeds $20 \mathrm{in}^{2}$, the effect of increasing plate size further does not have a significant influence on the bearing strength.

\subsubsection{Speck's Size Effect Factor}

Despite the negligible size effect displayed by the soft floor materials when the plate size exceeded 20 to 25 inch $^{2}$ as given above, it has been argued by some that the weak floor materials in the Illinois Basin coal mines would exhibit size effect (Yu et al., 1993; Pula et al.,1990). These researchers point out that the plate size used in the in-situ tests is much smaller when compared to the coal 


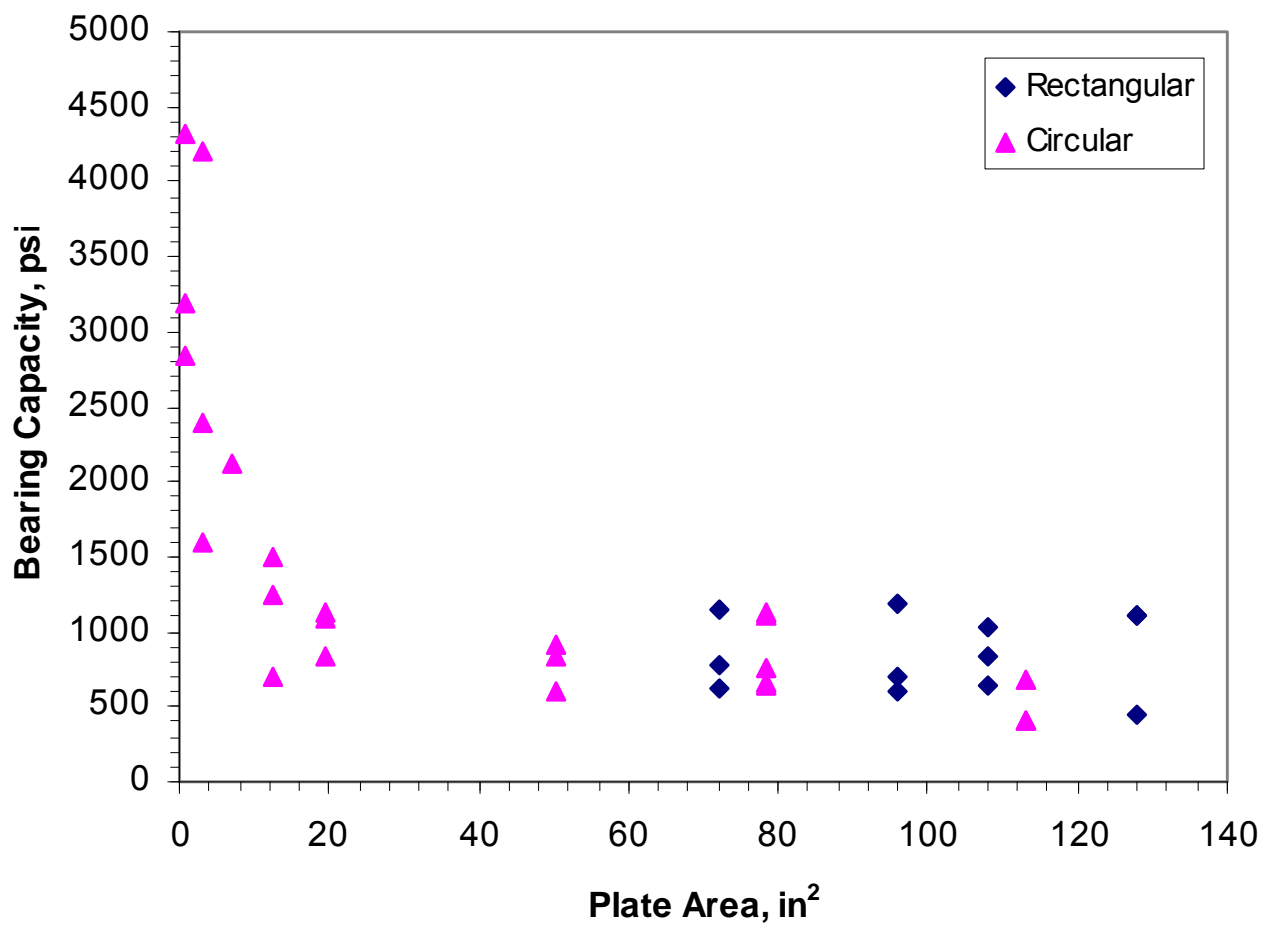

Figure 3.30. Size effect displayed by Barry and Nair data (1970).

pillars and thus some size effects must exist. With this line of reasoning, suggestions have been made in the past to correct the plate test data for the size effect. In the Illinois Basin, the most commonly used size effect factor for weak floor was suggested by Speck (1979) based on his studies at two Zeigler coal mines. He recommended a constant size effect multiplier equal to 0.15 . With this correction, Speck's plate bearing capacity equation for pillar design becomes

$$
q_{\text {Speck }}=0.15(2070-167 M C)
$$

Contrary to the common perception, the size effect factor suggested by Speck (1979) was to correct his laboratory triaxial strength equation (3.1) to provide a decent match with the in-situ plate tests conducted with 12-24 inch plates; it was not to correct the plate test data for full size pillars. In doing so, Speck (1979) assumed that the data obtained by the in-situ plate tests represented the "operational strength" for use in the design, which did not require any further correction for size effect. Speck (1979) also recommended a 0.6 reduction factor 
for the stronger claystone floor. Plate tests conducted at three sites in two coal mines (previous research by Ganow, 1975 and Rhodes, 1976) were the basis for the recommended reduction factors in the Speck's analysis.

It was shown in Figure 3.25 that Speck's laboratory triaxial strength equation provided a decent match with the large in-situ strength database up to a moisture content of about $8 \%$. Given that Speck recommended using a 0.15 reduction factor to estimate the plate strength, one can only infer that for some reasons the floor at the two Zeigler mines studied in Speck's research had exceptionally weaker material than is typical in the Basin. Careful study of the Speck's dissertation (1979) revealed that the extremely low in-situ plate test values obtained at the Zeigler's mines was because of the method of mining adopted. According to Speck, "the coal in both of the Zeigler coal mines is extracted using the 'conventional' mining method whereby a deep slot is first cut horizontally into the bottom of the face. A series of holes are then drilled into the coal and explosive devices are placed in them. After detonation, the broken coal is gathered, loaded, and transported to a conveyor belt which transports it to the surface." Even though the amount of blast induced damage in the floor would have been minimized by the bottom slot as compared to blasting off of the solid, still some significant amount of fracturing might have occurred in the floor as compared to the mechanized mining adopted in the rest of the mines in the plate test database.

It can be argued that if anything, Speck's studies show that for the "soillike" weak floor materials in the Illinois Basin, the size effect does not exist or the influence is minimal. This can be inferred by the fact that Speck's equation derived from the laboratory triaxial strength data on 2-inch samples provided a decent match with the in-situ plate test data shown in Figure 3.25. Of course, it is also possible that the 300 psi confining pressure used in Speck's triaxial tests could have been much greater than the actual confinement experienced by the floor materials at the tests sites in Figure 3.25. One might argue that owing to the higher confinement used in Speck's lab tests, the size effect may have been camouflaged. But the evidence available from in-situ tests conducted with 
different size plates discussed later points to the negligible size effect as the primary reason for the decent performance of Speck's equation rather than the higher confining pressure.

In the most popular Vesic-Speck method of floor bearing capacity estimation used in the Illinois Basin mines, equation (3.18) is directly used for the weak floor's cohesion instead of estimating it through equation (3.16). Speck (1979) felt that such direct substitution in Vesic's (1975) equation was necessary to explain the field behavior of the floor at the two Zeigler's mines he studied. Even though Speck did not realize it, but by sheer coincidence the size effect factor 0.15 he suggested basically converted his laboratory triaxial strength equation into equivalent weak floor cohesion for $\phi^{\prime}=0$ as assumed in the Vesic's bearing capacity model. This can be seen from equation (3.17) where the plate bearing capacity was divided by 6.17 to estimate the floor cohesion. Dividing the plate strength by 6.17 is equivalent to multiplying it by 0.16 , which is almost the same as the 0.15 multiplier that Speck recommended. Therefore, without realizing himself, Speck correctly estimated the weak floor cohesion in equation (3.18). Despite these pleasant coincidences, the reasonable performance of the Vesic-Speck model for almost three decades in the Basin strongly suggests that the size effect for the weak floor rocks is negligible.

\subsubsection{SIUC Size Effect Equations}

In contrast to the Speck's constant size effect factors, the SIUC researchers (Pula et al., 1990) proposed some equations that produce different correction factors based on the pillar size and the floor's moisture content. The SIUC studies (Pula et al., 1990; Yu et al., 1993) assumed that the size effect must exist indefinitely and there was no critical size beyond which the strength could be assumed constant. Therefore, the SIUC size effect equations require strength reduction corresponding to full-size coal pillar as given by the following equations: 


$$
\begin{aligned}
& R F_{\text {SIUC }}=\frac{1019-67 M C+\frac{908}{B_{\text {pillar }}}}{1019-67 M C+\frac{908}{B_{\text {plate }}}} \text { for claystone floor, } \\
& R F_{\text {SIUC }}=\frac{1510-156 M C+\frac{2518}{B_{\text {pillar }}}}{1510-156 M C+\frac{2518}{B_{\text {plate }}}} \text { for siltstone, and } \\
& R F_{\text {SIUC }}=\frac{1208-103 M C+\frac{1679}{B_{\text {pillar }}}}{1208-103 M C+\frac{1679}{B_{\text {plate }}}} \text { for all floor materials. }
\end{aligned}
$$

In the above equations $M C$ is the natural moisture content, $B_{\text {pillar }}$ is the pillar width in inches and $B_{\text {plate }}$ is the plate width in inches used for the in-situ tests. When using the plate test data for computing the bearing capacity underneath a coal pillar, the SIUC equations become,

$$
U B C_{\text {size-corrected }}=R F_{\text {SIUC }} U B C_{\text {plate }}
$$

with $U B C_{\text {plate }}$ estimated by equations (3.5) - (3.7).

The data used to derive the relationships in equations (3.19) to (3.21) were not published by the SIUC. What is interesting about the SIUC equations is that the reduction factor is a function of the plate and pillar sizes as well as the moisture content. It is not clear why the same size pillars would have different reduction factors for floors with different moisture contents.

Owing to the linear form of equations (3.19) - (3.21), the reduction factor becomes negative for a range of moisture values as shown in Figure 3.31. For very high moisture contents the reduction factor becomes positive again and attains values much greater than 1.0, which is meaningless. This sign change occurs because for very high moistures both the numerator and denominator become negative in equations (3.19) - (3.21). Also, if the regression in equations $(3.19)-(3.21)$ is meaningful, then for $B_{\text {plate }}$ equals to 6 inches and 12 inches (extreme plate sizes used in the SIUC tests), the denominator in equations (3.19) to (3.21) should bracket the bearing capacity given by SIUC relations in equations 
(3.5) to (3.7). But as the plots in Figure 3.32 show such is not the case. One possible explanation for this behavior is that in the multiple regression analysis conducted for equations (3.19) - (3.21), the regression constant for the plate size term might have shown statistical insignificance while producing a decent $R^{2}$ value because of the overriding negative influence of the moisture content on the plate bearing strength.

While the data was not published explicitly, SIUC plotted their size effect data in a graph (Yu et al., 1993) shown in Figure 3.33. In addition to the physically unacceptable behavior shown by equations (3.19) - (3.21), given the fact that very few tests were conducted with larger size plates, the data in Figure 3.33 does not strongly support the conclusion that size effect exists for these weak floor materials.

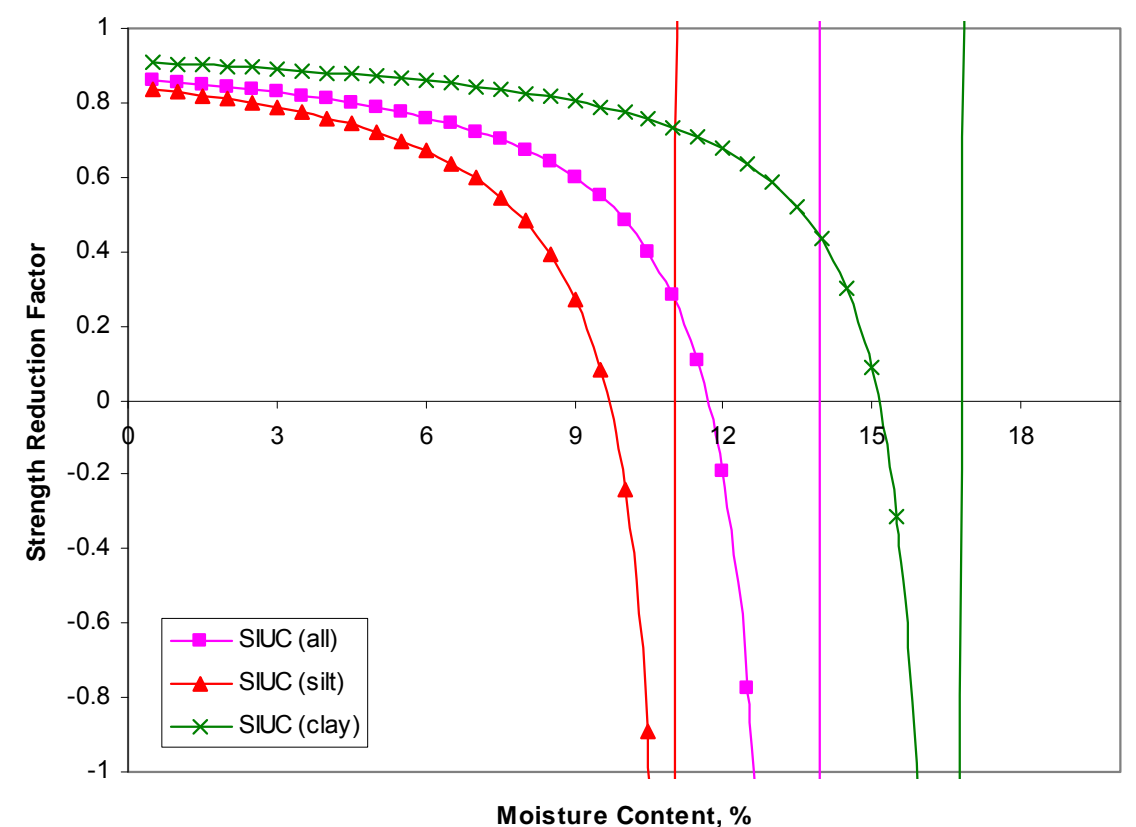

Figure 3.31. SIUC size effect factors against the moisture content.

When the ultimate bearing capacity data in Tables 3.2 and 3.3 were plotted against the area of the plate, no apparent size effect could be found as seen from Figure 3.34. In addition to the data in the two tables, some plate test data not included there has also been plotted in Figure 3.34. This additional data 
was not listed in Tables 3.2 and 3.3 as the moisture content of the floor at the test sites was not known.

Based on all the foregoing discussions, it can be concluded that there is not enough evidence to show that the plate test results need to be adjusted for

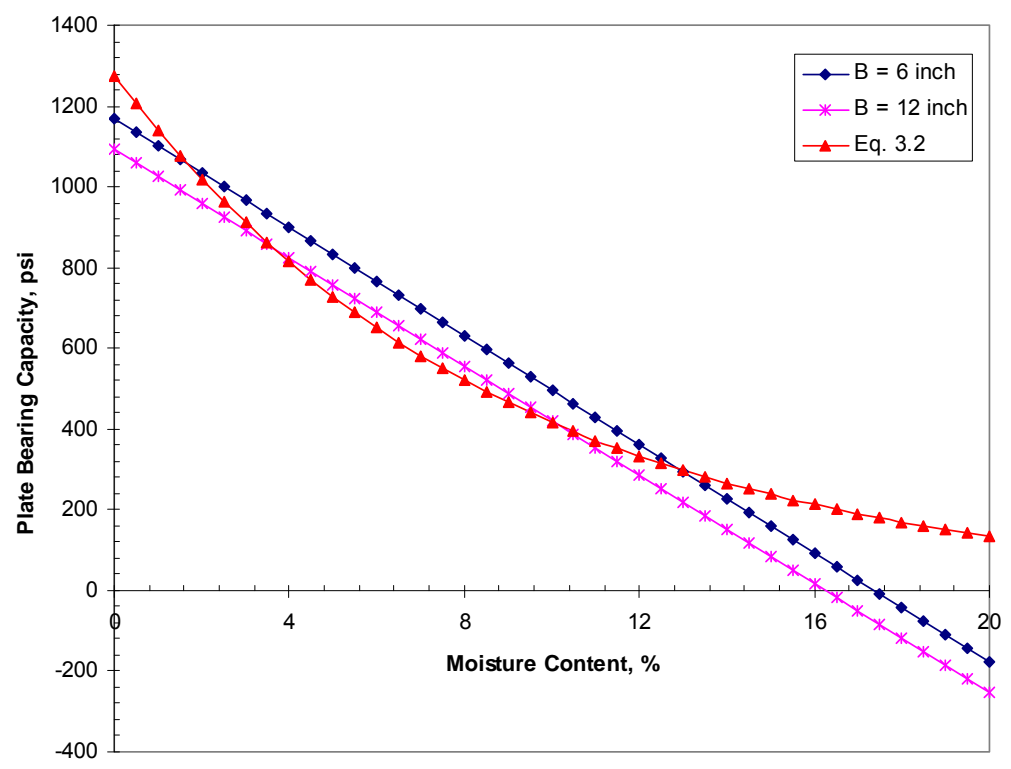

Figure 3.32. Plate bearing strength predicted by different SIUC equations.

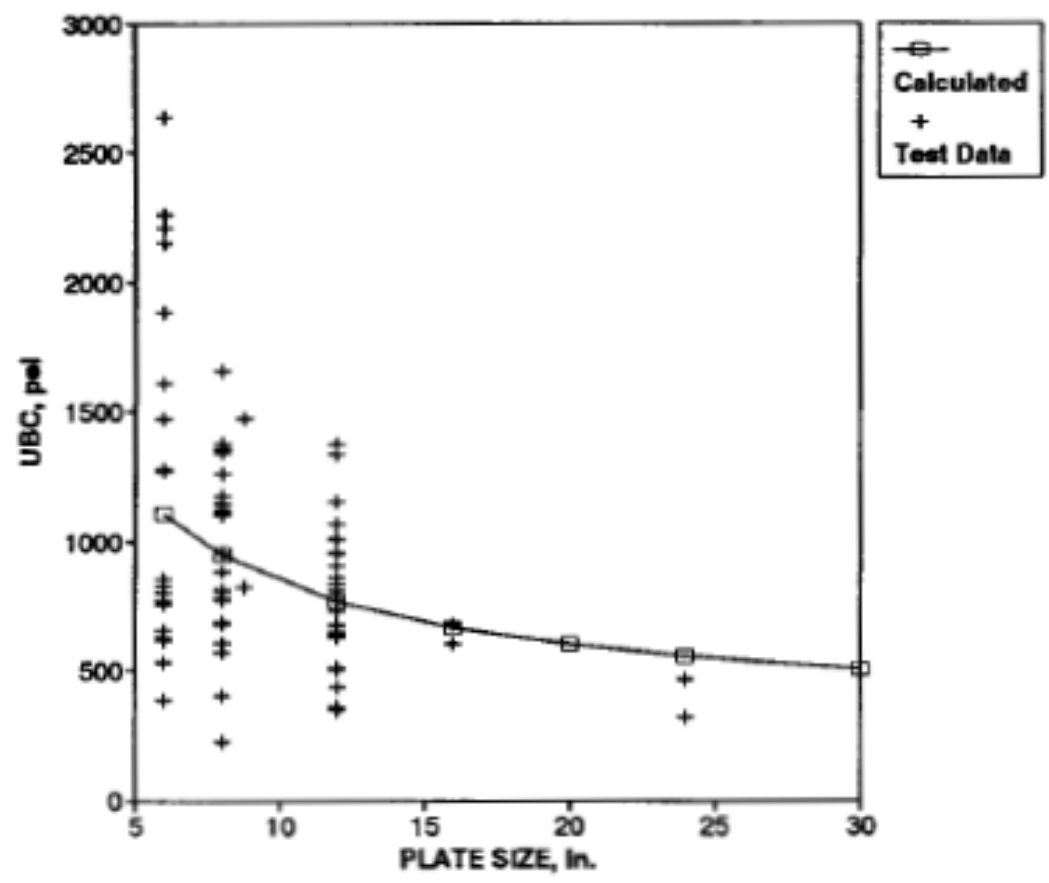

Figure 3.33. UBC vs plate size for the SIUC tests (Yu et al., 1993). 


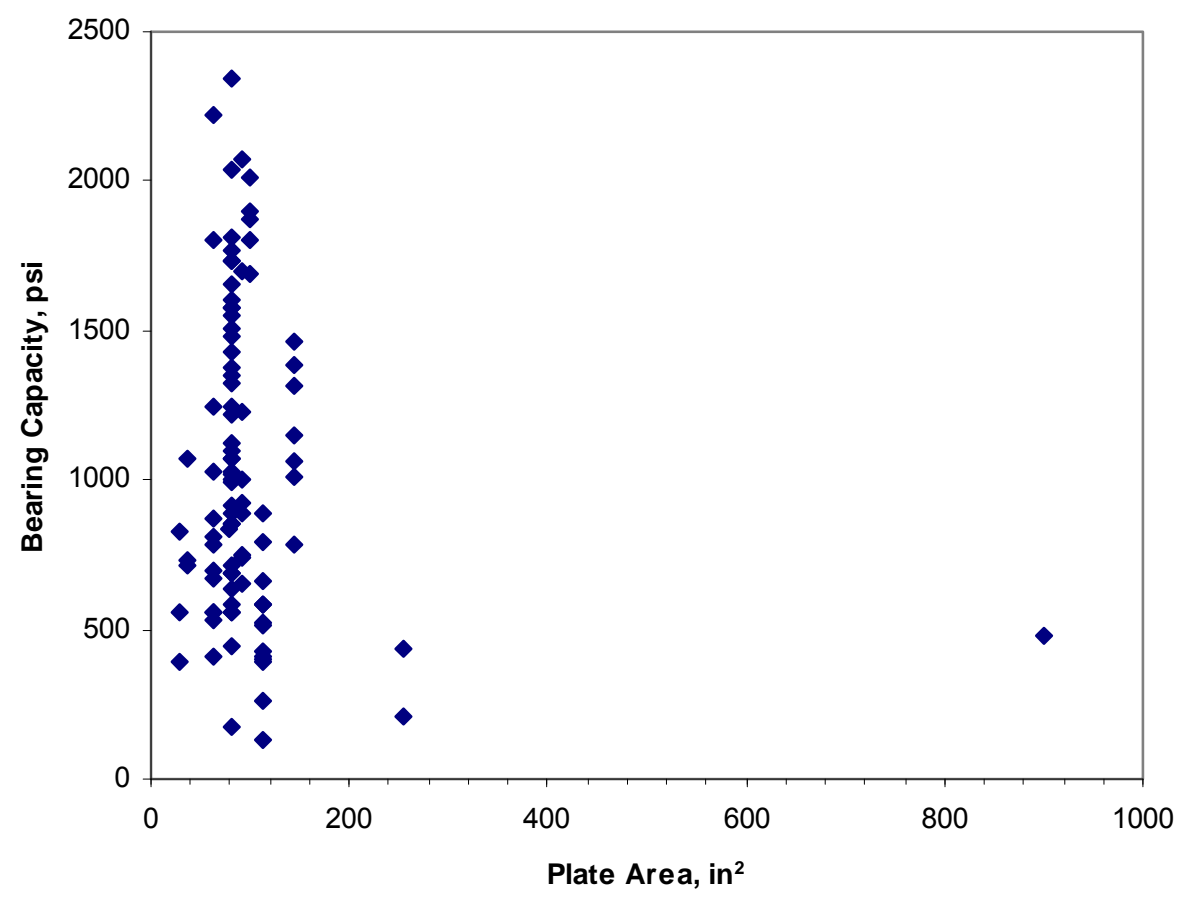

Figure 3.34. $U B C$ vs plate size for the plate test database in this research.

the size effect before using it to compute the floor bearing capacity underneath a pillar. Therefore, Gadde's plate bearing capacity equations could be used without further corrections when computing the floor strength below a coal pillar. This conclusion seems valid when it is considered further that it is extremely difficult to assess the exact effect of increasing plate size from underground tests for the following reasons:

- in order for any size effect studies to be meaningful, it is important to conduct tests with different size plates at locations that have similar moisture content;

- similarly, the test site floor lithology, especially the ratio of plate width to weak floor thickness must be same. The strong floor below should also be of similar nature or the ratio of the strong to weak floor shear strengths should be similar among the test sites;

- all other geo-mining conditions like the type of roof, method of mining, age of workings, rate of loading in the test etc must also be similar. 
Since it is almost impossible to have such similar geo-mining conditions in a real world situation, it is extremely difficult to accurately assess the size effect on floor bearing capacity. Even if there is some size effect, it is not necessary and is perhaps physically incorrect to apply the size reduction factors irrespective of the size of the pillar. As the knowledge available from coal pillar design showed (e.g., Salamon and Munro, 1967), there is no need to correct the strength for sizes exceeding the thickness of the weak floor. For any plate size greater than the weak floor thickness, the stronger bed below starts to influence the bearing capacity. It is ultra conservative in such circumstances to correct the floor strength as suggested by the SIUC relations given in equations (3.19) - (3.21).

\subsection{Angle of Internal Friction}

When strength behavior of the weak floor is described by the MohrCoulomb yield criterion, in addition to the cohesion value, information on the angle of internal friction is also needed. Owing to the problems with sampling and testing of the weak floor materials from the Illinois Basin coal mines, very little information is available on the magnitude of the friction angle. As a consequence of this practical difficulty, at present, bearing capacity analysis is carried out assuming a zero friction angle value for both the weak and strong floor layers. One of the initial attempts to estimate the friction angles was made by Rockaway and Stephenson (1979) using the rock borehole shear tester (RBST). Problems with the RBST instrumentation and the unacceptably large scatter in the data did not yield any useful information from this study. Later, Chugh (1986b) conducted some successful field studies using the RBST at two Illinois Coal mines. The instrument used in these studies was similar to that described by Haramy (1981) shown in Figure 3.35. As seen from this figure, the two diametrally opposite plates of the RBST pressed against an NX size borehole wall apply the predetermined normal stress to the rock. When the instrument is retracted out of the wall while maintaining the normal stress on the plate, the saw-tooth shaped section of the plates shears the rock. At failure, both the normal and shear stress values are recorded. Shear stress values obtained for different normal stresses 
will provide the necessary information to construct the Mohr's circles or to conduct a regression analysis to estimate the cohesion and the angle of internal friction values.

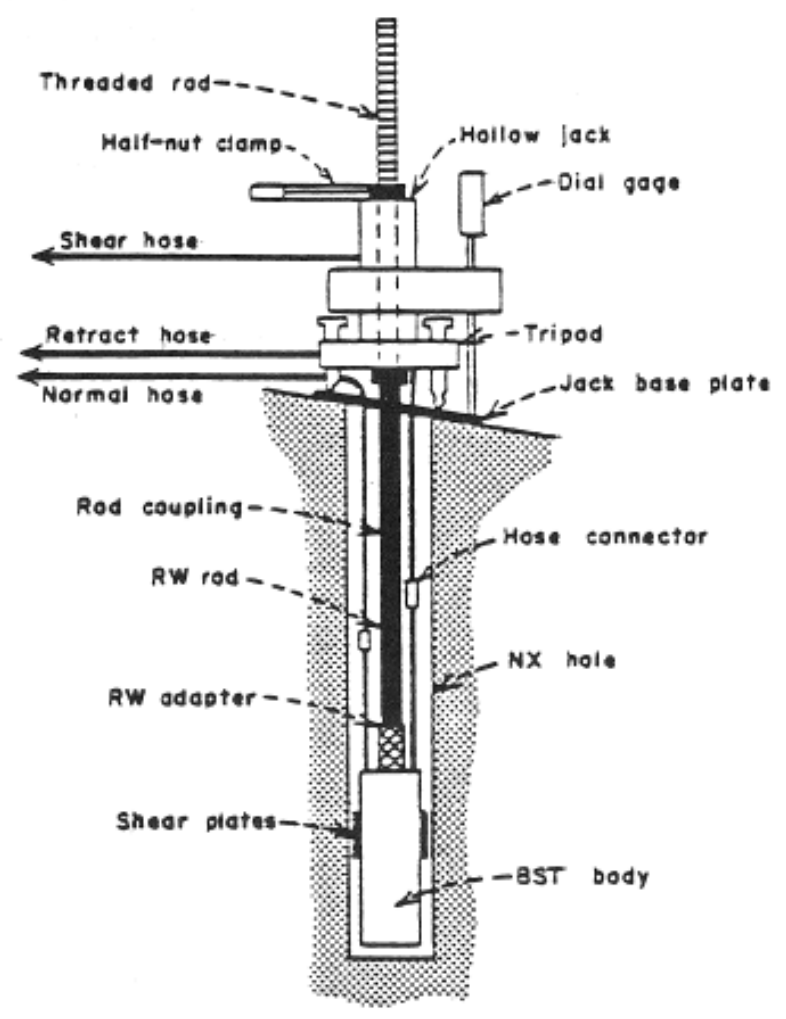

Figure 3.35. Bore hole shear tester developed by Haramy (1981).

Chugh (1986b) tested different rock types in the roof and floor at several sites in two Illinois coal mines. The angle of internal friction obtained for the underclay material from these tests is listed in Table 3.4. Also shown in the table are the range of normal stress values and the number of pairs of normal and shear stress data used to derive the friction angle. These in-situ tests conducted in an NX borehole showed that the angle of internal friction of underclay varied between 16 and 57 degrees at these two mines. Tests on other immediate floor materials at these two Illinois coal mines also showed non-zero friction angles in the same range as the underclay material. Barring these limited tests by Chugh (1986b), no other information could be found on in-situ or laboratory tests to estimate the friction angle for the underclay or claystone floor materials from the Illinois Basin mines. 
Table 3.4. In-situ borehole shear tests on underclay material at two Illinois coal mines (Chugh, 1986b).

\begin{tabular}{|c|c|c|l|c|c|c|}
\hline & Mine & Site & $\begin{array}{l}\text { Moisture } \\
\text { content, } \%\end{array}$ & $\begin{array}{l}\text { Normal } \\
\text { stress range, } \\
\text { psi }\end{array}$ & $\begin{array}{l}\text { Number } \\
\text { of tests }\end{array}$ & $\begin{array}{l}\text { Angle of } \\
\text { internal } \\
\text { friction, } \\
\text { psi } \\
\text { degrees }\end{array}$ \\
\hline 1 & 5 & 2.88 & $235-1014$ & 3 & 82.9 & 16.3 \\
\hline 2 & 1 & 4.5 & $235-1403$ & 4 & 198 & 35.4 \\
\hline & 3 & 3.08 & $235-1403$ & 4 & 398.9 & 28.2 \\
\hline & 4 & 5.56 & $235-1403$ & 4 & 361.6 & 32.4 \\
\hline & 4 & 1.01 & $235-1403$ & 4 & 148.2 & 57.3 \\
\hline & 5 & 5.92 & $235-1403$ & 4 & 487.2 & 20.3 \\
\hline & 5 & 5.63 & $235-1403$ & 4 & 261.4 & 26.9 \\
\hline & 5 & 6.36 & $235-1403$ & 4 & 169.5 & 27.8 \\
\hline
\end{tabular}

The only other research where some estimates of the weak floor friction angles were reported was by Marino and Choi (1999). From the back analysis of 12 sag subsidence case histories where weak floor failures were suspected to be the cause of instability, Marino and Choi (1999) estimated that the angle of internal friction for the underclay floor involved should have been between $21^{\circ}$ and $31^{\circ}$. For this analysis, it was assumed that the weak floor had negligible cohesion and the floor bearing capacity could be estimated using the Mandel and Salencon (1972) model.

This lack of information and the difficulties involved in conducting any field or laboratory tests warrant a simple indirect approach to estimate the friction angles for the floor materials. Even if such an indirect approach is very approximate, it is still better than assuming some arbitrary number. It has been shown in Chapter 2 that some indirect approximate methods were developed by soil mechanics researchers to estimate the peak and residual friction angles using data generated from simple index tests like the Atterberg limits and particle size analysis. It has also been shown in Chapter 2 that when actual tests are not conducted, the Atterberg limits could be estimated from the moisture content value. Even though limited, the data in Tables 3.2 and 3.3 show a similar strong correlation between the Atterberg limits and the moisture content as depicted in Figure 3.36. The correlation between the variables in Figure 3.36 is much 

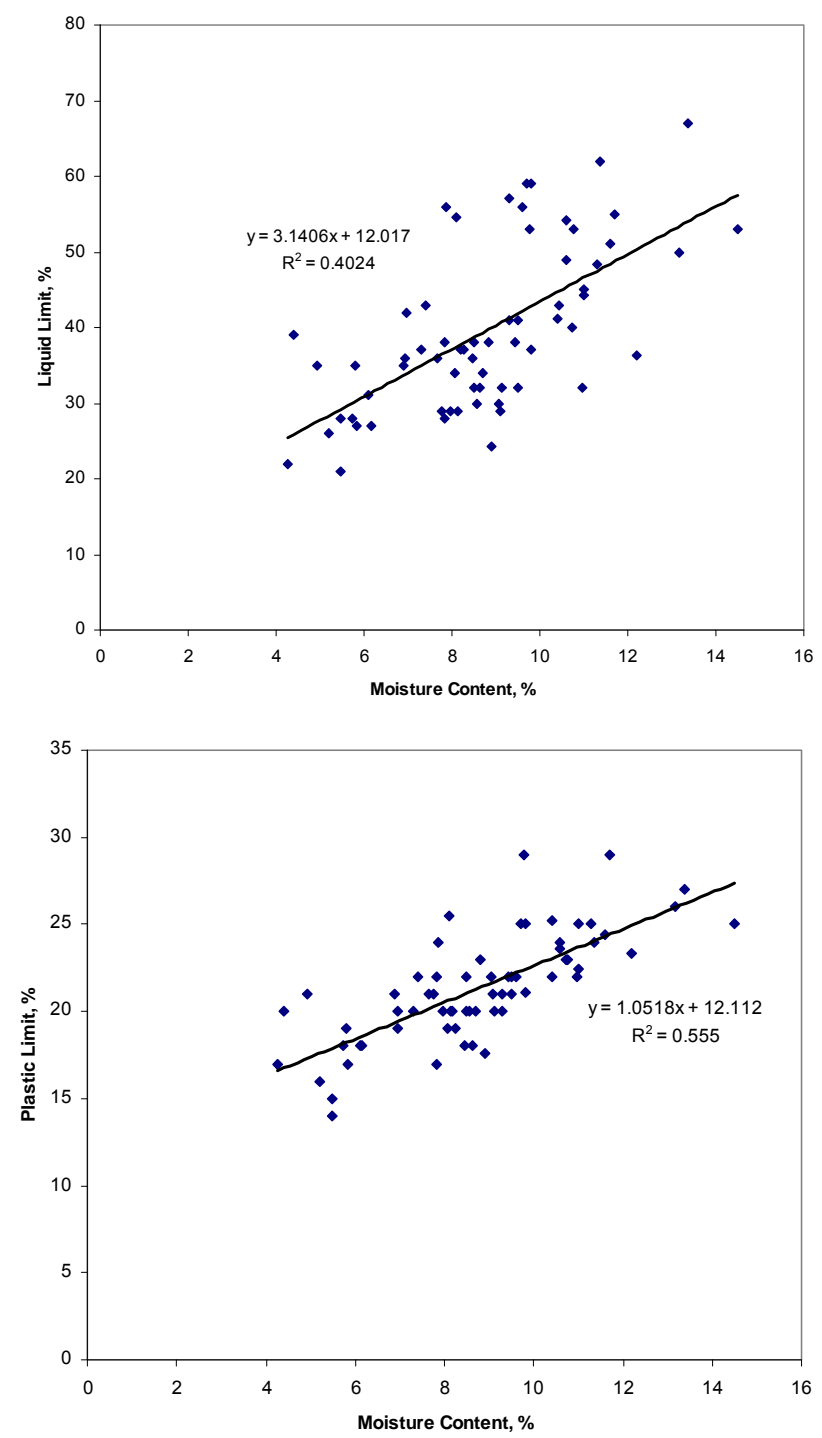

Figure 3.36. Relation between Atterberg Limits and moisture content for the data in Tables 3.2 and 3.3.

stronger than that shown by the laboratory data in Chapter 2. Considering the fact that the data in Chapter 2 are much larger and cover many more mines than that in Figure 3.36, it is suggested that notwithstanding the weaker correlation, the following equations derived in Chapter 2 could still be used for estimating the Atterberg limits from the moisture content value:

for the Herrin No.6 and equivalent seam floors.

$$
\begin{aligned}
& L L=39+3.0 M C \\
& P L=22+2.2 M C
\end{aligned}
$$

for the Springfied No.5 and equivalent seam floors: 


$$
\begin{aligned}
& L L=23+1.46 M C \\
& P L=13.5+0.7 M C
\end{aligned}
$$

Since enough data from Danville No. 7 are not available to develop similar relations as above, and considering that the floor nature of the No.7 and No.5 seams appear to be similar, equations $(3.24)-(3.25)$ may also be used for the No.7 seam as well.

Once the Atterberg limits are estimated by lab testing or through equations (3.22) and (3.25), the chart developed by Mesri and Abdel-Ghaffar (1993) in Figure 3.37 could be used to approximately compute the peak angle of internal friction. To test the validity of this approach, using the relations in equations (3.22) and (3.25) and the moisture value given in Chugh's tests in Table 3.4, the peak angle of internal friction has been estimated. The computed values are compared against the tested friction angles in Table 3.5. Obviously, it is realized that judging the performance of this simple procedure against just eight measurements is not sufficient. Nonetheless, the general range of friction angle values reported by Marino and Choi (1999) and the comparison of the data in Table 3.5 indicate that as a first approximation, the simple methodology suggested here is perhaps adequate. Apparently, more work remains to done in this direction before confident prediction of the friction angle can be made.

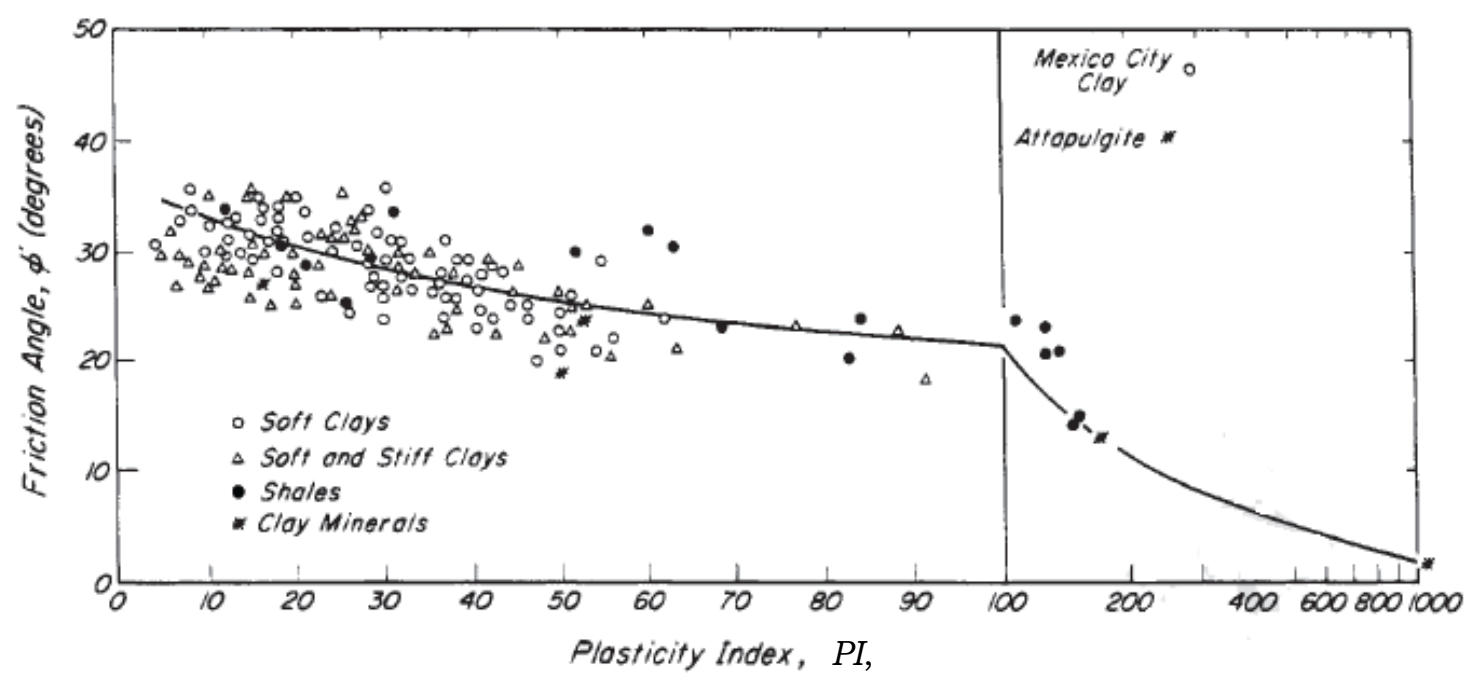

Figure 3.37. Relation between Atterberg Limits and peak friction angle (Mesri and AbdelGhaffar, 1993). 
Table 3.5. Comparison of friction angles from Chugh (1986b) tests and those computed using equations (3.22) and (3.25) in conjunction with Figure 3.37.

\begin{tabular}{|c|c|}
\hline $\begin{array}{l}\text { From In-situ } \\
\text { Tests }\end{array}$ & $\begin{array}{l}\text { From Figure } \\
3.37\end{array}$ \\
\hline 16.3 & 32 \\
\hline 35.4 & 29 \\
\hline 28.2 & 30.5 \\
\hline 32.4 & 29 \\
\hline 57.3 & 31 \\
\hline 20.3 & 28.5 \\
\hline 26.9 & 28.5 \\
\hline 27.8 & 28.5 \\
\hline
\end{tabular}

\subsection{In-Situ Deformation Modulus}

If pillar settlement over the weak floors is to be computed or if the bearing capacity analysis is to be done through numerical modeling, in addition to the cohesion and angle of internal friction values, knowledge on the deformation characteristics of the floor is also necessary. For a majority of routine design purposes, it is sufficient to assume that the weak floor bed is isotropic, homogeneous and behaves as a linearly elastic material before failure. When this approximation is made, the only two inputs needed to define the constitutive model completely are the modulus of deformation and the Poisson's ratio. For materials like the IL Basin weak floor that have lower friction angle values the Poisson's ratio may not significantly affect the floor bearing capacity or settlement computation and thus its value may be assumed to be 0.35 for routine modeling. However, some accurate information on the deformation modulus is necessary for settlement estimation or for numerical stress analysis.

As mentioned before, it is extremely difficult to sample and test the weak floor found in the Illinois Basin mines in laboratory. However, the plate test pressure-settlement curves obtained in this research provide information by which an indirect estimate of the floor deformation modulus could be made. The first systematic attempt to use the plate tests to compute the deformation modulus was made by the researchers at the Southern Illinois University, Carbondale (SIUC). Based on the pressure-settlement curves obtained from field 
tests conducted at seven Illinois coal mines, Pula et al., (1990) derived the following relationships to estimate the deformation modulus:

$$
\begin{array}{ll}
D M_{50}=54176(M C)^{-0.6} & \text { for claystone, } \\
D M_{50}=105873(M C)^{-0.88} & \text { for siltstone, } \\
D M_{50}=53103(M C)^{-0.47} & \text { for all weak floor strata, }
\end{array}
$$

where $D M_{50}$ is the deformation modulus estimated at $50 \%$ of the ultimate bearing capacity in the plate test and $M C$ is the moisture content in \%. Pressuredeformation curves from 68 plate tests, which included 55 claystone and 20 siltstone floors, formed the basis for equations 3.26 to 3.28. Pula et al., (1990) did not explain how the plate test data was analyzed to estimate the floor deformation modulus. From one of the earlier publication by Chugh (1986b), it appears that the following equation suggested by the ISRM had been used for computing the deformation modulus:

$$
E=\frac{d q}{d w_{z}} \frac{\pi}{4} D\left(1-\mu^{2}\right) I_{c}
$$

$$
\text { where } \quad \begin{array}{lll}
E & = & \text { deformation modulus, } \\
q & = & \text { applied pressure, } \\
w_{z} & = & \text { plate settlement, } \\
D & = & \text { plate diameter, } \\
\mu & = & \text { Poisson's ratio, } \\
I_{c} & = & \text { depth correction factor. }
\end{array}
$$

From the load-deformation curve obtained through in-situ plate tests, the slope of the curve within the elastic portion, $d q / d w_{z}$, can be estimated, which together with other inputs in equation (3.29) will provide an estimate of the deformation modulus. The depth correction factor is estimated for a circular plate using some graphs provided by the ISRM (1981). For the case of a square plate, Pytel (1998) gave the following equation to estimate the deformation modulus:

$$
E=\frac{q}{w_{z}} B_{p l}\left(1-\mu^{2}\right) I_{\rho} F_{e}
$$




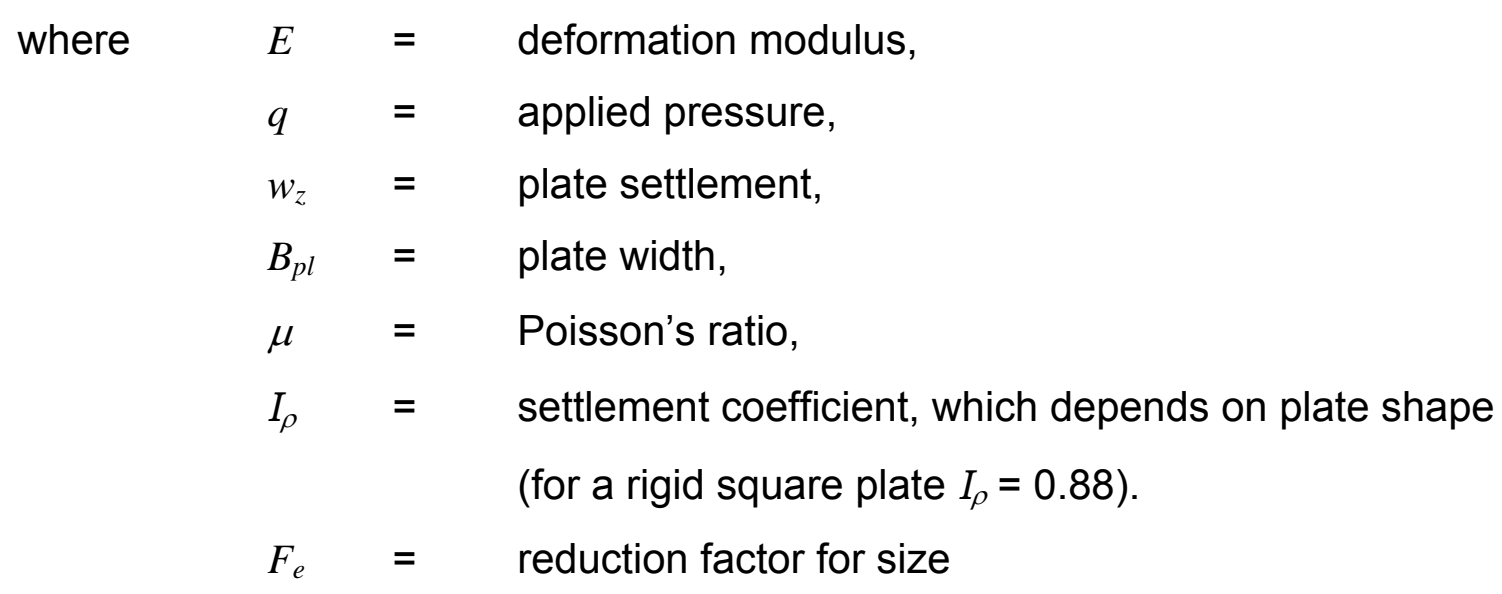
(0.4-0.85 for plate sizes between 6-12 inch).

A slightly different equation from (3.30) has been suggested by Bowles (1996) to compute the foundation settlements based on theory of elasticity as given below:

$$
w_{z}=q B_{p l} \frac{1-\mu^{2}}{E}\left(I_{1}+\frac{1-2 \mu}{1-\mu} I_{2}\right) I_{F}
$$

where $\quad E=$ deformation modulus,

$q \quad=\quad$ applied pressure,

$w_{z} \quad=\quad$ plate settlement,

$B_{p l}=$ plate width,

$\mu \quad=$ Poisson's ratio,

$I_{1}, I_{2}, I_{F}=\quad$ influence factors that depend on the plate size,

thickness of the weak floor, depth of plate base, and

Poisson's rato.

Bowles (1996) provided some relations and charts to estimate the values of the influence factors. The relationship in equation (3.31) is strictly valid for flexible plates only. However, if the plate is more close to being rigid, then Bowles (1996) suggested that equation (3.31) must be multiplied by 0.931 to estimate the settlement. For a Poisson's ratio of 0.35 and when the plate tests are assumed to have been conducted on a semi-infinite floor with $H / B_{p l}$ equals to $5(H=$ floor thickness; $B_{p l}=$ plate width), the following simplified version of equation (3.31) will provide an estimate of the deformation modulus: 


$$
E=0.4 \frac{d q}{d w_{z}} B_{p l}
$$

For some of the initial studies conducted here, both the ISRM and Bowles methods were used to compute the deformation modulus. These modulus values were then input to some numerical models which were constructed to check the validity of the two methods by comparing the model produced load-deformation curve with the field data. From this analysis, it was found that the ISRM equation overestimated the modulus for every case and a good match was obtained with equation (3.32). As an example, the excellent match obtained between the model results with equation (3.32) and field data are shown in Table 3.6. The plate settlement from the numerical models was obtained by running elastic models whose deformation modulus was computed by equation (3.32) when the vertical pressure given in the table was applied to the floor. Since the results in table 3.6 show that equation (3.32) provides an accurate estimate, it has been used for computing the deformation modulus for the entire plate test data analyzed next.

Table 3.6. Match between the numerical model results and field data.

\begin{tabular}{|c|c|c|}
\hline Plate pressure, psi & \multicolumn{2}{|c|}{ Plate settlement, inch } \\
\cline { 2 - 3 } & Field test & Numerical model \\
\hline 178 & 0.264 & 0.274 \\
\hline 273 & 0.267 & 0.202 \\
\hline 357 & 0.328 & 0.324 \\
\hline 536 & 0.592 & 0.586 \\
\hline 592 & 0.2 & 0.2 \\
\hline 642 & 0.08 & 0.079 \\
\hline
\end{tabular}

The plate pressure-settlement curves for all the data in Tables 3.2 and 3.3 are not available to estimate the deformation modulus at the individual sites. In fact, out of the 132 plate test data, the load-deformation curves were available for only 52 tests. Equation (3.32) has been used to calculate the deformation modulus using a fixed Poisson's ratio equal to 0.35 for these 52 test sites and the results are given in Table 3.7. It may be mentioned that to estimate the $d q / d w_{z}$ in equation (3.32), for each plate test, the plate settlements at $20 \%$ and $60 \%$ of the peak bearing capacity were used. A plot of the computed deformation modulus 
against the moisture content is provided in Figure 3.38. Since only a limited amount of data is available, the data were not split into two shelves and grouped together for the plot.

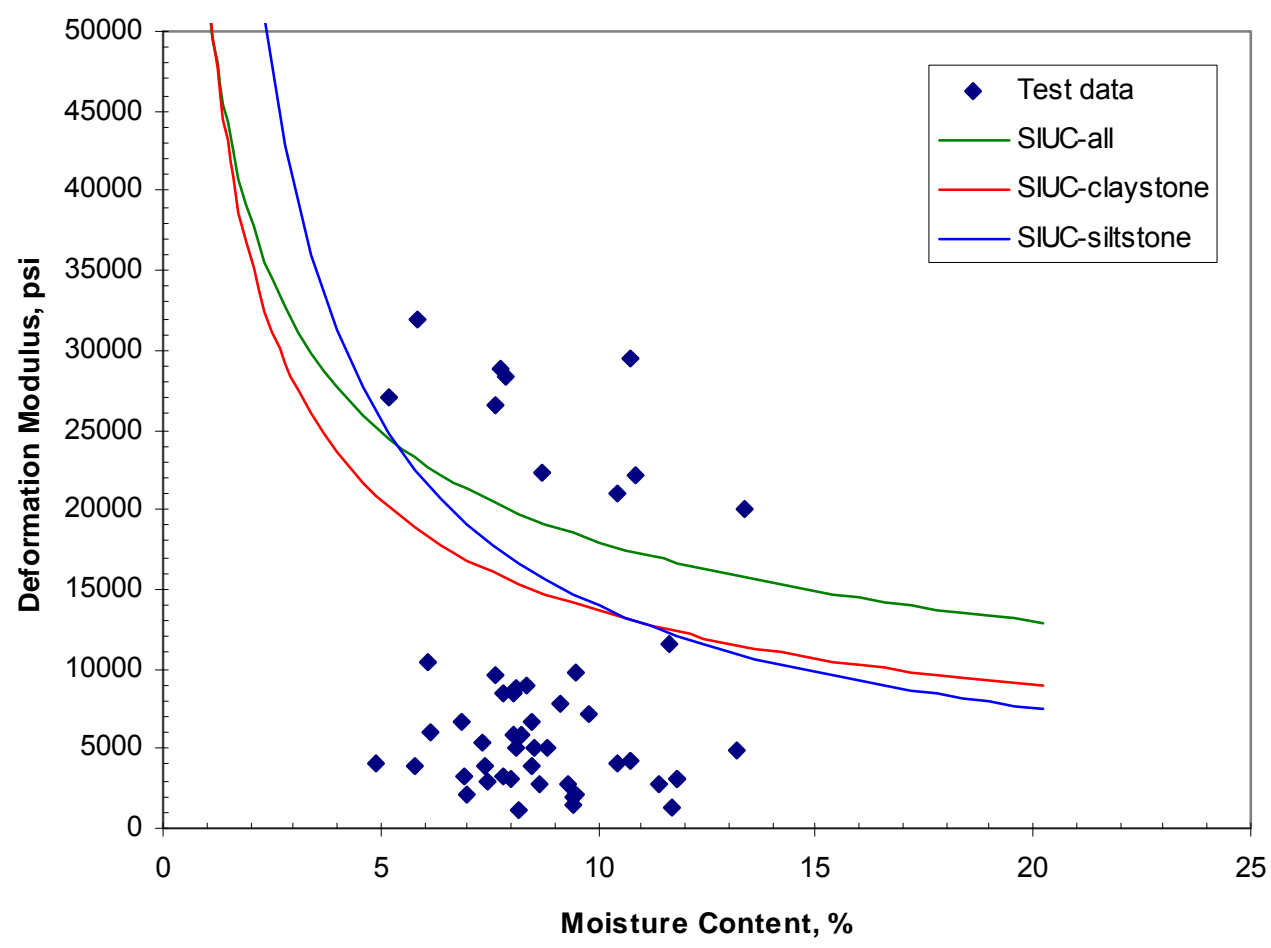

Figure 3.38.Deformation modulus versus moisture content.

The plot in Figure 3.38 shows that the scatter in the data is extremely high and very poor correlation is seen between the moisture content and the deformation modulus. Among the three SIUC relations for the deformation modulus given by equations (3.26)-(3.28), the claystone curve goes right through the middle of the data and performs better than the other two. Neither the amount of data nor the trends in Figure 3.38 are good enough to conduct any new regression. It appears that one of the reasons for the poor correlation in Figure 3.38 is due to the lack of a bearing pad between the plate and floor in these tests. As mentioned before, the small undulations in the floor could influence the amount of plate deformation, especially in the initial phase of the test. Even though part of this problem could have been compensated for by ignoring the plate settlements until the plate pressure reached $20 \%$ of the peak, some effect 
Table 3.7. Deformation modulus and other details from the plate test sites.

\begin{tabular}{|c|c|c|c|c|c|}
\hline Mine & $\begin{array}{r}\text { Moisture } \\
\text { Content, \% } \\
\end{array}$ & $\begin{array}{r}\text { Liquid } \\
\text { Limit, \% } \\
\end{array}$ & $\begin{array}{r}\text { Plastic } \\
\text { Limit, \% } \\
\end{array}$ & UBC, psi & $\begin{array}{l}\text { Deformation } \\
\text { Modulus, psi }\end{array}$ \\
\hline \multirow{15}{*}{1} & 10.88 & 125 & 34 & 854 & 22076 \\
\hline & 7.87 & 56 & 24 & 1606 & 28367 \\
\hline & 13.38 & 67 & 27 & 1024 & 20002 \\
\hline & 11.66 & 91 & 30 & 714 & 11557 \\
\hline & 13.17 & 50 & 26 & 998 & 4912 \\
\hline & 11.71 & 55 & 29 & 172 & 1313 \\
\hline & 9.78 & 53 & 29 & 638 & 7222 \\
\hline & 10.75 & 53 & 23 & 890 & 29470 \\
\hline & 10.43 & 104 & 26 & 855 & 21071 \\
\hline & 11.37 & 62 & 24 & 689 & 2772 \\
\hline & 5.79 & 35 & 19 & 894 & 3884 \\
\hline & 8.82 & 38 & 23 & 684 & 4990 \\
\hline & 4.92 & 35 & 21 & 740 & 4013 \\
\hline & 6.96 & 42 & 20 & 511 & 2194 \\
\hline & 7.31 & 37 & 20 & 638 & 5315 \\
\hline \multirow[t]{10}{*}{2} & 6.89 & 35 & 21 & 766 & 6727 \\
\hline & 8.46 & 36 & 18 & 1034 & 6691 \\
\hline & 8.64 & 32 & 18 & 421 & 2786 \\
\hline & 8.07 & 34 & 19 & 1085 & 8439 \\
\hline & 8.19 & 37 & 20 & 562 & 1107 \\
\hline & 8.26 & 37 & 19 & 798 & 5866 \\
\hline & 6.94 & 36 & 19 & 511 & 3223 \\
\hline & 9.31 & 41 & 21 & 421 & 2749 \\
\hline & 10.42 & 43 & 22 & 935 & 4044 \\
\hline & 9.44 & 38 & 22 & 753 & 1489 \\
\hline \multirow[t]{5}{*}{3} & 10.72 & 40 & 23 & 958 & 4300 \\
\hline & 6.1 & 31 & 18 & 1480 & 10396 \\
\hline & 7.84 & 29 & 17 & 1186 & 3258 \\
\hline & 11.82 & & & 445 & 3154 \\
\hline & 11.79 & & & 656 & 3086 \\
\hline \multirow[t]{10}{*}{4} & 7.75 & & & 556 & 28883 \\
\hline & 7.41 & & & 749 & 3843 \\
\hline & 9.46 & & & 580 & 2150 \\
\hline & 8.55 & & & 740 & 5044 \\
\hline & 7.66 & & & 781 & 9533 \\
\hline & 9.5 & & & 1031 & 9707 \\
\hline & 8.12 & & & 406 & 5023 \\
\hline & 8.49 & 32 & 20 & 912 & 3945 \\
\hline & 8.71 & 34 & 20 & 1230 & 22312 \\
\hline & 7.82 & 38 & 22 & 886 & 8428 \\
\hline \multirow[t]{6}{*}{5} & 7.65 & 36 & 21 & 921 & 26560 \\
\hline & 6.15 & 27 & 18 & 1479 & 6097 \\
\hline & 5.19 & 26 & 16 & 1700 & 27047 \\
\hline & 2.09 & & & 2074 & 209685 \\
\hline & 5.83 & & & 1944 & 31872 \\
\hline & 7.45 & & & 694 & 2980 \\
\hline
\end{tabular}


Table 3.7 (continued). Deformation modulus and other details from the plate test sites.

\begin{tabular}{|c|r|r|r|r|r|}
\hline Mine & $\begin{array}{c}\text { Moisture } \\
\text { Content, \% }\end{array}$ & $\begin{array}{c}\text { Liquid } \\
\text { Limit, \% }\end{array}$ & $\begin{array}{c}\text { Plastic } \\
\text { Limit, \% }\end{array}$ & UBC, psi & $\begin{array}{c}\text { Deformation } \\
\text { Modulus, psi }\end{array}$ \\
\hline 5 & 8.12 & & & 1528 & 8774 \\
& 8.38 & & & 556 & 8970 \\
& 9.15 & & & 694 & 7890 \\
& 7.98 & & & 556 & 3018 \\
& 9.43 & & & 667 & 1899 \\
& 8.05 & & & 806 & 5824 \\
\hline
\end{tabular}

of the crushed floor material might still have existed. Additionally, existence of a few strong hard spots below the test sites (like small limestone nodules) could make a dramatic difference to the plate settlement.

Despite the poor correlation shown in Figure 3.38, for the lack of a better alternative, it is recommended to use the SIUC deformation modulus equation for claystone for routine design work. If site specific plate test data is available, then the deformation modulus estimated from this data could be used in the analysis.

\subsection{Chapter Summary}

The literature review and the extensive field data analyzed for this chapter lead to the following broad conclusions:

- the three modes of failure identified for surface foundations exist in underground coal mines as well. Additionally, the 'softening' mode of failure seems to be important for long-term floor stability;

- the in-situ plate test setup used by all the researchers in the Illinois Basin mines was very similar. The surface preparation methods and the rate of loading used in the tests varied;

- the immediate floor at the plate test sites in this study exhibited general, local and punching shear failures as a function of the moisture content;

- the "let-the-floor-decide-the-loading-rate" approach provided some interesting insights on the floor failure mechanism. It appears that several small scale local failures occurred before the floor movements could be visually noticed; 
- the huge plate test database put together for this research demonstrated the conservative nature of the existing plate bearing capacity equations. The popular Speck's equation works reasonably well up to a moisture content of about $8 \%$, after which the underestimation is significant. For moistures above $12.4 \%$, Speck's equation produces negative floor strength. The different SIUC equations form the lower bound to the plate test data and hence are ultra conservative;

- new equations to estimate the plate bearing capacity as a function of moisture content have been developed for both the Eastern and Western shelves of the Basin. An equation has also been developed that is applicable to the entire Basin.

- some suggestions have been made to estimate the approximate angle of internal friction of the floor as a function of its natural moisture content;

- the existing modulus of deformation equations have been tested for their validity against a decent size in-situ test data. However, the plate test data exhibited too much scatter to develop any meaningful new correlations. Despite this, due to the lack of any better alternative, as a first approximation, it is suggested to use the SIUC claystone curve to compute the modulus of deformation as a function of the floor moisture;

- overall, the investigations in this chapter suggest that all the key engineering inputs for use with soil mechanics bearing capacity models or for numerical modeling can be fairly well estimated by knowing just the floor's natural moisture content. 


\section{CHAPTER}

\section{DETERMINATION OF FLOOR BEARING CAPACITY - SOIL MECHANICS APPROACH}

Underground coal mine pillars and foundations of a civil structure serve a broad similar purpose, i.e., effective transfer of loads imposed on them to the rock or soil over which they are formed. It has been shown in Chapter 2 that the engineering characteristics of coal mine soft floor could be described adequately within the realm of soil mechanics principles. Owing to these similarities, historically, when floor stability in underground coal mines was studied, the analyses relied heavily on foundation engineering principles. Several bearing capacity theories were utilized in the past for the purpose of floor strength estimation. In the Illinois Basin, the application of soil mechanics bearing capacity theories has matured to a stage where they are now routinely used for floor design.

Considering the significant role the traditional bearing capacity theories play in underground weak floor design, this chapter is devoted to the study of some such theories used in the past. While there are several bearing capacity theories available, in the Illinois Basin coal mines only two have found significant use. The strength theories developed by Vesic (1975), Mandel and Salencon (1969) were used in the past for pillar sizing. Between the two, Vesic's nonhomogeneous soil model is by far the most popular one and is the favored approach for regulatory approval purposes. Both these bearing capacity models will be discussed in this chapter including the assumptions and limitations when applied to coal mine floor design. Besides its historical importance and the fundamental framework it provides for bearing capacity estimation, a few in the Basin have used the Terzaghi-Prandtl-Reissner (Terzaghi et al., 1996) model for pillar design. Therefore, the discussions in the following sections will explore the Terzaghi's model as well. 
Theories on the bearing capacity of shallow foundations have been extensively discussed in several standard soil mechanics textbooks. Similarly, excellent reviews on bearing capacity theories from a mining application point of view are also available (Rockaway and Stephenson, 1979; Chugh, 1986b; Vasundhara, 2001). Therefore, in order not to be overly repetitive, in what follows only the high-level details of the general bearing capacity solutions are provided while the two models that found practical use in the Illinois Basin are discussed at some length.

\subsection{Bearing Capacity}

The design of a civil foundation is governed by either bearing capacity failure or limiting settlements (Terzaghi et al., 1996). When a foundation is designed against strength failure, the loads on the foundation are kept at levels below the supporting soil's bearing capacity modified by an acceptable safety factor. On the other hand, if the foundation can not tolerate settlements beyond a certain level to ensure its serviceability, then pre-failure deformation characteristics of the soil govern the design. Extensive theories - analytical, empirical and numerical - have been developed by soil mechanics researchers to assist in sizing a foundation based on the soil's bearing capacity or settlement.

Underground coal mine pillars in the Illinois Basin, on the other hand, are normally designed against floor bearing capacity failure alone. Very rarely, elastic and consolidation related floor displacements are considered in the design. Such small-scale settlement of pillars in a panel will not have noticeable effects on surface or underground. The effects of floor instability are noticed on the surface mainly because of the bearing capacity failure and the resulting large post-failure settlements. Although no supporting data were provided, analytical studies by Chugh and Pytel (1992) showed that differential settlements of adjacent pillars could sometimes cause roof instability in underground mines. On going research by the author to find a valid explanation for some time-dependent roof falls at a coal mine show that small-scale visco-elastic floor movements were the reason for such roof instability. Despite these limited indications that show the 
importance of pre-failure floor settlements, the majority of issues related to soft floor in coal mines occur as a result of the bearing capacity failure. Therefore, in what follows only the bearing capacity theories borrowed from foundation engineering are reviewed for their suitability for underground application.

\subsubsection{Terzaghi's Superposition Theory}

When a foundation is subjected to a monotonically increasing load and the corresponding deformations are monitored, load-deformation curves similar to those shown in Figure 4.1 are generated (Vesic, 1975). From these curves, it is possible to estimate the ultimate load that the foundation can support. Depending on factors like soil nature, rate of loading, etc., the ultimate load could be the peak in a load-deformation curve or a load at which a constant final rate of penetration begins as shown in Figure 4.1.

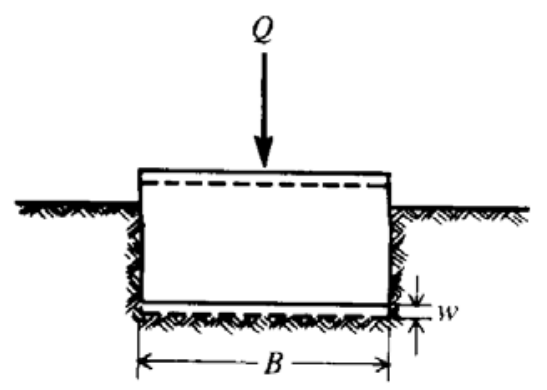

(a)

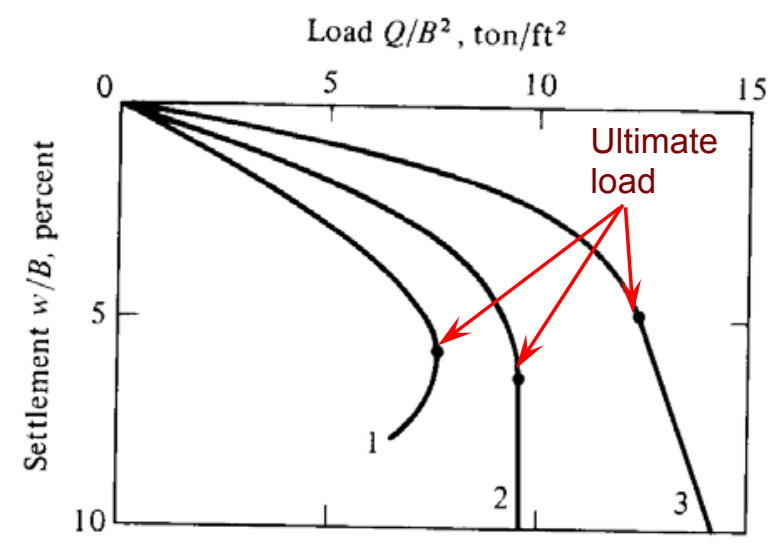

(b)

Figure 4.1. Load-vertical displacement relationship for a shallow foundation (after Vesic, 1975). 
Physical testing of real foundations for soil bearing capacity estimation as demonstrated in Figure 4.1 is extremely difficult and cost-prohibitive. Therefore, several methods were proposed to determine the ultimate load that a foundation could support based on theoretical considerations. Because of the complex material behavior, ill-defined boundary conditions and geometrical complexities, closed-from solutions for the general bearing capacity problem can not be obtained. Several assumptions must thus be made in order to provide an analytical solution. The following major approximations are made to obtain the bearing capacity of a seemingly very simple case - the case of a very long and narrow continuous (strip) foundation shown in Figure 4.2:

- the soil beneath the foundation is semi-infinte in extent and is homogeneous and isotropic;

- the load-deformation behavior of the underlying soil could be described using a rigid-perfectly-plastic model;

- no change in the soil volume occurs as the stress state reaches the critical limit;

- the foundation is in isolation and no interference with adjacent foundations occurs;

- the soil is weightless and no surcharge (weight of the soil above the foundation base level) exists;

- the soil satisfies the Mohr-Coulomb failure criterion;

- the deformation of the foundation itself could be ignored (rigid footing) and the foundation is loaded very slowly with no dynamic effects;

- the foundation is located above the water table.

In addition to the above, it is also necessary to assume the shape of the failure surface below the footing a priori in the traditional bearing capacity theories. The most commonly assumed failure surface for a weightless soil that has non-zero cohesion and friction is shown in Figure 4.2. Because of the confinement generated by the contact friction between the footing and the soil, zone $I$ in Figure 4.2 behaves elastically and thus physically acts like a wedge driving into the soil along with the footing. At the limit state, the soil in zones II 
and III has experienced shear failure and thus is in plastic state. The shear patterns in zone III are similar to the passive Rankine state while those in zone II resembles Rankine active state. As seen from Figure 4.2, one set of shear patterns in zone II radiates from the outer edge of the footing and thus zone II is also called the zone of radial shear (Terzaghi et al., 1996). The other set of shear pattern in zone II resembles that of logarithmic spirals whose centers are located at the outer edge of the base of the footing. Also shown in Figure 4.2 is the failure pattern below a footing resting on a cohesionless soil with non-zero friction and weight. In the latter case, the major difference is in the shape of the zone I which becomes somewhat curved as opposed to the straight edges seen in Figure $4.2(a)$.
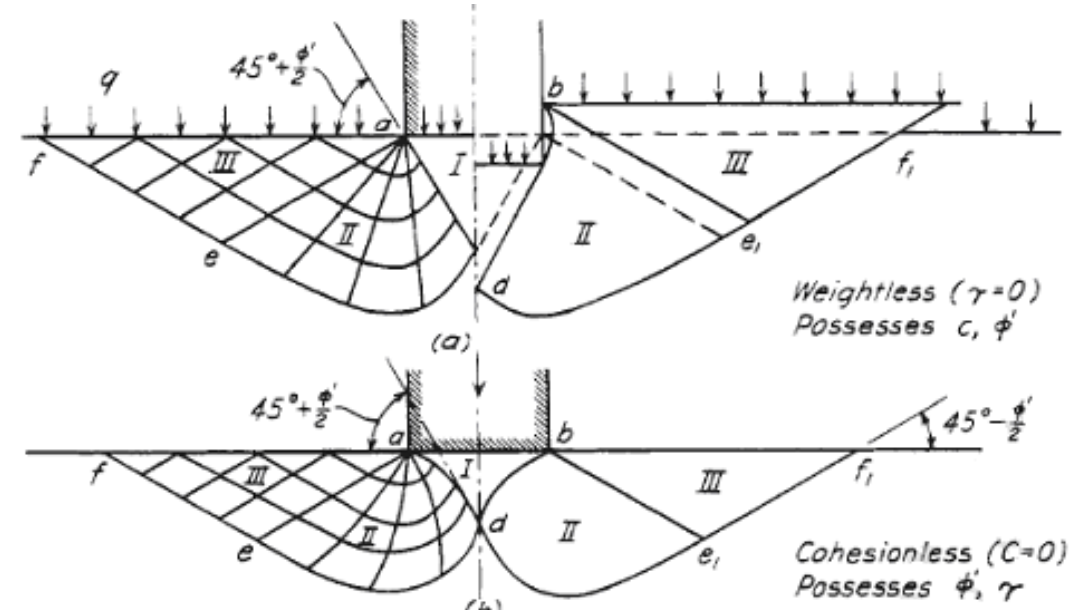

(b)

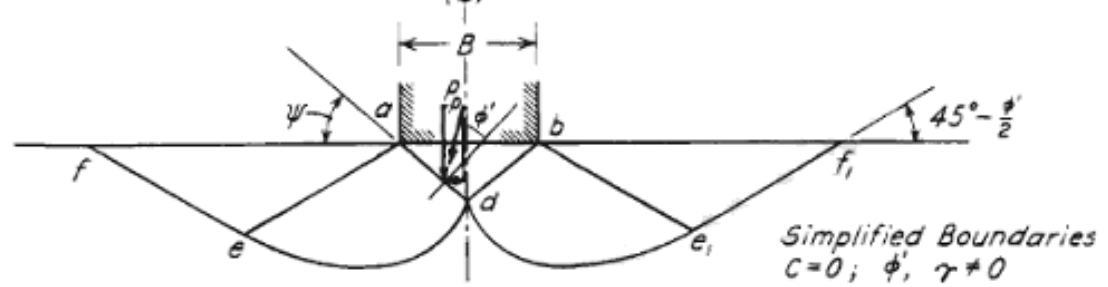

(c)

Figure 4.2. Outlines of the plastic zones when the soil reached limit state for a strip footing (Terzaghi et al., 1996).

When all the above approximations are made, an exact solution for the given bearing capacity problem could be obtained. Prandtl provided such a solution and it is given by (Terzaghi et al., 1996): 


$$
q_{c-s t r i p}=c N_{c}
$$

where $c$ is the soil cohesion and $N_{c}$ is called the bearing capacity factor for cohesion and is given by

$$
N_{c}=\cot \phi^{\prime}\left[e^{\pi \tan \phi^{\prime}} \tan ^{2}\left(45^{\circ}+\frac{\phi^{\prime}}{2}\right)-1\right]
$$

where $\phi$ is the effective soil friction angle.

Similarly, if all the above assumptions are kept the same and assume further that a uniform surcharge $q$ acts on the surface of the ground, then the shear failure pattern remains the same as in Figure 4.2. For such a situation also a closed-form solution exists due to Reissner (Terzaghi et al., 1996) and the bearing capacity increases from Equation (4.1) by the amount:

$$
q_{q-\text { strip }}=q N_{q}
$$

where $N_{q}$ is the bearing capacity factor for surcharge and is given by

$$
N_{q}=\left[e^{\pi \tan \phi^{\prime}} \tan ^{2}\left(45^{\circ}+\frac{\phi^{\prime}}{2}\right)\right]
$$

Derivation of the $N_{c}$ and $N_{q}$ solutions given above were provided in several standard textbooks on soil mechanics (Bowles, 1995; Das, 1999) and thus are not reproduced here.

It must be noted that under the assumptions made above, simple addition of equations (4.1) and (4.3) provided the exact total bearing capacity. In other words, the superposition of individual results matched the exact solution. The same superposition, however, will not provide exact solution if the weight of the soil material is also considered. Terzaghi et al., (1996) contends that since the material properties of a real soil can not be determined with precision, minor errors in bearing capacity estimation due to the superposition assumption will be inconsequential for practical design. Moreover, the superposition assumption provides conservative estimates of the bearing capacity. Therefore, the bearing capacity of a foundation for all practical purposes could be estimated by

$$
q_{\text {strip }}=c N_{c}+q N_{q}+\frac{1}{2} \gamma B N_{\gamma}
$$


where,

$$
\begin{array}{ll}
C & =\text { cohesion } \\
N_{c} & =\text { bearing capacity factor for cohesion } \\
q & =\text { surcharge due to the depth of the footing } \\
N_{q} & =\text { bearing capacity factor for surcharge } \\
\gamma & =\text { unit weight of the soil } \\
B & =\text { width of the footing } \\
N_{\gamma} & =\text { bearing capacity factor for soil weight }
\end{array}
$$

Equation (4.5) itemizes the bearing capacity as if three different conditions exist simultaneously in a given soil. The first term corresponds to a weightless soil with friction and cohesion and no surcharge; the second corresponds to frictional effects due to the surcharge, and the third term represents the effect of the weight of the soil itself with no surcharge. Under the assumption made for the strip footing above, exact solutions for $N_{c}$ and $N_{q}$ exist. But, a closed-form solution for $N_{\gamma}$ can not be obtained and several approximate solutions were proposed by different researchers over the years using a range of solution methods (Bowles, 1995; Terzaghi et al., 1996).

All the above discussions are applicable to a strip foundation under the influence of vertical loading. Real world applications, however, require solutions for several other geometries, loading conditions and soil formations. As mentioned before, for any realistic foundation situation, a closed-from solution does not exist. Therefore, Equation (4.5) has been modified with the introduction of additional variables to account for such factors as foundation shape, loading direction, depth, etc. The most general form of bearing capacity equation thus becomes (Bowles, 1995):

$$
q_{\text {strip }}=c N_{c} s_{c} d_{c} i_{c}+q N_{q} s_{q} d_{q} i_{q}+\frac{1}{2} \gamma B N_{\gamma} s_{\gamma} d_{\gamma} i_{\gamma}
$$

where

$$
\begin{array}{ll}
N_{c}, N_{q}, N_{\gamma} & =\text { bearing capacity factors, } \\
s_{c}, s_{q}, s_{\gamma} & =\text { shape factors } \\
d_{c}, d_{q}, d_{\gamma} & =\text { depth factors }
\end{array}
$$




$$
i_{c}, i_{q}, i_{\gamma}=\text { inclination factors, }
$$

Despite the availability of several versions of the three bearing capacity factors from different researchers, the following have been adopted by the majority (Bowles, 1995) and thus are adopted here:

$$
\begin{aligned}
& N_{c}=\cot \phi^{\prime}\left\lfloor N_{q}-1\right\rfloor \\
& N_{q}=\left[e^{\pi \tan \phi^{\prime}} \tan ^{2}\left(45^{\circ}+\frac{\phi^{\prime}}{2}\right)\right] \\
& N_{\gamma}=2\left(N_{q}+1\right) \tan \phi^{\prime}
\end{aligned}
$$

As will be explained in the next paragraph, for coal mine applications, the inclination and depth factors are normally not necessary. For an interested reader, expressions for the depth and inclination factors can be found in any standard soil mechanics text book and thus are not given here.

In adopting Equation (4.6) to coal mine application, several simplifications result. The geometrical setup for the bearing capacity problem in a typical coal mine in the Illinois Basin is shown in Figure 4.3. As seen from the figure, the pillars are located right at the surface of the weak floor and thus the effect of foundation depth on bearing capacity could be ignored. While coal mine underclays are not weightless and a typical pillar is much larger in size than a civil foundation, owing to the complexities in estimating $N_{\gamma}$ and also to be conservative, the third term in Equation (4.6) is normally ignored. Weightless underclay assumption does not make the estimated bearing strength ultraconservative because of the dominant role played by the cohesion term. The underestimation of the strength for normal Illinois Basin geo-mining conditions is less than $10 \%$. Additionally, since all the mineable coal seams in the Basin are nearly flat, the loads transferred by coal pillars to the floor are almost always vertical. Therefore, the inclination factors could also be ignored. As a result of these simplifications, if the weak floor is assumed to be semi-infinite, then its bearing capacity can be estimated by

$$
q_{\text {floor }}=c N_{c} s_{c}
$$


with $N_{c}$ value given by Equation (4.7).

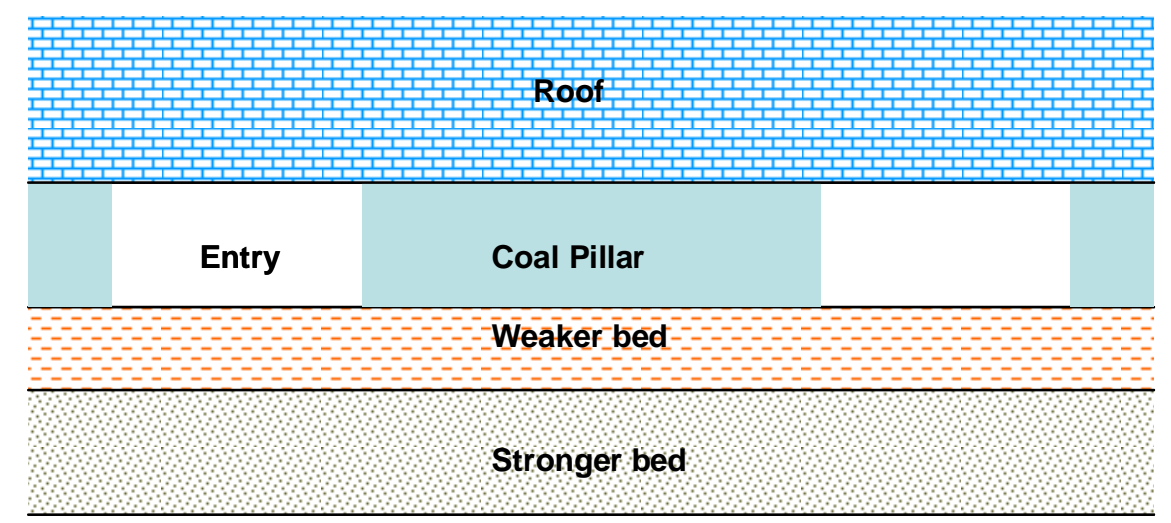

Figure 4.3. Typical underground coal mine geometry in the IL Basin coal mines.

Since the coal mine pillars could have several shapes in the plan view, it is necessary to retain the shape factor, $s_{c}$ in the bearing capacity equation. For homogeneous semi-infinite floor conditions, the shape factors proposed by De Beer are most popular (Vesic, 1975) as given below.

$$
\begin{aligned}
& s_{c}=1+\left[\frac{B}{L}\left(\frac{N_{q}}{N_{c}}\right)\right] \\
& s_{q}=1+\left[\frac{B}{L} \tan \phi^{\prime}\right] \\
& s_{\gamma}=1-\left[\frac{0.4 B}{L}\right]
\end{aligned}
$$

where $B$ is the footing width; $L$ is the footing length; $N_{c}$ and $N_{q}$ are the bearing capacity factors; and $\phi$ is the friction angle. As shown by Equation (4.10), for coal mine application only the shape factor corresponding to cohesion is needed.

It may be mentioned that for shapes other than a long-continuous footing, exact solutions for the bearing capacity factors do not exist. Therefore, some semi-empirical approaches have been used to derive the expressions in Equations (4.11) - (4.13). It appears that very little field verification data exists to show the validity of the shape factor expressions and thus their accuracy can not be verified (Bowles, 1995). In addition to foundation shape, soil's compressibility, rate of loading on the footing, presence of adjacent foundations, spatial and 
temporal variability of soil strength, horizontal stresses, water table and several other factors also affect the bearing capacity (Terzaghi et al., 1996; Bowles, 1995; Das, 1999).

It is important to notice from equations (4.10) - (4.13) that for the same width, the strength of floor below a long-continuous pillar is the lowest and that of a square pillar the highest with rectangular pillars in between. This sequence is just the reverse of that based on coal strength. For coal pillar strength, the sequence is long-continuous $>$ rectangular $>$ square for the same width.

\subsubsection{Vesic's Model for Non-homogeneous Soils}

The bearing capacity factors given in section 4.1.1 are applicable for a semi-infinite homogeneous soil below a foundation. As shown in Figure 4.3, however, coal mine floor conditions are non-homogeneous and the thickness of the weak floor is finite. If the weaker bed in Figure 4.3 is assumed to be semiinfinite, then very conservative estimates of the floor strength are made thus resulting in unnecessarily large pillars. Unfortunately, the coal mine situation given in Figure 4.3 defies rigorous analytical solution and thus not many bearing capacity equations are available in soil mechanics literature to represent such conditions. Among the available solutions, the difficulty of verifying any chosen equation's applicability for coal mine use makes the task of finding the right theory even more challenging.

Earlier researchers (Rockaway and Stephenson, 1979) from the University of Missouri, Rolla (UMR) picked a bearing capacity theory for non-homogeneous soil conditions developed by Vesic $(1970,1973,1975)$ for coal mine application. Although the Vesic's solution does not account for several aspects of coal mine bearing capacity problem, for the lack of a better alternative, this approach has been used for pillar design in the Basin for well over two decades and is currently the de facto method for regulatory approval purposes. It appears that the Vesic equation's widespread use is only fortuitous and certainly not because it represents the coal mining geo-mining conditions better. It just so happened that 
the first credible research group picked that particular equation and no viable better solutions were developed later thus leaving no alternative but to use whatever solution was available.

Obviously, the Vesic equation's inability to represent all aspects of a typical coal mine bearing capacity problem need not be seen as a major issue now. As long as the expected trends are reflected, and given enough time for practical application, any design approach - accurate or not - could be made to serve the intended purpose by picking up design stability factors that make up for the deficiencies in the chosen theory. That is exactly what has happened with the Vesic's solution. This bearing capacity model has been in use for so long in the Basin that on a majority of occasions the design stability factors set for the theory serve the purpose, i.e., prevention of long-term floor failures that have the potential to cause surface subsidence.

It is amazing that despite the widespread use of Vesic's theory, very little is known about the details of the model. Vesic did not publish finer details of the theory and as a matter of fact only a single readily accessible publication exists on the subject. In this classic publication on bearing capacity of shallow foundations, Vesic (1975) spent no more than a page on the details of the nonhomogeneous soil bearing capacity solution as it applies to coal mine conditions. Because very limited details are available, almost all of that discussion given in the Vesic's 1975 publication is reproduced here.

A very common type of soil non-homogeneity occurs when distinct soil layers of relatively constant thickness but with different strength characteristics exist at a location. Two situations are possible as shown in Figure 4.4. Apparently, only the condition shown in Figure 4.4 (a), where a soft layer overlies a stronger layer, applies to the majority of coal mines in the Illinois Basin.

In his paper, Vesic discussed the research done by a few others for the conditions shown in Figure 4.4. In particular, he mentioned works of Button (1953), Brown and Meyerhof (1969) and Hartmann (1925). Button (1953) analyzed similar conditions as in Figure 4.4 but for a fully saturated clay layer that exhibited general shear failure along cylindrical surfaces starting at the 
edges of the foundation. A later experimental work by Brown and Meyerhof (1969) showed that the failure surfaces assumed by Button were invalid. Hartmann (1925) proposed that the realistic failure mode for the situation in Figure 4.4 (a) appeared to be due to lateral plastic flow similar to that occurring in a solid squeezed between two rough parallel plates.

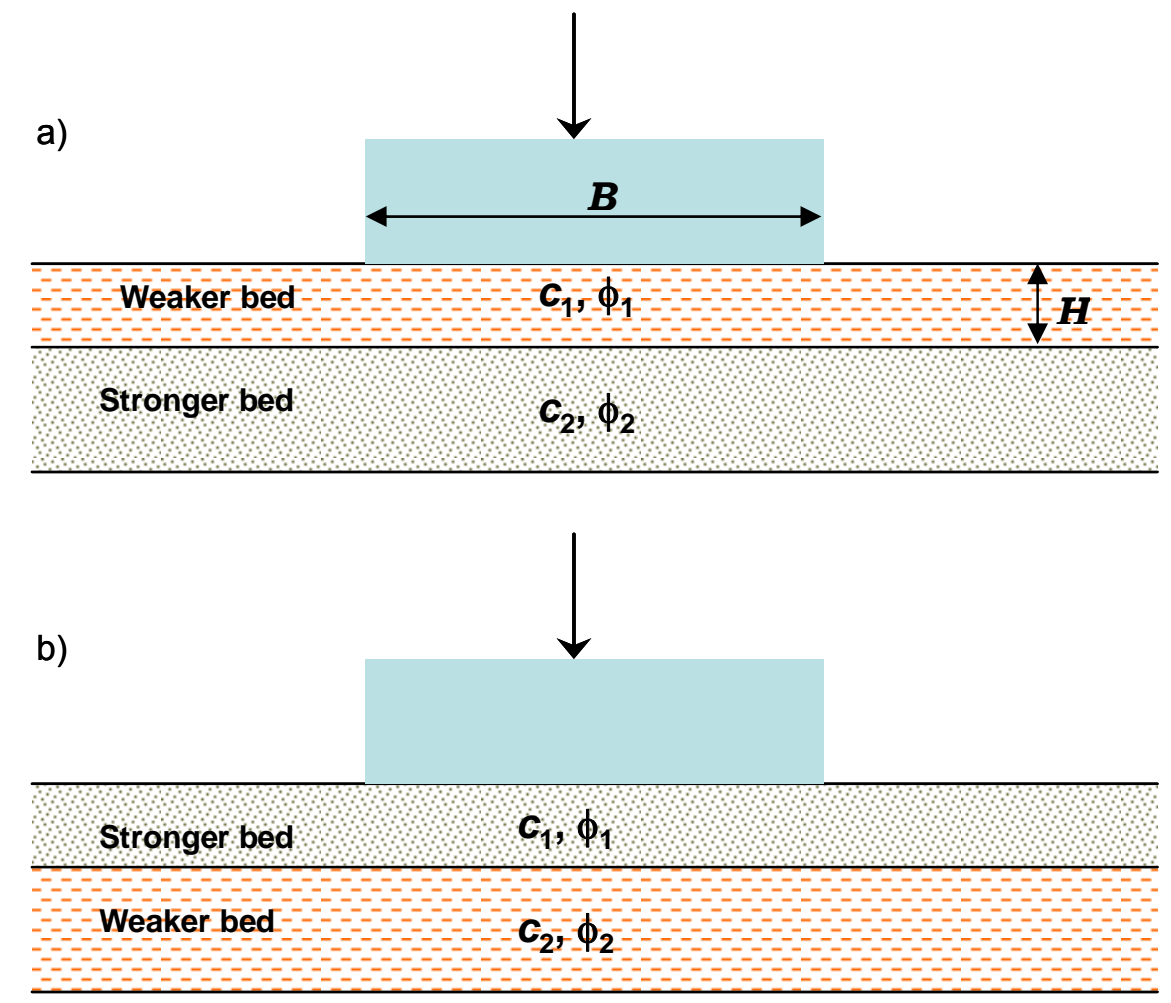

Figure 4.4. Two common situations of soil nonhomogeneity (after Vesic, 1975).

According to Vesic (1975), for zero surcharge, the bearing capacity of the footing for the situation shown in Figure 4.4 (a) is given by

$$
q_{\text {floor }}=c_{1} N_{m}
$$

where $c_{1}$ represents the undrained shear strength of the upper layer and $N_{m}$ is a modified bearing capacity factor given by

$$
N_{m}=\frac{K N_{c}^{*}\left(N_{c}^{*}+\beta-1\right)\left[(K+1) N_{c}^{*^{2}}+(1+K \beta) N_{c}^{*}+\beta-1\right]}{\left.\left\{K(K+1) N_{c}^{*}+K+\beta-1\right]\left[\left(N_{c}^{*}+\beta\right) N_{c}^{*}+\beta-1\right]\right\}-\left[\left(K N_{c}^{*}+\beta-1\right)\left(N_{c}^{*}+1\right)\right]}
$$


where,

$K=$ ratio of undrained shear strength of the lower stronger layer $\left(c_{2}\right)$ to the upper weaker layer $\left(c_{1}\right)$,

$N_{c}^{*}=s_{c} N_{c} ; N_{c}=5.14$ for $\phi=0$,

$s_{c}=$ shape factor given in Equation (4.11),

$N_{c}=$ bearing capacity factor for homogeneous semi-infinite soil given in Equation (4.7),

$\beta=$ punching index given by $\frac{B L}{[2(B+L) H]}$

with $B=$ width; $L=$ length of the footing; and $H=$ thickness of the upper weaker layer.

The most important aspect of Equation (4.14) is the modified bearing capacity factor, $N_{m}$ that takes into account the effect of non-homogeneity of the soil profile. However, in connection with the derivation of the expression for $N_{m}$, Vesic (1975) just mentions that, "by interpolation between known rigorous solutions of the related problems one can obtain the following expression for $N_{m} \ldots$.. Barring that one sentence nothing else was said about the derivation of $N_{m}$. Since the methodology followed in deriving $N_{m}$ in Equation (4.14) is central to fully appreciate the strengths and weaknesses of Vesic's approach, the author made an uneventful, yet a rather interesting attempt to find how the expression was derived. The author contacted Dr. Vesic's widow and visited their residence to search through his personal library with the hope to find the original derivation of the bearing capacity factor. The details are given in Appendix-I.

Even though the exact derivation of Equation (4.15) is not known, to assure its accuracy, it is important to check if the equation provides known solutions for certain limit conditions or if it provides physically unacceptable predictions for any feasible real world situation. In the limit, when $K=1$ the immediate floor will be of infinite thickness $(H \rightarrow \infty)$ and thus $\beta=0$. For this condition, Equation (4.14) should reduce to $s_{c} \cdot N_{c}$ as in Equation (4.10). Substituting $K=1, \beta=0$ in Equation (4.15) gives, 


$$
\begin{aligned}
& N_{m}=\frac{N_{c}^{*}\left(N_{c}^{*}-1\right)\left[2 N_{c}^{* 2}+N_{c}^{*}-1\right]}{\left\{\left[2 N_{c}^{*}+1-1\right]\left[N_{c}^{* 2}-1\right]\right\}-\left[\left(N_{c}^{*}-1\right)\left(N_{c}^{*}+1\right)\right]} \\
& N_{m}=\frac{N_{c}^{*}\left(N_{c}^{*}-1\right)\left[2 N_{c}^{* 2}+2 N_{c}^{*}-N_{c}^{*}-1\right]}{\left\{\left[2 N_{c}^{*}-1\right]\left[N_{c}^{* 2}-1\right]\right\}} \\
& N_{m}=\frac{N_{c}^{*}\left(N_{c}^{*}-1\right)\left[\left(2 N_{c}^{*}-1\right)\left(N_{c}^{*}+1\right)\right]}{\left\{\left[2 N_{c}^{*}-1\right]\left[N_{c}^{* 2}-1\right]\right\}}
\end{aligned}
$$

Cancelling the similar terms will lead to the correct result, $N_{m}=N_{c}^{*}$.

It has been noted by Pytel (1998) that Equation (4.15) provides invalid or physically unacceptable solutions for the following two conditions:

1. If $\beta<1$, then $N_{m}$ becomes less than $N_{c}^{*}$ which is inadmissible. It has been shown above that when the floor thickness becomes infinite, $N_{m}=N_{c}^{*}$, which is the correct solution. From these two observations it appears that there is a range of floor thicknesses over which Equation (4.15) yields inadmissible solutions before converging back to the correct theoretical solution at the limit $H \rightarrow \infty$. Therefore, Equation (4.15) should not be used when $\frac{B L}{2(B+L)}<H<\infty$.

2. When the thickness of the immediate floor keeps decreasing and in the limit when $H \rightarrow 0$, the value of $\beta \rightarrow \infty$. Then, Equation (4.15) reduces to,

$$
\underset{\text { Limit }}{K \rightarrow \infty} \frac{K N_{c}^{*}\left(N_{c}^{*}+\beta-1\right)\left[(K+1) N_{c}^{*^{2}}+(1+K \beta) N_{c}^{*}+\beta-1\right]}{\left.\left\{K(K+1) N_{c}^{*}+K+\beta-1\right]\left[\left(N_{c}^{*}+\beta\right) N_{c}^{*}+\beta-1\right]\right\}-\left[\left(K N_{c}^{*}+\beta-1\right)\left(N_{c}^{*}+1\right)\right]}
$$

Dividing both numerator and denominator by $\beta^{2}$ gives,

$$
\operatorname{Limit}_{\beta \rightarrow \infty} \frac{K N_{c}^{*}\left(\frac{N_{c}^{*}}{\beta}+1-\frac{1}{\beta}\right)\left[\frac{(K+1) N_{c}^{* 2}}{\beta}+\left(\frac{1}{\beta}+K\right) N_{c}^{*}+1-\frac{1}{\beta}\right]}{\left\{\left[\frac{K(K+1) N_{c}^{*}+K}{\beta}+1-\frac{1}{\beta}\right]\left[\left(\frac{N_{c}^{*}}{\beta}+1\right) N_{c}^{*}+1-\frac{1}{\beta}\right]\right\}-\left[\left(\frac{K N_{c}^{*}}{\beta}+1-\frac{1}{\beta}\right) \frac{\left(N_{c}^{*}+1\right)}{\beta}\right]}
$$


Evaluating the above limit and rearranging the terms gives,

$$
N_{m}=\frac{K N_{c}^{*}\left[K N_{c}^{*}+1\right]}{N_{c}^{*}+1}
$$

For these conditions, however, the physically admissible value of $N_{m}$ should be $K N_{c}^{*}$ (Pytel, 1998).

There is another limiting condition for which Equation (4.15) can be evaluated. This is when the ratio of cohesive strengths of the stronger and weaker beds is extremely high or in the limit when $K \rightarrow \infty$. For this situation, Equation (4.15) becomes,

$$
\underset{K \rightarrow \infty}{\text { Limit }} \frac{K N_{c}^{*}\left(N_{c}^{*}+\beta-1\right)\left[(K+1) N_{c}^{*^{2}}+(1+K \beta) N_{c}^{*}+\beta-1\right]}{\left.\left\{K(K+1) N_{c}^{*}+K+\beta-1\right]\left[\left(N_{c}^{*}+\beta\right) N_{c}^{*}+\beta-1\right]\right\}-\left[\left(K N_{c}^{*}+\beta-1\right)\left(N_{c}^{*}+1\right)\right]}
$$

Dividing both numerator and denominator by $K^{2}$ gives,

$$
\operatorname{Limit}_{K \rightarrow \infty} \frac{N_{c}^{*}\left(N_{c}^{*}+\beta-1\right)\left[\left(1+\frac{1}{K}\right) N_{c}^{* 2}+\left(\frac{1}{K}+\beta\right) N_{c}^{*}+\frac{\beta}{K}-\frac{1}{K}\right]}{\left\{\left[\left(1+\frac{1}{K}\right) N_{c}^{*}+\frac{1}{K}+\frac{\beta}{K^{2}}-\frac{1}{K^{2}}\right]\left[\left(N_{c}^{*}+\beta\right) N_{c}^{*}+\beta-1\right]\right\}-\frac{\left[\left(K N_{c}^{*}+\beta-1\right)\left(N_{c}^{*}+1\right)\right]}{K^{2}}}
$$

Evaluating the above limit yields,

$$
N_{m}=\frac{N_{c}^{*}\left(N_{c}^{*}+\beta-1\right)\left\lfloor N_{c}^{*^{2}}+\beta N_{c}^{*}\right\rfloor}{\left\{N_{c}^{*}\left[\left(N_{c}^{*}+\beta\right) N_{c}^{*}+\beta-1\right]\right\}}
$$

After cancelling similar terms and rearranging, we get

$$
N_{m}=\frac{N_{c}^{*}\left(N_{c}^{*}+\beta-1\right)\left[N_{c}^{*}+\beta\right]}{\left(N_{c}^{*}+\beta\right) N_{c}^{*}+\beta-1}
$$

When there is a reason to suspect that the main floor is several times stronger (e.g., strong limestone) than the immediate weak bed, then the 
simplified version in Equation (4.18) may be used to estimate the Vesic's bearing capacity factor.

The expression for $N_{m}$ given in Equation (4.15) is somewhat complex and the effect of different variables on its magnitude is not readily apparent. Since Vesic's solution in Equation (4.14) is widely used in the Illinois Basin coal mines, it is interesting to see how different geometric variables affect $N_{m}$. Similar parametric studies of the Vesic's solution were provided by Rockaway and Stephenson (1979) and Chugh (1986b). The effect of change in the immediate floor thickness on $N_{m}$ is plotted in Figure 4.5 for two different pillar widths of $B=$ $35 \mathrm{ft}$ and $B=80 \mathrm{ft}$ and moisture content values of $6 \%$ and $10 \%$. These pillar widths represent the limits of the sizes currently used in the Illinois Basin mines. The weak floor cohesion was estimated for the chosen moisture values using the Speck's equation given in chapter 3 .

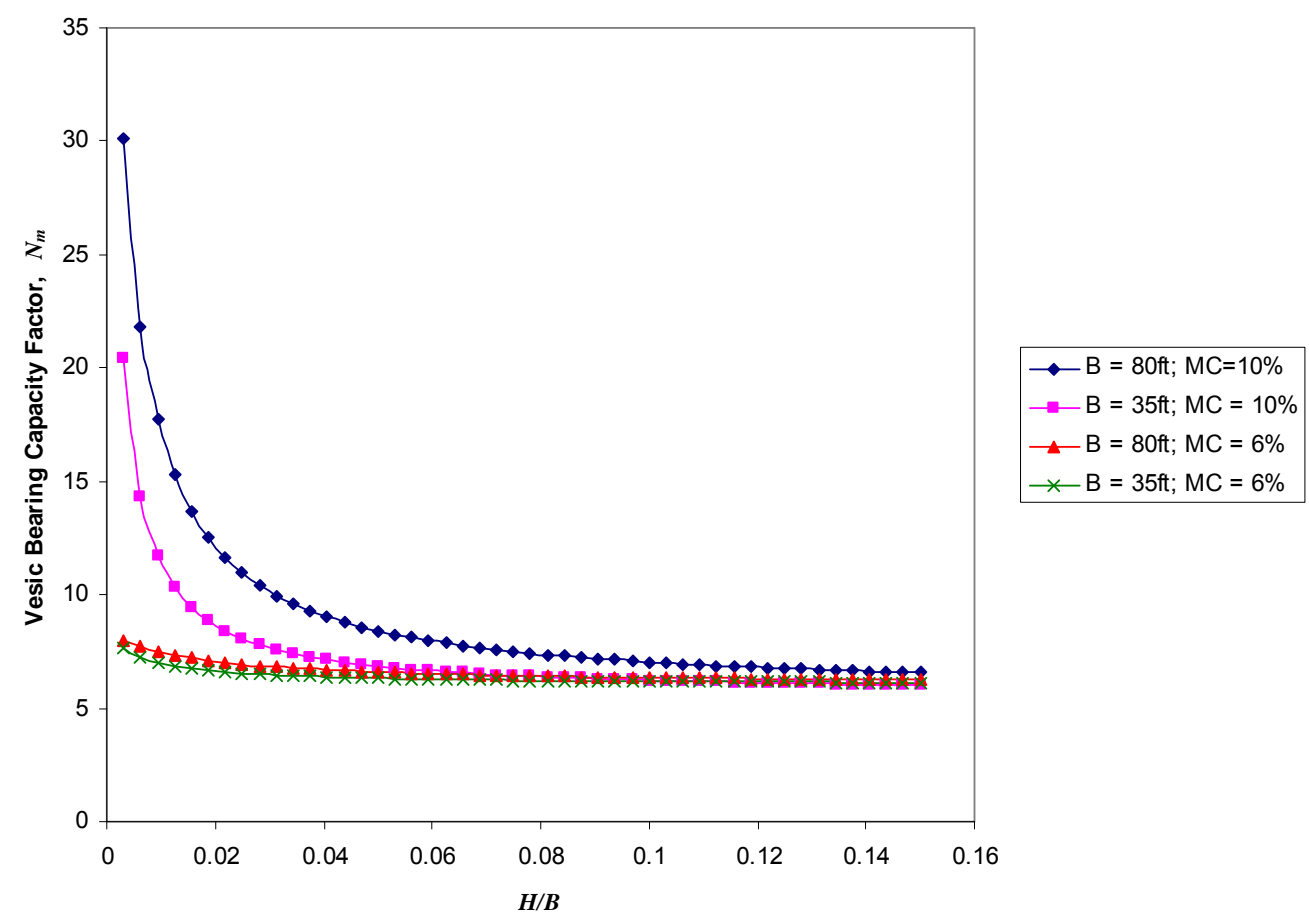

Figure 4.5. Effect of weak floor thickness on Vesic's bearing capacity factor, $N_{m}$.

Similarly, the effect of change in the ratio of $c_{2} / c_{1}$ on $N_{m}$ for the same pillar widths as in Figure 4.5 and for two floor thicknesses of $1 \mathrm{ft}$ and $6 \mathrm{ft}$ is plotted in Figure 4.6. Finally, the effect of pillar $L / B$ on $N_{m}$ is depicted in Figure 4.7. 


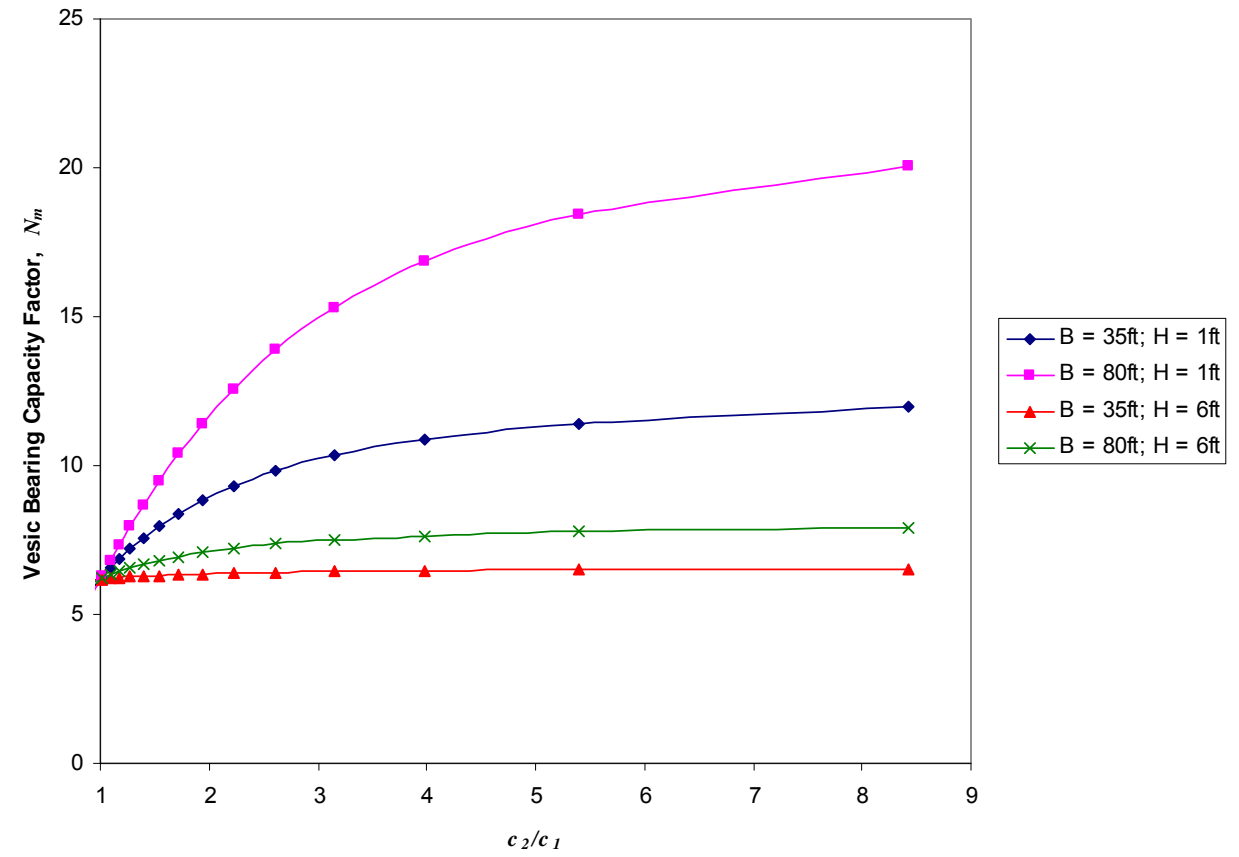

Figure 4.6. Effect of strength ratio, $c_{2} / c_{1}$ on Vesic's bearing capacity factor, $N_{m}$.

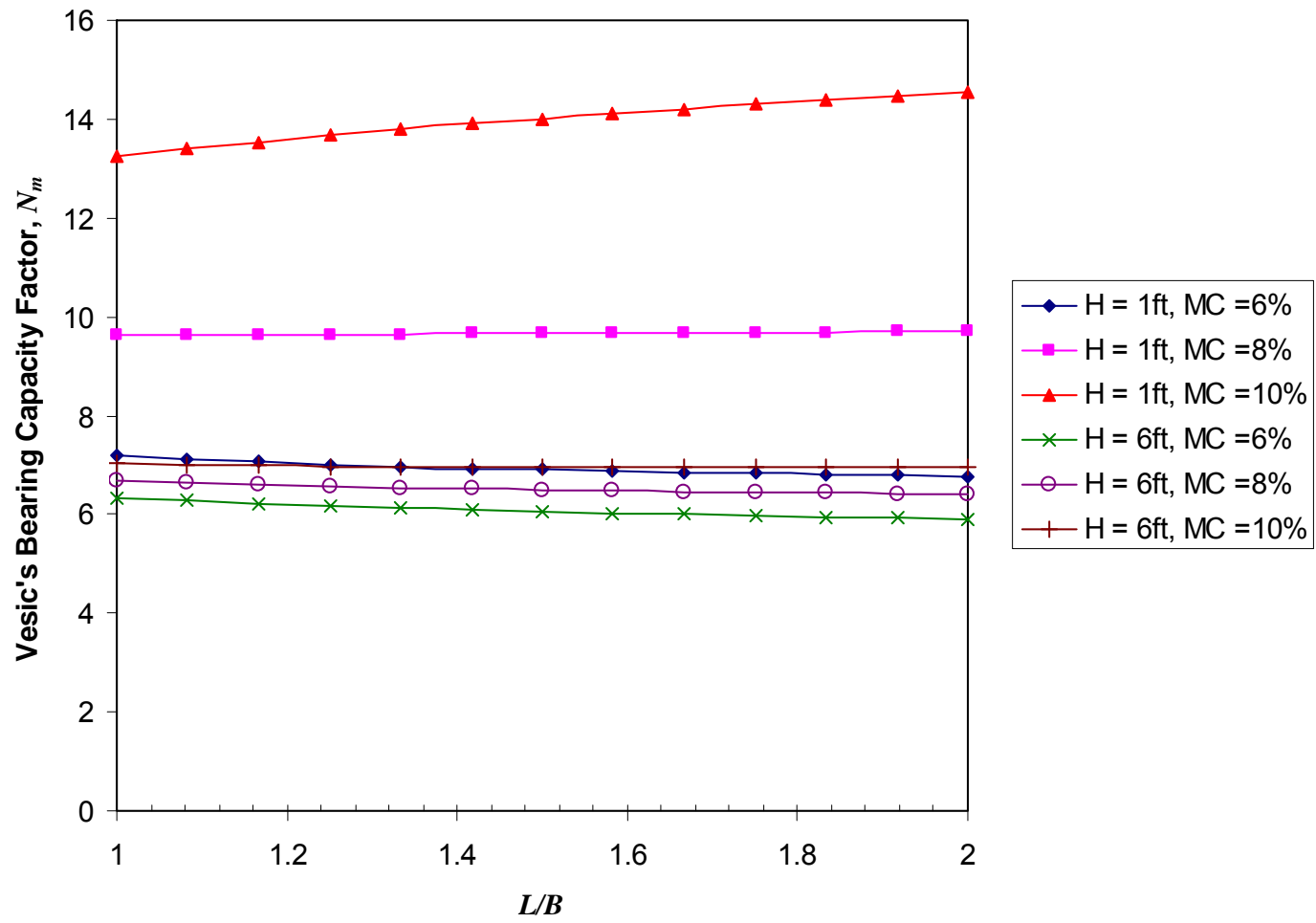

Figure 4.7. Effect of the pillar aspect ratio, $L / B$ on Vesic's bearing capacity factor, $N_{m}$. 
From the results in Figure 4.5 through Figure 4.7, the following observations could be made about the performance of Vesic's equation:

- with increasing floor thickness, the bearing capacity factor falls for a fixed pillar width, and after the $H / B$ ratio increases to a certain value, the change is negligible. At higher $H / B$ values, the effect of the presence of the stronger bed on the bearing capacity is significantly diminished by the thicker weak floor. For such thick immediate floors, the bearing capacity will not be influenced either by $H / B$ or by $c_{2} / c_{1}$;

- the effect of $H / B$ is different for different $c_{2} / c_{1}$ values. For lower strength ratio values, the effect of $H / B$ on $N_{m}$ is smaller as compared to when the contrast in the strength between the beds is higher. This basically means the bearing capacity factor value increases with increasing immediate floor moisture for a fixed strength of the stronger bed. This might seem surprising given that the floor strength drops significantly with moisture as shown in chapter 3. However, for $N_{m}$ computation, it is the ratio of $c_{2} / c_{1}$ that matters not the absolute value of $c_{1}$. Even though the $N_{m}$ value increases with moisture, the overall bearing capacity of the floor decreases as given by Equation (4.14);

- the positive effect of increasing pillar width is highly dependent on the value of $c_{2} / c_{1}$. For instance, as Figure 4.5 shows, the increase in the bearing capacity factor value is substantially higher for $10 \%$ moisture value (higher $c_{2} / c_{1}$ ) than for $6 \%$ (lower $c_{2} / c_{1}$ ) when the square pillar width is increased from $35 \mathrm{ft}$ to $80 \mathrm{ft}$;

- when $c_{2} / c_{1}$ ratio exceeds six, the bearing capacity change is negligible;

- overall, the aspect ratio of the pillar $(L / B)$ does not have a substantial effect on the bearing capacity. Also, the effect of $L / B$ is highly dependent on the ratio of $c_{2} / c_{1}$ and to some extent on $H / B$. The plots in Figure 4.7 show that the decrease of bearing capacity with increasing aspect ratio happens only when the $c_{2} / c_{1}$ value is close to 1.0 . For higher $c_{2} / c_{1}$ values, there was almost no change in the $N_{m}$ value up to a certain point and then 
for $c_{2} / c_{1}$ ratios in excess of 3 or so, the bearing capacity increased with $L / B$ in contrast to the conventional approach given in Equations (4.11)-(4.13).

Despite the fact that full details on the derivation of Vesic's bearing capacity factor are not known, the following basic assumptions and limitations inherent in the solution are known:

- it is applicable only for two layer soil non-homogeneity;

- both layers are frictionless cohesive soils $\left(\phi_{1}=0, c_{1} \neq 0\right.$ and $\left.\phi_{2}=0, c_{2} \neq 0\right)$ and each layer by itself is homogeneous and isotropic;

- both layers satisfy the Mohr-Coulomb failure criterion and behave as rigidperfectly-plastic materials;

- the effect of adjacent foundations is not considered;

- the non-homogeneous bearing capacity factor in Equation (4.15) was obtained by interpolation of known solutions; thus, errors in the existing solutions would have impacted the derivation of $N_{m}$. As a consequence, as discussed above, some known solutions were not reproduced or physically inadmissible results were obtained for certain conditions.

Because of these assumptions and limitations, Vesic's equation can not realistically represent typical coal mine conditions. The major improvement in Vesic's model over Terzaghi-Prandtl-Reissner's is the consideration of the soil's non-homogeneity. The fundamental question of whether Vesic's two-layer model provides accurate estimates of coal mine floor strength will be explored in greater detail in the next chapter.

\subsubsection{Pytel and Chugh's Adaptation of the Mandel and Salencon's model}

In their quest to find a better solution to the coal mine bearing capacity problem, Chugh and Pytel (1992) reviewed several non-homogeneous models available in the soil mechanics literature. Based on this review, they adopted the models proposed by Mandel (1965), Mandel and Salencon (1969) to derive a solution for coal mine application as discussed in Appendix II. Despite being more realistic, because of the several questionable assumptions, the need for more inputs including difficult to obtain friction angles, and the complex nature of 
the solution, the Pytel and Chugh model did not gain much popularity among practicing engineers in the Basin. Full details on the derivation, assumptions and limitations of the Pytel and Chugh model are provided in Appendix II. Owing to all the uncertainties discussed in Appendix II, no further analysis of the Pytel and Chugh's bearing capacity model is made in this dissertation.

\subsection{Application of the Bearing Capacity Models}

After excluding the Pytel and Chugh bearing capacity model from consideration, the only popular soil mechanics model left for use in coal mines is the Vesic's non-homogeneous solution given in Equation (4.14). As mentioned before, since its introduction to the coal mining community by the UMR researchers in 1979, almost all practical floor stability analysis in the Illinois Basin has been made with the Vesic's model. In fact, for practical use there are two different ways in which the Vesic's solution was used: Vesic-Speck and Vesic-CHC (Chugh and Pytel, 1992). As discussed below, the difference between these two versions lies in the way the weak floor cohesion is estimated.

\subsubsection{The Vesic-Speck Approach}

Apart from information on the geometry of the pillars and the weak floor, the only other input needed for the Vesic's equation is the shear strength of the weak and strong floors. As mentioned before, Vesic's solution is applicable only for the undrained conditions and thus the friction angle could be assumed to be zero for both floor layers. Consequently, only the cohesion values of the two layers are required to estimate the floor bearing capacity using Equation (4.14). In the most popular method used in the Illinois Basin called the Vesic-Speck approach, the cohesion term $\left(c_{1}\right)$ in Equation (4.14) is replaced by the laboratory triaxial strength equation developed by Speck given in Equation (3.1). Further, a reduction factor equal to 0.15 is applied to the triaxial strength estimate to account for the size effect. Therefore, the bearing capacity equation for the Vesic-Speck method could be rewritten as, 


$$
q_{\text {Vesci-Speck }}=0.15(2070-167 M C) N_{m}
$$

where $M C$ is the natural moisture content of the underclay or claystone and $N_{m}$ is the modified bearing capacity factor given by Equation (4.15).

Similarly, to estimate the shear strength ratio, $K$, needed for computation of the $N_{m}$ value, Speck (1979) suggested the following,

$$
K=\frac{248}{0.15(2070-167 M C)}
$$

The 248 psi value in Equation (4.20) for cohesion of the stronger bed was derived based on laboratory testing of claystone floor from two coal mines in Illinois by Speck (1979). The claystone strength was reduced by $60 \%$ to account for the size effect from laboratory scale to derive the final 248 psi recommended in Equation (4.20).

Notwithstanding the fact that Speck's adaptation of the Vesic bearing capacity equation has been the most popular method of pillar design in the Basin, for the reasons discussed extensively in Chapter 3, its application has several pitfalls, especially when used in the Western shelf of the Basin.

\subsubsection{The Vesic-Chugh-Haq-Chandrashekhar (Vesic-CHC) Approach}

The Vesic-CHC approach is different from the Vesic-Speck's only in how the cohesion of both layers $\left(c_{1}, c_{2}\right)$ is computed (Pytel, 1998). Both methods use the Vesic's solution in Equation (4.15) to compute the bearing capacity factor, $N_{m}$. The estimation of $c_{1}$ and $c_{2}$ in the Vesic-CHC method is made through equations (3.5) to (3.7) given in Chapter 3. As explained in Chapter 3, since the common plate sizes used for bearing capacity tests in underground coal mines are smaller, it may be assumed that the plate tests are conducted on a semiinfinite floor without incurring significant errors. Using this logic, in Vesic- $\mathrm{CHC}$, the cohesion of both floor layers is estimated by

$$
c_{1} \text { and } c_{2}=\frac{\left(R F_{\text {SIUC }}\right)\left(U B C_{\text {plate }}\right)}{6.17}
$$


In the above equation, $U B C_{\text {plate }}$ is estimated by equations (3.5) - (3.7). Similarly the reduction factors $R F_{\text {SIUC }}$ are estimated by equations (3.19) - (3.21).

As the discussions in Chapter 3 show, the plate bearing capacity equations developed by Pula et al., (1990) do not fit the field data well. Also, the data in Chapter 3 show that Pula's equations represent the lower bound to the test data and hence are unrealistically conservative. Moreover, for the reasons given in that same chapter, the strength reduction factors $\left(R F_{S I U C}\right)$ suggested with the Vesic-CHC approach are highly questionable and make the computed floor strength even more conservative.

\subsubsection{The Vesic-Gadde Approach}

Discussions in Section 4.1.2 showed that owing to the assumptions and limitations inherent in the Vesic's equation, it can not represent the coal mine floor bearing capacity problem well. It will be shown in Chapter 5 that Vesic's equation provides incorrect solutions even for the conditions for which it is supposed to work. Despite the recognition of these limitations, it is still recommended to use the Vesic's non-homogeneous solution for routine pillar design for three reasons:

1. there is a long history of its usage in the Basin and engineers, consultants and regulators are very familiar with the method. Any radical change at this stage may lead to several practical problems;

2. the rich experience with the use of Vesic's solution also means, despite its inapplicability, the design stability factors for which the methodology provides satisfactory performance under certain conditions are reasonably known. As long as these design stability factors are adhered to, it does not matter even if the bearing capacity solution is flawed;

3. finally, even though the numerical modeling methodology suggested in Chapter 5 is more accurate and versatile, for routine design purposes by engineers at the mines, computer modeling is still too complex, mysterious, time consuming and expensive. Therefore, abandoning the 
relatively simple traditional soil mechanics approach will be a tough task and perhaps very inconvenient for a majority of users.

Obviously, convenience and familiarity alone should not be the prime reasons for using an inaccurate methodology. Even though the accepted stability factors for the Vesic-Speck approach work reasonably well for certain mining conditions in the Illinois Basin mines, there are situations (e.g. high non-zero friction angles, more than two immediate floor layers, water pooling etc) where ultra conservative or unconservative designs are possible. If any unusual conditions are anticipated, the benefits of adopting a thorough floor stability investigation using the numerical modeling methodology given in Chapter 5 may outweigh the problems that may arise later due to the incorrect design approach used.

In any case, even if the Vesic's non-homogeneous solution is retained as the preferred soil mechanics model, there is a need to address the issues related to how the floor cohesion values are estimated. As discussed extensively in Chapter 3, both the Speck's and SIUC's plate bearing capacity equations did not work well when compared to the data collected from a large number of mines from all three states of the Basin. Further, it has been shown in Chapter 2 that there exist some significant differences in the nature of the floor in the Eastern and the Western shelves of the Basin due to the slightly different depositional environments. Based on these observations, in Chapter 3, two new plate bearing capacity equations were developed for the two regions of the Basin that best fitted the available data.

Discussions in Chapter 3 also showed that there was no evidence to suggest that floor strength decreased with increasing plate size beyond about 25 inch $^{2}$ area. Therefore, there is also no need to use the reduction factors such as those suggested by Speck and SIUC. For these reasons, it is believed that the proposed Vesic-Gadde approach will provide better representation of the floor stability when used in conjunction with the stability factors recommended later in this chapter. In essence, the Vesic-Gadde approach is exactly similar to the 
Vesic-Speck and Vesic-CHC except that the cohesion of both beds is estimated by equations developed in this dissertation as summarized below.

The laboratory data in Chapter 2 suggested that the nature of the floor in the Eastern and the Western shelves of the Basin was different. Therefore, using the plate bearing capacity equations developed in Chapter 3 , the cohesion of the immediate floor for the Vesic-Gadde approach is estimated by

$$
c_{1}=\frac{4164 e^{(-0.2 M C)}}{6.17},
$$

for the Eastern shelf mines, and

$$
c_{1}=\frac{1905 e^{(-0.1 M C)}}{6.17}
$$

for the Western shelf mines. In both of these equations $M C$ is the natural moisture content of the underclay or weak claystone.

When it comes to the strength of the main floor below the weak bed, no systematic approach has been suggested in the past. As given in Equation (4.20), Speck recommended a constant 248 psi value while SIUC used the same equations for both the weak and strong floor members. It may, however, be noted that SIUC did not test the stronger floor in mines or in laboratory to prove the validity of its recommendation. Because of this lack of a systematic approach, the designer can assume any reasonable number of his choice for $c_{2}$, if actual laboratory testing is not done. To resolve this problem, all the available uniaxial compressive strength data on stronger claystone beds as discussed in Chapter 2 were analyzed. Based on this analysis, and considering the fact that Vesic's nonhomogeneous solution assumes zero friction angle, the cohesion of the stronger floor can be estimated by

$$
c_{2}=\frac{6443 e^{(-0.34 M C)}}{2},
$$

for the \#6 seam in Illinois and \#11 seam in Western Kentucky. Similarly,

$$
c_{2}=\frac{10041 e^{(-0.4 M C)}}{2},
$$


for the \#5 seam in Illinois, Indiana and \#9 seam in Western Kentucky. For the lack of any data and for the similarities in the floor nature between the \#5 seam and the Danville No.7 seam as discussed in Chapter 2, Equation (4.25) may also be used for the later.

\subsection{Case History Applications}

The best way to judge the performance of the three different approaches discussed in section 4.2 is by comparing their predictions against known floor conditions in mines. In the following sections, some case history data has been used to accomplish this task. In addition to the data collected by Marino (1985), the Illinois Abandoned Mined Lands Reclamation Council and the Southern Illinois University, Carbondale (SIUC), additional cases are chosen from all three states of the Basin to see which floor bearing capacity method works best. In examining the validity of the floor stability analysis methods, distinction must be made between the short-term and long-term stability. As defined in Chapter 1, the short-term instability occurs during the useful lifespan of a mine opening and any instability after the mine workings are abandoned, falls under the long-term category. The short-term floor instability may or may not result in surface subsidence while the issues that arise in the long-term are known only through surface movements.

\subsubsection{Long-Term Stability}

\subsubsection{Marino's (1985) Ph.D. Work}

Surface subsidence over abandoned coal mines in Illinois has been investigated by Marino (1985) as a part of his Ph.D. work. In his research, thirteen cases of sag subsidence over twelve room-and-pillar and one longwall mines were investigated. Among these cases, however, only four had all the details necessary to conduct floor stability analysis using the three methods described in section 4.2. A brief discussion of the four case histories and the results of the stability analysis are presented in the following sections. It may be 
noted that some details like the moisture content of the immediate floor were not given in Marino's Ph.D. dissertation but were obtained from some other reports available from the Illinois Abandoned Mined Lands Reclamation Council on these case histories (Gibson, 2008).

Case 1: Surface damage as shown in Figure 4.8 had occurred over an abandoned room and pillar mine in the Herrin No.6 seam, which conducted operations between 1946 and 1974. The area shown in the map for Case 1 was mined somewhere between 1960 and 1967 and the subsidence event occurred after about 20 years. Damage to surface happened rather abruptly with little warning (Marino, 1985). The subsidence caused damage to three homes, a radio station building and cracked the asphalt pavement in the area.

As can be seen from Figure 4.8, the pillars were rectangular in shape with widths varying from 10 to $25 \mathrm{ft}$ and rooms were 20 to $45 \mathrm{ft}$ wide. From the research boreholes drilled into the subsided area, it was found that the depth of cover was about $135 \mathrm{ft}$. While there are five boreholes in the broader area surrounding Case 1, floor properties from Hole 2 and Hole 5 were used to assess floor stability factors in the unstable area. In doing so it has been assumed that the floor nature in the three unstable areas in Figure 4.8 was similar. It may be noted that there is one hole drilled in the stable area (Hole 1) adjacent to the subsided areas. The lithology and the floor properties revealed from Hole 1 and Hole 5 are shown in Figure 4.9 and Figure 4.10, respectively. Investigations through video cameras showed that the mine openings were filled with water to some extent. It appears that the zone of saturation did not penetrate deep into the floor underneath the pillars (Marino, 1985). Although no floor stability analysis was done, further field investigations showed that the weak unstable floor was the cause of the subsidence.

The floor stability factors (FSF) estimated using the three methods outlined in section 4.2 for some select pillars beneath the unstable area (1 to 9 in the area marked as Case 1 in Figure 4.8) are given in Table 4.1. The pillars were chosen near the subsidence monitoring lines as seen from Figure 4.8. The magnitude of surface movement along two monument lines for Case 1 area is 


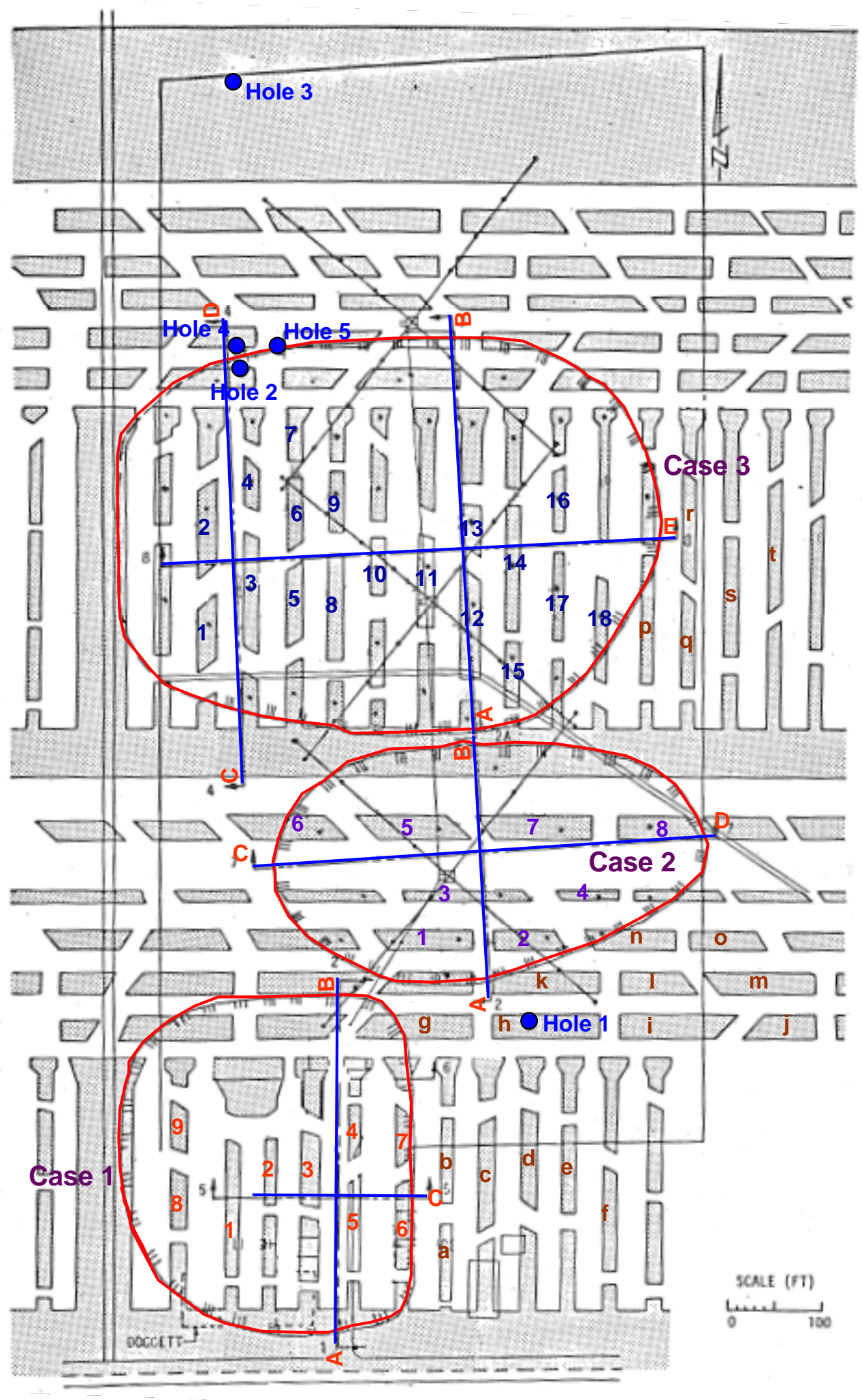

Figure 4.8. The unstable area, the representative geological column and the pillars selected for floor stability factor estimation for Case 1, Case 2 and Case 3. 


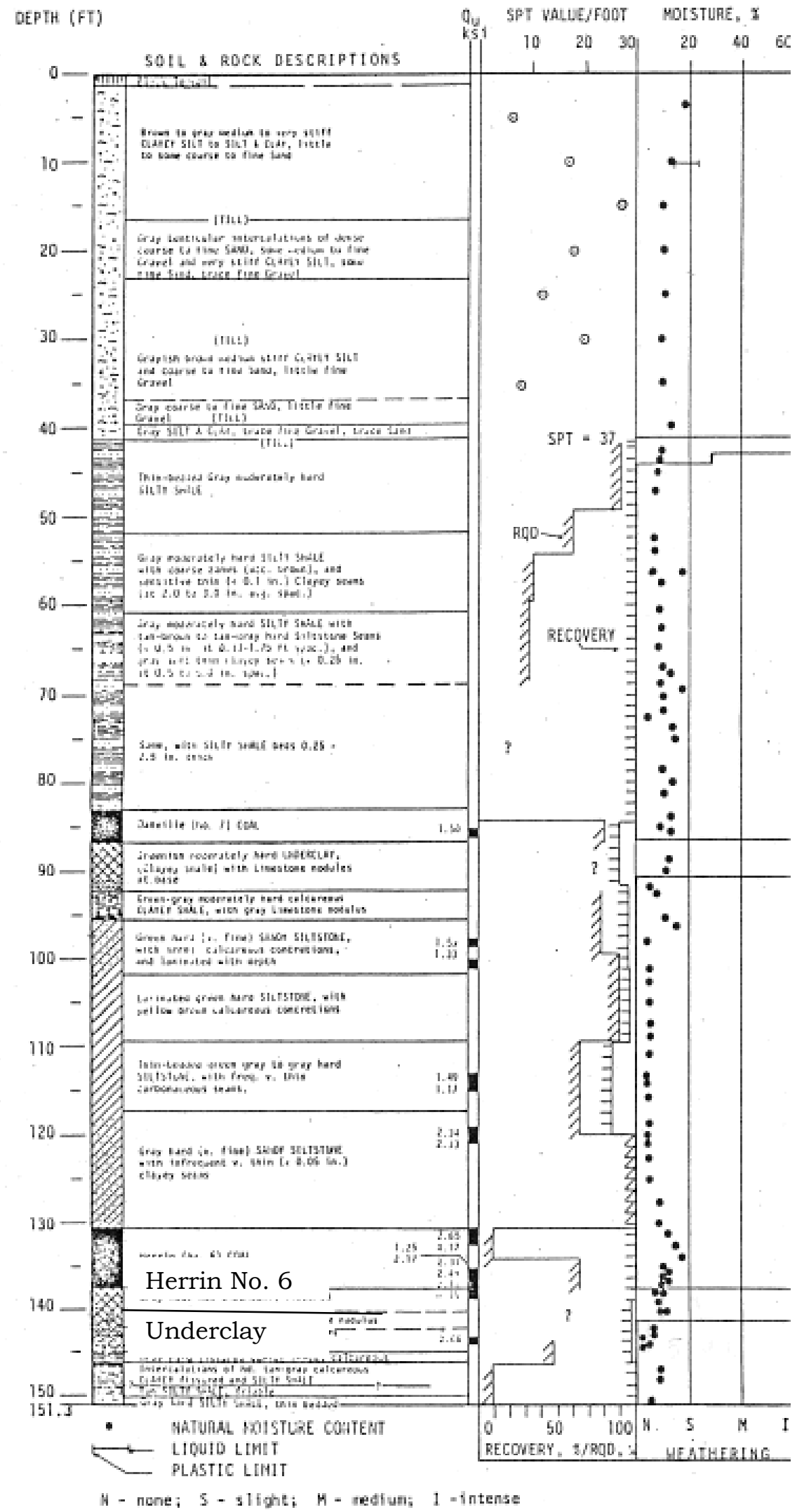

Figure 4.9. The geologic column and the moisture content data from Hole 1 in Figure 4.8. 


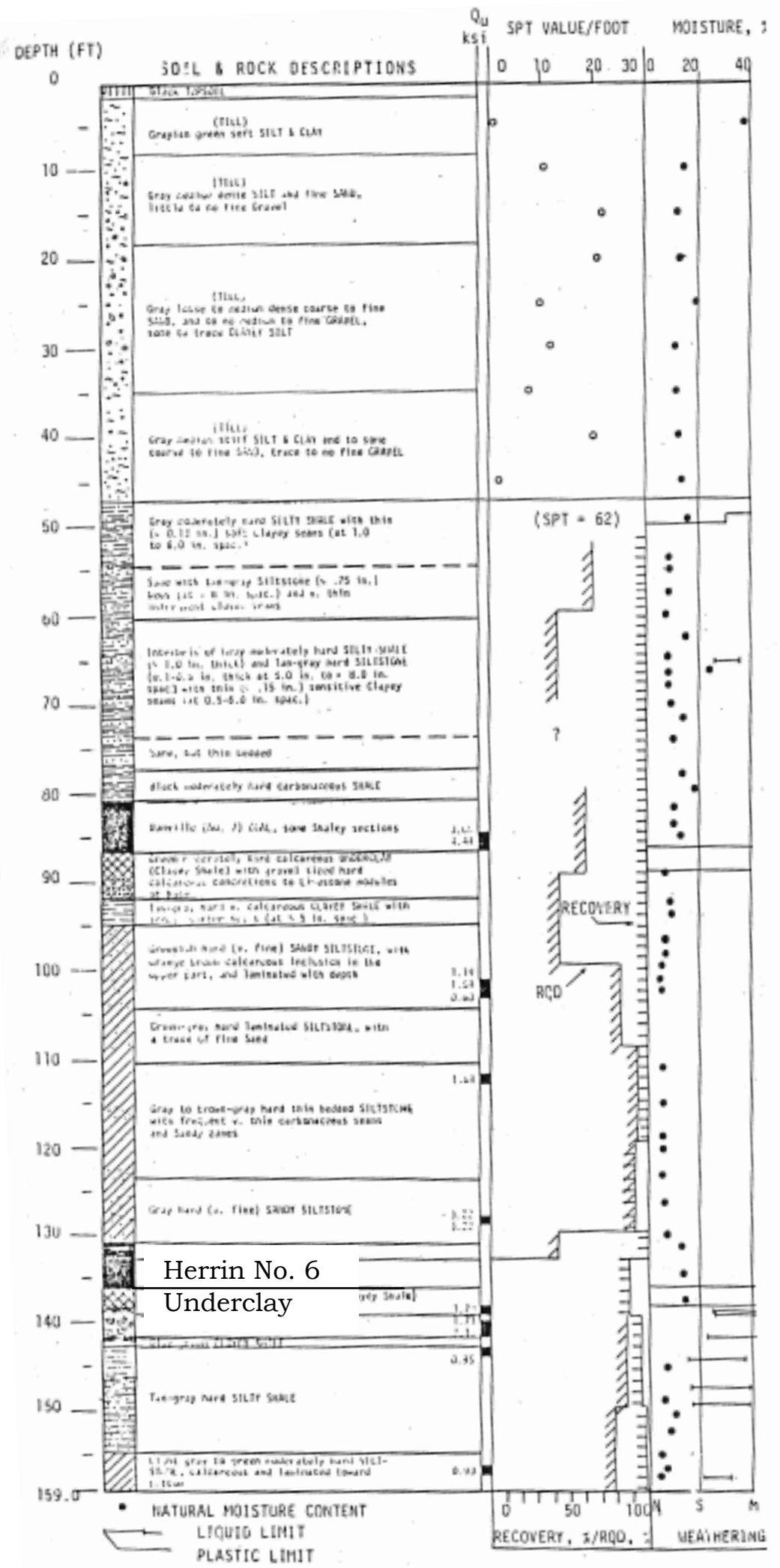

Figure 4.10. The geologic column and moisture content data form Hole 2 in Figure 4.8. 
a)

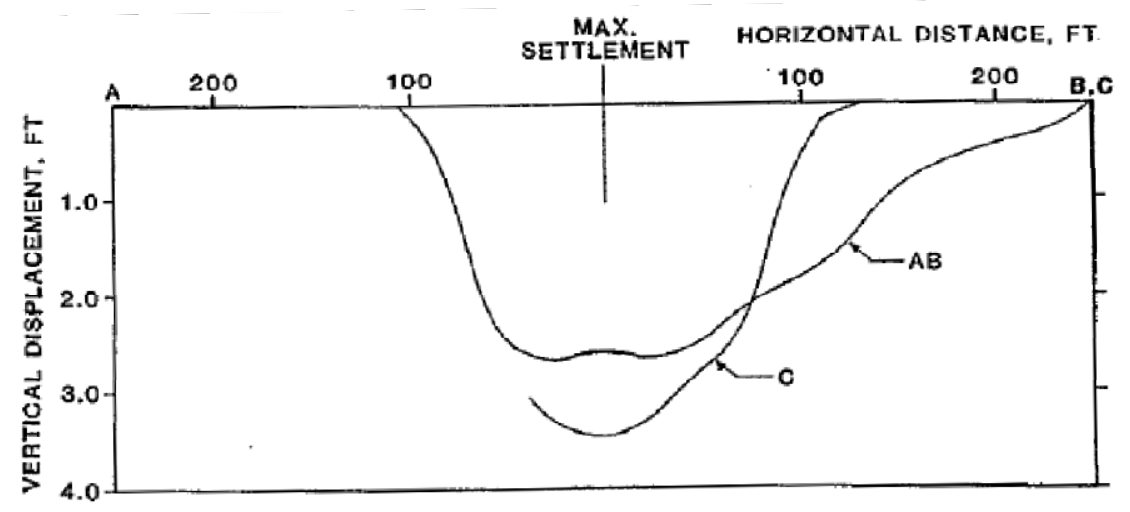

b)

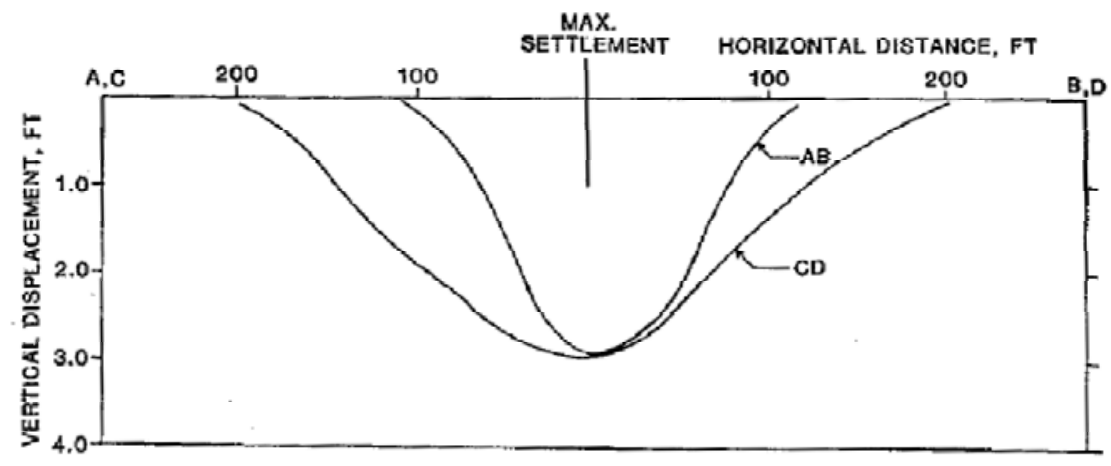

c)

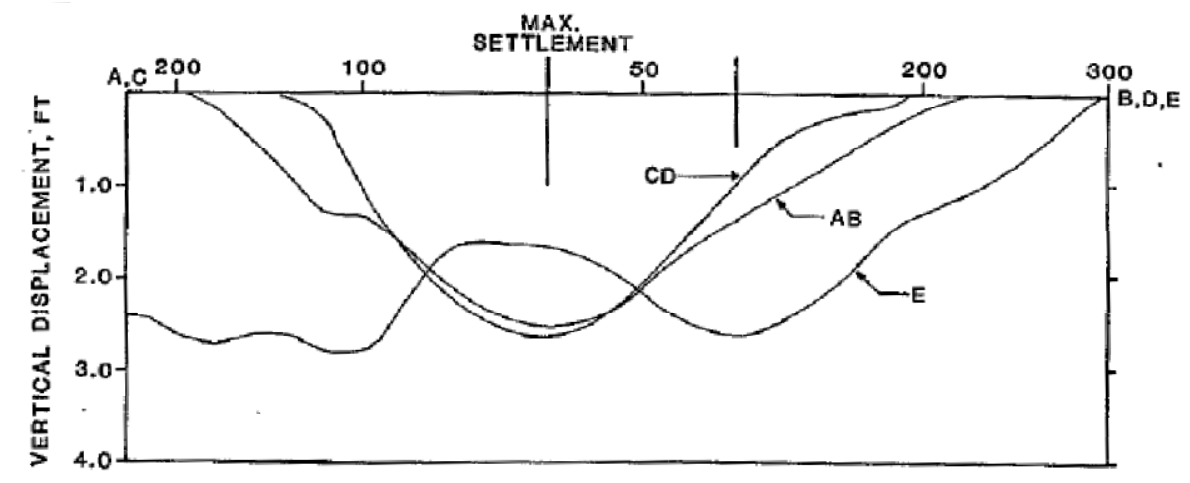

Figure 4.11. Subsidence measurements along the monument lines shown in Figure 4.8 for a) case 1, b) case 2 and c) case 3 (Marino, 1985).

plotted in Figure 4.11 (a). The subsidence data along line $C$ was not provided for the complete area of instability (Marino, 1985). Given that the center of the sag was measured along line $C$, however, it is reasonable to assume that the amount of subsidence would gradually reduce towards the edge of the unstable area. Comments on the stability analysis results will be made in section 4.3.3 later.

Case 2: This case comes from an adjacent area from the same mine as in Case 1. The affected area of the mine and the subsidence profile are shown 
in Figure 4.8 and Figure 4.11 (b), respectively. In this case the surface movements occurred about a year later than that in Case 1. Much of the settlement in this case appears to have occurred fairly rapidly and after about 6 weeks, one of the surface structures subsided by about $2.75 \mathrm{ft}$. For a few select pillars in Figure 4.8 (1 to 8 in the area marked as Case 2), floor stability factors were computed as given in Table 4.2.

Case 3: Similar to case 2, this event also occurred in the same mine as in case 1. The subsidence event occurred in November-December, 1976 just north of Case 2. The affected area of the mine and the subsidence outline are shown in Figure 4.8 and Figure 4.11(c), respectively. The surface movements in this case caused a radio tower to fall and damaged two more towers. For a few select pillars in Figure 4.8 (1 to 18 in the area marked as Case 3), floor stability factors were computed as given in Table 4.3. Discussion on the floor stability factors for both case 2 and case 3 will be made later.

Stable Pillars: Adjacent to the above three subsided areas, there are several stable pillars as shown in Figure 4.8. Additionally, a rock mechanics borehole (Hole 1) is also available from the stable area. Because of the availability of this essential information, several stable pillars were selected (a to $t$ in Figure 4.8) adjacent to the three unstable areas and their floor stability factors were computed as given in Table 4.4. A quick look at the stability factors computed by the Vesic-Gadde method in Table 4.1 through Table 4.4 clearly show that for a critical FSF of 1.5, almost all of the stable and unstable floor conditions could be explained well. Further discussion of the stability factors will be made later.

Case 4: The subsidence event reported for this case occurred in a Western shelf mine which extracted the Herrin No. 6 seam. The surface movements damaged two houses, utility lines and a major county road (Marino, 1985). The coal seam was at a depth of $162 \mathrm{ft}$ with underlying underclay of about 2 to $5 \mathrm{ft}$ thick. The bottom section of the underclay grades into a nodular limestone with shale below it. Below the damaged area shown in Figure 4.12, coal mining occurred in the 1950's by the room-and-pillar method. Investigations 
Table 4.1. Floor stability factors for Marino's case 1.

\begin{tabular}{|l|r|r|r|r|r|r|r|r|r|}
\hline Pillar Number & 1 & 2 & 3 & 4 & 5 & 6 & 7 & 8 & 9 \\
\hline Immediate floor thickness (ft) & 3.2 & 3.2 & 3.2 & 3.2 & 3.2 & 3.2 & 3.2 & 3.2 & 3.2 \\
\hline $\begin{array}{l}\text { Moisture Content of } \\
\text { immediate floor (\%) }\end{array}$ & 13.3 & 13.3 & 13.3 & 13.3 & 13.3 & 13.3 & 13.3 & 13.3 & 13.3 \\
\hline Location of the mine (shelf) & \multicolumn{7}{|c|}{ Western } \\
\hline Coal Seam & \multicolumn{7}{|c|}{ Herrin } \\
\hline $\begin{array}{l}\text { Moisture content of main floor } \\
\text { (\%) }\end{array}$ & 6.7 & 6.7 & 6.7 & 6.7 & 6.7 & 6.7 & 6.7 & 6.7 & 6.7 \\
\hline Depth of cover (ft) & 135 & 135 & 135 & 135 & 135 & 135 & 135 & 135 & 135 \\
\hline Pillar width (ft) & 15 & 13 & 20 & 13 & 13 & 16 & 16 & 17 & 17 \\
\hline Pillar length (ft) & 140 & 70 & 74 & 38 & 67 & 87 & 53 & 56 & 46 \\
\hline Entry width (ft) & 32 & 24 & 24 & 25 & 25 & 30 & 30 & 40 & 40 \\
\hline Crosscut width (ft) & 10 & 10 & 10 & 17 & 14 & 15 & 15 & 18 & 18 \\
\hline Tributary area load (psi) & 510 & 494 & 379 & 643 & 537 & 512 & 560 & 673 & 708 \\
\hline & \multicolumn{7}{|c|}{ FLOOR STRENGTH (psi) } & \multicolumn{7}{|c|}{} \\
\hline Vesic-Speck & -142 & -136 & -153 & -135 & -136 & -144 & -143 & -145 & -145 \\
\hline Vesic-CHC & 184 & 178 & 188 & 175 & 178 & 184 & 180 & 182 & 180 \\
\hline Vesic-Gadde & 567 & 544 & 585 & 532 & 543 & 566 & 555 & 561 & 556 \\
\hline & \multicolumn{7}{|c|}{ FLOOR STABILITY FACTORS } \\
\hline Vesic-Speck & -0.28 & -0.27 & -0.40 & -0.21 & -0.25 & -0.28 & -0.25 & -0.22 & -0.20 \\
\hline Vesic-CHC & 0.36 & 0.36 & 0.50 & 0.27 & 0.33 & 0.36 & 0.32 & 0.27 & 0.25 \\
\hline Vesic-Gadde & 1.11 & 1.10 & 1.54 & 0.83 & 1.01 & 1.11 & 0.99 & 0.83 & 0.78 \\
\hline
\end{tabular}

Table 4.2. Floor stability factors for Marino's case 2.

\begin{tabular}{|l|r|r|r|r|r|r|r|r|}
\hline Pillar Number & 1 & 2 & 3 & 4 & 5 & 6 & 7 & 8 \\
\hline Immediate floor thickness (ft) & 3.2 & 3.2 & 3.2 & 3.2 & 3.2 & 3.2 & 3.2 & 3.2 \\
\hline Moisture Content of immediate floor (\%) & 13.3 & 13.3 & 13.3 & 13.3 & 13.3 & 13.3 & 13.3 & 13.3 \\
\hline Location of the mine (shelf) & \multicolumn{7}{|c|}{ Western } \\
\hline Coal Seam & \multicolumn{7}{|c|}{ Herrin } \\
\hline Moisture content of main floor (\%) & 6.7 & 6.7 & 6.7 & 6.7 & 6.7 & 6.7 & 6.7 & 6.7 \\
\hline Depth of cover (ft) & 135 & 135 & 135 & 135 & 135 & 135 & 135 & 135 \\
\hline Pillar width (ft) & 20 & 20 & 10 & 10 & 27 & 27 & 27 & 27 \\
\hline Pillar length (ft) & 84 & 70 & 133 & 67 & 100 & 114 & 113 & 80 \\
\hline Entry width (ft) & 26 & 26 & 44 & 44 & 47 & 47 & 47 & 47 \\
\hline Crosscut width (ft) & 20 & 20 & 20 & 20 & 20 & 20 & 20 & 20 \\
\hline Tributary area load (psi) & 432 & 449 & 943 & 1065 & 500 & 489 & 490 & 520 \\
\hline & FLOOR STRENGTH (psi) \\
\hline Vesic-Speck & -154 & -153 & -128 & -127 & -171 & -172 & -172 & -169 \\
\hline Vesic-CHC & 189 & 187 & 176 & 174 & 201 & 202 & 202 & 198 \\
\hline Vesic-Gadde & 588 & 583 & 529 & 524 & 631 & 636 & 636 & 622 \\
\hline & 5LOOR STABILITY FACTORS \\
\hline Vesic-Speck & -0.36 & -0.34 & -0.14 & -0.12 & -0.34 & -0.35 & -0.35 & -0.33 \\
\hline Vesic-CHC & 0.44 & 0.42 & 0.19 & 0.16 & 0.40 & 0.41 & 0.41 & 0.38 \\
\hline Vesic-Gadde & 1.36 & 1.30 & 0.56 & 0.49 & 1.26 & 1.30 & 1.30 & 1.19 \\
\hline
\end{tabular}


Table 4.3. Floor stability factors for Marino's case 3.

\begin{tabular}{|c|c|c|c|c|c|c|c|c|c|c|c|c|c|c|c|c|c|c|}
\hline Pillar number & 1 & 2 & 3 & 4 & 5 & 6 & 7 & 8 & 9 & 10 & 11 & 12 & 13 & 14 & 15 & 16 & 17 & 18 \\
\hline Immediate floor thickness (ft) & 3.2 & 3.2 & 3.2 & 3.2 & 3.2 & 3.2 & 3.2 & 3.2 & 3.2 & 3.2 & 3.2 & 3.2 & 3.2 & 3.2 & 3.2 & 3.2 & 3.2 & 3.2 \\
\hline $\begin{array}{l}\text { Moisture content of } \\
\text { immediate floor }(\%)\end{array}$ & 13.3 & 13.3 & 13.3 & 13.3 & 13.3 & 13.3 & 13.3 & 13.3 & 13.3 & 13.3 & 13.3 & 13.3 & 13.3 & 13.3 & 13.3 & 13.3 & 13.3 & 13.3 \\
\hline $\begin{array}{l}\text { Moisture content of main floor } \\
(\%)\end{array}$ & 6.7 & 6.7 & 6.7 & 6.7 & 6.7 & 6.7 & 6.7 & 6.7 & 6.7 & 6.7 & 6.7 & 6.7 & 6.7 & 6.7 & 6.7 & 6.7 & 6.7 & 6.7 \\
\hline Depth of cover (ft) & 135 & 135 & 135 & 135 & 135 & 135 & 135 & 135 & 135 & 135 & 135 & 135 & 135 & 135 & 135 & 135 & 135 & 135 \\
\hline Pillar width (ft) & 20 & 20 & 16 & 16 & 16 & 16 & 16 & 16 & 17 & 17 & 16 & 22 & 22 & 16 & 16 & 13 & 13 & 10 \\
\hline Pillar length (ft) & 67 & 87 & 120 & 47 & 80 & 70 & 64 & 110 & 74 & 60 & 90 & 47 & 110 & 137 & 70 & 67 & 94 & 107 \\
\hline Entry width (ft) & 26 & 26 & 26 & 26 & 26 & 26 & 28 & 28 & 30 & 30 & 30 & 28 & 28 & 30 & 30 & 34 & 34 & 34 \\
\hline Crosscut width (ft) & 33 & 20 & 20 & 20 & 20 & 20 & 20 & 20 & 20 & 20 & 20 & 20 & 20 & 20 & 20 & 20 & 20 & 20 \\
\hline Tributary area load (psi) & 521 & 430 & 465 & 568 & 498 & 513 & 548 & 494 & 533 & 560 & 534 & 492 & 408 & 500 & 561 & 713 & 666 & 793 \\
\hline \multicolumn{19}{|c|}{ FLOOR STRENGTH (psi) } \\
\hline Vesic-Speck & -153 & -154 & -145 & -143 & -144 & -143 & -143 & -145 & -146 & -145 & -144 & -156 & -160 & -145 & -143 & -136 & -136 & -128 \\
\hline Vesic-CHC & 187 & 189 & 185 & 179 & 183 & 182 & 182 & 185 & 184 & 182 & 184 & 185 & 194 & 186 & 182 & 178 & 180 & 176 \\
\hline Vesic-Gadde & 581 & 589 & 571 & 552 & 564 & 561 & 559 & 570 & 568 & 563 & 567 & 577 & 607 & 573 & 561 & 543 & 548 & 528 \\
\hline \multicolumn{19}{|c|}{ FLOOR STABILITY FACTORS } \\
\hline Vesic-Speck & -0.29 & -0.36 & -0.31 & -0.25 & -0.29 & -0.28 & -0.26 & -0.29 & -0.27 & -0.26 & -0.27 & -0.32 & -0.39 & -0.29 & -0.26 & -0.19 & -0.20 & -0.16 \\
\hline Vesic-CHC & 0.36 & 0.44 & 0.40 & 0.32 & 0.37 & 0.36 & 0.33 & 0.37 & 0.34 & 0.33 & 0.34 & 0.38 & 0.48 & 0.37 & 0.32 & 0.25 & 0.27 & 0.22 \\
\hline Vesic-Gadde & 1.12 & 1.37 & 1.23 & 0.97 & 1.13 & 1.10 & 1.02 & 1.15 & 1.07 & 1.01 & 1.06 & 1.17 & 1.49 & 1.15 & 1.00 & 0.76 & 0.82 & 0.67 \\
\hline
\end{tabular}

(The mine was located in the Western shelf of the Basin and extracted Herrin No. 6 seam). 
Table 4.4. Floor stability factors for stable pillars adjacent to unstable Case 1 through Case 3.

\begin{tabular}{|c|c|c|c|c|c|c|c|c|c|c|c|c|c|c|c|c|c|c|c|c|}
\hline Pillar Number & a & $b$ & c & d & $\mathrm{e}$ & $\mathrm{f}$ & $\mathrm{g}$ & $\mathrm{h}$ & $\mathrm{i}$ & j & $\mathrm{k}$ & 1 & $\mathrm{~m}$ & $\mathrm{n}$ & 0 & $\mathrm{p}$ & $q$ & $r$ & $\mathrm{~s}$ & $\mathrm{t}$ \\
\hline Immediate floor thickness (ft) & 3.75 & 3.75 & 3.75 & 3.75 & 3.75 & 3.75 & 3.75 & 3.75 & 3.75 & 3.75 & 3.75 & 3.75 & 3.75 & 3.75 & 3.75 & 3.75 & 3.75 & 3.75 & 3.75 & 3.75 \\
\hline $\begin{array}{l}\text { Moisture Content of immediate floor } \\
(\%)\end{array}$ & 9.3 & 9.3 & 9.3 & 9.3 & 9.3 & 9.3 & 9.3 & 9.3 & 9.3 & 9.3 & 9.3 & 9.3 & 9.3 & 9.3 & 9.3 & 9.3 & 9.3 & 9.3 & 9.3 & 9.3 \\
\hline Location of the mine (shelf) & \multicolumn{20}{|c|}{ Western } \\
\hline Coal Seam & \multicolumn{20}{|c|}{ Herrin } \\
\hline Moisture content of main floor (\%) & 5.3 & 5.3 & 5.3 & 5.3 & 5.3 & 5.3 & 5.3 & 5.3 & 5.3 & 5.3 & 5.3 & 5.3 & 5.3 & 5.3 & 5.3 & 5.3 & 5.3 & 5.3 & 5.3 & 5.3 \\
\hline Depth of cover (ft) & 135 & 135 & 135 & 135 & 135 & 135 & 135 & 135 & 135 & 135 & 135 & 135 & 135 & 135 & 135 & 135 & 135 & 135 & 135 & 135 \\
\hline Pillar width (ft) & 12.5 & 12.5 & 17 & 16 & 12.5 & 12.5 & 28 & 28 & 28 & 28 & 24 & 24 & 24 & 22 & 22 & 12 & 13 & 13 & 16 & 15 \\
\hline Pillar length (ft) & 94 & 103 & 125 & 112 & 106 & 125 & 116 & 112 & 112 & 66 & 112 & 72 & 110 & 94 & 78 & 127 & 80 & 100 & 117 & 125 \\
\hline Entry width (ft) & 25 & 25 & 25 & 25 & 25 & 27 & 19 & 19 & 19 & 19 & 21 & 21 & 21 & 27 & 27 & 31 & 29 & 29 & 30 & 30 \\
\hline Crosscut width (ft) & 22 & 14 & 18 & 23 & 15 & 16 & 18 & 18 & 18 & 18 & 18 & 18 & 18 & 18 & 18 & 16 & 16 & 16 & 16 & 16 \\
\hline Tributary area load (psi) & 562 & 518 & 429 & 469 & 520 & 541 & 294 & 296 & 296 & 324 & 331 & 356 & 331 & 403 & 416 & 613 & 589 & 569 & 496 & 514 \\
\hline \multicolumn{21}{|c|}{ FLOOR STRENGTH (psi) } \\
\hline Vesic-Speck & 430 & 430 & 453 & 448 & 430 & 429 & 505 & 505 & 505 & 504 & 487 & 487 & 487 & 478 & 478 & 426 & 433 & 432 & 448 & 443 \\
\hline Vesic-CHC & 374 & 375 & 384 & 382 & 375 & 375 & 404 & 403 & 403 & 395 & 396 & 391 & 396 & 391 & 389 & 374 & 374 & 375 & 382 & 380 \\
\hline Vesic-Gadde & 792 & 794 & 838 & 826 & 794 & 796 & 922 & 920 & 920 & 888 & 891 & 870 & 890 & 869 & 861 & 792 & 794 & 798 & 827 & 820 \\
\hline \multicolumn{21}{|c|}{ FLOOR STABILITY FACTORS } \\
\hline Vesic-Speck & 0.76 & 0.83 & 1.06 & 0.96 & 0.83 & 0.79 & 1.72 & 1.71 & 1.71 & 1.55 & 1.47 & 1.37 & 1.47 & 1.19 & 1.15 & 0.70 & 0.74 & 0.76 & 0.90 & 0.86 \\
\hline Vesic-CHC & 0.67 & 0.72 & 0.90 & 0.81 & 0.72 & 0.69 & 1.37 & 1.36 & 1.36 & 1.22 & 1.20 & 1.10 & 1.20 & 0.97 & 0.93 & 0.61 & 0.64 & 0.66 & 0.77 & 0.74 \\
\hline Vesic-Gadde & 1.41 & 1.53 & 1.95 & 1.76 & 1.53 & 1.47 & 3.13 & 3.11 & 3.11 & 2.74 & 2.70 & 2.44 & 2.69 & 2.16 & 2.07 & 1.29 & 1.35 & 1.40 & 1.67 & 1.59 \\
\hline
\end{tabular}




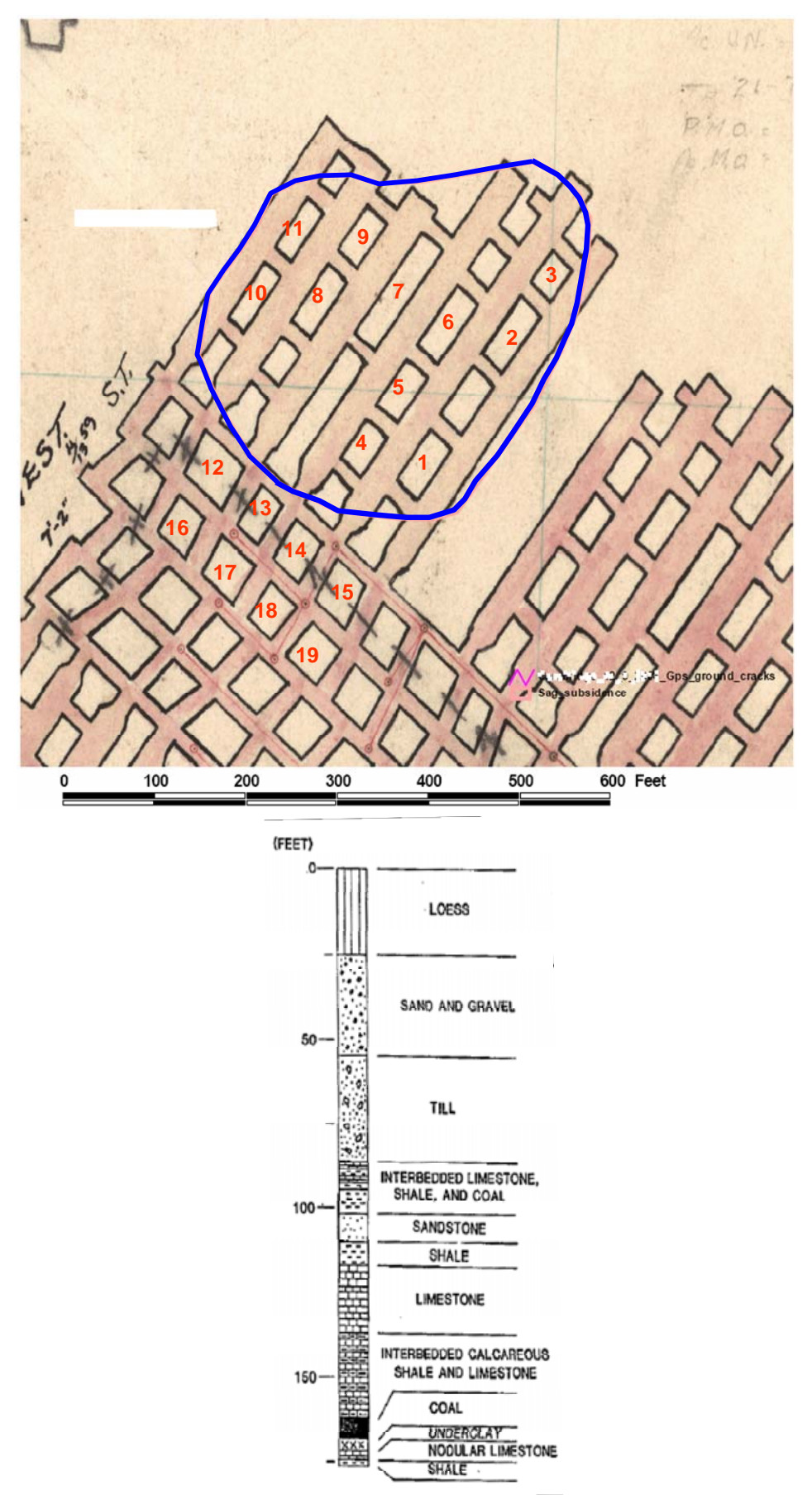

Figure 4.12. The subsided area and representative geological column for Case 4 (Marino, 1985).

through five boreholes drilled in the area showed that much of the roof remained stable although severe convergence was noticed. Some localized water pooling was also observed in the area. Marino (1985) mentioned that based on stability analyses and observations of site conditions it was concluded that floor instability 
was the prime cause of the subsidence. The surface subsidence monitored over the unstable area is plotted in Figure 4.13. The floor stability factors for some unstable and stable pillars were estimated using the three methods in section 4.2 and are given in Table 4.5 and Table 4.6. Unlike the first three cases, the moisture content of the stronger floor was not available for this case. Therefore, the average moisture for the Herrin seam floor given in Chapter 2 was used in the stability computations.

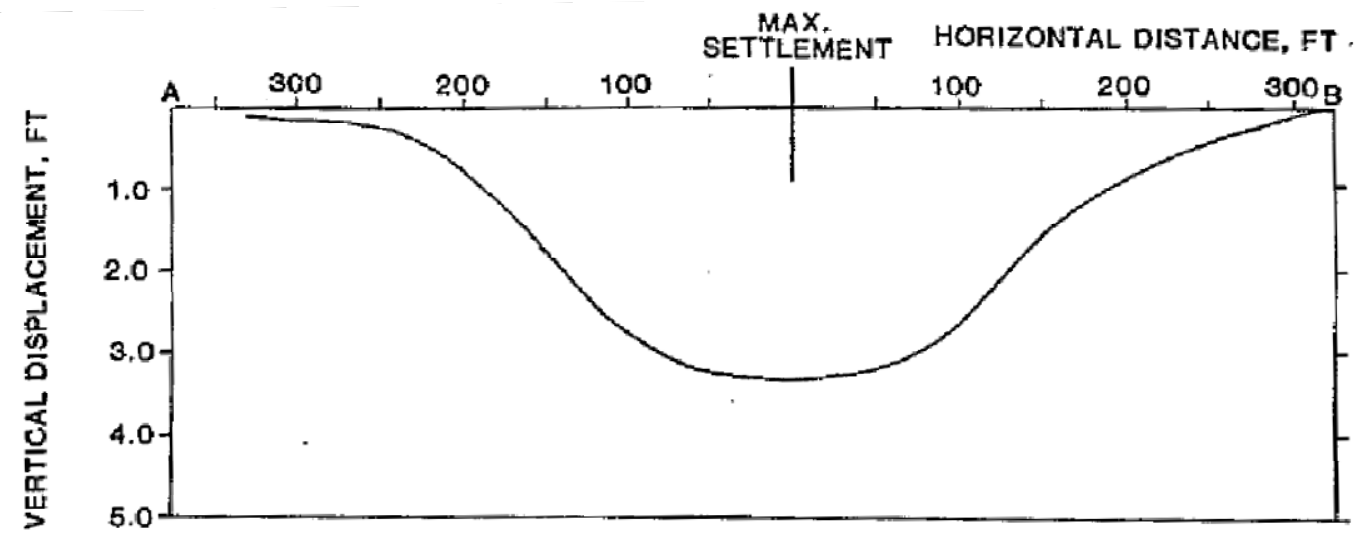

Figure 4.13. The subsided area, sag profile and representative geological column for Case 4 (Marino, 1985).

Table 4.5. Floor stability factors for unstable pillars in Marino's case 4.

\begin{tabular}{|c|c|c|c|c|c|c|c|c|c|c|c|}
\hline Pillar number & 1 & 2 & 3 & 4 & 5 & 6 & 7 & 8 & 9 & 10 & 11 \\
\hline $\begin{array}{l}\text { Immediate floor } \\
\text { thickness (ft) }\end{array}$ & 2.8 & 2.8 & 2.8 & 2.8 & 2.8 & 2.8 & 2.8 & 2.8 & 2.8 & 2.8 & 2.8 \\
\hline $\begin{array}{l}\text { Moisture content of } \\
\text { immediate floor }(\%)\end{array}$ & 13 & 13 & 13 & 13 & 13 & 13 & 13 & 13 & 13 & 13 & 13 \\
\hline $\begin{array}{l}\text { Moisture content of } \\
\text { main floor }(\%)\end{array}$ & 7 & 7 & 7 & 7 & 7 & 7 & 7 & 7 & 7 & 7 & 7 \\
\hline Depth of cover (ft) & 162 & 162 & 162 & 162 & 162 & 162 & 162 & 162 & 162 & 162 & 162 \\
\hline Pillar width (ft) & 28 & 28 & 28 & 28 & 28 & 28 & 28 & 28 & 28 & 22 & 22 \\
\hline Pillar length (ft) & 62 & 70 & 37 & 45 & 53 & 75 & 125 & 67 & 53 & 65 & 60 \\
\hline Entry width (ft) & 32 & 32 & 32 & 32 & 32 & 32 & 32 & 32 & 32 & 32 & 32 \\
\hline Crosscut width (ft) & 13 & 12 & 12 & 12 & 12 & 12 & 12 & 12 & 12 & 12 & 12 \\
\hline $\begin{array}{l}\text { Tributary area load } \\
\text { (psi) }\end{array}$ & 472 & 457 & 517 & 495 & 479 & 453 & 428 & 460 & 479 & 530 & 537 \\
\hline \multicolumn{12}{|c|}{ FLOOR STRENGTH (psi) } \\
\hline Vesic-Speck & -118 & -119 & -115 & -116 & -117 & -120 & -123 & -119 & -117 & -109 & -109 \\
\hline Vesic-CHC & 218 & 221 & 207 & 212 & 215 & 222 & 230 & 220 & 215 & 212 & 211 \\
\hline Vesic-Gadde & 647 & 654 & 615 & 628 & 638 & 658 & 682 & 652 & 638 & 622 & 619 \\
\hline \multicolumn{12}{|c|}{ FLOOR STABILITY FACTORS } \\
\hline Vesic-Speck & -0.25 & -0.26 & -0.22 & -0.23 & -0.24 & -0.26 & -0.29 & -0.26 & -0.24 & -0.21 & -0.20 \\
\hline Vesic-CHC & 0.46 & 0.48 & 0.40 & 0.43 & 0.45 & 0.49 & 0.54 & 0.48 & 0.45 & 0.40 & 0.39 \\
\hline Vesic-Gadde & 1.37 & 1.43 & 1.19 & 1.27 & 1.33 & 1.45 & 1.59 & 1.42 & 1.33 & 1.17 & 1.15 \\
\hline
\end{tabular}


Table 4.6. Floor stability factors for stable pillars in Marino's case 4.

\begin{tabular}{|l|r|r|r|r|r|r|r|r|}
\hline Pillar Number & 12 & 13 & 14 & 15 & 16 & 17 & 18 & 19 \\
\hline Immediate floor thickness (ft) & 2.8 & 2.8 & 2.8 & 2.8 & 2.8 & 2.8 & 2.8 & 2.8 \\
\hline $\begin{array}{l}\text { Moisture Content of immediate floor } \\
\text { (\%) }\end{array}$ & 13 & 13 & 13 & 13 & 13 & 13 & 13 & 13 \\
\hline Mine Location (shelf) & \multicolumn{7}{|c|}{ Western } \\
\hline Coal Seam & \multicolumn{7}{|c|}{ Herrin } \\
\hline Moisture content of main floor (\%) & 7 & 7 & 7 & 7 & 7 & 7 & 7 & 7 \\
\hline Depth of cover (ft) & 162 & 162 & 162 & 162 & 162 & 162 & 162 & 162 \\
\hline Pillar width (ft) & 50 & 30 & 40 & 45 & 40 & 45 & 35 & 40 \\
\hline Pillar length (ft) & 55 & 50 & 50 & 55 & 50 & 50 & 50 & 50 \\
\hline Entry width (ft) & 20 & 20 & 20 & 20 & 20 & 20 & 20 & 20 \\
\hline Crosscut width (ft) & 20 & 20 & 20 & 20 & 20 & 20 & 20 & 20 \\
\hline Tributary area load (psi) & 348 & 425 & 383 & 359 & 383 & 369 & 401 & 383 \\
\hline & FLOOR STRENGTH (psi) \\
\hline Vesic-Speck & -143 & -119 & -131 & -138 & -131 & -136 & -126 & -131 \\
\hline Vesic-CHC & 232 & 216 & 223 & 230 & 223 & 226 & 220 & 223 \\
\hline Vesic-Gadde & 705 & 641 & 671 & 693 & 671 & 683 & 657 & 671 \\
\hline & \multicolumn{7}{|c|}{} \\
\hline Vesic-Speck & \multicolumn{7}{|c|}{ FLOOR STABILITY FACTORS } \\
\hline Vesic-CHC & -0.41 & -0.28 & -0.34 & -0.38 & -0.34 & -0.37 & -0.31 & -0.34 \\
\hline Vesic-Gadde & 0.67 & 0.51 & 0.58 & 0.64 & 0.58 & 0.61 & 0.55 & 0.58 \\
\hline
\end{tabular}

\subsubsection{Illinois Abandoned Mined Lands Reclamation Council Database}

Some long-term subsidence case histories were gathered from the database of the Illinois Abandoned Mined Lands Reclamation Council (Gibson, 2008). The details are given below.

Case 5 and Case 6: These two subsidence events occurred over the same mine discussed in Marino's Case 4 given in section 4.3.1.1 above. The two recent subsidence events occurred in 1999 and 2008 and in close vicinity to the one described in Case 4. The extent of damaged surface from these two events is shown in Figure 4.14. The floor stability factors are given in Table 4.7 and Table 4.8, respectively, for case 5 and case 6 . It may be noted that for case 6 , three pillars $(10,11$ and 12) were chosen from the stable area right adjacent to the subsided area. Since no borehole was drilled in the exact area of instability for these two cases, all the necessary data was taken from case 4 given above.

Case 7: This is another subsidence case history from a mine in the Western shelf of the Basin. The subject mine extracted the Herrin no. 6 seam at 
a depth of about $112 \mathrm{ft}$, which is underlain by about $6 \mathrm{ft}$ underclay. The bed below underclay is moderately hard dark shale. Details on the time of mining and the exact year of the subsidence event were not available. Weak floor instability was considered to be the cause of the subsidence. Observations from a borehole camera showed that the mine openings were filled with water to a large extent. The portion of the mine that caused the surface subsidence is shown in Figure 4.15 and the floor stability computations are given in Table 4.9.
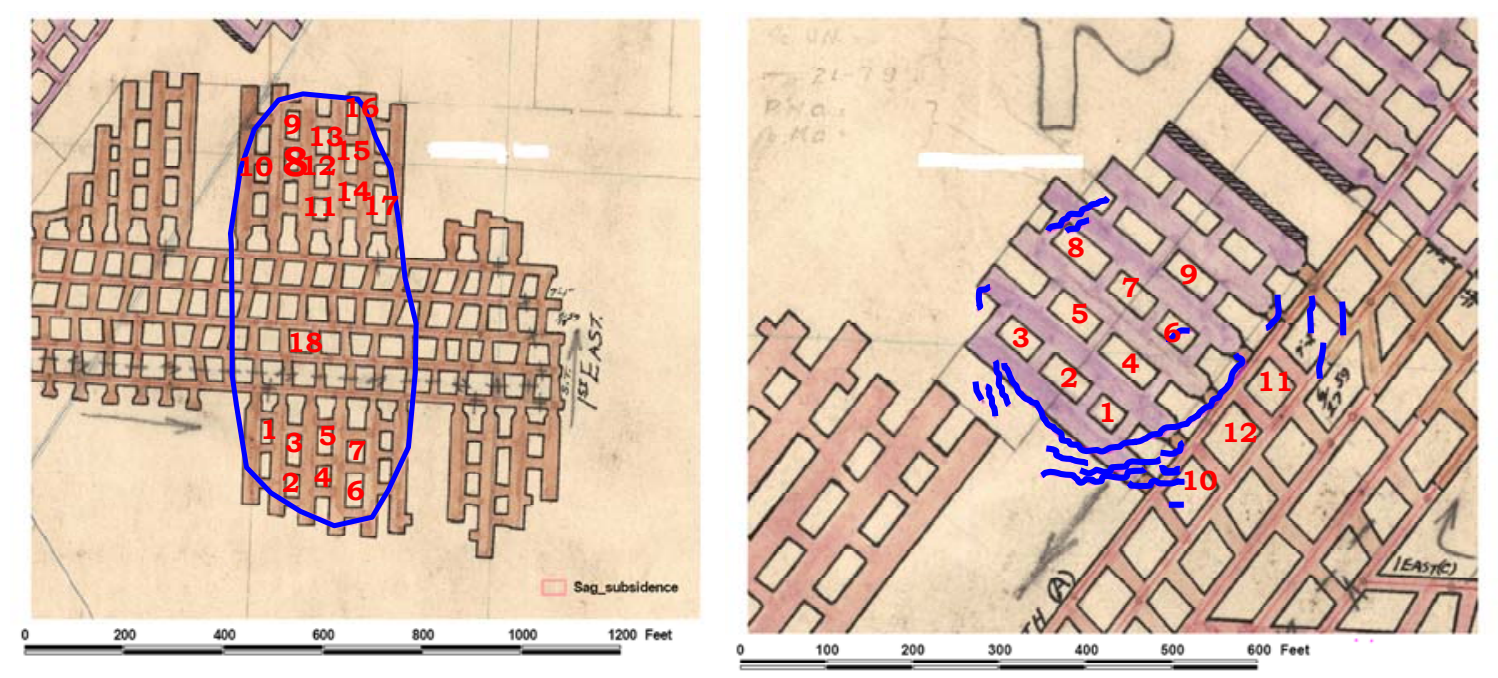

Figure 4.14. Limits of subsided area for case 5 and case 6.

Case 8: The surface movements at this Western shelf mine damaged the police headquarters building sitting above the mine site. The coal was extracted by the room-and-pillar method from a $7.3 \mathrm{ft}$ thick Herrin coal seam at a depth of about $220 \mathrm{ft}$. The floor below the coal seam was made of descending layers of soft underclay, and moderately hard to hard shale of variable thicknesses. The average thickness of the underclay, limestone zone, clayey shale and limestone units in the floor was 4.3, 3.0, 3.2 and $3.6 \mathrm{ft}$, respectively. Although variable moisture contents were measured from different boreholes drilled in the subsided area, the data from the middle of the subsidence trough showed very high moisture of about $20 \%$ in the immediate floor. From the available records it appears that the mine was dry at the time of ceasing operations in the subsided area, which was sometime in 1926. As the mine map in Figure 4.16 shows, the 
extraction ratio in the area of interest was about $57 \%$ with pillar widths between 20 and $40 \mathrm{ft}$ and room spans from 20 to $40 \mathrm{ft}$.

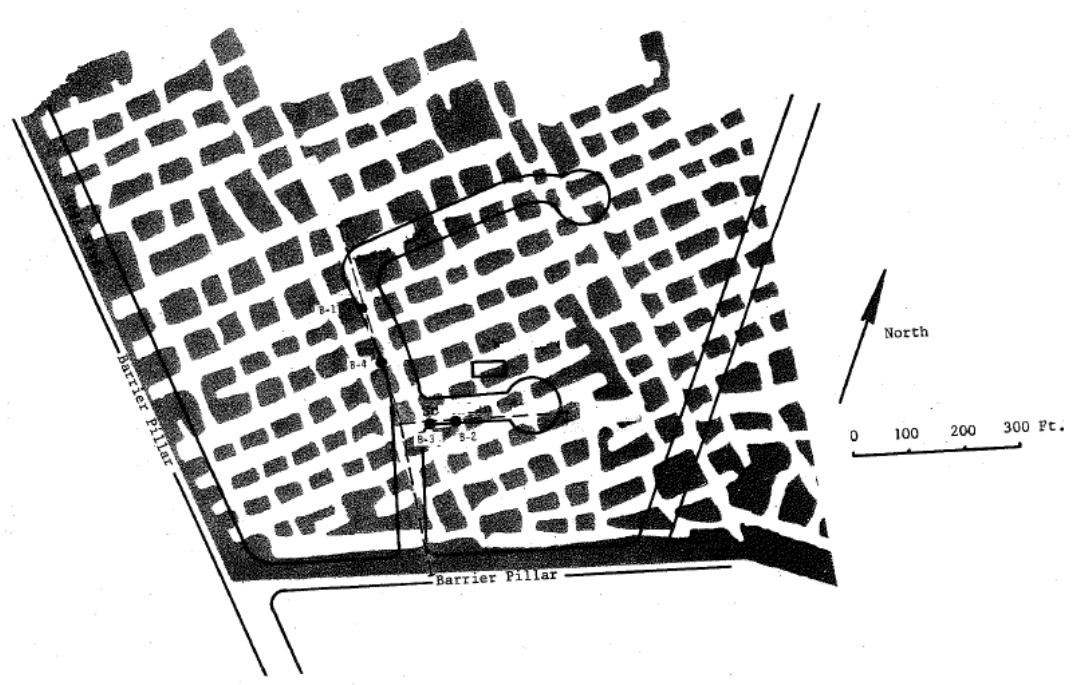

Figure 4.15. Portion of the mine involved in the subsidence for case history 7.

Observations through a borehole camera revealed that low strength clay existed right in the mid-portion of the sag area and relatively intact roof with essentially dry conditions. No pillar instability was noticed from these visual observations. Therefore, it was concluded that excess settlement of the pillars as they punched into the soft floor was the reason for the subsidence. For the floor stability calculations provided in Table 4.10 the immediate floor thickness obtained in borehole 1 was used.

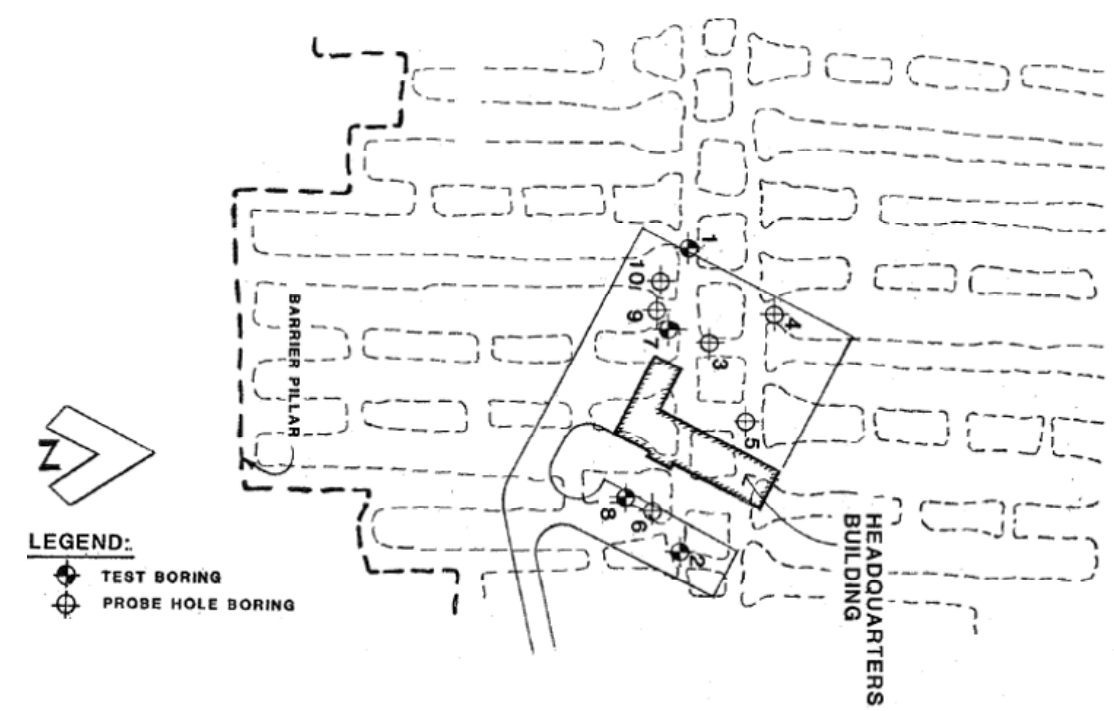

Figure 4.16. Portion of the mine involved in the subsidence for case history 8. 
Table 4.7. Floor stability factors for case 5.

\begin{tabular}{|c|c|c|c|c|c|c|c|c|c|c|c|c|c|c|c|c|c|c|}
\hline Pillar number & 1 & 2 & 3 & 4 & 5 & 6 & 7 & 8 & 9 & 10 & 11 & 12 & 13 & 14 & 15 & 16 & 17 & 18 \\
\hline $\begin{array}{l}\text { Immediate floor } \\
\text { thickness (ft) }\end{array}$ & 2.8 & 2.8 & 2.8 & 2.8 & 2.8 & 2.8 & 2.8 & 2.8 & 2.8 & 2.8 & 2.8 & 2.8 & 2.8 & 2.8 & 2.8 & 2.8 & 2.8 & 2.8 \\
\hline $\begin{array}{l}\text { Moisture content of } \\
\text { immediate floor (\%) }\end{array}$ & 13 & 13 & 13 & 13 & 13 & 13 & 13 & 13 & 13 & 13 & 13 & 13 & 13 & 13 & 13 & 13 & 13 & 13 \\
\hline $\begin{array}{l}\text { Moisture content of } \\
\text { main floor }(\%)\end{array}$ & 7 & 7 & 7 & 7 & 7 & 7 & 7 & 7 & 7 & 7 & 7 & 7 & 7 & 7 & 7 & 7 & 7 & 7 \\
\hline Depth of cover $(\mathrm{ft})$ & 162 & 162 & 162 & 162 & 162 & 162 & 162 & 162 & 162 & 162 & 162 & 162 & 162 & 162 & 162 & 162 & 162 & 162 \\
\hline Pillar width $(\mathrm{ft})$ & 22 & 31 & 31 & 31 & 31 & 35 & 35 & 31 & 31 & 31 & 35 & 35 & 35 & 27 & 27 & 27 & 31 & 45 \\
\hline Pillar length (ft) & 53 & 53 & 67 & 44 & 62 & 71 & 44 & 40 & 62 & 45 & 45 & 50 & 62 & 48 & 62 & 71 & 88 & 45 \\
\hline Entry width (ft) & 35 & 35 & 35 & 35 & 35 & 35 & 35 & 35 & 35 & 35 & 35 & 35 & 35 & 35 & 35 & 35 & 35 & 22 \\
\hline Crosscut width (ft) & 20 & 20 & 20 & 20 & 20 & 20 & 20 & 20 & 20 & 20 & 20 & 20 & 20 & 20 & 20 & 20 & 20 & 22 \\
\hline $\begin{array}{l}\text { Tributary area load } \\
\text { (psi) }\end{array}$ & 650 & 534 & 504 & 564 & 513 & 467 & 530 & 582 & 513 & 560 & 527 & 510 & 482 & 593 & 554 & 536 & 476 & 404 \\
\hline \multicolumn{19}{|c|}{ FLOOR STRENGTH (psi) } \\
\hline Vesic-Speck & -109 & -121 & -123 & -120 & -122 & -129 & -124 & -119 & -122 & -120 & -125 & -126 & -128 & -115 & -117 & -118 & -125 & -135 \\
\hline Vesic-CHC & 209 & 218 & 223 & 214 & 222 & 229 & 216 & 211 & 222 & 214 & 217 & 220 & 226 & 212 & 217 & 220 & 229 & 222 \\
\hline Vesic-Gadde & 613 & 649 & 665 & 635 & 660 & 685 & 647 & 628 & 660 & 637 & 648 & 657 & 674 & 628 & 643 & 650 & 681 & 671 \\
\hline \multicolumn{19}{|c|}{ FLOOR STABILITY FACTORS } \\
\hline Vesic-Speck & -0.17 & -0.23 & -0.24 & -0.21 & -0.24 & -0.28 & -0.23 & -0.20 & -0.24 & -0.21 & -0.24 & -0.25 & -0.26 & -0.19 & -0.21 & -0.22 & -0.26 & -0.33 \\
\hline Vesic-CHC & 0.32 & 0.41 & 0.44 & 0.38 & 0.43 & 0.49 & 0.41 & 0.36 & 0.43 & 0.38 & 0.41 & 0.43 & 0.47 & 0.36 & 0.39 & 0.41 & 0.48 & 0.55 \\
\hline Vesic-Gadde & 0.94 & 1.21 & 1.32 & 1.13 & 1.29 & 1.47 & 1.22 & 1.08 & 1.29 & 1.14 & 1.23 & 1.29 & 1.40 & 1.06 & 1.16 & 1.21 & 1.43 & 1.66 \\
\hline
\end{tabular}


Table 4.8. Floor stability factors for case 6.

\begin{tabular}{|c|c|c|c|c|c|c|c|c|c|c|c|c|}
\hline & \multicolumn{9}{|c|}{ Unstable } & \multicolumn{3}{|c|}{ Stable } \\
\hline Pillar number & 1 & 2 & 3 & 4 & 5 & 6 & 7 & 8 & 9 & 10 & 11 & 12 \\
\hline Immediate floor thickness (ft) & 2.8 & 2.8 & 2.8 & 2.8 & 2.8 & 2.8 & 2.8 & 2.8 & 2.8 & 2.8 & 2.8 & 2.8 \\
\hline $\begin{array}{l}\text { Moisture content of immediate floor } \\
(\%)\end{array}$ & 13 & 13 & 13 & 13 & 13 & 13 & 13 & 13 & 13 & 13 & 13 & 13 \\
\hline Moisture content of main floor (\%) & 7 & 7 & 7 & 7 & 7 & 7 & 7 & 7 & 7 & 7 & 7 & 7 \\
\hline Depth of cover (ft) & 162 & 162 & 162 & 162 & 162 & 162 & 162 & 162 & 162 & 162 & 162 & 162 \\
\hline Pillar width (ft) & 28 & 28 & 28 & 30 & 30 & 28 & 28 & 28 & 27 & 63 & 47 & 61 \\
\hline Pillar length (ft) & 37 & 58 & 47 & 70 & 58 & 47 & 58 & 70 & 60 & 49 & 49 & 49 \\
\hline Entry width (ft) & 32 & 32 & 32 & 32 & 32 & 32 & 32 & 32 & 32 & 32 & 32 & 32 \\
\hline Crosscut width (ft) & 15 & 15 & 15 & 15 & 15 & 15 & 15 & 15 & 15 & 15 & 15 & 15 \\
\hline Tributary area load (psi) & 549 & 492 & 515 & 457 & 474 & 515 & 492 & 474 & 498 & 359 & 400 & 363 \\
\hline \multicolumn{13}{|c|}{ FLOOR STRENGTH (psi) } \\
\hline Vesic-Speck & -115 & -118 & -116 & -122 & -121 & -116 & -118 & -119 & -117 & -152 & -138 & -151 \\
\hline Vesic-CHC & 207 & 217 & 213 & 223 & 219 & 213 & 217 & 221 & 217 & 233 & 226 & 232 \\
\hline Vesic-Gadde & 615 & 643 & 630 & 663 & 651 & 630 & 643 & 654 & 641 & 712 & 685 & 709 \\
\hline \multicolumn{13}{|c|}{ FLOOR STABILITY FACTORS } \\
\hline Vesic-Speck & -0.21 & -0.24 & -0.23 & -0.27 & -0.25 & -0.23 & -0.24 & -0.25 & -0.23 & -0.42 & -0.35 & -0.42 \\
\hline Vesic-CHC & 0.38 & 0.44 & 0.41 & 0.49 & 0.46 & 0.41 & 0.44 & 0.47 & 0.44 & 0.65 & 0.57 & 0.64 \\
\hline Vesic-Gadde & 1.12 & 1.31 & 1.22 & 1.45 & 1.37 & 1.22 & 1.31 & 1.38 & 1.29 & 1.98 & 1.71 & 1.95 \\
\hline
\end{tabular}


Table 4.9. Floor stability factors for case 7.

\begin{tabular}{|c|c|c|c|c|c|c|c|}
\hline Pillar number & 1 & 2 & 3 & 4 & 5 & 6 & 7 \\
\hline Immediate floor thickness (ft) & 6 & 6 & 6 & 6 & 6 & 6 & 6 \\
\hline $\begin{array}{l}\text { Moisture content of immediate floor } \\
(\%)\end{array}$ & 7.33 & 7.33 & 7.33 & 7.33 & 7.33 & 7.33 & 7.33 \\
\hline Moisture content of main floor $(\%)$ & 4 & 4 & 4 & 4 & 4 & 4 & 4 \\
\hline Depth of cover (ft) & 112 & 112 & 112 & 112 & 112 & 112 & 112 \\
\hline Pillar width (ft) & 36 & 20 & 28 & 24 & 24 & 40 & 32 \\
\hline Pillar length (ft) & 60 & 36 & 64 & 80 & 40 & 56 & 40 \\
\hline Entry width (ft) & 22 & 32 & 24 & 28 & 28 & 28 & 32 \\
\hline Crosscut width (ft) & 20 & 15 & 20 & 20 & 20 & 20 & 20 \\
\hline Tributary area load (psi) & 271 & 464 & 307 & 341 & 410 & 291 & 378 \\
\hline \multicolumn{8}{|c|}{ FLOOR STRENGTH (psi) } \\
\hline Vesic-Speck & 775 & 728 & 741 & 719 & 743 & 794 & 782 \\
\hline Vesic-CHC & 475 & 474 & 475 & 475 & 474 & 475 & 474 \\
\hline Vesic-Gadde & 1010 & 923 & 984 & 976 & 942 & 1017 & 967 \\
\hline \multicolumn{8}{|c|}{ FLOOR STABILITY FACTORS } \\
\hline Vesic-Speck & 2.86 & 1.57 & 2.41 & 2.11 & 1.82 & 2.73 & 2.07 \\
\hline Vesic-CHC & 1.75 & 1.02 & 1.55 & 1.39 & 1.16 & 1.63 & 1.25 \\
\hline Vesic-Gadde & 3.73 & 1.99 & 3.20 & 2.86 & 2.30 & 3.50 & 2.56 \\
\hline
\end{tabular}

Table 4.10. Floor stability factors for case 8.

\begin{tabular}{|l|r|r|r|r|r|r|r|r|}
\hline Pillar number & 1 & 2 & 3 & 4 & 5 & 6 & 7 & 8 \\
\hline Immediate floor thickness (ft) & 1.9 & 1.9 & 1.9 & 1.9 & 1.9 & 1.9 & 1.9 & 1.9 \\
\hline Moisture content of immediate & & & & & & & & \\
floor (\%) & 19.8 & 19.8 & 19.8 & 19.8 & 19.8 & 19.8 & 19.8 & 19.8 \\
\hline Moisture content of main floor (\%) & 11.7 & 11.7 & 11.7 & 11.7 & 11.7 & 11.7 & 11.7 & 11.7 \\
\hline Depth of cover (ft) & 220 & 220 & 220 & 220 & 220 & 220 & 220 & 220 \\
\hline Pillar width (ft) & 26 & 24 & 30 & 26 & 25 & 45 & 28 & 30 \\
\hline Pillar length (ft) & 106 & 68 & 75 & 380 & 70 & 45 & 85 & 85 \\
\hline Entry width (ft) & 39 & 39 & 39 & 42 & 42 & 22 & 37 & 32 \\
\hline Crosscut width (ft) & 22 & 22 & 22 & 20 & 11 & 15 & 22 & 22 \\
\hline Tributary area load (psi) & 747 & 860 & 736 & 681 & 768 & 491 & 723 & 644 \\
\hline \multicolumn{7}{|l|}{} \\
\multicolumn{7}{|c|}{ FLOOR STRENGTH (psi) } \\
\hline Vesic-Speck & -1411 & -1424 & -1454 & -1368 & -1430 & -1619 & -1434 & -1444 \\
\hline Vesic-CHC & 221 & 218 & 221 & 224 & 218 & 220 & 221 & 222 \\
\hline Vesic-Gadde & 291 & 288 & 295 & 291 & 290 & 307 & 293 & 295 \\
\hline & FLOOR STABILITY FACTORS \\
& -1.89 & -1.66 & -1.98 & -2.01 & -1.86 & -3.30 & -1.98 & -2.24 \\
\hline Vesic-Speck & 0.30 & 0.25 & 0.30 & 0.33 & 0.28 & 0.45 & 0.31 & 0.34 \\
\hline Vesic-CHC & 0.39 & 0.34 & 0.40 & 0.43 & 0.38 & 0.62 & 0.40 & 0.46 \\
\hline Vesic-Gadde
\end{tabular}




\subsubsection{3}

Case 9: While the case histories discussed so far resulted in some surface movements, this case did not cause any instability. The subject mine located in the Western shelf extracted the Herrin No. 6 coal seam between about 1980 - 1997. To this date no surface subsidence has been reported. Very detailed information on the mine geometry and floor characteristics was available. Throughout the mine, wherever detailed geological information was available through a rock mechanics borehole, the exact pillar and room dimensions were measured from the mine map for the stability analysis. In a few cases, the pillars were non-uniform in shape and dimensions as depicted in Figure 4.17 , in which the geometry nearest to one rock mechanics core hole is shown.

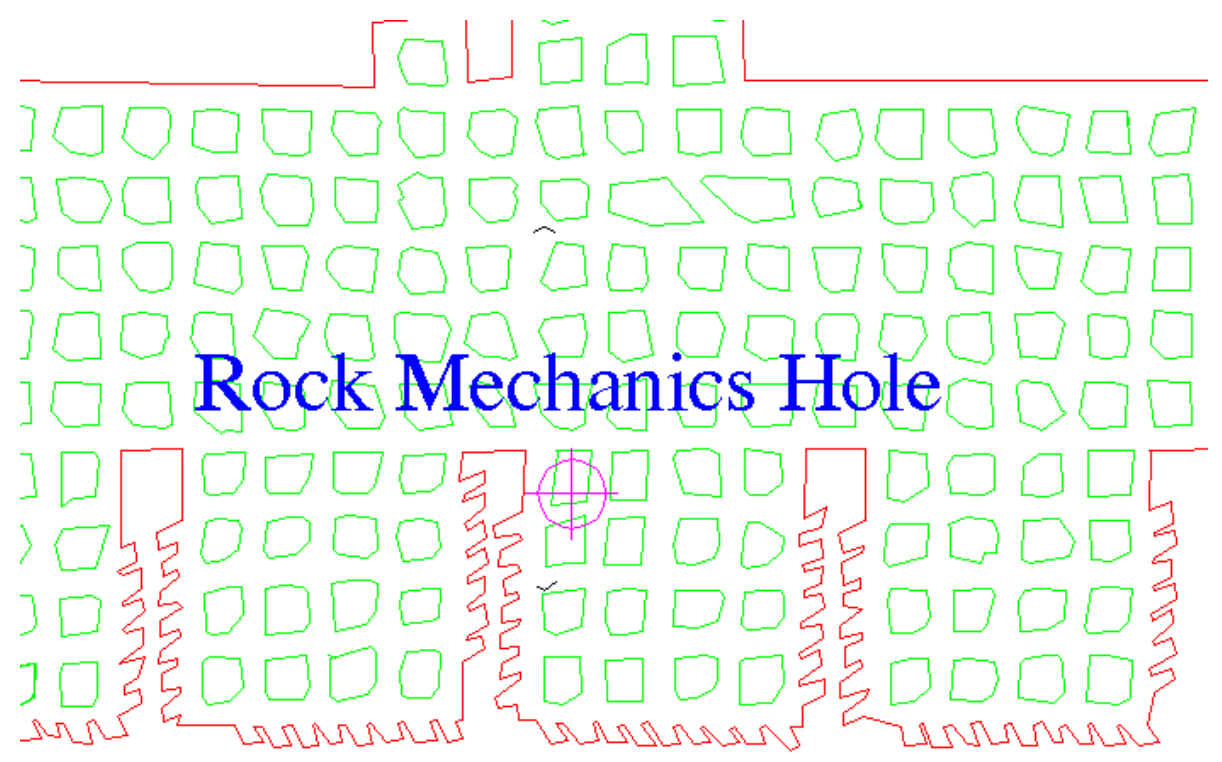

Figure 4.17. Pillar geometry near a rock mechanics borehole for the case history 9 .

When the pillar, entry and crosscut dimensions were not uniform, the corresponding tributary areas were computed using the AutoCAD program to estimate the vertical stress on the pillar. The effective square pillar and opening dimensions that resulted in the same tributary area stress as the non-uniform 
geometry are provided in Table 4.11. For the floor stability analysis, all the necessary information was available through a detailed rock mechanics testing program. Exact floor thickness, moisture content, main floor strength values were available as given in Table 4.11. For the stronger floor, the uniaxial compressive strength data were available from testing. Assuming the friction angle to be zero as required for the Vesic's model, the $c_{2}$ value was computed for the Vesic-CHC and Vesic-Gadde methods. For eighteen rock mechanics boreholes and for the pillar and opening dimensions right below the borehole, the floor stability factors estimated by the three methods are given in Table 4.11. Similar to the previous case histories, the stability factor results will be discussed later in section 4.3.3.

\subsubsection{An Indiana Coal Mine}

Case 10: At this mine, both short- and long-term issues were encountered due the presence of very thick or wet soft floor in a certain portion of the mine. Owing to some depositional differences, in the areas of the mine where surface subsidence occurred due to floor failures, the immediate floor thickness was much larger than was the case in the rest of the mine. Very detailed information on floor properties and mine geometry were available to compute floor stability factors with a high degree of confidence. The subject mine extracted 5 to $6 \mathrm{ft}$ thick coal seam at a depth of cover varying between 175 and $220 \mathrm{ft}$ in the area of instability. The area of the mine that resulted in the surface movements is shown in Figure 4.18. All the information necessary for floor stability factor estimation and the results of the analysis are provided in Table 4.12.

From the information available through exploratory drilling, it was not known that thick weak floor existed in the unstable areas at this mine. This is because of the normal practice of drilling only to a limited depth below the coal seam in the exploratory phase. Subsequent to the instability, some select closespaced drilling was done to a considerable depth below the coal seam. Where available, data from this later core drilling provided very detailed information on the lithology and engineering properties of the floor materials. 
Table 4.11. Floor stability factors for case 9.

\begin{tabular}{|c|c|c|c|c|c|c|c|c|c|c|c|c|c|c|c|c|c|c|}
\hline Pillar number & 1 & 2 & 3 & 4 & 5 & 6 & 7 & 8 & 9 & 10 & 11 & 12 & 13 & 14 & 15 & 16 & 17 & 18 \\
\hline $\begin{array}{l}\text { Immediate floor } \\
\text { thickness (ft) }\end{array}$ & 1.50 & 2.70 & 0.70 & 0.80 & 3.10 & 1.70 & 4.63 & 2.40 & 0.85 & 1.75 & 1.50 & 1.02 & 1.30 & 1.50 & 2.00 & 2.85 & 2.00 & 2.55 \\
\hline $\begin{array}{l}\text { Moisture content of } \\
\text { immediate floor }(\%)\end{array}$ & 13.77 & 9.44 & 15.50 & 11.41 & 16.31 & 10.29 & 10.00 & 12.19 & 10.00 & 9.17 & 12.31 & 12.37 & 10.98 & 14.06 & 8.99 & 10.00 & 13.17 & 11.10 \\
\hline $\begin{array}{l}\text { UCS of main floor } \\
\text { (psi) }\end{array}$ & 3347 & 4873 & 5771 & 1923 & 10089 & 23989 & 2822 & 650 & 31176 & 3580 & 8236 & 608 & 9424 & 2778 & 8316 & 2000 & 2000 & 6470 \\
\hline Depth of cover (ft) & 94 & 138 & 160 & 152 & 181 & 160 & 178 & 197 & 206 & 174 & 206 & 121 & 155 & 195 & 193 & 147 & 143 & 179 \\
\hline Pillar width (ft) & 25 & 32 & 36 & 39 & 31 & 37 & 31 & 34 & 33 & 28 & 44 & 50 & 50 & 50 & 28 & 27 & 33 & 47 \\
\hline Pillar length (ft) & 25 & 32 & 36 & 39 & 31 & 37 & 31 & 34 & 33 & 28 & 44 & 50 & 50 & 50 & 28 & 27 & 33 & 47 \\
\hline Entry width (ft) & 26 & 21 & 21 & 17 & 26 & 23 & 25 & 22 & 23 & 24 & 23 & 20 & 20 & 20 & 20 & 20 & 20 & 20 \\
\hline Crosscut width (ft) & 26 & 21 & 21 & 17 & 26 & 23 & 25 & 22 & 23 & 24 & 23 & 20 & 20 & 20 & 20 & 20 & 20 & 20 \\
\hline $\begin{array}{l}\text { Tributary area load } \\
\text { (psi) }\end{array}$ & 445 & 421 & 454 & 344 & 681 & 477 & 641 & 607 & 671 & 670 & 541 & 267 & 342 & 430 & 638 & 501 & 415 & 409 \\
\hline \multicolumn{19}{|c|}{ FLOOR STRENGTH (psi) } \\
\hline Vesic-Speck & -320 & 543 & -1302 & 365 & -778 & 481 & 396 & 43 & 687 & 634 & 25 & 10 & 439 & -554 & 643 & 423 & -175 & 287 \\
\hline Vesic-CHC & 189 & 435 & -174 & 525 & -888 & 497 & 347 & 241 & 705 & 488 & 391 & 279 & 585 & 218 & 496 & 365 & 229 & 394 \\
\hline Vesic-Gadde & 684 & 934 & 1057 & 1456 & 451 & 1102 & 761 & 704 & 1537 & 1059 & 1042 & 1102 & 1382 & 917 & 1038 & 819 & 714 & 934 \\
\hline \multicolumn{19}{|c|}{ FLOOR STABILITY FACTORS } \\
\hline Vesic-Speck & -0.72 & 1.29 & -2.87 & 1.06 & -1.14 & 1.01 & 0.62 & 0.07 & 1.03 & 0.95 & 0.05 & 0.04 & 1.28 & -1.29 & 1.01 & 0.84 & -0.42 & 0.70 \\
\hline Vesic-CHC & 0.42 & 1.03 & -0.38 & 1.52 & -1.30 & 1.04 & 0.54 & 0.40 & 1.05 & 0.73 & 0.72 & 1.04 & 1.71 & 0.51 & 0.78 & 0.73 & 0.55 & 0.96 \\
\hline Vesic-Gadde & 1.54 & 2.22 & 2.33 & 4.23 & 0.66 & 2.31 & 1.19 & 1.16 & 2.29 & 1.58 & 1.93 & 4.13 & 4.04 & 2.13 & 1.63 & 1.63 & 1.72 & 2.28 \\
\hline
\end{tabular}




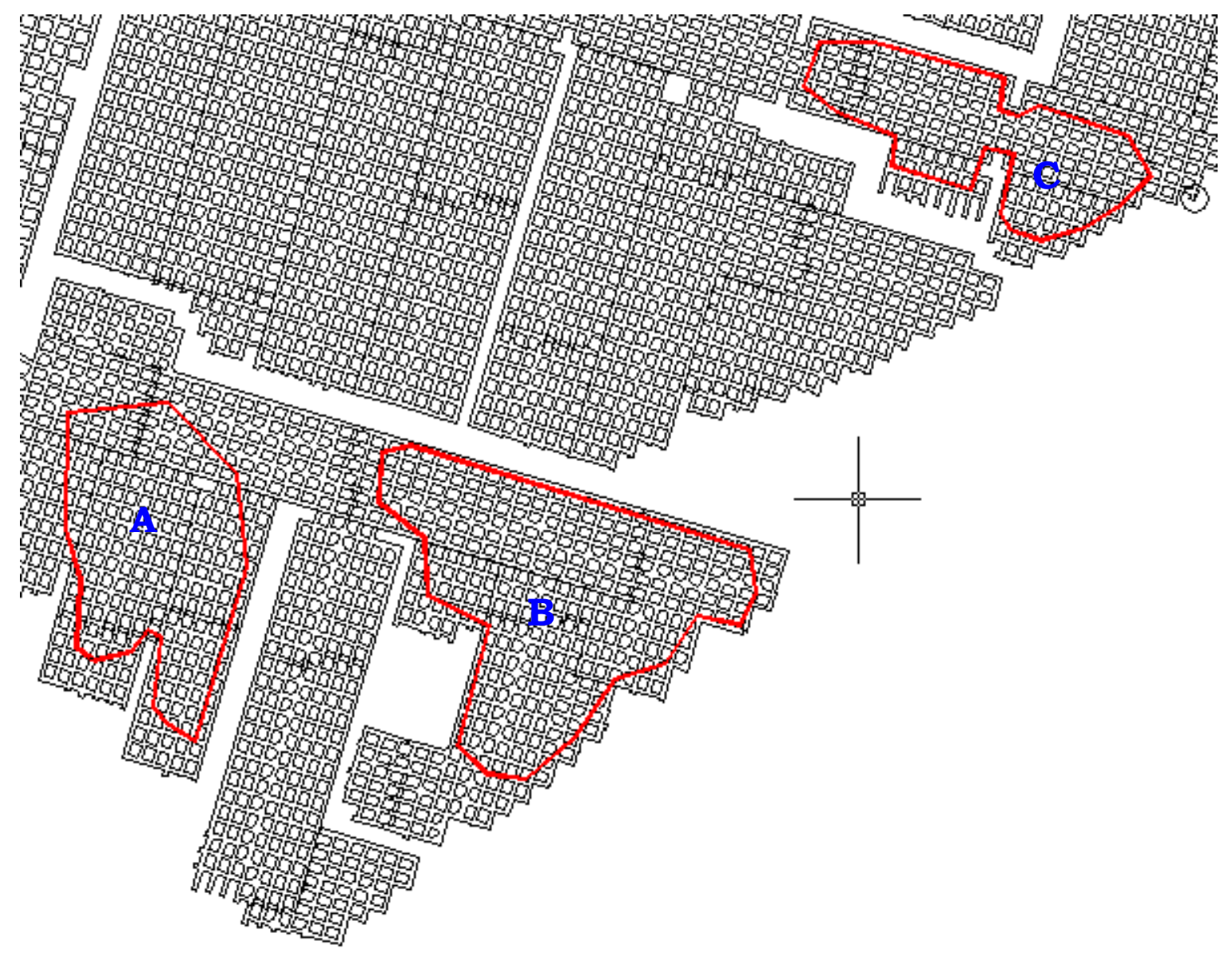

Figure 4.18. Stable and unstable areas for the case history 10.

Since the thickness of the immediate floor was much larger than normally encountered in the mine, use was made of the moisture content change with depth to estimate the exact thicknesses of the weak bed as shown in Figure 4.19. Further, from this mine it was possible to obtain all the necessary information to compute floor stability factors in a stable area right adjacent to the location of instability. Both the stable and unstable areas were developed more than a decade ago. However, the floor instability and the surface movements occurred within a year after abandonment of the area. Table 4.12 also gives the information on the stable floor stability factors for case 10 . For both stable and unstable cases, as discussed in Chapter 3 , the average moisture content for the entire weak bed was used in the analysis. It may also be mentioned that in the two unstable areas at the bottom of Figure 4.18 (A and B), wetter than normal conditions were encountered. 


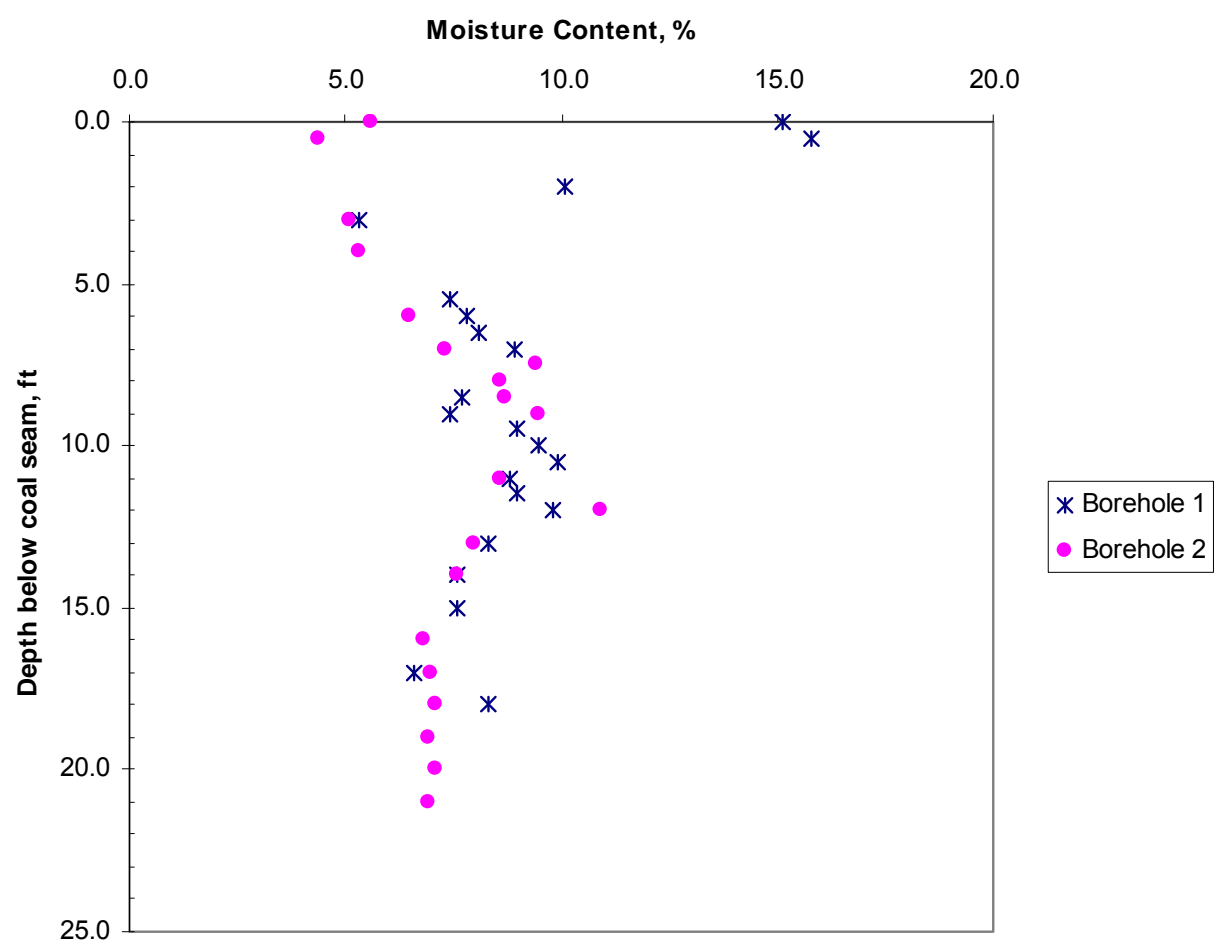

Figure 4.19. Change in the moisture content with depth below the coal seam for two boreholes near the unstable area for case history 10 .

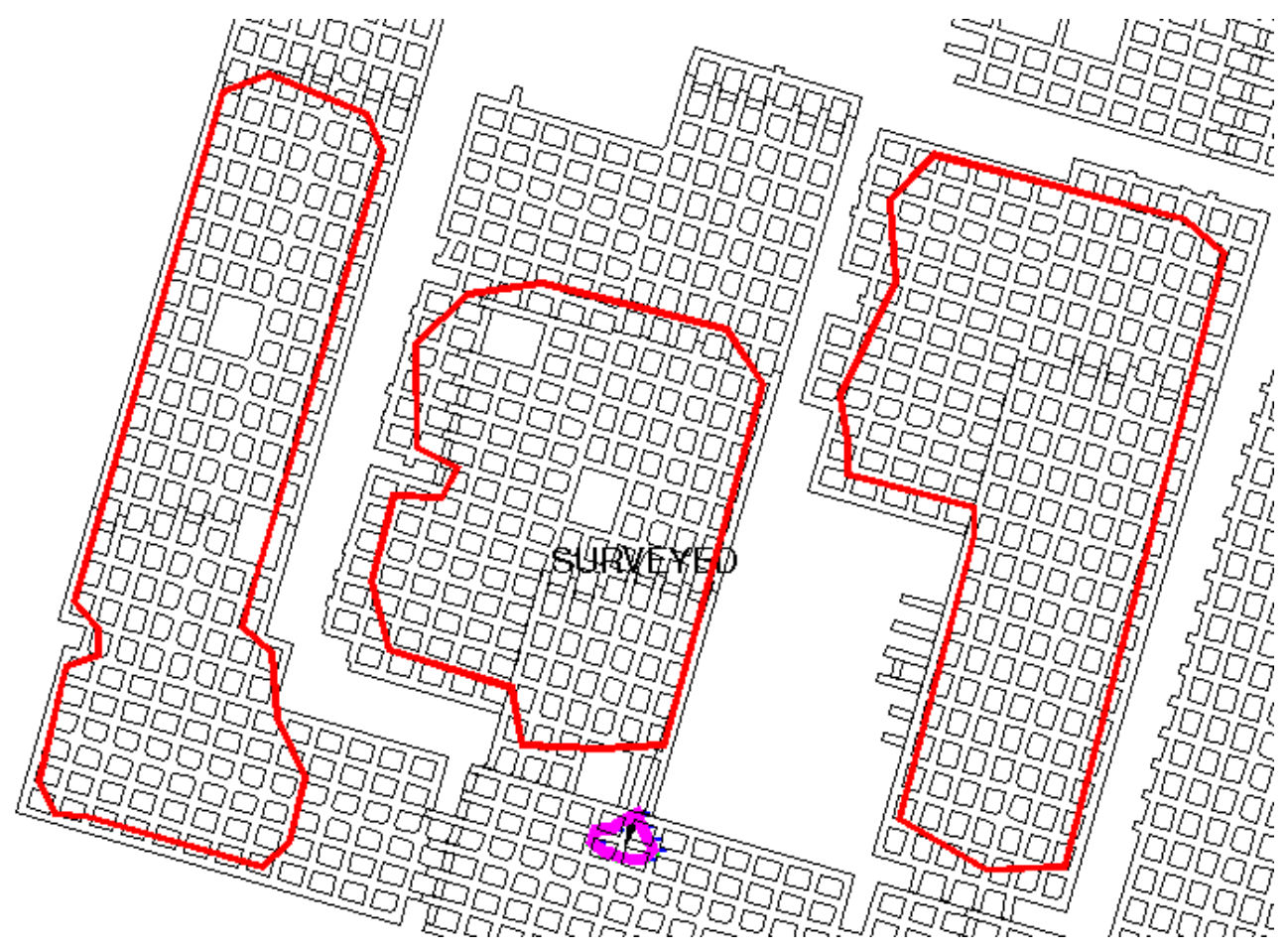

Figure 4.20. Stable and unstable areas for the case history 11. 


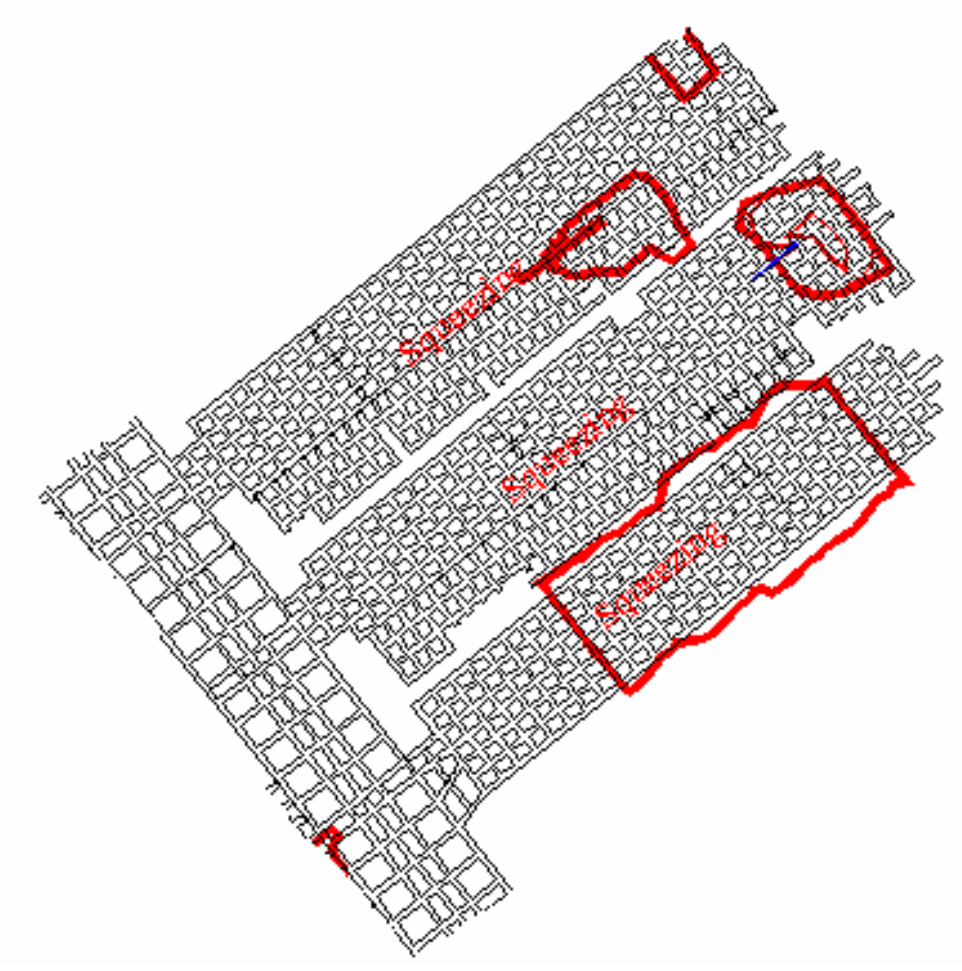

Figure 4.21. Stable and unstable areas for the case history 12.

Case 11 and Case 12: These two subsidence histories also come from the same mine discussed in case 10 above. The areas of the mine involved in the events were shown in Figure 4.20 and Figure 4.21. Floor stability factors estimated based on the information available from exploratory drill holes near the unstable areas and some adjacent stable excavations are given in Table 4.12.

\subsubsection{Some Other Stable Case Histories}

Case 13 through Case 17: In addition to the stable case histories discussed so far, a few pillars were chosen from five active coal mines and their floor stability factors were computed. At each of the five mines, boreholes were identified for which all the necessary rock mechanics information on the floor was available. Then, at the location of the boreholes the exact dimensions of the pillars and the adjacent entries were determined from the mine map. Case 13 and 14 extract No. 5 seam in the Eastern shelf whereas Case 15 and 16 mine the Herrin no. 6 but are located in the Eastern and the Western shelf, respectively. Mining in Case 17 occurs in the Herrin seam and is located in the Eastern shelf. 
Table 4.12. Floor stability factors for cases number 10,11 and 12.

\begin{tabular}{|c|c|c|c|c|c|c|c|c|c|c|c|c|c|c|c|c|}
\hline \multirow[b]{2}{*}{ Pillar number } & \multicolumn{9}{|c|}{ Unstable } & \multicolumn{7}{|c|}{ Stable } \\
\hline & 10 & 10 & 10 & 11 & 11 & 11 & 11 & 12 & 12 & 10 & 10 & 10 & 10 & 11 & 12 & 12 \\
\hline Immediate floor thickness (ft) & 3 & 12 & 8.7 & 3.5 & 2 & 7 & 6.3 & 12.6 & 15 & 10.2 & 4 & 11.5 & 4.2 & 11.2 & 5.8 & 13 \\
\hline $\begin{array}{l}\text { Moisture content of immediate floor } \\
(\%)\end{array}$ & 13.7 & 7.5 & 7.5 & 8.3 & 9.4 & 8 & 8.6 & 8.2 & 7.7 & 5.6 & 5.4 & 8.1 & 7.9 & 6.4 & 7.5 & 7.6 \\
\hline Moisture content of main floor (\%) & 8.2 & 7.2 & 5.4 & 7.8 & 7.7 & 6.3 & 4.5 & 2.5 & 6 & 1.9 & 8.1 & 7.7 & 7.3 & 1 & 2.5 & 5 \\
\hline Depth of cover (ft) & 190 & 190 & 196 & 240 & 220 & 220 & 214 & 197 & 193 & 176 & 212 & 201 & 212 & 233 & 206 & 205 \\
\hline Pillar width (ft) & 37 & 37 & 37 & 37 & 37 & 37 & 37 & 37 & 37 & 37 & 37 & 37 & 37 & 37 & 37 & 37 \\
\hline Pillar length (ft) & 47 & 47 & 47 & 47 & 47 & 47 & 47 & 47 & 47 & 47 & 47 & 47 & 47 & 47 & 47 & 47 \\
\hline Entry width (ft) & 18 & 18 & 18 & 18 & 18 & 18 & 18 & 18 & 18 & 18 & 18 & 18 & 18 & 18 & 18 & 18 \\
\hline Crosscut width (ft) & 18 & 18 & 18 & 18 & 18 & 18 & 18 & 18 & 18 & 18 & 18 & 18 & 18 & 18 & 18 & 18 \\
\hline Tributary area load (psi) & 439 & 439 & 453 & 555 & 509 & 509 & 495 & 456 & 446 & 407 & 490 & 465 & 490 & 539 & 476 & 474 \\
\hline \multicolumn{17}{|c|}{ FLOOR STRENGTH (psi) } \\
\hline Vesic-Speck & -272 & 722 & 739 & 707 & 625 & 680 & 597 & 616 & 683 & 1013 & 1107 & 635 & 744 & 890 & 770 & 703 \\
\hline Vesic-CHC & 169 & 461 & 465 & 421 & 391 & 437 & 412 & 415 & 446 & 590 & 557 & 426 & 444 & 530 & 485 & 451 \\
\hline Vesic-Gadde & 340 & 921 & 948 & 875 & 822 & 878 & 804 & 789 & 866 & 1361 & 1356 & 819 & 938 & 1146 & 1025 & 888 \\
\hline \multicolumn{17}{|c|}{ FLOOR STABILITY FACTORS } \\
\hline Vesic-Speck & -0.62 & 1.64 & 1.63 & 1.27 & 1.23 & 1.34 & 1.21 & 1.35 & 1.53 & 2.49 & 2.26 & 1.37 & 1.52 & 1.65 & 1.62 & 1.48 \\
\hline Vesic-CHC & 0.38 & 1.05 & 1.02 & 0.76 & 0.77 & 0.86 & 0.83 & 0.91 & 1.00 & 1.45 & 1.14 & 0.92 & 0.91 & 0.98 & 1.02 & 0.95 \\
\hline Vesic-Gadde & 0.77 & 2.10 & 2.09 & 1.58 & 1.62 & 1.73 & 1.62 & 1.73 & 1.94 & 3.34 & 2.77 & 1.76 & 1.91 & 2.13 & 2.15 & 1.87 \\
\hline
\end{tabular}


The floor stability factors determined using the three methods discussed in section 4.2 for the chosen pillars are given in Table 4.13 through Table 4.15. At the location of the pillars in these cases, none of the mines experienced any short or long-term floor instability.

Table 4.13. Floor stability factors for case 13 and 14.

\begin{tabular}{|l|r|r|r|r|r|r|r|r|r|}
\hline Case number & 13 & 13 & 13 & 13 & 14 & 14 & 14 & 14 & 14 \\
\hline Immediate floor thickness (ft) & 4.5 & 5.3 & 0.5 & 2.3 & 3.9 & 4.1 & 4.55 & 4.28 & 3.3 \\
\hline $\begin{array}{l}\text { Moisture content of immediate floor } \\
(\%)\end{array}$ & 5.67 & 4.3 & 3.9 & 2.63 & 4.91 & 5.9 & 6.29 & 5.98 & 5.57 \\
\hline Moisture content of main floor (\%) & 4 & 5.88 & 3.315 & 2.31 & 0.99 & 0.67 & 2.31 & 1.59 & 3.43 \\
\hline Depth of cover (ft) & 200 & 229 & 310 & 300 & 275 & 275 & 313 & 309 & 332 \\
\hline Pillar width (ft) & 72 & 34 & 59 & 41 & 53 & 50 & 46 & 35 & 54 \\
\hline Pillar length (ft) & 78 & 40 & 44 & 35 & 52 & 51 & 46 & 35 & 51 \\
\hline Entry width (ft) & 22 & 19.5 & 19 & 20 & 20 & 17 & 20 & 19 & 16.2 \\
\hline Crosscut width (ft) & 26 & 19 & 18 & 20 & 18.6 & 19 & 20 & 19 & 20 \\
\hline Tributary area load (psi) & 392 & $626^{*}$ & $674^{*}$ & $761^{*}$ & 579 & 569 & $677^{*}$ & $730^{*}$ & 676 \\
\hline \multicolumn{7}{|c|}{ FLOR STRENGTH (psi) } \\
\hline Vesic-Speck & 1155 & 1242 & 1656 & 1559 & 1244 & 1093 & 1016 & 1040 & 1186 \\
\hline Vesic-CHC & 625 & 679 & 791 & 861 & 716 & 641 & 582 & 595 & 641 \\
\hline Vesic-Gadde & 1796 & 1831 & 6115 & 3285 & 2033 & 1631 & 1411 & 1428 & 1826 \\
\hline \multicolumn{7}{|c|}{ FLOOR STABILITY FACTORS } \\
\hline Vesic-Speck & 2.95 & 1.98 & 2.46 & 2.05 & 2.15 & 1.92 & 1.50 & 1.42 & 1.75 \\
\hline Vesic-CHC & 1.60 & 1.09 & 1.17 & 1.13 & 1.24 & 1.13 & 0.86 & 0.82 & 0.95 \\
\hline Vesic-Gadde & 4.59 & 2.93 & 9.07 & 4.32 & 3.51 & 2.87 & 2.08 & 1.96 & 2.70 \\
\hline
\end{tabular}

Table 4.14. Floor stability factors for case 15 and 16.

\begin{tabular}{|l|r|r|r|r|r|r|r|r|r|}
\hline Case number & 15 & 15 & 15 & 15 & 16 & 16 & 16 & 16 & 16 \\
\hline Immediate floor thickness (ft) & 2.27 & 3.5 & 1.3 & 3.2 & 1.44 & 3.56 & 3 & 0.4 & 2.7 \\
\hline $\begin{array}{l}\text { Moisture content of immediate floor } \\
\text { (\%) }\end{array}$ & 7.73 & 6.34 & 5.17 & 5.47 & 10.7 & 12.5 & 7.35 & 9.1 & 11.38 \\
\hline Moisture content of main floor (\%) & 7.23 & 2.31 & 2.45 & 2.58 & 6.09 & 1.01 & 1.5 & 1.17 & 2.5 \\
\hline Depth of cover (ft) & 249 & 194 & 179 & 198 & 151 & 102 & 179 & 189 & 191 \\
\hline Pillar width (ft) & 42 & 40 & 49 & 46 & 45 & 45 & 45 & 45 & 45 \\
\hline Pillar length (ft) & 45 & 40 & 49 & 44 & 45 & 45 & 45 & 45 & 45 \\
\hline Entry width (ft) & 19 & 18 & 20 & 19 & 20 & 20 & 20 & 20 & 20 \\
\hline Crosscut width (ft) & 18 & 20 & 18 & 19 & 20 & 20 & 20 & 20 & 20 \\
\hline Tributary area load (psi) & 570 & 475 & 388 & 451 & 354 & 239 & 420 & 444 & 448 \\
\hline & FLOOR STRENGTH (psi) & & & \\
\hline Vesic-Speck & 897 & 1024 & 1373 & 1180 & 470 & -11 & 916 & 1465 & 219 \\
\hline Vesic-CHC & 460 & 588 & 773 & 655 & 401 & 254 & 558 & 1001 & 333 \\
\hline Vesic-Gadde & 1089 & 1434 & 2876 & 1794 & 1091 & 707 & 1236 & 3465 & 860 \\
\hline & FLOOR STABILITY FACTORS \\
\hline & 1.58 & 2.16 & 3.54 & 2.62 & 1.33 & 0.05 & 2.18 & 3.30 & 0.49 \\
\hline Vesic-Speck & 0.81 & 1.24 & 1.99 & 1.45 & 1.13 & 1.06 & 1.33 & 2.26 & 0.74 \\
\hline Vesic-CHC & 1.91 & 3.02 & 7.42 & 3.98 & 3.08 & 2.95 & 2.94 & 7.81 & 1.92 \\
\hline Vesic-Gadde & \multicolumn{7}{|l|}{} \\
\hline
\end{tabular}


Table 4.15. Floor stability factors for case 17.

\begin{tabular}{|c|c|c|c|c|c|c|c|c|c|c|c|c|c|c|c|c|c|c|}
\hline Pillar Number & 1 & 2 & 3 & 4 & 5 & 6 & 7 & 8 & 9 & 10 & 11 & 12 & 13 & 14 & 15 & 16 & 17 & 18 \\
\hline $\begin{array}{l}\text { Immediate floor } \\
\text { thickness (ft) }\end{array}$ & 1 & 1.5 & 1.5 & 3 & 2.5 & 2.5 & 2.5 & 1 & 2.5 & 3 & 3 & 2.5 & 1.5 & 2.5 & 1 & 0.5 & 1 & 1 \\
\hline $\begin{array}{l}\text { Moisture content of } \\
\text { immediate floor (\%) }\end{array}$ & 7 & 7.15 & 7.15 & 6.5 & 7.65 & 7.2 & 7.25 & 6.8 & 3.37 & 6.6 & 5.87 & 6.5 & 4.47 & 6.9 & 6.8 & 8.9 & 9.25 & 8.25 \\
\hline $\begin{array}{l}\text { Moisture content of } \\
\text { main floor }(\%)\end{array}$ & 5.92 & 4.45 & 4.45 & 5.88 & 5.6 & 2.56 & 5.4 & 5.34 & 0.7 & 5.88 & 2.9 & 4.25 & 5.21 & 3.5 & 4.6 & 7.02 & 5.46 & 4.2 \\
\hline Depth of cover (ft) & 270 & 265 & 265 & 257 & 257 & 265 & 249 & 262 & 265 & 234 & 227 & 244 & 228 & 249 & 260 & 235 & 196 & 249 \\
\hline Pillar width (ft) & 41 & 40 & 34 & 36 & 40 & 43 & 51 & 42 & 40 & 41 & 62 & 62 & 46 & 53 & 41 & 42 & 41 & 63 \\
\hline Pillar length (ft) & 43 & 43 & 43 & 42 & 40 & 41 & 53 & 36 & 38 & 43 & 42 & 56 & 50 & 55 & 37 & 39 & 42 & 59 \\
\hline Entry width (ft) & 18 & 18 & 18 & 18 & 18 & 19 & 18 & 18 & 18 & 20 & 18 & 18 & 18 & 19 & 18 & 18 & 18 & 18 \\
\hline Crosscut width (ft) & 18 & 18 & 18 & 18 & 19 & 19 & 18 & 19 & 18 & 20 & 18 & 18 & 20 & 19.5 & 19 & 18 & 18 & 18 \\
\hline $\begin{array}{l}\text { Tributary area load } \\
\text { (psi) }\end{array}$ & 620 & 613 & $654^{*}$ & $550^{*}$ & 618 & 629 & 508 & 643 & 637 & 574 & 471 & 468 & 500 & 515 & $674^{*}$ & 552 & 453 & $461^{*}$ \\
\hline \multicolumn{19}{|c|}{ FLOOR STRENGTH (psi) } \\
\hline Vesic-Speck & 1221 & 1070 & 1027 & 995 & 882 & 966 & 991 & 1252 & 1449 & 1008 & 1226 & 1144 & 1382 & 1049 & 1244 & 1288 & 875 & 1234 \\
\hline Vesic-CHC & 547 & 576 & 570 & 537 & 491 & 565 & 525 & 575 & 852 & 533 & 634 & 596 & 638 & 590 & 610 & 497 & 505 & 643 \\
\hline Vesic-Gadde & 1748 & 1610 & 1558 & 1330 & 1155 & 1369 & 1355 & 1849 & 2853 & 1329 & 1730 & 1696 & 2398 & 1571 & 1966 & 1590 & 1297 & 2047 \\
\hline \multicolumn{19}{|c|}{ FLOOR STABILITY FACTORS } \\
\hline Vesic-Speck & 1.97 & 1.75 & 1.57 & 1.81 & 1.43 & 1.54 & 1.95 & 1.95 & 2.27 & 1.76 & 2.60 & 2.44 & 2.77 & 2.03 & 1.85 & 2.33 & 1.93 & 2.68 \\
\hline Vesic-CHC & 0.88 & 0.94 & 0.87 & 0.98 & 0.79 & 0.90 & 1.03 & 0.89 & 1.34 & 0.93 & 1.35 & 1.27 & 1.28 & 1.15 & 0.91 & 0.90 & 1.11 & 1.40 \\
\hline Vesic-Gadde & 2.82 & 2.63 & 2.38 & 2.42 & 1.87 & 2.18 & 2.67 & 2.87 & 4.48 & 2.32 & 3.67 & 3.62 & 4.80 & 3.05 & 2.92 & 2.88 & 2.86 & 4.44 \\
\hline
\end{tabular}

* pillars were irregular and the tributary area was determined from mine map. 


\subsubsection{Short-Term Stability}

Short-term floor instability occurs during the useful lifespan of a mine opening. It is normally manifested in the form of slow to very slow floor heave which may shut the mine opening partially or completely in as little as a few hours to a few years. Some short-term floor issues may also lead to roof falls and surface subsidence. Case histories available in the literature and from the author's own collection are discussed below.

\subsubsection{The SIUC database}

As a part of a major research project, the Southern Illinois University, Carbondale, IL (SIUC) put together a database of case histories from several active mines in the state of Illinois (Chugh and Pytel, 1992). The SIUC database comprised 114 cases of stable and failed floors from the Herrin No. 6 seam. Using the Vesic-Speck, Vesic-CHC and Pytel-Chugh methods, floor stability factors were estimated for each case in the database (Chugh and Pytel, 1992). The results of the analysis are shown in Figures 4.22 and 4.23 for the failed and stable floor cases, respectively. Based on this case history analysis, SIUC found that in order to explain $100 \%$ of the unstable floor events, the floor stability factor values should be at least 2.0, 2.5, and 1.5 for the Vesic-Speck, Pytel-Chugh and Vesic-CHC, respectively. For each of these stability factor values and the methods, however, there were $40 \%, 20 \%$ and $4 \%$ of unexplained stable cases, respectively.

The SIUC back analysis (Chugh and Pytel, 1992) is the only comprehensive published work available on floor stability case histories in the Basin. No other work considered as many actual cases. For instance, the most popular Vesic-Speck approach has been originally tested only for two coal mines in the state of Illinois (Speck, 1981). Despite this uniqueness, several issues exist with the SIUC case history database as given below:

- from the description in the Chugh and Pytel (1992) paper, it appears that the results were applicable only for the short-term stability. Further, no 
clear criteria were given in the paper on how SIUC considered a particular case as stable or unstable. It is also not known among the total 114 cases, how many were stable and how many were unstable;

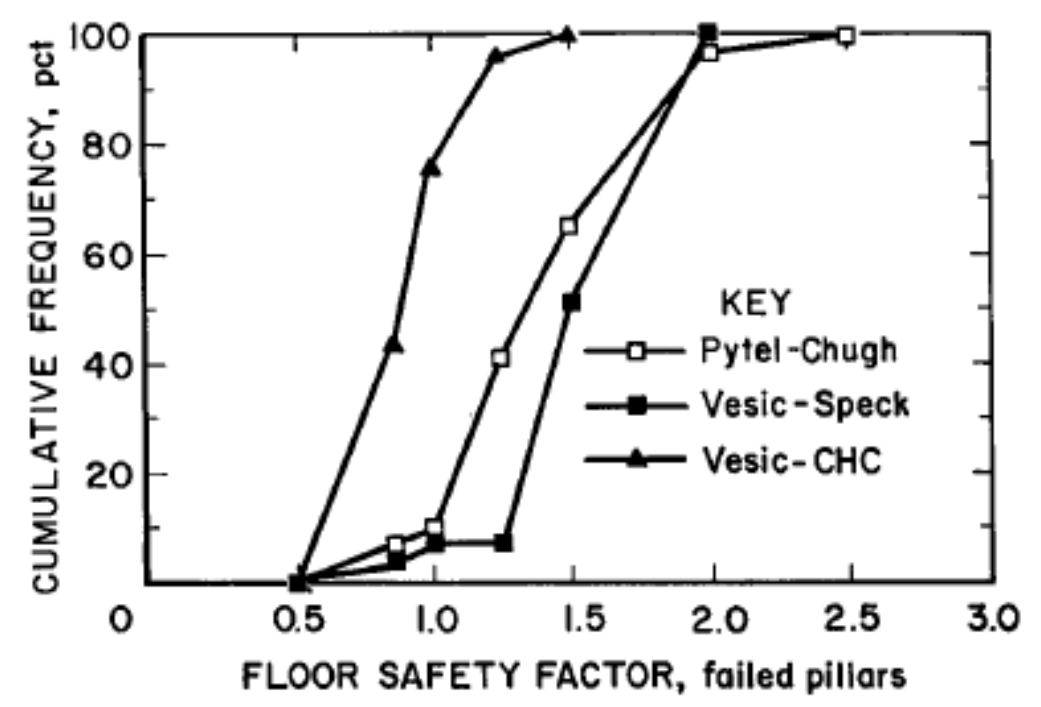

Figure 4.22. Cumulative frequency plot of floor stability factors for failed pillars (Pytel and Chugh, 1992).

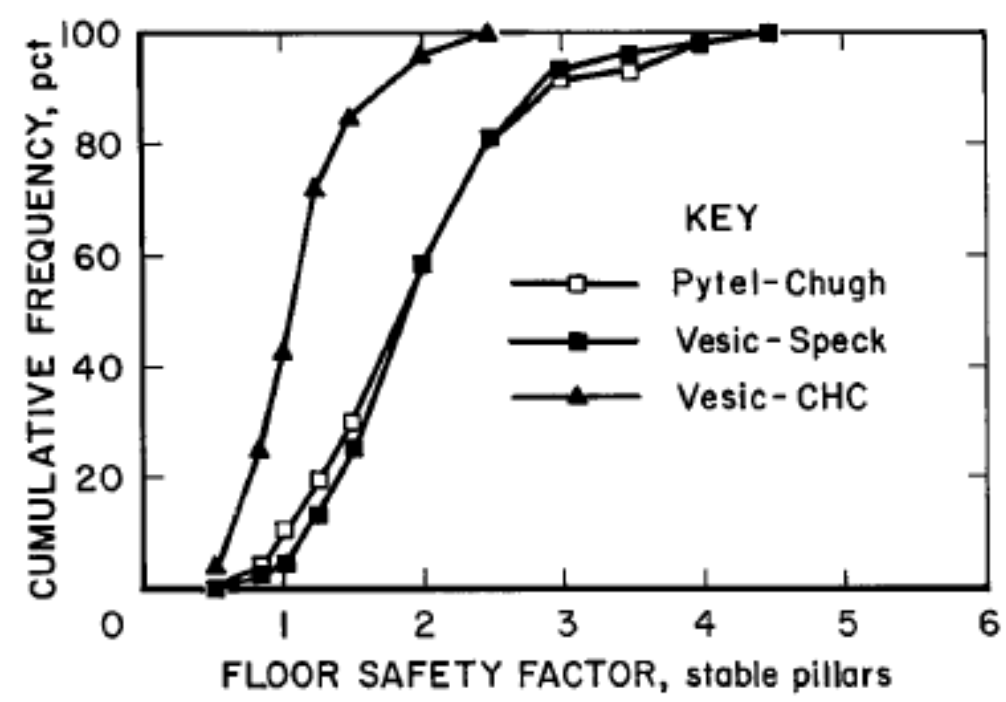

Figure 4.23. Cumulative frequency plot of floor stability factors for stable pillars (Pytel and Chugh, 1992).

- $\quad$ the most critical information needed for the floor stability assessment was not available for the case histories. Mine wide average values were used in the SIUC analysis for the moisture content, weak floor thickness and strong floor strength. Consequently, the usefulness of the back 
analysis becomes limited when such fundamental inputs were not available. Experience in the Basin shows that in almost every case, at the site of floor instability, some unusual conditions (thicker floor, higher moisture, etc.) exist as compared to the mine wide averages.

- $\quad$ the data were collected only from active coal mines, which according to SIUC experienced some floor instability during mining. As will be shown in Chapter 5, owing to the non-uniform vertical stresses, localized floor instability could occur without jeopardizing the integrity of the floor underneath the entire pillar. Therefore, such local floor movements underground should not be considered for developing design guidelines on long-term stability for subsidence prevention unless the instability is known to have caused surface movements. The SIUC paper (Chugh and Pytel, 1992) did not explain if such was the case with their database;

- the study was limited only to Herrin No. 6 seam and mines that operate in the state of Illinois.

Despite the above limitations, since the SIUC database was the only comprehensive case history collection ever made, it will be interesting to analyze those cases using the three methods described in section 4.2. As efforts were made to access the SIUC database, some other issues came into light. First, the original reports that Chugh and Pytel (1992) referred to in their paper on the database were no longer available. Not even a single copy could be located at SIUC or at the Illinois State Geological Survey. Second, it appears that there were several inaccuracies in the original data collected, which was the basis for the plots in Figure 4.22 and Figure 4.23. A concerted effort was made later to correct the inaccuracies and the new information was summarized in a report (Chugh et al., summarized by DeMaris, 1996). Unfortunately, however, this later summary report did not show which case history was stable and which was unstable. The only information available in the corrected report was the geometric and moisture content data for each case and the SIUC estimated floor and coal pillar stability factors. However, the most recent report also included some case histories from the Springfield No. 5 seam. Even though efforts were 
made to contact the SIUC researchers to find if they could recall or have any record to show which case history was stable and which was not, the author has had no luck.

Without knowing the condition of the floor, it is not possible to assess which method of floor stability analysis discussed above provides better results when applied to the corrected SIUC database. At the same time, the SIUC analysis (Chugh and Pytel, 1992) is of limited help because of the inaccuracies in the database discovered subsequently. Nonetheless, the floor stability factors for the SIUC new database were estimated to see if any information on relative performance could be obtained. In what follows, the floor stability factor values obtained using the Vesic-Speck, Vesic-CHC and Vesic-Gadde method for the SIUC database are given. This stability analysis has no more value than just to see what kind of floor stability factors were used by the active mine operators at the time the SIUC database was collected.

In order to estimate the floor stability factors for the SIUC database, it was assumed that the main floor cohesion $\left(c_{2}\right)$ was equal to 1150 psi. This was necessary to reproduce the Vesic-Speck floor stability factors given in the SIUC summary report (Chugh et al., summarized by DeMaris, 1996). The SIUC report did not provide the $c_{2}$ values used in their analysis. Additionally, for the VesicGadde analysis, the general plate bearing capacity equation given by Equation (3.11) was used since the SIUC database did not give any information on the geographic location of the mine in the Basin to apply the appropriate Gadde equations. The results of the stability analysis are given in Figures 4.24 and 4.25 for the No.6 seam and No.5 seam, respectively.

The plots in Figures 4.24 and 4.25 show that the Vesic-CHC method provides the most conservative stability factors while the Vesic-Gadde is the most optimistic with the Vesic-Speck in between. The analysis also shows that when the SIUC's recommended safety factors for the short-term stability given above are considered, then almost $100 \%$ of the cases from the No.5 seam should have experienced some floor stability issues. For the Herrin No. 6 seam, between 80 and $85 \%$ of the case histories should have had unstable floor. 
Although the details on how many cases have had floor instability were not available, such high percentage of mines experiencing problems seems highly unlikely, especially, given that much of the SIUC information was collected from the permitting applications (Chugh et al., summarized by DeMaris, 1996). Intuitively, the floor stability factors given by the Vesic-Gadde approach in Figures 4.22 and 4.23 appear more realistic than the other two.
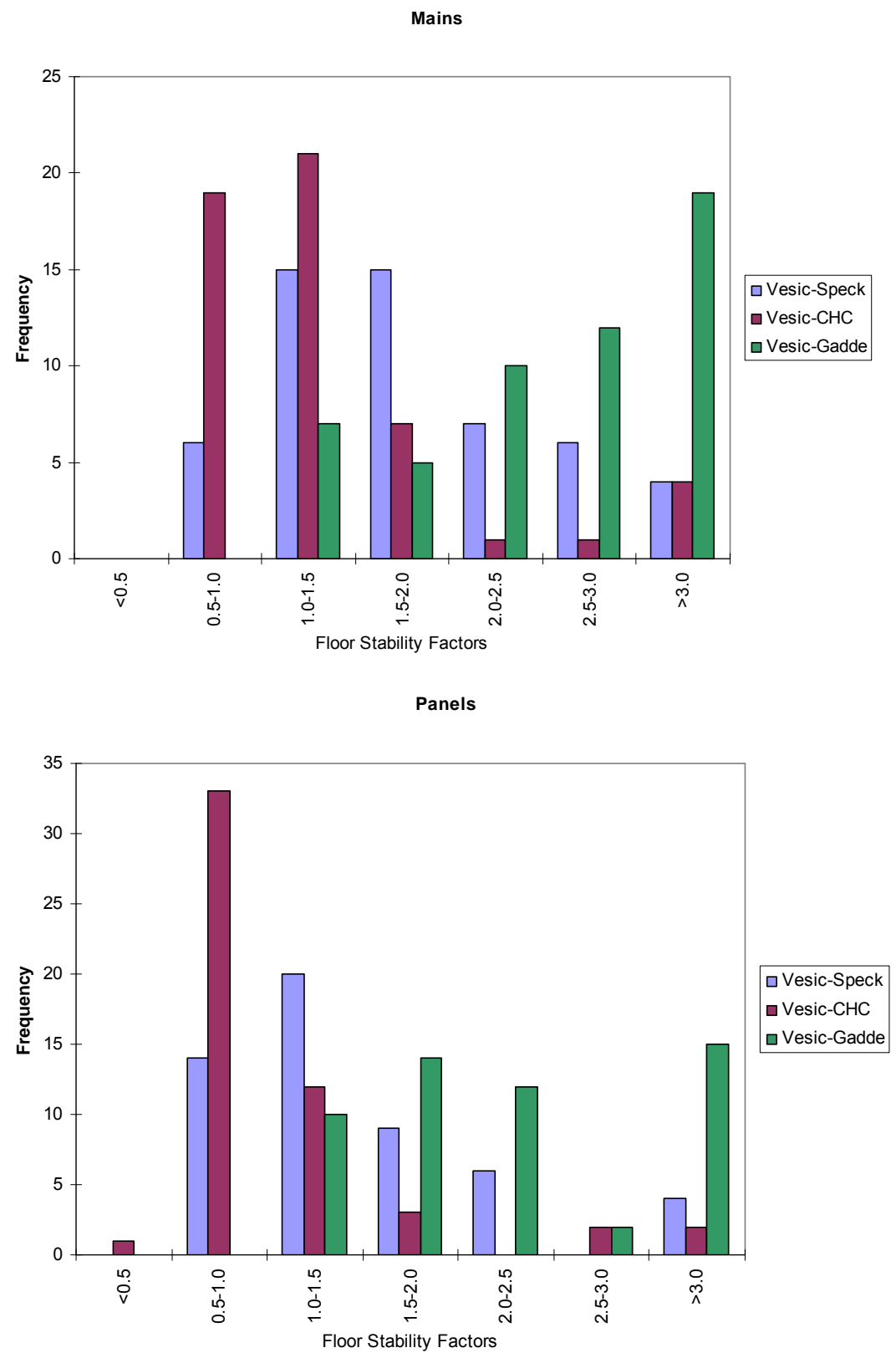

Figure 4.24. Comparison of floor stability factors for the SIUC No.6 seam data. 

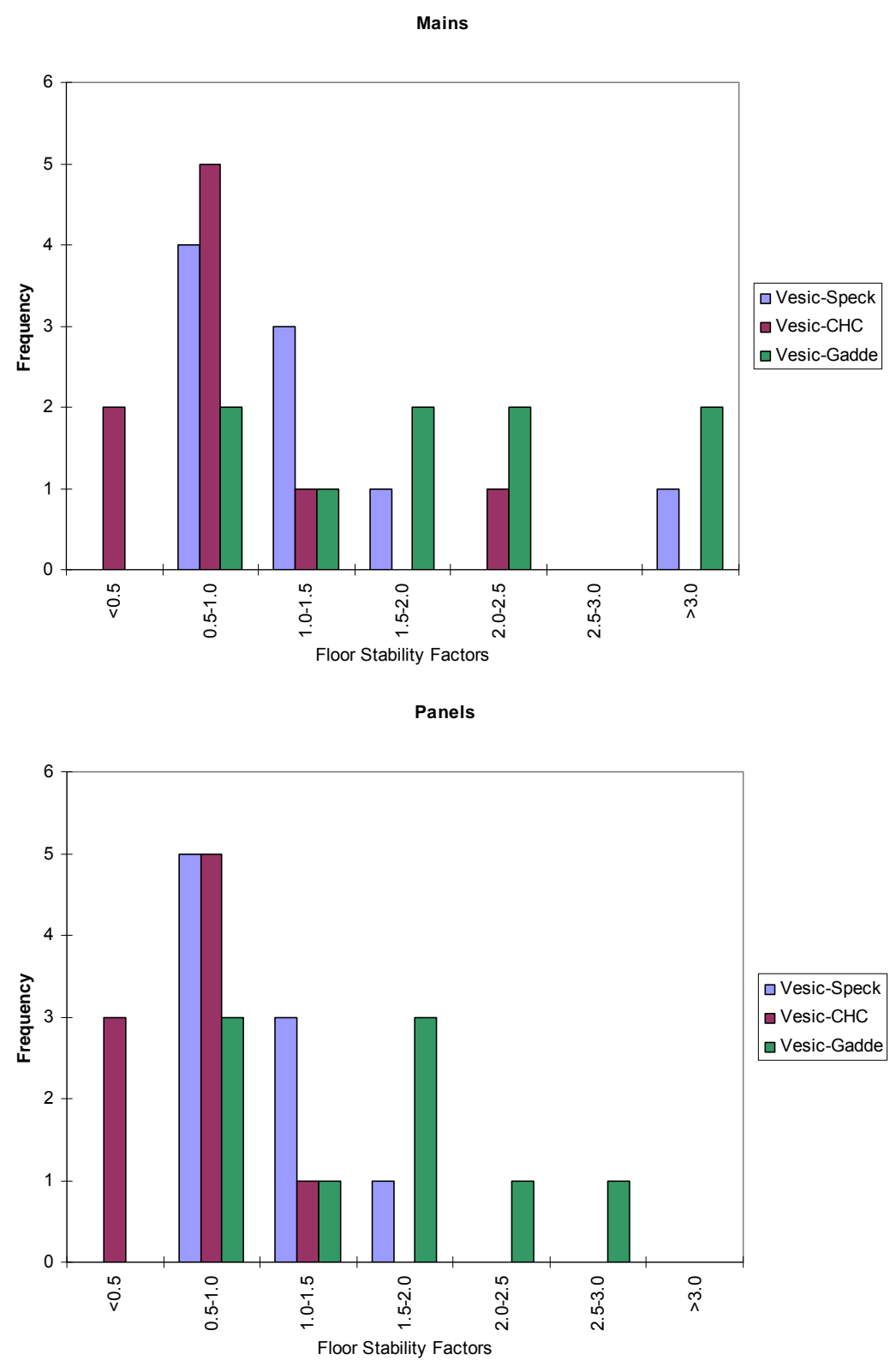

Figure 4.25. Comparison of floor stability factors for the SIUC No.5 seam data.

In the Ph.D. dissertation of Speck (1979), details on short-term floor instability at two Zeigler coal mines were provided. Eight cases, including two unstable and six stable, were analyzed to assess the validity of the newly developed Vesic-Speck floor stability analysis method. Localized floor instability occurred at a few locations in the mine as shown in Figure 4.26. Speck (1979) did not mention if any of the unstable floor conditions led to surface subsidence. 
The two coal mines extracted the Herrin No. 6 seam at 150 to $250 \mathrm{ft}$ below ground. The coal seam was very uniform in thickness varying only slightly between 6 and $7 \mathrm{ft}$. The immediate floor was comprised of 4 to $6.3 \mathrm{ft}$ underclay underlain by 11 to $21 \mathrm{ft}$ claystone. The floor heave at the mine did not occur uniformly and was localized to a few areas (Speck, 1981). Underground instrumentation to monitor floor deformations showed that at the heave sites, both underclay and claystone beds were involved in the instability. Field observations at the mine showed that floor heave occurred at areas where the underclay was thicker and its natural moisture content was higher. Speck's (1981) studies also showed that swelling of montmorillonite clay did not contribute much to the problem.

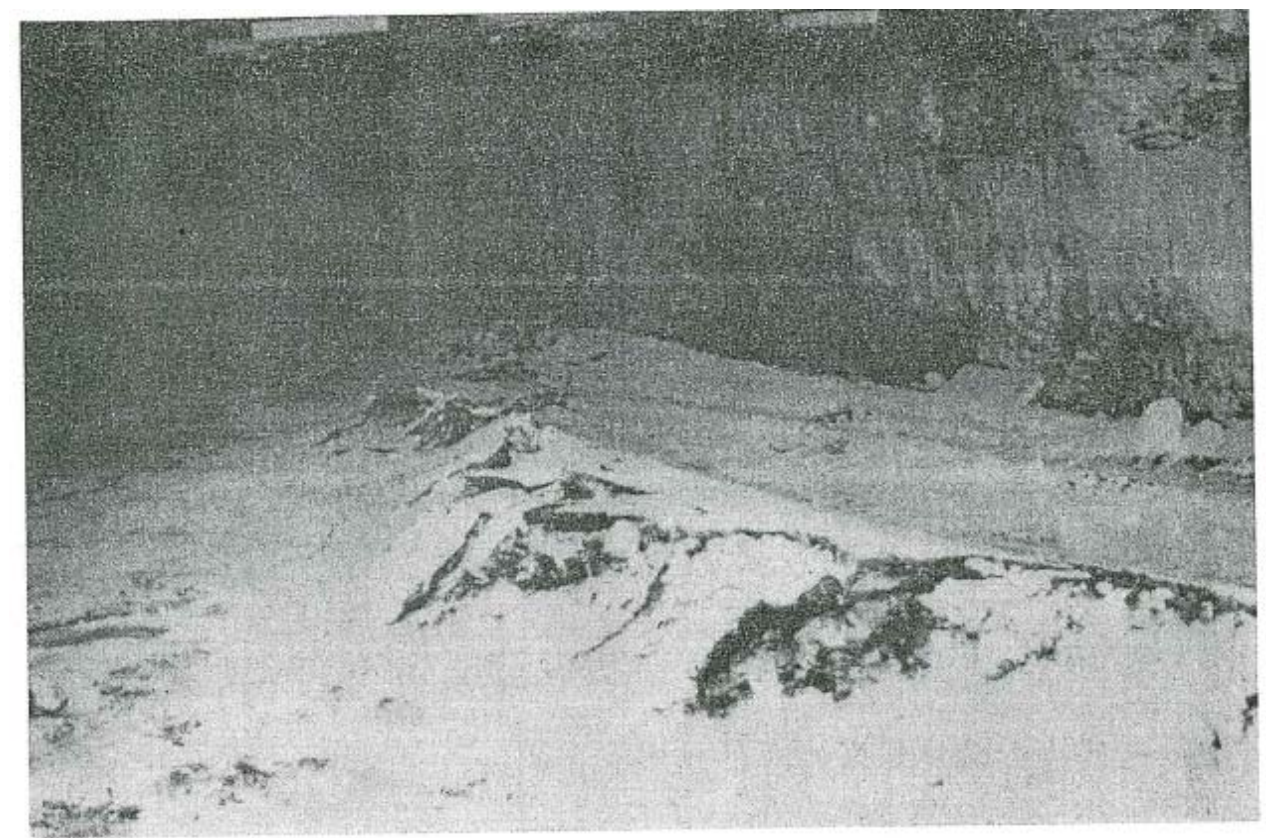

Figure 4.26. Initial stage of localized floor heave in a Zeigler coal mine (Speck, 1979).

From the different models available at the time, Speck (1979) felt that Vesic's non-homogeneous bearing capacity model discussed in section 4.1.2 was the best to apply to the Zeigler's conditions. Using the Vesic's model, Speck (1979) estimated what he called the floor 'heave factor' for the eight cases given in Table 4.16. Also included in Table 4.16 are the floor stability factors computed by the Vesic-CHC and Vesic-Gadde approaches. It may be noted that there are two rows of Vesic-Gadde results in table 4.16: one using $c_{2}=248$ psi as 
suggested by Speck and the other using the main floor strength equations developed by Gadde given in Section 4.2.3.

The results in Table 4.16 show that the Vesic-Speck approach predicts unstable floor conditions when the stability factor was below 1.0. Similar conclusion is provided by Vesic-CHC. For the Vesic-Gadde method, however, both heaved sites had stability factors above 1.0. When it comes to stable cases, both Vesic-Speck and Vesic-Gadde predicted the conditions accurately. Except for one case, the Vesic-CHC model computed floor stability factors below 1.0 for all the stable cases. Since the floor instability at the two Zeigler mines did not result in surface subsidence, an overall floor stability factor less than 1.0 is not necessary to cause the localized floor heave. This is due to the non-uniform vertical stresses on the floor which could fail the floor near pillar ribs without affecting the overall stability of the floor. This database once again shows the ultra conservative nature of the Vesic-CHC model. The very little difference between the Vesic-Gadde predictions using $c_{2}=248 \mathrm{psi}$ and using the Gadde's main floor strength equations reveals the general validity of the later relations.

\subsubsection{A Western Kentucky Coal Mine}

At this Western Kentucky mine which extracted the No. 9 seam by the room-and-pillar method, some local floor instability was noticed in a panel shown in Figure 4.27. The floor instability, which began in the travel and belt entry of the panel quickly spread to the entire panel width and shut the mine openings in a very short span of time. Subsequent to the floor movement, several roof falls were noticed in the panel as shown by the purple lines in Figure 4.27. In fact, the limit of the floor instability coincided exactly with the limit of the roof falls at the inby end shown in Figure 4.27. The mine openings closed so quickly that the operator had to cut through the heave to recover the equipment. During the recovery operation, it was noticed that inby the limit of roof falls shown in Figure 4.27, the floor was perfectly stable as is the normal 
case at the mine. Interestingly, no surface subsidence was reported over the panel.

Table 4.16. Floor stability factors for Speck's case histories.

\begin{tabular}{|c|c|c|c|c|c|c|c|c|}
\hline & \multicolumn{2}{|c|}{$\begin{array}{r}\text { Unstable } \\
\text { Floor } \\
\end{array}$} & \multicolumn{6}{|c|}{ Stable Floor } \\
\hline Immediate floor thickness (ft) & 6.25 & 6.3 & 6.25 & 3.5 & 5.5 & 5 & 4.5 & 3.9 \\
\hline $\begin{array}{l}\text { Moisture content of immediate floor } \\
(\%)\end{array}$ & 11.5 & 11 & 9.8 & 9.2 & 8.8 & 9.1 & 8.9 & 8.9 \\
\hline Cohesion of the main floor (psi) & 248 & 248 & 248 & 248 & 248 & 248 & 248 & 248 \\
\hline Moisture content of main floor (\%) & 6.7 & 7.7 & 5.7 & 5.4 & 5.3 & 7.3 & 6.1 & 6.1 \\
\hline Tributary area load $(\mathrm{psi})$ & 409 & 288 & 427 & 394 & 380 & 338 & 344 & 327 \\
\hline \multicolumn{9}{|c|}{ FLOOR STRENGTH (psi) } \\
\hline Vesic-Speck & 159 & 246 & 450 & 625 & 628 & 590 & 637 & 659 \\
\hline Vesic-CHC & 250 & 270 & 316 & 313 & 349 & 334 & 335 & 327 \\
\hline Vesic-Gadde $\left(c_{2}=248 \mathrm{psi}\right)$ & 468 & 514 & 646 & 806 & 793 & 763 & 806 & 829 \\
\hline $\begin{array}{l}\text { Vesic-Gadde (Gadde's main floor } \\
\text { strength equation) }\end{array}$ & 473 & 512 & 664 & 871 & 832 & 769 & 844 & 876 \\
\hline \multicolumn{9}{|c|}{ FLOOR STABILITY FACTORS } \\
\hline Vesic-Speck & 0.39 & 0.85 & 1.05 & 1.59 & 1.65 & 1.75 & 1.85 & 2.01 \\
\hline Vesic-CHC & 0.61 & 0.94 & 0.74 & 0.80 & 0.92 & 0.99 & 0.97 & 1.00 \\
\hline $\begin{array}{l}\text { Vesic-Gadde } \\
\left(c_{2}=248 \mathrm{psi}\right)\end{array}$ & 1.14 & 1.78 & 1.51 & 2.05 & 2.09 & 2.26 & 2.34 & 2.53 \\
\hline $\begin{array}{l}\text { Vesic-Gadde } \\
\text { (Gadde's main floor strength } \\
\text { equation) }\end{array}$ & 1.16 & 1.78 & 1.55 & 2.21 & 2.19 & 2.28 & 2.45 & 2.68 \\
\hline
\end{tabular}

The floor heave began as a minor movement along the rib lines and in the mid-portion of the entry which accelerated later to shut the opening and made them impassable. The floor heave also caused some rib rashing as shown in Figure 4.28 (a). The pillar sizes employed in the panel were determined using the Vesic-Speck approach and information available through nearby exploratory boreholes. Subsequent underground drilling in the unstable area and rock mechanics testing showed that the floor at the site of instability was thicker and wetter than indicated by the data from the exploration boreholes. The floor stability analysis made for some select pillars in the panel by the three methods discussed in section 4.2 is provided in Table 4.17. For the floor stability computations, the tributary area stress on the pillars was estimated by calculating the areas of the pillars and the tributary areas using the AutoCAD program. This was necessary because of the irregular shape of the pillars.

The floor stability analysis in Table 4.17 shows that for the pillars involved in the instability, the floor stability factors were less than 1.0 by all three methods 
of analysis. As before, the Vesic-CHC showed the least stability factors with Vesic-Speck and Vesic-Gadde in the increasing order. However, given that the floor instability was not noticed until after the entire panel was developed (a few months) and since the FSF for Vesic-Speck and Vesic-CHC are very low, the predictions given by Vesic-Gadde seems more reasonable than the other two.

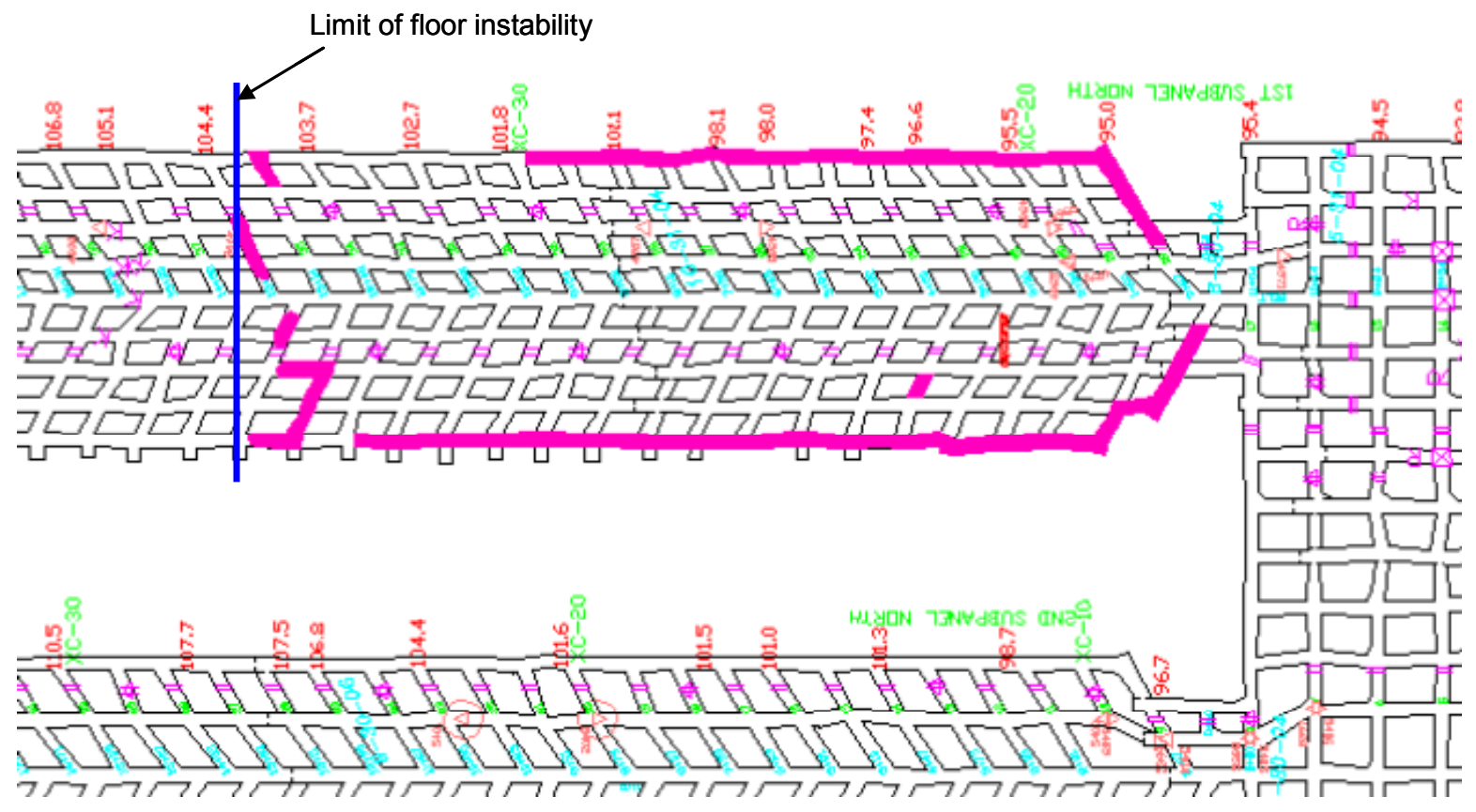

Figure 4.27. Area affected by floor instability at a Western Kentucky mine.

Table 4.17. Floor stability factors for the Western Kentucky mine.

\begin{tabular}{|c|c|c|c|c|c|}
\hline Pillar Number & 1 & 2 & 3 & 4 & 5 \\
\hline Immediate floor thickness (ft) & 5.0 & 5.0 & 5.0 & 5.0 & 5.0 \\
\hline Moisture content of immediate floor (\%) & 9.94 & 9.94 & 9.94 & 9.94 & 9.94 \\
\hline Moisture content of main floor $(\%)$ & 4.05 & 4.05 & 4.05 & 4.05 & 4.05 \\
\hline Depth of cover (ft) & 270 & 270 & 270 & 270 & 270 \\
\hline Pillar width (ft) & 29 & 35 & 33 & 34 & 36 \\
\hline Pillar length (ft) & 60 & 47 & 50 & 51 & 49 \\
\hline Tributary area load (psi) & 687 & 712 & 718 & 734 & 715 \\
\hline \multicolumn{6}{|c|}{ FLOOR STRENGTH (psi) } \\
\hline Vesic-Speck & 384 & 403 & 396 & 399 & 405 \\
\hline Vesic-CHC & 352 & 352 & 352 & 353 & 354 \\
\hline Vesic-Gadde & 644 & 645 & 645 & 648 & 650 \\
\hline \multicolumn{6}{|c|}{ FLOOR STABILITY FACTORS } \\
\hline Vesic-Speck & 0.56 & 0.57 & 0.55 & 0.54 & 0.57 \\
\hline Vesic-CHC & 0.51 & 0.49 & 0.49 & 0.48 & 0.49 \\
\hline Vesic-Gadde & 0.94 & 0.91 & 0.90 & 0.88 & 0.91 \\
\hline
\end{tabular}


a)

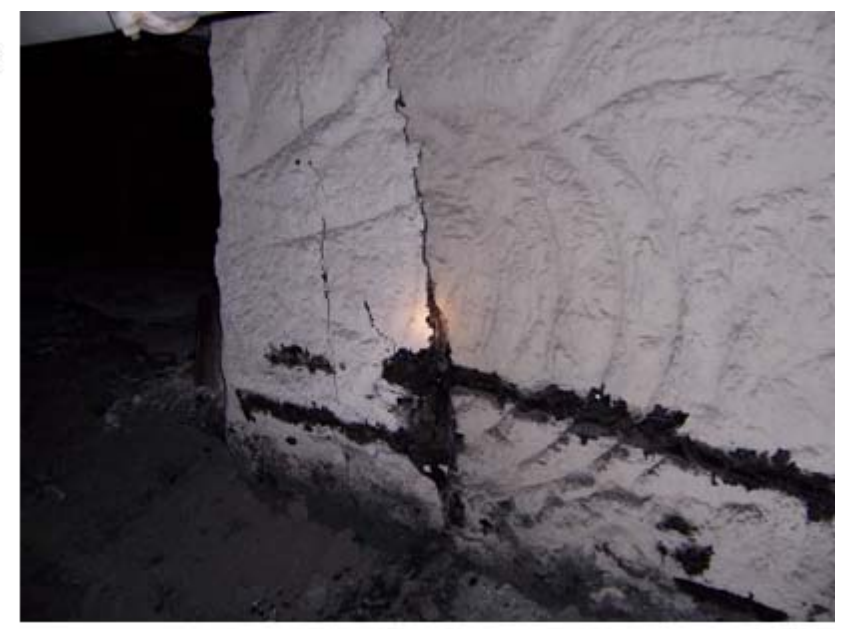

b)

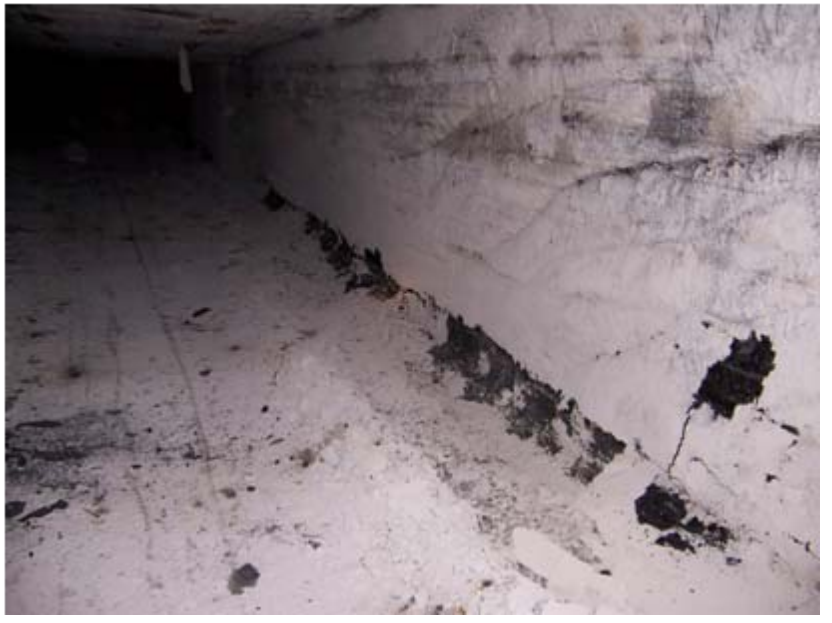

Figure 4.28. Pictures showing (a) rib rash and (b) floor heave adjacent to the rib line at a Western Kentucky coal mine.

\subsubsection{4 $\quad$ An Indiana Coal Mine}

This short-term floor instability occurred at the same mine as in case history 10 discussed in section 4.3.1.4. The instability occurred during the development of the mains through a thick weak floor area, which was not known ahead of time from exploratory drilling. The area involved in the floor heave is shown in Figure 4.29. From this map it may be noted that at the most inby end of the mains, the pillar size was increased considerably. This was the consequence of the floor instability noticed in some adjacent panels and the subsequent mapping of the thick floor areas. While the bigger pillar area of the 
mains remained stable, the outby areas with smaller pillars started squeezing. The floor deformations occurred slowly enough to recover the equipment and abandon the mains completely. The floor stability factors for this area are given in Table 4.18 below.

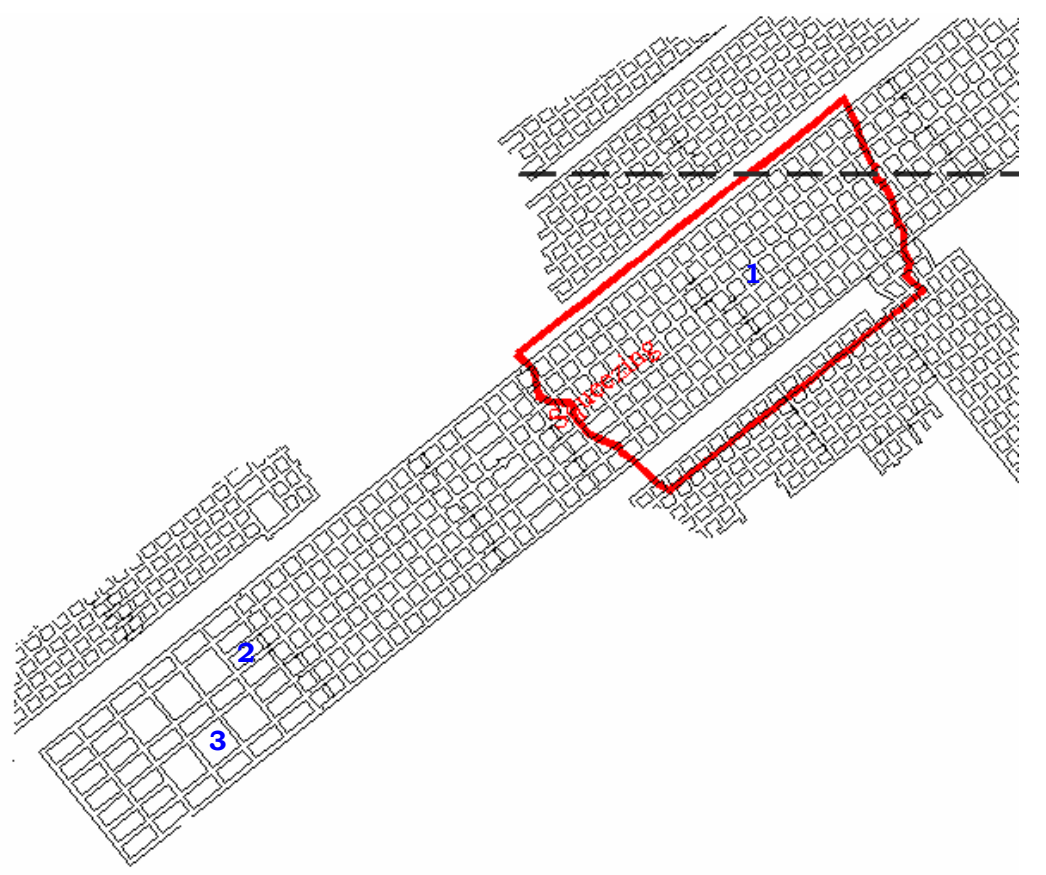

Figure 4.29. Short-term floor instability at an Indiana coal mine.

Table 4.18. Floor stability factors in the mains at an Indiana coal mine.

\begin{tabular}{|c|c|c|c|c|c|c|}
\hline Case type & \multirow{2}{*}{\multicolumn{2}{|c|}{$\frac{\text { unstable }}{1}$}} & \multicolumn{4}{|c|}{ stable } \\
\hline \multirow{2}{*}{$\begin{array}{l}\text { Pillar Number } \\
\text { Immediate floor thickness (ft) }\end{array}$} & & & \multicolumn{2}{|c|}{2} & \multicolumn{2}{|c|}{3} \\
\hline & \multicolumn{2}{|c|}{12.6} & 12.6 & 15 & 12.6 & 15 \\
\hline Moisture content of immediate floor (\%) & 8.2 & 7.7 & 8.2 & 7.7 & 8.2 & 7.7 \\
\hline Moisture content of main floor (\%) & 2.5 & 6 & 2.5 & 6 & 2.5 & 6 \\
\hline Depth of cover (ft) & 197 & 193 & 197 & 193 & 197 & 193 \\
\hline Pillar width (ft) & 52 & 52 & 52 & 52 & 122 & 122 \\
\hline Pillar length (ft) & 52 & 52 & 122 & 122 & 122 & 122 \\
\hline Entry width (ft) & 18 & 18 & 18 & 18 & 18 & 18 \\
\hline Crosscut width (ft) & 18 & 18 & 18 & 18 & 18 & 18 \\
\hline Tributary area load (psi) & 402 & 393 & 342 & 335 & 292 & 286 \\
\hline \multicolumn{7}{|c|}{ FLOOR STRENGTH (psi) } \\
\hline Vesic-Speck & 650 & 718 & 609 & 667 & 720 & 779 \\
\hline Vesic-CHC & 420 & 447 & 434 & 452 & 460 & 460 \\
\hline Vesic-Gadde & 811 & 881 & 858 & 911 & 956 & 979 \\
\hline \multicolumn{7}{|c|}{ FLOOR STABILITY FACTORS } \\
\hline Vesic-Speck & 1.62 & 1.83 & 1.78 & 1.99 & 2.47 & 2.72 \\
\hline Vesic-CHC & 1.05 & 1.14 & 1.27 & 1.35 & 1.58 & 1.61 \\
\hline Vesic-Gadde & 2.02 & 2.24 & 2.51 & 2.72 & 3.28 & 3.42 \\
\hline
\end{tabular}




\subsubsection{Design Stability Factors}

The results of the long-term floor stability analysis conducted in section 4.3.1.1 are summarized in Figures 4.30 through 4.32 for the Vesic-Speck, Vesic$\mathrm{CHC}$ and Vesic-Gadde approaches, respectively. Based on these histograms, the following broad conclusions could be drawn about the performance of the three methods.

The Vesic-Speck approach: this method predicts physically unrealistic negative stability factors when the moisture content value exceeds $12.4 \%$. Considering the fact that such high moisture values are a common occurrence in the Western shelf mines, the Vesic-Speck approach should not be used for floor design in this part of the Basin. Despite its widespread use, based on the distribution in Figure 4.28, it is not possible to define an unambiguous critical floor stability factor that differentiates stable and unstable case histories for the long-term stability.

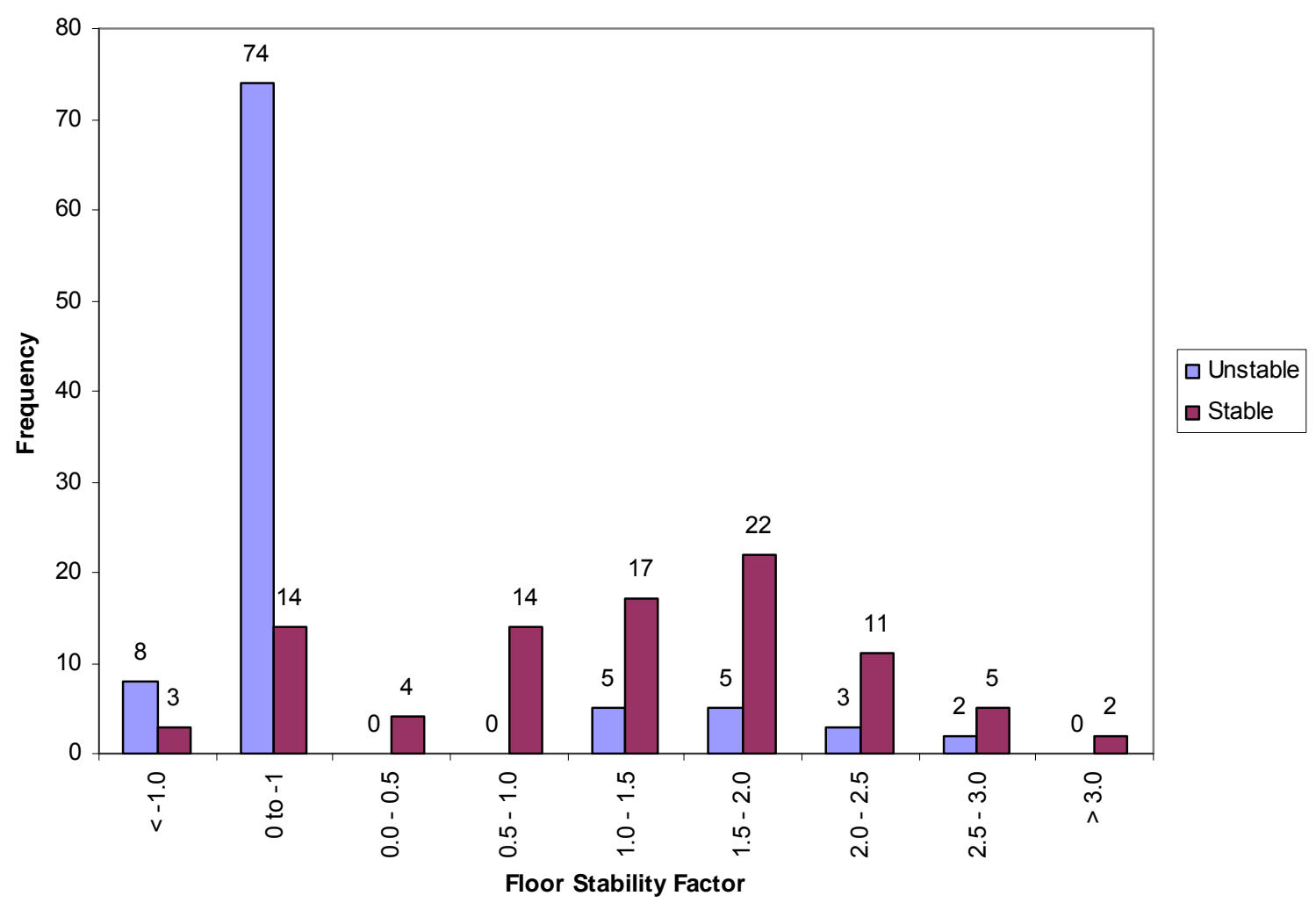

Figure 4.30. The long-term case history FSF distribution for the Vesic-Speck approach. 
While the floor stability factor (FSF) equal to 1.5 explains about $90 \%$ of the unstable cases, $84 \%$ of the total 97 unstable floor cases have had negative values. Further, $84 \%$ of all the long-term unstable cases had FSF less than 1.0. From the discussions in section 4.3.2, some short-term floor instability is very likely when the Vesic-Speck FSF is less than 1.0. However, the case histories given in section 4.3.1 did not report such short-term floor problems. Additionally, about $57 \%$ of the 92 stable pillar cases have had floor stability factor less than 1.5. The only general conclusion that could be drawn from the case history analysis is that the Vesic-Speck method will provide acceptable pillar sizes for long-term stability when the moisture content is less than $10 \%$ for the Eastern shelf mines and below $8 \%$ for the Western shelve operations with a design stability factor greater than 1.5. If the Vesic-Speck FSF value falls below 1.0, then some short-term floor instability is likely.

The Vesic-CHC approach: for the reasons discussed in Chapter 3, the Vesic-CHC approach computes the lowest safety factor values for both stable and unstable cases. There were two pillar cases for which the Vesic-CHC also

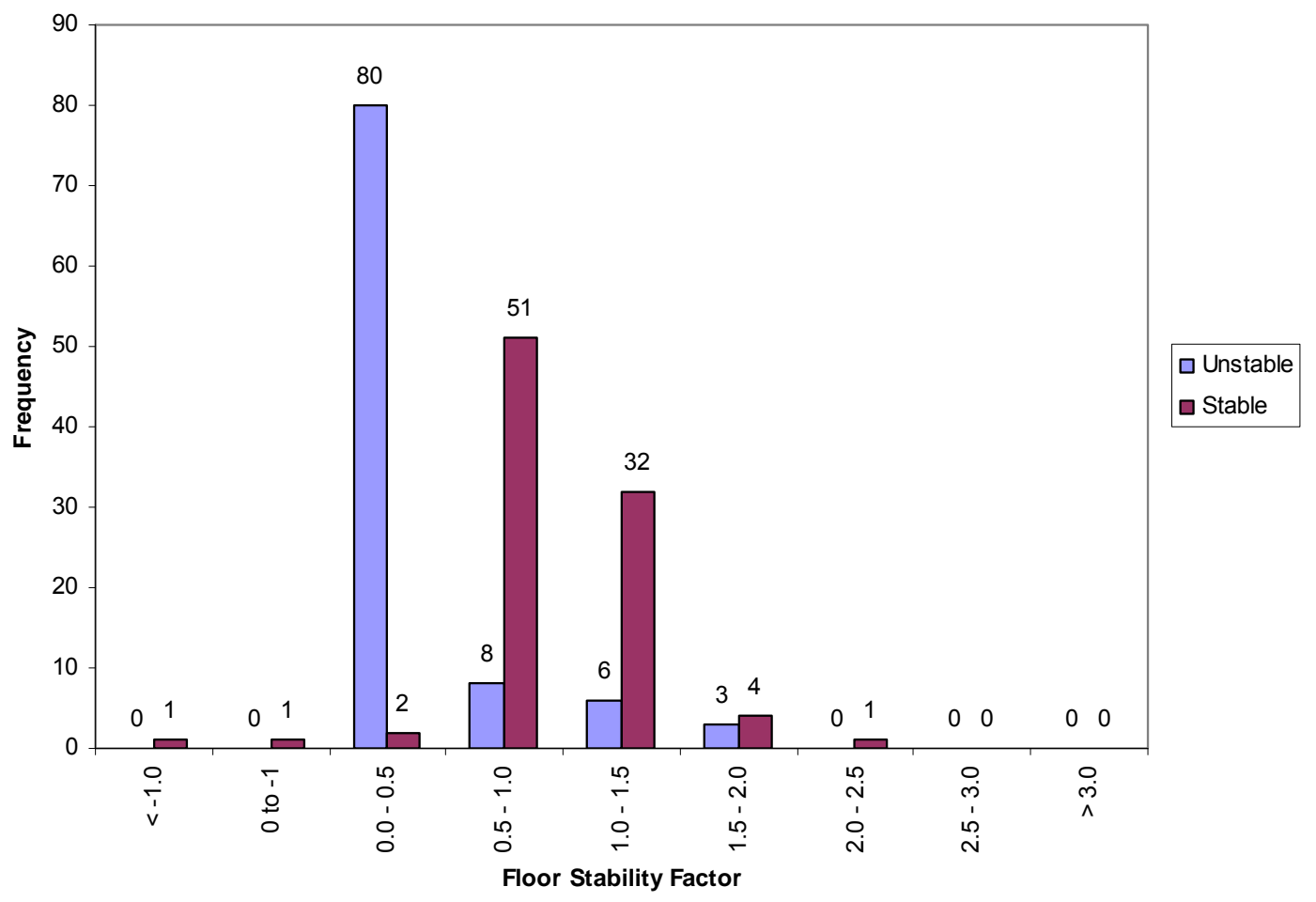

Figure 4.31. The long-term case history FSF distribution for the Vesic-CHC approach. 
predicted negative safety factors because of the below zero strength reduction factor calculated for very high moisture contents. Unlike the Vesic-Speck method, however, for the Vesic-CHC method clear distinction exists between the stable and unstable cases if the design stability factor is chosen as 0.5 as seen from Figure 4.31. Such exceptionally low floor stability factor requirement for the long-term stability is a consequence of the low strength predicted by Pula's (1990) equations discussed in Chapter 3 . When the design stability factor for long-term stability is 0.5 , it will be extremely difficult to differentiate at what FSF value short-term floor problems will be experienced. For this apparent ultra conservative nature of the method, Vesic-CHC will be difficult to use for practical design purposes.

The Vesic-Gadde approach: when the stability factor distribution shown in Figure 4.32 is compared with the previous two methods, the merit of the VesicGadde approach is apparent. This method not only differentiates the stable and unstable cases well, but also explains bulk of the long-term unstable cases if the critical design stability factor value is chosen as a meaningful 1.5. In fact, for this design FSF, $81 \%$ of the 97 unstable pillars have values below 1.5 and only $21 \%$ have stability factor below 1.0. Additionally, of the 92 stable pillars studied, only 8 pillars had floor stability factors less than 1.5 and only one case had stability factor less than 1.0. Obviously, not a single pillar had a negative stability factor. It must be remembered that the Vesic-Gadde approach is the only method that provides a simple way to realistically estimate the strength of the "stronger" floor as well. Therefore, the Vesic-Gadde method could be used for pillar sizing in any part of the Basin with a floor stability factor in excess of 1.5 to ensure the long-term stability. Similar to Vesic-Speck, if the Vesic-Gadde FSF value falls below 1.0, then there is a high chance that some short-term floor instability might be experienced.

It may be mentioned that given the range of depths in the case histories, the recommended 1.5 FSF is valid only up to a depth of about $250 \mathrm{ft}$. Because some stable case histories have depth in between 250 and $300 \mathrm{ft}$, the 1.5 design FSF may be used with caution in this range. However, at depths in 
excess of $300 \mathrm{ft}$, such high FSF as 1.5 may not be necessary for the long-term stability. This conclusion is based on the experience gained from the use of empirical methods for coal pillar design. For coal pillars, it was found that at greater depths the required pillar stability factor for the same expected level of performance decreased with depth (Mark, 2006). Until some case histories are available for depths exceeding $300 \mathrm{ft}$, floor stability factors in the range of 1.3 to 1.5 may be used with the Vesic-Gadde method for long-term stability at those depths.

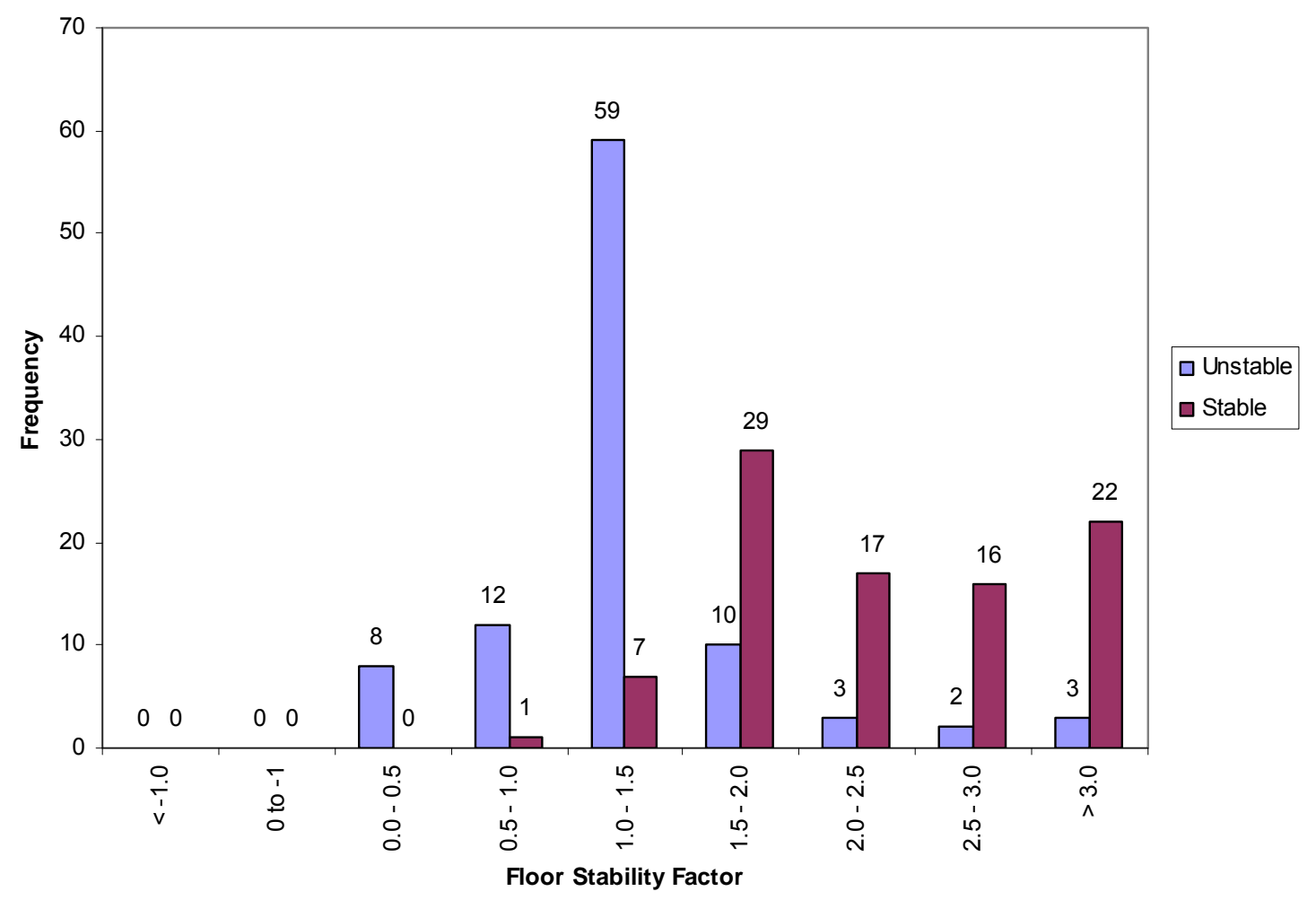

Figure 4.32. The long-term case history FSF distribution for the Vesic-Gadde approach.

Some general comments: In addition to the specific comments made on the three floor strength methods above, some general observations on the case histories are in order. When it comes to stable floor, thousands of case histories could have been collected since only a few mines, and then only in some localized spots, experience unstable floor conditions. But it was decided to use only a few case histories where detailed geologic, rock mechanics and mine 
geometry information was available. Besides, experience in the Basin's mines show that the conclusions drawn above on the stable cases are valid in general. The difficult part, however, is to collect information on the unstable events. When looking at the published case history information on both short- and longterm floor issues, it was overwhelmingly clear that in a majority of cases, the most critical information necessary for the stability analyses was not available in sufficient detail. For instance, in his Ph.D. work Marino (1985) examined 13 trough subsidence case histories in the state of Illinois from mines that extracted the No.6 seam. In that dissertation, not a single case among the 13 had all the necessary geo-mining and rock mechanics information available to assess the cause of the subsidence with certainty. It was only after contacting some other sources, the necessary information for the four cases discussed by Marino could be obtained. The main reason for this lack of data is that all the 13 cases were related to mines that were developed anywhere between 1880 and 1980 at times when not enough importance was given to quantitative methods of floor stability analysis. When rooms as wide as $60 \mathrm{ft}$ are employed with pillars as narrower as $10 \mathrm{ft}$, without detailed information, it is hard to conclude whether pillar failure, roof caves or floor squeeze caused the surface subsidence. Further, Marino (1985) reported some water accumulation in some of his cases. However, much is not known about the extent of water-logging, the magnitude of head, permeability of the floor and for how long the workings were soaked in water. Without such information, it is not possible to assess the effect of floor 'softening' on the computed floor stability factors. Because of these limitations and the simplifications made in computing the FSF, limited reliance can be placed on such case histories when examining the validity of a floor design method or in establishing acceptable design stability factors to prevent long-term instability.

The available data on the unstable cases discussed in section 4.3.1 and 4.3.2 also show that in almost every floor failure incident, some unanticipated conditions existed. In a majority of cases the surprising element was either excess moisture or very thick underclay/claystone. This observation leads to the 
conclusion that with the normal limited exploration drilling, it is almost impossible to not have any unanticipated events even if the best of the floor bearing capacity theories is used. When it comes to very old mines, the amount of drilling data available is next to nothing. Further, with older mines, it is not known if the available mine maps accurately reflect the actual pillar and room dimensions employed.

During the case history analysis where very detailed information was available, it was sometimes noticed that within the depth of interest in the floor, more than two layers of strata existed with weaker and stronger layers intermixed. For such cases, the predictions made by the two-layer Vesic's model will not be completely correct. The numerical modeling methodology discussed in Chapter 5 would be the best option to handle such complex floor layers. Moreover, the general floor bearing capacity models discussed above should not be used if there is a reason to suspect significant water pooling can occur in the mine. Because of the complex 'softening' effects accompanied by such water accumulation, the floor bearing capacity could be drastically reduced as discussed in chapter 5 .

Only for a few of the case histories discussed above, detailed investigations were conducted after the instability occurred. For the remaining cases, geo-mining information available from the nearest exploratory borehole was used in the stability analyses presented. Since the moisture content of the floor in the mine openings could change with time, using the virgin ground rock mechanics data could lead to some errors in predicting the stability factors for the long-term subsidence events. It may also be noted that while multiple pillar dimensions were analyzed for the above case histories, in a majority of cases the same moisture content and floor thickness data was used for the entire panel. Point by point variability of properties could also influence the conclusions drawn above on the performance of the three floor strength methods.

For the case history analysis, the average vertical stress on the floor was estimated using the tributary area theory. When pillars of different sizes exist in the same panel with variable floor properties, it is more than likely that 
progressive failure would occur starting with the pillar that has the lowest floor stability factor. In such an event, the vertical stress on the adjacent pillars would be higher than estimated by the tributary area method due to the excess load shed by the failing pillar. However, owing to the lack of the detailed information necessary to conduct numerical stress analysis, the simple tributary area theory was assumed to be valid. However, such simplified stress analysis method is needed due to the fact that in practice very few people would ever conduct a numerical analysis for pillar sizing, especially, at the permitting stage.

In summary, the limited geo-mechanical information available in relation to the long-term floor stability case histories discussed above is typical of what can be realistically expected in practice. Therefore, the recommended Vesic-Gadde design floor stability factor of 1.5 indirectly includes this inadequacy of the data. Further, the design stability factor also considers the inaccuracies introduced by the use of the simple tributary area theory as opposed to a realistic progressive failure model. Unless some extraordinary conditions warrant, in reality none of the subsidence events on abandoned mines will be subjected to a thorough scientific scrutiny by coal companies to generate all the required rock mechanics information for an accurate stability analysis.

It may be noticed that in arriving at the design floor stability factor for the Vesic-Gadde method, somewhat higher emphasis was put more on the stable floor cases than the unstable ones. This might seem counterintuitive given that avoiding the unstable floor situation is the ultimate design goal. However, considering all the uncertainties given in the preceding paragraphs with the unstable floor case histories and for the relatively reliable information available for the stable cases, heavy reliance was put on the later. It is hoped that future research will provide more reliable unstable floor cases and consequently better define the design floor stability factors for long-term stability.

As will be discussed in Chapter 5, the non-uniform vertical stress distribution on pillars could cause localized floor heave without affecting the overall stability of the floor below a pillar. Consequently, short-term floor failures could occur for any stability factor below 1.5. Even though the case history 
analysis did not provide any conclusive information on the critical floor stability factor for short-term stability by the Vesic-Speck or Vesic-Gadde approaches, until more data is available, it is recommended to use 1.0 as the design FSF for this purpose. In reality, since almost all of the Illinois Basin mines design their pillars for long-term floor stability, the recommended FSF for short-term stability will not be of much practical consequence anyway.

\subsection{Steps in Using the Vesic-Gadde Approach}

The following step-by-step methodology is suggested when using the VesicGadde method to estimate the floor bearing capacity:

1. drill a reasonable number of holes in the area of interest,

2. run geophysical logs (gamma, density, caliper and where possible, sonic) in each borehole available (cored or not cored),

3. using the geophysical logs and physical observations of the core, identify the weaker section of the immediate floor when the total thickness of the claystone bed is high. (If the claystone bed is thicker than $4 \mathrm{ft}$, careful examination of the geophysical logs and cores is necessary to identify the weaker section. In such cases there is a high chance that the entire claystone may not be weak);

4. determine the natural moisture content of the well protected immediate floor cores on 6 inch to $1 \mathrm{ft}$ intervals (moisture change with floor depth may also be used to estimate the weak floor thickness);

5. if enough core recovery is available, test the main floor for shear strength preferably in triaxial cells. Otherwise, determine the moisture content, if the stronger floor is claystone;

6. using the moisture content data, estimate the cohesion of the weak immediate floor $\left(c_{1}\right)$ using the appropriate Gadde's equation given in Equation (4.22) or (4.23);

7. similarly, estimate the cohesion of the stronger bed $\left(c_{2}\right)$ using Equation (4.24) or (4.25);

8. estimate Vesic's bearing capacity factor $N_{m}$ using Equation (4.15); 
9. using all the above inputs, calculate the floor bearing capacity by Equation (4.14);

10. compute the average vertical stress on the coal pillar using the tributary area or any other suitable approach;

11. for long-term stability choose a pillar size that ensures at least a stability factor of 1.5 against floor bearing capacity failure;

12. if enough cases of stable and unstable floor conditions are available at a mine, then the design stability factor that better discriminates the actual case histories should be used instead of the general 1.5 value suggested above;

13. if any conditions exist that invalidate the assumptions in Vesic's nonhomogeneous soil model, it is better to use numerical modeling as described in Chapter 5 for an accurate estimation of the floor bearing capacity.

\subsection{Chapter Summary}

The highlights of the foregoing discussions in this chapter could be summarized as given below:

- because of its soil like engineering behavior, the bearing capacity of the underclay floors could be studied using soil mechanics principles;

- among the available bearing capacity models, despite its limitations, Vesic's non-homogeneous soil model is by far the most popular choice for pillar sizing in the Illinois Basin mines;

- the Pytel-Chugh approach is very complex and is based on dubious assumptions and thus has not found wider practical use;

- Vesic's non-homogeneous bearing capacity model is currently used in two different forms: Vesic-Speck and Vesic-CHC;

- a reasonably large number of unstable case histories were collected to study the validity of the Vesic-Speck, Vesic-CHC and Vesic-Gadde methods; 
- back analysis of the case histories showed that among the three versions of the Vesic's adaptation, the Vesic-Gadde approach provided more reasonable predictions;

- for the Western shelf mines and for mines in the Eastern shelf with high moisture content, the Vesic-Speck approach provides extremely low or negative safety factors;

- the Vesic-CHC estimated floor stability factors were the lowest among the three methods studied. For very high moisture contents, the Vesic$\mathrm{CHC}$ method also computes negative safety factors;

- for the long-term stability, it is recommended that the Vesic-Gadde methodology may be used with a minimum design floor stability factor of 1.5. For short-term stability a FSF equal to 1.0 is perhaps sufficient. Given the range of depths in the case histories, the recommended 1.5 FSF is valid only up to a depth of about $250 \mathrm{ft}$. Because some stable case histories have depth in between 250 and $300 \mathrm{ft}$, the 1.5 design FSF may be used with caution in this range. However, at depths in excess of $300 \mathrm{ft}$, such high FSF as 1.5 may not be necessary for the long-term stability. Until some case histories are available, floor stability factors in the range of 1.3 to 1.5 may be used with the Vesic-Gadde method for long-term stability at depths exceeding $300 \mathrm{ft}$.

- if the moisture content is less than $8 \%$ for the Western shelf mines and below $10 \%$ for the Eastern shelf, then the Vesic-Speck approach may also be used with 1.5 floor stability factor to prevent surface subsidence. For moisture contents above these limits, long-term floor stability is possible for Vesic-Speck floor stability factors less than 1.5. Similar to Vesic-Gadde, for short-term stability a minimum of $1.0 \mathrm{FSF}$ is suggested for the Vesic-Speck method. 


\section{CHAPTER}

\section{DETERMINATION OF FLOOR BEARING CAPACITY - NUMERICAL MODELING}

\subsection{Introduction}

In chapter 4, some traditional bearing capacity models from soil mechanics literature have been reviewed along with their limitations. From this examination, it was clear that no model existed that could account for the idiosyncrasies of a typical coal mine floor stability problem. Ideally, any model for addressing the coal mine bearing capacity problem illustrated in figure 5.1 should be able to consider the following:

- different geometries of pillars in the plan view (square, rectangular, longcontinuous, parallelogram, and irregular);

- $\quad$ presence of multiple pillars in close proximity at uniform or variable spacing;

- $\quad$ multiple layers of strata with variable thickness that exist in the floor within the zone of influence of a coal pillar;

- $\quad$ each layer of rock in the floor is deformable and normally has non-zero values of cohesion, friction angle, and density;

- some of the floor strata may not be adequately described by the MohrCoulomb failure criterion;

- volumetric expansion of the floor strata is possible in the post-failure state (dilatation effects may not be ignored);

- $\quad$ spatial variation of floor properties (both laterally and with depth);

- $\quad$ time-dependent deformation and failure of the floor;

- effect of any water accumulation on time-dependent pore water pressure changes and accompanying strength degradation;

- non-uniform vertical stress distribution on coal pillars; 
- presence of in-situ horizontal stresses.

In a coal mine, pillars of several shapes exist. It is not unusual to find pillars of different shapes in the same panel. For instance, mines that employ perimeter mining create some odd shaped pillars right next to rectangular or square pillars. Interaction of floor beneath such complex shaped pillars in close proximity could have substantial effect on the system stability. Although in a majority of cases it may not be necessary to account for the strata beneath the second layer in the floor, a few core holes show that when the underclay and the bed below it are thin, several layers of variable thickness could exist within the zone of influence of a pillar.
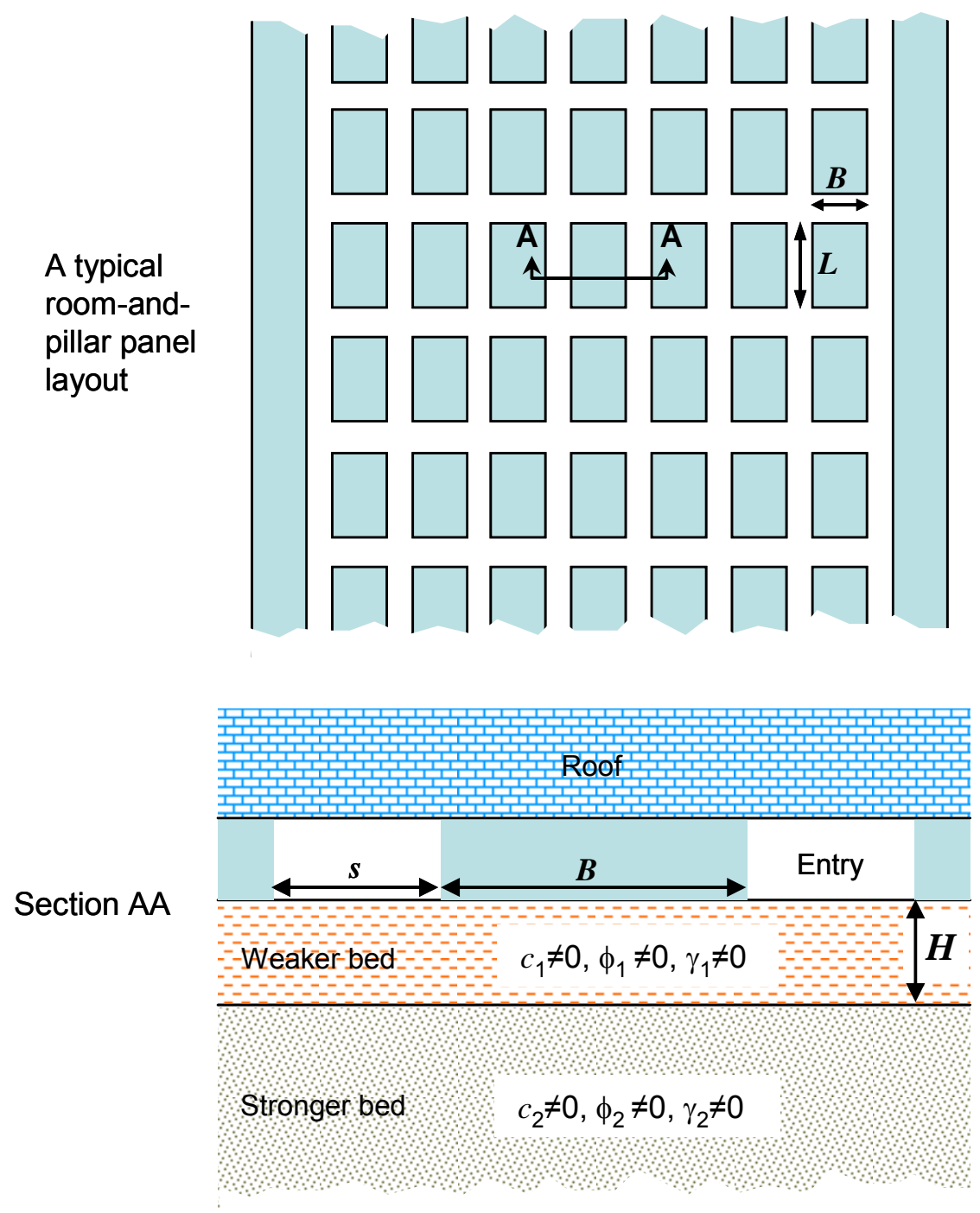

Figure 5.1. Features of a typical coal mine bearing capacity problem. 
As mentioned in Chapter 4, the traditional bearing capacity theories assume that the soil below a foundation is rigid up to the point of failure. Such assumption, while unreal, may not introduce significant errors for an isolated footing on a homogeneous semi-infinite soil. Ignoring the effect of deformability, however, could influence the estimated bearing capacity in a multi-layer, multiple pillar situation.

The bearing capacity analysis should also be able to account for different types of constitutive behaviors of the floor materials. For instance, the loaddeformation curves shown in Chapter 3 indicate that the underclay floor can behave like a perfectly-plastic, strain-softening or strain-hardening material depending on the amount of moisture present. Further, some of the floor materials that lie below underclay may not necessarily be well described by the Mohr-Coulomb failure criterion. Even though the Mohr-Coulomb criterion results in a lot of simplifications in the analysis and is a valid model for a majority of cases, for an accurate description of the strength behavior, it may be necessary to adopt some nonlinear failure criteria (Gadde et al., 2007).

Traditional bearing capacity theories assume that the volume of the soil does not change in the plastic state. For stiffer and stronger claystone, sandstone and limestone main floors, assuming zero volume change in the postfailure state may not be realistic. Therefore, the bearing capacity model should also be able to include non-associated flow rules with non-zero dilatation angles.

The laboratory and in-situ test data given in Chapters 2 and 3 show the extreme variability of the physico-mechanical properties of the floor materials. Whether or not to include the spatial distribution of the properties in a bearing capacity analysis depends on the nature of the variability. If the properties exhibit extreme randomness and vary from point to point even below a single pillar, then the cumulative effect of the randomness may not result in a significantly different estimate of the bearing capacity as compared to that provided by the average of the properties. But, if there is a systematic trend to the variability, then the effect on computed bearing capacity could be substantial. 
Past research (Pytel, 1998) shows that the underclay material can exhibit time-dependent deformations and creep failure which may lead to surface subsidence or underground opening instability. Therefore, the bearing capacity analysis may sometimes need to be based on the time-dependent properties of the floor material. Additionally, some of the long-term effects may arise just because of the change in moisture content of the floor with time. It is not inconceivable that some of the mines will accumulate water after a panel is sealed off. In such a case, the floor stability analysis should be able to incorporate the seepage of the accumulated water through floor members. As the results in Chapter 3 indicate, the floor strength will fall substantially with an increase in the moisture content. Therefore, the bearing capacity analysis should be able to simulate the water seepage and be able to modify the strength characteristics of the floor material as a function of the changed moisture content.

In the conventional bearing capacity theories, the load on a foundation is assumed to be uniformly distributed. Underground coal pillars, in contrast, will always have non-uniform vertical load on them. Therefore, it is important to investigate the effect of such non-uniform vertical load on the floor bearing capacity. Further, underground openings are always subjected to some amount of pre-mining horizontal stresses. Given that the underclay material is normally 'soft', the magnitude of in-situ horizontal stresses may not be very high. Even then, the pre-mining horizontal stresses will have some impact on the floor bearing capacity and thus must be accounted for in the analysis.

All the discussions so far treat the floor as an isolated component of the underground opening stability. But, in reality, the floor, coal pillar and roof function together as a system and interact with each other. It is often necessary to consider the entire system stability rather than any one component's integrity. In such cases, the analysis method should be able to incorporate the interaction effects of the different components of the entire system.

When all the requirements set forth so far are considered, it is impossible to provide a closed-form solution to the coal mine bearing capacity problem. An 
alternative, however, exists. With the tremendous advancements made in the computer hardware and the advent of sophisticated numerical modeling tools over the past two decades, it is now possible to incorporate almost every single aspect of the bearing capacity problem identified in the above paragraphs in the analysis. Such flexibility and versatility is achieved because numerical models deal with a complex problem by following a 'parts-to-whole' approach. In a numerical model, the final solution to a 'big' problem is obtained by putting together solutions to several 'small' problems. It is easier to incorporate any degree of complexity at the 'parts' level as compared to including at the 'whole' level as accomplished in a closed-from solution.

Numerical models also simulate the bearing capacity problem in a physically defendable fashion. For instance, with modeling there is no need to partition the bearing capacity components like what was done with traditional methods given in equation (4.5). With modeling, the combined effect of the three components will be automatically included. Similarly, there is no need to assume the geometry of the failure surfaces a priori as is necessary for the traditional methods. When solved with numerical models, the failure surfaces evolve as a part of the solution. Above all, almost every aspect of the bearing capacity problem identified above can be included in the modeling, which is impossible with any other solution method.

On a more fundamental level, numerical modeling does not suffer from some of the limitations of the classical methods used in the bearing capacity estimation. For instance, in one of the most popular traditional methods of the bearing capacity estimation called the method of characteristics, if the weight of the soil is to be included, then the static and kinematic requirements must be treated separately while it is physically necessary for both of them to be treated simultaneously (Frydman and Burd, 1997). In contrast, numerical modeling approaches, like the finite element method, ensure that both static and kinematic requirements are satisfied simultaneously at each stage of the solution.

While numerical modeling may appear to be a panacea for complex structural analysis, when it comes to ground control applications it must be 
remembered that our ability to obtain realistic inputs needed for the analysis is far outpaced by what a typical numerical model is capable of doing. Additionally, the numerical modeling approach suffers from the following limitations:

- since a 'formula' can not be obtained, individual models need to be run for every single problem at hand;

- numerical models, in general, are very time consuming to solve and require user expertise;

- solutions obtained by numerical models are only approximate. Although the word 'approximate' is used literally here, improper discretization of the problem domain may lead to unacceptable errors. However, by employing proper meshing schemes, on a majority of cases, it should be possible to achieve practically acceptable solution accuracy within the limitations of the resources normally available to a common modeler.

Despite these restrictions, there is no better alternative to numerical modeling if all the features of a coal mine floor bearing capacity problem need to be included in the analysis. Therefore, this chapter is devoted to apply numerical modeling to study several aspects of the floor stability problem. Specifically, the modeling technique will be used to study the validity of Vesic's equation, the interaction effect of multiple pillars, influence of spatial variability of strength properties, non-uniform distribution of pillar loads, dilation angle, floor thickness, pillar shape and floor softening on the bearing capacity.

Use of numerical modeling to investigate coal mine floor stability is not totally new. Some interesting work was done in the past by researchers from several coal producing countries (Rockaway and Stephenson, 1979; Chandrashekhar, 1990; Bandopadhay, 1982; Deb et al., 2000; Vasundhara, 2001; Bhattacharyya and Seneviratne, 1992; Yavuz et al., 2003). The past studies, however, relied heavily on two-dimensional modeling to explain some site-specific field behavior or were limited to a few parametric studies of limited applicability. One of the first modeling exercises for floor stability analysis was conducted by Rockaway and Stephenson (1979). They noted that there were severe limitations that restricted the application of conventional bearing capacity analysis to the mine floor stability 
problem. Specifically, two issues were pointed out by Rockaway and Stephenson (1979): stability of a three-layer floor system noticed at an Illinois Basin coal mine, and estimation of the amount of settlement needed for the underclay floor to transfer stresses deeper into the strata. The finite element meshes used by them and the results of the analysis for the cases of two- and three-layered floor systems are shown in Figure 5.2 and Figure 5.3, respectively.
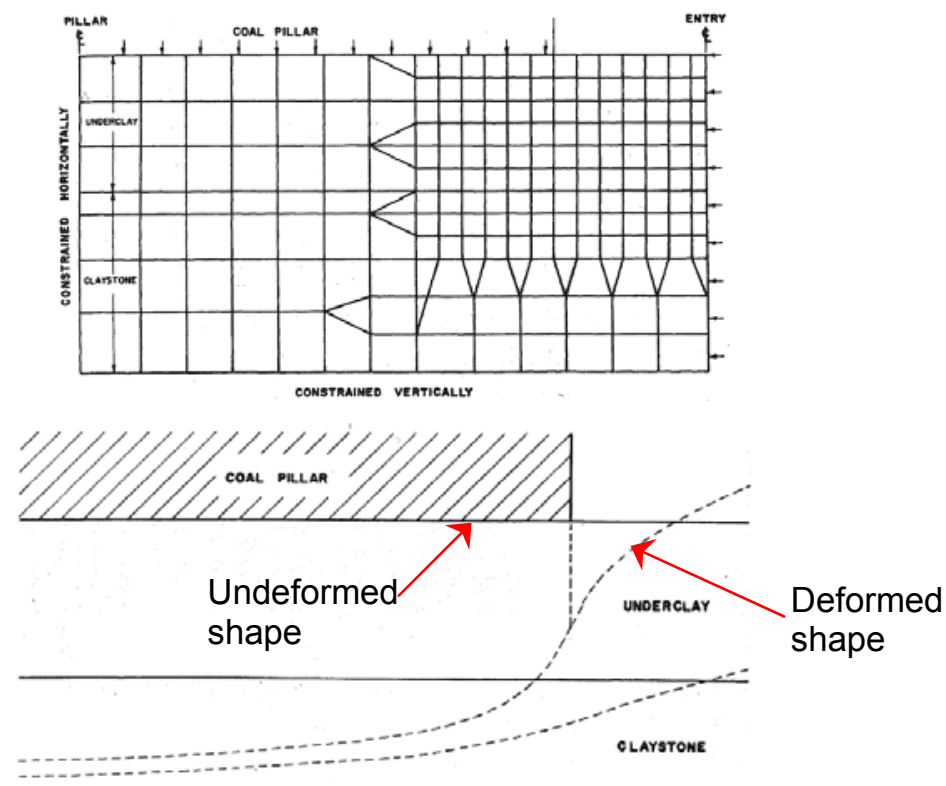

Figure 5.2. The finite element mesh and the results for a two-layered floor system obtained by Rockaway and Stephenson (1979).
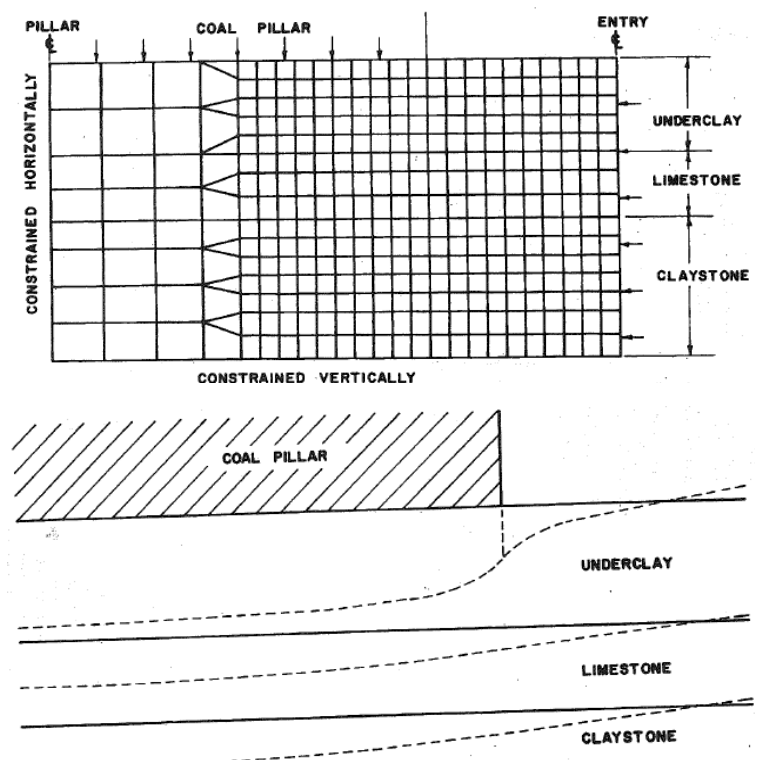

Figure 5.3. The finite element mesh and the results for a three-layered floor system obtained by Rockaway and Stephenson (1979). 
Numerical modeling studies were conducted by Chugh et al., (1984) on the effects of soft floor on retreat mining at an Illinois Basin coal mine. For this study, two-dimensional elastic-plastic finite element modeling was conducted to develop design charts for determining the safe percentage of extraction that minimized floor heave. Field measured floor movement data was used to calibrate the finite element models.

Bandopadhay (1982) reported the results of 2-D finite element modeling, where the effect of pillar splitting on stress distributions at a Western Kentucky mine was studied. Some field data was used to calibrate the numerical models. He concluded that the underclay thickness could have significant effect on the convergence and the pillar's ability to punch into the floor. Bandopadhay's studies also showed that in a low horizontal stress environment, the roof-pillar contact shear stresses increased with increasing underclay thickness as shown in figure 5.4 .

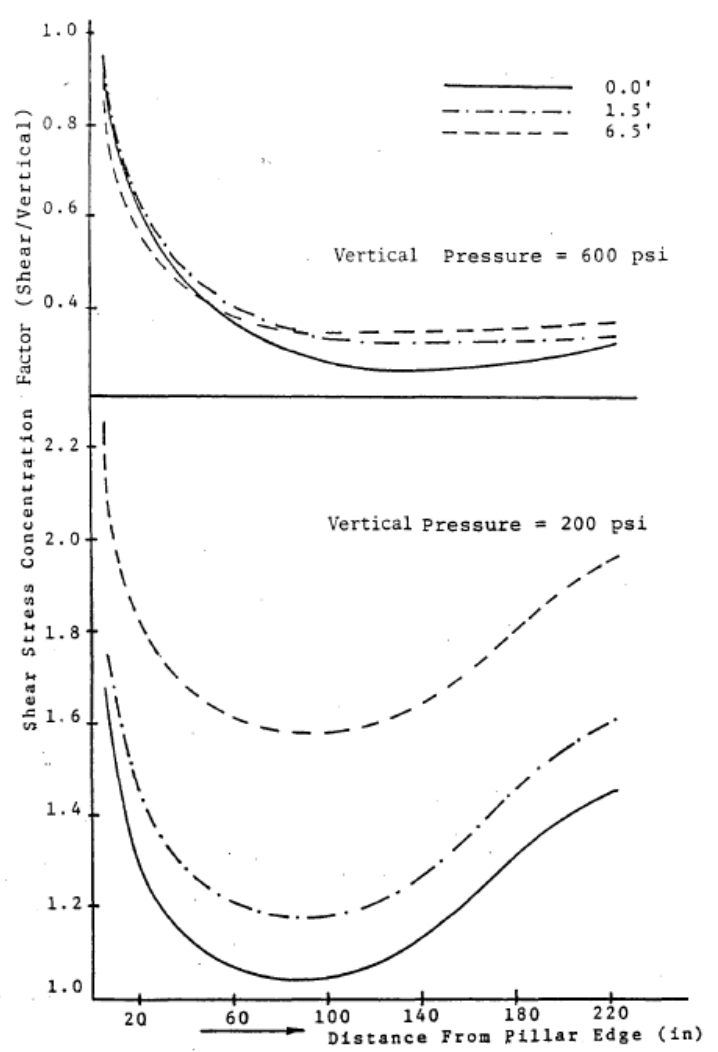

Figure 5.4. Change in maximum shear stress as a function of underclay thickness (Bandopadhay, 1982). 
Two-dimensional elasto-plastic time-dependent stress analysis was conducted by Caudle et al., (1988) to study the unstable floor conditions encountered at a room-and-pillar coal mine in Illinois. Their work indicated that it was important to consider the nonlinear material behavior of underclay to obtain satisfactory results. Chandrashekhar (1990) as a part of his Ph.D. work used 3-D finite element modeling to study the effect of weak floor on mine opening stability. His 3-D models contained 1008 elements and 5069 nodes. Based on a few 3-D isotropic, elastic models he concluded that with increasing floor thickness the vertical and horizontal deformations in the floor increased. The horizontal floor displacements obtained in the numerical models matched with field observations and showed that the underclay material typically flowed outward from benearth the pillars (Chandrashekhar, 1990).

Among all the available modeling works on weak floor bearing capacity, the most meaningful analysis was perhaps done by Marino and Choi (1999). Although this paper has not received as much attention as it deserved, the modeling methodology used was very realistic. Using some data on long-term subsidence due to floor failures, Marino and Choi (1999) developed the concept of floor 'softening' illustrated in Figure 5.5. The field observations led them to conclude that two types of softening could occur in the floor. One was due to the action of excess moisture and the other was stress driven. Marino and Choi (1999) developed some intriguing concepts to estimate the zone of softening and used some existing empirical relationships to determine the material properties for the softened zone. Their modeling results indicated that the floor bearing capacity decreased with an increase in the depth of the softened zone with the lowest strength obtained when the entire thickness of the immediate floor was softened. Such reduction in the strength was due to the decreased amount of passive wedge resistance offered by the softened floor at the pillar perimeter. This concept of 'softening' will be explored further in this chapter.

Two-dimensional finite element modeling of longwall extraction was simulated by Deb et al., (2000) to study the effect of weak floor on ground control. In these models, a realistic simulation of the shield-supports was attempted. The 
modeling studies showed that the thickness and material properties of weak floor could have significant effect on shield loading, abutment stresses, displacements and failure zones around the longwall face area. An example of the distribution of Drucker-Prager yield zones around the longwall face area obtained by them is shown in Figure 5.6.

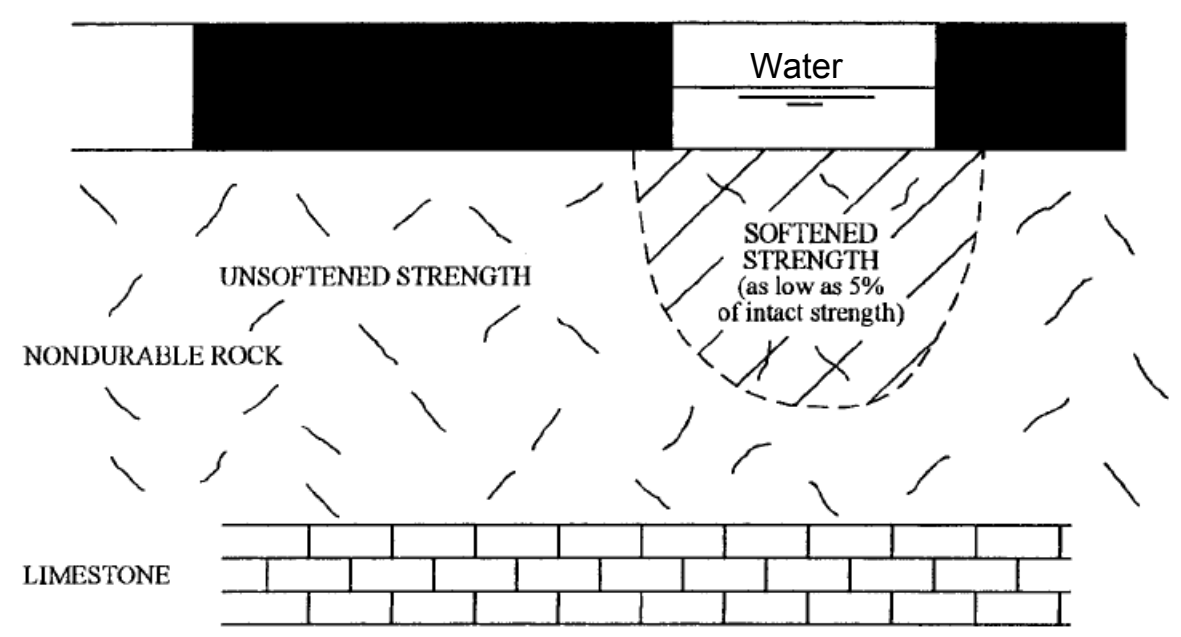

Figure 5.5. Concept of floor softening developed by Marino and Choi (1999).

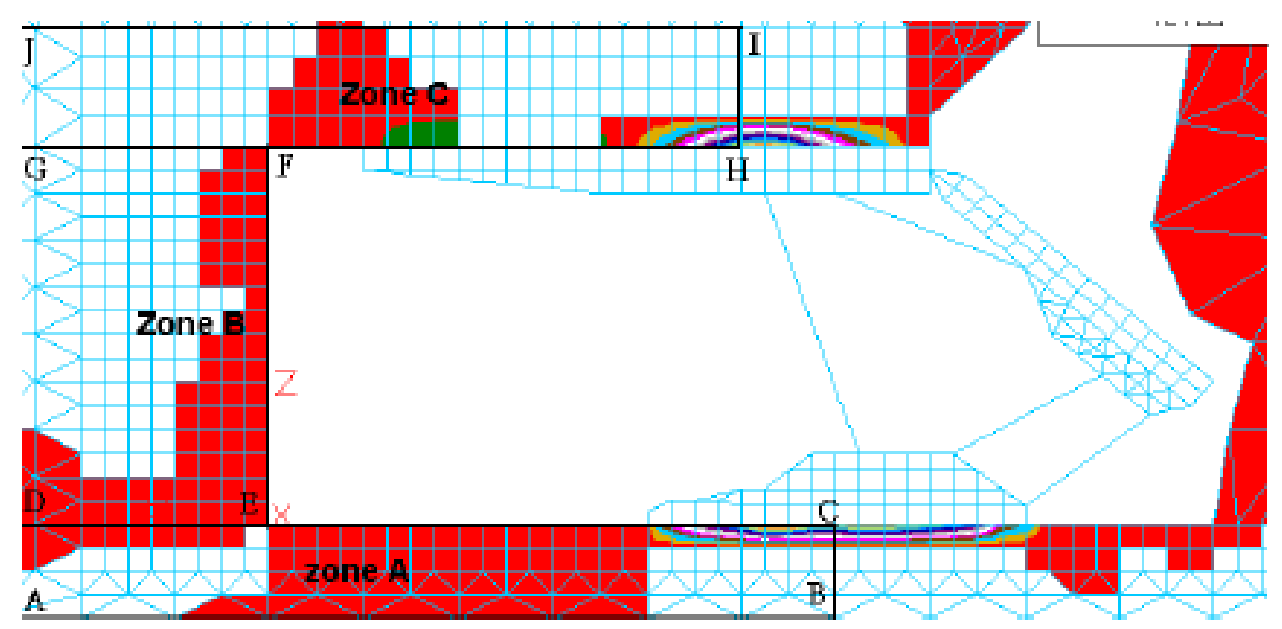

Figure 5.6. Distribution of yield zones around longwall face area under weak floor conditions simulated by Deb et al., (2000).

Wang (1996) used finite element models to study the floor stability at a Western Kentucky and a West Virginia coal mine to come up with pillar sizes that ensure long-term stability. Even though not directly related to the bearing capacity of weak floor, Heasley and Salamon (1994) reported an interesting 
modeling work where the effect of soft floor on coal pillar strength was investigated. By using strain-softening constitutive model for coal, they estimated the correction factors necessary for a traditional coal pillar strength formula as a function of weak floor thickness. Their results suggested that depending on the floor's strength and thickness, the coal pillar strength estimate could be affected by as much as 20 percent.

In Australia, Bhattacharya and Seneviratne (1992) conducted elastic twodimensional finite element modeling to study the effect of different rock materials and thicknesses on floor heave in a partial extraction situation. This study showed that the maximum floor displacement increased with decreasing Young's modulus and increasing floor thickness. An extensive review of the Australian research on soft floor issues was provided by Vasundhara (2001) in her Ph.D. dissertation. Additionally, she also ran a large number of parametric models to study the effect of different variable on floor stability. The 2-D modeling conducted using the finite difference package FLAC, considered different parameters that reflected the Great Northern seam mining environment in New South Wales, Australia. Vasundhara (2001) summarized the modeling results in the form of some nomograms for field use. She, however, mentioned that the modeling was done for a certain mine site with specific dimensions and rock properties and thus the results should not be used for a different site. Broadly speaking, Vasundhara's (2001) results indicate that the floor heave increases with decreasing Young's modulus, increasing floor thickness, depth of cover and roadway width, and with a decrease of pillar width.

Yavuz et al., (2003) studied floor heave problems in the transport road of a longwall coal mine in Turkey using three-dimensional finite difference modeling. For the analysis, they used elastic-plastic constitutive behavior with MohrCoulomb equivalents of Hoek-Brown failure criterion. This Turkish study basically focused on calibrating the numerical models with a case-history and then using the best-fit inputs for better gallery design that would minimize floor heave in future longwall panels. One of the deformed geometries of the modeled gallery in the Yavuz et al., (2003) study is shown in Figure 5.7. 


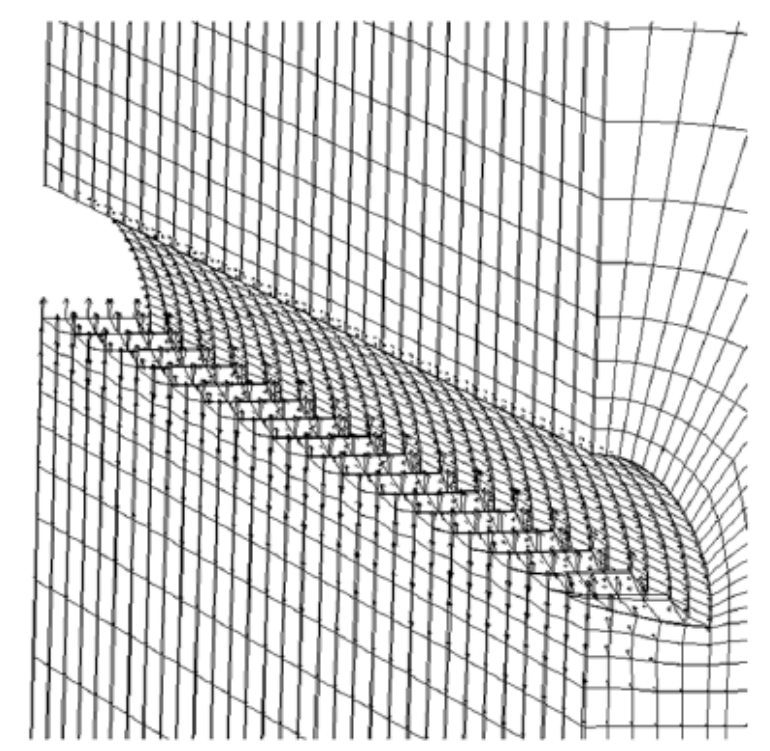

Figure 5.7. Floor heave in a longwall gallery simulated by Yavuz et al., (2003).

While the above discussed modeling studies were successful in accomplishing their specific objectives, within the knowledge of this author, no nonlinear modeling study was ever conducted to estimate the floor bearing capacity per se while considering the broader unique characteristics of coal mines. Although by no means comprehensive, this chapter and Chapter 6 will try to provide the first step in filling that gap. The basic aim of the modeling conducted here is to demonstrate the potential of the numerical approach to solve complex coal mine floor stability problems. Besides, it is felt that there is no need to conduct exhaustive number of parametric studies to develop some "design equations" based on modeling. This is because of the widespread availability of advanced modeling software tools which make the task of running a few site-specific bearing capacity problems a trivial matter. Further, if one has to develop a comprehensive floor strength equation while considering every single variable listed at the beginning of this chapter even within a reasonable range of values, the large number of combinations that need to be considered will make such an endeavor unfeasible for a single dissertation.

For all the research here, the numerical modeling code, Fast Lagrangian Analysis of Continua in 3Dimensions (FLAC ${ }^{3 \mathrm{D}}$ ), developed by Itasca (2007) has been used. FLAC $^{3 D}$ is by far the most popular code used for geotechnical 
engineering applications globally and has been in use for almost 15 years. Besides its popularity, the powerful features of the code allow easier incorporation of every aspect of the coal mine floor stability problem identified at the beginning of this chapter. The explicit Lagrangian solution scheme and the mixed discretization procedures adopted in $\mathrm{FLAC}^{3 \mathrm{D}}$ using the finite difference approach makes it a powerful tool to deal with nonlinear problems. Further, the explicit scheme makes it easier to apply loads and deformations in a manner analogous to physical tests (Itasca Consulting Group, Inc. 2007). Such a solution methodology also provides the model response in a physically comparable manner. Finally, FLAC $^{3 \mathrm{D}}$ provides a programming language called $\mathrm{FISH}$, which facilitates addition of functionalities that are not included in the standard features of the program and also helps automate several aspects of modeling.

\subsection{Application of Numerical Modeling in the Foundation Engineering Literature}

While the coal mining use of numerical modeling for floor stability analysis was rather limited, there is a deluge of publications in the soil mechanics literature that studied the bearing capacity of footings with this technique. From the extensive literature review, it appears that the earliest attempt to apply finite element method to predict bearing capacity was made by Zeinkiewicz, et al., (1975). Their analysis produced good match with the theoretical bearing capacity given by equation (4.5). The first more realistic application of numerical modeling, however, was made by Griffiths in a classic paper in 1982. In this study, Griffiths using the finite element method estimated the bearing capacity factors of a $c-\phi$ soil and found good match with the theoretical prediction. This Griffiths' classic work also showed the conservative nature of the superposition assumption given by equation (4.5). Although the fundamental framework developed by Griffiths is still valid, some aspects of the modeling, like the mesh employed, are primitive compared to what can be done today. The finite element mesh used in the Griffiths work is shown in Figure 5.8., and the match he got between modeling and theoretical results is shown in Figure 5.9. 


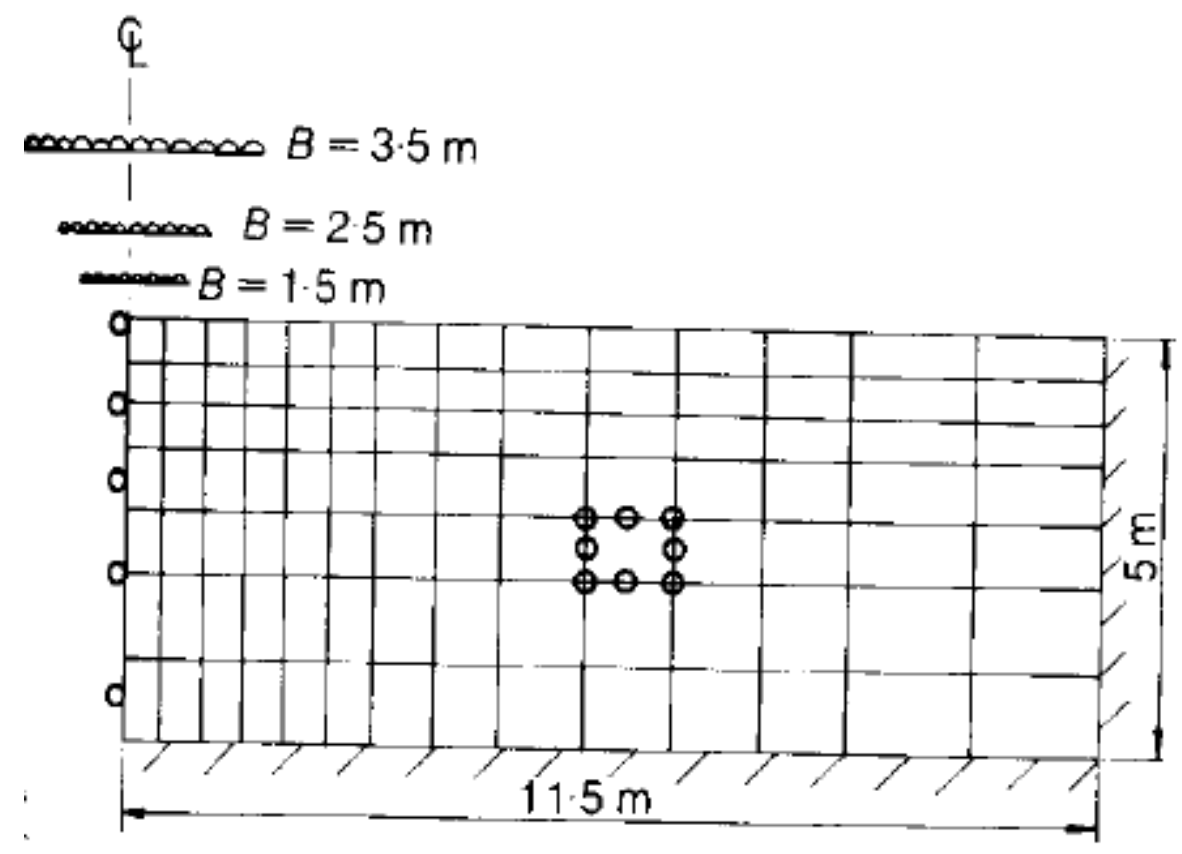

Figure 5.8. the finite element mesh used in the Griffiths' (1982)study.

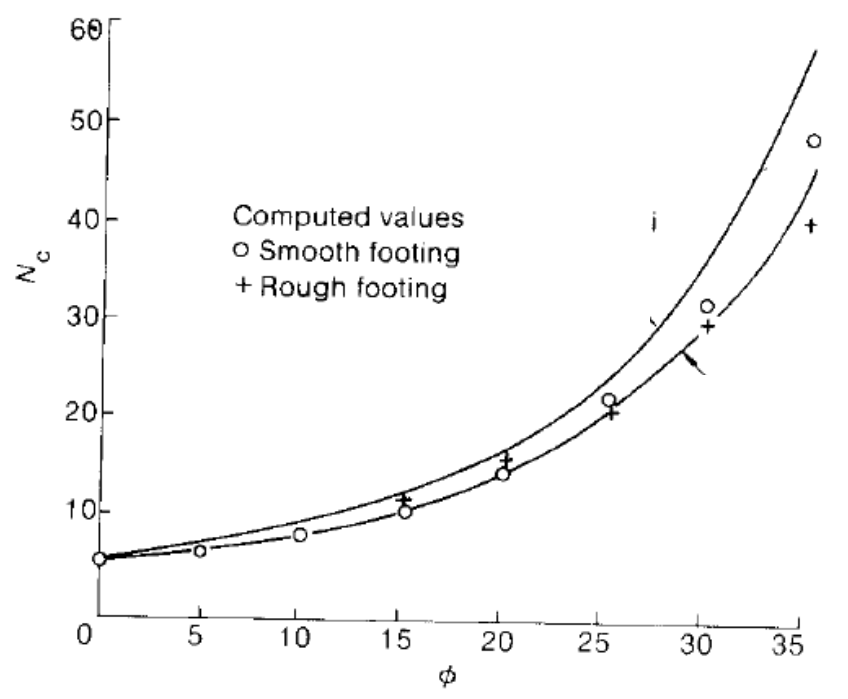

Figure 5.9. Comparison of theoretical and modeling computed $N_{c}$ values (after Griffiths, 1982).

Burd and Frydman (1997) used finite element and finite difference models to study the strength of a rigid foundation resting on a drained sand layer, which is underlain by an undrained clay bed. This analysis showed that the traditional bearing capacity methods for sand-clay layers, where the sand layer is accounted for in the analysis by spreading the area over which loads act in the 
bottom clay bed, will produce erroneous results if a constant spread angle is used for all soil conditions.

Some modeling on bearing capacity was done with a focus to incorporate the dilatational effects exhibited by dense granular materials or stiff cohesive soils in their plastic state. The general observation from these works is that the dilatation effects could influence the bearing capacity and should not be ignored. Manoharan and Dasgupta's (1995) studies showed an increase in the bearing capacity factors with an increase in the dilatation angle. Frydman and Burd (1997) also studied the effect of dilatation angle on bearing capacity but their study considered only a cohesionless soil supporting a surface footing. In effect, Frydman and Burd (1997) focused only on estimating the value of $N_{\gamma}$. Modeling by Yin et al., (2001) showed that the dilation angle $(\psi)$ has significant effect on the values of the three bearing capacity factors. For the conditions modeled in their study, they estimated that the relative difference in the magnitude between associated $(\psi=\phi)$ and zero-volume change conditions $(\psi=0)$ for $N_{c}, N_{q}$ and $N_{\gamma}$ was $2.6 \%, 4.3 \%$ and $8.9 \%$, respectively, for $\phi=15^{\circ}$ and was $57.9 \%, 68.4 \%$ and $66.8 \%$, respectively, when $\phi=45^{\circ}$. Almost similar results on dilation angle effect were reported for circular footings by Erickson and Drescher (2002).

Numerical modeling was also used by some workers to conduct limit analysis to estimate the upper and lower bounds of a particular bearing capacity problem. Finite element numerical limit analysis was done by Ukritchon et al., (1998) to evaluate the undrained stability of surface footings on nonhomogeneous and layered clay deposits under the combined effects of vertical, horizontal and moment loading. Merifield et al., (1999) used the finite element method to derive rigorous bounds to the bearing capacity of a two layer clay problem. Research by Michalowski and Dawson (2002) to compare bearing capacity estimates from upper bound limit analysis and numerical models showed that the kinematic constraints imposed in limit solutions caused the significant overestimation of the bearing capacity. For smooth footings, their research revealed the diagonal symmetry of deformation field for a square footing as shown in Figure 5.10. 


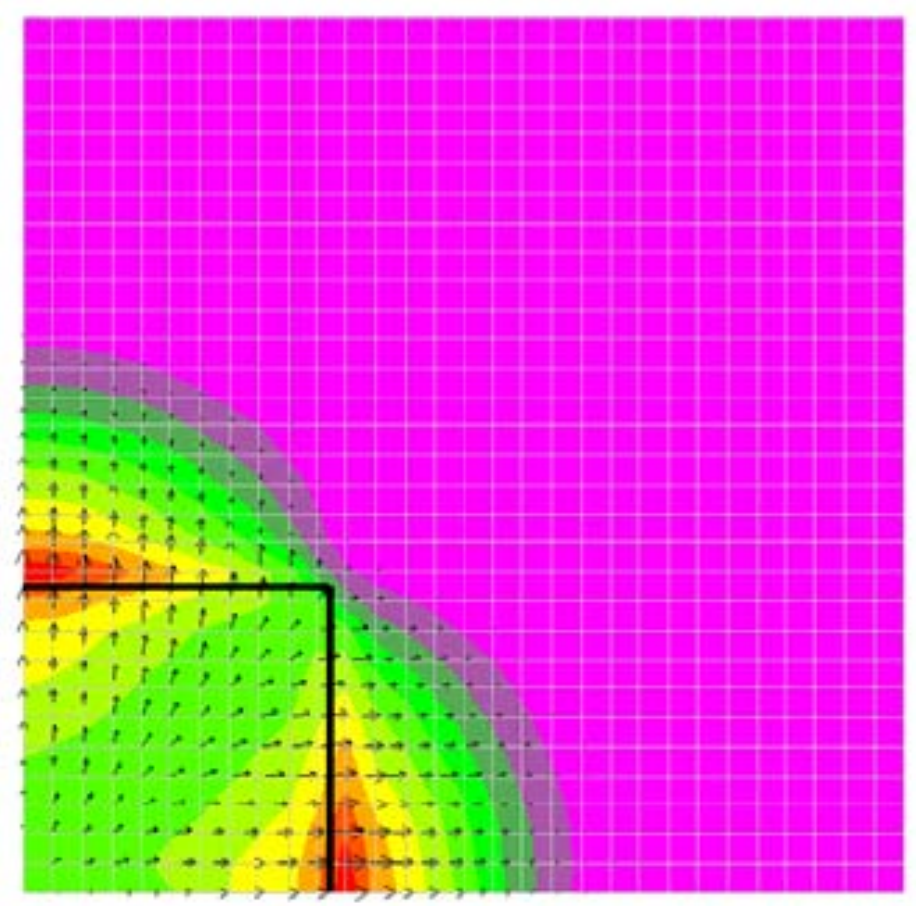

Figure 5.10. Diagonal symmetry of surface displacements for a smooth square footing (Michalowski and Dawson, 2002).

Similar use of finite element modeling for limit analysis was made by Shiau et al., (2003) to study the bearing capacity of a strip footing resting on a sand layer, which in turn sat over a clay bed. For soil layers obeying the associated flow rule, the results from Shiau's limit analysis bracketed the true bearing capacity to within $\pm 10 \%$ or better. Rigorous solutions for bearing capacity of strip, square, circular and rectangular foundations on clay were determined by Salgado et al., (2004) using finite element based limit analysis. Also derived with the limit analysis were the shape and depth factors for making confident adjustments to the bearing capacity. From the limit analysis, they proposed the following equation for the shape effect of shallow foundations when $1 \leq L / B \leq 5$ :

$$
s_{c}=1+0.12 \frac{B}{L}+0.17 \sqrt{\frac{D}{B}}
$$

where $B$ and $L$ are the foundation width and length, respectively, and $D$ is the depth of the foundation. It may be noted that when $D=0$, the shape factor for a 
square footing according to equation (5.1) is 1.12 which is much less than that obtained by De Beer's equation (4.11).

An exclusive investigation of the shape factors for square and rectangular footings was made by Zhu and Michalowski (2005) using the finite element modeling. For a homogeneous semi-infinite Mohr-Coulomb soil, the shape factor for the cohesion term obtained by these model is given as

$$
s_{c}=1+\left(1.8 \tan ^{2} \phi+0.1\right) \sqrt{\frac{B}{L}}
$$

When compared to equation (4.11), the modeling based version in (5.2) underestimates the shape effect on bearing capacity for smaller friction angles and overestimates when $\phi$ is higher (Zhu and Michalowski, 2005). Modeling by Gourvenec et al., (2006) to estimate the shape factors for square and rectangular rough footings on homogeneous undrained clay resulted in the following equation:

$$
S_{c}=1+0.214 \frac{B}{L}-0.067\left(\frac{B}{L}\right)^{2}
$$

Unlike equation (5.1) and (5.2), for $\phi=0$, Gourvenec's shape factor for a square pillar is almost equal to that given by equation (4.11). Additional numerical modeling results on the shape factors for rectangular footings on undrained homogeneous semi-infinite clay were given by Gourvenec (2007). In this later study, Gourvenec considered the effect of vertical, horizontal and moment loads on the footings.

If footings are placed in close proximity to each other, then the resulting interference of failure zones could alter the bearing capacity and load-settlement behavior of each when compared to the isolated condition. Such interference effects are more pronounced in frictional soils than undrained cohesive soils (Griffiths et al., 2006). Probabilistic studies on interference effects of multiple footings were reported by Griffiths et al., (2006) using a combination of the finite element method and random field theory. For the undrained clay case considered, the displacement pattern and the deformed geometry obtained for the case of two interfering footings with random variation of shear strength are 
shown in Figure 5.11. Overall, Griffiths et al., (2006) showed that the random variation of strength led to lower bearing capacity than that given by the average properties.

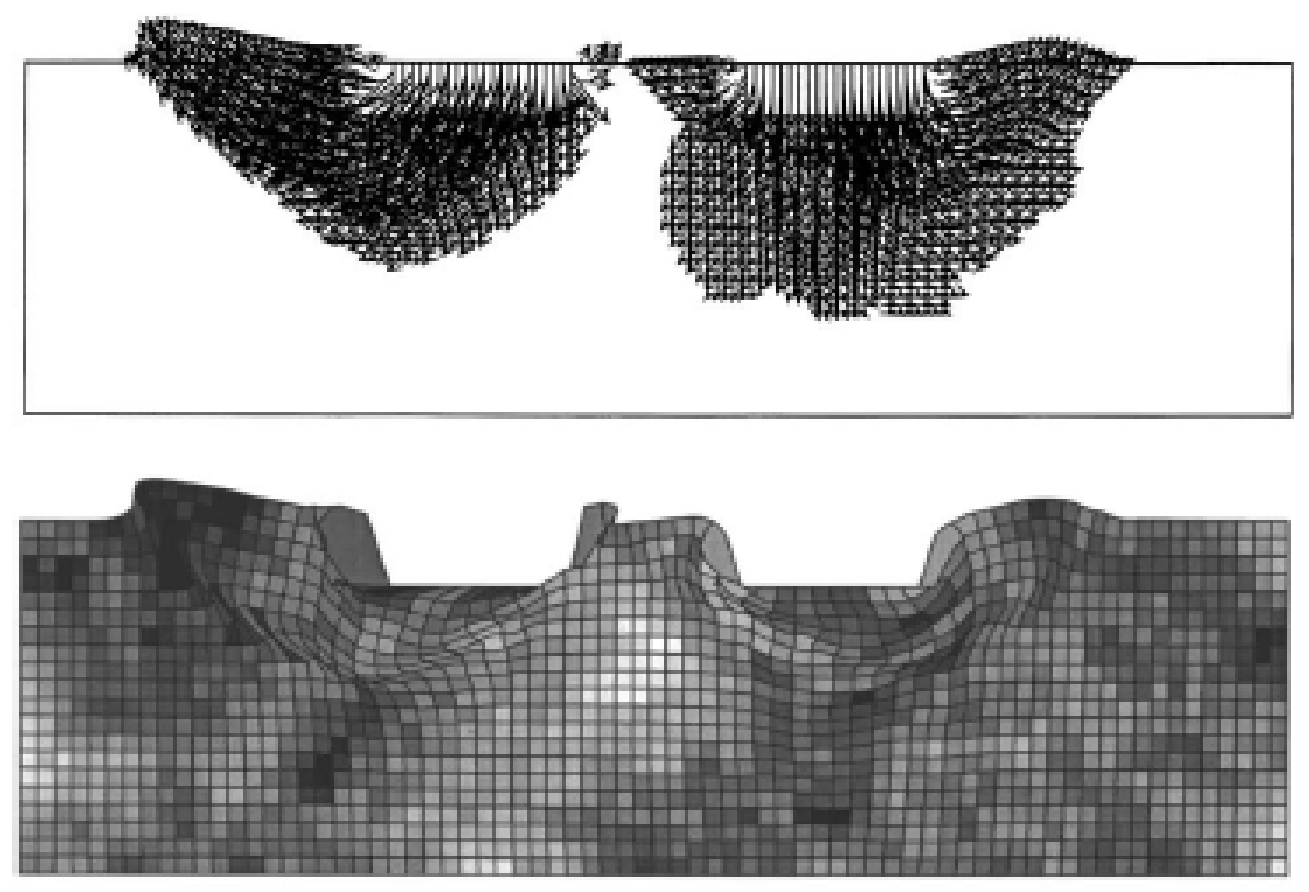

Figure 5.11. Displacements and deformed geometry of two interfering footing over stochastic clay (Griffiths et al., 2006).

Interference effects of multiple strip footings under general loading conditions (vertical, horizontal and moment) were investigate by Gourvenec and Steinepreis (2007) using finite element modeling. For the undrained soil conditions modeled in this study, the results in Figure 5.12 were obtained for vertical loading on the foundations. The results show that when $\phi=0$, the maximum gain in bearing capacity due to the interference effects is less than $5 \%$.

Bulk of the modeling done on bearing capacity assumed that the displacement of the footing prior to attaining the ultimate load was very small. Such small-strain assumptions may not be correct when high deformations comparable to the element size are induced. Wang and Carter (2002) studied a two-layer clay bearing capacity problem considering the geometric nonlinearities due to large plastic deformations. For the particular case where the layer 
immediately beneath the foundation is stronger than the one deeper, Wang and Carter (2002) found that consideration of geometric nonlinearities in modeling could have substantial effect on the computed bearing capacity.

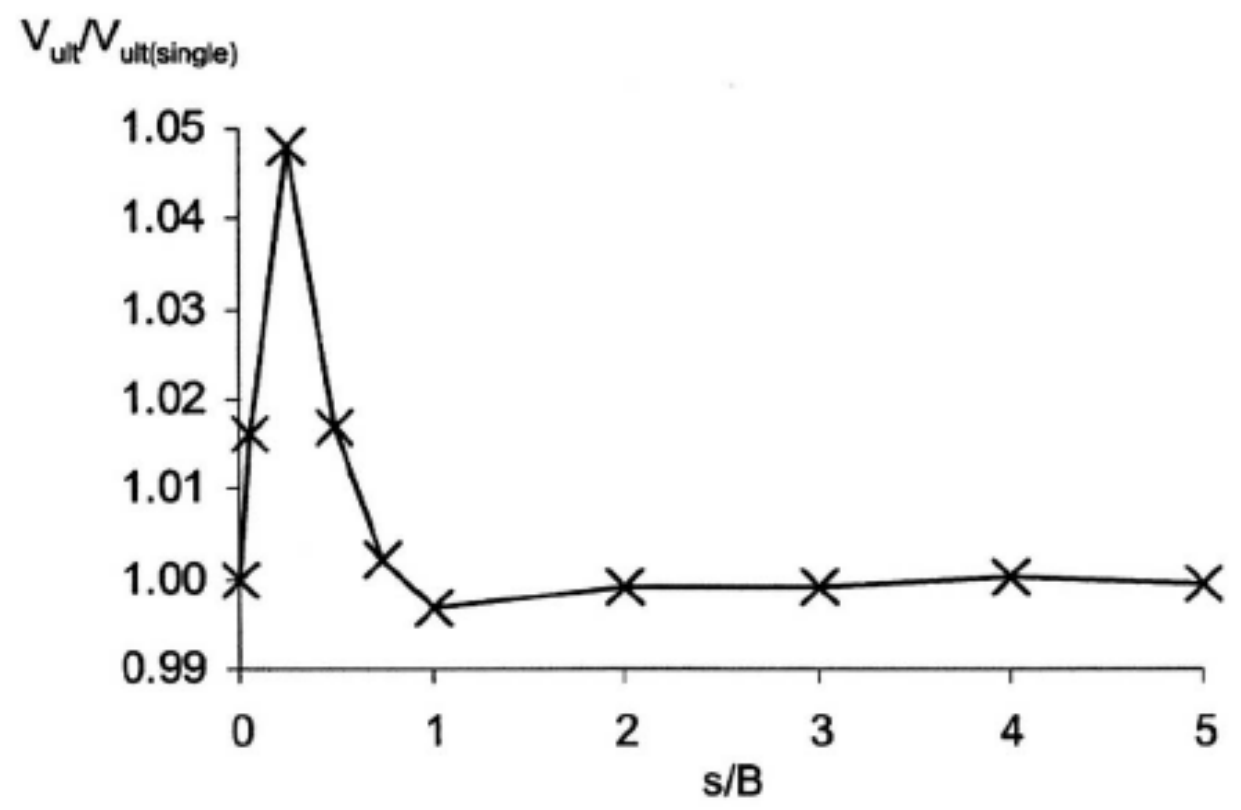

Figure 5.12. Bearing capacity under vertical loading $\left(V_{u l t}\right)$ normalized by limit strength of an isolated footing $\left(V_{\text {ult(single })}\right)$ as a function of spacing $(s)$ over footing width $(B)$

(Gourvenec and Steinepreis, 2007).

The effect of multiple footing interaction on bearing capacity has also been investigated using numerical limit analysis. Kumar and Kouzer (2007) reported results of an upper bound limit analysis done in conjunction with finite elements and linear programming to compute the bearing capacity of two interfering rough footings resting on a cohesionless medium. The theoretical efficiency factors estimated by their analysis are shown in Figure 5.13. (The efficiency factor is the ratio of the magnitude of failure load for a strip footing of given width $B$, in the presence of the second footing, to that of an isolated footing of the same width). Kumar and Kouzer's (2007) results further confirm that significant interference effects occur only at higher friction angles. Although the results in Figure 5.13 are for purely frictional soils, they show almost no influence of nearby foundation when the friction angle is zero. 


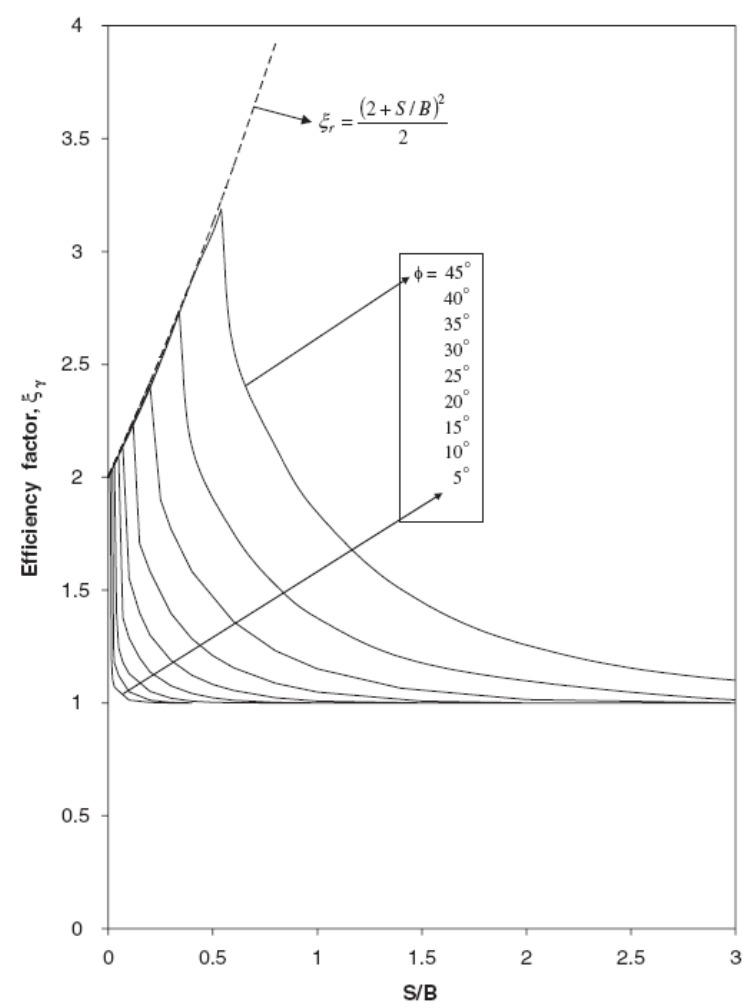

Figure 5.13. Variation of efficiency factor with spacing for different friction angles (after Kumar and Kouzer, 2007).

The effect of spatial random variability of undrained shear strength $(\phi=0)$ on the bearing capacity of clay was investigated using a combination of the finite element method and random field theory (Griffiths and Fenton, 2001; Griffiths et al., 2002; Fenton and Griffiths, 2003). The randomness of the property was described by three parameters, its mean, standard deviation, and spatial correlation length. The spatial correlation length describes the distance over which the spatially random values will tend to be correlated in the underlying Gaussian field. Simply put, larger values of the spatial correlation length represent smooth property variation while the smaller values, a ragged field. The modeling and statistical analyses showed that the soil strength heterogeneity, described by a spatially varying log-normal distribution, can significantly reduce the mean bearing capacity of a strip footing on undrained clay (Griffiths and Fenton, 2001; Griffiths et al., 2002). These studies also show that the spatial variability will have more pronounced negative effect on smooth footings than on rough ones. 
Two- and three-dimensional finite element modeling using ABAQUS program was conducted by Gourvenec and Randolph (2003) to study the effect of combined loading (vertical, horizontal and moment) on the bearing capacity of strip and circular foundations. This study considered conditions similar to those encountered in offshore engineering applications. The modeling also considered the effect of varying clay strength with depth. The results showed that the effect of soil non-homogeneity on the shape of the failure envelope depended on the loading conditions of the footing and thus a uniform failure surface assumption inherent in traditional bearing capacity theories may result in erroneous bearing capacity estimation (Gourvenec and Randolph, 2003).

Extensive number of field plate tests and finite element modeling were used by Thome et al., (2005) to develop a semi-empirical approach for the estimation of bearing capacity of circular foundations. For this analysis, the supporting soil consisted of two layers: the upper layer being cemented and the lower a weakly bonded tropical residual soil. The general modeling methodology followed in this case was similar to the others described so far. Settlement estimations for single and multiple rectangular footings were made using the finite element method by Lee et al., (2008). The modeling results showed that the strain influence factor used for the computation of settlements was influenced both by the shape of the footing and the presence of adjacent footings.

Even though the computer programs used differed and the purposes varied, from the above review of the numerical modeling published in the soil mechanics literature, the following conclusions could be drawn:

- numerical modeling is an effective tool to address complex bearing capacity problems. Modeling can not only reproduce the solutions obtained from classical bearing capacity theories but also can do a lot more;

- almost all the modelers used vertical displacements as the means to apply footing loads (displacement controlled rather than stress controlled);

- where allowed, symmetry of the geometry was exploited to reduce the model size; 
- the contact between the footing and the soil below was either smooth or rough. The smooth contact was simulated by applying displacement restraints in the vertical direction while allowing free movement in the horizontal direction on the nodes that corresponded to the footing region. Similarly, for rough contact, the nodes were fixed in both vertical and horizontal directions;

- the magnitude of the displacement rate applied to simulate footing loading varied between the different modelers and it appeared to depend on the mesh size employed;

- the bearing capacity was estimated by monitoring the sum of the vertical forces acting on the nodes that represented the footing and dividing the sum by the area of the footing;

- bulk of the modeling was done by assuming elastic-perfectly plastic constitutive behavior satisfying the Mohr-Coulomb yield criterion;

- shear strain rates could be used to identify the zone of soil in plastic state at any stage of the numerical solution;

- proper mesh sizing was necessary to obtain accurate results;

- majority of the modelers noted that it took longer to get convergence for higher friction angles and for rough footing-soil contacts;

- a few authors discussed the issue of singularity problems at the edge of the footing because of an abrupt change in the stress conditions. To compensate for this effect, when computing the bearing capacity, some used an adjusted footing size increased by an amount equal to half the width of the element right next to the footing in the model.

\subsection{Development of a Numerical Modeling Methodology}

The coal mine bearing capacity problem illustrated in Figure 5.1 can not be solved analytically if all the factors listed in section 5.1 are considered. The discussions in section 5.2 show that numerical modeling offers a viable and perhaps the only available alternative to simulate any realistic bearing capacity problem. The experience from foundation engineering indicates that the 
numerical models must be fine tuned in order to obtain accurate results. Therefore, the first step in developing a proper numerical modeling methodology is to 'calibrate' the process such that theoretical solutions are reproduced within a reasonable tolerance. This calibration is necessary because the modeling results are sensitive to the mesh size adopted for the simulation. Further, when displacement controlled loading is employed in the models, it is also necessary to arrive at a loading rate consistent with the mesh size employed so as to reproduce theoretical solutions for the simulated case. That particular mesh density and the loading rate value which provided match with the theoretical solutions can then be used for further studies.

The simplest bearing capacity problem for which an exact closed-form solution exists is that of a strip footing resting on a semi-infinite homogeneous weightless soil given by equation (4.1). This situation will be modeled in this section to verify the proposed modeling methodology. If the modeling procedure is accurate, then the calibrated mesh density and rate of loading used for a certain cohesion and friction angle should reproduce theoretical solutions for any other strength inputs. As mentioned before, explicit numerical models like $F L A C^{3 D}$ allow collapse studies to be conducted in a way analogous to actual load tests. Similar to real tests, such numerical studies can be conducted by displacement or load control. Since displacement controlled loading is more stable in the post-failure region and simulates a rigid footing effect, it has been used in the present modeling. For the calibration purposes, a numerical model with semi-infinite floor in plane strain situation was built and displacement loading was applied on a region representative of a continuous foundation as shown in Figure 5.14.

In a numerical model when displacement is used to simulate the loading, singularity conditions arise at the edge of the footing (Itasca, 2007). This is because in the model the soil node at the footing edge is connected to the element adjacent to it. Owing to this continuity, the displacement jump that occurs at the footing edge in reality happens in the model at some point over the adjacent element. To handle this numerical implementation problem, it was 
assumed that the displacement jump occurred at the midpoint of the adjacent element and accordingly the footing area was increased by half the width of the element when the bearing capacity was computed (Itasca, 2007). During the course of this study, it was noticed that the effect of displacement singularity became negligible if a very fine mesh was used for numerical model discretization. Estimation of the resultant load on the footing, monitoring the magnitude of vertical displacement and computing the 'apparent area' needed for the bearing capacity estimation were accomplished at each step in the models via a subroutine written using the $F I S H$ language of the $F L A C^{3 D}$ program.

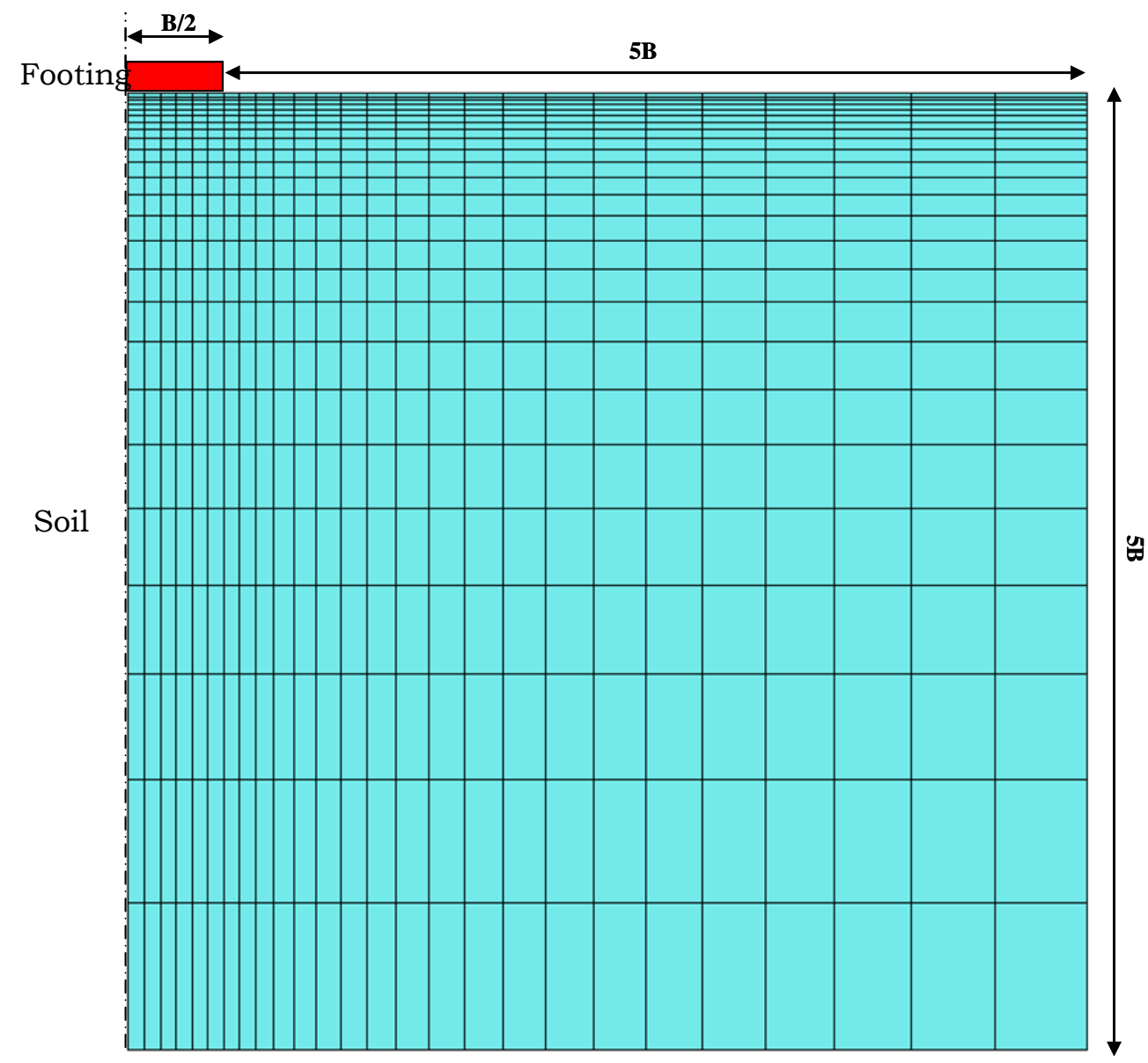

Figure 5.14. FLAC ${ }^{3 D}$ mesh used in the verification models.

As the results given later in this section show, by the time a foundation reaches its limit load, the magnitude of post-failure deformations induced is pretty large when compared to the element size employed in the modeling. Therefore, 
ideally, for such deformations, it is more appropriate to simulate the problem in the 'large strain' mode. In other words, the geometric nonlinearities must be considered. Since the numerical modeling code used in this study does not have the 'adaptive meshing' scheme to change the mesh density in the zone of high deformations, if finite strains are considered in the modeling, then the updated geometry of the elements will be so distorted that the solution will stop due to the resulting 'bad geometry.' For this reason, the modeling in this dissertation is limited to the small strain mode. This restriction did not appear to influence the solution accuracy much as indicated by the extremely good match obtained between the theoretical and model results.

Past research (Griffiths, 1982) showed that for the case of a weightless soil with surface footing, the size of the footing used in the simulation did not alter the computed bearing capacity. Similarly, the magnitude of cohesion value used also did not influence the estimated bearing capacity factor, $N_{c}$. Some trial runs made in this study confirmed the validity of these conclusions. Therefore, in all the studies in this dissertation, unless specifically noted, the width of the footing was kept constant at 12 inches. When the advantage of symmetry was exploited, using $1 \mathrm{ft}$ wide footing greatly facilitated adoption of very fine meshes and yet was possible to solve the models within a reasonable amount of time. It may be noted from Figure 5.14 that a graded meshing scheme was used to ensure high element density in the areas of higher stress concentrations. The model boundaries were extended to five times the footing width in both directions. The boundary conditions applied were rollers along the two vertical planes and fixed nodes at the bottom of the model.

It is a well known fact that the accuracy of numerical modeling results improves with mesh refinement. The process of improving solution accuracy with successive increase in the number of elements employed is called 'convergence.' Since the modeling estimated bearing capacity is sensitive to the mesh size employed, convergence studies were conducted to check if the discretization scheme in Figure 5.14 is adequate. For the semi-infinite homogeneous soil case, the results in Table 5.1 were obtained with successively 
finer mesh. Since the solution error is about 5\% with 918 elements and the improvement obtained by further refinement is not substantial, the mesh size employed in Figure 5.14 was deemed sufficient for the current proposes. While the number of elements used here might seem very small, considering the fact that a large number of steps are needed to reach the limit state in the models, the model run times were not proportionally small, especially for higher friction angle values. Moreover, in 3-D models, the number of elements was significantly increased to ensure similar element density as given in Figure 5.14.

Table 5.1. Numerical convergence studies for the mesh size effect.

\begin{tabular}{|c|c|}
\hline $\begin{array}{c}\text { Number of } \\
\text { element }\end{array}$ & $\begin{array}{c}\text { Ratio of Model to } \\
\text { Prandtl } \\
\text { Bearing Capacity }\end{array}$ \\
\hline 702 & 1.07 \\
\hline 918 & 1.05 \\
\hline 1404 & 1.04 \\
\hline 1566 & 1.03 \\
\hline
\end{tabular}

For the verification models in this section, the cohesion value was arbitrarily chosen as $150 \mathrm{psi}$ and the friction angle was varied from $0^{\circ}$ to $30^{\circ}$ on $5^{\circ}$ increments. Similarly, the modulus of deformation value was estimated by the claystone version in equation (3.26) for an arbitrarily chosen moisture content equal to $8 \%$. A constant Poisson's ratio equal to 0.35 was used in all the models. The soil was assumed to satisfy the Mohr-Coulomb yield function with perfectlyplastic behavior. It was also assumed that the soil did not exhibit volume change in the post-yield state. Although a non-zero density value was used for the floor in the models, because of the extremely small width of the footing considered, the computed bearing capacity was almost the same as that of a weightless soil. The mesh density and the loading rate were fine tuned for the $5^{\circ}$ friction angle case, and then kept constant for much of the research in this dissertation. Obviously, it was not possible to get an exact match for the mesh density when different geometric parameters were varied, but every effort was made to keep the discretization as close to the one used in the verification models as possible. 
For the simulations made in this section, both rough and smooth footingsoil contacts were considered. Although for the Prandtl problem discussed here, there is only a negligible difference between the rough and smooth footing bearing capacities, such similarity can not be expected for every situation possible in an underground coal mine. However, for the later studies in this work, only the smooth contact was simulated as the real boundary conditions between a coal pillar and the floor are normally not known. Moreover, past research (for example, Griffiths, 1982) shows that the roughness of footing-soil contact will influence $N_{\gamma}$ term more than the other two in equation (4.5). For a coal mine situation the effect of the last two terms in equation (4.5) is normally ignored, and thus the boundary conditions at the pillar-floor contact may not have substantial impact on the model floor strength. Additionally, the smooth contact conditions will result in a conservative estimate of the bearing capacity and therefore will err on the safer side. In order to make the modeling results independent of the model conditions, all the geometric variables and the corresponding bearing capacities will be presented in normalized, dimensionless forms.

The modeling results indicated that the discretization given in Figure 5.14 with a loading corresponding to a vertical displacement rate of $6 \times 10^{-4}$ inch/step would provide bearing capacity match to within $3.5 \%$ of the theoretical value. The computed and theoretical bearing capacity factors are given in Table 5.2 for different friction angles. In addition to computing the limit load, with numerical approach, it was also possible to study the evolution of failure zones at different stages of loading. For the case of $c=150 \mathrm{psi}$ and $\phi=5^{\circ}$, the load-deformation curve obtained for a rough footing from modeling is shown in Figure 5.15. For the different points shown on this curve, the extent of yielded elements is shown in Figure 5.16. As mentioned before, the shear strain rate at any stage of loading indicates the zones of elements in active plastic state. The shear strain rate contours at point $\mathrm{H}$ of Figure 5.15 are plotted in Figure 5.17. Also shown in Figure 5.17 are the velocity contours at the same state of loading.

The results given in Table 5.2 clearly show that for the chosen mesh density and the corresponding displacement rate applied, numerical modeling 
provided an excellent match when compared with the theoretical predictions. In fact, for the smooth foundation contact case the match was almost exact while for a rough footing, modeling consistently overestimated the bearing capacity. Even for the rough footing case, however, the overestimation was less than $3.5 \%$. Therefore, for all practical purposes the modeling reproduced the theoretical results accurately. Moreover, the plots in Figures 5.16 and 5.17 show

Table 5.2. Comparison of theoretical and modeling based bearing capacity factor, $N_{c}$ for a constant cohesion equals to 150 psi.

\begin{tabular}{|c|c|c|c|}
\hline Friction Angle, degrees & \multicolumn{3}{|c|}{ Bearing Capacity Factor, $N_{c}$} \\
& Theoretical & Model - smooth footing & Model-rough footing \\
\hline 0 & 5.14 & 5.15 & 5.24 \\
\hline 5 & 6.49 & 6.49 & 6.65 \\
\hline 10 & 8.35 & 8.31 & 8.61 \\
\hline 15 & 10.99 & 10.99 & 11.36 \\
\hline 20 & 14.85 & 14.89 & 15.37 \\
\hline 25 & 20.76 & 20.80 & 21.47 \\
\hline 30 & 30.22 & 30.23 & 30.52 \\
\hline
\end{tabular}

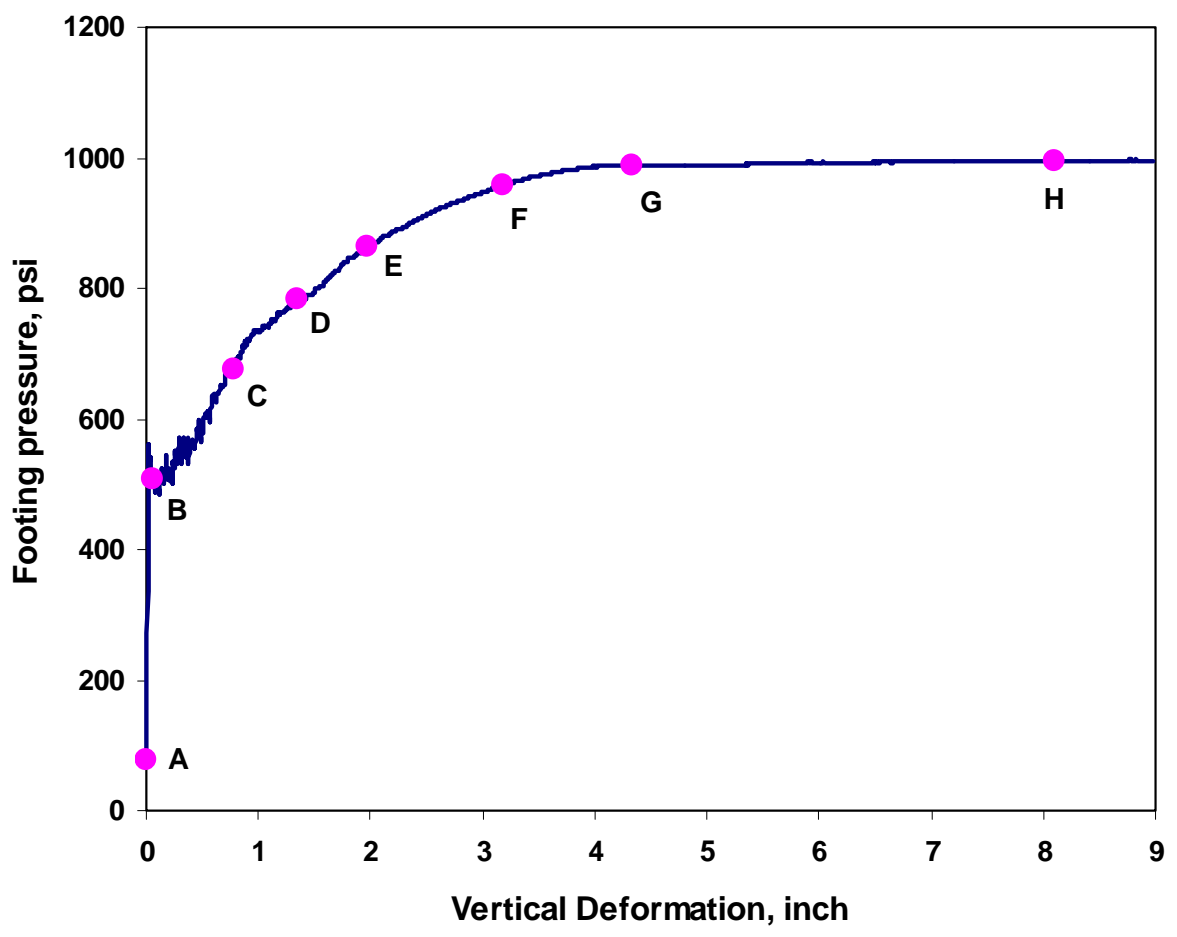

Figure 5.15. Pressure-deformation curve obtained from FLAC ${ }^{3 \mathrm{D}}$ modeling for $c=150 \mathrm{psi}$ and $\phi=5^{\circ}$ for a strip footing on semi-infinite homogeneous soil. 


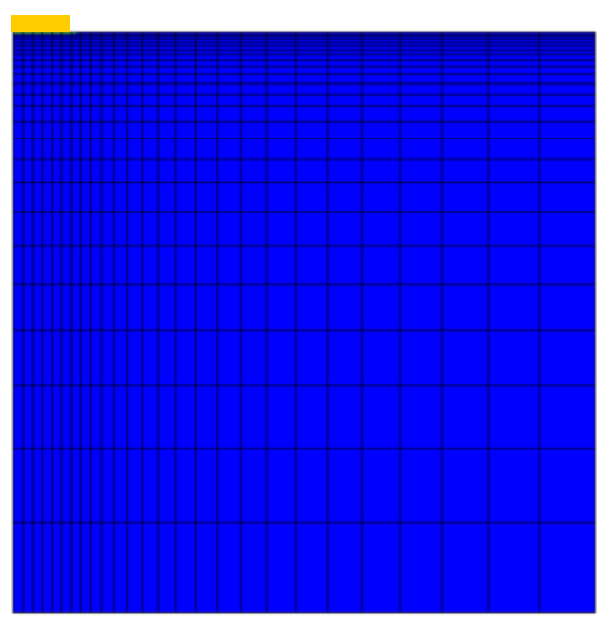

Point A

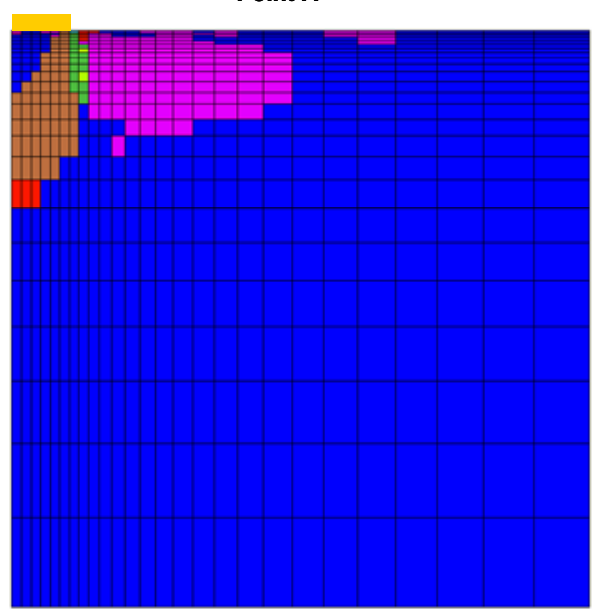

Point C

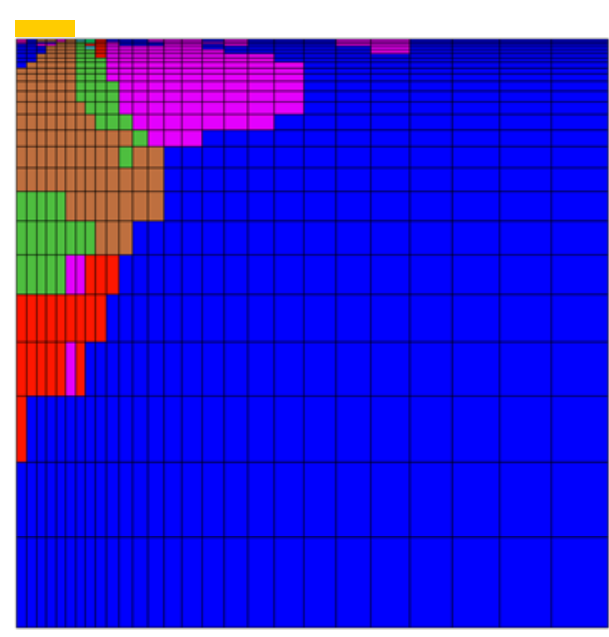

Point E

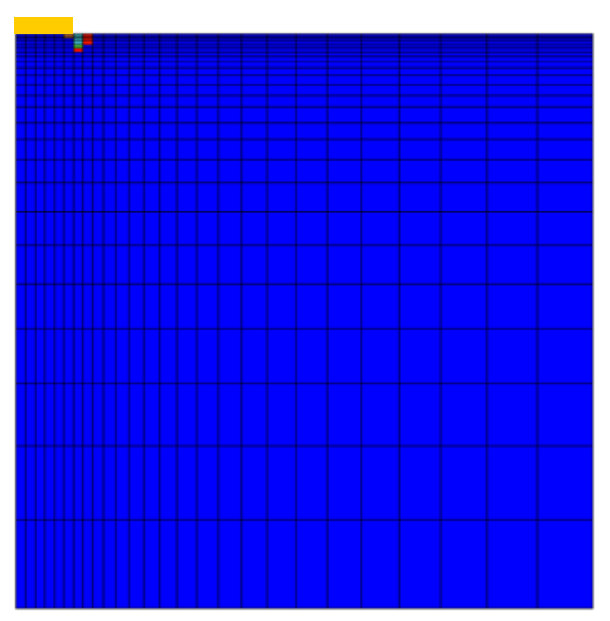

Point B

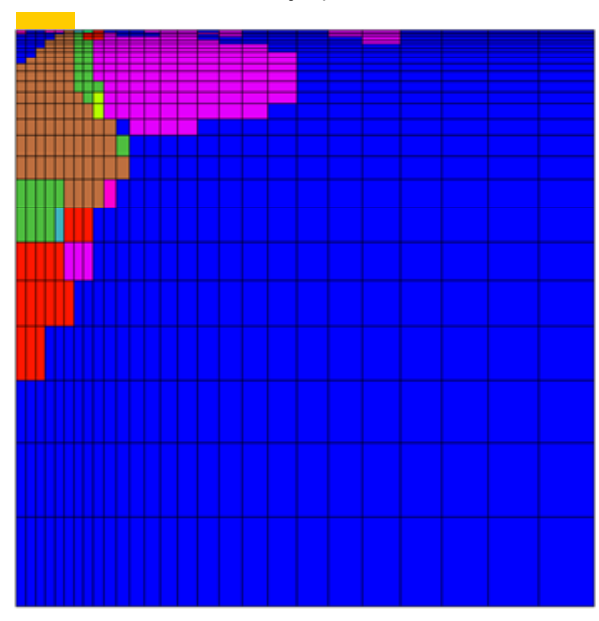

Point D

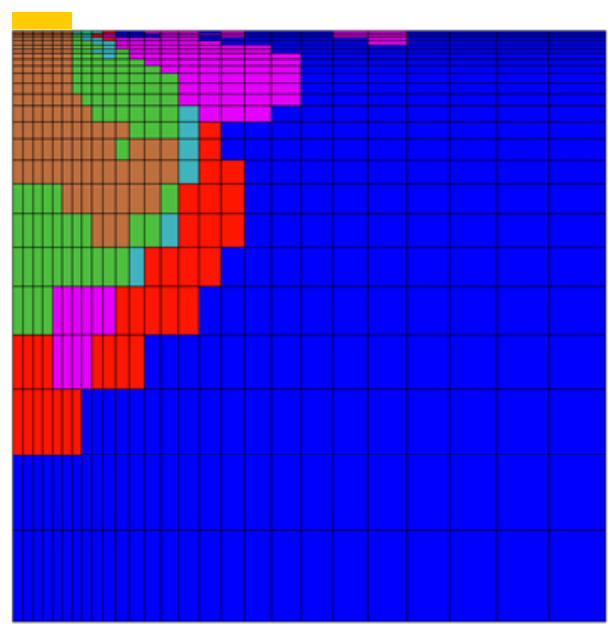

Point F

Figure 5.16. Extent of yielding for different loading points identified in Figure 5.15 (Blue elements are elastic and the other colors indicate yield zones at different stages of solution). 


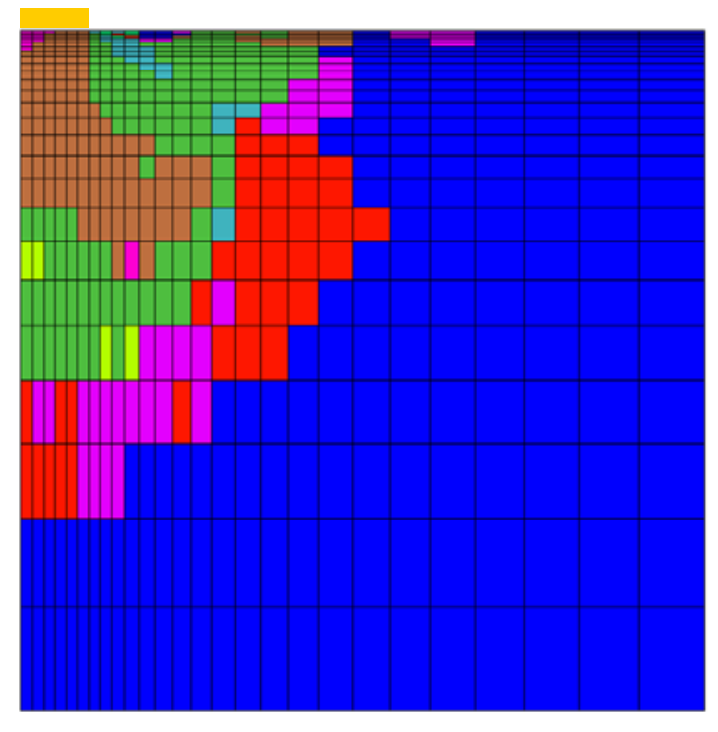

Point G

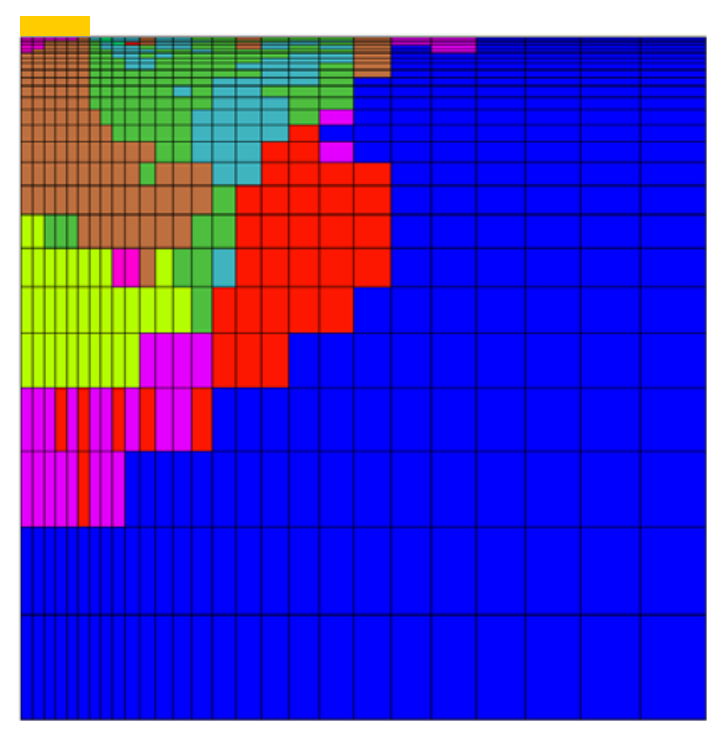

Point H

Figure 5.16 (Continued). Extent of yielded elements for different loading points identified in Figure 5.15.

a)

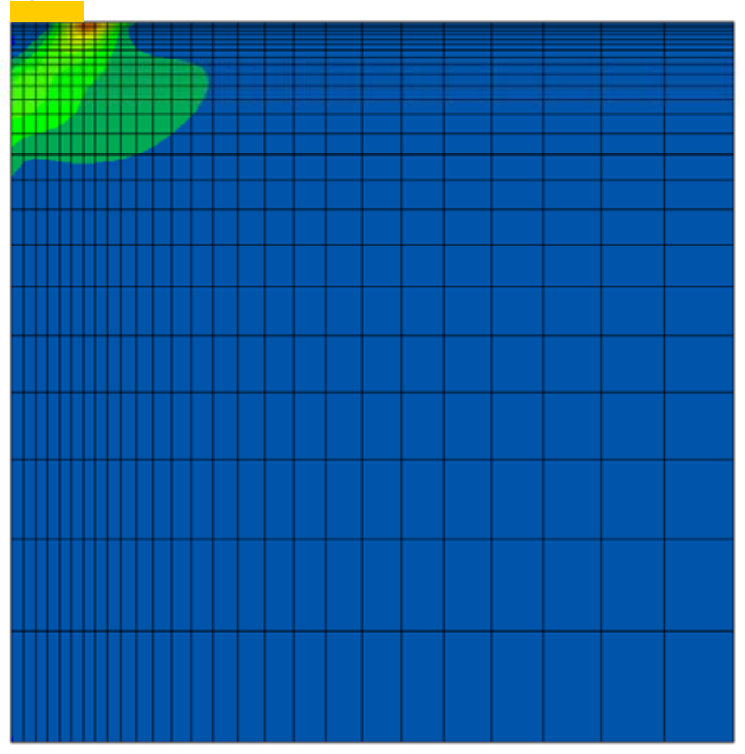

b)

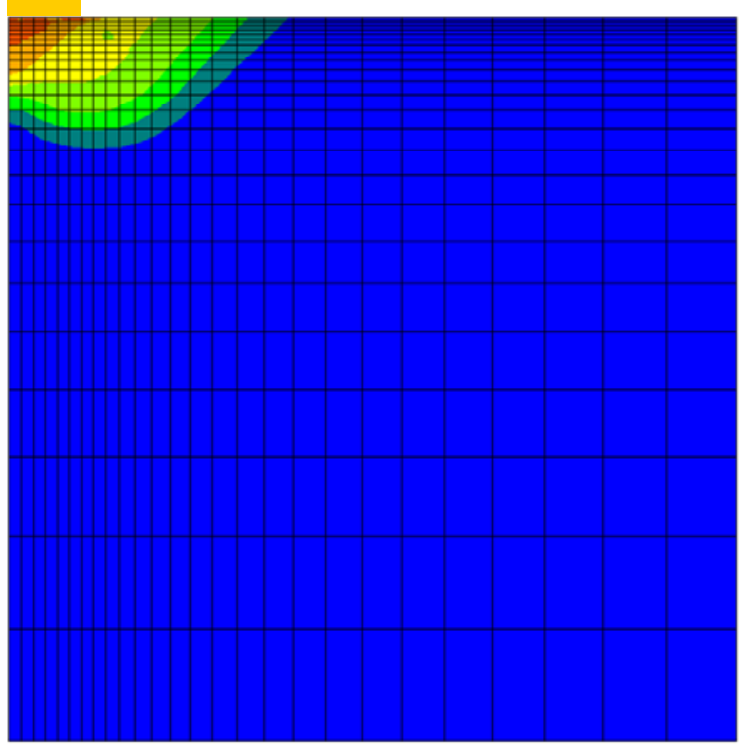

Figure 5.17. Contours of a) shear strain rate and b) velocity for the loading state corresponding to point $H$ in Figure 5.15.

that numerical modeling also reproduced the failure mechanism in a realistic manner. The yield zone distribution in Figure 5.16 shows that an elastic wedge existed below the foundation until the loading reached about $85 \%$ of its limit value. Similarly, even when the foundation loading was way into the post-failure 
state, the 'active' plastic zones were confined to a narrow zone at the footing edge as illustrated in Figure 5.17 (a). The shear strain rate in this figure basically showed which part of the model was actively flowing at the time the results were obtained. Unlike the Prandtl's assumption, however, the limits of the elastic wedge did not coincide with the edge of the foundation but lied somewhat inside as shown in Figure 5.17(a). The velocity (or displacement) contours in Figure 5.17 (b) reproduced the limits of passive wedge similar to that assumed in the Prandtl's model illustrated in Figure 4.2.

\subsection{Effect of Different Variables on the Classical Bearing Capacity Solution}

After verifying the numerical modeling's accuracy, the next step is to introduce some of the coal mine specific variables into the Prandtl type analysis to evaluate their effect on the estimated bearing capacity. The exact effect of the additional variable could be assessed by how much the model's bearing capacity departed from that of the homogeneous semi-infinite soil situation studied in section 5.3 or some other base case. As mentioned before, only the case of surface footing is considered in this dissertation and thus all the following discussions will be limited to this case.

\subsubsection{Shape Effect}

The results in section 5.3 are applicable only for a strip footing where the length is several times greater than the width. In a coal mine, only the longcontinuous barrier pillars are similar to strip footings. The rest of the pillars normally are either square or rectangular. Geometrically, square and strip footings are the lower and upper bounds to a rectangular footing. Since the case of strip footing has been studied in section 5.3 , the discussions here will focus on the square footing. Obviously, for the rectangular footings, the results will fall between these two bounds.

As mentioned in chapter 4 , a closed-form solution for the bearing capacity does not exist for geometric shapes other than a strip footing. Therefore, several semi-empirical approaches have been developed over the years to make 
corrections to the strip footing solution to account for different shapes of foundations. A summary of the modeling results obtained for the square footings is given in Table 5.3. For different friction angles, the values of cohesion, dilation angle and footing width were kept the same. These model results clearly support the broader conclusion that the bearing capacity of a square pillar is higher than that of a strip footing of the same width. The shape factors given in equations (4.11) to (4.13), however, appear to underestimate the bearing capacity of the square footings for higher friction angles. As discussed in section 5.2, such mismatch between traditional semi-empirical shape factors and modeling solutions were also reported by some in the foundation engineering literature. If the semi-empirical shape factors given in equations (4.11) to (4.13) are valid, then the ratio between model strength and the shape corrected Prandtl strength should be around 1.0. But, the results in Table 5.3 do not show that to be the case always. The match between shape corrected Prandtl solution and the modeling results is very good up to a friction angle of about $15^{\circ}$, after which the models show higher bearing capacity than the conventional approach. Therefore, for the semi-infinite homogeneous soil case, it can be concluded that the conventional shape factor equations provide as good or conservative estimate of floor strength compared to the model results and thus err on the safer side.

The conventional shape factors are applicable for the case of a rough footing base and therefore the model results in Table 5.3 were also obtained for the same contact condition. The displacement vectors at the limit state for the square footing for $\phi=5^{\circ}$ are plotted in Figure 5.18 (a) and the shear strain rate contours are provided in Figure 5.18 (b). The diagonal symmetry of the displacement patterns such as that reported by Michalowski and Dawson (2002) can be seen in the square footing displacement field. Further, the amount of heave adjacent to the footing has the highest magnitude in the mid potion and kept reducing toward the footing corner. When the shear strain rate contours for the square footing are examined, at the limit state, a small portion of non-active plastic zone similar to that seen in Figure 5.17 (a) can be found. 
Table 5.3. Comparison of Model and traditional bearing capacity estimates for an isolated square footing resting on a semi-infinite homogeneous floor.

\begin{tabular}{|c|c|}
\hline $\begin{array}{c}\text { Friction Angle, } \\
\text { Degrees }\end{array}$ & $\begin{array}{c}\text { Ratio of model strength to } \\
\text { shape-corrected Prandtl } \\
\text { Strength }\end{array}$ \\
\hline 5 & 0.96 \\
\hline 10 & 0.97 \\
\hline 15 & 1.01 \\
\hline 20 & 1.06 \\
\hline 25 & 1.11 \\
\hline 30 & 1.19 \\
\hline
\end{tabular}

a)

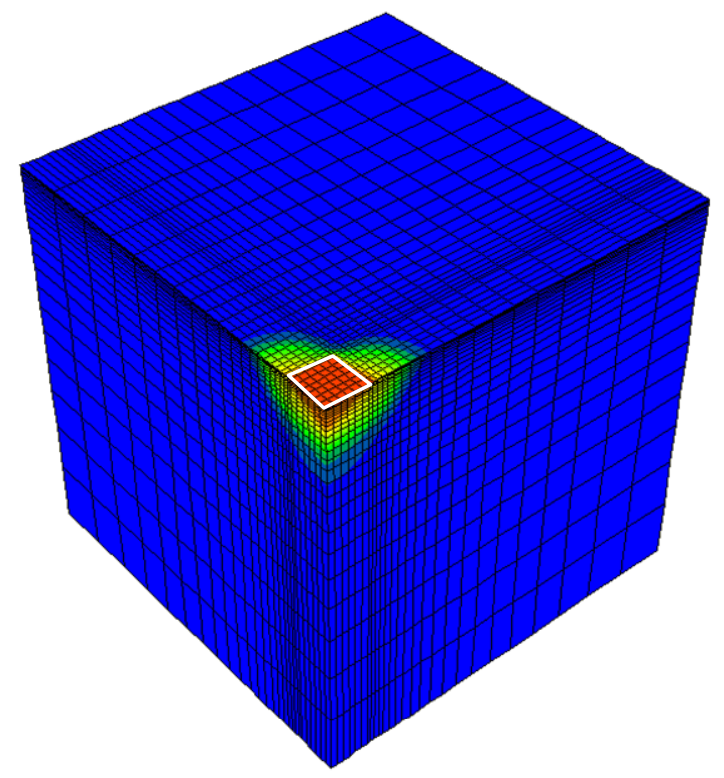

b)

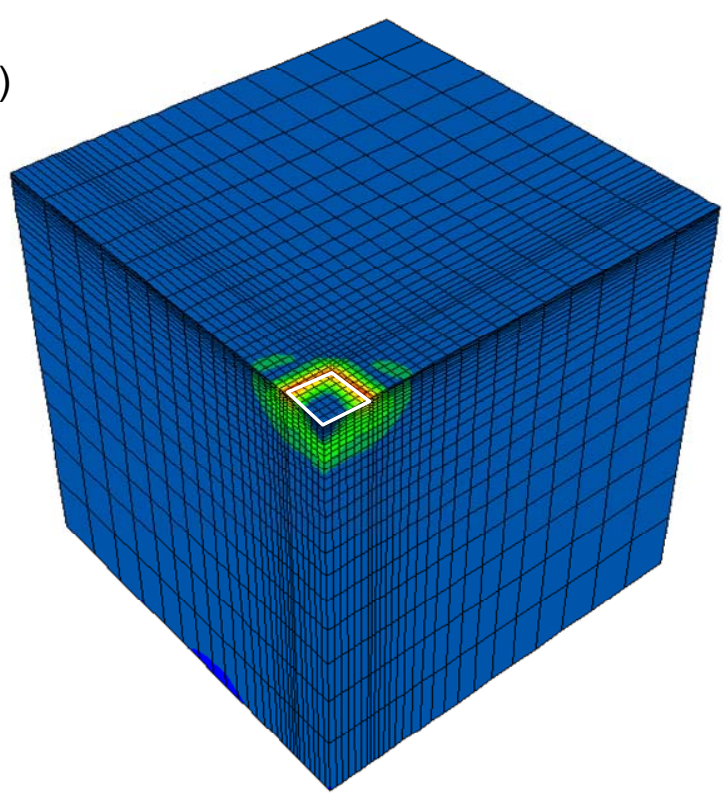

Figure 5.18. Contours of a) displacement and b) shear strain rate for a square footing on semi-infinite homogeneous floor for $\phi=5^{\circ}$ (parameter values highest for red, lowest for blue with green in between).

\subsubsection{Finite Floor Thickness}

The Prandtl's solution given by equation (4.5) assumes that the soil below the foundation is semi-infinite in extent. In a coal mine, however, the immediate floor always has a finite thickness. Therefore, if all other modeling variables are kept the same and only the immediate floor thickness is varied, then the bearing capacity estimate changes as shown in Figure 5.19. In this figure, the ratio of 
model strength to Prandtl's bearing capacity is plotted as a function of the ratio of footing width to floor thickness. Similar to the Mandel and Salencon's assumptions given in Chapter 4, for the present simulation, the rest of the model below the immediate floor was assumed to be elastic and thus of infinite strength. The results clearly show that if the immediate floor thickness is very small compared to the footing width, then there is a significant increase in the bearing capacity. With decreasing $B / H$, the bearing capacity decreases exponentially. Qualitatively, these preliminary modeling results confirm the general trends from the traditional methods discussed in Chapter 4.

$\sigma_{\mathrm{c}}=734 \mathrm{psi} ; \phi=20^{\circ} ;$ Semi-infinite Strip footing

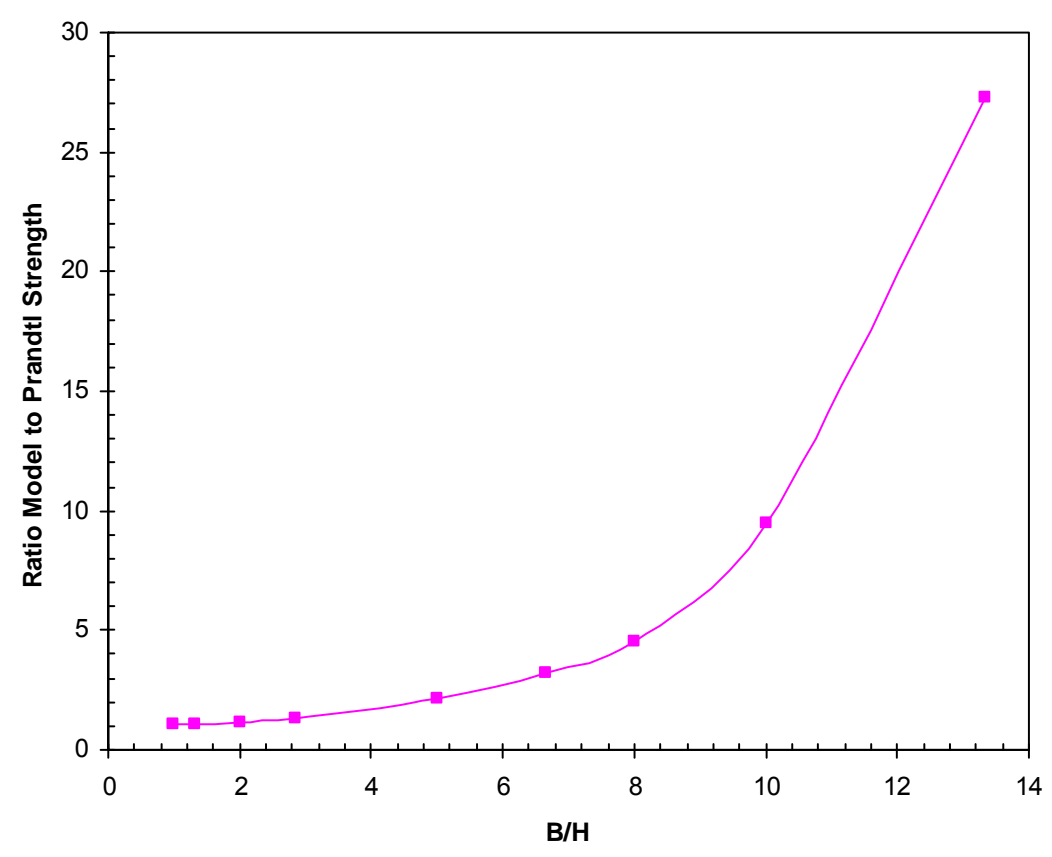

Figure 5.19. Change in bearing capacity as a function of floor thickness.

At the limit state, the shear strain rate contours along with displacement vectors for two different $\mathrm{B} / \mathrm{H}$ ratios are plotted in Figure 5.20. These results clearly show that if the bed below the immediate weak floor is very strong, then at the limit state, the floor fails by plastic movement in the horizontal direction. This situation is analogous to squeezing soft cheese between two steel plates. 
a)

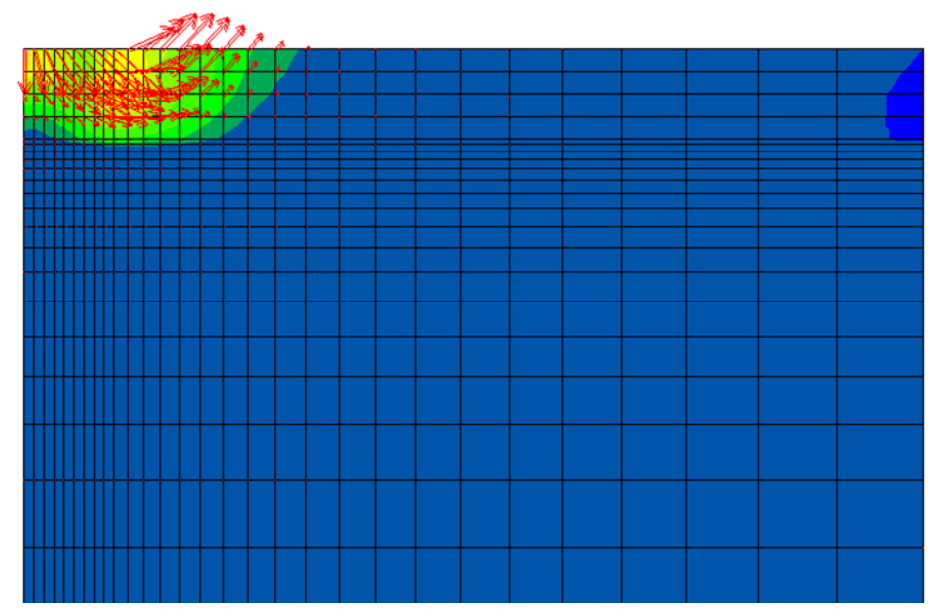

b)

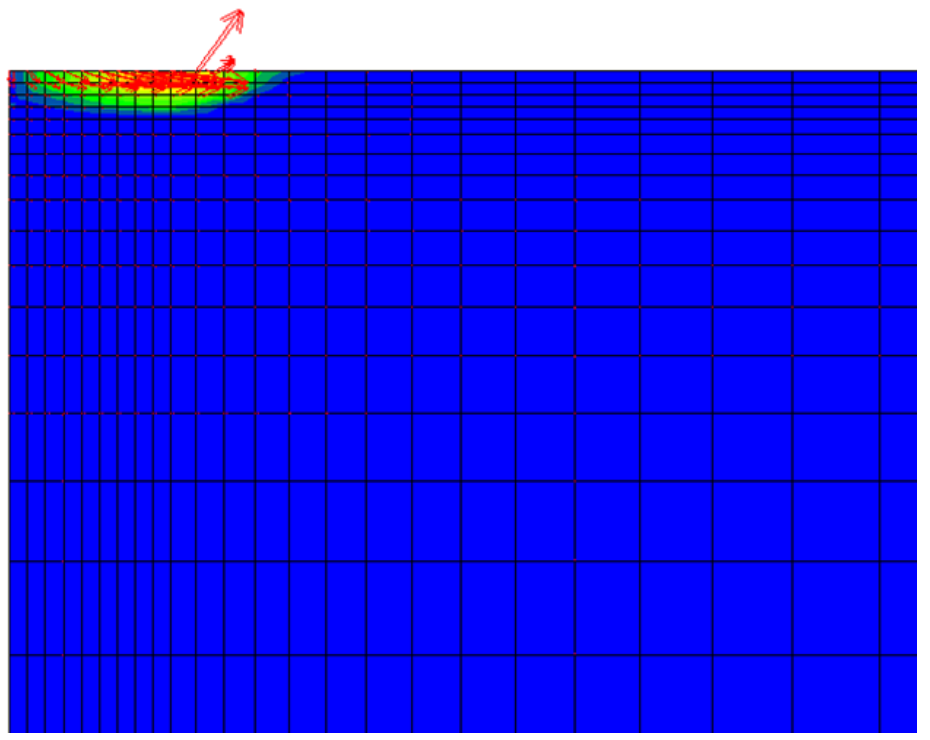

Figure 5.20. Shear strain rate contours along with displacement vectors for a) $B / H=2$ b) $B / H=13.3$.

\subsubsection{Ratio of Floor Strengths}

The results in section 5.4.2 are valid when the bed below the immediate weak floor is infinitely strong. In real world, such situations rarely exist. When the weak floor is underlain by a strong bed, the ratio of the strengths of the two beds affects the floor bearing capacity. For the case when $B / H=6.67$, the effect of different ratios of cohesion for the two floor beds on bearing capacity is shown in Figure 5.21. From this analysis it is clear that when the strength ratio is six or above, the system behavior is similar to that of an infinitely strong main floor given in section 5.4.2. 
$\phi=20^{\circ} ; \sigma_{\mathrm{c}}=734 \mathrm{psi} ; \mathrm{H} / \mathrm{B}=0.15 ;$ strip foundation

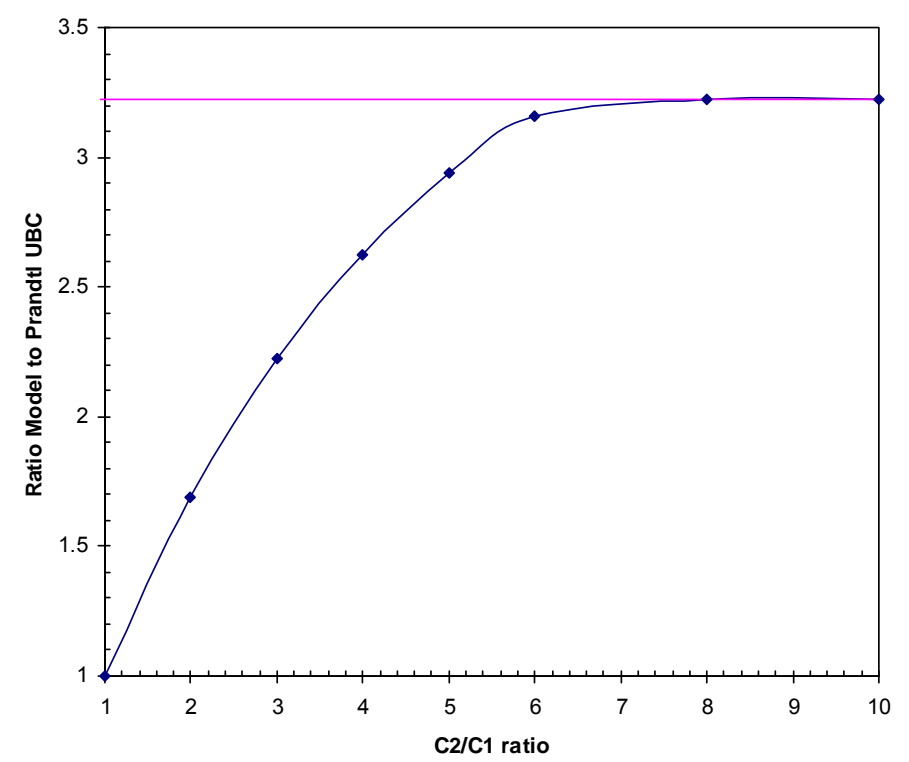

Figure 5.21. The effect of floor strength ratio on bearing capacity.

\subsubsection{Strength Variation with Depth}

From the in-situ plate test data given in Chapter 3, it was found that the plate bearing capacity is dependent on the moisture content of the weak floor. In Chapter 2, it was also shown that the moisture content changes with depth in the floor. Given these two observations, it is likely that the strength of immediate floor material increases or decreases with depth depending on whether moisture content decreases or increases. The effect of such strength variation with depth is modeled in this section. Although the results in section 5.4.3 also account for strength change with depth, in those models the strength of each layer was kept constant. For the sake of simplicity, the variation of moisture content and hence strength, was assumed to be linear from top to bottom in the immediate floor bed modeled here. If enough information is available, any type of strength variation can be included in the numerical analysis.

In Figure 5.22, the change in floor bearing capacity is plotted against the ratio of floor cohesion at the bottom to that at the top of the immediate floor bed. 
The multiplier along X-axis in Figure 5.22 has been used to linearly increase or decrease the cohesion value of the immediate floor bed from top to bottom. For example, a multiplier value of 0.8 will ensure the cohesion value to decrease linearly from top to bottom such that the strength at the immediate floor bottom is 0.8 times that at the top. The bed below the immediate floor has been assumed to be of infinite strength in these models. Also, the friction angle and the $H / B$ ratio have been kept constant.

$$
\phi=20^{\circ} ; \psi=0 ; H / B=0.15
$$

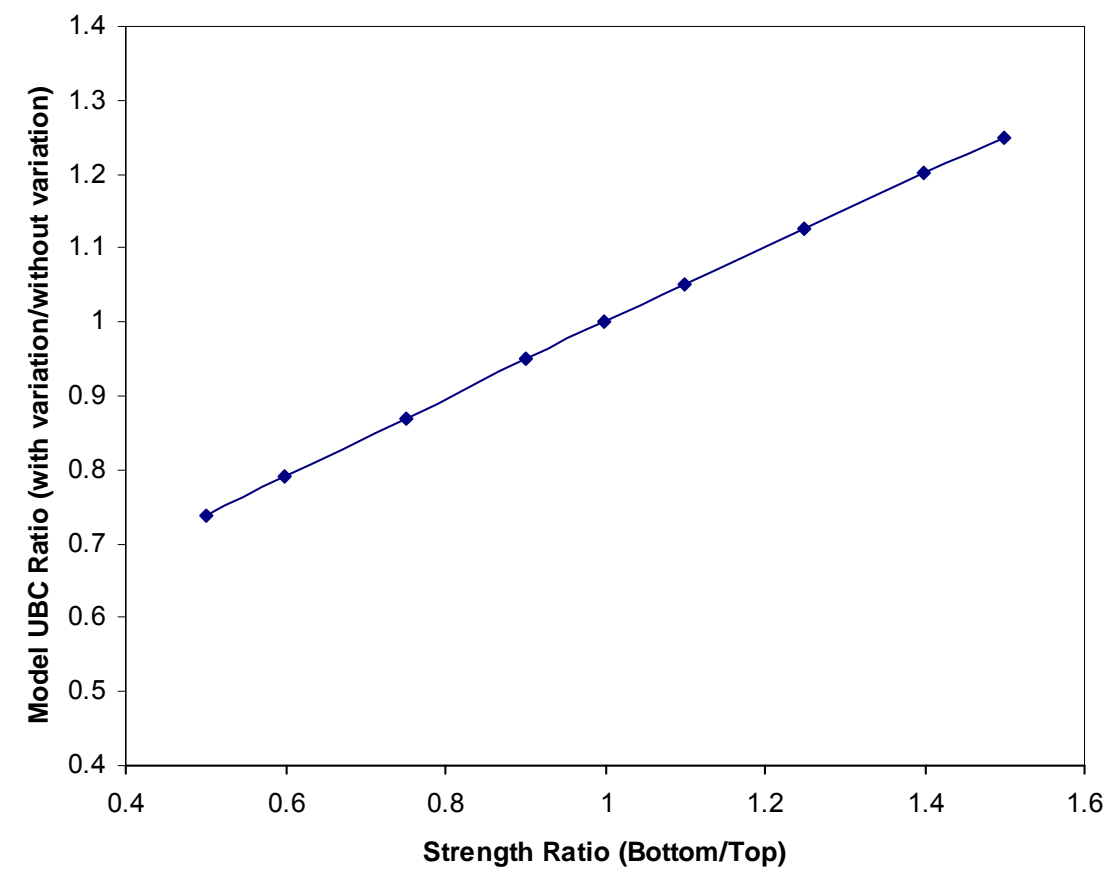

Figure 5.22. Change in Bearing Capacity for a linear variation of floor cohesion.

The results in Figure 5.22 show that when the immediate floor cohesion decreases with depth, the floor bearing capacity is lower than that estimated based only on the strength tests conducted on samples collected from the surface of the floor. The opposite trend occurs if the floor cohesion increases with depth. Since some of the coal mine data in Chapter 2 show that the moisture content of the floor increases with depth, ignoring such variation and assigning uniform cohesion values to the entire immediate floor will lead to conservative estimates of the bearing capacity. 


\subsubsection{Multiple Footing Interaction}

Some of the traditional bearing capacity theories studied in Chapter 4 showed that when multiple footings existed in close proximity, their interaction with each other would have a positive effect on their individual bearing capacities. This interaction effect will be investigated in more details later in this chapter. In the preliminary models run here, only the case of a semi-infinite homogeneous soil with multiple footings is investigated. The results in Figure 5.23 clearly show that if several footings exist at a spacing of $s$, then the bearing capacity is higher than that given by equation (4.5), which is valid only for an isolated footing. However, when the spacing becomes comparable to the footing width, the interaction effects diminish.

$\phi=20^{\circ} ; \sigma_{c}=743 \mathrm{psi} ;$ Semi-infinte strip footing

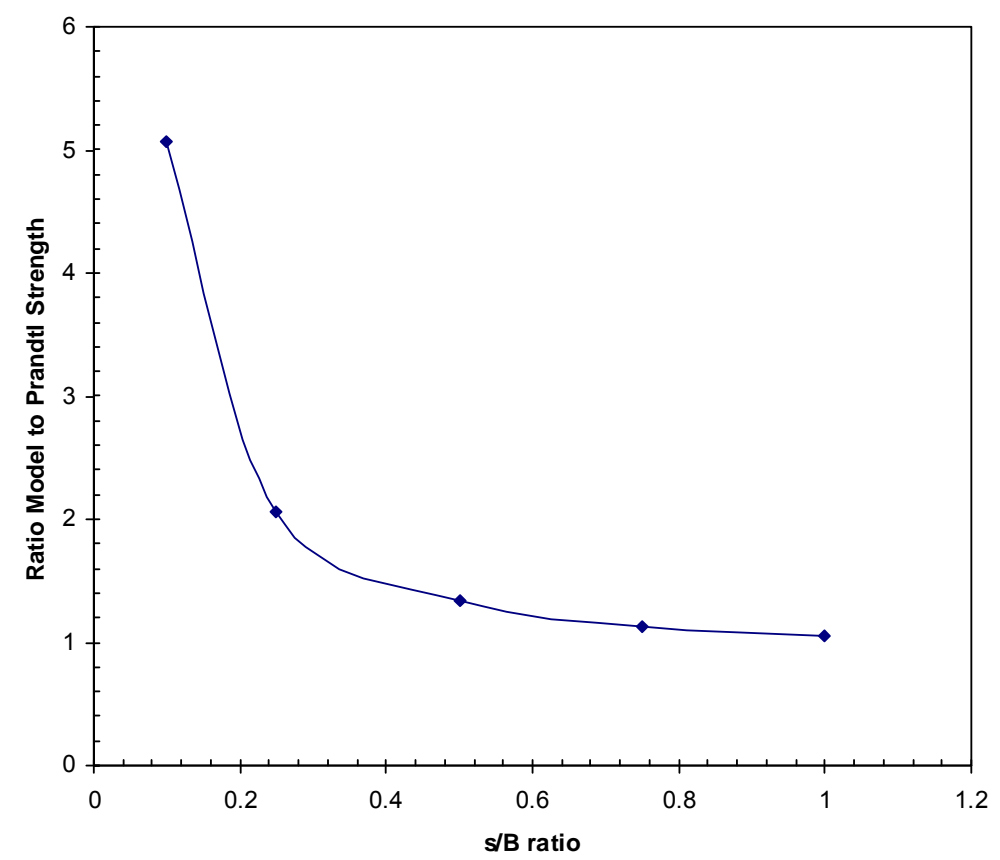

Figure 5.23. The effect of footing spacing on bearing capacity.

\subsubsection{Effect of Volumetric Expansion}

All the modeling done so far assumed that there was no change in the material volume in the post-failure state. As the in-situ load-deformation curves in 
chapter 3 show underclay floors exhibit brittle behavior if the natural moisture content is low. It is also known that brittle rocks normally dilate in their postfailure state. Such volume increase is defined by a parameter called the dilation angle, $\psi$. In the traditional bearing capacity solutions it is difficult to include the effect of dilation and such complications could easily be handled with numerical modeling.

For rocks, $\psi$ value varies between zero and the angle of internal friction of the material, $\phi$. If $\psi=0$, then there is no volume change in the post-failure state. When $\psi$ becomes equal to $\phi$, the condition is called the associated flow. For real geologic materials, $\psi$ is less than $\phi$ but is more than 0 . The effect of varying $\psi$ between 0 and $\phi$ on floor bearing capacity is shown in Figure 5.24.

$$
\phi=20^{\circ} ; \sigma_{c}=734 \text { psi; Semi-infinite strip footing }
$$

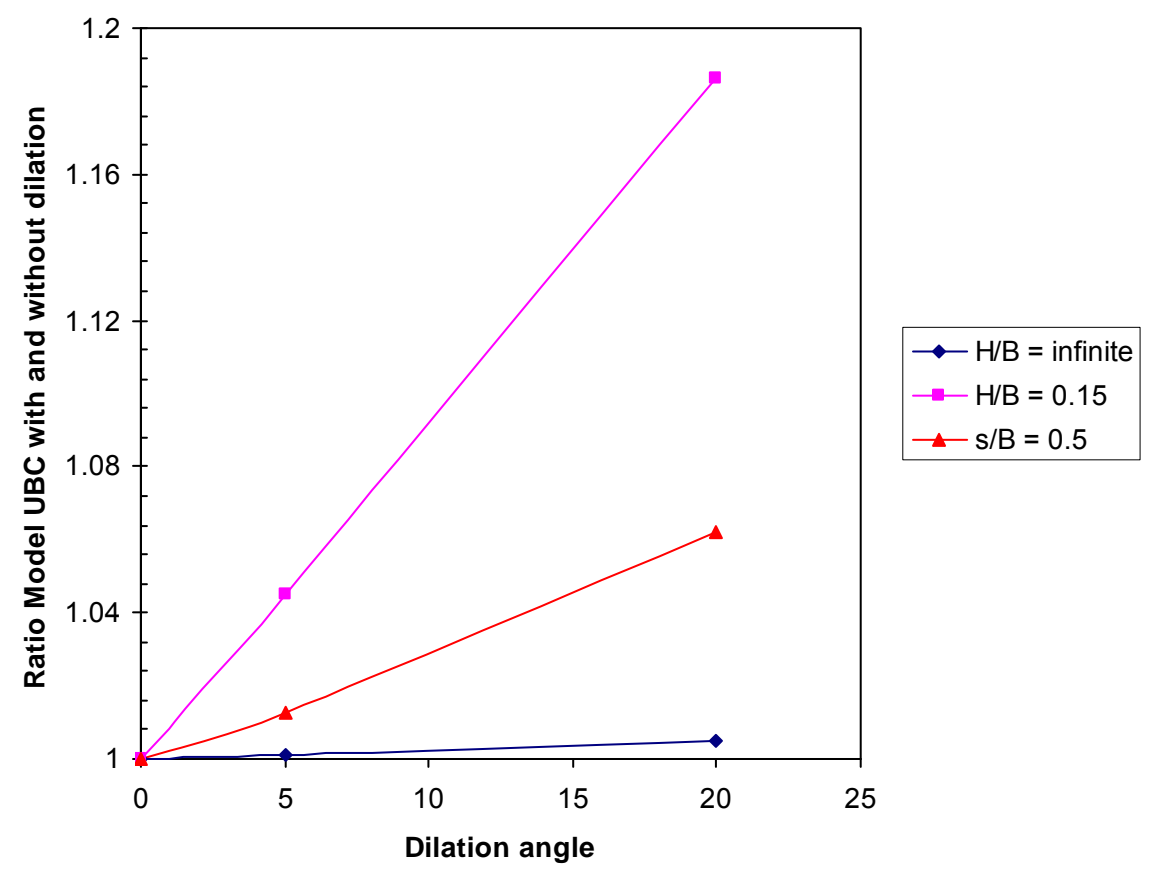

Figure 5.24. Ratio of model ultimate bearing capacity with and without including dilation angle for different model conditions.

For Figure 5.24, models were run with a constant cohesion and friction angle values but for three different dilation angles, $\psi=0^{\circ}, 5^{\circ}, 20^{\circ}$. The results were obtained for three cases of a) semi-infinite floor, b) $H / B=0.15$, and c) for 
the semi-infinite case with multiple footings at $s=0.5 B$. The results show that for the semi-infinite isolated footing case, the nonassociativity has negligible effect on the bearing capacity. The dilation angle, however, can have significant influence on the bearing capacity both when the floor thickness is finite and when multiple footings exist in close proximity. In all the cases, with increasing dilation angle, the bearing capacity increased. A plot of the shear strain rate along with displacement vectors is provided in Figure 5.25 for the homogeneous semiinfinite floor case for two different dilation angles. These plots show that with increasing dilation angle, the depth of active plastic zones decreases and also the floor movements get intensified at the edge of the footing and outby.

a)

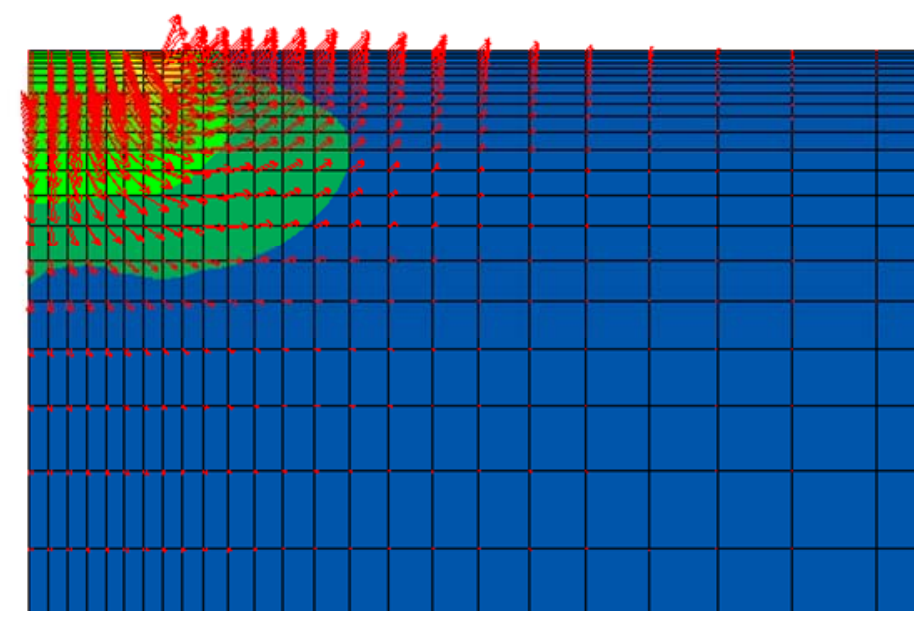

b)

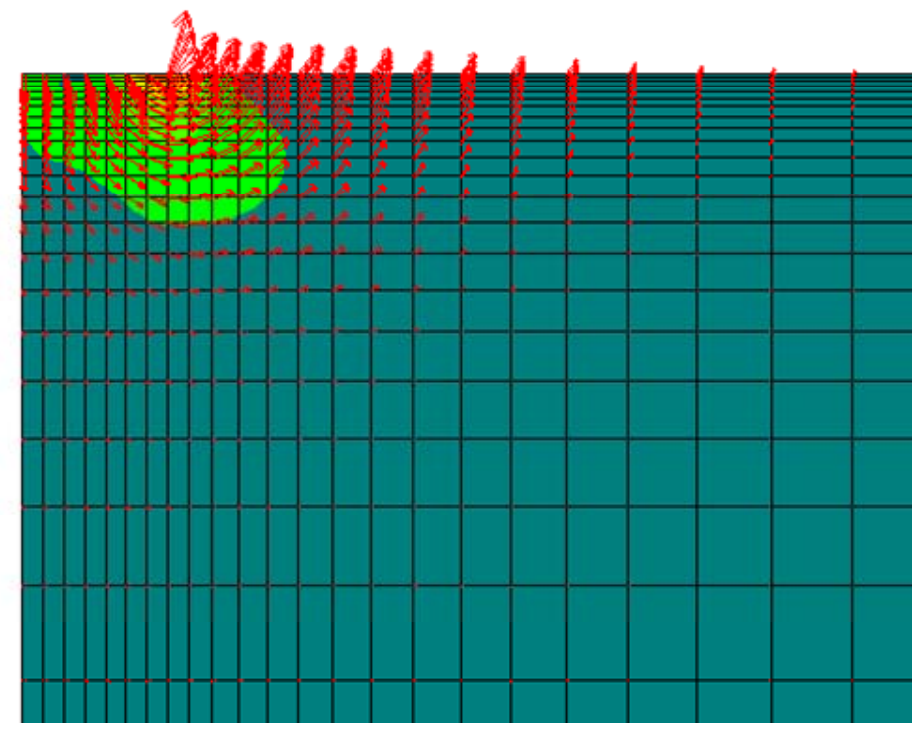

Figure 5.25. Contours of shear strain rate along with displacement vectors for the case of semi-infinite strip footing with a) $\psi=5^{\circ}$ and b) $\psi=20^{\circ}$. 


\subsection{Verification of the Vesic's Non-homogeneous Bearing Capacity Equation}

It has been noted in Chapter 4 that the Vesic's non-homogeneous soil bearing capacity solution given by equation (4.14) is by far the most popular method used in the Illinois Basin coal mines for floor stability analysis. Despite its widespread use very little is known about the finer details of its derivation to fully appreciate its merits and limitations. It is not even known whether the model provides accurate solution at least for the conditions for which it is supposed to apply. The numerical modeling methodology developed in the above sections will be used to address these issues.

Apparently, when all the desirable features of a model for coal mine application given in section 5.1 are considered along with the assumptions inherent in Vesic's derivation, it is clear that this solution can not represent the coal mine conditions well. Therefore, the only question that needs to be investigated is whether equation (4.14) is valid for the conditions for which it was derived. As mentioned in chapter 4, Vesic's model is valid only under the following conditions:

- a two-layered soil system,

- the angle of internal friction for both layers is zero,

- both layers by themselves are homogeneous,

- square, rectangular and strip footings,

- zero volume change in the post-failure state,

- no adjacent footings exist in close proximity,

- the Mohr-Coulomb yield criterion is valid.

When these limiting conditions are considered in conjunction with the bearing capacity problem illustrated in Figure 5.1, the only variables whose effect needs to be investigated for the Vesic's equation verification are,

- Immediate floor thickness,

- ratio of cohesion of the two floor layers, and

- the aspect ratio of the footing. 
Several models were run using the methodology developed in section 5.3 to study the effect of the three variables listed above on floor bearing capacity. The model results will be presented in a dimensionless form to make them independent of the model conditions.

In the Illinois Basin coal mines, in a majority of cases the pillar widths used fall between $35 \mathrm{ft}$ and $80 \mathrm{ft}$, rib-to-rib. Similarly, excluding barriers the pillar aspect ratios (length/width) rarely exceed 1.5. The widths of the opening employed vary from $18 \mathrm{ft}$ to $22 \mathrm{ft}$. As discussed in Chapter 2, the weak floor stratum associated with the major mineable coal seams has thickness ranging between $1 \mathrm{ft}$ and $6 \mathrm{ft}$. Given this geometric data, models run within the bounds of the following values will cover almost all the Illinois Basin coal mines,

$\begin{array}{lll}B / H & - & 100 \text { to } 5, \\ L / B & - & 1 \text { to } 2, \text { and } \\ C_{2} / c_{1} & - & 1 \text { to } 5 .\end{array}$

(B: pillar width; $L$ : pillar length; $H$ : weak floor thickness; $c_{1}$ : weak floor cohesion; $c_{2}$ : strong floor cohesion). Specifically, several 3-D numerical models were run for the following combinations of the variables to verify the accuracy of Vesic's model:

$\begin{array}{lll}B / H & - & 100,40,20,10,5 \\ B / L & - & 1,0.8,0.65,0.5 \\ C_{2} / c_{1} & - & 1,2,3,4,5 .\end{array}$

In the numerical models, a constant cohesion value equal to 150 psi was used for the weak floor with angle of internal friction set to zero for both floor beds. The cohesion value for the stronger floor was estimated based on the $c_{2} / c_{1}$ value used for that model. The entire floor was assumed to exhibit perfectlyplastic behavior satisfying the Mohr-Coulomb yield criterion. Similar to Vesic, the stronger bed was assumed to be semi-infinite in extent and thus has been extended to the bottom limit of each model. Smooth foundation was assumed in the simulation and the boundary conditions were similar to those in Section 5.3. An example mesh used for Vesic's equation verification is shown in Figure 5.26. 


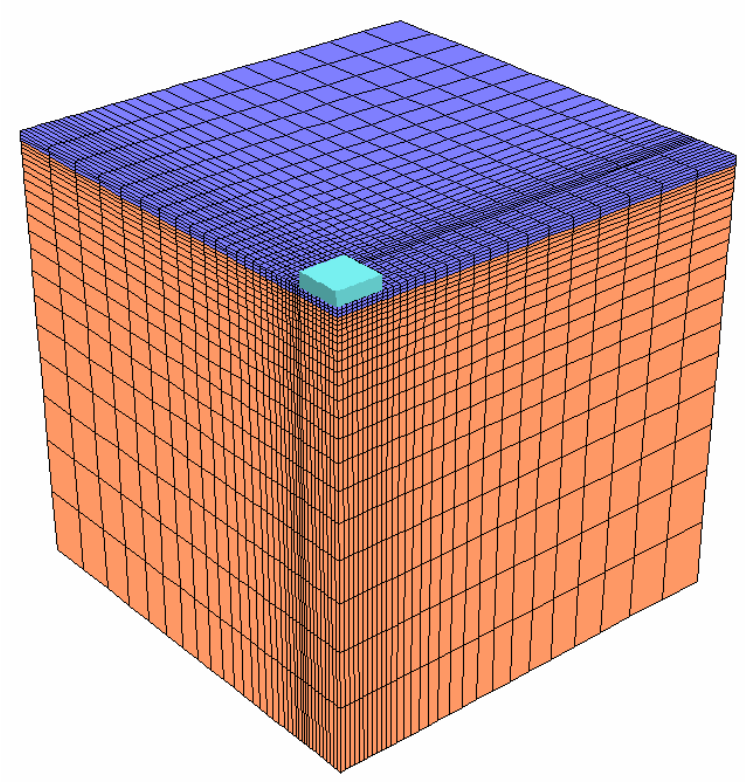

Figure 5.26. FLAC ${ }^{3 D}$ mesh used for Vesic equation verification for a square footing with $B / H=10$ and $c_{2} / c_{1}=3$ (also shown is the footing).

All the modeling results for the Vesic equation verification are summarized in Table 5.4 through Table 5.6. Some key results are also plotted in Figure 5.27 through Figure 5.30.

Table 5.4. Model results for different input variables and $B / H=100$.

\begin{tabular}{|r|r|r|c|c|}
\hline$B / H$ & \multicolumn{1}{|c|}{$B / L$} & $C_{2} / c_{1}$ & $N_{\text {m-model }}$ & $N_{\text {m-model }} / N_{\text {m-Vesic }}$ \\
\hline 100 & 0.5 & 1 & 5.37 & 0.95 \\
100 & 0.65 & 1 & 5.41 & 0.93 \\
100 & 0.8 & 1 & 5.45 & 0.91 \\
100 & 1 & 1 & 5.51 & 0.89 \\
100 & 0.5 & 2 & 10.29 & 1.00 \\
100 & 0.65 & 2 & 10.40 & 1.02 \\
100 & 0.8 & 2 & 10.46 & 1.03 \\
100 & 1 & 2 & 10.47 & 1.05 \\
100 & 0.5 & 3 & 14.93 & 1.15 \\
100 & 0.65 & 3 & 15.07 & 1.20 \\
100 & 0.8 & 3 & 15.13 & 1.23 \\
100 & 1 & 3 & 15.14 & 1.27 \\
100 & 0.5 & 4 & 19.29 & 1.33 \\
100 & 0.65 & 4 & 19.37 & 1.39 \\
100 & 0.8 & 4 & 19.43 & 1.44 \\
100 & 1 & 4 & 19.37 & 1.49 \\
100 & 0.5 & 5 & 23.56 & 1.53 \\
100 & 0.65 & 5 & 23.44 & 1.59 \\
100 & 0.8 & 5 & 23.34 & 1.64 \\
100 & 1 & 5 & 23.13 & 1.70 \\
\hline
\end{tabular}


Table 5.5. Model results for different input variables and $B / H=40,20$ and 10 .

\begin{tabular}{|c|c|c|c|c|}
\hline$B / H$ & $B / L$ & $c_{2} / c_{1}$ & $N_{m-\text { model }}$ & $N_{m \text {-model }} / N_{m \text {-Vesic }}$ \\
\hline 40 & 0.5 & 2 & 9.54 & 1.23 \\
\hline 40 & 0.65 & 2 & 9.79 & 1.27 \\
\hline 40 & 0.8 & 2 & 9.81 & 1.27 \\
\hline 40 & 1 & 2 & 9.79 & 1.27 \\
\hline 40 & 0.5 & 3 & 13.45 & 1.56 \\
\hline 40 & 0.65 & 3 & 13.49 & 1.59 \\
\hline 40 & 0.8 & 3 & 13.39 & 1.59 \\
\hline 40 & 1 & 3 & 13.29 & 1.59 \\
\hline 40 & 0.5 & 4 & 16.59 & 1.82 \\
\hline 40 & 0.65 & 4 & 16.28 & 1.83 \\
\hline 40 & 0.8 & 4 & 16.12 & 1.84 \\
\hline 40 & 1 & 4 & 15.74 & 1.82 \\
\hline 40 & 0.5 & 5 & 18.81 & 2.00 \\
\hline 40 & 0.65 & 5 & 18.28 & 1.99 \\
\hline 40 & 0.8 & 5 & 17.83 & 1.98 \\
\hline 40 & 1 & 5 & 17.01 & 1.92 \\
\hline 20 & 0.5 & 2 & 8.63 & 1.31 \\
\hline 20 & 0.65 & 2 & 8.69 & 1.31 \\
\hline 20 & 0.8 & 2 & 8.61 & 1.29 \\
\hline 20 & 1 & 2 & 8.47 & 1.25 \\
\hline 20 & 0.5 & 3 & 9.85 & 1.42 \\
\hline 20 & 0.65 & 3 & 9.54 & 1.38 \\
\hline 20 & 0.8 & 3 & 9.21 & 1.32 \\
\hline 20 & 1 & 3 & 8.76 & 1.25 \\
\hline 20 & 0.5 & 4 & 9.86 & 1.39 \\
\hline 20 & 0.65 & 4 & 9.55 & 1.35 \\
\hline 20 & 0.8 & 4 & 9.22 & 1.30 \\
\hline 20 & 1 & 4 & 8.77 & 1.23 \\
\hline 20 & 0.5 & 5 & 9.90 & 1.37 \\
\hline 20 & 0.65 & 5 & 9.57 & 1.33 \\
\hline 20 & 0.8 & 5 & 9.22 & 1.29 \\
\hline 20 & 1 & 5 & 8.77 & 1.22 \\
\hline 10 & 0.5 & 2 & 6.84 & 1.15 \\
\hline 10 & 0.65 & 2 & 6.73 & 1.12 \\
\hline 10 & 0.8 & 2 & 6.61 & 1.08 \\
\hline 10 & 1 & 2 & 6.45 & 1.03 \\
\hline 10 & 0.5 & 3 & 6.85 & 1.14 \\
\hline 10 & 0.65 & 3 & 6.73 & 1.10 \\
\hline 10 & 0.8 & 3 & 6.61 & 1.07 \\
\hline 10 & 1 & 3 & 6.45 & 1.02 \\
\hline 10 & 0.5 & 4 & 6.85 & 1.13 \\
\hline 10 & 0.65 & 4 & 6.73 & 1.10 \\
\hline 10 & 0.8 & 4 & 6.61 & 1.07 \\
\hline 10 & 1 & 4 & 6.45 & 1.02 \\
\hline 10 & 0.5 & 5 & 6.85 & 1.12 \\
\hline 10 & 0.65 & 5 & 6.73 & 1.09 \\
\hline 10 & 0.8 & 5 & 6.61 & 1.06 \\
\hline 10 & 1 & 5 & 6.45 & 1.02 \\
\hline
\end{tabular}


Table 5.6. Model results for different input variables and $B / H=5$.

\begin{tabular}{|r|r|c|c|c|}
\hline B/H & \multicolumn{1}{|c|}{$B / L$} & $c_{2} / c_{1}$ & $N_{\text {m-model }}$ & $N_{\text {m-model }} / N_{\text {m-Vesic }}$ \\
\hline 5 & 1 & 1 & 5.38 & 0.87 \\
5 & 0.8 & 1 & 5.35 & 0.90 \\
5 & 0.65 & 1 & 5.30 & 0.91 \\
5 & 1 & 2 & 5.60 & 0.93 \\
5 & 0.8 & 2 & 5.63 & 0.97 \\
5 & 0.5 & 2 & 5.65 & 1.01 \\
5 & 0.65 & 2 & 5.66 & 0.99 \\
5 & 1 & 3 & 5.60 & 0.94 \\
5 & 0.8 & 3 & 5.63 & 0.97 \\
5 & 0.5 & 3 & 5.66 & 1.02 \\
5 & 0.65 & 3 & 5.66 & 1.00 \\
5 & 1 & 4 & 5.60 & 0.94 \\
5 & 0.8 & 4 & 5.64 & 0.98 \\
5 & 0.5 & 4 & 5.67 & 1.02 \\
5 & 0.65 & 4 & 5.66 & 1.00 \\
5 & 1 & 5 & 5.60 & 0.95 \\
5 & 0.8 & 5 & 5.64 & 0.98 \\
5 & 0.5 & 5 & 5.67 & 1.02 \\
5 & 0.65 & 5 & 5.66 & 1.00 \\
\hline
\end{tabular}

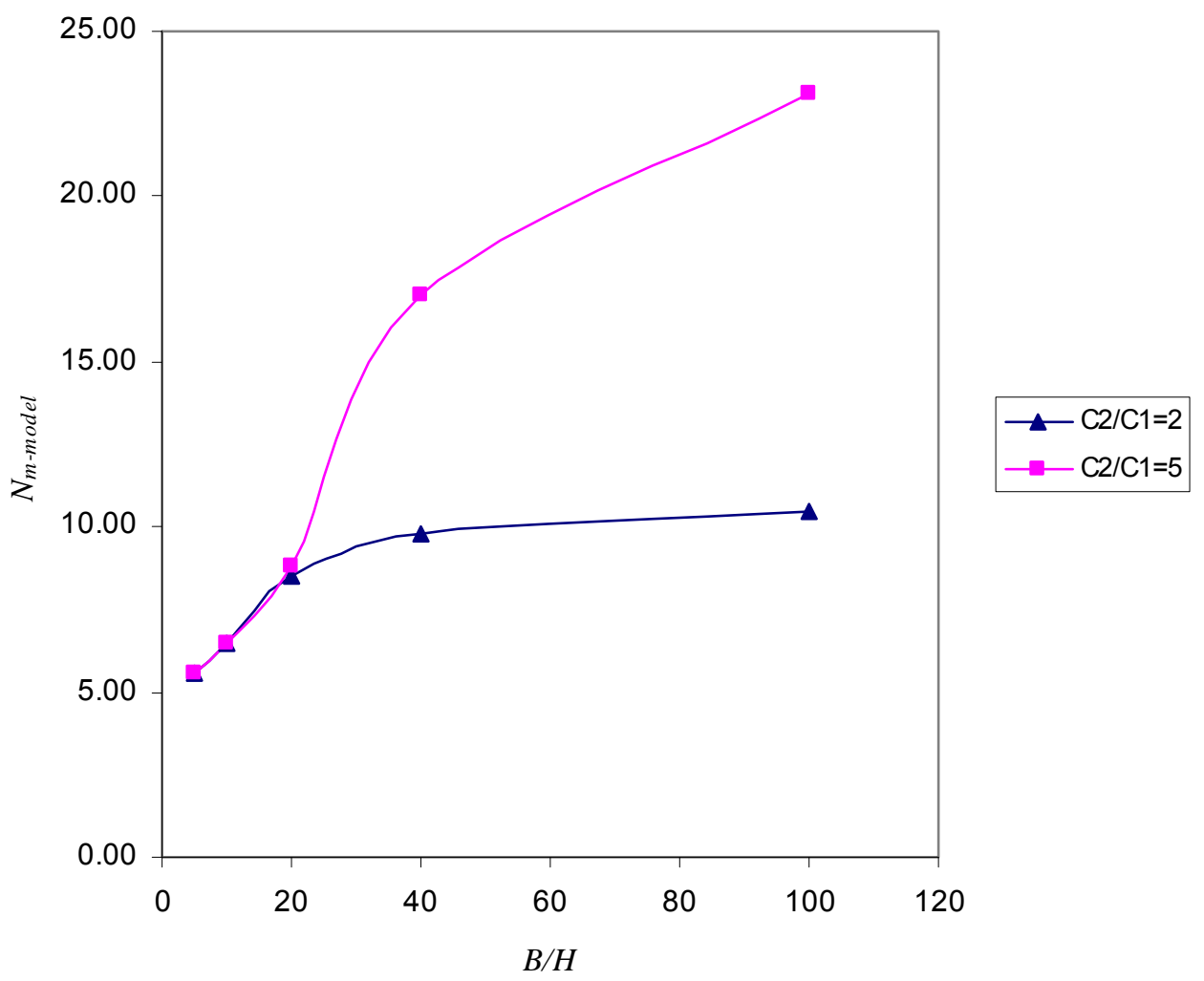

Figure 5.27. Change in model bearing capacity factor with $B / H$ for a square footing. 


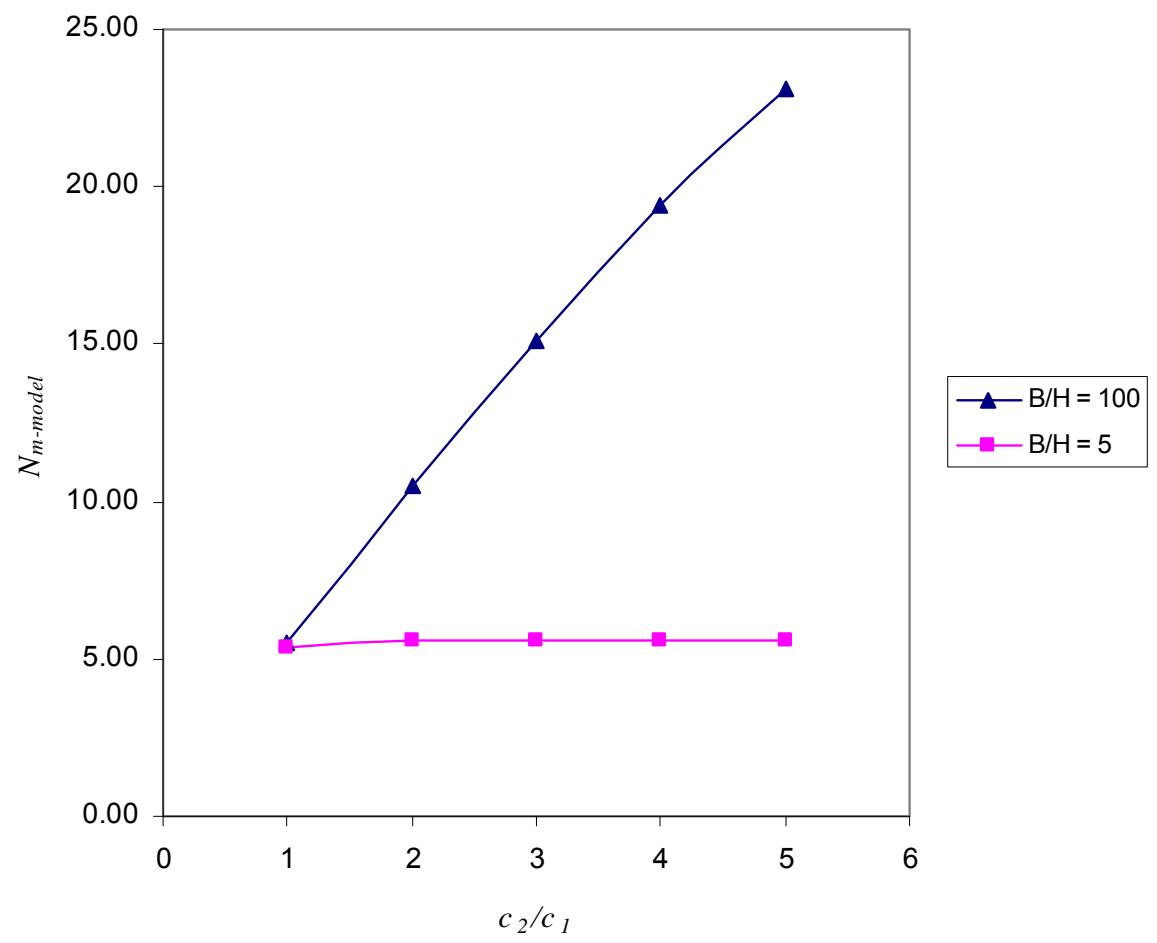

Figure 5.28. Change in model bearing capacity factor with $c_{2} / c_{1}$ for a square footing.

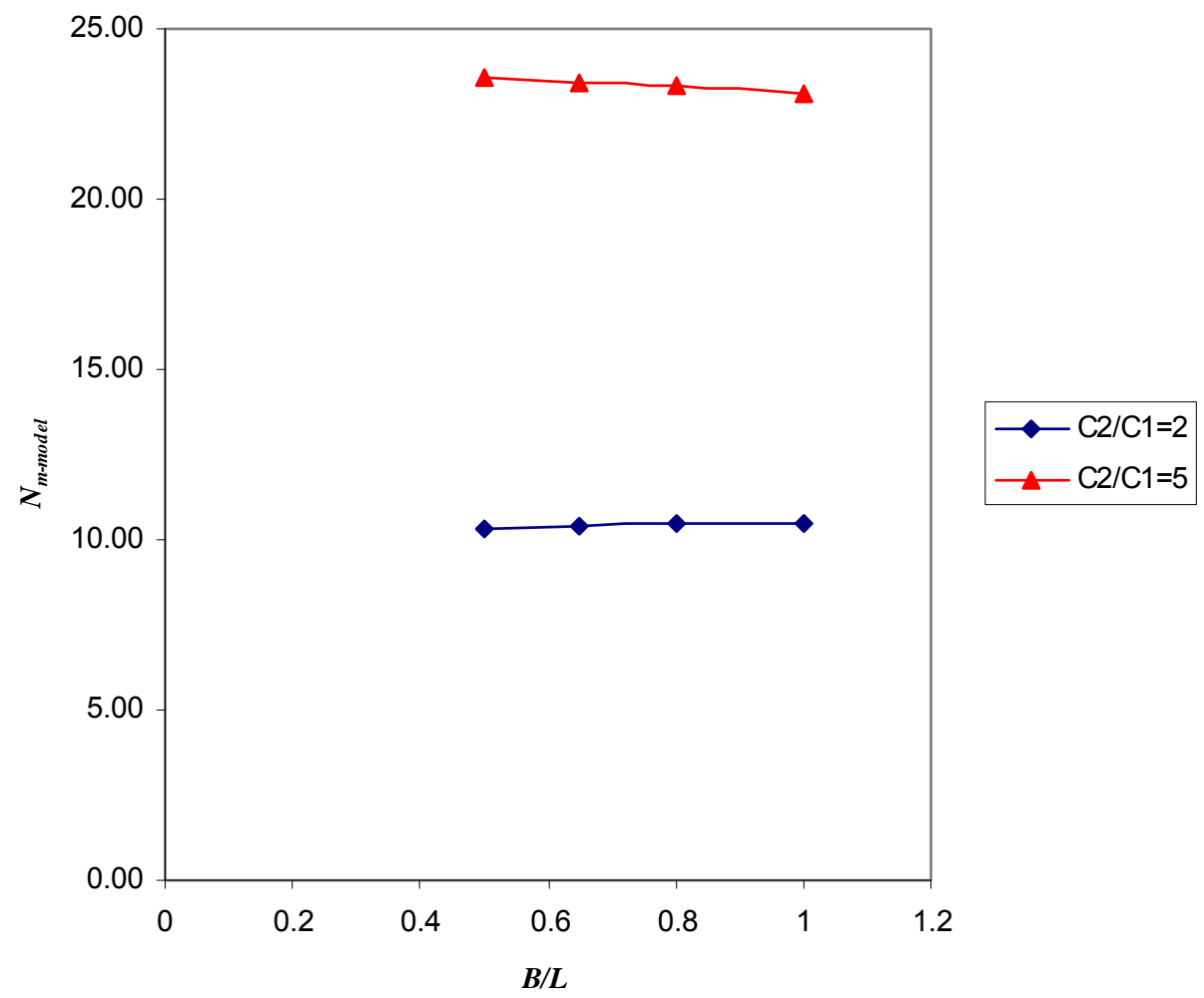

Figure 5.29. Change in model bearing capacity factor with $B / L$ for $B / H=100$. 


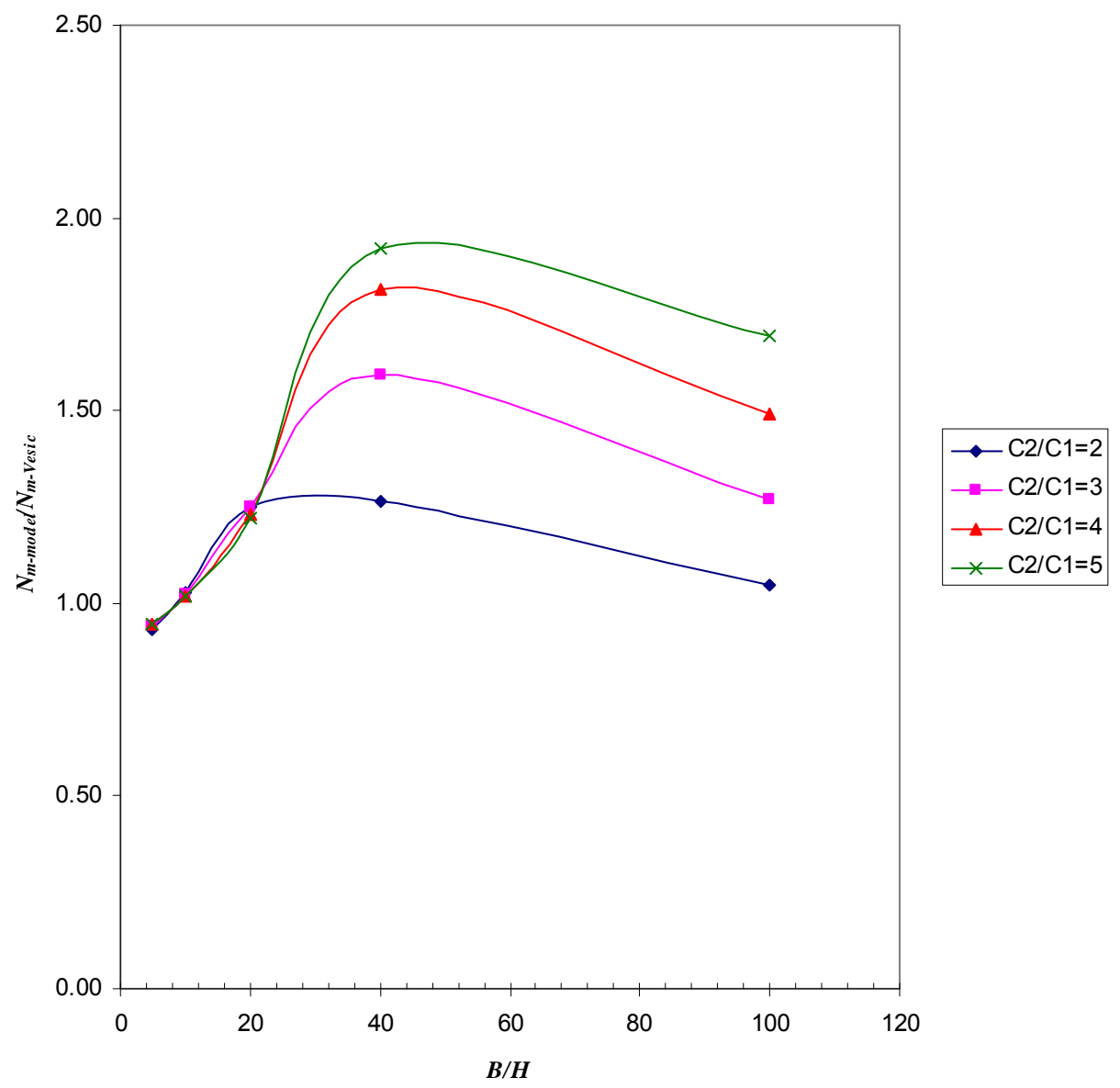

Figure 5.30. Change in the ratio of model- to Vesic bearing capacity factors as a function of $\mathrm{B} / \mathrm{H}$ for a square footing.

From the above model estimates of the bearing capacity factor, $N_{m \text {-model }}$, the following conclusions can be drawn about the performance of the Vesic's bearing capacity equation:

o overall, the Vesic's non-homogeneous soil model given by equation (4.14) underestimates the bearing capacity of the floor. The underestimation depends on several factors and could be negligible to significant;

0 bearing capacity increases with increasing $B / H$ ratio. However, the rate and trend of increase depends on $c_{2} / c_{1}$ and $B / L$ ratios;

0 bearing capacity increases with increasing $c_{2} / c_{1}$ ratio and the amount of increase depends on $B / H$ and $B / L$ ratios; 
o the effect of pillar aspect ratio $(L / B)$ is negligible on the computed floor strength. The change in the bearing capacity for different $B / L$ values depends on $c_{2} / c_{1}$ and $B / H$ ratios;

o as the thickness of the floor increases for a constant pillar width, at some point, the presence of stronger bed below will not have much effect on the bearing capacity. From the model results, it appears that if the $B / H$ ratio is less than 5 , then the effect of stronger bed could be ignored;

o finally, as seen from figure 5.30, the most significant finding of the modeling exercise is that the underestimation of bearing capacity by the Vesic's equation was different for different $B / H$ values even when the $c_{2} / c_{1}$ and $B / L$ ratios were held constant. The models showed that the error in the Vesic's estimation increased continuously with $\mathrm{B} / \mathrm{H}$ up to a value of about 40 after which it fell with further increase in $B / H$. These results also showed that if the $B / H$ value was less than about 20 , then the bearing capacity computed by the Vesic's equation had negligible error and was acceptable for all practical purposes. The trends in Figure 5.30 were due to the different rates of increase in bearing capacity predicted by the numerical and Vesic's models with increasing $B / H$. This difference could be clearly seen in Figure 5.31.

Based on the foregoing discussions in this section, it can be concluded that the Vesic's bearing capacity solution underestimates the floor strength in a majority of practical situations in the Illinois Basin coal mines. The underestimation depends on the values of $B / H, c_{2} / c_{1}$ and $B / L$ values and could be as high as $200 \%$. It must be reminded that the Vesic's solution does not consider several other factors discussed in section 5.4, which can have significant positive impact on the floor strength. Therefore, for a typical Illinois Basin coal mine, when all the factors listed in section 5.1 are considered, it is safe to conclude that the use of the Vesic's equation results in an ultra conservative estimate of the floor strength. This poor performance of Vesic's 
equation need not disqualify it as a design tool, however. As mentioned in Chapter 4, the Vesic's model has been used in the Illinois Basin for well over two decades and thus a good amount of practical experience is available with its application.

a)

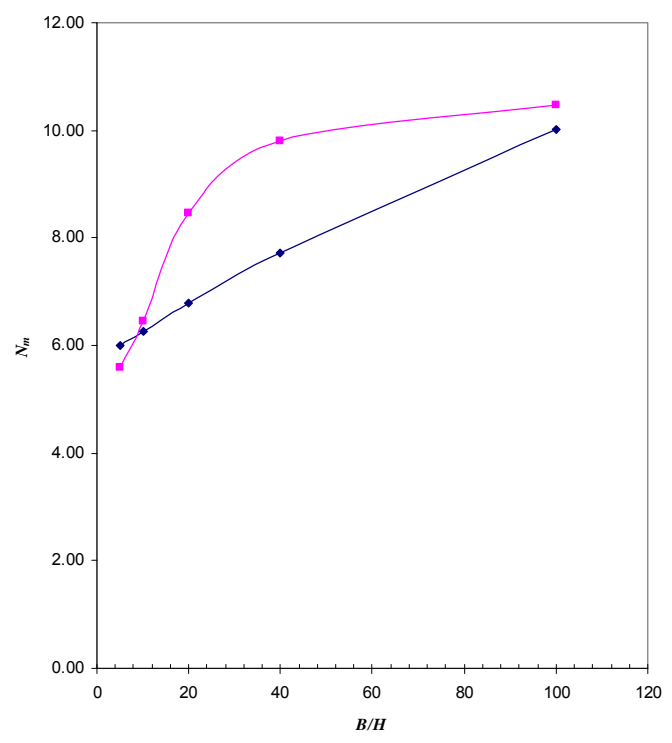

b)

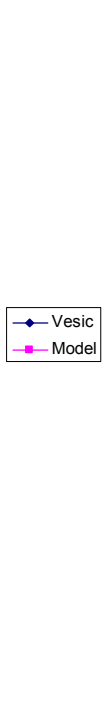

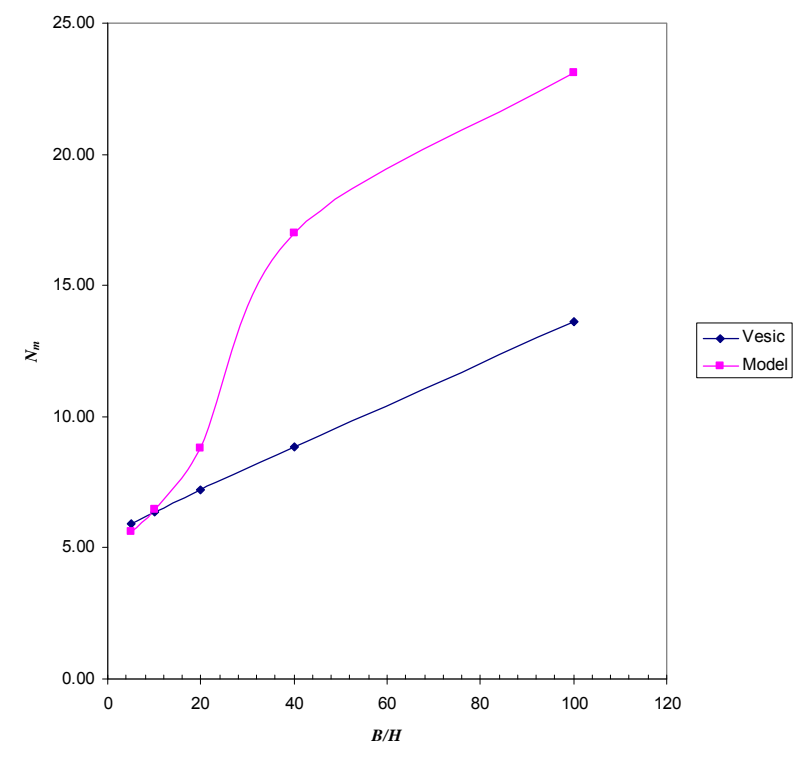

Figure 5.31. Increasing in bearing capacity factor, $N_{m}$ with $\mathrm{B} / \mathrm{H}$ for a square footing when a) $c_{2} / c_{1}=2$, b) $c_{2} / c_{1}=5$.

It may be argued that from a long-term subsidence prevention view point, even twenty-five plus years of application is still too short to conclude that the current design standards based on the Vesic's equation are adequate. However, such an argument could be countered by the fact that no other design equation had been used that long in the Basin and mines that have designed pillars based on the Vesic's equation have not reported surface subsidence as frequently as the mines that were active before 1980. This is not to say no subsidence events occurred at mines that employed the Vesic's equation. But, in those infrequent instabilities, within the knowledge of this author, some unusual conditions were encountered like accumulation of large amount of water, unknown thick underclay etc. In reality, the errors in the Vesic's equation pale when compared to the inaccuracies in determining the necessary inputs needed for the analysis. Further, even if the basic model is flawed, given enough time for the practical 
application, satisfactory design could be accomplished by choosing appropriate design safety factors that make up for the deficiencies in the chosen model.

Despite the fact that there is no written standard available, currently in the Illinois Basin coal mine when floor bearing capacity is computed using the VesicSpeck approach, coal pillars are sized for a design stability factor between 1.3 and 1.5. At the first look, these stability factor values might appear small for the long-term floor stability. In the foundation engineering practice, higher safety factors in the range of 3.0 are recommended for the long term stability of footings. When compared to the later, the coal mine floor stability factors look unconservative. Yet, very few Illinois Basin coal mines that employed the VesicSpeck approach have experienced surface subsidence even twenty plus years after the mining was completed. This seemingly contradictory performance of the Vesic-Speck approach is due to the fact that the Vesic's bearing capacity model significantly underestimates the floor strength when all the feature of a typical coal mine are considered. Therefore, what appears to be a 1.3 or 1.5 stability factor by design, can in reality be as high as 2.0 or 5.0 depending on the site specific conditions.

Based on the numerical modeling results discussed in this section and the obvious underestimation of bearing capacity by the Vesic's equation and for the reasons discussed in Chapter 4, it can be concluded that the Vesic-Gadde approach could be used in conjunction with the recommended stability factors with confidence. If higher confidence in the design is necessary, then the numerical modeling methodology developed here could be used with the input properties determined from different equations discussed in chapters 2 and 3 or by actual testing.

\subsection{Non-uniform pillar stress distribution}

In all the traditional bearing capacity theories, the vertical load on the footing was assumed to be uniformly distributed. But, in underground coal mines, it is known that the vertical stress over a pillar is highly nonlinear. Although some authors (Chugh and Pytel, 1992) have recognized this issue before, no study has 
ever been done on the effect of non-uniform stress distributions on the computed bearing capacity. The numerical modeling methodology developed here offers an opportunity to study this aspect of the bearing capacity problem.

When a realistic coal mine geometry is considered, in addition to the nonuniform stress distribution over the coal pillar, some horizontal pre-mining stresses also exist in the floor. For the 'soft' underclay material, the magnitude of the horizontal stresses may not be very high. Nevertheless, some non-zero horizontal stresses exist in the floor. In order to account for all these effects, an actual case of a coal mine with weak immediate floor has been chosen. For the sake of simplicity, only two dimensional modeling has been conducted here. The geometry near the coal seam employed in the model is shown in Figure 5.32. The model contains an $18 \mathrm{ft}$ wide entry and $52 \mathrm{ft}$ wide pillar resting on a $7 \mathrm{ft}$ thick weak claystone floor.

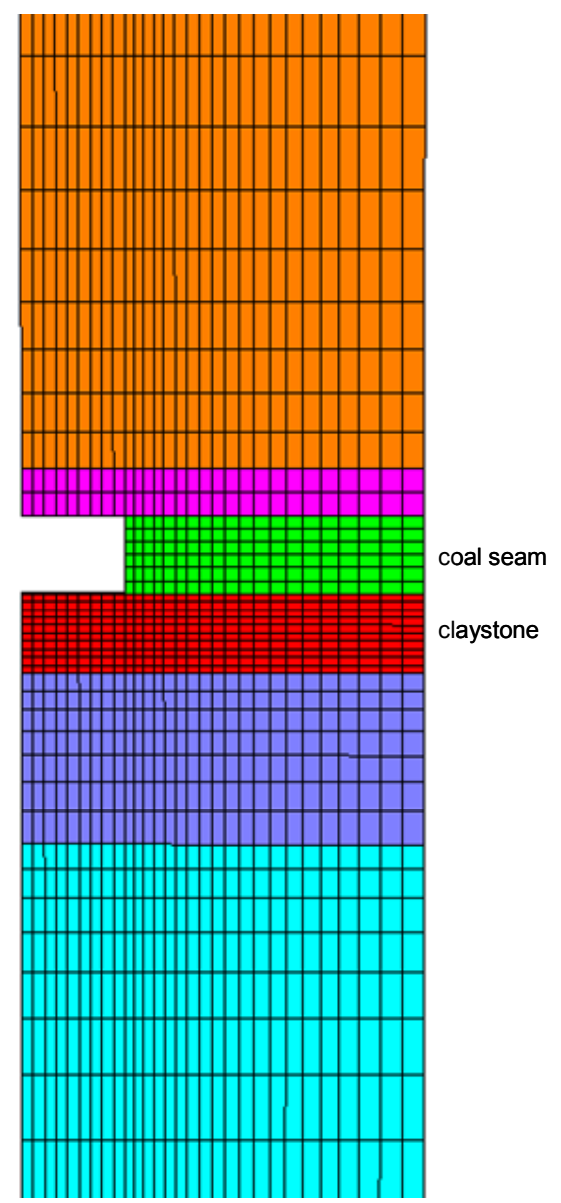

Figure 5.32. Part of the modeled geometry to study the non-uniform vertical stress distribution effect on bearing capacity. 
In the above model, the claystone floor has been assumed to behave in a perfectly plastic manner satisfying the Mohr-Coulomb yield criterion. An arbitrarily chosen cohesion and friction angle values equal to 300 psi and $20^{\circ}$, respectively were assigned to the claystone floor. The rest of the model was assigned elastic properties. After the initial model was solved to incorporate the Poisson's ratio based horizontal stresses in the model, the mine opening was created and the model was solved again to equilibrium. At this stage, the top boundary of the model was subjected to displacement controlled loading until the floor material completely reached its limit state. The resultant of the vertical stress on the first layer of floor below the pillar was monitored continuously as the model was being solved using a FISH function. The result of the simulation is plotted in Figure 5.33 where the average vertical stress on the floor below the coal pillar is plotted against the number of model steps.

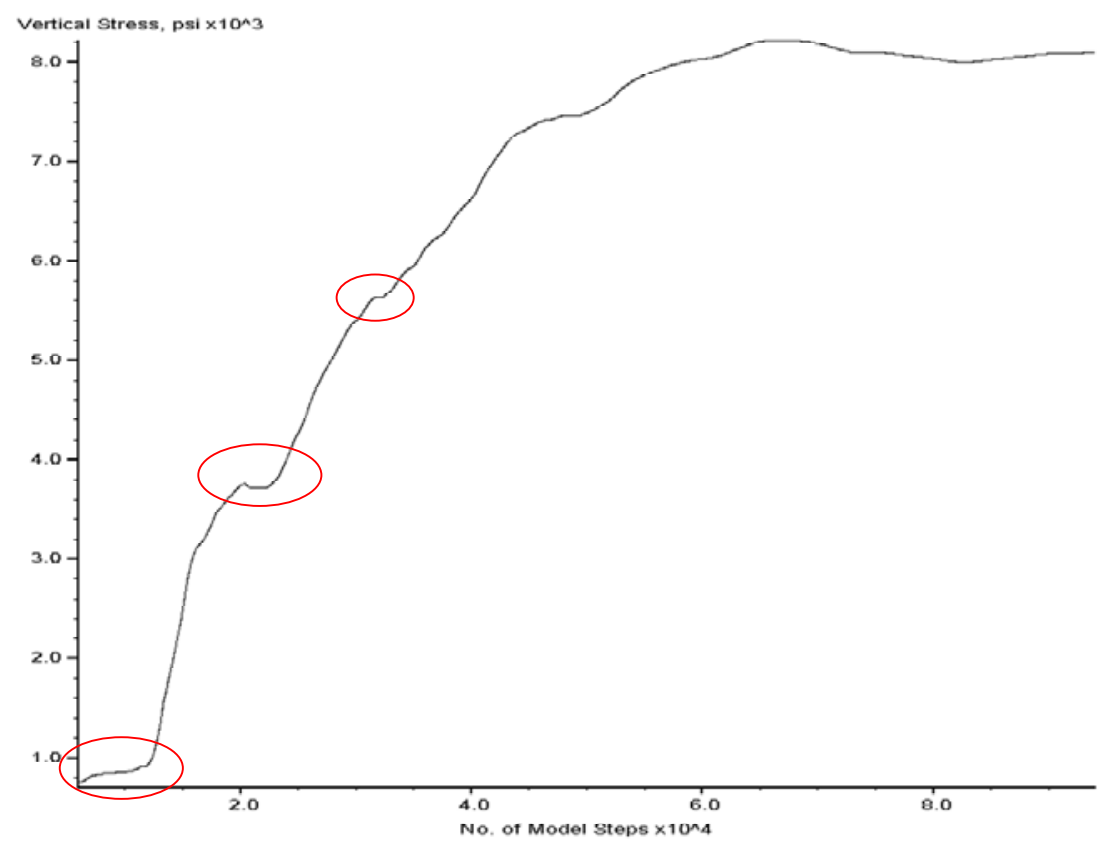

Figure 5.33. The variation of resultant vertical stress on floor for a non-uniform pillar stress distribution.

Similarly, to simulate the situation of a rigid plate loading on the floor, in a different model, the entire cover above the coal pillar was removed as shown in Figure 5.34 and the displacement loading was applied over the top of coal pillar. 
This later model was not solved for equilibrium before commencing the displacement loading. The vertical stress variation on the floor for this loading situation is plotted in Figure 5.35 .

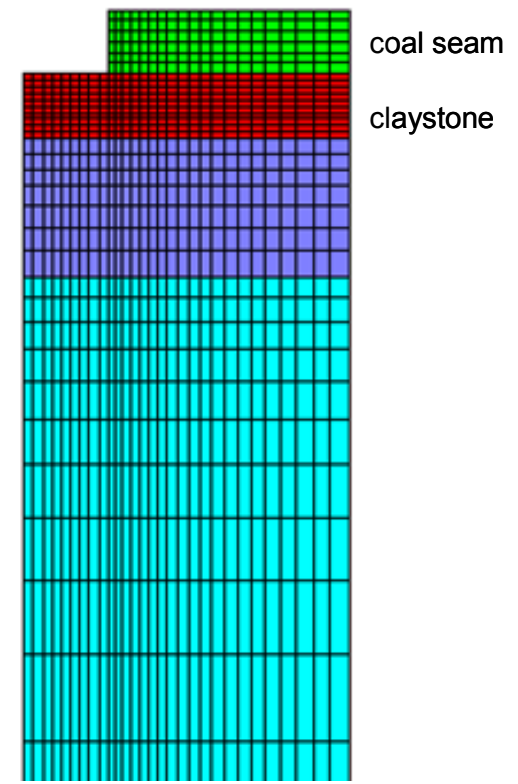

Figure 5.34. Part of the modeled geometry to study the uniform loading effect on bearing capacity.

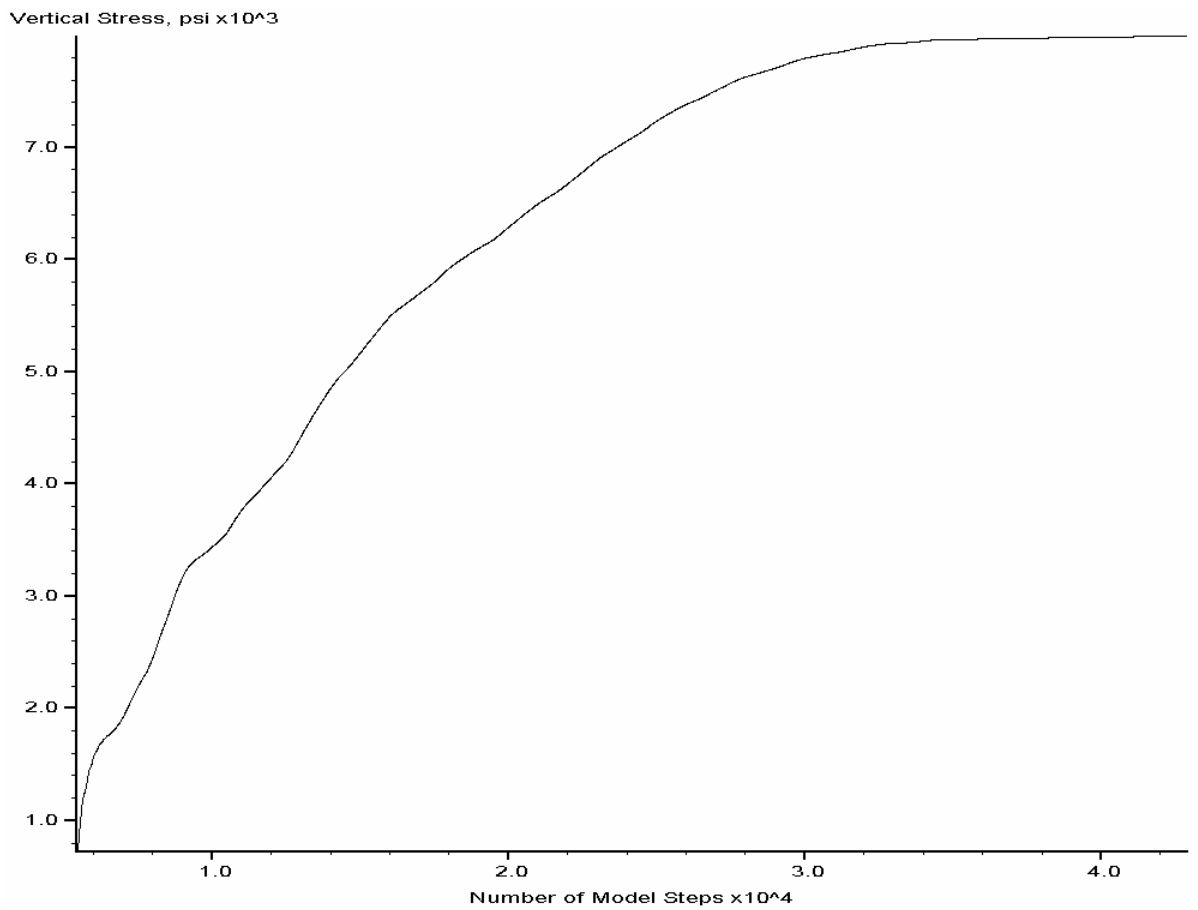

Figure 5.35. The variation of resultant vertical stress on floor for the uniform vertical displacement induced loading. 
The modeling results showed that the limit stress value for the nonuniform pillar loading case was $828 \mathrm{psi}$ and that for the rigid plate condition was $800 \mathrm{psi}$ for the assumed inputs. Therefore, consideration of the realistic vertical stress distribution on the coal pillar did not alter the ultimate bearing capacity by no more than about $3 \%$. The slightly higher bearing capacity in the non-uniform load case was due the existence of small horizontal stresses in the floor as compared to the model in Figure 5.34 where no horizontal stresses were applied. At the limit state, the extent of yielding and the shear strain rate distribution also looked similar in both cases. There is one major difference, however. As shown by the red ellipses in Figure 5.33, for the case of non-uniform stress distribution, several localized floor failures occurred before reaching the limit state. For this case, it was found that when additional loads were induced in the coal pillar by the uniform displacement loading, in areas close to the pillar rib where the highest vertical stress was acting before, the floor failure commenced. As the floor below the rib failed, the vertical stress was transferred deeper into the coal pillar thus establishing another stress concentration zone. With further displacement loading, progressively deeper portions of the floor reached limit states in a rather abrupt fashion resulting in the stair-stepped stress variation shown in Figure 5.33. Such stress variation, however, appears to not have altered the ultimate bearing capacity of the floor.

It must be reminded here that under a rigid plate or when uniform displacement loading is applied to the floor, the vertical stress on the floor is nonuniformly distributed as shown in Figure 3.14. Therefore, progressive failure of floor occurs even without mining induced vertical stresses when the loading is applied through uniform vertical displacement. However, when mining induced vertical stress acts on the pillar, the extent of non-uniformity becomes much larger. Besides, applying the uniform vertical displacement at the top of the deformable coal pillar reduces the amount of non-uniformity in vertical stress distribution as opposed to a rigid plate situation.

The localized floor failures due to the non-uniform vertical stress explain the practical observation that every floor instability seen underground similar to 
that in Figure 5.36 does not lead to surface subsidence. Under the influence of non-uniform vertical pillar stress, areas close to the pillar rib could experience localized floor failure resulting in heave in the adjacent mine opening while the larger portion of the pillar itself has stable floor. Detailed in-situ investigations by Vasundhara et al., (2001) in Australia prove the validity of this conclusion. Therefore, from a subsidence prevention point of view, it is the limit state that matters not the localized floor instabilities such as those in Figure 5.36. This observation indicates that when collecting data to develop design guidelines for surface subsidence prevention, localized underground instabilities should not be considered unless there is evidence that the floor failures led to surface movements.

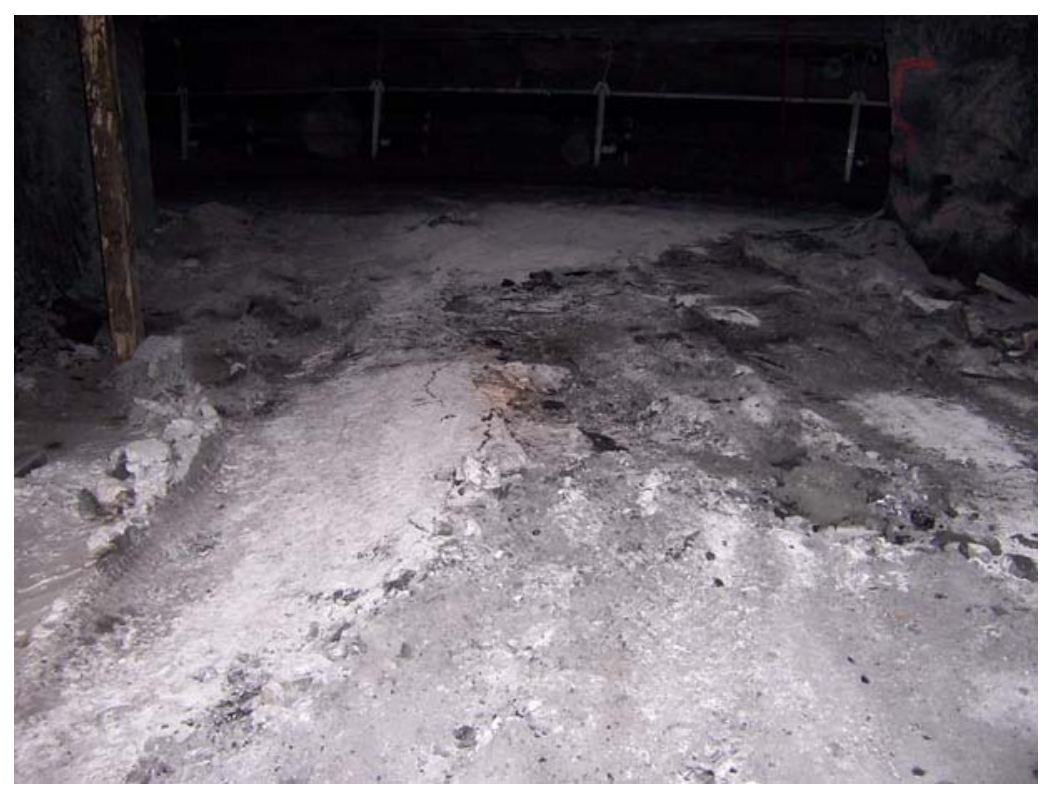

Figure 5.36. Localized floor instability noticed in an Illinois Basin coal mine.

Although very limited study was done, the preliminary results given here show that when computing the ultimate bearing capacity, the difference between the uniform displacement loading and non-uniform stress distribution is negligible. The nature of stress distribution seems to affect only the path traversed to reach the limit state but not the limit value itself. Therefore, the results obtained under uniform displacement loading could perhaps be used for pillar design without incurring significant errors in the computed bearing capacity. 


\subsection{Pillar Spacing Effect}

In every coal mine, multiple pillars exist in close proximity and thus the influence of interference effects on floor bearing capacity can not be ignored. The preliminary modeling results given in section 5.4 .5 clearly showed the positive effect of footing interactions on the bearing capacity. The results in section 5.4.5, however, apply only to the case of multiple strip footings resting on a homogeneous semi-infinite floor. Therefore, models that represent coal mine conditions are necessary to fully appreciate the interference effects of multiple pillars. Since a detailed study of the pillar interference for a range of possible situations in underground coal mines is beyond the scope of this dissertation, in this section, an attempt has been made to estimate the limits of bearing capacity change when extreme values for the model inputs are assumed. Such a study will show the maximum possible influence of the presence of multiple pillars on the computed floor bearing capacity for typical Illinois Basin coal mine conditions. The modeling results will also provide an idea on the possible limits to the errors that can occur by ignoring the pillar interference effect in the Vesic's equation.

When the range of geometric conditions encountered in a majority of coal mines in the Illinois Basin are considered, the following extremes for different model inputs will include most of the mines:

$\begin{array}{lll}\text { geometry } & - & \text { strip, square } \\ B / H & - & 40,4 \\ s / B & - & 0.2,0.66 \\ c_{2} / c_{1} & - & 2,5 \\ \phi_{1}, \phi_{2} & - & 0^{\circ}, 35^{\circ}\end{array}$

For all the models, symmetry conditions were exploited to simulate the effect of the presence of multiple pillars. Similarly, using $1 \mathrm{ft}$ wide pillars on the surface of the floor will ensure only the first term in equation (4.5) is included in the analysis. The floor materials were assumed to behave in a perfectly-plastic manner satisfying the Mohr-Coulomb yield criterion. Each layer of floor by itself was assumed to be homogeneous and isotropic. Uniform loading was applied through displacements at the top of the floor over the region represented by the 
pillar. The floor contact conditions were assumed to be smooth. Typical meshes used for one case each of strip and square pillar are shown in Figure 5.37. The model results are presented in Tables 5.7 and 5.8 for the square and strip footing cases, respectively. The influence of multiple pillar interaction is assessed by two different values in these tables: the ratio of model strengths computed with and without the presence of multiple pillars; and the ratio of model strength with multiple pillars to the corresponding strength predicted by the Vesic's equation. The first ratio will show the exact extent of the interaction effect while the later indicates the error in the Vesic's estimate when the effect of adjacent pillars is ignored.

a)

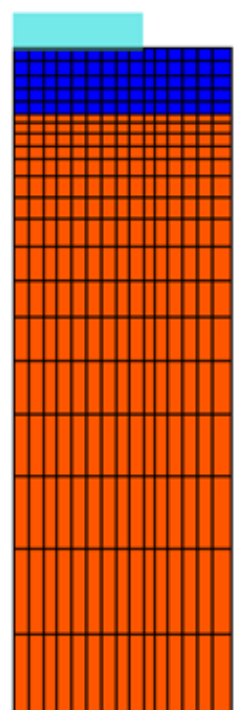

b)

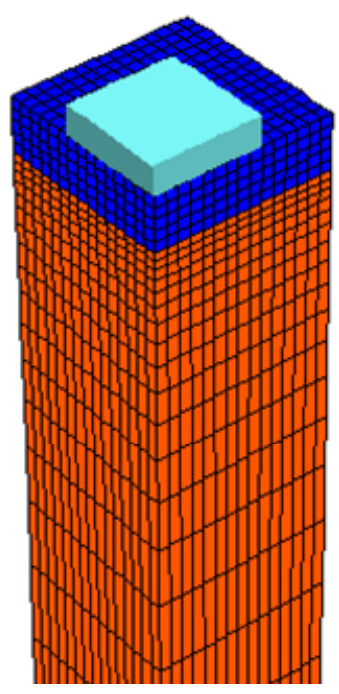

Figure 5.37. Typical meshes used for the simulation of adjacent pillar effect for a) strip and b) square pillars.

While the numerical values are different, qualitatively, the results in Tables 5.7 and 5.8 support the findings from the classical theories given in Chapter 4 . The major conclusions from the models can be summarized as:

- when the friction angle of both floor layers is zero, the interaction effect of adjacent pillars is negligible;

- irrespective of the $B / H$ value if the top layer is frictionless, even when the stronger layer has non-zero friction angle value, there is a negligible interaction effect; 
- when the friction angle of the weak floor layer is zero and the ratio of $B / H$ is small, there is not only a negligible influence of the adjacent pillar but also the Vesic's equation provides a reasonable estimate of the bearing capacity;

Table 5.7. Effect of interference of multiple square footings in close proximity.

\begin{tabular}{|c|c|c|c|c|c|c|}
\hline$\phi_{1}$ & $\phi_{2}$ & $c_{2} / c_{1}$ & $\mathrm{~B} / \mathrm{H}$ & $s / B$ & $\begin{array}{c}\text { Ratio Model } \\
\text { strength with } \\
\text { and without } \\
\text { adjacent pillars }\end{array}$ & $\begin{array}{l}\text { Ratio Model } \\
\text { strength with } \\
\text { adjacent pillars } \\
\text { and Vesic's } \\
\text { estimate }\end{array}$ \\
\hline 0 & 0 & 2 & 40 & 0.66 & 1.00 & 1.23 \\
\hline 0 & 0 & 2 & 40 & 0.20 & 1.05 & 1.28 \\
\hline 0 & 35 & 2 & 40 & 0.66 & 0.98 & 1.73 \\
\hline 0 & 35 & 2 & 40 & 0.20 & 1.03 & 1.81 \\
\hline 35 & 35 & 2 & 40 & 0.66 & 1.22 & 21.06 \\
\hline 35 & 35 & 2 & 40 & 0.20 & $>4.25$ & \\
\hline 0 & 0 & 2 & 4 & 0.66 & 1.00 & 0.91 \\
\hline 0 & 0 & 2 & 4 & 0.20 & 1.05 & 0.95 \\
\hline 0 & 35 & 2 & 4 & 0.66 & 1.00 & 0.91 \\
\hline 0 & 35 & 2 & 4 & 0.20 & 1.05 & 0.95 \\
\hline 35 & 35 & 2 & 4 & 0.66 & 1.05 & 17.20 \\
\hline 35 & 35 & 2 & 4 & 0.20 & $>3.4$ & \\
\hline 0 & 0 & 5 & 40 & 0.66 & 1.00 & 1.51 \\
\hline 0 & 0 & 5 & 40 & 0.20 & 1.03 & 1.56 \\
\hline 0 & 35 & 5 & 40 & 0.66 & 0.98 & 1.51 \\
\hline 0 & 35 & 5 & 40 & 0.20 & 0.99 & 1.52 \\
\hline 35 & 35 & 5 & 40 & 0.66 & 1.31 & 43.88 \\
\hline 35 & 35 & 5 & 40 & 0.20 & $>2.6$ & \\
\hline 0 & 0 & 5 & 4 & 0.66 & 1.00 & 0.93 \\
\hline 0 & 0 & 5 & 4 & 0.20 & 1.05 & 0.98 \\
\hline 0 & 35 & 5 & 4 & 0.66 & 1.00 & 0.93 \\
\hline 0 & 35 & 5 & 4 & 0.20 & 1.04 & 0.98 \\
\hline 35 & 35 & 5 & 4 & 0.66 & 0.94 & 21.90 \\
\hline 35 & 35 & 5 & 4 & 0.20 & $>2$ & \\
\hline
\end{tabular}

- interaction of adjacent pillars will influence the bearing capacity only if the immediate floor has non-zero angle of internal friction. When both layers have $\phi=35^{\circ}$ and $s / B=0.2$, the models did not reach limit state even after solving for more than half a million to a million model steps. The ratio values shown for these strength values in Tables 5.7 and 5.8 are based on the average floor stress obtained when the solution was terminated. 
Therefore, if both layers of the floor have higher non-zero friction values, then such conditions result in virtually indestructible floor and the pillar design may depend on the coal strength rather than the floor's;

- if the floor materials are frictional and cohesive, then the Vesic's equation severely underestimates the floor strength;

- in almost every case studied, the effect of adjacent pillars on bearing capacity is higher for strip pillars than for the square pillars. Therefore, rectangular pillars will gain more from their neighbors than square pillars of same width.

Table 5.8. Effect of interference of multiple strip footings in close proximity.

\begin{tabular}{|c|c|c|c|c|c|c|}
\hline$\phi_{1}$ & $\phi_{2}$ & $c_{2} / c_{1}$ & $B / H$ & $s / B$ & $\begin{array}{l}\text { Ratio of Model } \\
\text { strength with } \\
\text { and without } \\
\text { adjacent pillars }\end{array}$ & $\begin{array}{l}\text { Ratio of Model } \\
\text { strength with } \\
\text { adjacent pillars } \\
\text { and Vesic's } \\
\text { estimate }\end{array}$ \\
\hline 0 & 0 & 2 & 40 & 0.66 & 1.02 & 1.20 \\
\hline 0 & 0 & 2 & 40 & 0.20 & 1.18 & 1.40 \\
\hline 0 & 35 & 2 & 40 & 0.66 & 1.01 & 2.33 \\
\hline 0 & 35 & 2 & 40 & 0.20 & 1.01 & 2.31 \\
\hline 35 & 35 & 2 & 40 & 0.66 & 2.60 & 27.99 \\
\hline 35 & 35 & 2 & 40 & 0.20 & $>8$ & \\
\hline 0 & 0 & 2 & 4 & 0.66 & 1.19 & 1.08 \\
\hline 0 & 0 & 2 & 4 & 0.20 & 1.26 & 1.14 \\
\hline 0 & 35 & 2 & 4 & 0.66 & 1.19 & 1.08 \\
\hline 0 & 35 & 2 & 4 & 0.20 & 1.26 & 1.14 \\
\hline 35 & 35 & 2 & 4 & 0.66 & 2.35 & 26.54 \\
\hline 35 & 35 & 2 & 4 & 0.20 & $>6$ & \\
\hline 0 & 0 & 5 & 40 & 0.66 & 1.02 & 1.69 \\
\hline 0 & 0 & 5 & 40 & 0.20 & 1.04 & 1.71 \\
\hline 0 & 35 & 5 & 40 & 0.66 & 1.01 & 1.74 \\
\hline 0 & 35 & 5 & 40 & 0.20 & 1.00 & 1.73 \\
\hline 35 & 35 & 5 & 40 & 0.66 & 2.61 & 49.14 \\
\hline 35 & 35 & 5 & 40 & 0.20 & $>3.5$ & \\
\hline 0 & 0 & 5 & 4 & 0.66 & 1.19 & 1.08 \\
\hline 0 & 0 & 5 & 4 & 0.20 & 1.26 & 1.14 \\
\hline 0 & 35 & 5 & 4 & 0.66 & 1.19 & 1.08 \\
\hline 0 & 35 & 5 & 4 & 0.20 & 1.26 & 1.14 \\
\hline 35 & 35 & 5 & 4 & 0.66 & 1.80 & 35.47 \\
\hline 35 & 35 & 5 & 4 & 0.20 & $>3.6$ & \\
\hline
\end{tabular}

The reason for the dramatic increase in the bearing capacity with the friction angle in the presence of multiple pillars could be seen from the minimum 
principal stress contours and the displacement vectors plotted in Figure 5.38. As the vertical load on the pillar increased, the horizontal floor movements induced in the adjacent entry were restricted to some extent by the presence of the nearby pillar. This restraint to the displacements induced higher confining pressures in the floor, which substantially increased the triaxial strength of the floor when the friction angle was non-zero. Similarly, for the same amount of confinement, the higher the friction angle, the higher the floor triaxial strength. For this reason, when the friction angle of the immediate floor was zero, even though the adjacent pillar was offering similar restraint, the floor strength did not increase as for the non-zero friction angle case.

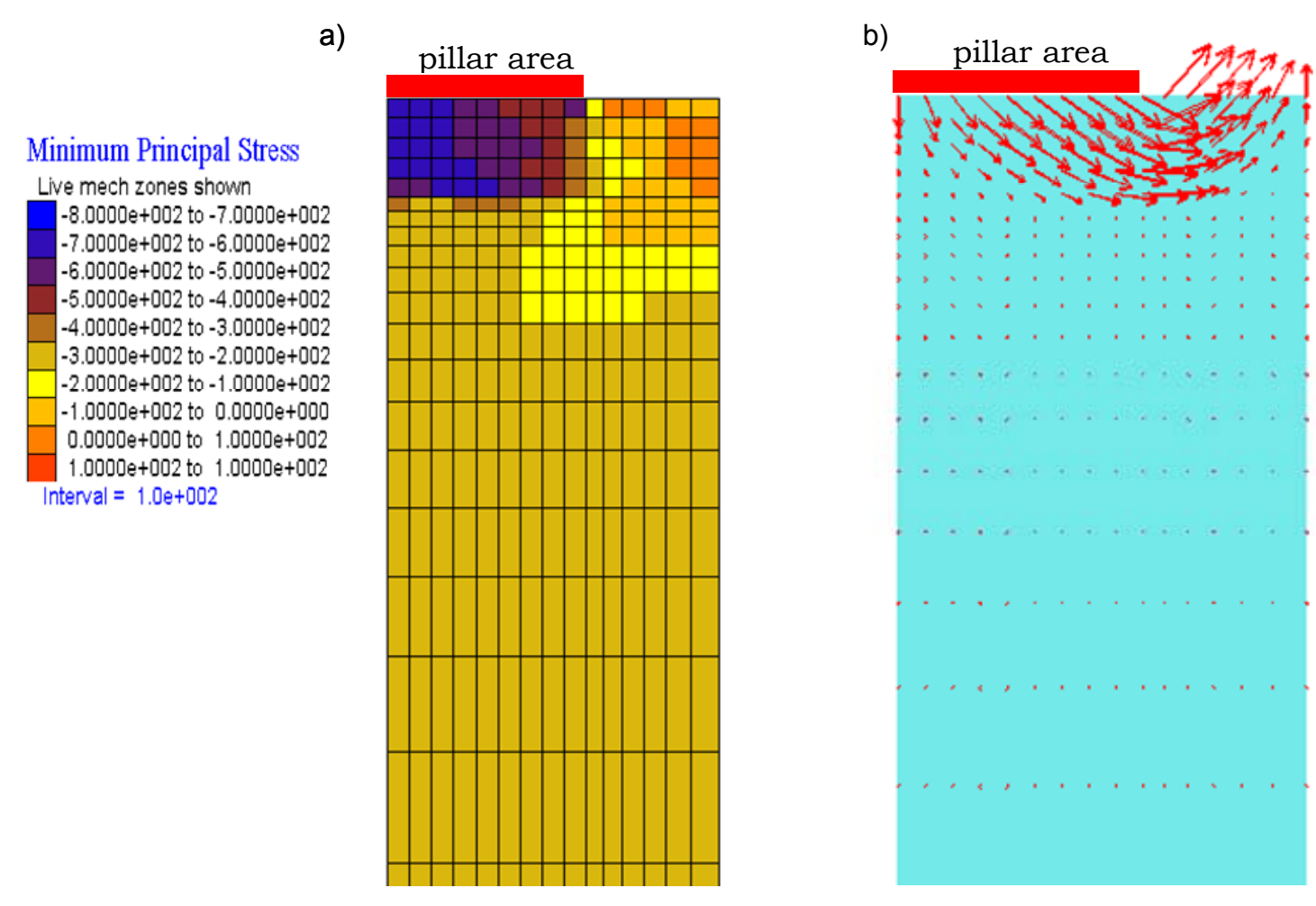

Figure 5.38. Model results for multiple strip pillars, a) contours of minimum principal stress, (negative numbers indicate compression) and b) displacement vectors at the limit state.

It has been noted above that the effect of adjacent pillars has more positive effect on the bearing capacity of a strip pillar than a square one. The reason for this difference could be seen by comparing the minimum principal stress and displacement vector plots shown in Figure 5.39 with those in Figure 
5.38. In both these figures, the model conditions were exactly the same except for the geometry of the pillar. The results show that in case of a square pillar, the amount of floor movement in the entry adjacent to the pillar keeps decreasing from the mid-portion towards the pillar corner. As a result, the horizontal confinement generated in the floor kept decreasing from the middle of the pillar to the intersection area as seen from Figure 5.39 (a). Since the overall confinement of the floor below the pillar is lower for the square pillar, for the same friction angle value, a strip pillar will have higher bearing capacity as demonstrated by the values given in Tables 5.7 and 5.8.
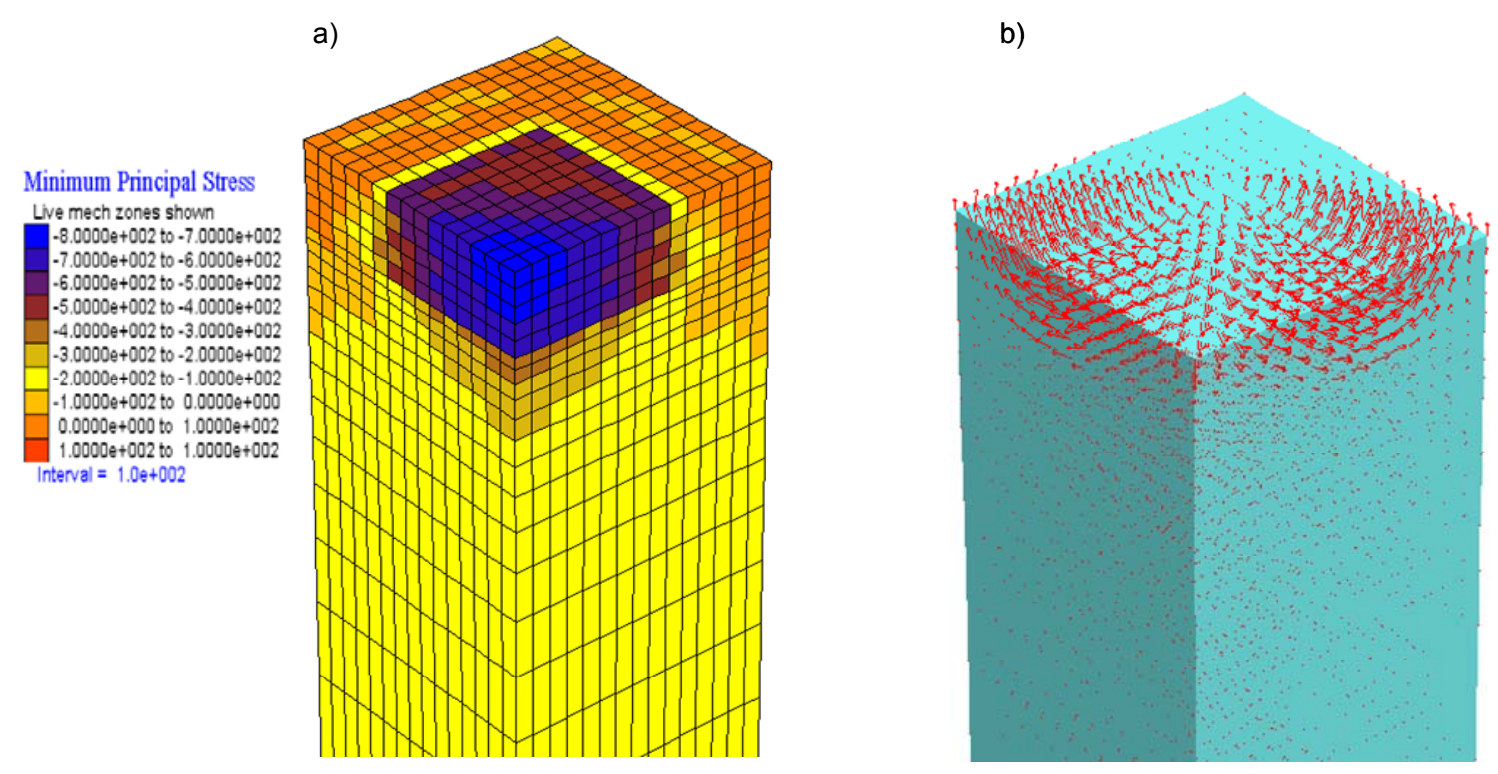

Figure 5.39. Model results for multiple square pillars, a) contours of minimum principal stress, (negative numbers indicate compression) and b) displacement vectors at the limit state.

\subsection{Spatial Distribution of Underclay Properties}

Laboratory data in Chapter 2 and in-situ properties discussed in Chapter 3 show that there is a significant variability in the values of the physico-mechanical properties of the floor materials in the Illinois Basin coal mines. The variability is seen both at small and large scales. The data collected for this work show that properties can vary widely at the mine level, panel level or even within an area covered by a single pillar. The randomness of the properties could have some 
influence on the bearing capacity estimates. It is a normal practice in the coal industry to test for different rock properties on cores recovered from a few select boreholes across a reserve area. Unless there is a special need, very rarely, rock testing is conducted at multiple points in very close proximity, for example, in an area covered by a single coal pillar. Therefore when random variation of rock properties is discussed, the reference is normally made to the variability of point data over a large area such as the entire mine, panel or reserve. For instance, in the reliability principles based approach suggested by Pytel (1998), uniform strength properties were assumed below a single coal pillar even though on a panel scale, property variability was considered. However, research by Griffiths and coworkers (Griffiths and Fenton, 2001; Griffiths et al., 2002; Fenton and Griffiths, 2003) showed that for the bearing capacity determination, the scale of random variability is extremely important. Some of the plate tests conducted by for this work in close proximity indicated that random variability of floor strength is possible at different points below even a single coal pillar.

In this section, an attempt has been made to examine the effect of random variation of floor properties on an extremely small scale on the floor bearing capacity. Besides shedding some light on the effect of such strength variability, this exercise has been carried out to demonstrate the unlimited range of conditions that can be simulated using the numerical modeling methodology developed in this chapter. When discussing the moisture content of floor materials in Section 2.3, it has been shown that when a large database of properties was considered, the variability could be described by a normal distribution. The mean and standard deviation values for floor moisture content were estimated in chapter 2 for different major coal seam floors in the Illinois Basin. It has been shown in Chapter 3 that the Gadde's equation provides the most realistic estimate of the in-situ plate bearing capacity as a function of the moisture content.

In order to implement random property variability on a small scale in the numerical models, a random number generator was used to assign different moisture content values to different points below a coal pillar. The random 
moistures were drawn from a pool of normally distributed values whose mean and standard deviation were taken from Chapter 2. Then using the Gadde's equation, the strength of the floor for each individual point was estimated corresponding to the moisture value at that point. The randomly assigned cohesion values for a strip footing sitting on a semi-infinite floor are shown in Figure 5.40. It may be noted in this figure that only half a footing was considered in the model and thus for this exercise it was assumed that there was symmetry in the randomness. This was not due to any restrictions in the modeling but was assumed for the sake of simplicity.

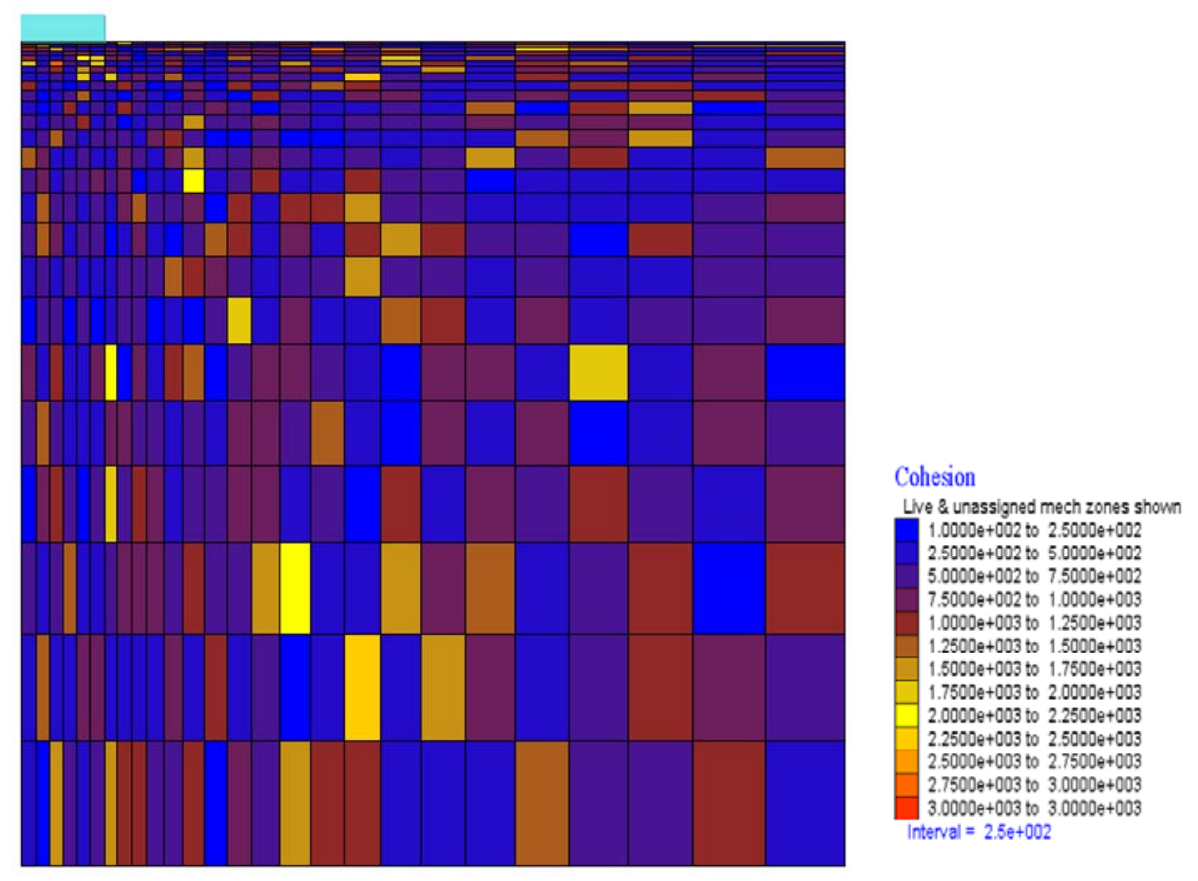

Figure 5.40. Random values of cohesion assigned to different points in the floor.

When multiple tests are conducted on a rock material, the normal practice is to use the average value of the parameter for the design. For instance, if a large number of samples corresponding to each element in Figure 5.40 are tested for their strength and if it is necessary to estimate the floor bearing capacity for such a situation, then the normal practice would lead one to average the individual numbers and use the mean value in the design. Such arithmetic average of the individual cohesion values in Figure 5.40 was computed and assigned uniformly to the floor in the model shown in Figure 5.41. When the 
models in Figure 5.40 and Figure 5.41 were solved using the displacement loading approach described before, the stress-deformation curves shown in Figure 5.42 were obtained.

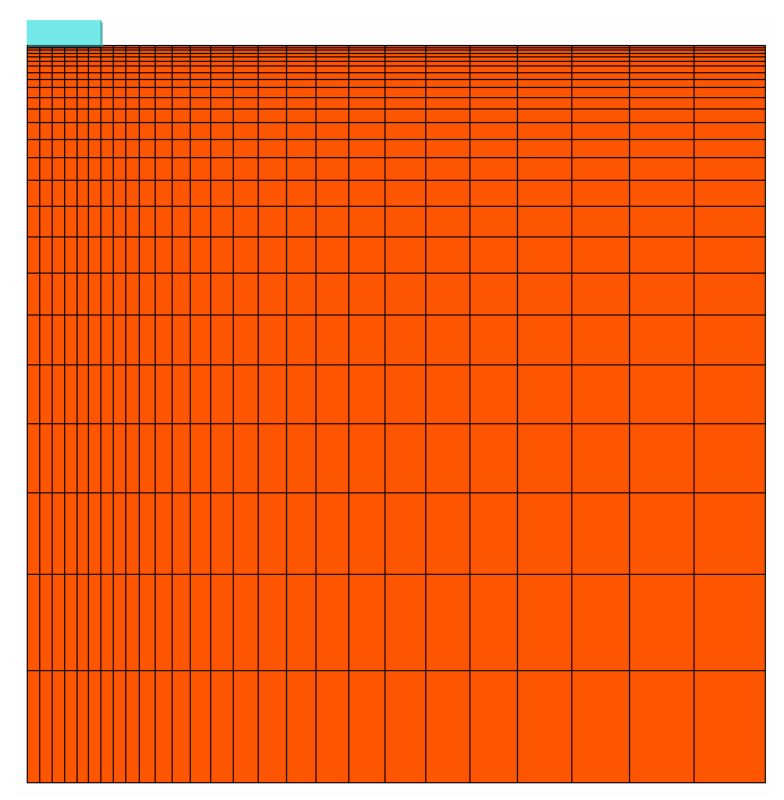

Figure 5.41. Uniform cohesion value (596 psi) assigned to different points in the floor for the same conditions as in Figure 5.40 .

a)

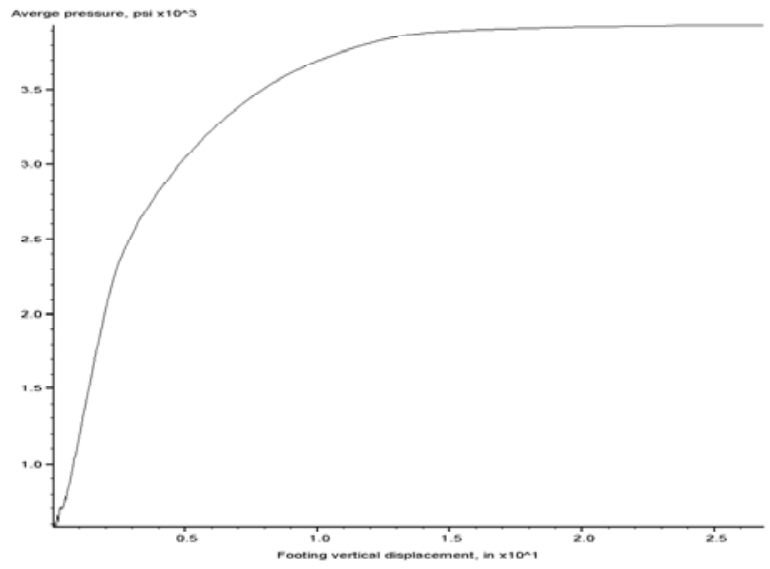

b)

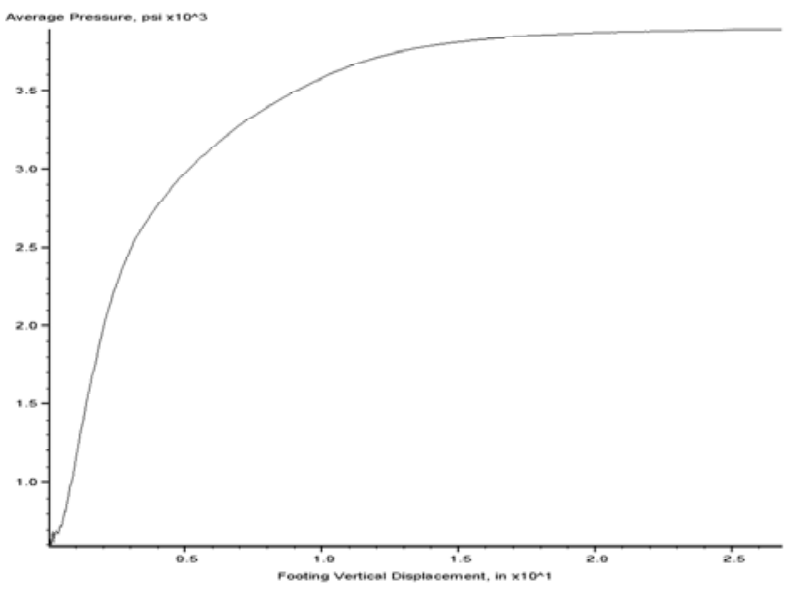

Figure 5.42. Average pressure-vertical deformation curves for a) uniform, and b) randomly distributed floor properties.

The peak stress values obtained from the model runs were 3939 psi and $3895 \mathrm{psi}$, respectively for the uniform and randomly distributed properties. From 
these results it can be concluded that if the randomness exists on a very small scale, which is more likely than not in the real world, then the difference in the magnitude of bearing capacity estimated by the average properties versus using the exact point value distribution is negligible. Such similarity in the limit values is because of the fact that as the scale of randomness decreases, the weakest path of failure becomes increasingly tortuous and its length correspondingly longer. As a consequence, the failure path will take the shorter route cutting through the harder materials. Griffiths and Fenton (2001) note that in the limit, when the scale of randomness becomes zero, the optimum failure path will look exactly the same as in a uniform material with strength equal to the mean value.

From the above discussions, it can be broadly concluded that the higher the randomness of the properties, the closer the bearing capacity estimate will be to that given by the average strength properties. As mentioned in the preceding paragraph, for this conclusion to be valid, the randomness must exist on a very small scale. Past experience with the floor properties show that more often than not small scale randomness exists and thus the bearing capacity studies conducted with the mean strength values is adequate for routine design purposes. If there is any reason to believe that variation in the properties occurs on a scale of a single pillar or more, then such random variability may need to be considered in the overall panel or mine design.

\section{9 'Softening' Effects}

When some localized floor failures such as those described in section 5.6 occur or when a large amount of water accumulates in the mine openings, the strength properties of floor materials near the pillar ribs change. Such strength changes due to excess stress or moisture increase are termed 'softening' (Marino and Choi, 1999). Therefore, in effect, softening results in a highly nonuniform spatial distribution of floor properties near the pillar ribs. Plastic yielding of the floor under excess stress will result in a substantial reduction in its strength properties only if the underclay exhibits strain-softening behavior. In contrast, any increase in the moisture content of the floor will lead to strength degradation as 
discussed in Chapter 3. Either way, the softening effects lead to a decrease in the floor strength in the affected area.

As the discussions in Chapter 3 show, some strain-softening behavior was noticed during plate tests conducted in several Illinois Basin coal mines when the natural moisture content was low. But, in a majority of cases, the behavior was close to being perfectly-plastic than strain-softening. For this reason, in this section only the effect of moisture induced softening is studied. If there is enough evidence that strain-softening constitutive model describes the floor behavior better, then the numerical modeling methodology discussed in this chapter can handle such situations also.

The most exhaustive account of the softening effects on claystone type strata was provided by Botts (1986) in his Ph.D. dissertation on the engineering behavior of clay shales. When commenting on the difficulties in assessing and predicting the engineering behavior of clay shales, he notes, "...clay shales are intermediate in behavior between rock and soil", and "...clay shales tend to transgress from rock-like to soil-like materials within a relatively short time period. Changes in the strength of clay shales can be very drastic, commonly exhibiting $40 \%$ to $80 \%$ reductions in shear strength over periods ranging from 2 to 70 years. Internal friction angles of $20^{\circ}$ to $30^{\circ}$ in unaltered clay shales are often reduced to extremely low values of $2^{\circ}$ to $6^{\circ}$ after softening."

It must be mentioned that all the data and discussions in the Botts' dissertation apply to clay shales that have free surfaces available to get weathered by the action of moisture, e.g., highwalls. It is also important to have high degree of jointing in the strata. Therefore, when drawing parallels with coal mines, only the floor material in the entries and crosscuts will experience softening similar to that described in Botts' dissertation provided enough conduits exist for the moisture penetration. Given enough time for seepage, floor deeper into the coal pillar may also get softened depending on its permeability.

Based on field observations of stiff clay shales, Botts (1986) proposed a simple fissure softening model, which he opined was the primary mechanism for the progressive deterioration of the clay shales. A schematic of the Botts' 
mechanism is shown in Figure 5.43. In stage 1, the fissured clay shale has experienced no alteration. Some deterioration has been initiated along fissures in stage 2 , which progressively got worse in stage 3 and stage 4 , at which point the shale was totally degraded.
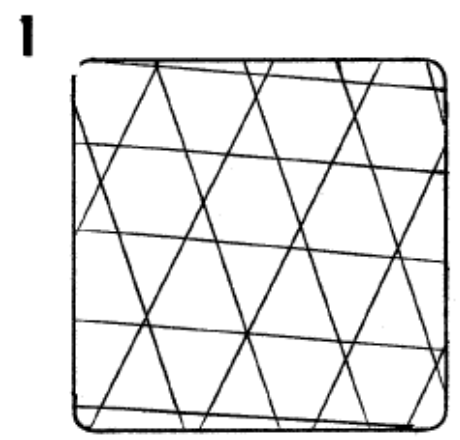

3

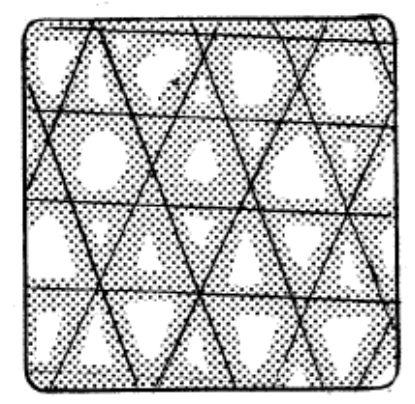

2

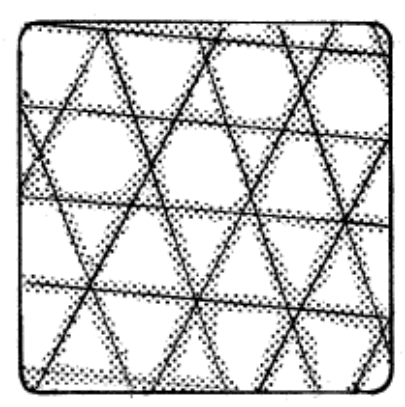

4

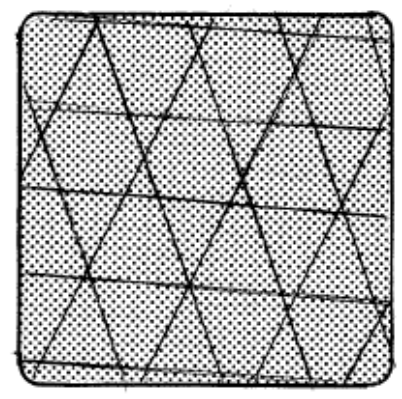

Figure 5.43. Schematic of progressive deterioration of clay shales (Botts, 1986).

For the different stages of softening illustrated in Figure 5.43, Botts (1986) also discussed how the constitutive behavior would change as shown in Figure 5.44. In effect, the clay shale which is a very brittle material in stage 1 , gets transformed into a perfectly-plastic material at the limit of softening in stage 4 . It is not inconceivable that similar mechanism may operate in underground coal mines. For this to happen, the key requirement, however, is the existence of a large number of discontinuities in floor that increase its permeability. Normal underclay, claystone and shale are highly impermeable materials. Without the aid of fractures, it is hard for any water to seep deeper into the floor to have any noticeable effect on the bearing capacity. 
As mentioned earlier in this chapter, Marino and Choi (1999) were the first to recognize the effect of softening on floor stability in the Illinois Basic coal mines. They also conducted some numerical modeling studies to estimate the extent of bearing capacity reduction with softening. For this study, closed-form elastic relationships were used to assess the stress distribution in the floor below
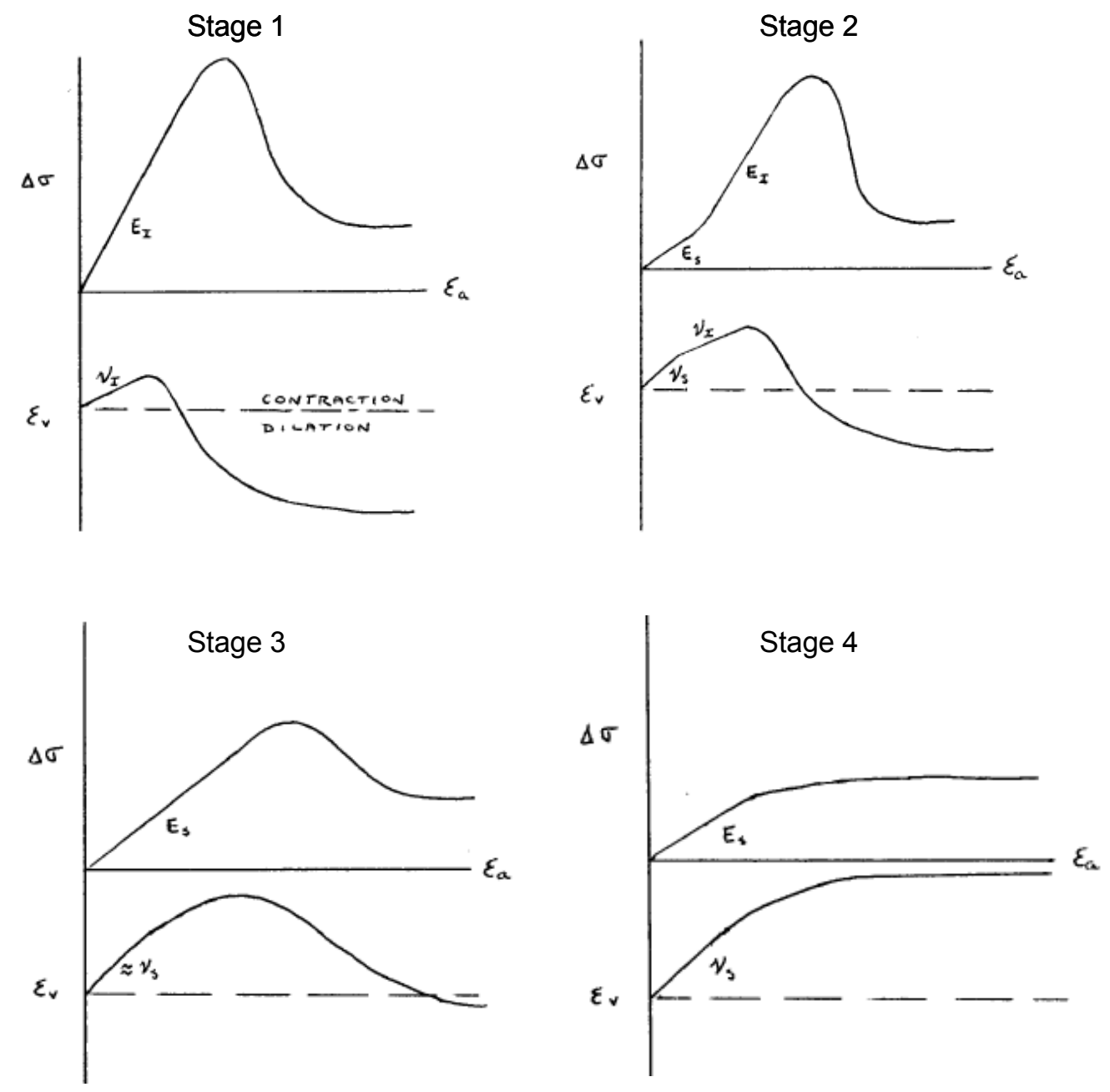

Figure 5.44. Schematic of the possible change in the constitutive behavior as a function of softening illustrated in Figure 5.43 (Botts, 1986).

the rooms and pillars. Uniform loading on the floor was assumed and the distribution of vertical stress was described in terms of a parameter called the original stress ratio (OSR). Using the moisture content values obtained from two abandoned coal mines where subsidence occurred after about 20 years, Marino and Choi (1999) estimated the depth of floor softening at the time of instability in 
those mines. In order to estimate the depth of softened zone in the floor, it was necessary to determine the value of critical OSR. Speck's plate bearing capacity equation given in Chapter 3 has been used to estimate the degree of swelling required to transform the floor into a fully softened state (Marino and Choi, 1999).

While the approach suggested by Marino and Choi (1999) is reasonable, it is also possible to estimate the extent of softened zone using numerical modeling. With the latter, it is possible to conduct a transient seepage analysis to estimate the change in moisture content in the floor for a given amount of water head acting on the mine floor. Depending on the permeability of the floor, the seepage analysis will show how far the excess moisture can penetrate into the floor as a function of time. At each time period, the floor properties can be estimated using several equations given in Chapter 3 as a function of the moisture content at the point of interest. Then, an independent numerical bearing capacity analysis can be conducted while considering the spatial distribution of the cohesion values determined from the seepage analysis. This exercise can be repeated for different time periods of interest. It may be noted that in this procedure the mechanical and seepage analyses are done independent of each other. This separation has been suggested for the sake of simplicity and is not a limitation of modeling. If desired, a coupled analysis could be done where the effects of fluid-rock interaction can be included simultaneously. Although this author has conducted some seepage analyses, the studies were still in their preliminary stages and thus are not included in this dissertation. The seepage analyses conducted so far, however, show the feasibility of the procedure.

No matter how the zone of softening is estimated, the numerical bearing capacity analysis described in this chapter could be used to study its effect on the floor stability. As an example, the bearing capacity of a strip footing is computed for different depths of floor softening shown in Figure 5.45. For these models it has been assumed that multiple footings exist at $s / B=0.66$ and the immediate floor has finite thickness given by $B / H=0.25$. Also the friction angle for both floor layers in the unsoftened condition was assumed to be $20^{\circ}$. Similarly before softening, an arbitrarily chosen cohesion value equal to 150 psi was 
assigned to the immediate floor bed and the main floor's cohesion was assumed to be 450 psi. For the softened floor, the cohesion was dropped to zero and the friction angle was assumed to be $15^{\circ}$. For different depths of softening, the bearing capacity factor, $N_{c}$ changed as given in Table 5.9.

No softening

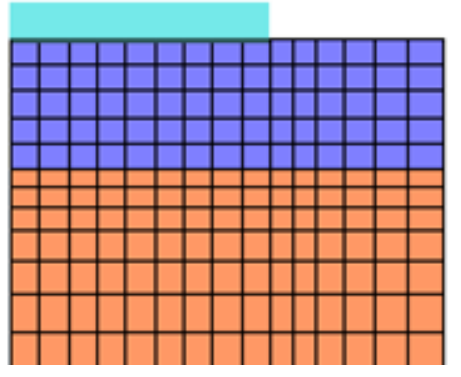

3-element deep

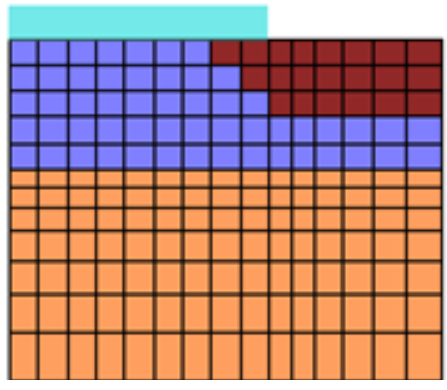

1-element deep

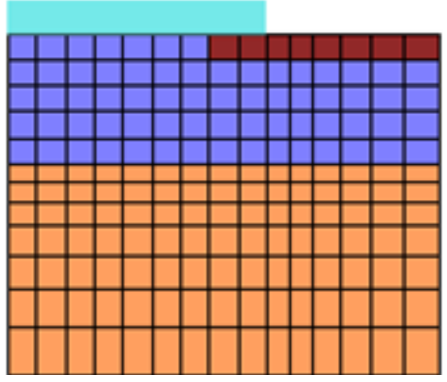

4-element deep

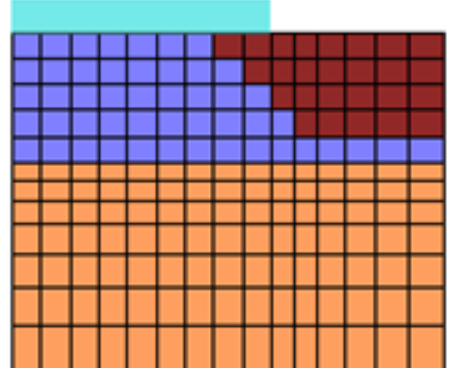

2-element deep

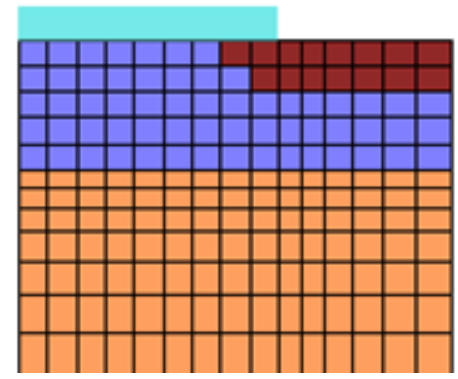

5-element deep

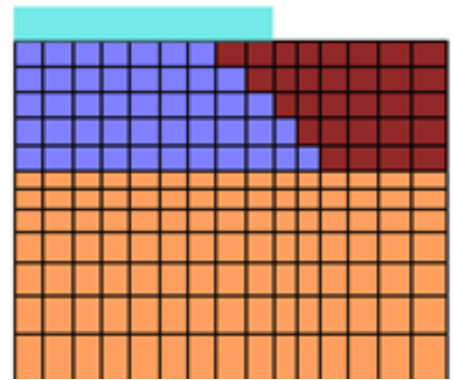

Figure 5.45. Different depths of softening considered for the analysis (dark brown - softened zone; light blue - unsoftened immediate floor; light brown - main floor; cyan - footing).

Table 5.9. Change in the bearing capacity factor, $N_{c}$ with depth of softening.

\begin{tabular}{|c|c|}
\hline Depth of softening & Bearing Capacity Factor, $N_{c}$ \\
\hline Zero & 23.13 \\
\hline 1-element & 12.01 \\
\hline 2-element & 10.23 \\
\hline 3-element & 8.84 \\
\hline 4-element & 7.63 \\
\hline 5-element & 6.71 \\
\hline
\end{tabular}

This example analysis of the softening effect on bearing capacity shows that significant drop in floor strength can occur if water pooling occurs on the floor and sufficient fracturing exists in the floor to allow the water to percolate deeper 
into the floor. Indeed, the drop in the strength even with the limited amount of softening shown in Figure 5.45 is so high that perhaps no practically adoptable pillar can stop floor failures in such a situation. While this kind of 'softening' analysis is useful for forensic investigation of surface subsidence events after the fact, the following practical restraints will limit its use as a routine design tool at the stage of mine planning:

- there is practically no way to know how much water to expect at different parts of a coal mine before development;

- even when some water sources are identified before or after mining, no simple methods exist to predict how much water will find its way to the mining workings and how long such seepage will continue;

- it is almost impossible to get an idea of the extent of fracturing that exists in the floor before the mine is opened or even after it is developed;

- practically no data exists on the permeability characteristics of the floor materials, let alone their spatial and temporal variations.

Therefore, barring some forensic investigations, at this stage there appears to be no more value of the softening analysis than to use it as a tool to understand the possible effects such floor degradation can have on the bearing capacity. Finally, it is important to understand that the floor softening under the action of excess moisture will have significant impact on the system stability and lead to surface subsidence only if such water exists extensively in a sizeable portion of a panel. Small volumes of water that are normally seen in a typical coal mine will only have a very localized influence on floor stability, which is normally not noticeable.

\subsection{Steps in Using the Author's Numerical Modeling Approach}

The following step-by-step methodology is suggested when using the author's numerical modeling approach to estimate the floor bearing capacity:

1. drill a reasonable number of holes in the area of interest,

2. run geophysical logs (gamma, density, caliper and where possible, sonic) in each borehole available (cored or not cored), 
3. using the geophysical logs and physical observations of the core, identify the weaker section of the immediate floor when the total thickness of the claystone bed is very high (based on the past experience, if the claystone bed is thicker than $4 \mathrm{ft}$, careful examination of the geophysical logs and cores is necessary to identify the weaker section. In such cases there is a high chance that the entire claystone may not be weak);

4. determine the natural moisture content of the well protected immediate floor cores on 6 inches to $1 \mathrm{ft}$ intervals (moisture change with floor depth may also be used to estimate the weak floor thickness);

5. if project economics permit, determine the Atterberg limits and clay fraction of the weaker floor;

6. if enough core recovery is available, test the main floor for shear strength preferably in triaxial cells. Otherwise, estimate the moisture content, Atterberg limits and clay fraction, if the stronger floor is claystone;

7. from the moisture content values, estimate the angle of internal friction using different relationships and charts discussed in Chapter 2;

8. similarly, using the moisture content data, estimate the plate bearing capacity value using the Gadde's equation given in Chapter 3. Choose the appropriate Gadde's equation depending on the geographical location of the mine in the Basin. For the main floor strength estimation, use the appropriate equation for the coal seam under consideration;

9. estimate the bearing capacity factor, $N_{c}$ corresponding to the friction angle computed in step 7 using equation (4.7). Also calculate the shape factor $s_{c}$ with equation (4.11). Divide the plate strength in step 8 by $s_{c} N_{c}$ to estimate the cohesion of the bed;

10. when the stronger claystone floor is not tested in the lab, repeat steps 7-8 to compute its angle of internal friction and cohesion values;

11. calculate the modulus of deformation values for both floor layers using equation (3.26). Assume a Poisson's ratio of 0.35 for both beds;

12. build a numerical model corresponding to the exact or scaled-down pillar, entry and floor dimensions with as high a mesh density as possible. Include 
as many site-specific geo-mining features in the numerical model as necessary;

13. for a majority of the routine designs, the Mohr-Coulomb yield criterion with perfectly plastic constitutive behavior and zero volume change in postfailure state assumption is perhaps sufficient. As the load-deformation curves obtained from in-situ plate tests in Chapter 3 show, at lower moistures, the floor may exhibit strain-softening behavior. In such cases, the modeling must use strain-softening constitutive model;

14. run a bearing capacity analysis using the displacement control approach suggested in this chapter to estimate the limit load;

15. compute the average vertical stress on the coal pillar using the Tributary area or any other approach;

16. choose a pillar size that ensures at least a stability factor of 2 to 3 against floor bearing capacity failure. These stability factors are applicable only when the floor bearing capacity is computed with numerical modeling while considering non-zero friction angles, effect of adjacent pillars etc.

\subsection{Chapter Summary}

Based on the discussions in the preceding sections of this chapter, the following conclusions are drawn:

- when all the geometric and material property aspects of a typical coal mine bearing capacity problem are considered, it is impossible to provide a closed-form solution for floor strength estimation.

- limited numerical modeling studies were conducted in the past to study the coal mine floor stability problem. The past studies, however, were limited to explain some site-specific floor behavior or were based on a few parametric studies.

- extensive use of numerical modeling has been made in the foundation engineering discipline to estimate the bearing capacity of footings under different conditions. 
- within the knowledge of this author, no modeling study was conducted in the past to study the bearing capacity of coal floors per se while considering the unique characteristics of the Illinois Basin coal mines.

- the nonlinear numerical modeling methodology adopted in this chapter reproduced theoretical solutions accurately.

- it will take several dissertations to study each aspect of the coal mine bearing capacity problem in sufficient details with modeling. Therefore, only some preliminary analyses were conducted in this chapter to demonstrate the strength of the numerical modeling to estimate floor strength and to shed some light on the possible errors incurred by using conventional theories borrowed from the soil mechanics literature.

- it is felt that there is no need to conduct exhaustive number of parametric studies to develop some "design equations" based on modeling. This is because of the widespread availability of advanced modeling software tools which make the task of running a few site-specific bearing capacity problems a trivial matter.

- the modeling results indicate that the following factors will have negligible to significant positive impact on the floor strength:

o shape of the pillar,

o finite thickness of the immediate floor,

o ratio of the strength of the stronger to weaker floor,

o decrease of moisture content with depth below a pillar,

o existence of multiple pillars in close proximity,

o non-zero dilation angle,

o and, most importantly, non-zero angle of internal friction.

- similarly, the following factors can negatively influence the floor bearing capacity:

o increase of moisture content with depth below a pillar,

0 accumulations of large amount of water in the mine workings.

- the modeling exercise showed that non-uniform pillar stress distribution may not significantly alter the ultimate bearing capacity value as compared to the 
rigid plate loading. With non-uniform stresses, however, several localized failures occur in the stress concentration zones before the entire floor below a pillar reaches its limit state. Therefore, limited floor heave in underground openings need not imply floor failure below the whole pillar. Even if some bearing capacity is lost for a particular pillar that experienced some localized floor heave, noticeable surface subsidence will not occur unless the floor reaches the limit state over a sizeable portion of the panel. From a subsidence prevention point of view, it is the system failure that matters, not the localized floor heave noticed in a limited section of a panel. Therefore, the objective of the floor stability analysis must be clear before making significant changes to pillar layout after each event of floor instability noticed underground. The short- and long-term stability issues must be differentiated for this purpose. Otherwise, unnecessarily large pillars may be used when there is no need. The possibility of localized instability also indicates that when collecting data for back analysis of any floor strength equation from a subsidence prevention point of view, limited floor heave noticed underground should not be considered unless there is evidence that such failures translated to surface movements.

- It appears that the random variability of floor strength properties may not have a substantial effect on the bearing capacity if the variability occurs over a small scale. Practical experience indicates that floor properties vary from point to point even within a distance as small as a few feet. In the event of high property variability, the floor bearing capacity can be estimated by using the average strength properties without incurring significant errors. If there is reason to believe that a reasonable level of consistency exists in the floor nature over an area of a single coal pillar or more, then such sparse randomness must be considered in the stability analysis of the entire panel.

- For the first time, in this research, the accuracy of floor bearing capacity estimated by the Vesic's non-homogeneous equation has been verified. It was found that the Vesic's equation did not provide accurate solutions even 
for the conditions for which it was supposed to apply. The correction needed for the bearing capacity factor, $N_{m}$ for a range of Illinois Basin coal mine conditions was provided in tables 5.4 through 5.6 and in Figure 5.30. This inaccuracy in the theoretical solution when combined with several other factors that can have positive impact on the bearing capacity shows that the floor bearing capacity is very severely underestimated by the Vesic's solution for a majority of field conditions. This discovery explains why the seemingly low design stability factors around 1.5 can provide long-term stability when the pillars are designed with the Vesic-Speck approach. Considering that the Speck's equation provides physically unrealistic floor cohesion values under some conditions and the Vesic's equation is ultraconservative, it can be safely concluded that the Vesic-Gadde equation could be used confidently along with the recommended stability factors throughout the Basin.

- If there are any special circumstances that disqualify the use of the VesicGadde approach like pooling of a large amount of water, random property variation over longer distances, time-dependent deformation, existence of more than two layers of strata in the immediate floor, etc., then the floor bearing capacity could be computed using the general numerical modeling methodology developed in this chapter. With the modeling methodology, every practically conceivable situation can be studied with a high degree of confidence provided reasonably representative inputs are available. When site-specific data are not available, some sensitivity studies could be conducted within the range of values given for different physico-mechanical properties provided in Chapter 2 and Chapter 3 . If the numerical modeling methodology is adopted for floor bearing capacity estimation, then the design stability factors used in the foundation engineering may be used for the pillar sizing, not the 1.5 value recommended for the Vesic-Gadde approach. In the foundation engineering applications, stability factor values in the range of 2 to 3 are recommended for spread footings. 


\section{CHAPTER}

\section{FLOOR STABILITY DURING PERIMETER MINING}

\subsection{Introduction}

Perimeter mining is a special variant of the room-and-pillar method that a few coal mines in the United States adopt to achieve higher extraction ratios than are normally possible. The mine layout for perimeter extraction looks similar to a typical room-and-pillar operation except that some select additional cuts are taken either from the panel barriers or from a few designated pillars within a panel or both as shown in Figure 6.1. Even though perimeter mining has been used for several years in the U.S., not a single publication could be found in the literature on ground control issues associated with this method. While it is possible that some mines in different coalfields in the U.S. might have some experience with perimeter mining, it appears that the overwhelming majority of mines that employed this special form of room-and-pillar mining were from the Illinois Basin. Such preponderance is perhaps due to the large number of constraints (e.g., prime farm land) that the Illinois Basin mines face in employing full extraction retreat methods as opposed to their other U.S. counterparts.

The perimeter cut layout and sequencing are normally decided from three different view points: ground control, ventilation and productivity. The width and depth of perimeter cuts must be such that no adverse roof control issues arise during the mining process. Once extracted, roof control in perimeter cuts is not an issue since the roof is not normally bolted and the area is dangered off. The pillar stumps created between adjacent perimeter cuts must be of sufficient size to assure their stability and to prevent floor failures. Similarly, all the normal ventilation related requirements for a room-and-pillar operation apply to the perimeter cuts as well. The quantity and quality of air, the amount of dust in the air must all comply with applicable federal regulations. The cut sequencing used 
in a panel is normally decided so as to optimize the productivity. For instance, two different cut sequences and cut angles are shown in Figures 6.1 and 6.2 for two different size panels that maximize the productivity.

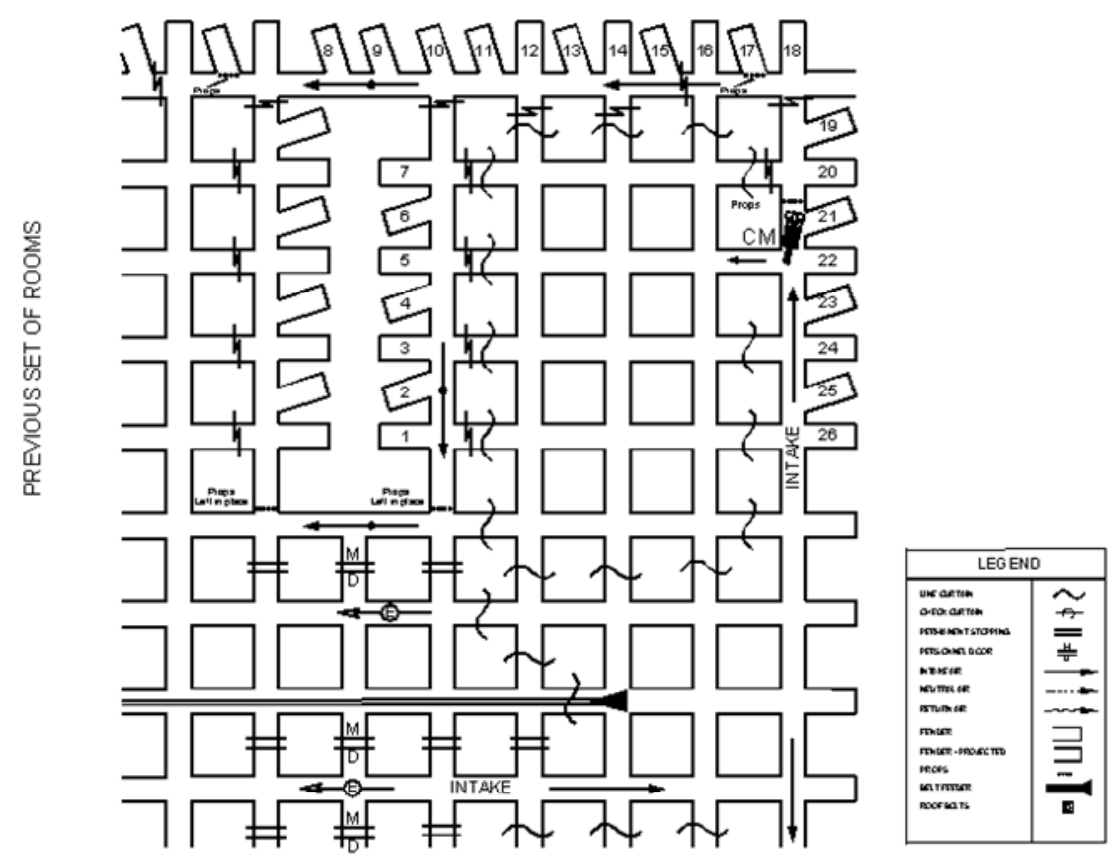

Figure 6.1. Perimeter cut sequence for four pillars wide rooming.

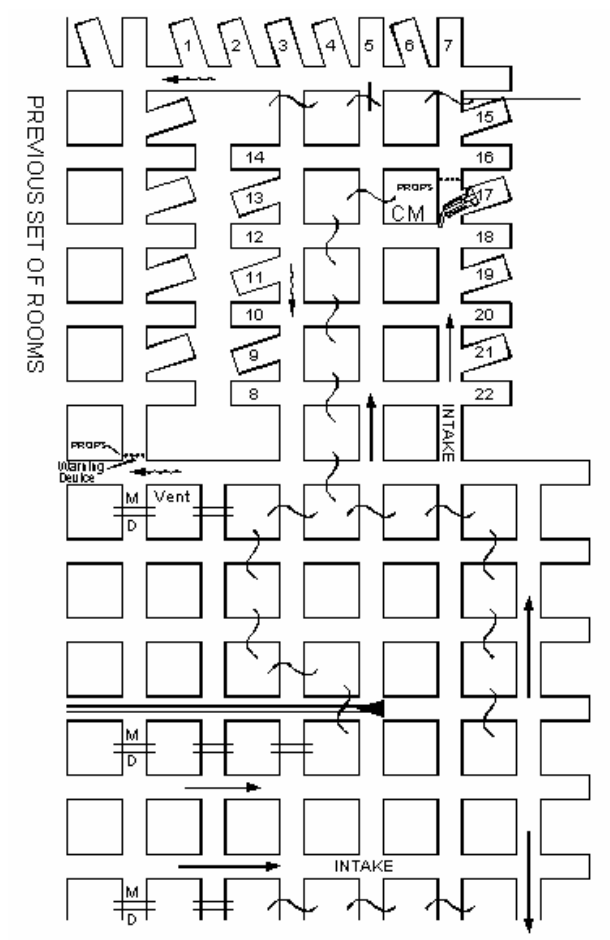

Figure 6.2. Perimeter cut sequence for two pillars wide rooming. 
From the two layouts shown in figures 6.1 and 6.2, it may also be noticed that all the perimeter cuts are not parallel to each other. Cuts that are in line with an existing entry or crosscut are taken head on while those in the middle of pillars are taken at an angle. Some cuts are also taken parallel to each other in the panel barrier as is done for cuts 8-11 in Figure 6.1. Some mines in the Basin also take all perimeter cuts in a panel parallel to each other. It appears that the productivity difference between the parallel and nonparallel perimeter cuts is negligible and mines adopt different patterns just for convenience. It is some what more convenient to take the perimeter cut aligned with an entry or crosscut as there is no need to turn the continuous miner which is needed for the angle cuts.

As mentioned before, except for the very short-term stability needed for safe coal cutting, roof control is not an issue in the perimeter cuts as the area is normally dangered off immediately after finishing the cut. Similarly, short-term pillar and floor stability are also not of major concern after the area is made inaccessible. If surface subsidence needs to be prevented, however, the longterm stability of both the coal stumps and the floor is extremely important. A large amount of research was done on coal pillar strength in that past and several nice accounts of the work are available in the literature (Mark, 2006) and thus will not be discussed here. The irregular shape pillars created in perimeter mining, however, require numerical modeling based approaches to study the pillar stability. No simple equations are available to estimate the strength or loads acting on the perimeter pillars. Among all the available numerical models, displacement discontinuity or boundary element codes will be most convenient for this purpose. In particular, the displacement discontinuity code, LaModel (Heasley, 1998, 2008) is well suited due to its several inbuilt functionalities and the ease with which large areas of the panel could be analyzed in a very short span of time. While good amount of knowledge base exists to deal with pillar stability, no work is available on floor behavior associated with perimeter cuts so far and this chapter will provide the first step in developing a systematic approach to address the issue. 


\subsection{In-Situ Plate Bearing Tests}

The first step in understanding the stability of floor in perimeter cuts is to study its behavior through field strength tests. In-situ plate load tests similar to those discussed in Chapter 3 were conducted at five coal mines in three states of the Basin given in Table 6.1. Since the perimeter cuts are normally made in long rectangular or continuous barrier pillars, conducting tests with scaled down plate sizes representative of the actual pillars is extremely difficult. Therefore, it was decided to conduct plate tests with only a part of the perimeter pillar as shown in Figure 6.3. The dimensions of the perimeter plate shown in Figure 6.3 represent the scaled-down version of a part of the actual pillar employed at a Southern Illinois coal mine in the Western shelf. The size of the plate was chosen such that a compromise is made between the need to include decent size perimeter cuts in the plate and the capacity of the loading system. The plate in Figure 6.3 has an effective loading area equal to $90.65 \mathrm{inch}^{2}$. The thickness of the plate was 2 inches. Such thick plate was used to maintain rigid loading conditions in the tests. In addition to the perimeter plate tests, at every site in each mine, tests were also conducted with a 9" x 9" square plate. The perimeter and square plate tests were done within 10 to $15 \mathrm{ft}$ of each other. Both types of plates were used at each site to provide a reference point and to assess the relative influence of the special geometry created by the perimeter cuts on floor strength.

Table 6.1. Perimeter plate tests summary.

\begin{tabular}{|c|c|c|c|}
\hline Mine & Coal Seam & State & $\begin{array}{l}\text { Number of } \\
\text { Perimeter plate } \\
\text { tests }\end{array}$ \\
\hline A & Herrin No.6 & IL & 2 \\
\hline B & Danville No.7 & IN & 2 \\
\hline C & No. 9 seam & KY & 3 \\
\hline D & Herrin No. 6 & IL & 3 \\
\hline E & Springfield No.5 & IL & 4 \\
\hline
\end{tabular}

Because only a part of the long perimeter pillar is simulated by the plate in Figure 6.3, the consequent alteration of boundary conditions along two edges of 
the plate may have some influence on the test results. The numerical modeling results given later, however, show the error to be negligible.

Similar to the tests described in Chapter 3, except for one test no lime base was employed for any of the tests given in Table 6.1. To ensure uniform loading over the slotted plate in Figure 6.3, a solid rectangular plate was placed on the top as shown in Figure 6.4.
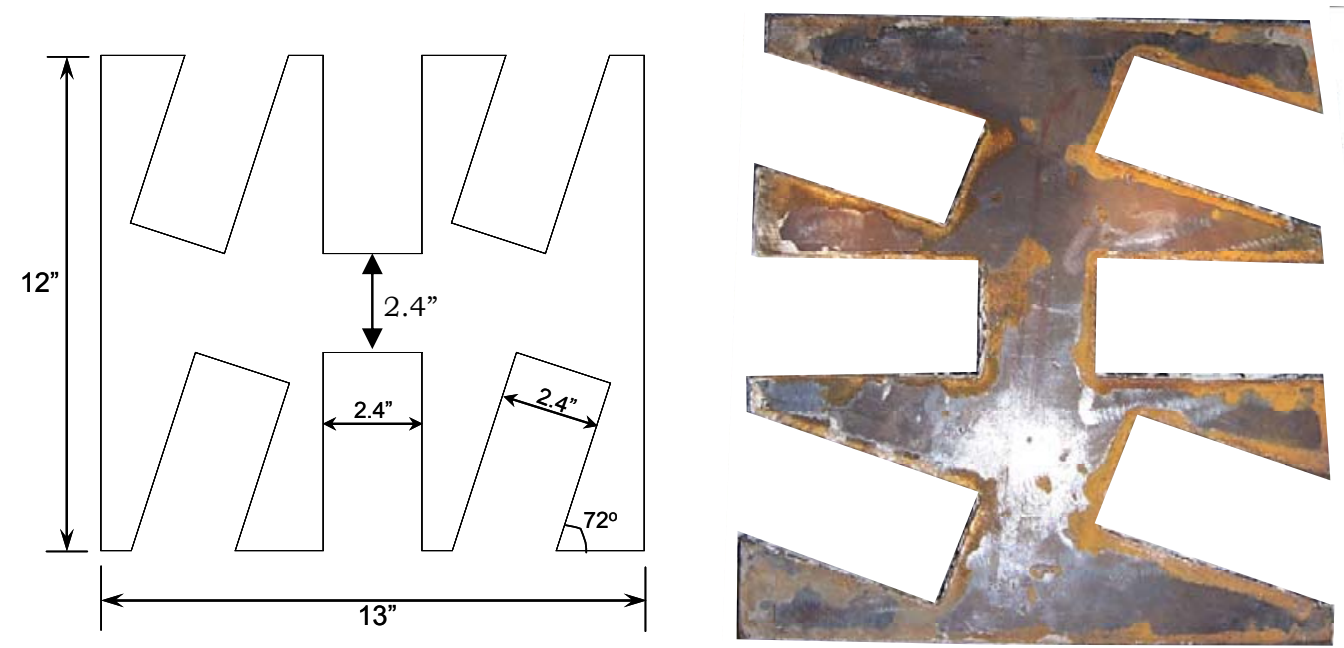

Figure 6.3. Geometry of the perimeter plate used in the field tests.

\subsubsection{Failure Mechanism}

During each test, as the perimeter plate was being subjected to increasing loads, the load-deformation curve was continuously monitored and the response of the floor was periodically photographed and documented. Some views of the condition of the floor at the initiation of the failure and after the limit load in a particular test are shown in Figures 6.5 and 6.6. The plate pressure-deformation curves obtained for some tests are plotted in Figure 6.7 through Figure 6.9.

The failure patterns shown in figures 6.5 and 6.6 correspond to the general shear failure discussed in chapter 3 . Some pressure-deformation curves in Figure 6.7 indicate the brittle nature of the claystone floor. For these cases, up to about $60 \%$ of the peak load, the floor in the test behaved elastically at which point some nonlinearity started appearing. Initial floor failure began around the plate ribs at about $90 \%$ of the peak load as indicated by the small pressure drop in Figure 6.7 and shown by the floor condition in Figure 6.5. With continued plate 
loading, the floor started accepting additional load until the stresses reached the limit state after which a significant drop in the bearing capacity occurred. The floor movements in the perimeter cuts at the limit state shown in Figure 6.6 corresponds to the classic floor heave normally noticed in coal mines. Further, at some test locations the failed material displayed dilatation, which is characteristic of the brittle failure as indicated by the sudden drop in the post-peak bearing capacity shown by some curves in Figure 6.7.

The data for some tests plotted in Figures 6.7 through 6.9 was obtained before automated data collection system was developed. Consequently, the sawteeth behavior is not observed in those plots. In addition to brittle failure, the floor at some of the test sites displayed near perfectly-plastic to slightly strain-hardeing behavior as well. The relative position of different curves in figures 6.7 through 6.9 depended to a large extent on the moisture content of the floor at the test site.

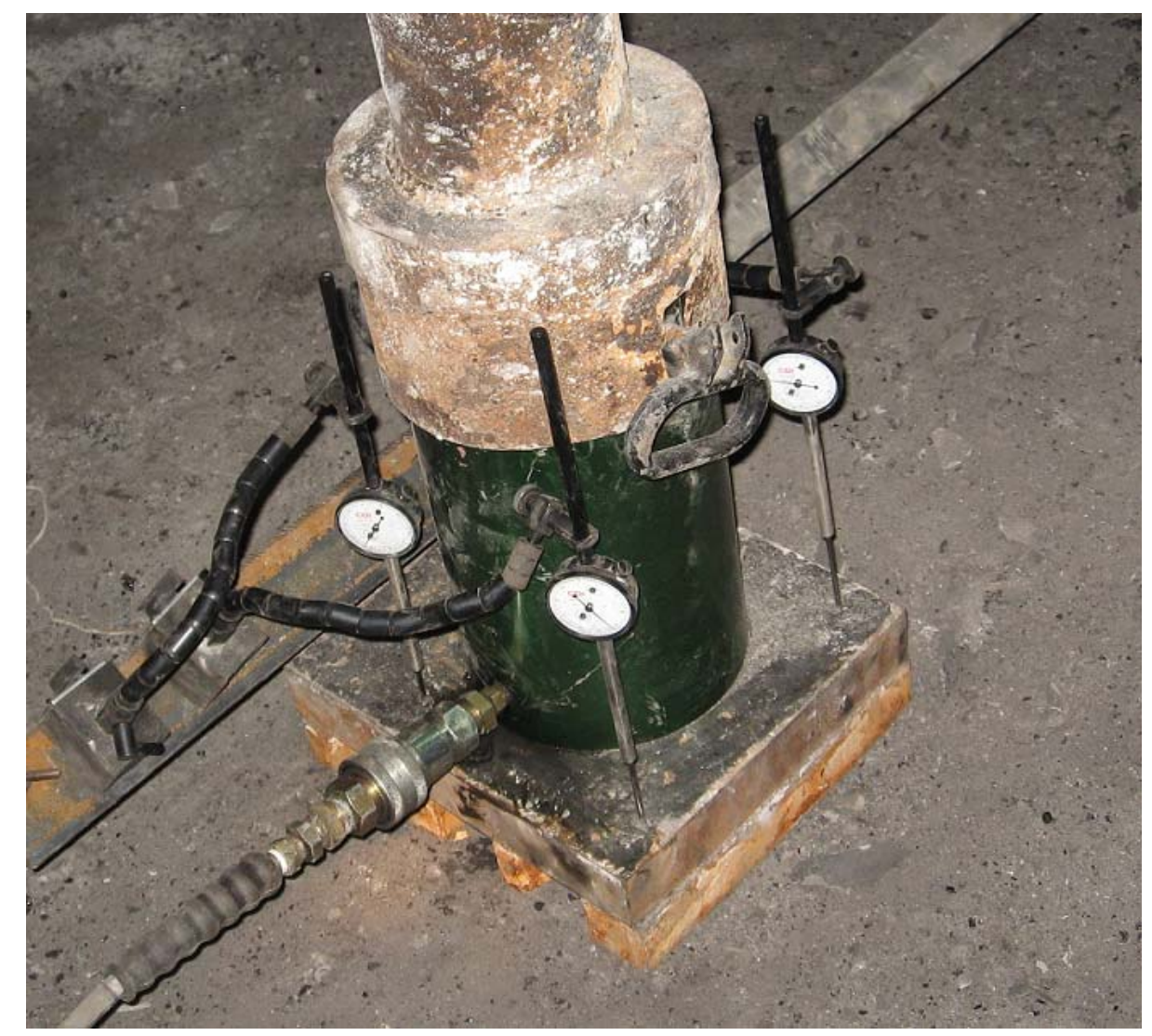

Figure 6.4. Perimeter plate loaded by a solid rectangular plate. 

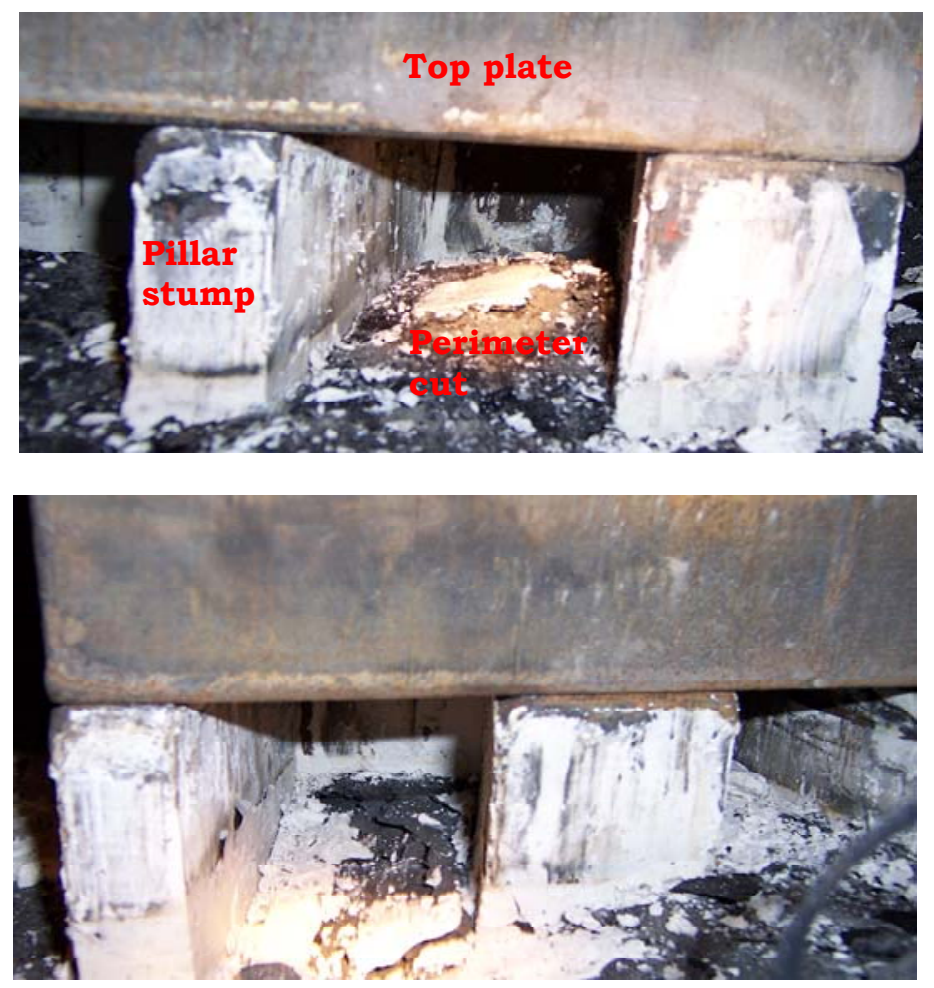

Figure 6.5. Two views of the initial stage of failure development in the perimeter cuts.
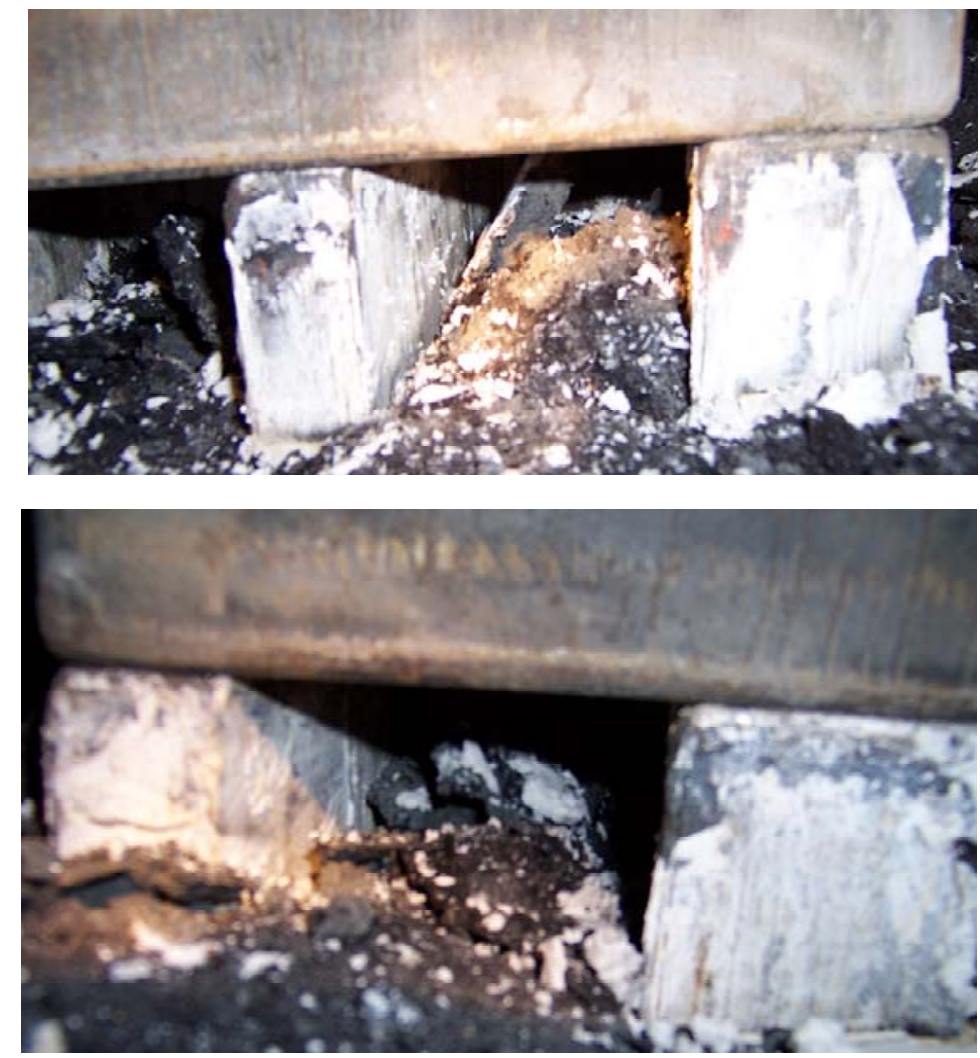

Figure 6.6. Two views of the final stage of failure in the perimeter cuts. 


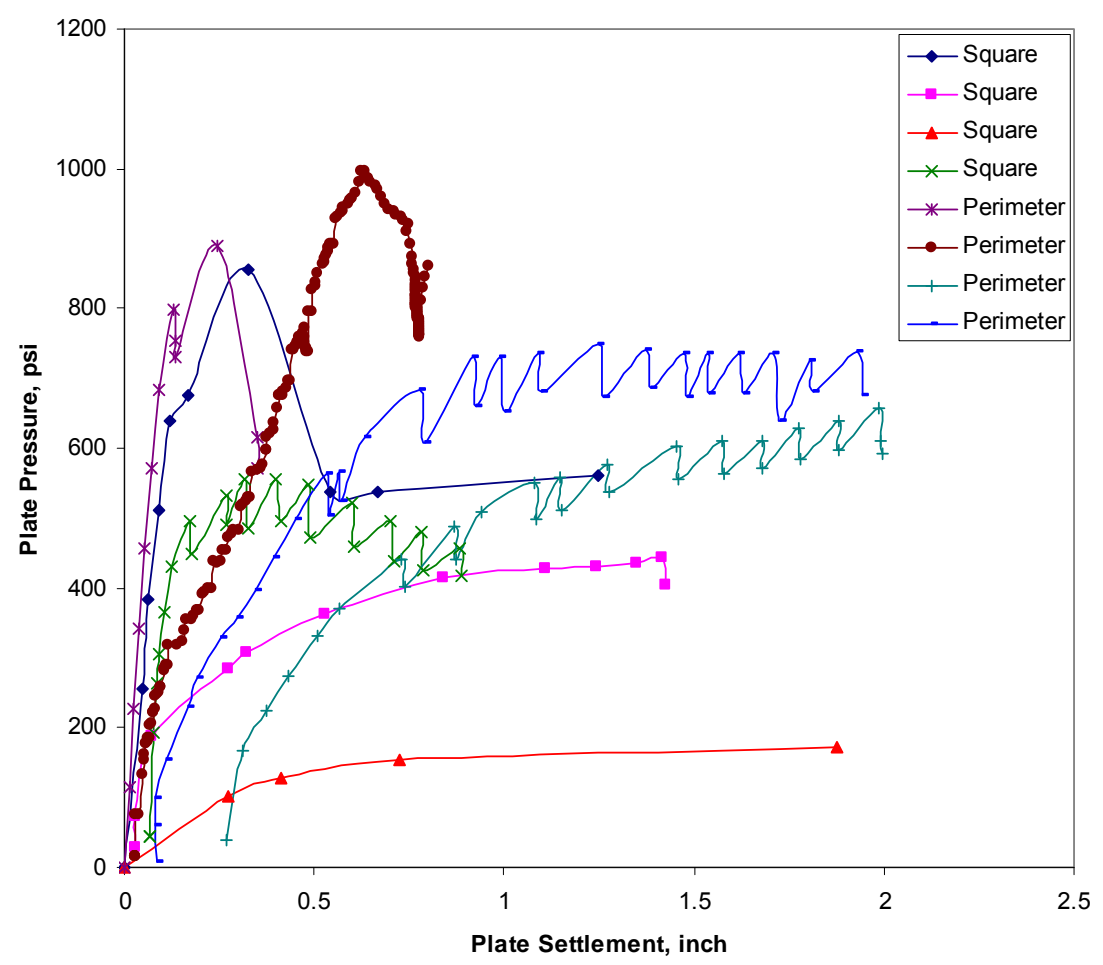

Figure 6.7. Pressure-deformation curve obtained from No.6 seam floor.

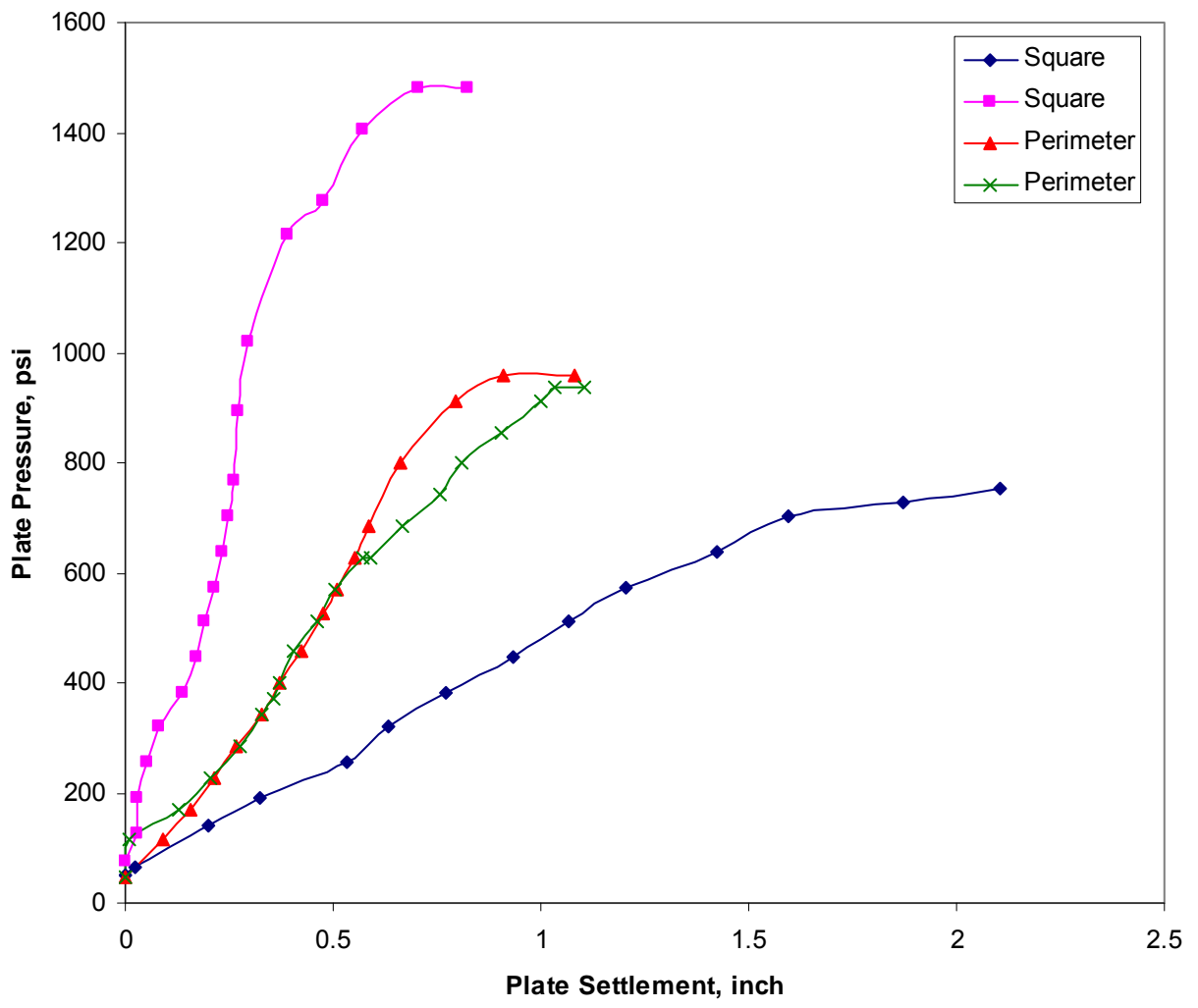

Figure 6.8. Pressure-deformation curve obtained from No.9 seam floor in KY. 


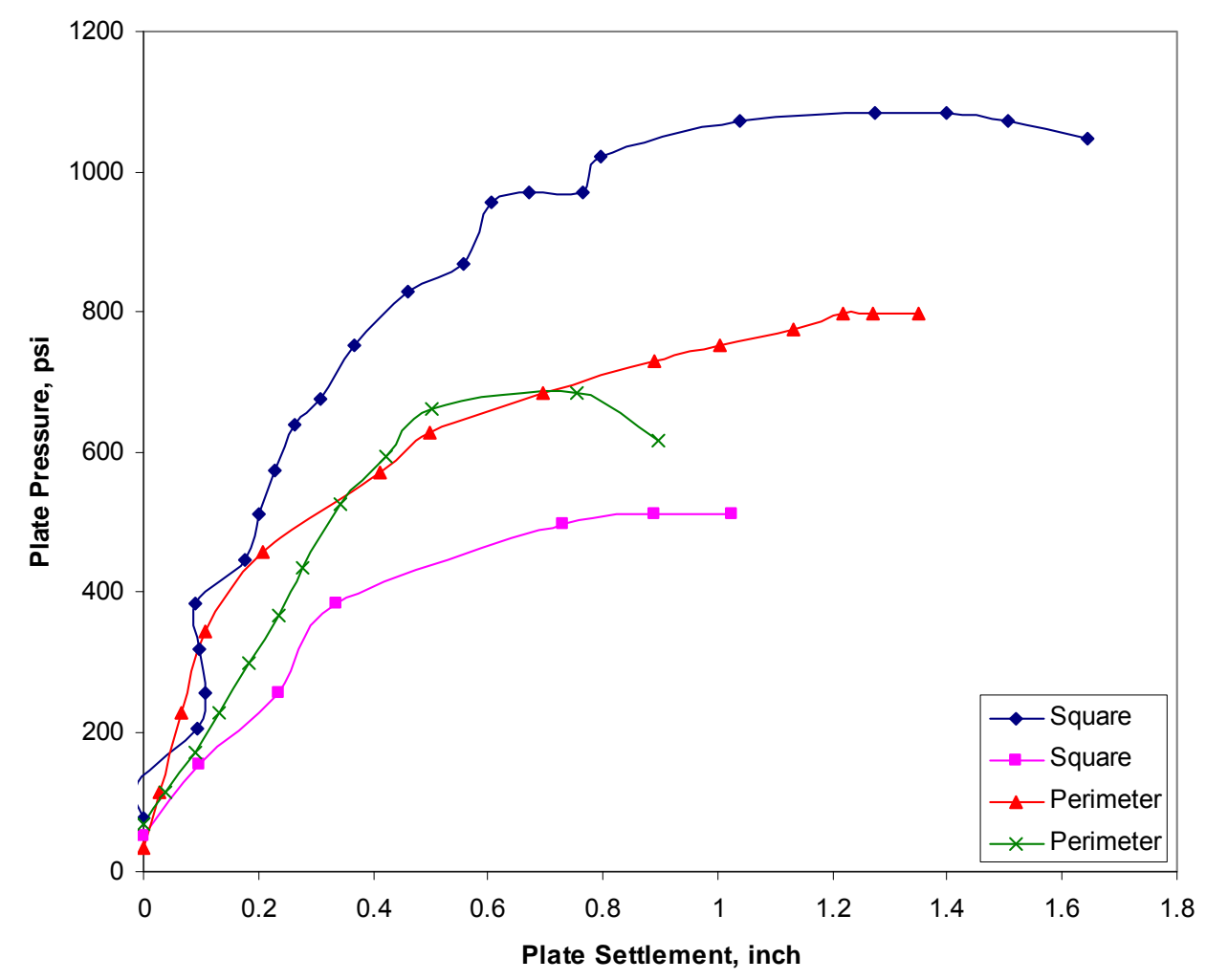

Figure 6.9. Pressure-deformation curve obtained from No.7 seam floor in IN.

\subsubsection{Plate Test Results}

The results of all the perimeter and square plate tests for the five mines are given in Table 6.2. The table also gives the natural moisture content at each test site and the liquid and plastic limit values where available. The average values of the bearing capacity and moisture content from these tests for each mine are listed in Table 6.3. The mean strength when considered together with the corresponding moisture content values indicates that the bearing capacity of floor beneath a perimeter pillar is as strong as or somewhat stronger than that below a square pillar. At the first look, the plate test results would appear counterintuitive for the following reasons:

a) by removing coal in the perimeter pillars, the effective area over which the vertical stress is distributed is reduced. Consequently, the vertical stress on the floor should be higher and thus should fail at lower loads than a continuous or square pillar of the same width; 
b) further, if the floor material has a non-zero friction angle, then removal of coal in a part of the perimeter pillar would reduce the confinement in the floor and thus its load bearing capacity;

c) it has been mentioned in Chapter 4 that the bearing capacity of a long continuous footing is less than that of a square footing of the same width;

d) discussions in chapter 3 showed that there is very small to negligible influence of plate size on bearing capacity when the plate area exceeds 20 inch $^{2}$. Since the perimeter plate employed in the field tests is larger than the 9 inches square plate used for comparison, some negative effect of the size might exist.

Despite all these counterproductive factors, the field test results in Table 6.2 suggest otherwise. There are five main reasons for this rather surprising result:

1. since the plates in the tests were made of very thick steel which is several times stiffer and stronger than the floor, the tests simulated a condition where the coal stumps and the central pillar are extremely stable. Such ultra strong pillars would not yield in the tests and thus there will not be any load shedding that might normally happen in a progressively failing perimeter pillar;

2. despite the higher non-uniform vertical stresses on the perimeter pillar and thus the floor below, as the discussions in Chapter 5 showed, the ultimate load bearing capacity would not change much due to such stress distribution;

3. as discussed in chapter 5 , the presence of multiple pillars in close proximity influence each other's bearing capacity positively. In a perimeter mining situation, there are multiple odd shaped stumps very close to each other to have significant interference as opposed to a regular barrier or square pillar. Even though the gain in the floor bearing capacity due to the interference effect is not very high because of the lower stump width to spacing ratio but appears to be sufficient to produce higher strength than a square plate; 
Table 6.2. Individual perimeter and square plate test results from each site at the five mines.

\begin{tabular}{|c|c|c|c|c|c|c|c|}
\hline Mine name & Coal Seam & Site No. & Plate type & $\begin{array}{l}\text { Moisture } \\
\text { content, \% }\end{array}$ & $\begin{array}{l}\text { Bearing } \\
\text { Capacity, psi }\end{array}$ & $\begin{array}{l}\text { Liquid } \\
\text { Limit, \% }\end{array}$ & $\begin{array}{l}\text { Plastic } \\
\text { Limit, \% }\end{array}$ \\
\hline \multirow{6}{*}{ Mine A } & \multirow{6}{*}{ Herrin No.6 } & 1 & Perimeter & 10.75 & 890 & 53 & 23 \\
\hline & & & Square & 10.43 & 855 & 104 & 26 \\
\hline & & & Square & 11.37 & 689 & 62 & 24 \\
\hline & & 2 & Perimeter & 13.17 & 998 & 50 & 26 \\
\hline & & & Square & 11.66 & 714 & 91 & 30 \\
\hline & & & Square & 13.38 & 1024 & 67 & 27 \\
\hline \multirow{4}{*}{ Mine B } & \multirow{4}{*}{ Danville 7} & 3 & Perimeter & 8.26 & 798 & 37 & 19 \\
\hline & & & Square & 8.19 & 562 & 37 & 20 \\
\hline & & 4 & Perimeter & 8.82 & 684 & 38 & 23 \\
\hline & & & Square & 5.79 & 894 & 35 & 19 \\
\hline \multirow{6}{*}{ Mine C } & \multirow{6}{*}{$\begin{array}{l}\text { Kentucky } \\
\text { No.9 }\end{array}$} & 5 & Square & 9.31 & 421 & 41 & 21 \\
\hline & & & Perimeter & 10.42 & 935 & 43 & 22 \\
\hline & & 6 & Square & 9.44 & 753 & 38 & 22 \\
\hline & & & Perimeter & 10.72 & 958 & 40 & 23 \\
\hline & & 7 & Square & 6.1 & 1481 & 31 & 18 \\
\hline & & & Perimeter & 7.84 & 1186 & 28 & 17 \\
\hline \multirow{6}{*}{ Mine D } & \multirow{6}{*}{ Herrin No.6 } & 8 & Square & 11.82 & 445 & & \\
\hline & & & Perimeter & 11.79 & 656 & & \\
\hline & & 9 & Square & 7.75 & 556 & & \\
\hline & & & Perimeter & 7.41 & 749 & & \\
\hline & & 10 & Square & 9.46 & 580 & & \\
\hline & & & Perimeter & 8.55 & 740 & & \\
\hline \multirow{8}{*}{ Mine E } & \multirow{8}{*}{$\begin{array}{l}\text { Springfield } \\
\text { No.5 }\end{array}$} & 11 & Square & 8.49 & 912 & 32 & 20 \\
\hline & & & Perimeter & 8.71 & 1230 & 34 & 20 \\
\hline & & 12 & Square & 7.82 & 886 & 38 & 22 \\
\hline & & & Perimeter & 7.65 & 921 & 36 & 21 \\
\hline & & 13 & Square & 6.15 & 1479 & 27 & 18 \\
\hline & & & Perimeter & 5.19 & 1700 & 26 & 16 \\
\hline & & 14 & Square & 4.25 & 1765 & 22 & 17 \\
\hline & & & Perimeter & 2.09 & 2074 & & \\
\hline
\end{tabular}

Table 6.3. Average values of the bearing capacity and moisture content from the plate tests.

\begin{tabular}{|c|c|c|c|c|}
\hline \multirow{2}{*}{ Mine } & \multicolumn{2}{|c|}{ Perimeter } & \multicolumn{2}{c|}{ Square } \\
\cline { 2 - 5 } & $\begin{array}{c}\text { Bearing } \\
\text { Capacity, psi }\end{array}$ & $\begin{array}{c}\text { Moisture } \\
\text { content, \% }\end{array}$ & $\begin{array}{c}\text { Bearing } \\
\text { Capacity, psi }\end{array}$ & $\begin{array}{c}\text { Moisture } \\
\text { content, \% }\end{array}$ \\
\hline A & 944 & 12 & 821 & 12 \\
\hline B & 741 & 9 & 728 & 7 \\
\hline C & 1027 & 10 & 885 & 8 \\
\hline D & 715 & 9 & 527 & 10 \\
\hline E & 1481 & 6 & 1261 & 7 \\
\hline
\end{tabular}


4. realistically, since at the test sites the floor was not saturated with water, its angle of internal friction will most likely be non-zero. It has been shown in Chapter 5 that the interaction of multiple pillars will have substantially greater positive effect on the floor bearing capacity for non-zero friction angles. Therefore, it is possible that the gain in the strength due to the multiple stumps in a perimeter pillar has more than offset the reduction in strength due to the factors (a) to (d) discussed in the preceding paragraph;

5. finally, since only a part of the perimeter pillar was simulated in the field tests, the shape factor for the bearing capacity will be higher than 1.0, which applies only to a long continuous barrier pillar.

In addition to the data in Table 6.2, when all other square plate tests done at the five mines are plotted against the test site's natural moisture content, no significant difference between the perimeter and square plate results could be observed as seen in Figure 6.10. Therefore, based on the field test data it can be

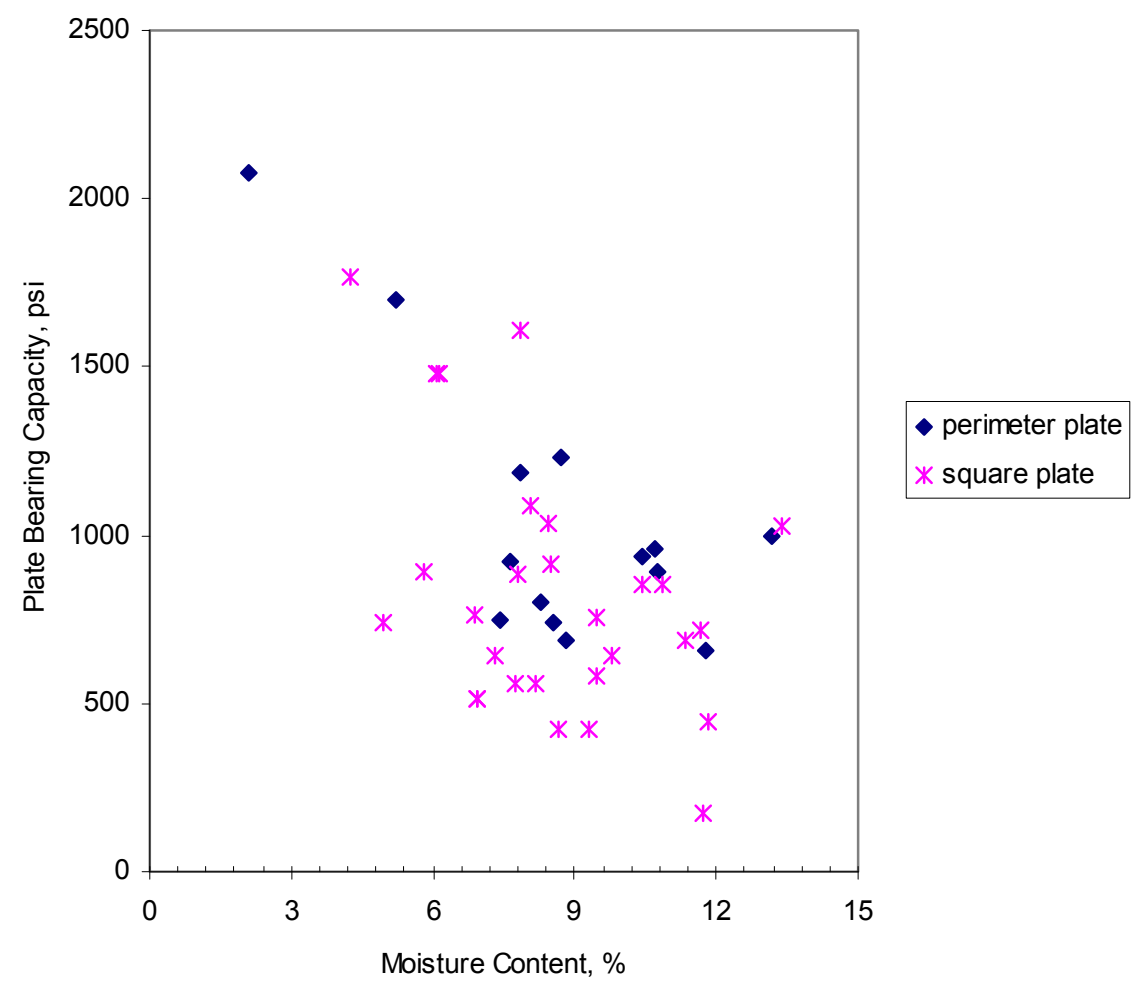

Figure 6.10. Natural moisture content vs bearing capacity plot for all the square and perimeter plate tests conducted at the five mines in Table 6.1. 
concluded that if the coal itself is stable, then the overall floor bearing capacity of a perimeter pillar is comparable to slightly higher than a square pillar of the same overall width (pre-perimeter cut barrier width). Extraction of coal from the barrier does not seem to alter the bearing capacity significantly. Although negligible, the odd shaped cuts taken from the barrier appear to help improve the overall bearing capacity. This conclusion will be further examined from a more fundamental point of view in the next section.

\subsection{Numerical Bearing Capacity Analysis of the Perimeter Cuts}

It has been shown in Chapter 5 that the nonlinear numerical modeling methodology can provide accurate estimates of the floor bearing capacity. It has also been shown that the displacement controlled loading over the region of a pillar or footing is the most effective approach to compute the limit value of the bearing capacity. The modeling results discussed in chapter 5 further revealed that the non-uniform vertical stress distribution on coal pillars did not alter the ultimate floor bearing capacity but only affected the path leading to the limit state. It must be apparent that when the coal mine bearing capacity problem involving square, rectangular and long barrier pillars can not be solved analytically, for shapes as complex as perimeter cut pillars such rigorous solutions are inconceivable. Therefore, once again numerical modeling approach is resorted to studying bearing capacity of the floor below perimeter cut pillars.

\subsubsection{Coal Pillar Stability}

From the in-situ plate test results given in tables 6.2 and 6.3, it was found that if the coal itself did not fail, then the overall bearing capacity of a perimeter cut pillar was almost the same as that of a square pillar or somewhat higher. Therefore, the first step in examining the system stability of a perimeter mined panel is to study the stability of coal itself in the perimeter pillars. Owing to the complex shape of the perimeter pillars, the simple tributary area method will not work for the average vertical stress estimation. As the typical perimeter mining layout in Figure 6.1 shows, there exist several square or rectangular pillars right 
next to a perimeter pillar in a panel. Therefore, when the overall system stability is considered for subsidence prevention, it is important to examine the stress distribution over pillars while including as many pillars in the immediate vicinity of the perimeter pillars as possible. Within the experience of the author the most effective way to simulate such complex situations is by using the displacement discontinuity code, LaModel developed by Heasley $(1998,2008)$. This numerical code has many attractive features to study the pillar stability in large areas of tabular deposits as compared to its other modeling counterparts. The problem geometry can be automatically imported from SurvCadd program, material properties corresponding to Mark-Bieniawski (Mark, 1992; Mark and Chase,1997) equation can be automatically computed and pillar stability factors are easily estimated. Further, when the requirements of a normal designer (simplicity, ease of use and quick results) are considered, there is no need to conduct more detailed finite element type analysis as the later approaches require a lot more expertise and are very time consuming.

As an example, the LaModel computed vertical stress distribution in the area involving perimeter mining for a coal mine in the Herrin no. 6 seam is shown in Figure 6.11 The average depth of cover for this coal mine is about $250 \mathrm{ft}$ and the mining height is between 5 and $6 \mathrm{ft}$. The normal pillar size employed in the rooms is $60 \mathrm{ft} \times 60 \mathrm{ft}$ (centers) with $20 \mathrm{ft}$ wide entries. For the modeling in Figure 6.11 , the maximum depth of $300 \mathrm{ft}$ was used to examine pillar stability under the worst possible scenario. The following default inputs were used in the LaModel analysis:

$\begin{array}{lll}\text { layer thickness } & - & 50 \mathrm{ft} \\ \text { modulus of deformation of coal } & - & 0.3 \mathrm{e} 6 \mathrm{psi} \\ \text { modulus of deformation of rock } & - & 3 \mathrm{e} 6 \mathrm{psi} \\ \text { in-situ strength of coal } & - & 900 \mathrm{psi}\end{array}$

There are several ways by which the stability factor of the perimeter pillar could be computed: 
a) use the individual element safety factors calculated by the LaModel program and average those numbers;

b) split the perimeter pillar into two parts: long continuous barrier and small coal stumps as shown in Figure 6.12. Export the vertical stress output from the LaModel program for the continuous pillar and stumps to estimate the average vertical stress of each. Calculate the strength of the individual parts using the Mark-Bieniawski (Mark, 2006) equation. For the coal stumps, compute the effective pillar width by means of Wagner's (1974) equation,

$$
w_{e}=\frac{4 A}{C}
$$

where $A$ is the area of the pillar and $C$, its perimeter in the plan view. Estimate the pillar strength by treating the coal stump to be a square pillar of width equal to $w_{e}$ given by equation 6.1. The strength of coal stumps may also be estimated using the procedure suggested by Mark and Zelanko (2001).

c) If preferred, the strength of the perimeter pillar could be calculated using three-dimensional numerical modeling such as that described by Gadde and Sheorey (2001), Morsey and Peng (2001) and Dolinar and Esterhuizen (2007). This detailed numerical modeling requires lots of inputs and user expertise to produce realistic estimate of the average pillar strength. When the perimeter pillar strength is computed by detailed modeling, the vertical stress for the stability factor computation could be obtained by averaging the LaModel output for all the elements representing the pillar;

d) finally, 3-D numerical finite element type stress analysis can be conducted on a representative area of a panel to estimate local element safety factors or plastic yield zones via a suitable rock mass failure criterion.

The stability factors estimated by the method (b) for the pillars shown in Figure 6.11 are given in Table 6.4. Since the stability factors for the stumps and the central long pillar are in excess of 2.0 (Mark and Chase, 1997), from coal strength point of view, the perimeter pillar's long-term stability is assured. 
The choice of the coal pillar stability analysis depends on the available resources and the level of detail necessary. For a majority of routine design purposes, the simple approach suggested in (b) above will be sufficient. It may be noted, however, that the partitioning of pillar into individual parts as in Figure 6.12 is somewhat unrealistic. In a perimeter pillar, attachment of coal stumps to the long central part will have mutually beneficial effect on the strength of the two individual components. Besides being extremely simple, however, ignoring the positive interaction effect will only lead to a conservative estimation of the perimeter pillar stability factor and thus will err on the safer side. If the perimeter pillar shows long-term stability by partitioning as in Figure 6.12, then its stability is automatically assured in the original condition. The dissection of the pillar, however, may prove unsatisfactory when the estimated stability factors are marginally lower than the desired value. In such cases it is preferable to use detailed numerical modeling for the stability analysis.

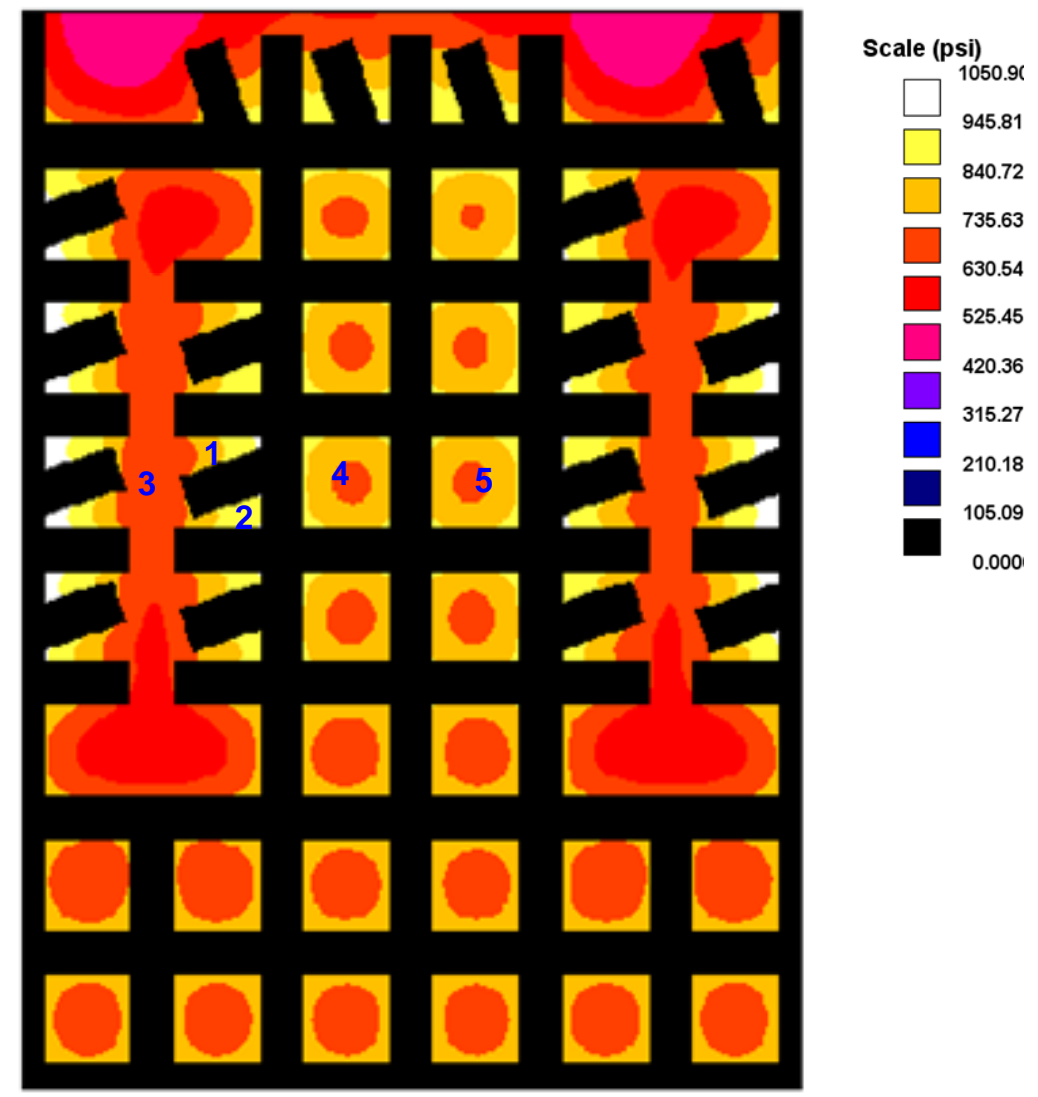

Figure 6.11. Vertical stress distribution on different pillars in a panel using perimeter mining. Table 6.4. Stability factors for different pillars in Figure 6.11. 


\begin{tabular}{|c|c|c|c|}
\hline Pillar No. & $\begin{array}{l}\text { Average } \\
\text { stress from } \\
\text { LAMODEL, psi }\end{array}$ & $\begin{array}{l}\text { Strength of } \\
\text { pillar, psi }\end{array}$ & $\begin{array}{l}\text { Stability } \\
\text { factor }\end{array}$ \\
\hline 1 & 765 & 1590 & 2.08 \\
\hline 2 & 726 & 1686 & 2.32 \\
\hline 3 & 668 & 2343 & 3.51 \\
\hline 4 & 719 & 3226 & 4.49 \\
\hline 5 & 730 & 3226 & 4.42 \\
\hline
\end{tabular}

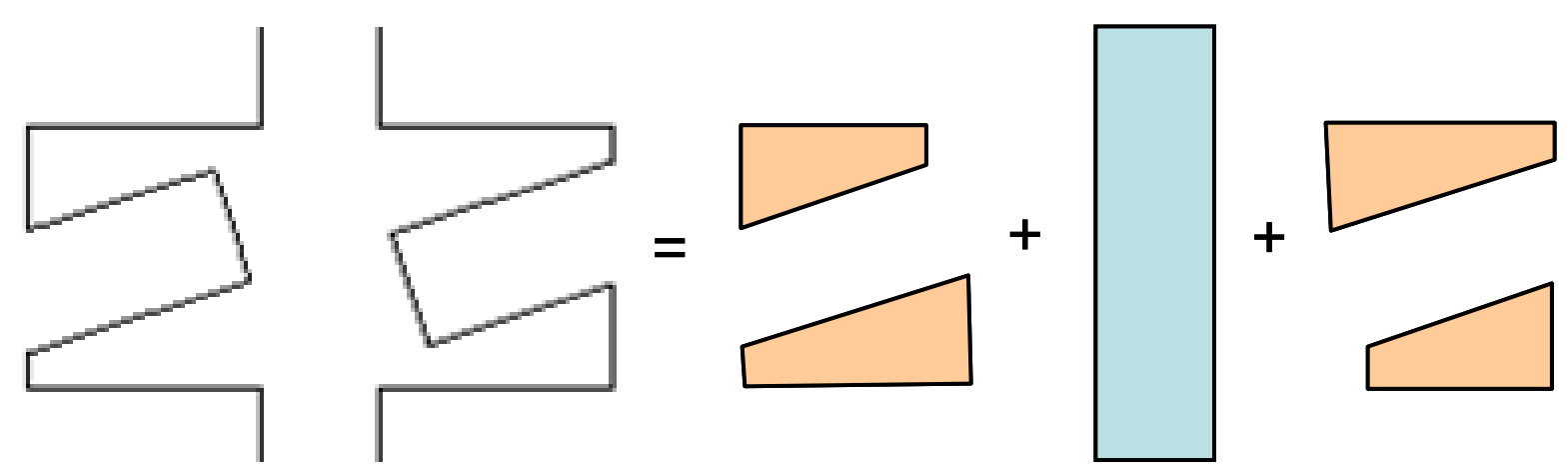

Figure 6.12. Partitioning of perimeter pillar into individual components.

\subsubsection{Floor Bearing Capacity}

Once the stability of coal stumps has been assured by LaModel or some other stress analysis, the next step is to examine if the average vertical stress on the perimeter pillar is less than the average bearing capacity of the floor below the pillar. So far no systematic method is available to compute the bearing capacity of floor when supporting a perimeter pillar. The in-situ plate tests in section 6.2 showed that the bearing capacity of a perimeter pillar can be computed without much error by assuming it to be a square pillar of the same width. With the field tests, however, it was not clear to what extent the limited size of the perimeter plate influenced the results. In this section, nonlinear three dimensional modeling as discussed in Chapter 5 will be used to study the bearing capacity of the full perimeter pillar as used in practice. Such modeling will also show if the conclusions from field plate tests are valid or not.

If every possible situation in underground coal mines is considered, then there will be an infinite number of combinations for which models need to be run. 
In order to make the modeling exercise manageable, the floor stability analysis in this section is restricted to the conditions assumed in the Vesic's nonhomogeneous model. The reason for this also lies in the fact that at present the Vesic's non-homogeneous bearing capacity model is the most popular method used in the Illinois Basin coal mines for floor stability analysis. Further, if the modeling results support the conclusions in section 6.2, then the same simple Vesic's model used for regular pillar stability could be used for perimeter pillar analysis as well. As discussed in Chapter 4, for normal mining conditions, if the floor stability factor (FSF) using the Vesic-Gadde approach is in excess of 1.5, then the pillar will have long-term stability. Similarly, for the short-term stability, the Vesic-Gadde FSF must exceed 1.0. So far, no case history could be found where short- or long-term floor stability issues were reported for perimeter mining and thus it can not be conclusively verified if the recommended Vesic-Gadde FSF values will work for the perimeter pillars as well. But, given the limited area covered by the perimeter pillar in a typical panel, it is felt that the suggested FSF will provide satisfactory pillar performance in all cases.

For a ready reference, the assumptions inherent in the Vesic's (1975) nonhomogeneous floor bearing capacity model are provided here.

- the solution is applicable only for two layer soil non-homogeneity;

- both layers are frictionless cohesive soils $\left(\phi_{1}=0, c_{1} \neq 0\right)$ and $\left(\phi_{2}=0, c_{2} \neq\right.$ 0 ) and each layer by itself is homogeneous;

- both layers satisfy Mohr-Coulomb failure criterion and behave as rigidperfectly-plastic materials;

- effect of adjacent foundations is not accounted.

When the above assumptions are considered, the only model variables that need to considered for the analysis are the two ratios $B / H$ and $c_{2} / c_{1}(B$ : pillar width; $H$ : weak layer thickness; $c_{2}$ : stronger layer cohesion; $c_{1}$ : weak layer cohesion). As the discussions in Chapter 5 showed, ignoring some of the realistic conditions in coal mines only results in conservative estimates of the floor stability which could be taken care of by the appropriate design floor stability factors. If necessary, the very general numerical modeling approach adopted here could be used to 
estimate the floor bearing capacity while considering as many site-specific variables as desired.

In order to compare the modeling results in this section with those of a square pillar, the same variable values as in section 5.5 were used here:

$$
\begin{array}{lll}
B / H & - & 100,40,20,10,5 \\
c_{2} / c_{1} & - & 1,2,3,4,5 .
\end{array}
$$

It may be reminded that the range of variables given above cover majority of the Illinois Basin coal mines. An example mesh used in the present modeling is shown in Figure 6.13. The scaled down version of the perimeter pillar in this figure corresponds to the plate size in Figure 6.3 except that in the models, the perimeter pillar is considered to be of infinite length. Even though the plate used in the field tests or the actual perimeter pillars do not have symmetric cuts, symmetry conditions are imposed in the model in Figure 6.13. This was done to reduce the model size and to simplify the modeling process. Since the goal of this modeling is to compare the performance of a square plate with a perimeter plate of same width, it is assumed that as long as the number of cuts is same, the pattern may not affect the results appreciably. It may also be reminded that when the effect of the surcharge and the weight of the soil are ignored, the size of the foundation will not have any influence on the computed bearing capacity.

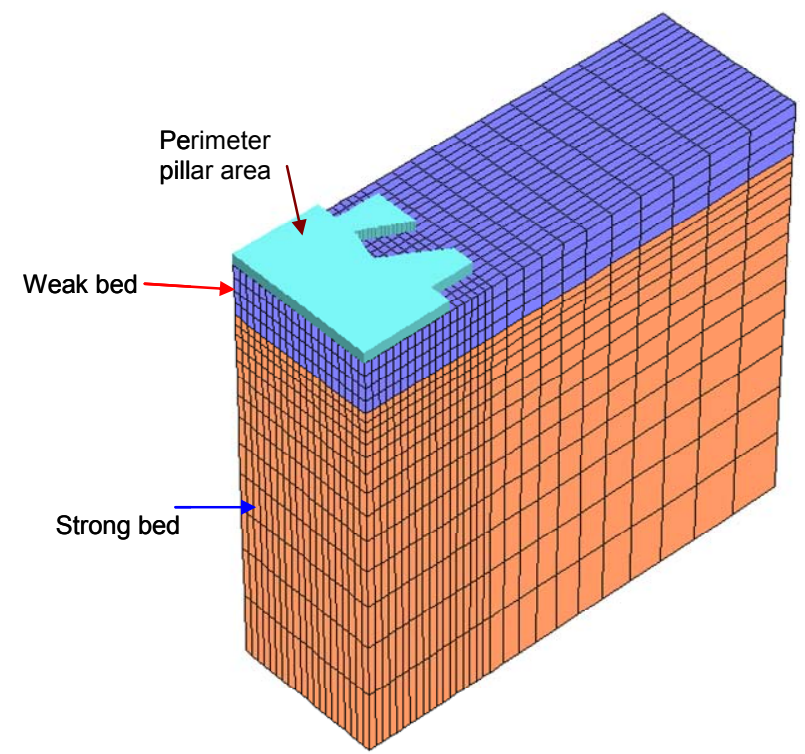

Figure 6.13. Part of the model used for the perimeter pillar floor bearing capacity analysis. 
The results of the numerical bearing capacity analysis for all the models are summarized in Table 6.5. The bearing capacity factors for the corresponding square pillar from numerical models and from Vesic's non-homogeneous equation (4.15) are also given in the table. The bearing capacity factor $\left(N_{m-m o d e l}\right.$ perimeter) must be multiplied by the weak bed cohesion $\left(c_{1}\right)$ to obtain the bearing capacity of the floor for the perimeter pillars. Some selective plots of the results in Table 6.5 are given in figures 6.14 and 6.15. A plot of the vertical displacement and vertical stress contours are shown in Figure 6.16 and Figure 6.17, respectively. Analysis of the numerical modeling results also clearly show that the average bearing capacity of the floor beneath a perimeter pillar is generally higher than that of a square pillar of same width, the same conclusion reached from the field plate tests.

Table 6.5. Summary of the numerical modeling results for the perimeter pillar models.

\begin{tabular}{|c|c|c|c|c|}
\hline $\mathrm{B} / \mathrm{H}$ & $c_{2} / c_{1}$ & $N_{m \text {-model-square }}$ & $N_{\text {m-model-perimeter }}$ & $N_{m \text {-Vesic-square }}$ \\
\hline 0 & 1 & 5.38 & 5.16 & 6.17 \\
\hline 100 & 2 & 10.47 & 9.96 & 10.01 \\
40 & 2 & 9.79 & 9.67 & 7.73 \\
20 & 2 & 8.47 & 8.52 & 6.79 \\
10 & 2 & 6.45 & 7.77 & 6.27 \\
5 & 2 & 5.60 & 6.63 & 6.01 \\
\hline 100 & 3 & 15.14 & 14.76 & 11.93 \\
40 & 3 & 13.29 & 14.13 & 8.35 \\
20 & 3 & 8.76 & 11.15 & 7.01 \\
10 & 3 & 6.45 & 8.29 & 6.31 \\
5 & 3 & 5.60 & 6.66 & 5.95 \\
\hline 100 & 4 & 19.37 & 19.55 & 12.99 \\
40 & 4 & 15.74 & 18.55 & 8.67 \\
20 & 4 & 8.77 & 12.99 & 7.12 \\
10 & 4 & 6.45 & 8.29 & 6.33 \\
5 & 4 & 5.60 & 6.66 & 5.93 \\
\hline 100 & 5 & 23.13 & 24.25 & 13.64 \\
40 & 5 & 17.01 & 22.97 & 8.86 \\
20 & 5 & 8.77 & 13.43 & 7.19 \\
10 & 5 & 6.45 & 8.29 & 6.34 \\
5 & 5 & 5.60 & 6.66 & 5.91 \\
\hline
\end{tabular}

From the numerical modeling results given above, the following specific conclusions could be drawn about the floor bearing capacity of the perimeter pillars: 
- the limited length of the perimeter plate used in the in-situ tests did not have a significant influence on the results;

a)

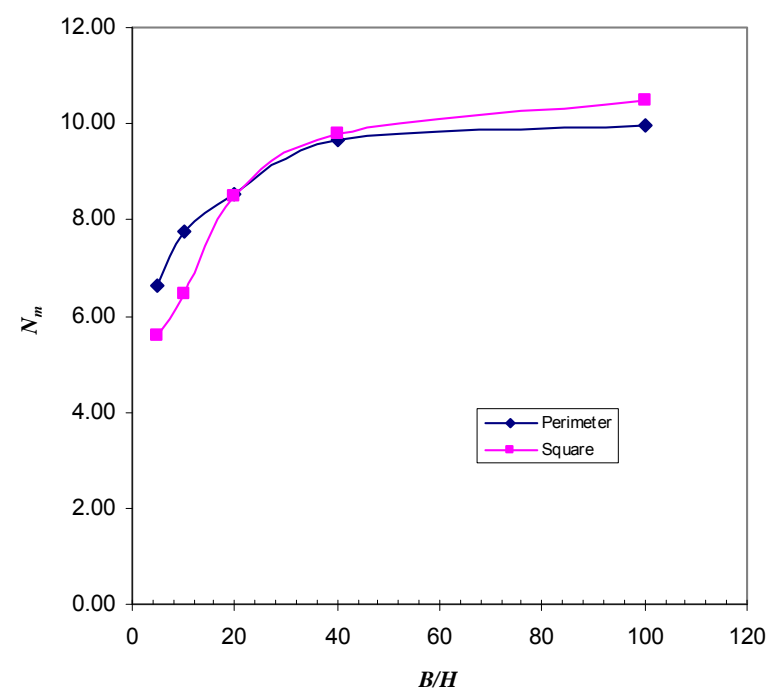

b)

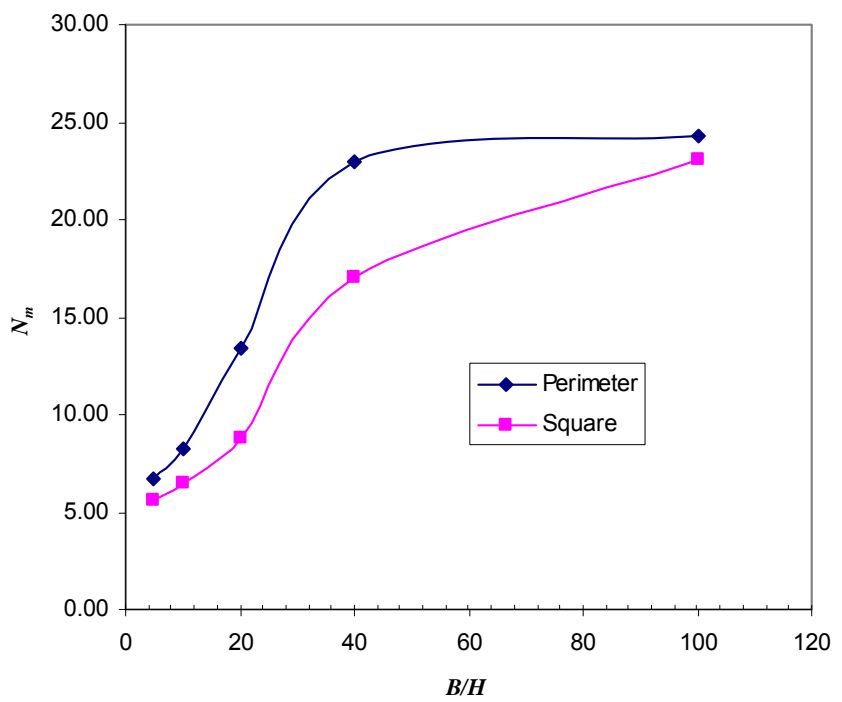

Figure 6.14. Change in $N_{m}$ with $B / H$ when (a) $c_{2} / c_{1}=2$ and b) $c_{2} / c_{1}=5$.

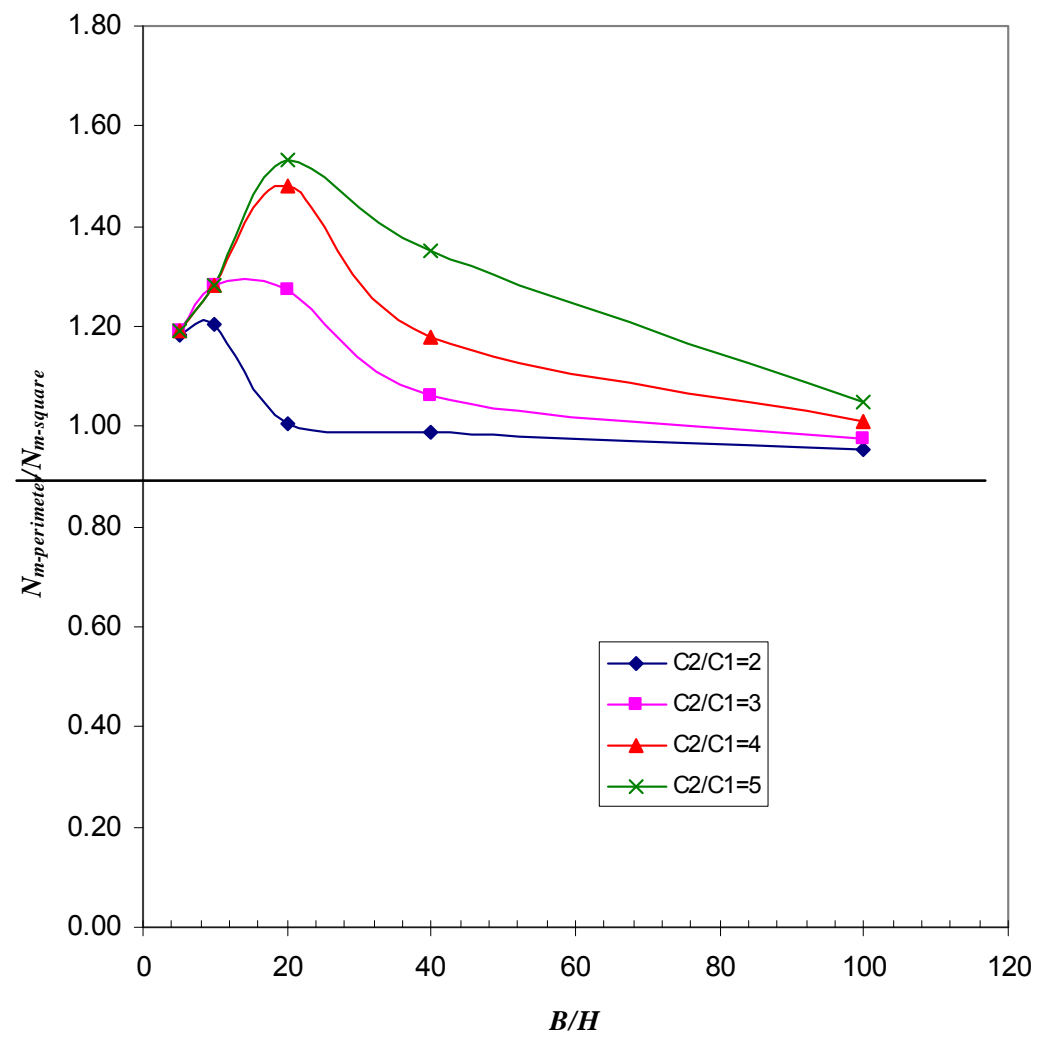

Figure 6.15. Change in the ratio of the model computed perimeter and square pillar bearing capacity for different $c_{2} / c_{1}$ values. 
Contour of Z-Displacement Magfac $=0.000 \mathrm{e}+000$ Live mech zones shown $-6.0000 \mathrm{e}-001$ to $-5.0000 \mathrm{e}-001$ -5.0000 e-001 to 0.0000 e+000 0.0000 e +000 to $5.0000 \mathrm{e}-001$ $5.0000 \mathrm{e}-001$ to $1.0000 \mathrm{e}+000$ 1.0000 e+000 to $1.5000 \mathrm{e}+000$ $1.5000 \mathrm{e}+000$ to $2.0000 \mathrm{e}+000$ 2.0000 e+000 to $2.5000 e+000$ 2.5000 e+000 to $3.0000 \mathrm{e}+000$ $3.0000 e+000$ to $3.4071 e+000$ nterval $=5.0 \mathrm{e}-001$

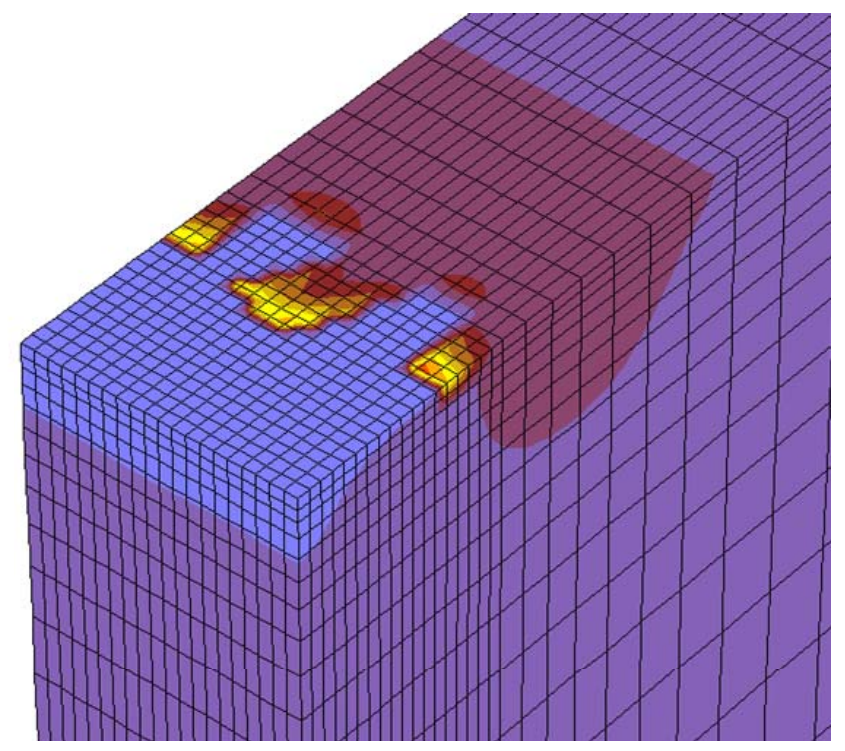

Figure 6.16. Vertical displacement contours at the limit state for $B / H=20$ and $c_{2} / c_{1}=3$ (negative sign shows downward movement).

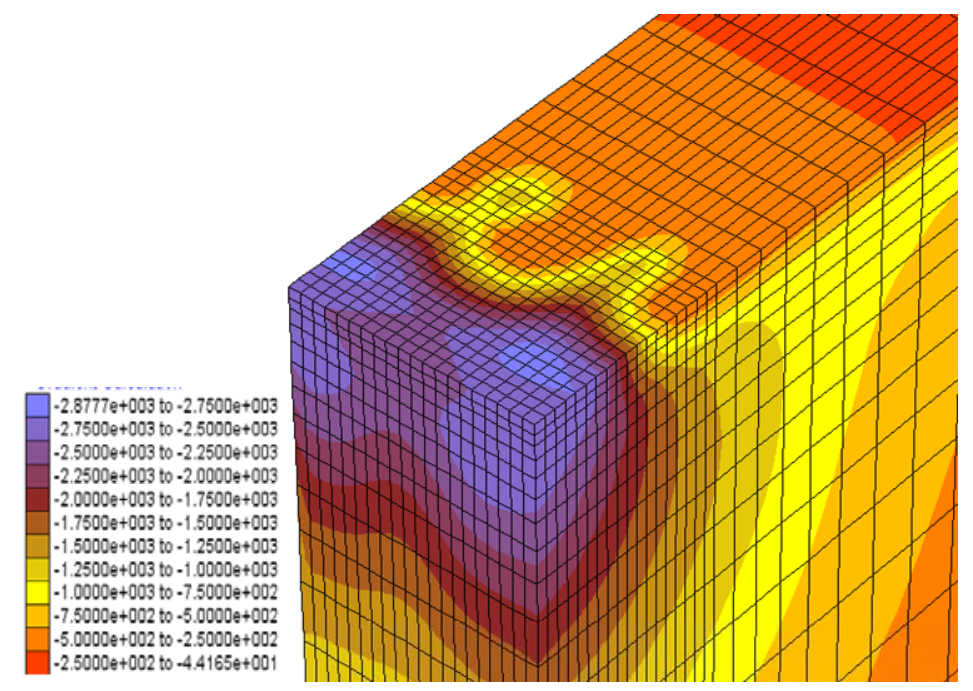

Figure 6.17. Vertical stress contours at the limit state for $B / H=20$ and $c_{2} / c_{1}=3$ (negative sign shows compression).

- the difference between the square and perimeter pillar floor strengths depends on both $\mathrm{B} / \mathrm{H}$ and $\mathrm{c}_{2} / \mathrm{c}_{1}$ ratios;

- the bearing capacity of a perimeter pillar is in general greater than a square pillar of the same width; 
- for lower weak bed thicknesses and when the strength difference between the two floor layers is smaller, the perimeter pillar bearing capacity is slightly lower than that of a square pillar of the same width;

- except for the infinitely thick weak floor condition, Vesic's nonhomogeneous model for square pillars consistently underestimates the floor strength of the perimeter pillar of the same width. Therefore, the use of Vesic's solution will result in conservative estimation of the floor stability factor for perimeter pillars as was the case with the square pillars;

- for these and the reasons given in Chapter 4, the Vesic-Gadde model could be used with the recommended floor stability factors for routine perimeter pillar designs.

From the above discussions, one might make the inference that a square pillar with and without perimeter cuts will have the same floor stability. While the cut and uncut square pillars might have similar bearing capacity, the floor stability factors will not be the same. This is because the creation of the perimeter cuts will reduce the pillar's load-bearing area, which will increase the average vertical stress applied to the floor. Consequently, the perimeter cut pillar will have a smaller floor stability factor.

The next obvious question that needs to be answered is the reason for the trends shown by the field plate tests and the numerical analysis. Once again, the results from the numerical models provide the explanation. In order to illustrate the reason for the better than expected performance of the perimeter pillars, a plot of the deformed geometry of the floor along with the displacement vectors is shown in Figure 6.18 for the perimeter pillar and in Figure 6.19 for the square pillar. For comparison purposes, for the same model inputs, the results obtained from a model run with a long continuous barrier pillar of the same width are plotted in Figure 6.20. The plots in these three figures correspond to the limit state of the floor. It appears that because of the restraint in the out of plane direction for the long continuous barrier, the floor material flows plastically in the horizontal direction similar to the way a cheese cube compressed between two steel plates would flow. In the case of the square pillar, the floor still moves in the 


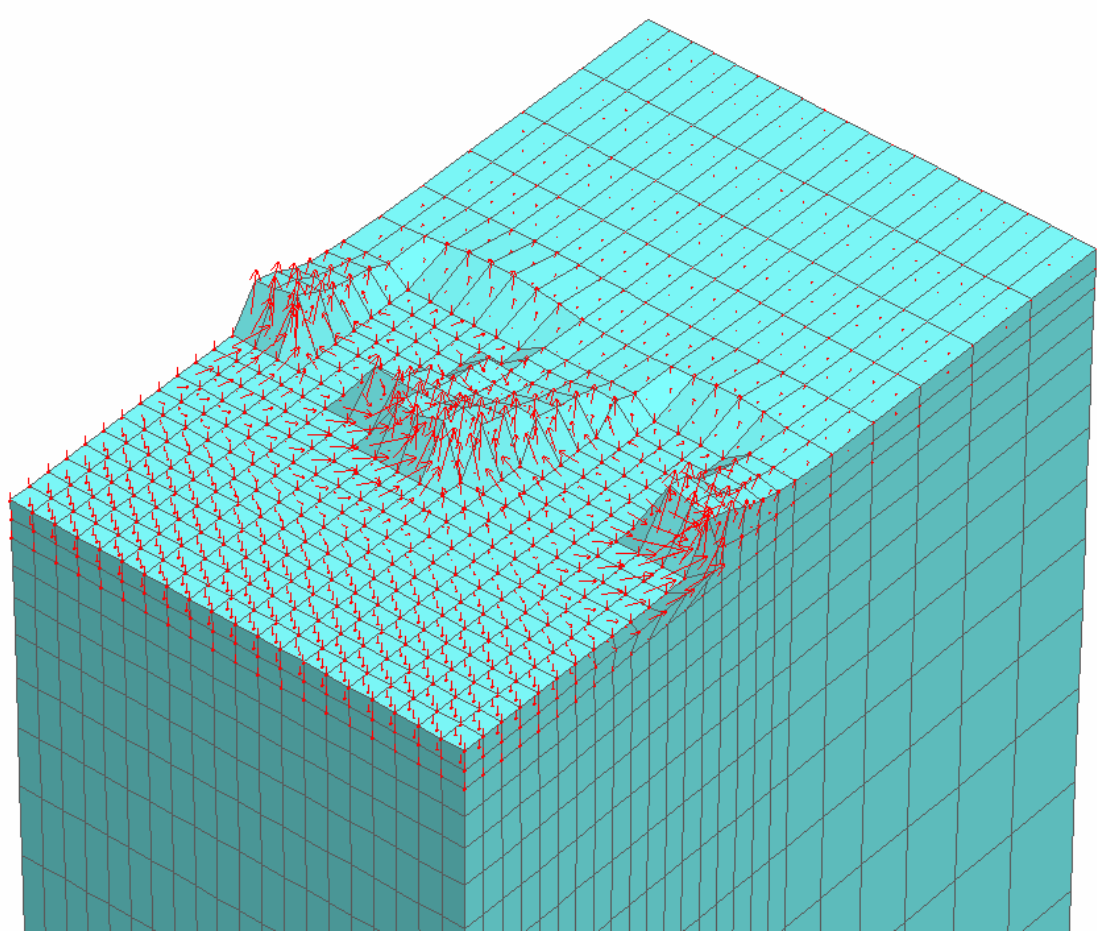

Figure 6.18. Deformed floor and displacement vectors for perimeter pillar when $B / H=20$ and $c_{2} / c_{1}=3$ (only half width is shown).

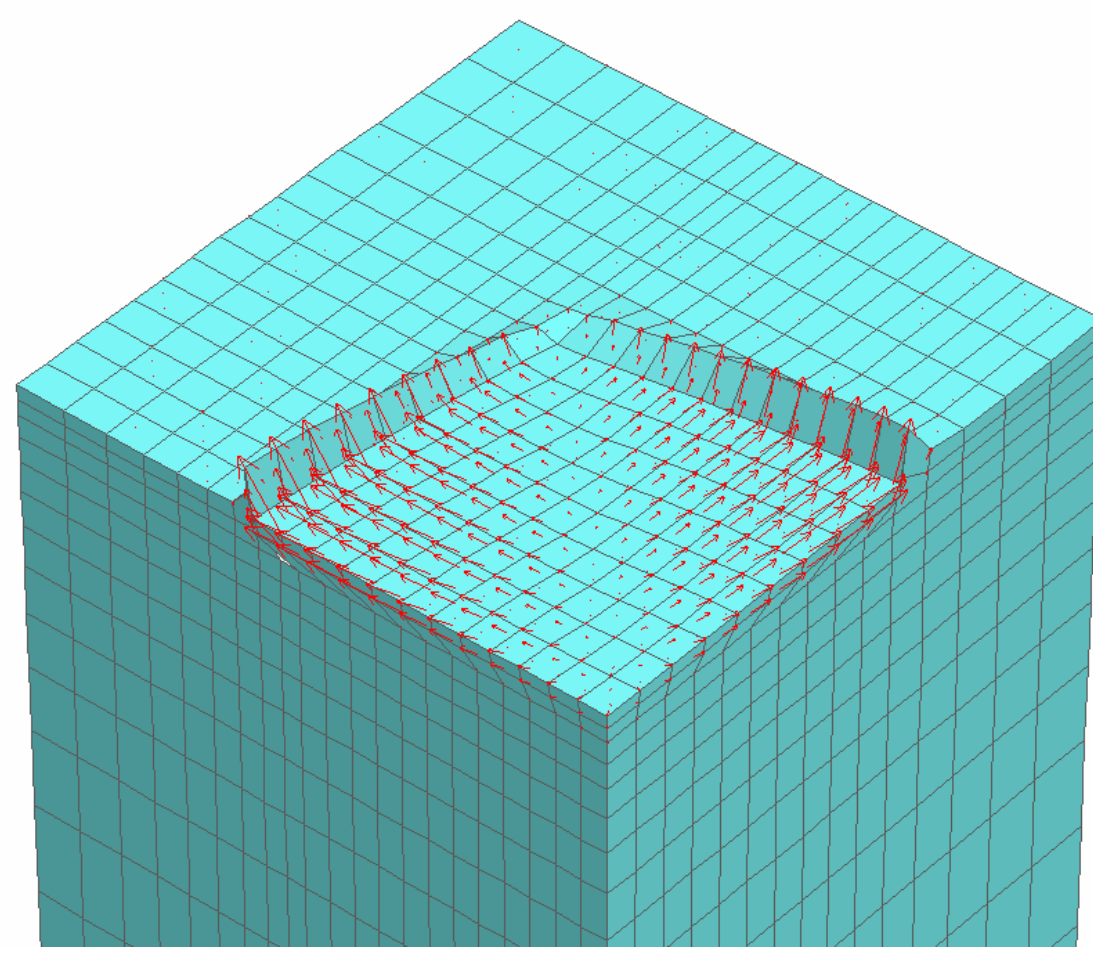

Figure 6.19. Deformed floor and displacement vectors for square pillar when $B / H=20$ and $c_{2} / c_{1}=3$ (only a quarter pillar area shown). 


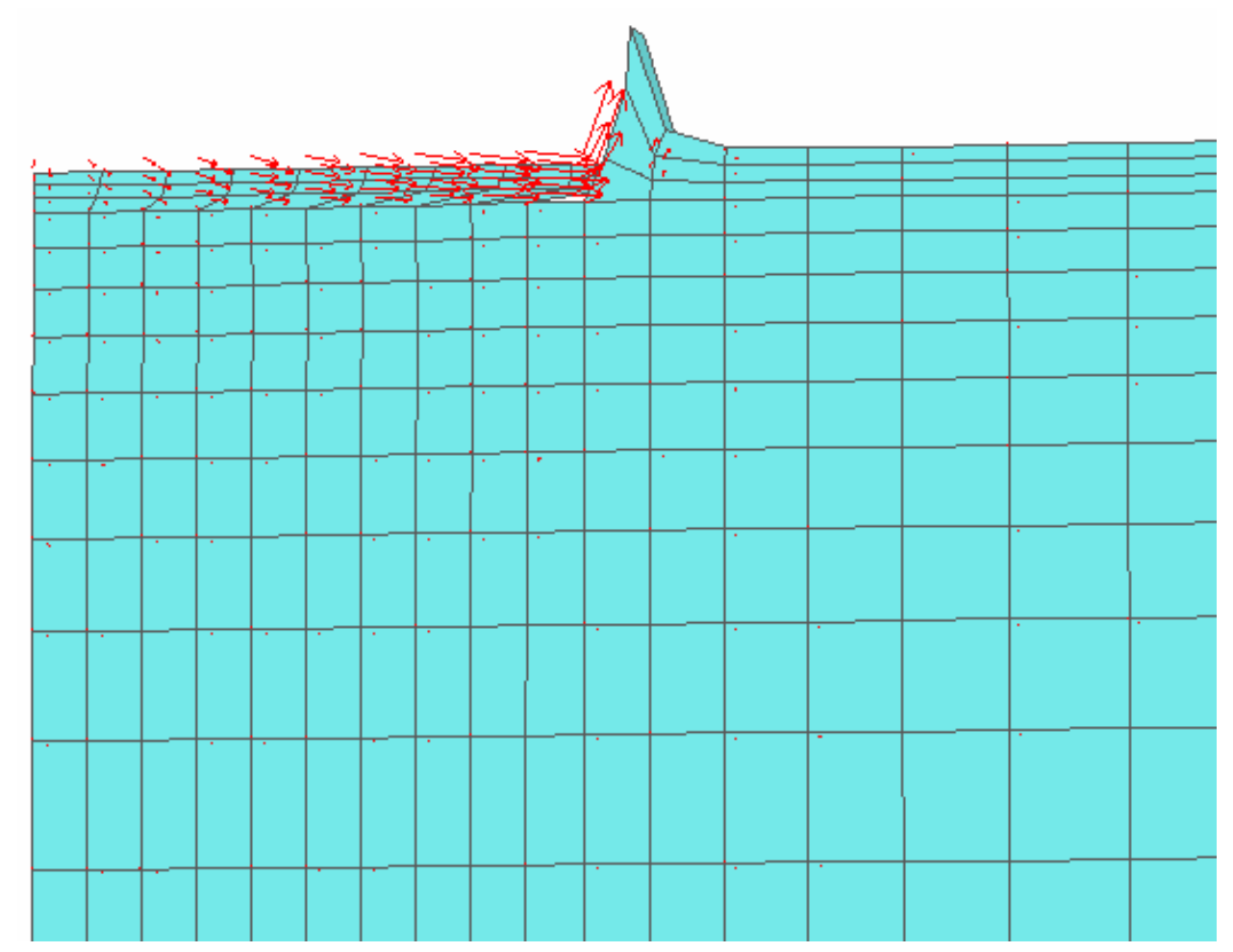

Figure 6.20. Deformed floor and displacement vectors for a strip pillar when $\mathrm{B} / \mathrm{H}=20$ and $c_{2} / c_{1}=3$ (only half pillar area shown)

horizontal direction at the limit state, but the amount of material oozing out keeps reducing from the mid-section of the pillar towards the corner. The diagonal symmetry in the square pillar deformation seen in Figure 6.19 is the reason for the higher floor bearing capacity as compared to a strip pillar of the same width. In contrast to the strip and square pillars, creation of the perimeter cuts in the barrier significantly altered the floor movement beneath the pillar as seen from Figure 6.18. In this case, instead of complete horizontal movement, much of the floor was displaced vertically at the limit state. Further, only a small area adjacent to the perimeter cuts moved horizontally. In essence, more work was required to bring the floor material to limit state underneath a perimeter pillar as compared to a square or strip pillar of same width. The extra work is consumed towards bringing the entire floor to its peak capacity while displacing it in the vertical direction, which is harder than pushing out along the horizontal path as happened in the case of square and strip pillars. 


\subsection{Steps in Assessing the Perimeter Pillar Floor Stability}

Based on the above work, for designing stable perimeter pillars the following step-by-step approach is suggested:

1. drill a reasonable number of holes in the area of interest,

2. run geophysical logs (gamma, density, caliper and where possible, sonic) in each borehole available (cored or not cored),

3. using the geophysical logs and physical observations of the core, identify the weaker section of the immediate floor when the total thickness of the claystone bed is very high (based on the past experience, if the claystone bed is thicker than $4 \mathrm{ft}$, careful examination of the geophysical logs and cores is necessary to identify the weaker section. In such cases there is a high chance that the entire claystone may not be weak);

4. determine the natural moisture content of the well protected immediate floor cores on 6 inches to $1 \mathrm{ft}$ intervals (moisture change with floor depth may also be used to estimate the weak floor thickness);

5. if enough core recovery is available, test the main floor for shear strength preferably in triaxial cells. Otherwise, determine the moisture content, if the stronger floor is claystone;

6. conduct a numerical stress analysis to estimate the vertical stress distribution on the perimeter pillars using LaModel or some other program;

7. if detailed numerical models are not used to study the local stability of the perimeter pillar, then split the pillar into solid long central part and smaller stumps as shown in Figure 6.12. Estimate the strength of the stumps using the Wagner's equivalent pillar width formula given in equation (6.1) and the Mark-Bieniawski pillar strength equation;

8. similarly, compute the strength of the central long pillar using the MarkBieniawski formula;

9. using the average vertical stress on the stumps and the long pillar obtained from the numerical modeling, estimate the pillar stability factors. If the stability factor for both the stumps and the central part of the perimeter pillar 
exceeds 2.0, then the pillar's long-term stability is assured from the coal strength point of view;

10. using the floor moisture content data, estimate the cohesion of the weak immediate floor $\left(c_{1}\right)$ by the appropriate Gadde's equation given in chapter 4;

11. similarly, estimate the cohesion of the stronger bed $\left(c_{2}\right)$ using equation (4.28) or (4.29);

12. by treating the perimeter pillar as a square pillar of width equal to the precut size as shown below, estimate Vesic's bearing capacity factor $N_{m}$ using equation (4.15);

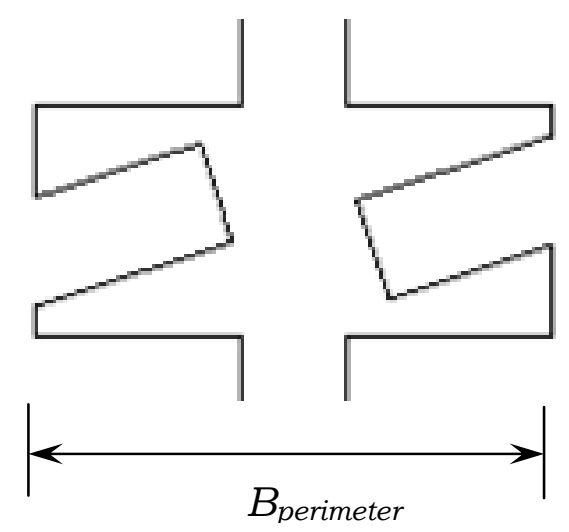

13. using all the above inputs, calculate the floor bearing capacity by equation (4.14);

14. compute the average vertical stress on the entire perimeter pillar from the numerical models in step 6 above;

15. for the long-term stability choose a pillar size that ensures at least a VesicGadde stability factor of 1.5 against the floor bearing capacity failure;

16. if any conditions exist that invalidate the assumptions in Vesic's nonhomogeneous soil model, it is better to use the numerical modeling approach described in section 6.3 for an accurate estimation of the floor bearing capacity.

\subsection{Chapter Summary}

The key points of the research presented in this chapter could be summarized as given below: 
- systematic research has been undertaken for the first time to study the bearing capacity of weak floor materials underneath a perimeter pillar;

- some in-situ plate bearing tests were conducted at five coal mines in three states of the Basin using a specially designed plate template;

- three-dimensional nonlinear numerical modeling was conducted to study the effect of different variables on the floor bearing capacity of a perimeter pillar;

- the plate test data and the modeling showed that the floor bearing capacity of a perimeter pillar is as good as or better than a square pillar of the same width;

- under normal Illinois Basin mine conditions, as long as the coal in the perimeter pillar exhibits long-term stability, the floor stability analysis could be done using the Vesic-Gadde model and the recommended stability factors. For any special conditions, the numerical modeling method is a better option. 


\section{CHAPTER}

\section{CONCLUSIONS}

In the preceding chapters, detailed conclusions pertinent to the contents of each chapter were provided. Therefore, in order to be not overly repetitive, only major conclusions of the research are provided below.

1. Owing to the sea transgression and regression on geological time scale and the resulting cyclothems, in the Illinois Basin coal mines, every major coal seam is consistently underlain by weak underclay or claystone material. Consequently, mining system designs in the Basin must consider the stability of weak floor for both short- and long-term stability.

2. The depositional environment and some past studies show that the nature of the immediate floor may not be the same throughout the Basin. The extensive database on several laboratory properties put together for this research conclusively show that the average engineering behavior of the weak floor below the Herrin No. 6 and its equivalent seams (No. 11 in KY) differs considerably between the Eastern and the Western shelves of the Basin. While there are similarities, the differences in the engineering nature are significant to propose this dichotomy. Owing to the limited amount of data from the Western shelf, similar conclusion could not be reached for the No.5 or No.7 seam floors. Considering the depositional environment, until contrary evidence is available, it is suggested to treat the floors associated with all major coal seams to be different in the Eastern and the Western shelves.

3. The DuQuoin monocline with its northward hypothetical extension could be considered as the separating line between the Eastern and Western shelves. For practical purposes, the US route 51 in Illinois may be used to divide the Basin into the two shelves. Mines that are located to the west of the route 51 will fall in the Western shelf and those to the east in the Eastern shelf. 
4. When the immediate floor is vaguely labeled as "claystone" and if its thickness exceeds 3.5 to $4 \mathrm{ft}$, then efforts must be made to see if only the top portion of the bed is underclay or weak claystone. Physical observation of cores and moisture content change with depth below the seam could provide some idea on the differences in the quality of the floor. Limited work discussed in this dissertation show that tremendous potential exists for the basic geophysical logs for weak floor thickness estimation. Similarly, the laboratory data discussed in Chapter 2 suggests that sonic logging could be used for weak floor engineering property estimation.

5. The laboratory database put together for this research is easily the largest such effort ever made on the Illinois Basin weak floor covering all three states of the Basin. In addition to examining the practical significance of the trends shown by individual laboratory properties, some soil mechanics concepts have been utilized to qualitatively assess the meaning of different properties. Interpretation of the index tests using the soil mechanics guidelines may seem inadequate given the lack of direct validation studies for mining application. Nonetheless, the general qualitative interpretation of the index tests in understanding the nature of the floor is perhaps acceptable as the fundamental mechanisms remain valid.

6. The huge laboratory database was also used to develop inter-relationships between different properties. These studies show that the simple, inexpensive and reliable moisture content test can provide a reasonable estimate of every engineering property needed for ground control application. Therefore, the moisture content of the floor is all that is necessary for a preliminary floor stability analysis. The empirical relations have poor to good $R^{2}$ values. Given this, it may be tempting to dismiss the value of the developed correlations. It must be remembered, however, that the equations were developed by lumping together data collected from different coal mines that are scattered in three states of the Basin. When some variability in rock properties exist even on such small scales as a few feet, it is not surprising to see significant scatter when data from an area as vast as the Illinois Basin is analyzed with a 
single equation and as function of a single independent variable. When the multitude of variables that could impact the floor properties are kept in mind, the correlations developed in this dissertation are extremely significant for the trends they display. It is not recommended, however, to use the empirical relations as a substitute for site-specific laboratory testing when such an opportunity exists. It is anticipated that the laboratory correlations developed will be mainly used for a thorough floor stability analysis when dealing with older, abandoned mines where the required inputs are not normally available.

7. Similar to the laboratory studies, the largest in-situ plate test database has been assembled for this research for weak floors in all three states of the Basin associated with three major coal seams. When compared against this data, the conservative nature of the existing plate bearing capacity equations was revealed. The popular Speck's equation works reasonably well up to a moisture content of about $8 \%$, after which the underestimation is significant. For moistures above $12.4 \%$, Speck's equation produces physically meaningless negative floor strength. The different SIUC equations form the lower bound to the plate test data and hence are ultra conservative. Considering the differences in the nature of the floor between the Eastern and Western shelves of the Basin, the following new equations have been developed to estimate the cohesion of the weak floor $\left(c_{1}\right)$ in psi for use with the Vesic's non-homogeneous model:

$$
c_{1}=\frac{4164 e^{(-0.2 M C)}}{6.17},
$$

for the Eastern shelf mines, and

$$
c_{1}=\frac{1905 e^{(-0.1 M C)}}{6.17}
$$

for the Western shelf mines. In both these equations $M C$ is the natural moisture content of the underclay or weak claystone.

8. When the strong bed in the floor below underclay is claystone, the following equations have been developed to estimate its cohesion $\left(c_{2}\right)$ in psi for use with the Vesic's model: 


$$
c_{2}=\frac{6443 e^{(-0.34 M C)}}{2},
$$

for the \#6 seam in Illinois and \#11 seam in Western Kentucky. Similarly,

$$
c_{2}=\frac{10041 e^{(-0.4 M C)}}{2},
$$

for the \#5 seam in Illinois, Indiana and \#9 seam in Western Kentucky. For the lack of any data and for the similarity in the floor nature between the \#5 seam and the Danville No.7 seam as discussed in Chapter 2, Equation (7.4) may also be used for the later.

9. If the floor bearing capacity is estimated by any methods that require the angle of internal friction value, then the empirical approach suggested by Mesri and Abdel-Ghaffar shown in Figure 7.1 could be used as the first approximation.

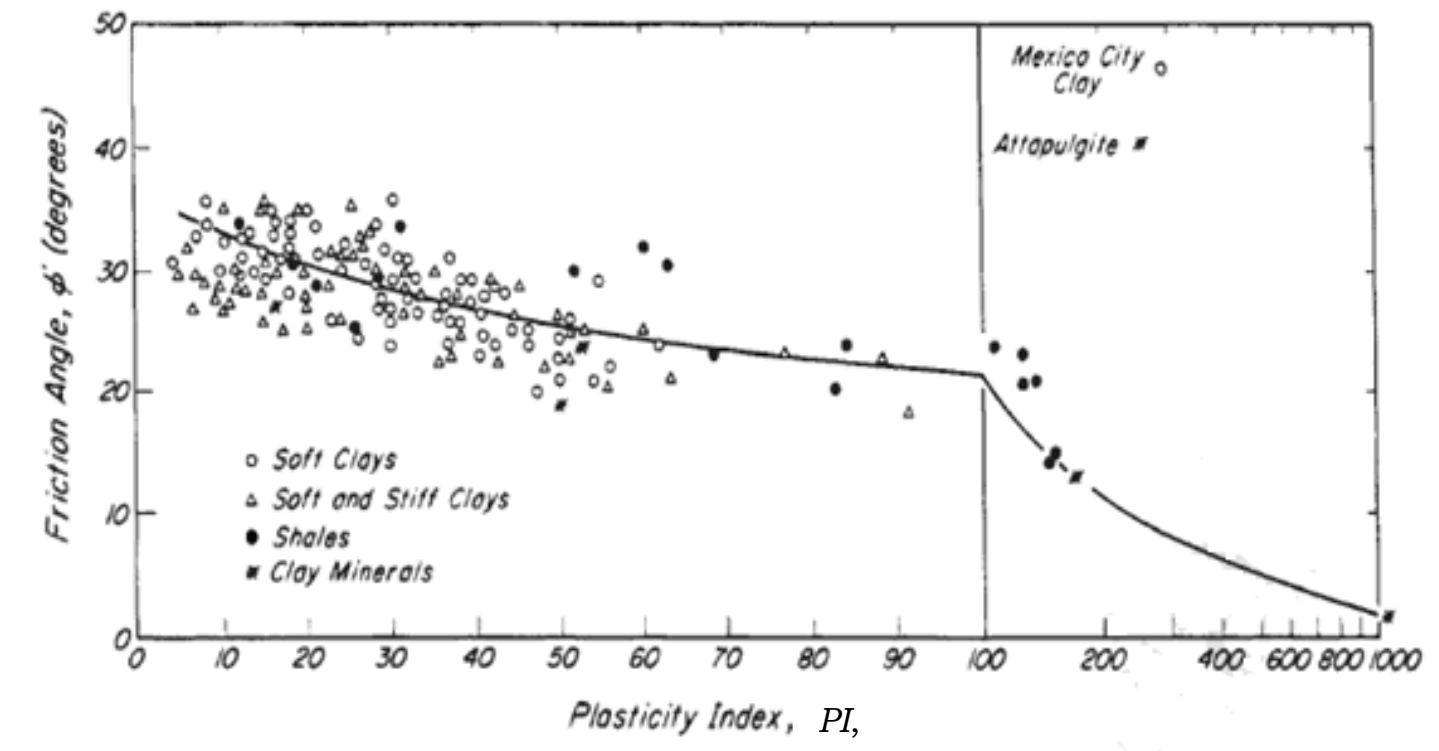

Figure 7.1. Peak friction angle as a function of plasticity index (Mesri and Abdel-Ghaffar,1993).

Similarly, if the residual friction angle is needed for the stability analysis, then the empirical methodology given by Stark and Eid in Figure 7.2 could be used. The plasticity index $(P I)$ and the clay-fraction size $(C F)$ needed for using Figures 7.1 and 7.2 could be approximately estimated by, for the Herrin No.6 and equivalent seam floors: 


$$
\begin{aligned}
& L L=39+3.0 M C \\
& P L=22+2.2 M C,
\end{aligned}
$$

for the Springfied No.5 and equivalent seam floors:

$$
\begin{aligned}
& L L=23+1.46 M C \\
& P L=13.5+0.7 M C .
\end{aligned}
$$

And the plasticity index $(P I)=L L-P L$. Similarly, the clay-size fraction $(C F)$ for Figure 7.2 could be approximately calculated from moisture content $(M C)$ using the following relations.

The Herrin seam and its equivalents:

$$
C L A Y_{\text {FRAC }}=C F=21 M C^{0.48}
$$

The Springfield seam and its equivalents:

$$
C L A Y_{\text {FRAC }}=C F=20 M C^{0.46}
$$

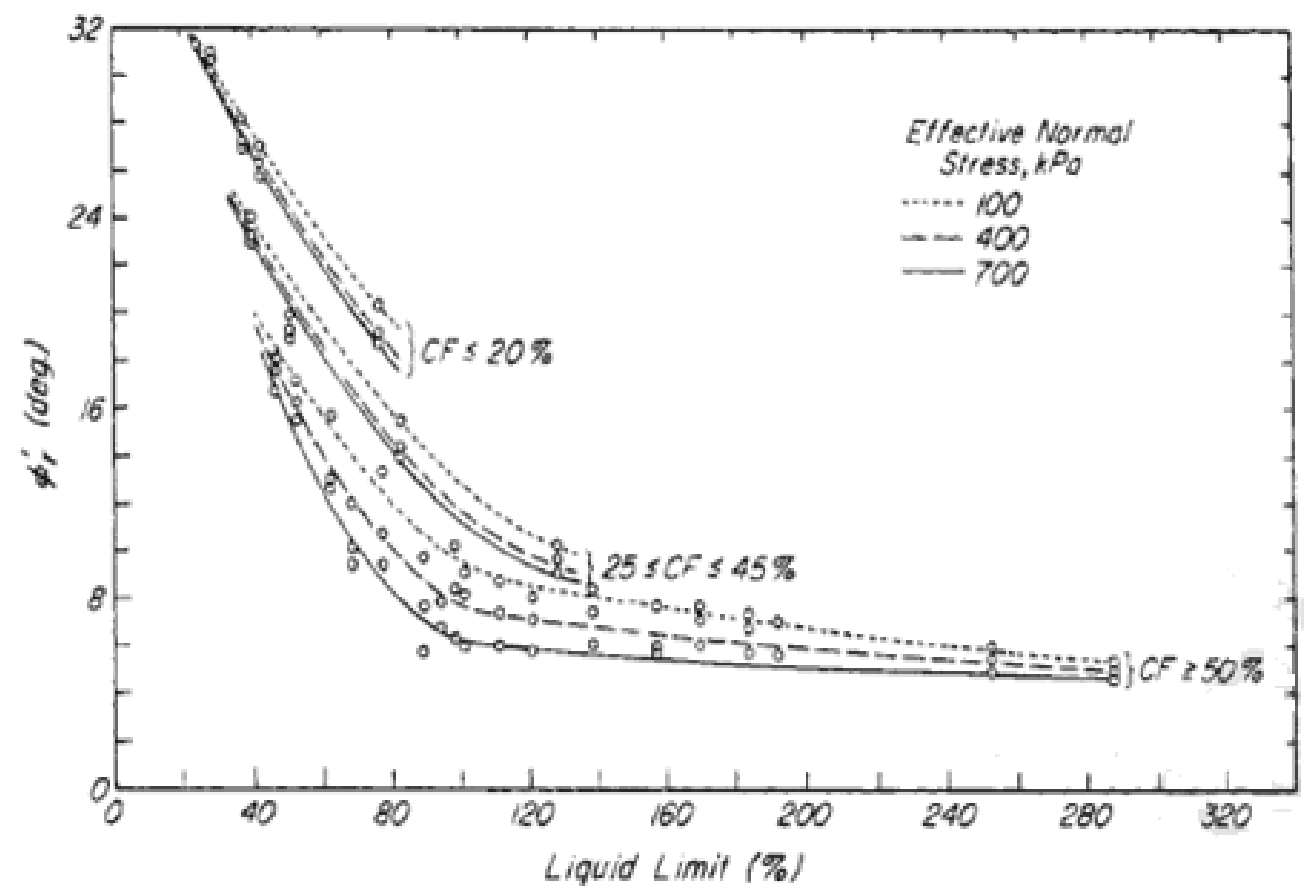

Figure 7.2. Residual friction angle as a function of the liquid limit and clay-size fraction (Stark and Eid, 1994).

Even though the relation between the modulus of deformation $\left(D M_{50}\right)$ of the floor and the moisture content is very poor, for the lack of a better 
alternative, the following SIUC relation could be used as the first approximation:

$$
D M_{50}=54176(M C)^{-0.6}
$$

The modulus value is estimated in psi in equation (7.9).

10. Among the different soil mechanics models for the bearing capacity estimation, Vesic's two-layer non-homogeneous model is by far the most popular method used in the Basin. This model is currently used in two different forms: Vesic-Speck and Vesic-CHC. Comparison of the performance of these two models and the new Vesic-Gadde approach against several case histories of stable and unstable floors showed that the Vesic-Gadde method provided the best prediction of floor conditions among the three. The large case history analysis showed that the long-term stability of floor could be ensured if the Vesic-Gadde floor stability factor (FSF) is at least 1.5. Given the range of depths in the case histories, the recommended 1.5 FSF is valid only up to a depth of about $250 \mathrm{ft}$. Because some stable case histories have depth in between 250 and $300 \mathrm{ft}$, the 1.5 design FSF may be used with caution in this range. However, at depths in excess of $300 \mathrm{ft}$, such high FSF as 1.5 may not be necessary for the long-term stability. Until some case histories are available, floor stability factors in the range of 1.3 to 1.5 may be used with the Vesic-Gadde method for long-term stability at depths exceeding $300 \mathrm{ft}$.

11. The non-uniform vertical stress distribution on pillars could cause localized floor heave without affecting the overall stability of the floor below a pillar. Consequently, short-term floor failures could occur for any stability factor below 1.5. However, when the Vesic-Gadde floor stability factor is less than 1.0, the chances of some floor failure occurring are high. Even though the case history analysis did not provide any conclusive information on the critical floor stability factor for the short-term stability by the Vesic-Speck or VesicGadde approaches, until more data is available it is recommended to use 1.0 as the design FSF for this purpose. In reality, since a majority of the Illinois Basin mines design their pillars for long-term floor stability, the recommended 
FSF for the short-term stability will not be of much practical consequence anyway.

12. Through this research it was possible to define the approximate limiting conditions within which the Vesic-Speck approach may be used. If the moisture content is less than $8 \%$ for the Western shelf mines and below $10 \%$ for the Eastern shelf, then the Vesic-Speck approach may also be used with 1.5 floor stability factor to prevent surface subsidence. For moisture contents above these limits, long-term floor stability is possible for Vesic-Speck floor stability factors less than 1.5. Similar to Vesic-Gadde, for short-term stability a minimum of 1.0 FSF is suggested for the Vesic-Speck method. The Vesic$\mathrm{CHC}$ computed ultra conservative floor strength and FSF $=0.5$ explains the long-term stable and unstable cases well.

13. When all the geometric and material property aspects of a typical coal mine bearing capacity problem are considered, it is impossible to provide a closedform solution for the floor strength estimation. Three-dimensional numerical modeling, however, provides a viable alternative for this purpose while incorporating all of the idiosyncrasies of a typical coal mine. Detailed modeling conducted in this dissertation showed the significant to negligible influence of several variables on floor bearing capacity. Through modeling, the accuracy of Vesic's model has been verified for the first time. It was found that the popular Vesic's model can not provide accurate solutions even for the conditions for which it was supposed to work.

14. Despite the inaccuracy of Vesic's two-layer model, for normal mining conditions and routine applications, it is suggested to use the Vesic-Gadde approach with the recommended floor stability factors. This is because the design floor stability factor of 1.5 indirectly accounts for the inaccuracies of the model. However, if special circumstances like pooling of large amount of water, random property variation over longer distances, time-dependent deformation, more than two layers of strata in the immediate floor, etc. exist, then the floor bearing capacity might be computed using the general numerical modeling methodology developed in this research. However, if the 
modeling methodology is adopted, then the design stability factors used in the foundation engineering may be used for the pillar sizing - not the 1.5 value recommended for the Vesic-Gadde approach. In the foundation engineering applications, safety factor values in the range of 2 to 3 are recommended for spread footings.

15. Finally, for the first time field and numerical studies were conducted to understand the stability of weak floor below special shaped pillars created during perimeter mining. These studies show that the floor bearing capacity of a perimeter pillar could be estimated by treating it as a square pillar of width equal to the pre-cut barrier width using the Vesic's non-homogeneous model. While the average bearing capacity is similar for the square and perimeter pillars of same width, the floor stability factor will not be the same. Owing to the higher average vertical stress on the perimeter pillar than a square pillar of the same width, the former will have a lower floor stability factor. 


\section{REFERENCES}

ACIRL. (1987). Evaluation of Subsidence and Pillar Design Criteria for Corranbong Colliery (Report No. 08/1364).

Afrouz, A. (1975a). Floor Behaviour along Longwall Roadways. Int. J. of Rock Mech. and Min. Sci., Vol. 12, 229-240.

Afrouz, A. (1975b). Yield and Bearing Capacity of Coal Mine Floor. Int. J. of Rock Mech. and Min. Sci., Vol. 12, 241-253.

Aggson, J.R. (1978). Coal Mine Floor Heave in the Beckley Coalbed, An Analysis. U.S. Bur. Mines R.I. 8274, 32 p.

Aggson, J.R., and Curran, J. (1978). Coal Mine Ground Control Problems Associated with a High Horizontal Stress Field. SME annual meeting, Denver, CO, $19 \mathrm{p}$.

Ames, P. (2008). Personal Communication.

Asquith, G.B., and Gibson,C.R. (1982). Basic Well Log Analysis for Geologists. The American Association of Petroleum Geologists, Tulsa, Okalhoma, 216 p.

ASTM Standard D 1194-94 (2002). Test Method for Bearing Capacity of Soil for Static Load and Spread Footings. ASTM International, West Conshohocken, PA, Annual book of standards, Vol. 04.08.

ASTM Standard D 2216-05 (2009). Standard Test Methods for Laboratory Determination of Water (Moisture) Content of Soil and Rock by Mass. ASTM International, West Conshohocken, PA, Annual book of standards, Vol. 04.08.

ASTM Standard D4318-05 (2009). Standard Test Methods for Liquid Limit, Plastic Limit, and Plasticity Index of Soils. ASTM International, West Conshohocken, PA, Annual book of standards, Vol. 04.08.

ASTM Standard D 2487-06E01 (2009). Standard Practice for Classification of Soils for Engineering Purposes (Unified Soil Classification System). ASTM International, West Conshohocken, PA, Annual book of standards, Vol. 04.08. 
ASTM Standard D422-63R07 (2009). Standard Test Method for Particle-Size Analysis of Soils. ASTM International, West Conshohocken, PA, Annual book of standards, Vol. 04.08.

ASTM Standard D421-85R07 (2009). Standard Test Method for Particle-Size Analysis of Soils. ASTM International, West Conshohocken, PA, Annual book of standards, Vol. 04.08.

ASTM Standard D2845-08 (2009). Standard Test Method for Laboratory Determination of Pulse Velocities and Ultrasonic Elastic Constants of Rock. ASTM International, West Conshohocken, PA, Annual book of standards, Vol. 04.08.

Bandopadhay, C., (1982). Analysis of Soft Floor Interaction on Underground Mining at a Western Kentucky Mine. M.S. Thesis, Southern Illinois University, Carbondale, IL.

Barry, A.J., and Nair, O.B. (1970). In-Situ Tests of Bearing Capacity of Roof and Floor in Selected Bituminous Coal Mines - A Progress Report, Longwall Mining. U.S. Bureau of Mines, RI 7406, 20 pp.

Bauer, R. (2008). Personal communication.

Bhattacharya, A.K., and Seneviratne, S.P.(1992). A Study of Floor Heave in the Mines of the Southern Coalfield of New South Wales by Two Dimensional Finite Element Modelling. Paper in the proceedings of the $11^{\text {th }}$ Int. conf. on ground control in mining, the University of Wollongong, NSW, 297-301.

Botts, M. E. (1986). The Effects of Slaking on the Engineering Behavior of Clay Shales. Ph.D. thesis submitted to the University of Colorado, Boulder, CO, $262 \mathrm{p}$.

Bowles, J.E. (1996) Foundation Analysis and Design. $5^{\text {th }}$ Edition, McGraw-Hill Publishers, 1024p.

Brown, J.D., and Meyerhof, G.G. (1969). Experimental study of bearing capacity in layered clays. Proceedings of $7^{\text {th }}$ International Conference on Soil Mechanics and Foundation Engineering, Mexico City, Vol. 2, 45-51.

Burd, H.J., and Frydman, S. (1997). Bearing capacity of plane-strain footings on layered soils. Can. Geotech. J., 34: 241-253. 
Button, S.J. (1953). The bearing capacity of footings on a two-layer cohesive subsoil. Proceedings of $3^{\text {rd }}$ International Conference on Soil Mechanics and Foundation Engineering, Zurich, Vol. 1, 332-335.

Casagrande, A. (1932). Research on the Atterberg limits of soils. Public Roads, 13, 121-136.

Casagrande, A. (1948). Classification and identification of soils. Trans. ASCE, 113, 901-991.

Caudle, R.D., Chugh, Y.P., Albarracin, H., Chandrashekhar, K., and Liang, C. (1988). Effects of Soft Floor Interaction on Room-and-Pillar Mining - A Progress Report. Paper published in the Annual Generic Mineral Institute (Mine Systems and Ground Control) Meeting, Tuscaloosa, AL.

Chandrashekhar, K. (1990). Effects of Weak Floor Interaction on Underground Room-and-Pillar Coal Mining. Ph.D. dissertation, Southern Illinois University, Carbondale, IL, $345 \mathrm{p}$.

Chlumecky, N. (1968). A Method for Testing the Bearing Capacity of Floor Strata. Mining Engineering, Vol. 20, No.3, 68-71.

Chugh, Y.P. (1986a). Laboratory Characterization of Immediate Floor Strata Associated with Coal Seams in Illinois. Final Report to Mine Subsidence Research Program, Illinois State Geological Survey, Champaign, Urbana, Illinois, May, $112 \mathrm{p}$.

Chugh, Y.P. (1986b). In Situ Strength Characteristics of Coal Mine Floor Strata in Illinois. Final Report to Mine Subsidence Research Program, Illinois State Geological Survey, Champaign, Urbana, Illinois, September, 160 p.

Chugh, Y.P. (2008). Personal communication.

Chugh, Y.P., Bandopadhay, C., and Caudle, R.D. (1984). Effect of Soft Floor Interaction on Retreat Mining at an Illinois Basin Coal Mine. Paper in proc. of. Conference on Stability in Underground Mining II, International Society of Rock Mechanics, Cambridge, England, September, 56-71.

Chugh, Y.P., Pula, O., and Pytel, W.M. (1990). Ultimate bearing capacity and settlement of coal pillar sub-strata. Int. J. of Min. and Geol. Eng., 8, 111130. 
Chugh, Y.P., and Pytel, W.M. (1992). Design of Partial Extraction Coal Mine Layouts for Weak Floor Strata Conditions. U.S. Bureau of Mines IC 9315, 32-49.

Chugh. Y.P. et al., summarized by DeMaris, P.J. (1996). Identification of Mine Characteristics, Conditions, and Procedures for Design of Stable Partial Extraction Room-and-Pillar Mines in the Herrin and Springfield Coal Seams in Illinois. Illinois State Geological Survey, Springfield, IL.

CMRI (2000). Report on weak floor stability problems at GDK-5A Incline mine of Singareni Collieries Company Limited, Ramagundem Area, 22 p.

Das, B.M. (1999). Shallow Foundations: Bearing Capacity and Settlement. CRC Press, $384 \mathrm{p}$.

Deb, D., Ma, J., and Chugh, Y.P. (2000). A Numerical Analysis of the Effects of Weak Floor Strata on Longwall Face Ground Control. Preprint No. 00-134, Paper presented at the SME annual meeting, Salt Lake City, UT, Feb 28Mar.1.

Department of the Army (1983). Foundations in Expansive Soils. Technical manual TM 5-818-7, $95 \mathrm{p}$.

Department of the Army and the Air Force. (1983). Soils and geology procedures for foundation design of buildings and other structures (except hydraulic structures). Army TM 5-818-1, 204 p.

Dolinar, B, Misic, M., and Trauner, L. (2007). Correlation between surface area and Atterberg limits of fine-grained soils. Clays and Clay Minerals, Vol. 55, No. 5, 519-523.

Dolinar, D., and Esterhuizen, G. (2007). Evaluation of the Effects of Length on Strength of Slender Pillars in Limestone Mines Using Numerical Modeling. Proceedings of the $26^{\text {th }}$ International Conference on Ground Control in Mining, Morgantown, WV, 304-313.

Dulaney, R.L. (1960). The Structural Strength of Coal Mine Floors. Unpublished thesis submitted to the Virginia Polytechnic Institute, Blacksburg, VA, $74 \mathrm{p}$.

Elrick, S. (2008). Personal communication. 
Erickson, H. L., and Drescher, A. (2002). Bearing Capacity of Circular Footings. Journal of Geotechnical and Geoenvironmental Engineering, Vol. 128, No. 1, 38-43.

Faria Santos, C., and Bieniawski, Z.T. (1989). Floor Design in Underground Coal Mines. Rock Mechanics and Rock Engineering, 22, 249-271.

Fener, M., Kahraman, S., Bay, Y., and Gunaydin, O. (2005). Correlations between P-wave velocity and Atterberg limits of cohesive soils. Can. Geotech. J., 42: 673-677.

Fenton, G.A., and Griffiths, D.V. (2003). Bearing-capacity prediction of spatially random $c-\phi$ soils. Can. Geotech. J., 40: 54-65.

Freer, J., (1892). Mine Creeps. Illinois Mining Journal, Vol. 1, No.3, 238-243.

Frydman, S., and Burd, H.J. (1997). Numerical Studies of Bearing-Capacity Factor $\mathrm{N}_{\gamma}$. (1997). Journal of Geotechnical and Geoenvironmental Engineering, ASCE, 123(1), 20-29.

Gadde, M.M., and Sheorey, P.R. (2001). Numerical estimation of pillar strength in coal mines. Int. J. Rock Mech. Min. Sci., 38, 1185-1192.

Gadde, M., Rusnak, J., Honse, J., and Peng, S. (2007). On Rock Failure Criteria for Coal Measure Rocks. Paper in the proceedings of the $26^{\text {th }}$ International Conference on Ground Control in Mining, West Virginia University, Morgantown, 361-369.

Ganow, H.C. (1975). A Geotechnical Study of the Squeeze Problem Associated with the Underground Mining of Coal. Unpublished thesis submitted to the University of Illinois, Champaign, IL, 253 p.

Giasi, C.I., Cherubini, C., and Paccapelo, F. (2003). Evaluation of compression index of remoulded clays by means of Atterberg limits. Bull. Eng. Geol. Env., 62: 333-340.

Gibson, R. (2008). Personal communication.

Gourvenec, S. (2007). Shape effects on the capacity of rectangular footings under general loading. Geotechnique, 57, No. 8, 637-646. 
Gourvenec, S., and Randolph, M. (2003). Effect of Strength Non Homogeniety on the Slope of Failure Envelopes for Combined Loading of Strip and Circular Foundations on Clay. Geotechnique, Vol. 53, No.6, 575-586.

Gourvenec, S., Randolph, M., and Kingsnorth, O. (2006). Undrained Bearing Capacity of Square and Rectangular Footings. The Int. J. of Geomech., Vol.6, No.3, 147-157.

Gourvenec, S., and Steinepreis, M. (2007). Undrained Limit States of Shallow Foundations Acting in Consort. International Journal of Geomechanics, Vol 7, No.3, 194-205.

Griffiths, D.V. (1982). Computation of bearing capacity factors using finite elements. (1982). Geotechnique 32, No. 3, 195-202.

Griffiths, D.V., and Fenton, G.A. (2001). Bearing capacity of spatially random soil: the undrained clay Prandtl problem revisited. Geotechnique, 51, No. 4, 351-359.

Griffiths, D.V., Fenton, G.A., and Manoharan, N. (2002). Bearing Capacity of Rough Rigid Strip Footing on Cohesive Soil: Probabilistic Study. Journal of Geotechnical and Geoenvironmental Engineering, Vol. 128, No. 9, 743755.

Griffiths, D.V., Fenton, G.A., and Manoharan, N. (2006). Undrained Bearing Capacity of Two-Strip Footings on Spatially Random Soil. International Journal of Geomechanics, Vol 6, No.6, 421-427.

Grim, R.E., and Allen, V.T. (1938). Petrology of the Pennsylvanian underclays of Illinois. Geol. Soc. America Bull. Vol. 49, 1485-1513.

Hall, R.D. (1909). Squeezes in Mines and Their Causes. Mines and Minerals, Vol. 30, No.5, 286-287.

Haramy, K.Y. (1981). Borehole Shear Tester: Equipment and Technique. USBM IC 8867, 16 pp.

Haramy, K., and McDonnell, J. (1986). Floor Heave Analysis in a Deep Coal Mine. Paper in Proceedings of $27^{\text {th }}$ U.S. Symposium on Rock Mechanics. Univ. of Tuscaloosa, AL, June, 520-525. 
Hartmann, W. (1925). Uber die Integration der Differentialgleichungen des ebenen Gleichgewichtszustandes fur den allgemein - plastischen Korper, Thesis, University of Gottingen.

Hatch, J.R., and Affolter, R.H. (2002). Resource Assessment of the Springfield, Herrin, Danville and Baker Coals in the Illinois Basin, Chapter C: Geologic Overview, U.S. Geological Survey Professional Paper 1625-D, 23 p.

Hatherly, P., Sliwa, R. Turner, R. and Medhurst, T. (2003). Quantitative geophysical log interpretation for rock mass characterisation. End of Grant Report, ACARP Project C11037.

Heasley, K.A. (1998). Numerical Modeling of Coal Mines with a Laminated Displacement-Discontinuity Doce. Ph.D. Dissertation, Colorado School of Mines, May, $187 \mathrm{pp}$.

Heasley, K.A. (2008). Some Thoughts on Calibrating LaModel. Proceedings of the $27^{\text {th }}$ International Conference on Ground Control in Mining, Morgantown, WV, 7-13.

Heasley, K.A., and Salamon, M.D.G. (1994). The Effect of Weak Floor on Pillar Strength. Paper in the proceedings of the $5^{\text {th }}$ Conference on Ground Control for Midwest U.S. Coal Mines, Collinsville, IL, 71-87.

Hobbs, D.W. (1969a). Strata Movement Around Mine Roadways: Results of Scale Model Studies. The Mining Engineer, May, 461-471.

Hobbs, D.W. (1969b). Scale Model Studies of Strata Movement Around Mine Roadways - IV. Road Way Shape and Size. Int. J. of Rock Mech. and Min. Sci., Vol. 6, No. 4, 365-404.

Holland, C.T. (1962a). Design of Pillars for Overburden Support - Part I. Mining Cong. Jour., Vol. 48, No.3, 24-28.

Holland, C.T. (1962b). Design of Pillars for Overburden Support - Part II. Mining Cong. Jour., Vol. 48, No.4, 66-71.

Hopkins, T.C. (1901). A Short Discussion of the Origin of the Coal Measure Fire Clays. The American Geologist, Vol. 28, 47-51.

Huddle, J.W., and Patterson, S.H. (1961). Origin of Pennsylvanian Underclay and Related Seat Rocks. Geol. Soc. Amer. Bull. Vol. 72, 1643-1660. 
Hunt, G. (2006). Personal communication.

Hustrulid, W. A. (1976). A Review of Coal Pillar Strength Formulas. Rock Mechanics, 8, 115-145.

ISRM. (1981). Suggested methods for determining in situ deformability of rock. Rock Characterization Testing and Monitoring, ISRM Suggested Methods, ed. E.T. Brown, Pergamon Press, Oxford, 143-148.

Itasca Consulting Group (2007). Fast Lagrangian Analysis of Continua in 3Dimensions, Minneapolis, Minnesota, USA.

Jayanti, S. (1991). A finite element analysis of bearing capacity of coal pillars on weak floor strata. Ph.D. dissertation submitted to the Southern Illinois University, Carbondale.

Jenkins, J.D. (1955). Mechanics of Floor Penetration in Mines. Iron and Coal Trades Review, Vol. 171, No. 4560, 541-547.

Jenkins, J.D. (1957). The Bearing Capacity of Mine Floors. Colliery Gaurdian, Vol. 195, No. 5039, 397-400.

Jenkins, J.D. (1958). Some Investigations into the Bearing Capacities of Floors in the Northumberland and Durham Coalfields. Trans. Of the Institution of Mining Engineers, Vol. 117, Part II, 725-738.

Jenkins, J.D. (1960). A Laboratory and Underground Study of the Bearing Capacity of Mine Floors. Third International Conference on Strata Control, Paris, May, 1960, C5, 227-240.

Keller, W.D. (1946). Evidence of texture on the origin of the Cheltenham fireclay of Missouri and associated shales. J. Sed. Petrology, vol. 16, no.2, 63-71.

Kosanke, R.M., Simon, J.A., Wanless, H.R., and Willman, H. (1960). Classification of the Pennsylvanian Strata of Illinois. Illinois State Geological Survey R.I. 214, 26 p.

Krishna, R., and Whittaker, B.N. (1973). Floor Lift in Mine Roadways. Colliery Guardian, November, 396-402.

Kumar, D., and Das. S.K. (2005). An experimental study of the parameters influencing ultimate bearing strength of weak floor strata using physical modeling. Geotechnical and Geological Engineering, 18, 1-15. 
Kumar, J., and Kouzer, K.M. (2007). Bearing capacity of two interfering footings. Int. J. Numer. Anal.Meth. Geomech. Vol.32, Issue 3, 251-264.

Kwasniewski, M. (1990). Effect of Moisture on the Mode of Deformation and Failure of Coal Measure Mudstone under Triaxial Compression. Proceedings of Strata Control in Deep Mines, Balkema, Rotterdam, 169186.

Latilla, J., and Oldroyd, C. (1996). Report on Stability of 5 Seam Bord and Pillar Workings Beneath Eskom Pylons, Matla No.2 Mine. Report by Rock Engineering Consultants.

Latilla, J. (2004). Weak Floors and their Influence on Pillar Stability in Southern African Collieries. Proceedings of SANIRE - The Miner's Guide through the Earth's Crust, South African National Institute of Rock Engineering, 71-78.

Lee, J., Eun, J., Prezzi, M., and Salgado, R. (2008). Strain Influence Diagrams for Settlement Estimation of Both Isolated and Multiple Footings in Sand. Journal of Geotechnical and Geoenvironmental Engineering, Vol. 134, No. 4, 417-427.

Li, G., and Smith, M. (1998). Planning for Time-Dependent Subsidence. Paper in the proceedings of the Conference on buildings and structures subject to ground movement, Newcastle, 11-13 July, 1998, 181-188.

Logan, W.E. (1842). On the character of the beds of clay lying immediately below the coal seams of South Wales. Geol. Soc. London Proc., vol. 3, 275-277.

Madsen, F.T. (1999). Suggested methods for laboratory testing of swelling rocks. ISRM suggested methods (SMs): Second series. Int. J. Rock Mech. Min. Sci., 36, 291-306.

Mandel, J. (1965). Interference Plastique de Semmelles Filantes. Proceedings of the $6^{\text {th }}$ International Conference on Soil Mechanics and Foundation Engineering, Montreal, 3, 127-131.

Mandel, J., and Salencon, J. (1969). Force Portante d'un Sol Su tune Assise Rigide. Proceedings of the $7^{\text {th }}$ International Conference on Soil Mechanics and Foundation Engineering, Mexico City, 2, 157-164. 
Mandel, J., and Salencon, J. (1972). Force Portante d'un Sol Sur une Assise Regide Etude (Theoretique). Geotechnique, 22(1), 79-93.

Manoharan, N., and Dasgupta, S.P. (1995). Bearing capacity of surface footings by finite elements. Comp. and Struct., 54(4), 563-586.

Mark, C. (1992). Analysis of longwall pillar stability (ALPS): an update. Proceedings of the Workshop on Coal Pillar Mechanics and Design. USBM IC 9315, 238-249.

Mark, C. (2006). The Evolution of Intelligent Coal Pillar Design: 1981-2006. Paper in the proceedings of the $25^{\text {th }}$ International Conference on Ground Control in Mining, Morgantown, WV, 325-334.

Mark,C., and Chase, F.E. (1997). Analysis of Retreat Mining Pillar Stability (ARMPS). Proceedings of the New Technology for Ground Control in Retreat Mining. NIOSH IC 9446, 17-34.

Mark, C., and Zelanko, J.C (2001). Sizing of Final Stumps for Safer Pillar Extraction. Proceedings of the $20^{\text {th }}$ International Conference on Ground Control in Mining, Morgantown, WV, 59-66.

Merifield, R.S., Sloan, S.W., and Yu, H.S. (1999). Rigorous plasticity solutions for the bearing capacity of two-layered clays. Geotechnique, 49, No. 4, 471490.

Marino, G. (1985). Subsidence Damaged Homes Over Room and Pillar Mines in Illinois. Unpublished Ph.D. thesis submitted to the University of Illinois, Urbana-Champaign, IL, $431 \mathrm{p}$.

Marino, G.G., and Choi, S. (1999). Softening Effects on Bearing Capacity of Mine Floors. Journal of Geotechnical and Geoenvironmental Engineering, Vol. 125 , No. $12,1078-1089$.

Mesri, G. and Abdel-Ghaffar, M.E.M. (1993). Cohesion Intercept in Effective Stress-stability Analysis. J. Geotech. Eng., Vol. 119, No. 8, 1229-1249.

Michalowski, R.L., and Dawson, E.M. (2002). Three-dimensional Analysis of Limit Loads on Mohr-Coulomb Soil. Foundations of Civil and Environmental Engineering, No. 1, 137-147. 
Mitchell, J.K., and Soga, K. (2005). Fundamentals of Soil Behavior. Third edition, John Wiley \& Sons, $592 \mathrm{p}$.

Moore, R.C. (1936). Stratigraphic Classification of the Pennsylvanian Rocks of Kansas. Kansas Geological Survey Bulletin, Vol. 22, 256 p.

Moore, R.C. (1940). Coal: its properties, analysis, classification, geology, extraction uses and distribution. $2^{\text {nd }}$ edition, John, Wiley \& Sons, $473 \mathrm{p}$.

Morsey, K., and Peng, S.S. (2001). Typical Complete Stress-Strain Curves of Coal. Proceedings of the $20^{\text {th }}$ International Conference on Ground Control in Mining, Morgantown, WV, 210-217.

Nelson, J. (2008). Personal communication.

Nelson, A. (1947). Floor Movements and Their Control. Iron and Coal Trades Rev., vol.146, No. 4136.

Nemcik, J.A., Indraratna, B., and Gale, W. (2000). Floor failure analysis at a longwall mining face based on the multiple sliding block model. Geotechnical and Geological Engineering, 18, 175-192.

O'Brian, N.R. (1964). Origin of Pennsylvanian Underclays in the Illinois Basin. Geol. Soc. Amer. Bull. Vol. 75, 823-832.

Parham, W.E. (1964). Lateral Clay Mineral Variations in Certain Pennsylvanian Underclays. Proc. $12^{\text {th }}$ Natil. Conf. on Clays and Clay Minerals, 581-602.

Peng, S.S. (2008). Coal Mine Ground Control. Third edition, Department of Mining Engineering, West Virginia University, Morgantown, WV, 750 pp.

Peng, S.S., Tsang, P. and Wang, Y.J. (1992). Mechanism of Floor Heave - A case Study. Proceedings of 10th Annual Workshop of Generic Technology Centers for Mine System Design and Ground Control, University of Idaho, November, 53-64.

Pytel, W.M. (1998). SIU Panel.3D Roof-Pillar-Floor Interaction Analysis Model and Its Application in Mining Engineering. A book published by CUPRUM, Poland, $315 \mathrm{p}$.

Pytel, W.M. (2006). Personal communication.

Pula, O., Chugh, Y.P., and Pytel, W.M. (1990). Estimation of Weak Floor Strata Properties and Related Safety Factors for Design of Coal Mine Layouts. 
Paper in the proceedings of the $31^{\text {st }}$ U.S. Symposium on Rock Mechanics. Eds. W.A. Hustulid and G.A. Johnson, Rotterdam: Balkema, 93-100.

Riefenberg, J. (1995). Towards a method of determining floor quality in an underground coal mine. Proceedings of the $14^{\text {th }}$ International Conference on Ground Control in Mining, Morgantown, WV, 200-208.

Rhodes, G.W. (1978). Plate Bearing Tests on Coal Mine Underclays. Unpublished M.S. Thesis submitted to the University of Missouri, Rolla, 69 p.

Rockaway, J.D., and Stephenson, R.W. (1979). Investigation of the Effects of Weak Floor Conditions on the Stability of Coal Pillars. Report No. BUMINES-ofr-12-81.

Salgado, R., Lyamin, A.V., Sloan, S.W., and Yu, H.S. (2004). Two- and threedimensional bearing capacity of foundations in clay. Geotechnique, 54, 5, 297-306.

Sharma, B., and Bora, P. (2003). Plastic limit, liquid limit and undrained shear strength of soil - reappraisal. J. Geotech. Geoenv. Eng., Vol. 129, No. 8 , 774-777.

Schultz, L.G. (1958). Petrology of underclays. Geol. Soc. America Bull. Vol. 69, 363-402.

Seedsman, R. (1987). Floor Heave in the Great Northern Seam, Report to Newcom Collieries Pty. Ltd. (Internal Report).

Seedsman, R., and Gordan, N. (1991). Methods to optimise mining operations affected by weak claystone materials. NERDDC end of grant report (project 1336).

Shankar, S. (1987). Geotechnical properties of immediate floor strata from an Illinois coal mine. Ph.D. dissertation submitted to the Southern Illinois University, Carbondale.

Shepherd, R. (1970). Current Work on Strata Displacement Around Roadways. Proceedings of the Symposium on Strata Control in Roadways, the Institution of Mining Engineers, 91-111. 
Shiau, J.S., Lyamin, A.V., and Sloan, S.W. (2003). Bearing capacity of a sand layer on clay by finite element limit analysis. Can. Geotech. J., 40: 900915.

Skempton, A. W. (1953). The colloidal activity of clay. Proceedings of the Third International Conference on Soil Mechanics and Foundation Engineering, Zurich, Vol. I, 57-61.

Spangler, M.G., and Handy,R.L. (1982). Soil Engineering, fourth edition. Harper and Row, Publishers, New York, 819 p.

Speck, R. (1979). A Comparative Evaluation of Geologic Factors Influencing Floor Stability in Two Illinois Coal Mines. Ph.D. Thesis submitted to the University of Missouri, Rolla, $265 \mathrm{p}$.

Speck, C.R. (1981). The influence of certain geologic and geotechnical factors on coal mine floor stability - A case study. Paper in the proceedings of the first conference on ground control in mining, Morgantown, WV, 44-49.

Spencer, C.W. (1955). A petrographic study of the underclay of the No.6 coal in Illinois. M.S. Thesis submitted to the University of Illinois, UrbanaChampaign, IL.

Sridharan, A. and Nagaraj, H.B. (2005). Hydraulic conductivity of remolded finegrained soils versus index properties. Geotechnical and Geological Engineering, 23:43-60.

Stankus, J., and Peng, S.S. (1994). Floor bolting for control of mine floor heave. Mining Engineering, September, 1099-1102.

Stark, T.D., and Eid, H.T. (1994). Drained Residual Strength of Cohesive Soils. J. Geotech. Eng., Vol. 120, No. 5, 856-871.

Stout, W. (1923). Origin of Coal Formation Clays. Transactions of the American Ceramic Society, Vol. 17, 557-591.

Su, D.W.H, Scandrol, R.O., and Hasenfus, G. (1993). Development and Evaluation of a Floor-Bearing Capacity Test Apparatus. Proceedings of the $12^{\text {th }}$ International Conference on Ground Control in Mining, Morgantown, WV, 357-365. 
Surkov, A.V., Shtumpf, G.G., and Egorov, P.V. (1997). Heaving of Floor Rock in Development Workings of Coal Mines, and Evaluation of the Main Controlling Factors. J. of Min. Sci., Vol. 33, No.2, 152-164.

Tandon, S. (1987). Field strength-deformation characteristics of immediate floor strata in Illinois coal mines. Ph.D. dissertation submitted to the Southern Illinois University, Carbondale.

Terzaghi, K., Peck, R.B., and Mesri, G. (1996). Soil Mechanics in Engineering Practice, $3^{\text {rd }}$ Edition, John Wiley \& Sons, Inc., 592 p.

Thakur, D. N. (1972). Mechanism of Floor Heaving in Underground Roadways and Measures for its Control. Symposium of Rock Mechanis: Rock Mechanics Theory and Practice. Min. Met. Div., Inst. Eng., Dhanbad, India, 258-277.

The Environmental Protection Agency. (1978). Field and Laboratory Methods Applicable to Overburdens and Minesoils. EPA-600/2-78-054, 204 p.

Thome, A., Donato, M., Consoli, N.C., and Graham, J. (2005). Circular footings on a cemented layer above weak foundation soil. Can. Geotech. J., 42: 1569-1584.

Tsang, P., and Peng, S.S. (1992). A Model for Floor Stability Analysis. Proceedings of Symposium on New Technology in Mine Health and Safety, SME-AIME, held in conjunction with SME Annual Meeting, February, Phoenix, AZ, 225-233.

Udden, J.A. (1912). Geology and Mineral Resources of the Peoria Quadrangle, Illinois. U.S. Geol. Surv., Bull. 506, 103 p.

Ukritchon, B., Whittle, A.J., and Sloan, S.W. (1998). Undrained Limit Analysis for Combined Loading of Strip Footings on Clay. Journal of Geotechnical and Geoenvironmental Engineering, Vol. 124, No. 3, 265-276.

Vasundhara. (2001). Geomechanical Behaviour of Soft Floor Strata in Underground Coal Mines. Ph.D. Thesis submitted to the University of New South Wales.

Vasundhara, Li, G., Byres, R., Hebblewhite, B., and Martin, S. (2001). Long Term Stability of Mine Workings in Soft Floor Environment: Geomechanical 
Investigations at Cooranbong Colliery. Proceedings of the $21^{\text {st }}$ International Conference on Ground Control in Mining, Morgantown, WV, 180-183.

Vesic, A.S. (1963). Bearing capacity of deep foundations in sand, National Academy of Sciences, National Research Council, Highway Research Record, 39, 112-153.

Vesic, A.S. (1970). Research on Bearing Capacity of Soils (unpublished).

Vesic, A.S. (1973). Analysis of Ultimate Loads of Shallow Foundations. J. Soil Mech. and Found. Div., ASCE, Vol. 99, No. SM1, 45-73.

Vesic, A.S. (1975). Bearing Capacity of Shallow Foundations. Foundation Engineering Handbook, Winterkorn, H.F., and Fang, H., Eds., Van Nostrand Reinhold, Co., 121-147.

Wagner, H. (1974). Determination of the Complete Load-Deformation Characteristics of Coal Pillars. Proceedings of the $3^{\text {rd }}$ Int. Soc. Rock Mech., Denver, CO, 1076-1081.

Wang, Y. (1996). Mechanisms and Control of Mine Floor Heave. Ph.D. dissertation submitted to the West Virginia University, $138 \mathrm{pp}$.

Wang, C.X., and Carter, J.P. (2002). Deep Penetration of Strip and Circular Footings into Layered Clays. The Int. J. of Geomech., Vol.2, No.2, 205232.

Weller, J.M. (1931). The conception of cyclical sedimentation during the Pennsylvanian period. Illinois State Geological Survey Bulletin 60, 163177.

Wesley, L.D. (2003). Residual strength of clays and correlations using Atterberg limits. Geotechnique, 53, No.7, 669-672.

White, W.A. (1954). Properties of Clay as Related to Coal Mining Problems. IL Min. Inst. Proc., 33-38.

White, W.A. (1956). Underclay Squeezes in Coal Mines. Mining Engineering, vol. 8, No.10, 1024-1028. 
Whittaker, B.N., and Batchelor, A.S. (1972). Rationalization and Computer Analysis of Gate Roadway Deformation. The Mining Engineer, April, 335350.

Wilson, M.J. (1965). The Underclays of the South Wales Coalfield East of the Vale of Neath. The Mining Engineer, Vol. 124, April, 389-404.

Worthen, A.H. (1866). Geology. Illinois State Geological Survey Bulletin 1, 1-504.

Wuest, W.J. (1993). Controlling Coal Mine Floor Heave: An Overview. U.S.B.M Information Circular 9326, 17 p.

Yavuz, M., Iphar, M., Aksoy, M., and Once, G. (2003). Evaluation of floor heaving in galleries by numerical analysis. Paper in the proceedings of the Application of Computers and Operations Research in the Minerals Industries, South African Institute of Mining and Metallurgy, 185-190.

Young, L.E., and Stock, H.H. (1916). Subsidence Resulting from Mining. University of Illinois Eng. Expt. Sta. Bull., No. 91, 205 p.

Yilmaz, I. (2000). Evaluation of shear strength of clayey soils by using their liquidity index. Bull. Eng. Geo. Env., 59: 227-229.

Yin, J., Wang, Y., and Selvadurai, A.P.S. (2001). Influence of Nonassociativity on the Bearing Capacity of a Strip Footing. Journal of Geotechnical and Geoenvironmental Engineering, Vol. 127, No. 11, 985-989.

Yukselen, Y., and Kaya, A. (2006). Prediction of cation exchange capacity from soil index properties. Clay Minerals, 41: 827-837.

Yu. Z., Chugh, Y.P., and Yang, G. (1993). Determination of Plate Size Effect on Ultimate Bearing Capacity of Weak Floor in Underground Coal Mines Using a Boundary Integral Approach. Proceedings of the $12^{\text {th }}$ International Conference on Ground Control in Mining, Morgantown, WV, 350-356.

Zhu, M., and Michalowski, R.L. (2005). Shape Factors for Limit Loads on Square and Rectangular Footings. Journal of Geotechnical and Geoenvironmental Engineering, Vol. 131, No. 2, 223-231.

Zienkiewicz, O.C., Humpheson, C., and Lewis, R. (1975). Associated and nonassociated viscoplasticity and plasticity in soil mechanics. Geotechnique 25, No.4, 671-689. 


\section{Appendix - I}

\section{An Unforgettable Experience}

It was mentioned in Chapter 4 that finer details related to the Vesic's two-layer bearing capacity model were never published. I thought without knowing how the equation was derived, it would be difficult to judge its strengths and weaknesses. Therefore, I decided to make an effort to find how the equation was derived. In the chapter on the "Bearing Capacity of Shallow Foundations" published in the Foundation Engineering handbook in 1975, when the two-layer nonhomogeneous soil bearing capacity was discussed, Vesic referred to an unpublished research report in relation to the equation that I was focusing on. I thought if that unpublished report could be found, then probably the derivation of the two-layer model could be found. Towards this end, I first contacted Dr. Thomasz Hueckel, a soil mechanics professor in the Civil Engineering Department of Duke University, Durham, NC. Dr. Aleksandar Sedmak Vesic was employed by the Duke University before his untimely death in 1982 at the age of 57 . Dr. Vesic derived the two-layer model when he was working for the Duke University. When Dr. Hueckel couldn't provide any leads on the possible methodology behind the derivation, I contacted the Vesic Library at Duke. The librarian there, Ms. Linda Martinez, told me that Dr. Vesic's widow donated some research documents to the library and I could visit the library anytime to see if the document I was looking for was a part of that collection. Ms. Martinez also mentioned that some more Dr. Vesic's research was still with his wife and perhaps it would be better if I made an attempt to contact Mrs. Vesic directly. Of course, the librarian told me she was not sure if Mrs. Vesic would agree to see a total stranger that I was.

When I called Dr. Vesic's widow, Mrs. Milena Sedmak Vesic, she was very friendly and to my utter delight agreed to see me at her residence to talk about her husband's research on August 4, 2006. Later when I visited her along with Ms. Martinez, she confessed that she regretted her decision to see a total stranger without thinking twice. As superstitious as Mrs. Vesic was, she told me that she thought Dr. Vesic from heavens told her that the stranger she was going to see had all good intentions and was worth meeting. When I first met Mrs. Vesic, I was impressed by her agility and sharp memory both of which are exceptional for an octogenarian that she was. I also learned that she was an engineer herself and was intimately associated with several of Dr. Vesic's research projects. One thing that I repeatedly noticed during the entire time that I spent with her was the tremendous pride that she took in her husband's accomplishments. She was thrilled to learn that her husband's work was being used for pillar sizing in underground coal mines. Apparently, Dr. Vesic never knew that his work was used in coal mining.

Mrs. Vesic was so kind that she let me access Dr. Vesic's personal library at their residence and allowed me to sort through all the documents in the collection. A partial view of Dr. Vesic's personal library is shown in Figure A.1. A picture that Ms. Martinez took of both Mrs. Vesic and me with Dr. Vesic's picture in the background is shown in Figure A.2. Another picture showing Mrs. Vesic and Ms. Martinez is in Figure A.3.

As I sifted through Dr. Vesic's personal library, I realized that he was a very organized person and was careful to keep everything related to any project that he worked on. I had the opportunity to see the original hand-written drafts of several of his celebrated papers on foundation engineering. Unfortunately for me, the pages that showed the derivation of the two-layer Vesic's 
equation were not found in any his personal collection. However, I found the original manuscript that Dr. Vesic prepared for the landmark chapter on "Bearing Capacity of Shallow Foundations", which was the original reference for the two-layer model used in coal mines. The page of the draft where Dr. Vesic hand wrote the equation for the modified bearing capacity factor is shown in Figure A.4.

During my search, I found a document, which appeared to be a draft of some textbook. Mrs. Vesic told me that Dr. Vesic prepared part-I of a text book that he wanted to publish on "Introduction to Soil Mechanics." Unfortunately, Dr. Vesic passed away before he had the chance to finish the book. The cover of the draft for this text book is shown in Figure A.5. Mrs. Vesic gave me a copy of the draft. During the same search, I found a copy of the proceedings of the landmark conference on "Bearing Capacity and Settlement of Foundations" organized by Dr. Vesic in 1965. This conference was attended by some of the legendary researchers in foundation engineering like Ralph Peck, Brinch Hansen, De Beer, Lambe and several others. Mrs. Vesic told me that Dr. Vesic was extremely proud of the conference throughout his later years for the impact it had on the science of foundation engineering. Mrs. Vesic autographed on the inside cover of a copy of the proceedings that she gave me for my personal collection, which is shown in Figure A.6. This proceedings has a page that showed Dr. Vesic's biography, which is reproduced in Figure A.7.

Even though the original goal of the visit was not met, I returned from Durham with a satisfied feeling. It was really educational for me to see the personal side of an accomplished researcher. I felt extremely grateful to Mrs. Vesic for her kindness and for being such a nice host. In fact, she took me to her favorite restaurant in town for lunch. I spent almost six hours with her on that day. I later learned that she was suffering from serious health problems and needed to visit doctors very frequently. She finally succumbed to her long illness and died on May 26, 2007. After that August 2006 trip, I stayed in constant touch with her until her death. While the time I spent at Dr. Vesic's residence was short, the memories are long and will remain with me for the rest of my life. 


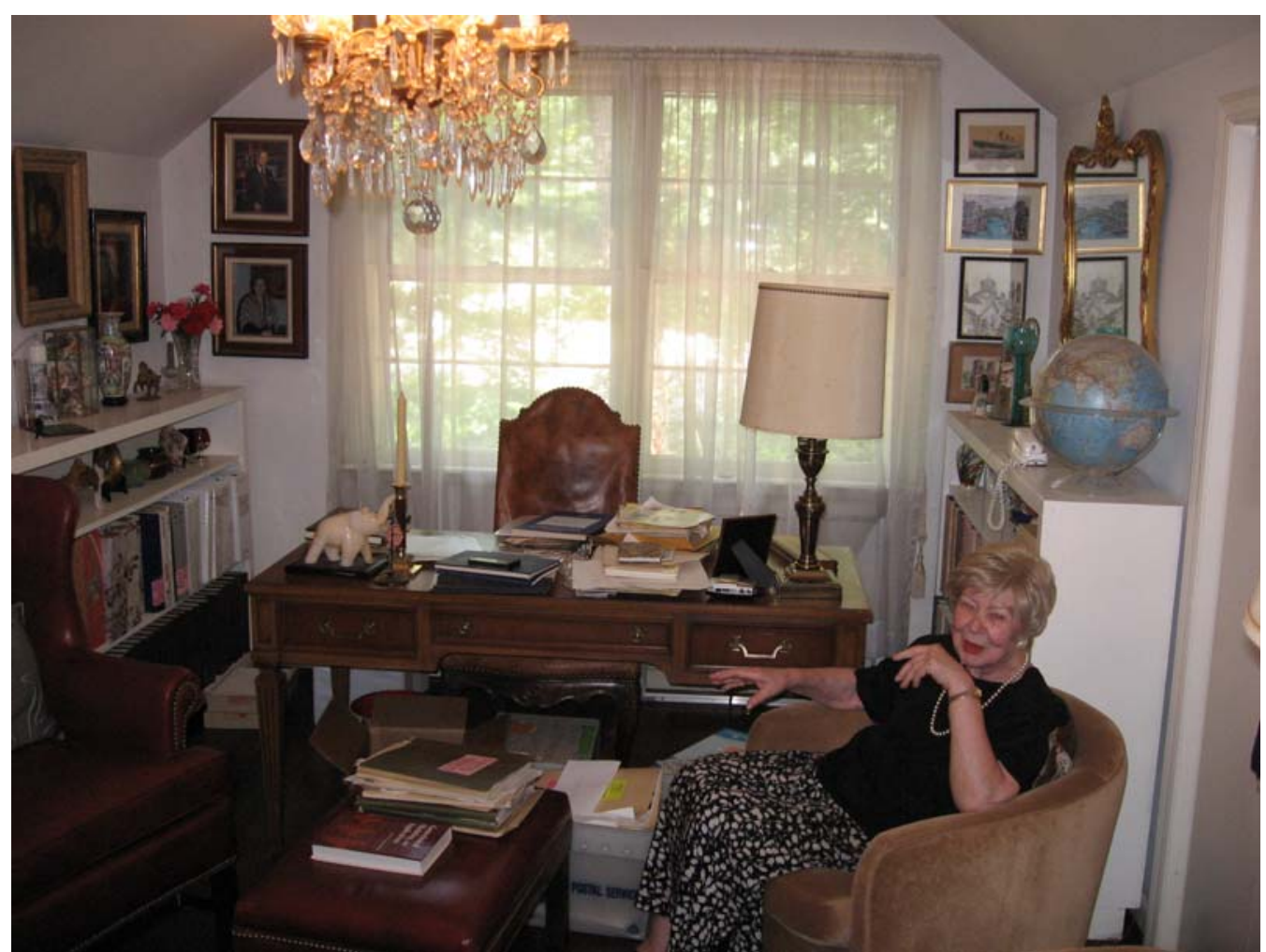

Figure A.1. Partial view of Dr. Vesic's home office.

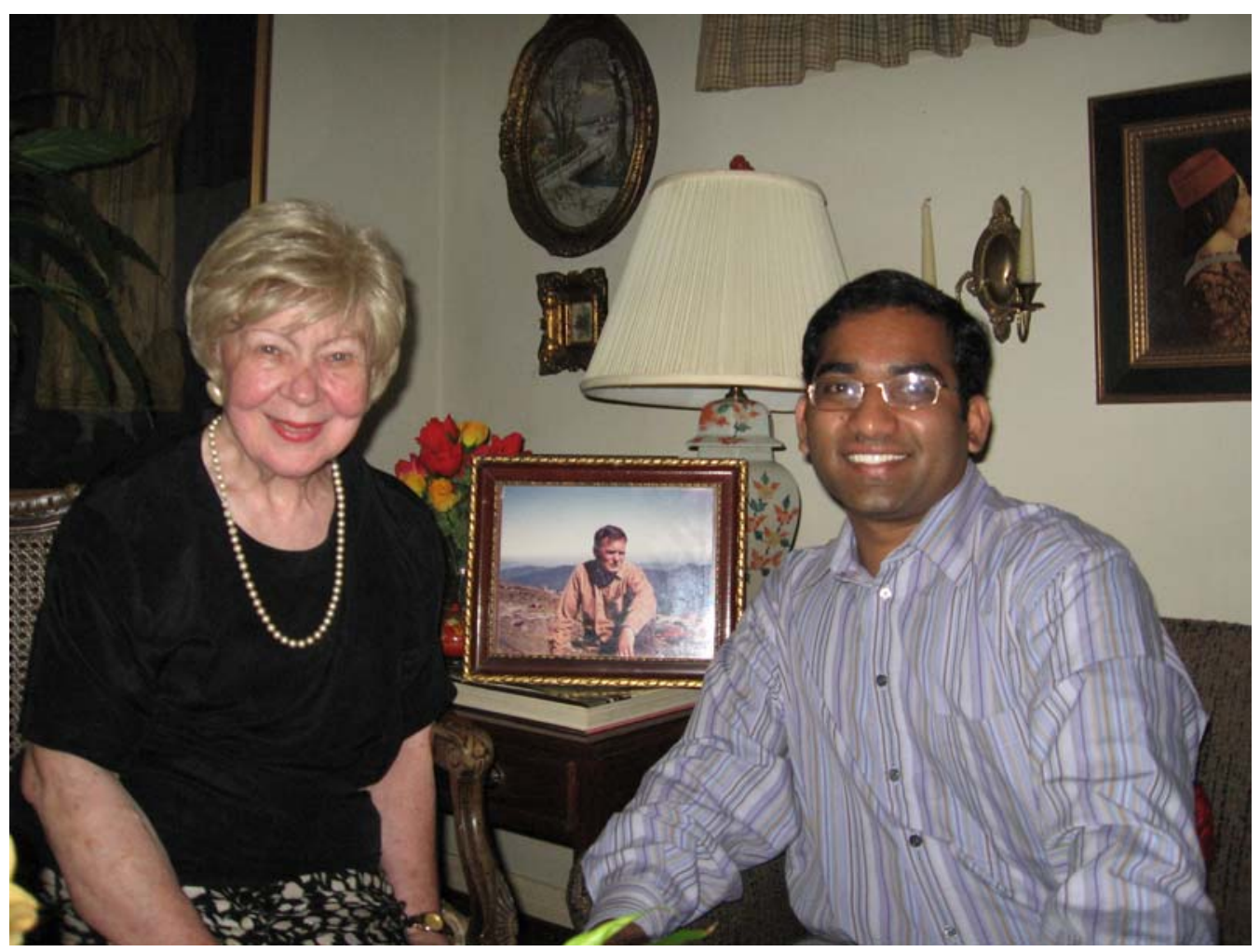

Figure A.2. Mrs. Vesic and I with Dr. Vesic's picture in the background. 


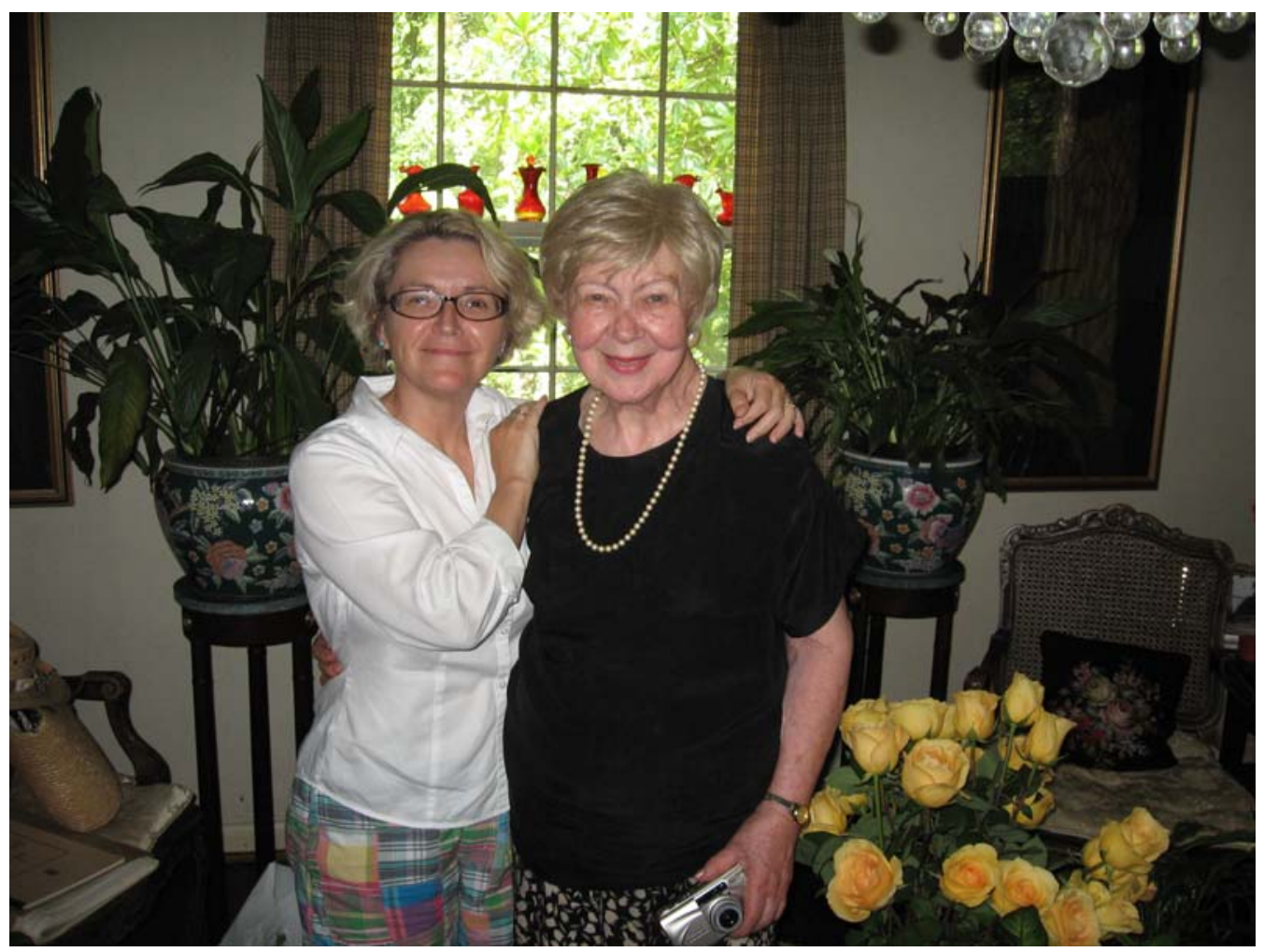

Figure A.3. Ms. Linda Martinez with Mrs. Vesic. 


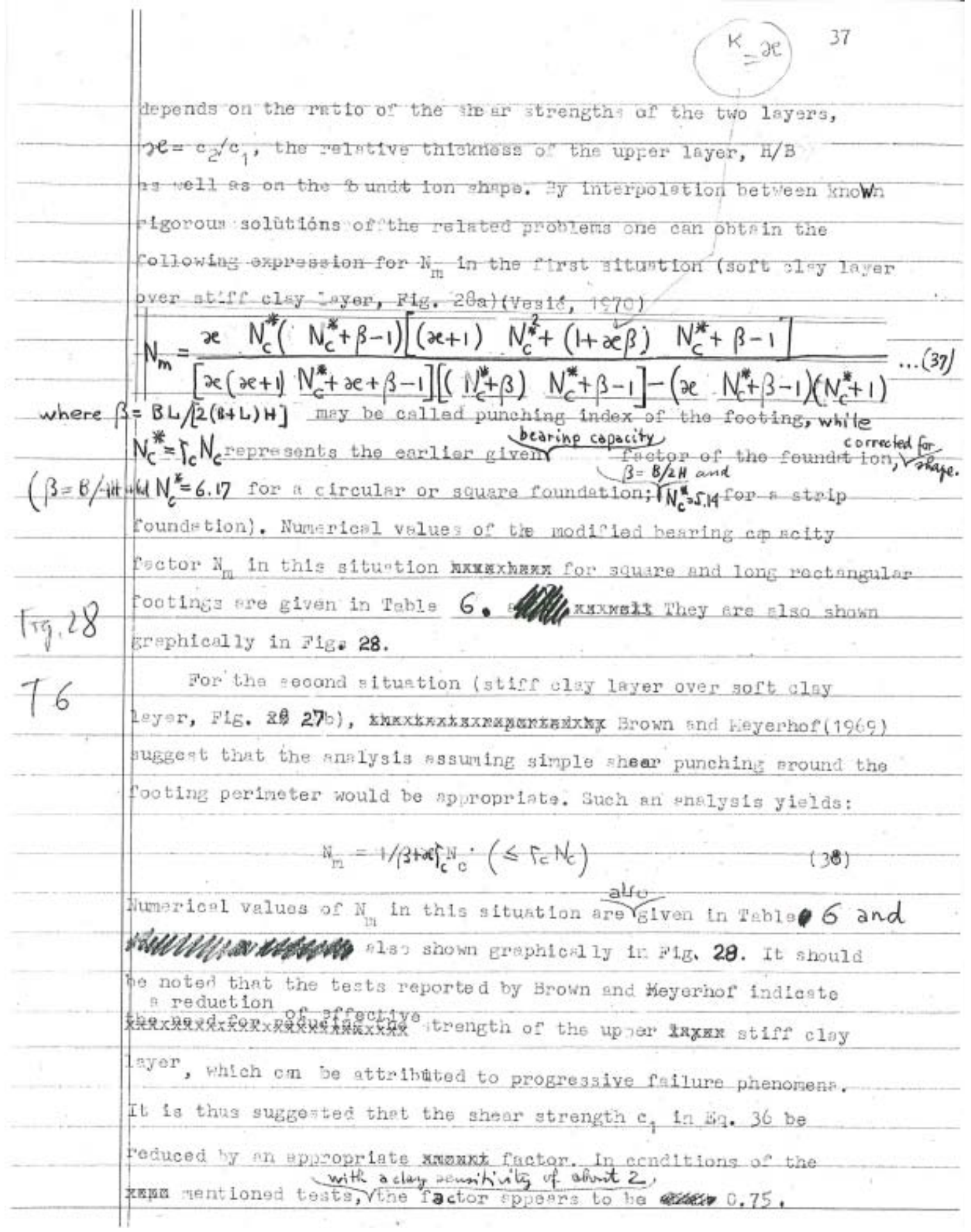

Figure A.4. Original manuscript with Dr. Vesic's hand written modified bearing capacity factor equation. 


\section{SCHOOL of ENGINEERING DUKE UNIVERSITY}

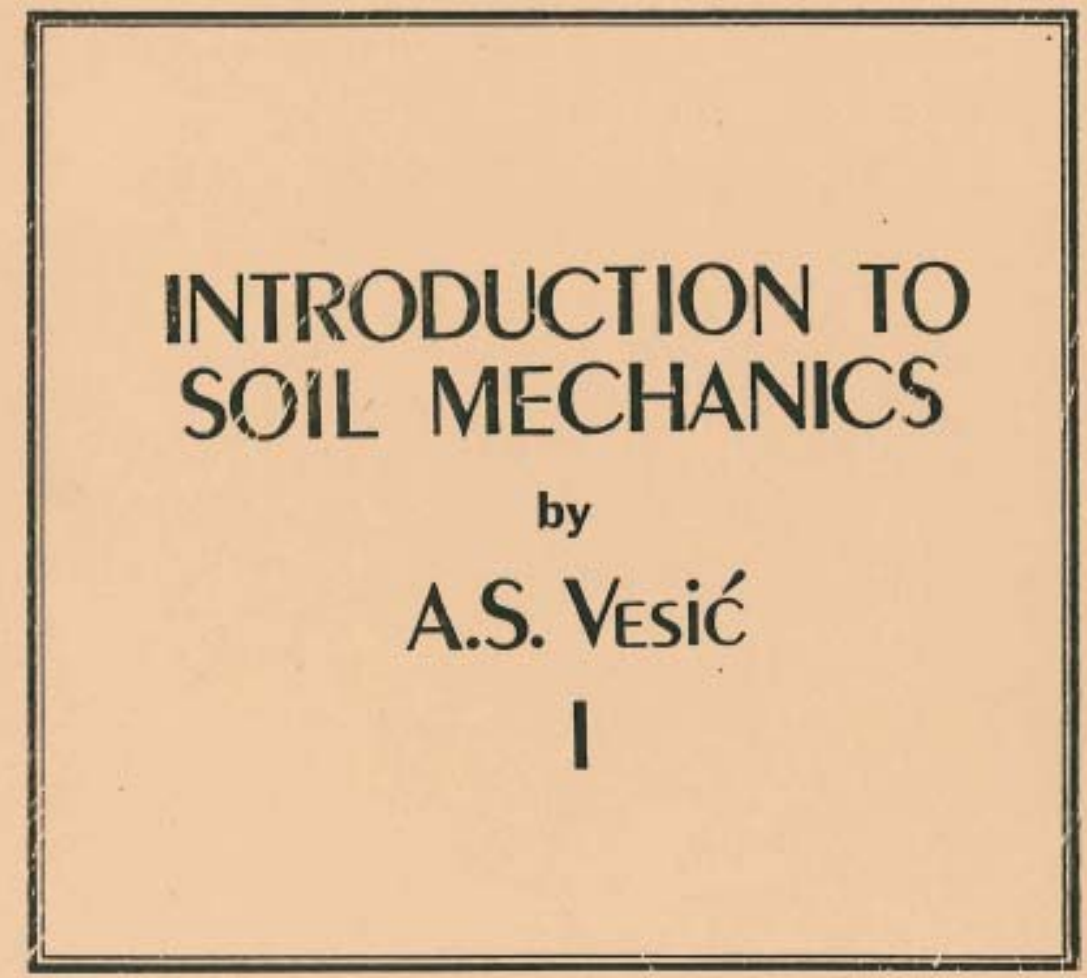

Figure A.5. Cover page of the draft of a text book that Dr. Vesic left unfinished. 


\section{BEARING CAPACITY AND SETTLEMENT OF FOUNDATIONS}

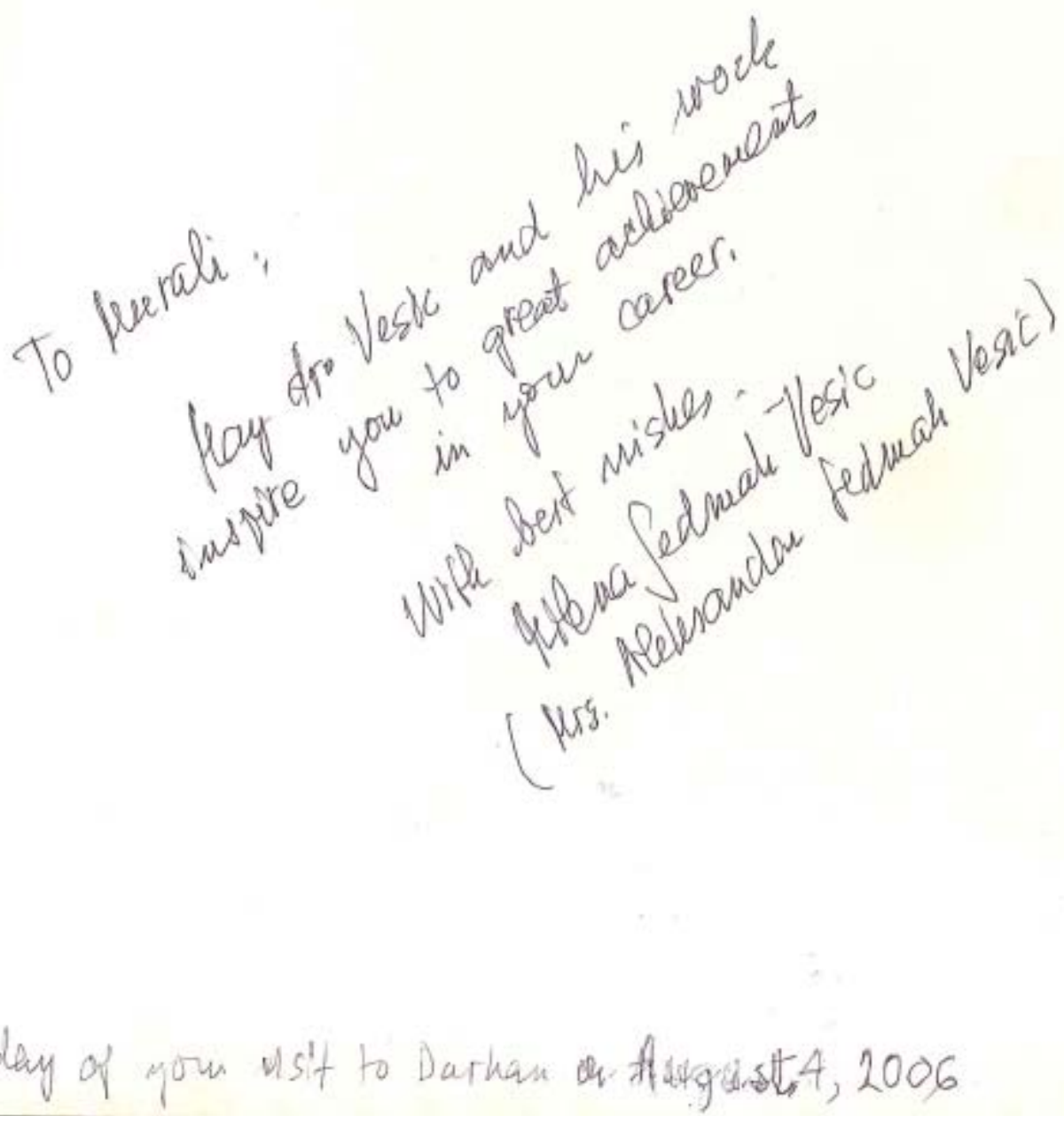

Figure A.6. Mrs. Vesic autographed on the inside cover of the proceedings on "Bearing Capacity and Settlement of Foundations" that she presented me. 
Angewande Mathematik und Mechanik 1, No. 1, pp. 1520.

Purss, H. (1933): Die Tragfahigkeit von Pfallgruppen in Beziebung zu pp. $625-627$.

Renssute H (1924): Zam Erddrackproblem, Proceedings, First Int Conf, Applied Mechanies, Delft, pp. 295-311.

Roajssry, F. 1. and C. F. Mokuson (1964): Sand Displace. ment and Compactioe Around, Vol. I, No. 2, pp. 81-93, Skempron, A. W., A. A. Yussin, and R. E. Gisson (1953) Theorie de la force portante des pieux; Annales de I'Insti63-64, pp. 285-290.

Terzach, K. (1943): Theorstical Soil Mechanies, New York (J. Wiley \& Sons).

1953): The Pearing Capacity of a Pile: Proceedings, Third Int. Conf. Soil Mech. Found. Engrg. Zurich, Vol. II, pp. 84-93.

VAN DER VEeN, C. and L. Boessma (1957): The Bearing Capacity of a Pile Predetermined by a Cone Penetration

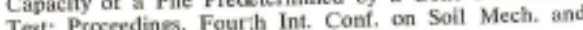
Found. Figrg., London., Vol. II, pp. 76-78.

Yesté, A (1063): Bearing Capacity of Deep Foundations in Sand, Notionat Acadeny of Sciences, National Research Sand, National Academy of Sciences, Nation. 112-153.

\section{Bographical. Note ON AUthoB}

Born in Yugoslaviz, ALEKSANDAR SEDMAK VESIĆ Born in Yugoslavia, horors from the School of Natural graduated with highest horors from the Belgrade. He was Sciences and the Technical University the degree of Doctor of later awarded by the same University "Fundamental Problems Science for his dissertation entited "Fus.

of Theory and Analysis of Pile Grotps. Following a six-year ca eer as a lecturer at the Teebnical foundations engineer, as wall as a lecturer at in 1956 to do University a' Beigrade, he Ieft Yugestavis in post-doctorat research it the Nutionat Geotecth to the United States to jois the faculty of Georgia institute of Technology and became a naturalized American citizen in 1964, The same year he accepted his present position of Professor of Civil Engineering at Duke University,

He has diected a number of research projects, and is the He has diccted a recoged research papers on bearing capacity author of miny recognizans, phenomenology and me-

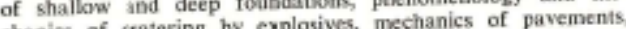
chanics of tratering by explosiver of piles and pile-groups soil-structure interaction, hehavior behavion of soils under high under lateral loads and mectunicar behs confining pressures.

(n) on earth pressure and foundation problems for several organizations in the United States tion problens for several organizationse includes design of and abroad. His enginecring experience includes design of prize-winnin; concrete bridges, as well as earth-retaining. underground and fore staction studies for industrial boildings. bridges and dams.

bridges and dams. An actiwe member of several professional and he Committee cieties, he in currently serking is Chair hishoy Research on Theory of Pavement Design of the Highwy Reseirch Board and Chasirman of the Subcommitee on In-Sint Tests of Soils and Rock of the American Society for Testing and Materials $\mathrm{He}$ is also currently a member of the Publications Committee of the Soil Mechanics Division of the ASCE, as well as of two committces of the Soils, Geology and Foundawell as of
Vesté, A. and R. D. Bakkspal.e (1963): On Streat Strength of Sund at Very High Pressures, American Society of Test. ing and Miterials, Symposium on laboratory Shear Strength Tes ing of Soils, Ottawn, Canada.

Veste S. (1964a): Investigations of Bearing Capacity of Piles in Sand; Proceedings, North American Conference on Deep Foundations, Mexico City.

resic, A. S. (19s4b): Model Testing of Deep Foundations in Sand and Scaling Laws, Panel Discussion, Session II, Proceedings, North American Conference on Deep Foundations, Mexico City.

VesaC A. S. (1965a): A Study of Bearing Capacity of Pile Foundations Final Report, Project B-189, Engineering Experiment Station, Georgia Institute of Technology, Atlanta, Ga. IIn preparation).

VEStĆ, A S. (1965b) - Expansion of a Cavity in an Infinite Solid (to be published).

Vrstc A S and G. W. Clougar (1966): Behavior of Grantr. presented is the ASCE Meeting in Miami Beach (in preparation".

Zwaek, H $(1953)$ : Mesures sur modèles reduits du frottement Latéral et de la résistance de pointe des póeux; Annales de I'Institut Technique du Bâtiment et des Travaux Publics, 6, No. 63-64, pp. $367-370$.

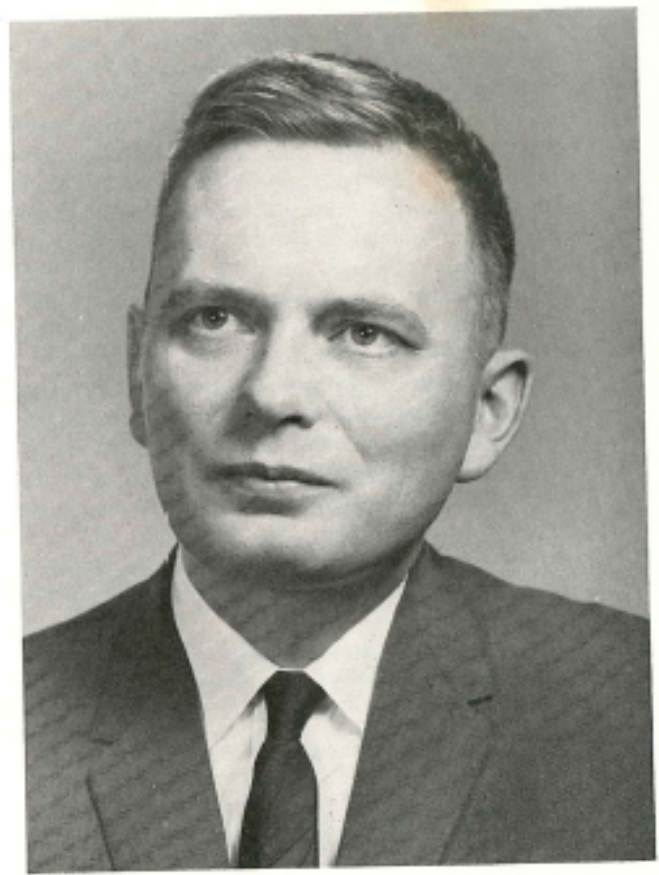

Figure A.7. Dr. Vesic's brief Biography. 


\section{Appendix - II}

\section{Derivation of the Pytel and Chugh Bearing Capacity Model}

Any bearing capacity model to estimate floor strength in underground coal mines must be able to account for the following factors shown in Figure A2.1 (Chugh and Pytel, 1992):

- finite thickness of the weaker layer underlain by a stronger bed;

- both floor layers possess cohesion, friction and weight;

- different pillar shapes including square, rectangle and long-continuous; and

- adjacent pillars that might influence each others floor bearing capacity.

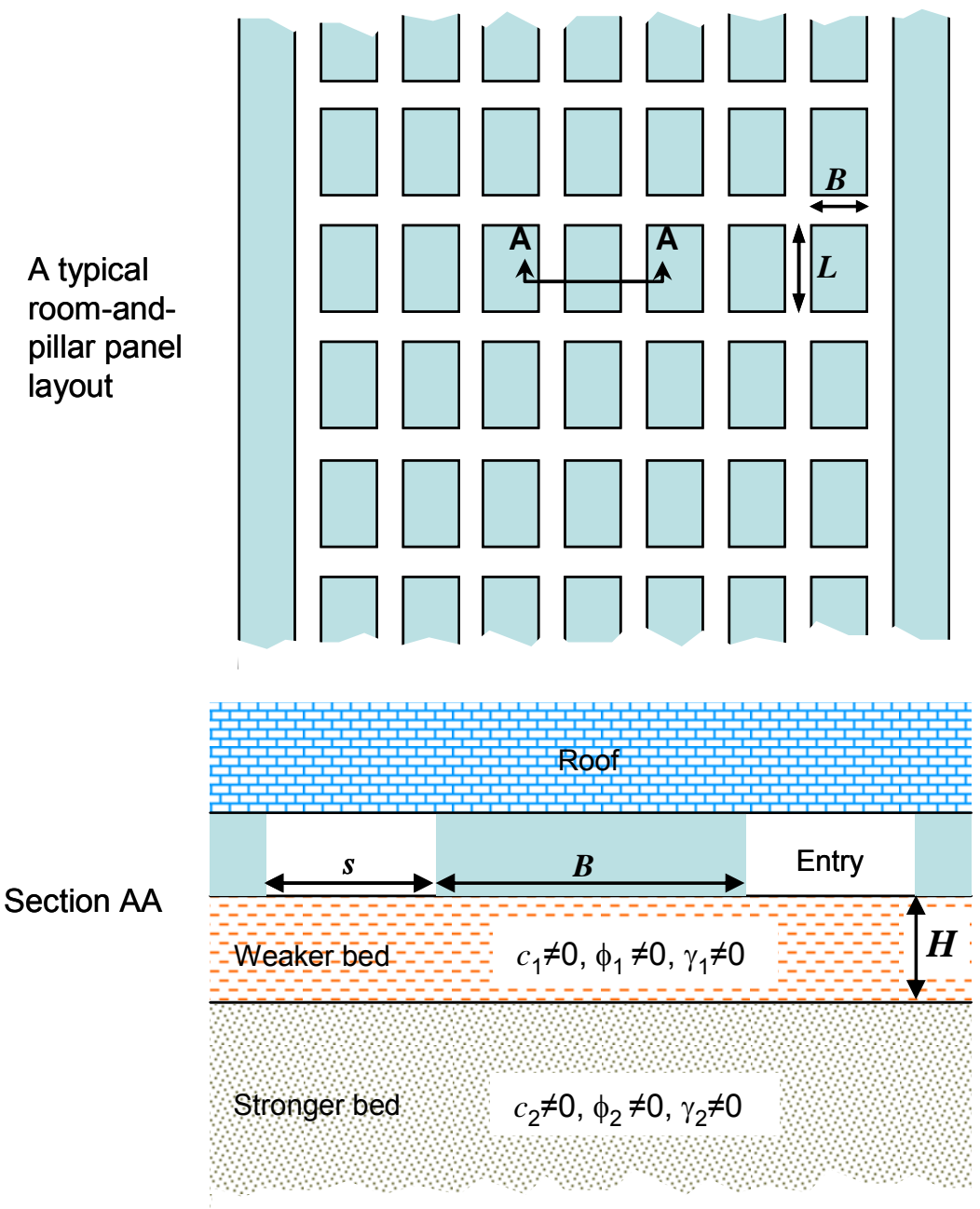

Figure A2.1. Geometry of a coal mine floor bearing capacity problem. 
In their quest to find a better solution for the coal mine bearing capacity problem, Chugh and Pytel (1992) reviewed several non-homogeneous models available in the soil mechanics literature. Based on their literature review, Chugh and Pytel (1992) classified the available solutions into the following five groups:

1. foundations on two-layer cohesive soils with angle of internal friction for both layers being zero;

2. foundations on two-layer cohesionless soils with non-zero friction values;

3. foundations on two-layer soils that have non-zero cohesion and friction values;

4. foundations on weak deformable layer overlying a bedrock;

5. foundations on nonhomogeneous soil exhibiting variation of cohesion with depth and has non-zero friction.

Chugh and Pytel (1992) compared several approaches representing the above five categories for their performance as shown in Figure A2.2.
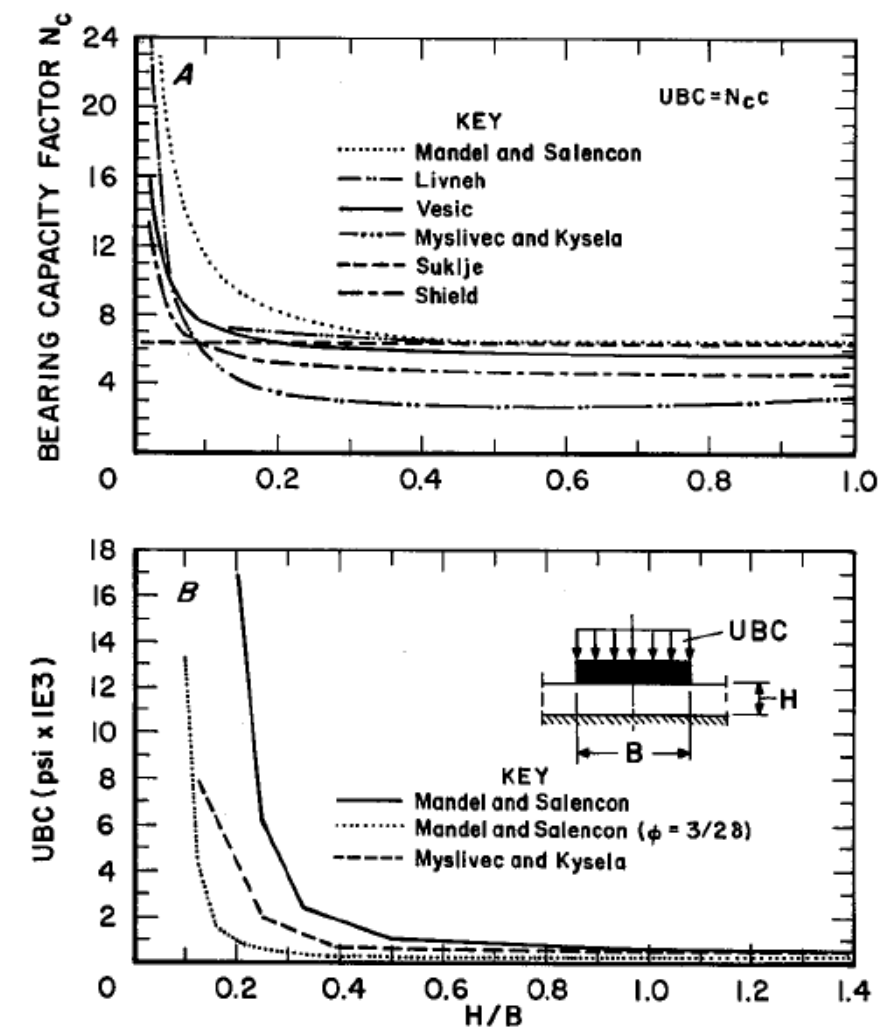

Figure A2.2. Comparison of several non-homogeneous bearing capacity solutions (Chugh and Pytel, 1992). 
Based on this extensive literature review, Chugh and Pytel (1992) found that for a cohesive and frictional two-layer bearing capacity problem, there was only a single method available, which was developed by Mandel (1965) and Mandel and Salencon (1969). Further, Chugh and Pytel (1992) found that the Mandel and Salancon's solution would also be able to account for the effect of adjacent footings. The Mandel and Salencon's solution was obtained for the case of a two-layered soil where the weaker layer rests on an infinitely rigid bottom layer. Their bearing capacity estimate obtained by the method of characteristics for a surface foundation sitting on a weightless soil is given by

$$
U B C=c \cdot \xi N_{c} \cdot s_{c} \cdot F_{c}
$$

where $c$ is the cohesion, $N_{c}$ is the bearing capacity factor, $s_{c}$ the shape factor, $\xi$ is called the factor of majoration and $F_{c}$ is a Mandel-Salencon factor. The $\xi$ and $F_{c}$ values were provided in graphical form and are shown in Figure A2.3.
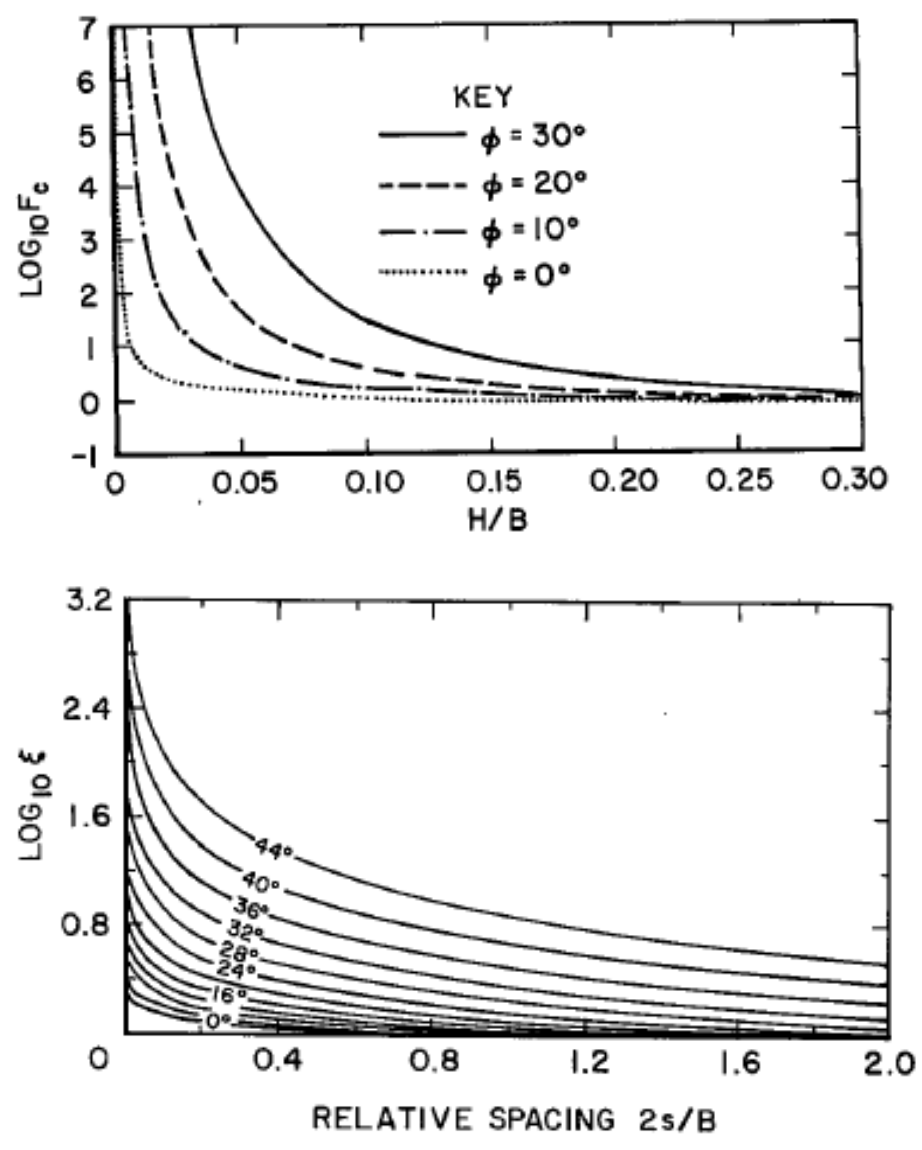

Figure A2.3. the Mandel and Salencon's factors for different friction angle values. (Chugh and Pytel, 1992). 
As mentioned previously, a rigorous closed-form solution for conditions in Figure A2.1 can not be obtained. Therefore, Chugh and Pytel (1992) adopted the Mandel and Salencon's solutions to estimate the strength of floor below coal pillars as shown in Figure A2.4. In order to fully appreciate the applicability of the Pytel and Chugh model, it is imperative to understand how the Mandel and Salencon's solutions were incorporated into the coal mine bearing capacity problem. In any of their publications, Pytel and Chugh did not provide the complete derivation of their methodology. Therefore, the solution is derived stepby-step as given below. The derivation given below was verified by Dr. Pytel through several email communications with the author in 2006 (Pytel, 2006).

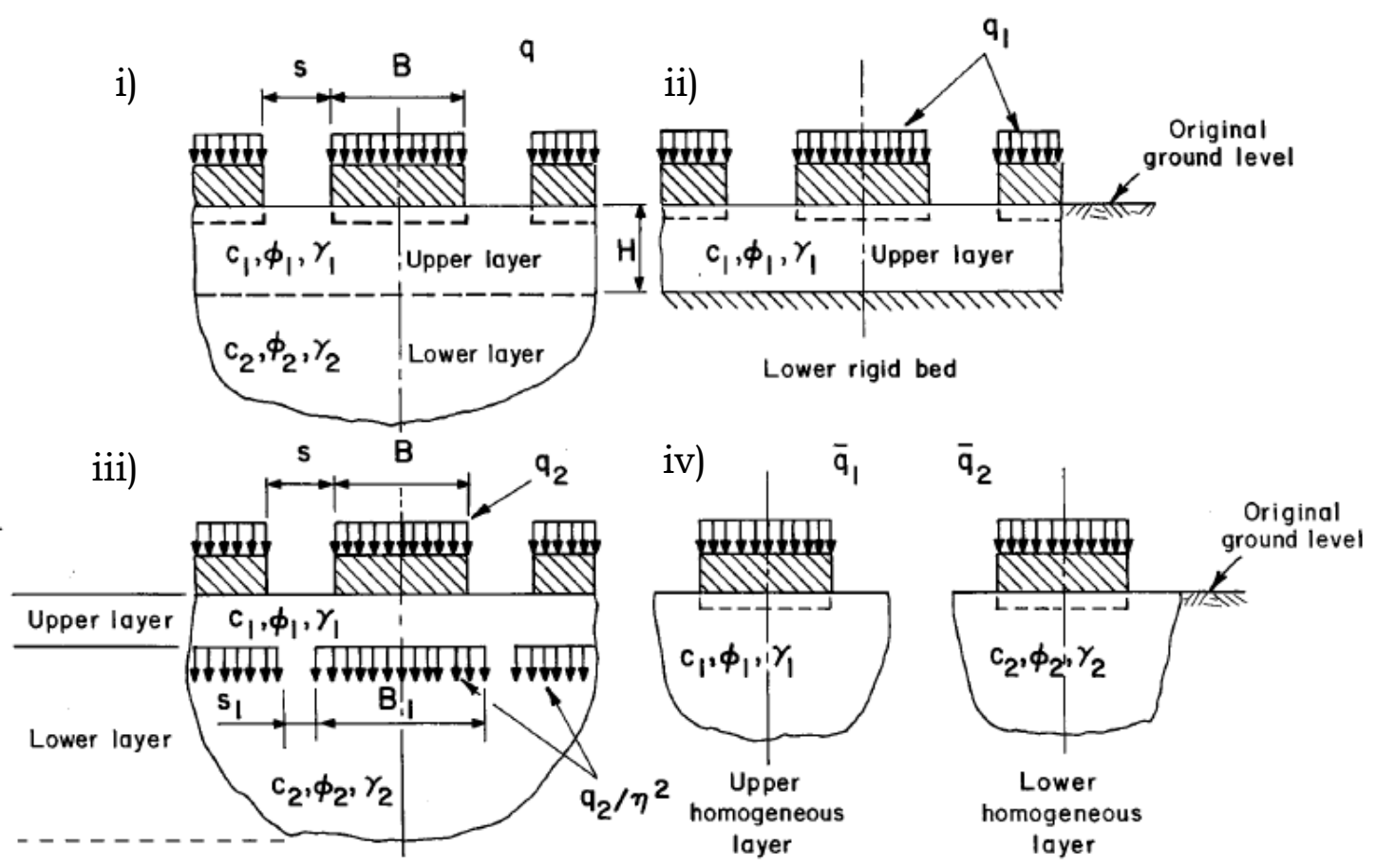

Figure A2.4. Chugh and Pytel's representation of a coal mine bearing capacity problem.

As shown in Figure A2.4 (i), a typical coal mine bearing capacity problem includes multiple pillars of width $B$ spaced $s$ apart which rests on a finite layer of weak floor $\left(c_{1}, \phi_{1}, \gamma_{1}\right)$ of thickness $H$ underlain by another deformable stronger layer $\left(c_{2}, \phi_{2}, \gamma_{2}\right)$. In order to use the available solutions given by Mandel and Salencon, the basic bearing capacity problem was split into several pieces as shown in Figure A2.4 (ii) - (iv). After the partitioning, Chugh and Pytel (1992) 
assumed that a reasonable estimate of the bearing capacity is provided if the different strength components shown in Figure A2.4 are combined by a function of the form

$$
q=\frac{q_{1} q_{2}}{q_{1}+q_{2}}+E_{r r} \frac{\bar{q}_{1}}{\bar{q}_{2}}
$$

In the above equation,

$q_{1}$ is the bearing capacity of the top weak layer resting over a rigid bed rock with no effect of adjacent pillars considered;

$q_{2}$ is the bearing capacity of the bottom rock layer supporting a pillar whose width is $B / \eta$ in the presence of multiple pillars at a spacing equal to $s+B-(B / \eta)$. Here the floor is considered semi-infinite in extent;

$E_{\gamma}$ is the error term;

$\bar{q}_{1}, \bar{q}_{2}$ are the bearing capacities for individual semi-infinite layers with no effect of adjacent pillars, and

$\eta$ is the coefficient of stress distribution below the center of a uniformly loaded area given by (Pytel, 1998)

$$
\eta=\frac{2}{\pi}\left\{\arctan \frac{\frac{L}{B}}{\frac{H}{B} \sqrt{1+\left(\frac{L}{B}\right)^{2}+\left(\frac{H}{B}\right)^{2}}}\left(\frac{H}{L}\right)\left[\sqrt{1+\left(\frac{H}{B}\right)^{2}}+\sqrt{\left(\frac{L}{B}\right)^{2}+\left(\frac{H}{B}\right)^{2}}-\sqrt{1+\left(\frac{L}{B}\right)^{2}+\left(\frac{H}{B}\right)^{2}}-\frac{H}{B}\right]\right\}
$$

where the different symbols have the standard meaning used in this dissertation.

Other than for mathematical convenience, no physical basis exists for Equation (A2.2) and selection of its form is solely based on satisfying the following boundary conditions:

$$
\begin{aligned}
& q \rightarrow q_{1} \text { if } q_{2} \rightarrow \infty \\
& q \rightarrow q_{2} \text { if } q_{1} \rightarrow \infty(H \rightarrow 0) \\
& q \rightarrow 0 \text { if } q_{1} \rightarrow 0
\end{aligned}
$$

Ignoring the effect of surcharge and self-weight of floor layers and using the Mandel's bearing capacity solution given by Equation (A2.1), the following expressions could be obtained (Chugh and Pytel, 1992). 


$$
\begin{aligned}
& \bar{q}_{1}=c_{1} N_{c_{1}} s_{c} \bar{F}_{c_{1}} \\
& \bar{q}_{2}=c_{2} N_{c_{2}} s_{c} \bar{F}_{c_{2}} \\
& q_{1}=c_{1} N_{c_{1}} s_{c} F_{c_{1}} \\
& q_{2}=c_{2} N_{c_{2}} s_{c} \bar{F}_{c_{2}} \alpha \xi_{2}
\end{aligned}
$$

where $\bar{F}_{c_{1}}$ and $\bar{F}_{c_{2}}$ are the Mandel-Salencon factors for homogeneous semi-infinite floor conditions $\left(\bar{F}_{c}=0.778\right.$ for $\phi=0^{\circ} ; \bar{F}_{c}=0.691$ for $\phi=10^{\circ} ; \bar{F}_{c}=0.585$ for $\phi=20^{\circ}$; $\bar{F}_{c}=0.46$ for $\phi=30^{\circ}$ ) and $\alpha=1 / \eta^{2}$.

By combining equations (A2.4) and (A2.6) we get,

$$
q_{1}=\bar{q}_{1} F_{c}^{*}
$$

where $F_{c}^{*}=\frac{F_{c_{1}}}{\bar{F}_{c_{1}}}$.

Similarly, combining equations (A2.5) and (A2.7) we get

$$
q_{2}=\alpha \xi_{2} \bar{q}_{2}
$$

The error term in Equation (A2.2) will be at its maximum when

$$
E_{r r}=q_{1 s}-\frac{q_{1} q_{2}}{q_{1}+q_{2}}
$$

Substituting Equation (A2.10) in Equation (A2.2) gives

$$
q=\left[\frac{q_{1} q_{2}}{q_{1}+q_{2}}+\left(\frac{\bar{q}_{1}}{\bar{q}_{2}}\left\{q_{1 s}-\frac{q_{1} q_{2}}{q_{1}+q_{2}}\right\}\right)\right]
$$

with $q_{1 s}$ being the bearing capacity of homogeneous semi-infinite layer composed of the upper layer material including the effect of adjacent pillars and is equal to $\xi_{1} \bar{q}_{1}$.

Substituting the individual expressions derived for the different terms in Equation (A2.11) gives 


$$
q=\left[\frac{\bar{q}_{1} F_{c}^{*} \cdot \alpha \xi_{2} \bar{q}_{2}}{\bar{q}_{1} F_{c}^{*}+\alpha \xi_{2} \bar{q}_{2}}+\left(\frac{\bar{q}_{1}}{\bar{q}_{2}}\left\{\xi_{1} \bar{q}_{1}-\frac{\bar{q}_{1} F_{c}^{*} \cdot \alpha \xi_{2} \bar{q}_{2}}{\bar{q}_{1} F_{c}^{*}+\alpha \xi_{2} \bar{q}_{2}}\right\}\right)\right]
$$

Taking $\bar{q}_{1}$ out of brackets in Equation (A2.12) yields

$$
q=\bar{q}_{1}\left[\frac{F_{c}^{*} \cdot \alpha \xi_{2} \bar{q}_{2}}{\bar{q}_{1} F_{c}^{*}+\alpha \xi_{2} \bar{q}_{2}}+\left(\frac{\bar{q}_{1}}{\bar{q}_{2}}\left\{\xi_{1}-\frac{F_{c}^{*} \cdot \alpha \xi_{2} \bar{q}_{2}}{\bar{q}_{1} F_{c}^{*}+\alpha \xi_{2} \bar{q}_{2}}\right\}\right)\right]
$$

The expression $\frac{F_{c}^{*} \cdot \alpha \xi_{2} \bar{q}_{2}}{\bar{q}_{1} F_{c}^{*}+\alpha \xi_{2} \bar{q}_{2}}$ in Equation (A2.13) can be simplified if both the numerator and the denominator are divided by $F_{c}^{*} \cdot \alpha \xi_{2} \bar{q}_{2}$ thus

$$
\frac{\frac{F_{c}^{*} \cdot \alpha \xi_{2} \bar{q}_{2}}{F_{c}^{*} \cdot \alpha \xi_{2} \bar{q}_{2}}}{\frac{\bar{q}_{1} F_{c}^{*}}{F_{c}^{*} \cdot \alpha \xi_{2} \bar{q}_{2}}+\frac{\alpha \xi_{2} \bar{q}_{2}}{F_{c}^{*} \cdot \alpha \xi_{2} \bar{q}_{2}}}=\frac{1}{\frac{\bar{q}_{1}}{\alpha \xi_{2} \bar{q}_{2}}+\frac{1}{F_{c}^{*}}}=\frac{1}{\frac{\bar{q}_{1}}{\bar{q}_{2}} \cdot \frac{1}{\alpha \xi_{2}}+\frac{1}{F_{c}^{*}}}
$$

Substituting this simplified expression back in Equation (A2.13) gives

$$
q=\bar{q}_{1}\left[\frac{1}{\frac{\bar{q}_{1}}{\bar{q}_{2}} \cdot \frac{1}{\alpha \xi_{2}}+\frac{1}{F_{c}^{*}}}+\left(\bar{q}_{\bar{q}_{2}}\left\{\xi_{1}-\frac{1}{\frac{1}{\alpha \xi_{2}}+\frac{1}{F_{c}^{*}}}\right\}\right)\right],
$$

which is the Pytel and Chugh's bearing capacity equation (Chugh and Pytel, 1992; Pytel, 1998). It may be noted that the $\frac{\bar{q}_{1}}{\bar{q}_{2}}$ term in the substituted simplified expression in the innermost bracket in Equation (A2.14) was equal to 1.0 because to derive the maximum possible error in Equation (A2.10), it was assumed $\bar{q}_{1}=\bar{q}_{2}$.

Now, that the complete details of the Chugh and Pytel's bearing capacity solution are known, the following fundamental issues are apparent from the derivation. 
A. There is no physical basis for assuming that the form given in Equation (A2.2) provides a realistic estimation of coal mine floor strength. Other than for mathematical simplicity, there is no valid reason to pick the linear form when several other equations will also satisfy the same boundary conditions as Equation (A2.2). In fact, a whole family of equations of the form

$$
\frac{1}{q^{n}}=\frac{1}{q_{1}^{n}}+\frac{1}{q_{2}^{n}}(\text { for } n>0)
$$

will also satisfy the exact same boundary conditions as Equation (A2.2). When the author pointed out this fundamental issue, Pytel (2006) speculated that if $n>$ 1 in Equation (A2.15), the departure of the computed bearing capacity from the "real" solution could be higher. When the "real" solution of the coal mine bearing capacity problem is not known, it is impossible to conclude if higher $n$ values or any $n$ value will provide the accurate solution. However, Pytel (2006) corrected Equation (A2.14) and proposed a more general solution as given below.

$$
q=\frac{\bar{q}_{1}}{\left[\left(\frac{\bar{q}_{1}}{\bar{q}_{2}} \frac{1}{\alpha \xi}\right)^{n}+\left(\frac{1}{F_{c}{ }^{*}}\right)^{n}\right]^{\frac{1}{n}}}
$$

In connection with this new derivation, Pytel (2006) stated that the value of $n$ would be different for different geotechnical conditions and mining geometries. He provided some charts for $n$ values as given in figures A2.5 through A2.7.

For the solution in Equation (A2.16), the conditions

$$
\begin{aligned}
& \frac{s}{B} \geq \frac{1}{\eta}-1, \\
& \frac{s}{B} \geq \frac{2 \cos \left(\frac{\pi}{4}-\frac{\phi}{2}\right) \frac{H}{B} \exp \left[\left(\frac{\pi}{4}-\frac{\phi}{2}\right) \tan \phi\right]}{\cos \phi}, \text { and } \\
& \frac{\xi_{1}}{\alpha \xi}<1, \frac{\xi_{1} \bar{F}_{c 1}}{F_{c 1}}<1 \text { must be satisfied. }
\end{aligned}
$$




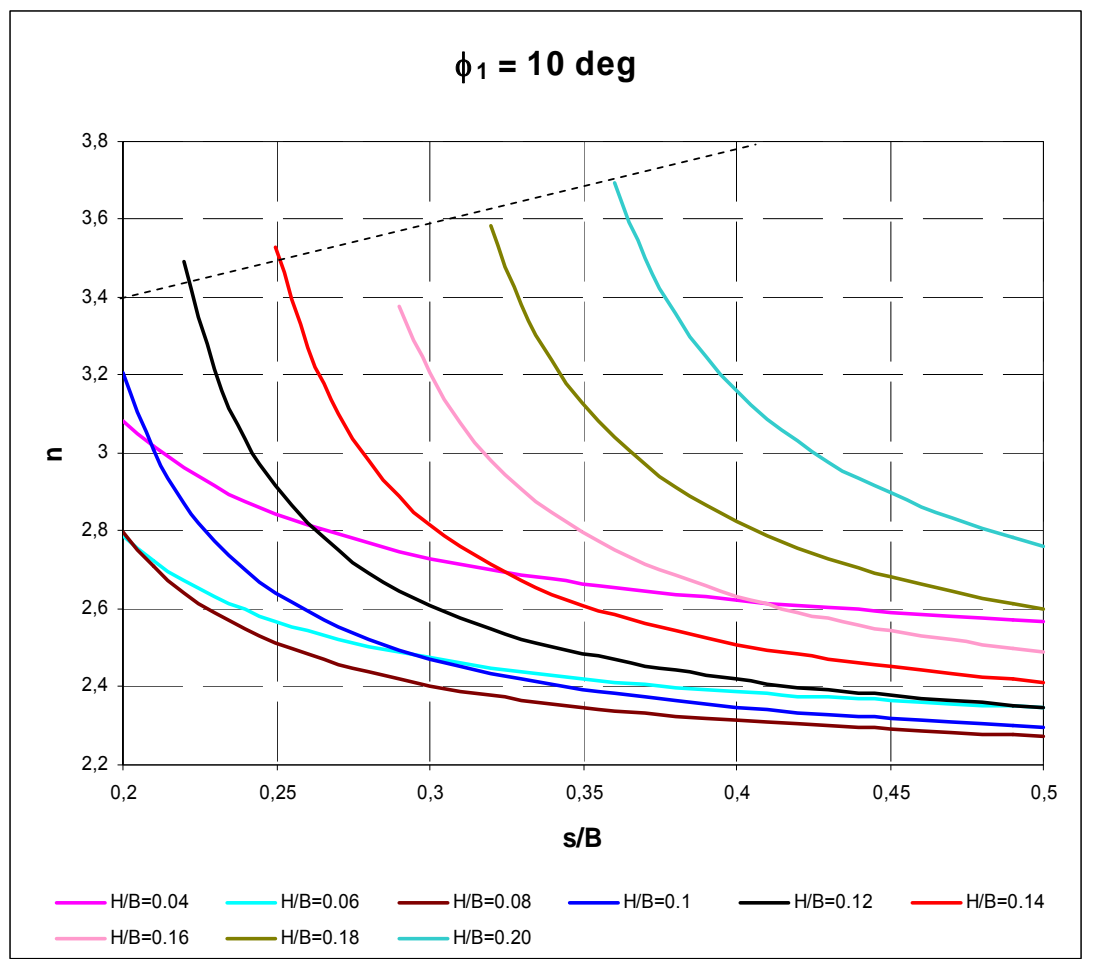

Figure A2.5. Value of $n$ in Equation (A2.16) for different $H / B$ values and $\phi=10^{\circ}$ (Pytel, 2006).

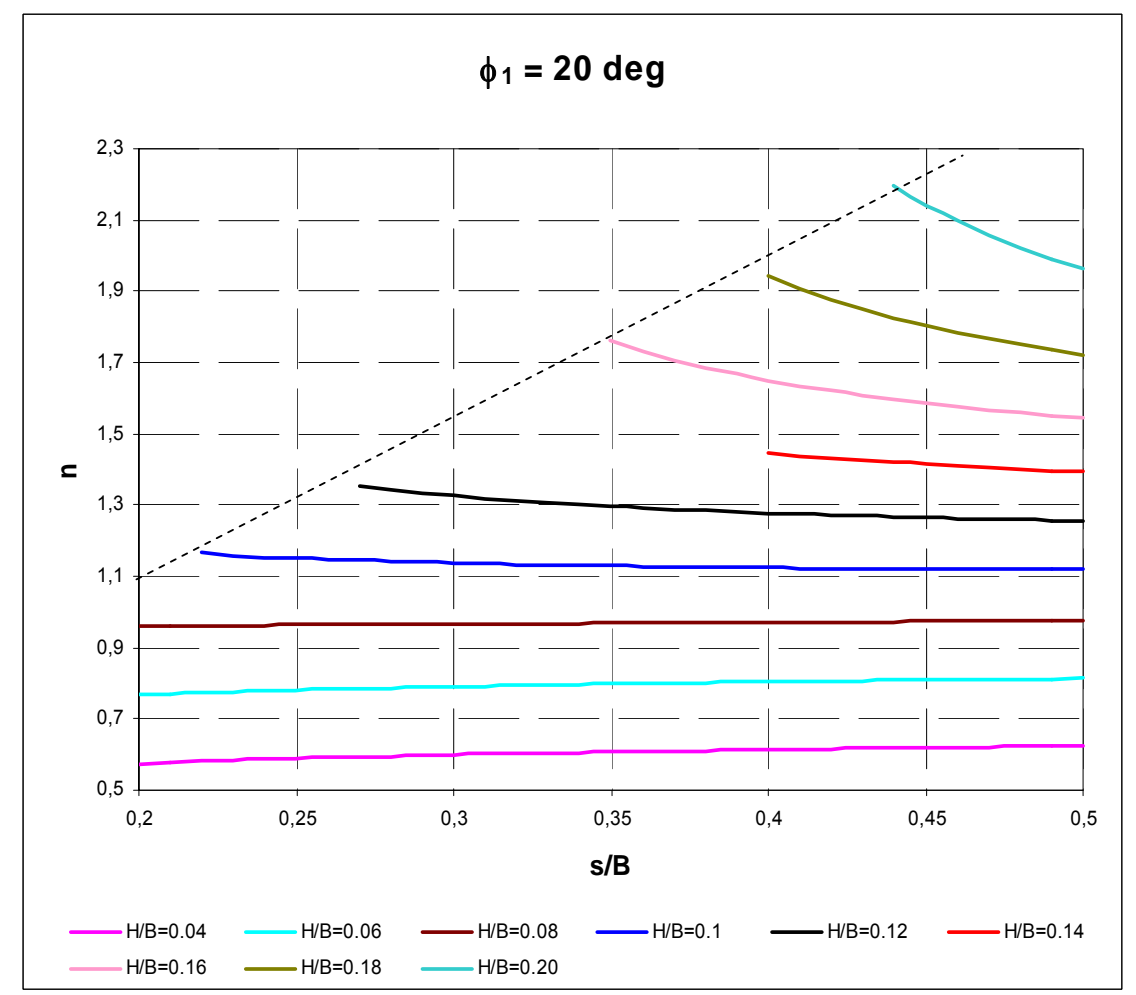

Figure A2.6. Value of $n$ in Equation (A2.16) for different $H / B$ values and $\phi=20^{\circ}$ (Pytel, 2006). 


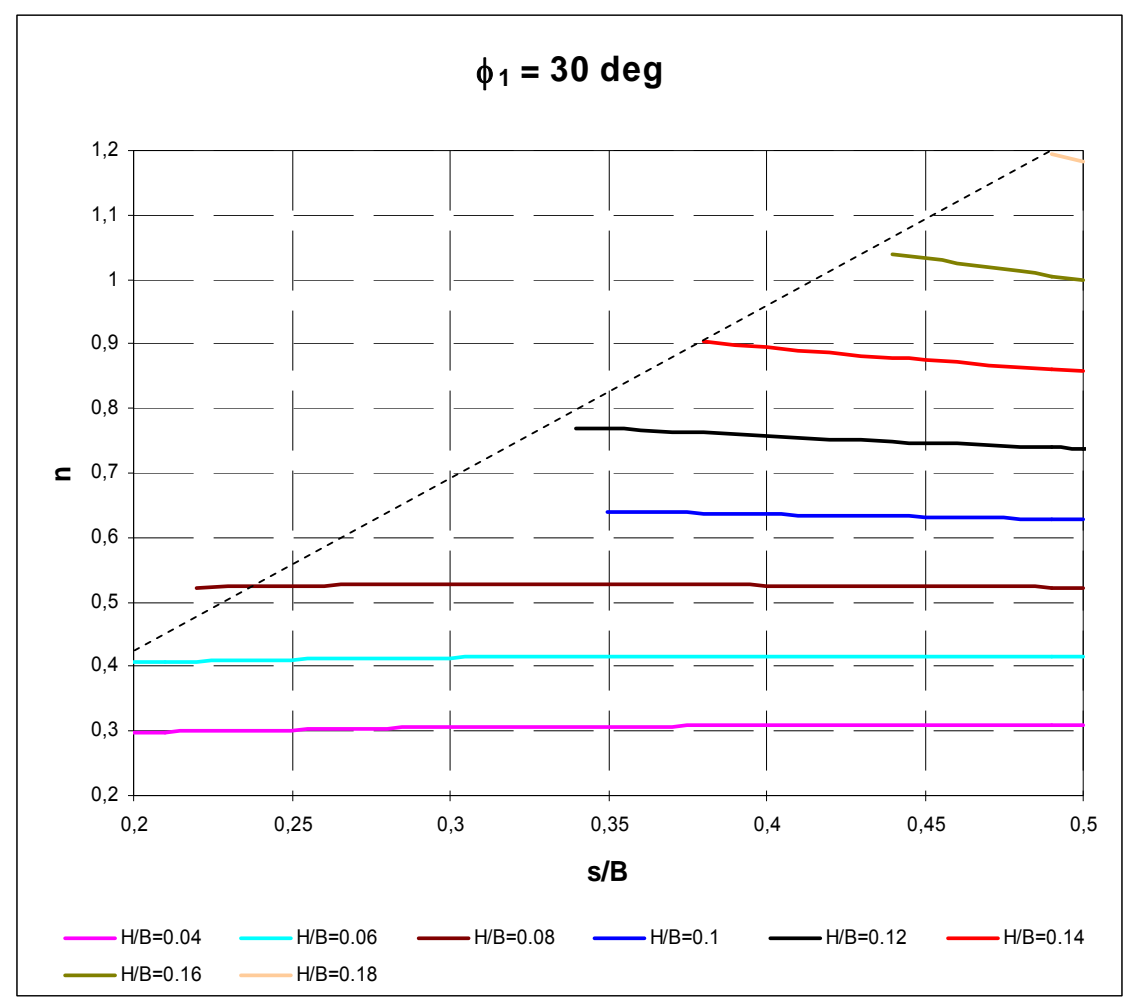

Figure A2.7. Value of $n$ in Equation (A2.16) for different $H / B$ values and $\phi=30^{\circ}$ (Pytel, 2006).

It may be noted that within the knowledge of this author the solution given in Equation (A2.16) has not been published by Pytel yet. Obviously Equation (A2.16), similar to Equation (A2.14), is based purely on theoretical considerations and has not been verified by any field or numerical investigations and thus suffers the same limitations as its predecessor. It is interesting to note that when $n=1$, Equation (A2.16) does not reduce to Equation (A2.14). This is due to somewhat slightly different assumptions made in deriving Equation (A2.16), which do not drastically alter the computed bearing capacity.

B. It is not immediately apparent from the derivation given above, why the error term in Equation (A2.2) takes the form $E_{r r} \frac{\bar{q}_{1}}{\bar{q}_{2}}$. Also, when $\bar{q}_{1}=\bar{q}_{2}$ it is not clear why $q$ becomes $q_{1 s}$ (with $q_{1 s}$ being the bearing capacity of homogeneous semi-infinite layer composed of the upper layer material including the effect of adjacent pillars and is equal to $\xi_{1} \bar{q}_{1}$ ). When $\bar{q}_{1}=\bar{q}_{2}$ the situation physically means that there is an isolated pillar on a semi-infinite floor composed of one material. In 
that situation, one would assume $q$ to become equal to $\bar{q}_{1}$ instead of $\xi_{1} \bar{q}_{1}$. This is because $\bar{q}_{1}, \bar{q}_{2}$ are defined as the bearing capacities for individual semi-infinite layers with no effect of adjacent pillars.

To this issue, Pytel (2006) responded that the error term was assumed to have the form $E_{r r} \frac{\bar{q}_{1}}{\bar{q}_{2}}$ because it was able to express conveniently the deviation from the exact value as a function of difference in the two layers' strength parameters. If $\bar{q}_{1}=\bar{q}_{2}$, then $c_{1}=c_{2}$ and $\phi_{1}=\phi_{2}$, and thus the two-layer system transforms into one-layer system with a row of pillars on the boundary surface.

Knowing $E_{r r}=\frac{\bar{q}_{2}}{\bar{q}_{1}}\left\{q-\frac{q_{1} q_{2}}{q_{1}+q_{2}}\right\}$, we can find that for $\bar{q}_{1}=\bar{q}_{2}$ (i.e. by assumption: $c_{1}=$ $c_{2}$ and $\left.\phi_{1}=\phi_{2}\right)$ and as $H \rightarrow 0, q \rightarrow \bar{q}_{2} \xi$. Similarly, as $q_{1} \rightarrow \infty, q_{2} \rightarrow \bar{q}_{2} \xi$ and therefore $E_{r r}=0$ as desired. Under these conditions, the overall strength is given by

$$
q=\frac{\bar{q}_{1}}{\frac{\bar{q}_{1}}{\bar{q}_{2}} \frac{1}{\alpha \xi}+\frac{1}{F_{c}^{*}}} .
$$

which is another form of the Pytel and Chugh floor bearing capacity solution, and is the same as substituting $n=1$ in Equation (A2.16). Pytel (2006) further suggested that all the new versions of Pytel-Chugh equations derived as a consequence of this author's suggestions should be supported by some kind of numerical analyses, e.g. FEM. He further opined that the Pytel-Chugh approach was perhaps a better solution among available answers since nobody knew what the exact solution was for the coal mine bearing capacity problem (Pytel, 2006).

C. The Mandel's solution for the effect of adjacent foundations described in his 1965 paper that Chugh and Pytel (1992) referenced applies only to a semiinfinite homogeneous soil supporting several strip footings. Similarly, the Mandel and Salencon (1969) model for the bearing capacity of a frictional and cohesive immediate floor material assumes rigid stronger layer below the soft floor. Because of these different sets of assumptions, it is not possible to suggest if the Pytel and Chugh's synthesis given above will provide an accurate solution to the 
coal mine bearing capacity problem. Further, when the equations for adjacent foundation effect were reproduced from the Mandel's 1969 paper, it appears Chugh and Pytel (1992) misquoted and misapplied them. Mandel (1965) considered the effect of adjacent foundations on bearing capacity by applying some corrections factors as

$$
N_{c}^{\prime}=F N_{c}, N_{q}^{\prime}=\xi N_{q}, \quad N_{\gamma}^{\prime}=G N_{\gamma}
$$

where unprimed bearing capacity factors corresponds to an isolated foundation situation, $F$ is factor of majoration for cohesion, $G$ is another factor of majoration for weight effect and $\xi$ is related to $F$ by

$$
\xi=\left[(F-1)\left(1-\frac{1}{N_{q}}\right)\right]+1 .
$$

But, Chugh and Pytel (1992) swapped the multipliers for $N_{c}^{\prime}$ and $N_{q}^{\prime}$ as

$$
N_{c}^{\prime}=\xi N_{c}, N_{q}^{\prime}=F N_{q}, \quad N_{\gamma}^{\prime}=G N_{\gamma}
$$

Since the effect of $N_{q}^{\prime}$ and $N_{\gamma}^{\prime}$ terms are normally ignored for coal mine floor strength estimation, using the value of $\xi$ instead of $F$ for correcting the cohesion term will introduce some errors. Nowhere in their paper, Chugh and Pytel (1992) discussed any reasons for the switch nor provided any other reference where Mandel might have made the change himself.

In Summary, even though Pytel (2006) believes that the Pytel and Chugh's approach is perhaps the best available solution to a coal mine bearing capacity problem, the following issues remain:

- no physical basis exists for Equation (A2.2), which is the root of all other derivations;

- similarly, no basis exists for defining and combining different strength terms as given in Equation (A2.2);

- by altering the basic form of Equation (A2.2), several solutions for the bearing capacity are possible. Among these infinite solutions, it is not apparent how any particular solution could be picked; 
- although Mandel and Salencon's solutions account for non-homogeneous soils and the effect of adjacent foundations, those derivations are good only when the stronger layer is infinitely rigid and the footing is long and continuous. Assuming such conditions for a coal mine situation will lead to unconservative estimates of floor strength;

- limited case-history analysis by Chugh and Pytel (1992) showed that the bearing capacity was significantly overestimated by their methodology. This is not surprising given that the Mandel and Salencon's solutions assume the stronger layer below the weaker bed to be infinitely strong and the interference effects were derived for multiple strip footings.

- different Mandel and Salencon factors needed for the Pytel and Chugh's equation are not easily obtainable. This is because the Mandel and Salancon papers written in French only show the values of their factors in graphical form. Reading off the values from graphs is a cumbersome and tedious process that is prone to errors;

- finally, the Pytel and Chugh's approach is very complex and includes so many variables that it is overwhelming for any normal designer to use the equation with confidence. It is for this reason that no practical case could be found where Pytel and Chugh's approach was the preferred method of floor design. Even though the effort to derive a better solution for the coal mine bearing capacity problem is praiseworthy, because of the questionable assumptions that are not physically defendable and the esoteric nature of the solution that shunned away practical users, the Pytel and Chugh approach has not gained much recognition beyond the academic circles. 


\section{$\underline{\text { VITA }}$}

Murali M. Gadde was born in India in the southern state of Andhra Pradesh. After getting his bachelors degree in mining engineering from Osmania University in 1996, he went to work as a fellow and scientist at the Central Mining Research Institute (CMRI), India. Between 1996 and 2002, Murali worked on about 50 research and consulting projects at CMRI. In 2002 he moved to U.S. for his graduate studies. He completed his Masters degree in mining engineering from West Virginia University in 2003. After graduation, Murali completed his course work towards his Ph.D. and in 2005 got employed by Peabody Energy as the lead ground control engineer. Since then he worked on close to 150 different ground control projects in the U.S. and Australia. While working full-time on the job, Murali completed his Ph.D. in mining engineering from WVU in December, 2009.

During the past thirteen years since completing his bachelors degree, Murali worked on several important research projects and published extensively. His twenty-three publications till date cover research on in-situ stresses, pillar design, rock failure criteria, support design, numerical modeling, weak floor stability and explosion resistant mine seals. Murali got four gold medals for his top-ranking academic performance during his B.S., and WVU mining engineering faculty graduate student award in 2004. He is also the recipient of the 2008 SME J.W. Woomer award given to young professionals for their contributions to the U.S. coal mining industry.

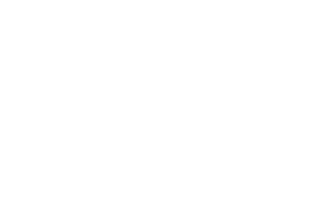

